\title{
Results of Scoping Tests for Open-Cycle OTEC Components Operating with Seawater
}

\author{
F. Zangrando \\ D. Bharathan \\ H. J. Green \\ H. F. Link \\ B. K. Parsons \\ J. M. Parsons \\ A. A. Pesaran \\ Solar Energy Research Institute \\ C. B. Panchal \\ Argonne National Laboratory
}

September 1990

Prepared under Task No. 012031

Solar Energy Research Institute

A Division of Midwest Research Institute

1617 Cole Boulevard

Golden, Colorado 80401-3393

Prepared for the

U.S. Department of Energy

Contract No. DE-AC02-83CH10093 


\section{NOTICE}

This report was prepared as an account of work sponsored by an agency of the United States government. Neither the United States government nor any agency thereof, nor any of their employees, makes any warranty, express or implied, or assumes any legal liability or responsibility for the accuracy, completeness, or usefulness of any information, apparatus, product, or process disclosed, or represents that its use would not infringe privately owned rights. Reference herein bo any specific commercial product, process, or service by trade name, trademark, manufacturer, or othenwise does not necessarily constitute or imply its endorsement, recommendation, or favoring by the United States government or any agency thereof. The views and opinions of authors expressed herein do not necessarly state or reflect those of the United States government or any agency thereof.

Printed in the United Stapes of America

Available from:

National Technical Information Service

U.S. Department of Commerce

5285 Port Royal Road

Springfield, VA 22161

Price: Microfiche A01

Printed Copy A18

Codes are used for pricing all publications. The code is determined by the number of pages in the publication. Information pertaining to the pricing codes can be found in the current issue of the following publications which are generally available in most libraries: Energy Research Absracts (ERA); Government Reporis Announcements and Index (GRA and I); Scientific and Technical Abstract Reports (STAR); and publication NTIS-PR-360 available from NTIS at the above address. 
This document describes experimental verification and testing of key opencycle ocean thermal energy conversion (OC-OTEC) components using seawater as the operating fluid. Tests were performed under the U.S. Department of Energy's Ocean Energy Technology Program in FY 1988 and FY 1989. The research is part of an overall effort to assess and solve the technical problems leading to the development of 1 and-based or near-shore OC-OTEC systems ranging in size from 2 to $15 \mathrm{MW}_{e}$.

The work described in this document was completed primarily under a task entitled "Open-Cycle OTEC Experiments"; additional tasks supported component design, installation, and operation of the test facility. The effort involved cooperation among three institutions: the Solar Energy Research Institute (SERI), Argonne National Laboratory (ANL), and the Pacific International Center for High Technology Research (PICHTR). Operational support was provided by the Natural Energy Laboratory of Hawaii (NELH). The Seacoast Test Facility (STF), where the equipment was installed and the tests were conducted, is located on the grounds of NELH, at Keahole Point, Kailua-Kona, Hawaii.

The results described here complement extensive experimental and analytical results obtained using fresh water. They provide the required technical basis for competent engineering design of a facility--the net power-producing experimental apparatus (NPPE)--in which net power will be produced for the first time using OC-OTEC technology.

Contributions from dedicated individuals have ensured success of the research effort. Special thanks are due to Leonard J. Rogers, Director of the U.S. DOE Wind/Ocean Technologies Division, for program direction and financial support; Andrew Trenka, SERI Oceans Program Leader during the period of testing, for his drive and leadership; Doug Powell and Chester Wells of SERI for support in fabrication and installation of test articles and for instrument calibration; Karin Dukehart and Agatha Ramos of SERI for administrative support; Lyle Genens and Clarence Clark of ANL for design and installation of equipment; Thomas Daniel and Jan War of NELH for directing and coordinating NELH support during construction and testing; Ernest Galt, Aarne Haas, and Kent Merrill of NELH for their assistance with construction and operations; and Travis Tarumoto of PICHTR for his assistance in operations.

With respect to the carbon-dioxide experiment, thanks are due to Peter $R$. Guenther of Scripps Institution of Oceanography for coordination of Scripps' participation; Timothy Lueker of Scripps for performing the laboratory analysis; and Miles Anderson of NELH for assisting with the seawater sampling.

Gratitude is also expressed to Linda. Bevard of SERI for editing and patiently coordinating the material from the various authors. 
TP-3561
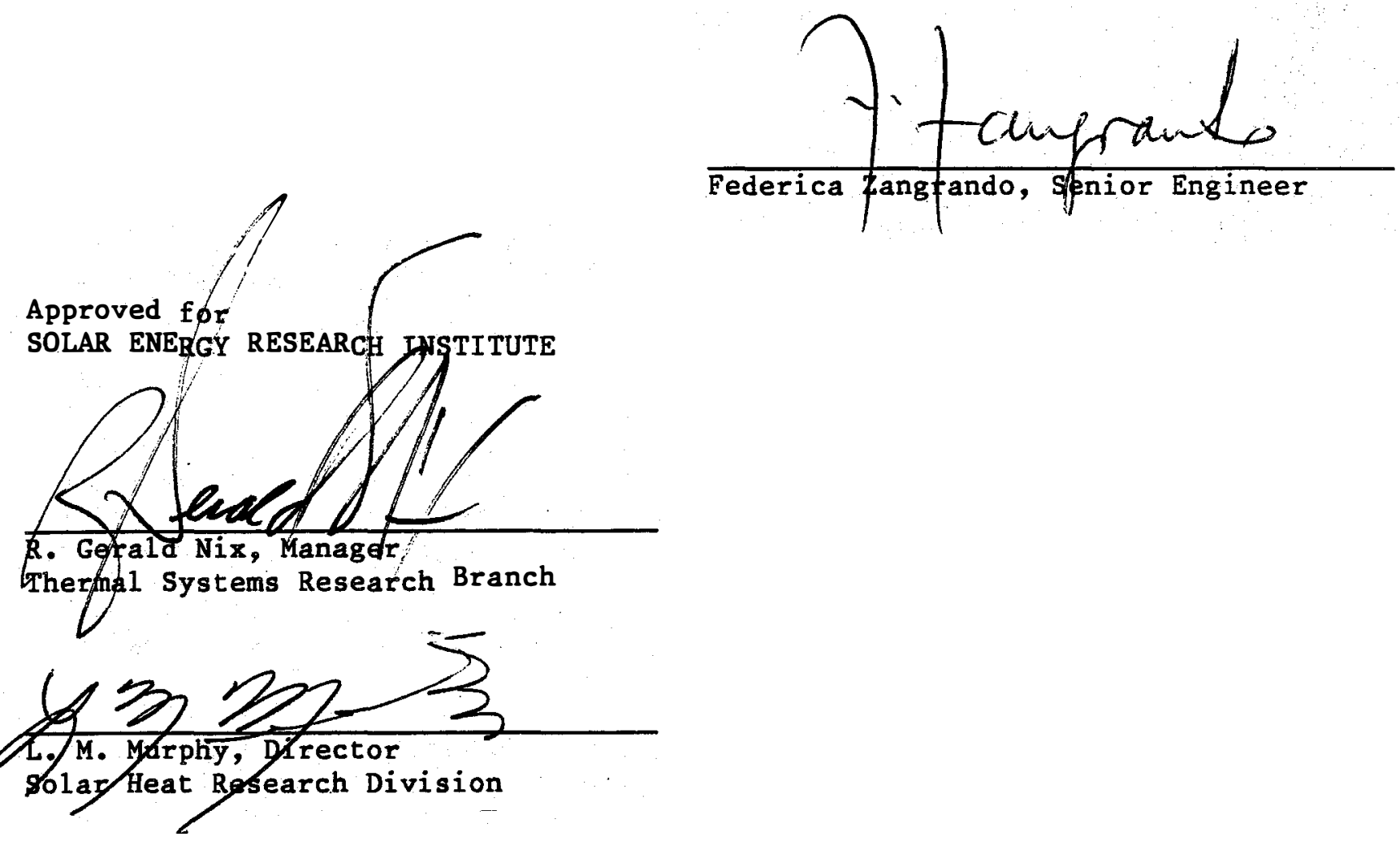

$1 v$ 


\section{SUMAARY}

\section{OVERVIEW}

This report presents comprehensive documentation of the experimental research conducted on open-cycle ocean thermal energy conversion (OC-OTEC) components operating with seawater as a working fluid. The results of this research are presented in the context of previous analysis and fresh-water testing; they provide a basis for understanding and predicting with confidence the performance of all components of an OC-OTEC system except the turbine: Seawater tests have confirmed the results that were obtained in fresh-water tests and predicted by the analytical models of the components. A sound technical basis has been established for the design of larger systems in which net power will be produced for the first time from OC-OTEC technology. Design and operation of a complete OC-OTEC system that produces power will provide sufficient confidence to warrant complete transfer of OC-OTEC technology to the private sector.

\section{OBJECTIVE}

The primary objective of the research is to develop high-performance components and analytical models of components in the parameter range suitable for OC-OTEC applications. The goals of the research described herein are to establish a data base for and verify the performance of key OC-OTEC components operating in seawater, to validate existing analytical models of these components, and to document experimental and analytical work for use in designing a net power-producing OC-OTEC system.

\section{DISCUSSION}

This document reports results of Phase I and Phase II tests conducted at the Seacoast Test Facility (STF) in the Heat- and Mass-Transfer Scoping Test Apparatus (HMTSTA) between February 1988 and May 1989. This apparatus is large and has a thermal capacity greater than $1 \mathrm{MW}$. It consists of all major components of an OC-OTEC system except the turbine, and it uses warm and cold seawater as the process fluids. Some tests were conducted with fresh water and repeated with seawater to obtain direct comparative data. The equipment has been instrumented carefully and has provided very reliable data for all the main components of an OC-OTEC system.

The HMTSTA system for the Phase I tests was configured with the flash evaporator, mist eliminator, warm-seawater predeaerator, and surface condenser; and detailed tests were conducted with each of these components. For Phase II tests, the surface condenser was replaced by a direct-contact condenser (DCC) and the system was operated to conduct detailed tests on the DCC and to characterize the composition of gas flowing through the system and the level of carbon dioxide release. Each component's performance is described in a separate chapter written by the principal investigator responsible for technical aspects of the specific tests. The system configuration, description of the equipment, instrumentation, and operational aspects are described in Chapter 2 and they are not repeated in the chapters describing component performance. 
Tests of flash evaporation were conducted with spouts of varying heights and diameters, using both single- and multiple-spout configurations. Results showed that spout evaporators are the technology of choice for OC-OTEC systems. Steam can be produced near the theoretical limit for use of warm water (thermal effectiveness of 0.9 or above) and a seawater superheat above $2^{\circ} \mathrm{C}$. Spouts up to $0.25 \mathrm{~m}$ in diameter, at spout heights as 1 ow as $0.5 \mathrm{~m}$, and with large volume flow through the evaporator chamber, can attain this high performance while maintaining low-loss hydraulics. No flow instabilities were observed for the multiple spouts tested.

The mist eliminator removes the small droplets of seawater that are carried with the steam as it flows out of the evaporator. The commercially available chevron-type mist eliminator performed as expected. A similar mist eliminator located 2-3 m above the evaporator spouts will provide adequate water-droplet removal with minimal gas pressure losses. No further research needs are anticipated.

In scoping predeaeration experiments, concentrations of dissolved oxygen in seawater were measured and used to estimate noncondensable gas desorption levels. At typical OC-OTEC evaporator pressures, $75 \%$ to $95 \%$ of dissolved oxygen contained in the warm seawater was desorbed in the flash-evaporation process. This gas must be removed from the system. Results suggest that up to $60 \%$ of dissolved oxygen in warm seawater can be desorbed in the predeaerator for pressures around $9 \mathrm{kPa}$. Preliminary calculations show that by using a simple warm-water predearation scheme, the pumping power to remove noncondensable gases from an OC-OTEC plant could be decreased by $25 \%$. This results in a potential increase in a plant's gross output of about $3 \%$.

In the surface-condenser experiments, data for OTEC conditions were obtained using existing test units for the main and vent condensers, and uncertainty in performance prediction methods was determined. Test data for the unenhanced parallel-plate condenser with cross-flow configuration were used to validate the computer model for the main condenser. The vent condenser performed poorly because of difficulty in controlling the R-12 refrigeration system, which served as a heat sink for this component. Experimental difficulties with the vent condenser operation and instrumentation prevented verification of the gas-side mass balance, leading to potentially large uncertainties in gas concentrations calculated. Small gas-side pressure losses were obtained.

Tests of the DCC established its feasibility for operation with seawater and validated detailed analytical models. Tests showed that two DCC stages using structured packing fill are the technology of choice for OC-OTEC systems producing electricity. An area ratio of $3: 1$ between the cocurrent and the countercurrent stage is sufficient to provide excellent performance. The DCC condenses more than $98 \%$ of the incoming steam and can achieve thermal effectiveness approaching 0.9 , indicating that the system requires only $10 \%$ more than the theoretical minimum for use of seawater and venting requirements. Packings less than $1 \mathrm{~m}$ high will achieve this performance with incoming steam about $6^{\circ} \mathrm{C}$ warmer than incoming seawater, and steam loading of $0.4 \mathrm{~kg} / \mathrm{m}^{2} \mathrm{~s}$ for the first stage, resulting in low hydraulic losses. Results obtained with seawater and fresh water are virtually the same within measurement error. Predictions made with computer models developed at SERI to describe heat- and mass-transfer processes in the DCC stages compare well with experimental data, and the models provide a suitable engineering design tool for larger systems. 
Because excessive $\mathrm{CO}_{2}$ in the atmosphere contributes to the environmentally damaging greenhouse effect, the issue of its release (both immediate and long term) is important to OC-OTEC research. Measurement of immediate emissions from the flash evaporator and DCC indicates that release of $\mathrm{CO}_{2}$ is slightly greater than the quantity of dissolved molecular $\mathrm{CO}_{2}$ in the incoming seawater. Thus, estimated maximum emission from an OC-OTEC plant is $38.5 \mathrm{~g} / \mathrm{kWh}$, which is 15-25 times lower than the emission from a fossil fuel-fired electric power plant.

Careful attention was given to the quality and repeatability of the data collected. Appendix A documents the predicted measurement uncertainty of the various measurements and calculated performance parameters; repeatability of the data collected is discussed under each chapter and compared to the predicted uncertainty. The extensive set of data collected and the resulting calculated parameters are presented in Appendix B.

\section{CONCLUSIONS}

Extensive data were collected for key OC-OTEC components of large size operating with seawater. The data were used to validate detailed analytical models describing the heat- and mass-transfer processes occurring in the heat exchangers. Results have confirmed the very high performance of spout evaporators and direct-contact condensers that was observed during earlier freshwater experiments and was predicted by the analytical models. These experimental results can be accepted with confidence and can be extrapolated with acceptable engineering risk to a more prototypical system scale. The extensive data base on OC-OTEC components provides the technical confidence that the expected performance will be achieved in a net power-generating system in which performance of the overall OC-OTEC system can be verified. 
TABLE OF CONTENTS

Page

PREFACE ............................................... 111

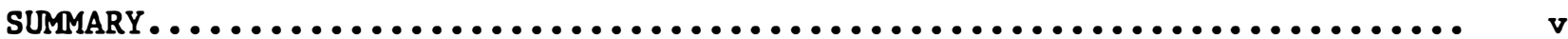

TABLE OF CONTENTS.........................................

LIST OF FIGURES ...........................................

LIST OF TABLES $\ldots \ldots \ldots \ldots \ldots \ldots \ldots \ldots \ldots \ldots \ldots \ldots \ldots \ldots \ldots \ldots \ldots \ldots \ldots \ldots \ldots \ldots \ldots \ldots \ldots$

1.0 INTRODUCTION .........................................

1.1 Principles of Operation in an Open-Cycle System............. 3

1.2 Ocean Energy Technology Program........................ 4

1.3 Progress of OC-OTEC............................... 5

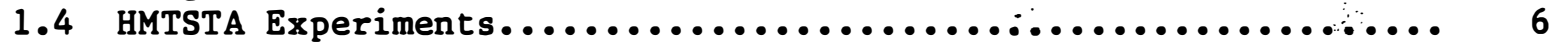

1.5 Organization of the Report.......................... 7

1.6 References....................................... 7

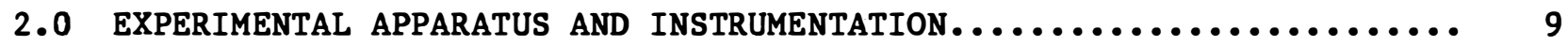

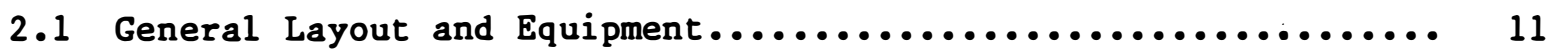

2.1 .1 Phase I Apparatus............................... 12

2.1.1.1 Seawater Supply System................... 12

2.1.1.2 Evaporator Vessel and Sump Tanks............ 12

2.1 .1 .3 Surface Condensers..................... 16

2.1 .1 .4 Auxiliaries............................ 21

2.1 .2 Phase II Apparatus............................... 21

2.1 .2 .1 Direct-Contact Condenser (DCC) Vessel........

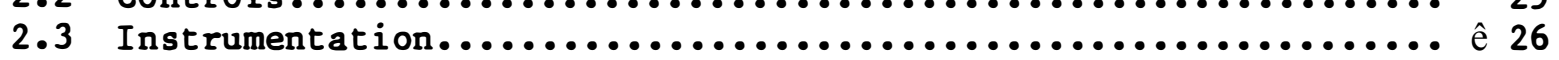

2.3 .1 Temperature Sensors............................. 26

2.3.2 Pressure Sensors................................ 33

2.3 .3 Flowmeters................................... 33

2.3 .4 Level Indicators.............................. ê 34

2.3.5 Dissolved Oxygen Sensors........................... 34

2.3.6 Exhaust Gas Flow............................... 35

2.3.7 Data Acquisition System (DAS) ................... 36

2.3 .8 System Leak Rate................................ 36

2.4 Operation of the Test Apparatus....................... 37

2.4 .1 Setting of Test Conditions...................... 37

2.4 .1 .1 Sensor Consistency...................... 38

2.4 .1 .2 Heat Balance.......................... 38

2.4.2 Stability and Limitations of the Facility............. 38

2.4.3 Calibrations................................... 39

2.5 References........................................... 39 
3.0 EVAPORATOR TESTS $\ldots \ldots \ldots \ldots \ldots \ldots \ldots \ldots \ldots \ldots \ldots \ldots \ldots \ldots \ldots \ldots \ldots \ldots \ldots \ldots \ldots$

3.1 êNomenclature...................................... 42

3.2 Background..................................... 43

3.2.1 Experimental Investigations..................... ê43

3.2.2 Analytical Methods............................ 47

3.2 .3 Objectives.................................. 48

3.3 Evaporator Performance Parameters........................ 48

3.3.1 Thermal Effectiveness.......................... ê49

3.3.2 Water Pressure Loss............................... ê49

3.3.3 Fraction of Dissolved Noncondensable Gas Released....... ê 49

3.3 .4 Spout Flow Stability........................... 50

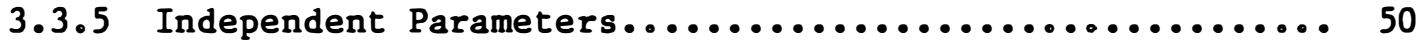

3.4 Test-Specific Equipment and Instrumentation.............. 51

3.4.1 Apparatus.................................. ê51

3.4 .2 Measurement Consistency......................... 52

3.5 Seawater Evaporator Results......................... 57

3.5.1 Thermal Performance............................ ê57

3.5.2 Release of Dissolved Gases......................... 64

3.5.3 Spout Hydraulics............................... ê 64

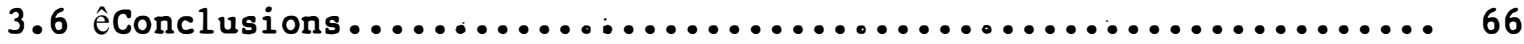

3.7 Applicability of Test Results to the Net Power-Producing

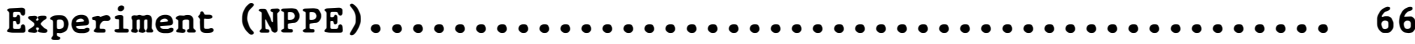

3.8 Further Research Needs.............................. 67

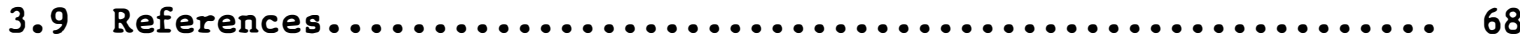

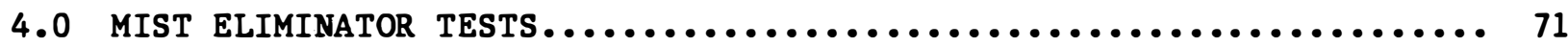

4.1 Background...................................... 73

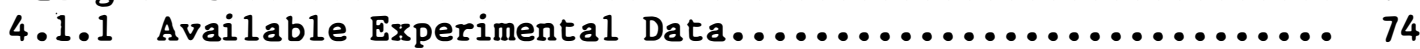

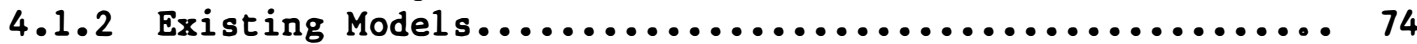

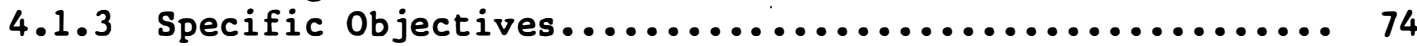

4.2 Definition of the Governing Parameters................... 75

4.2.1 Pressure-Loss Coefficient....................... ê75

4.2.2 Efficiency of Droplet Removal.................... 75

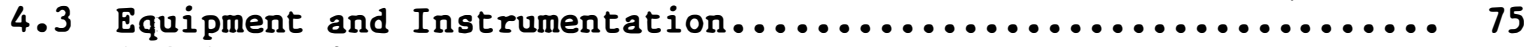

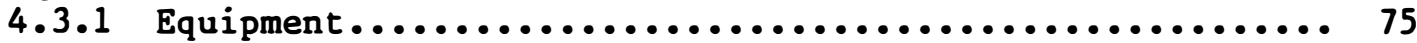

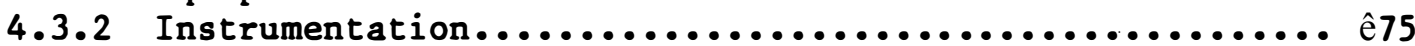

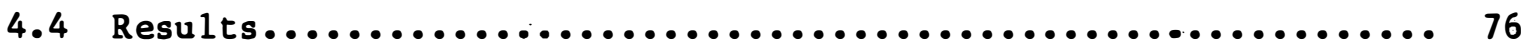

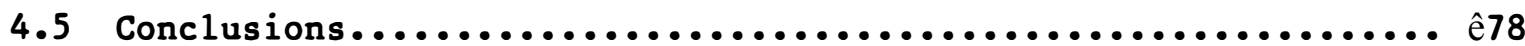

4.6 Applicability of Test Results to Net Power-Producing Experiment (NPPE) ................................ ê78

4.7 Further Research Needs............................. ê78

4.8 References....................................... 78 


\section{TABLE OF CONTENTS (Continued)}

5.0 OXYGEN DESORPTION FROM WARM SEAWATER.................... 79

5.1 Nomenclature...................................... 80

5.2 Background............................................... 81

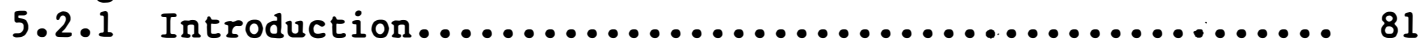

5.2.2 Previous Experimental Work...................... 81

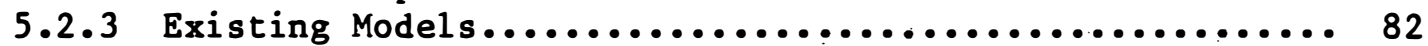

5.2 .4 Scope of the Present Work....................... 82

5.3 Definition of Performance and Test Parameters............... 83

5.3.1 Performance Parameters........................... 84

5.3.2 Test Parameters................................. 84

5.4 Test-Specific Equipment and Instrumentation.............. 86

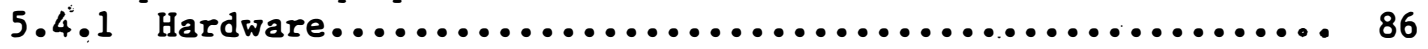

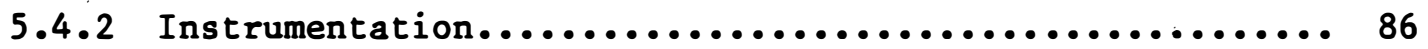

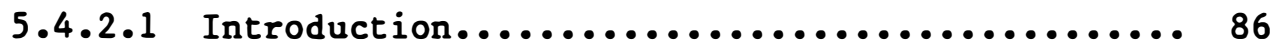

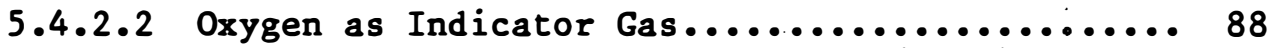

5.4.2.3 Measurements of Dissolved Oxygen (D.0.)....... 90

5.4.3 Experimental Procedure.......................... ê92

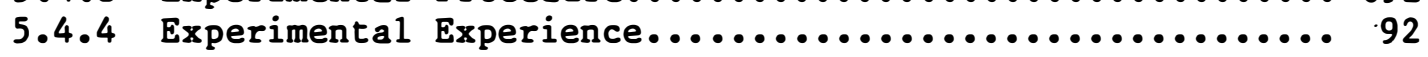

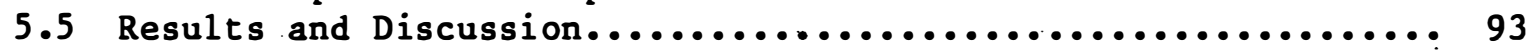

5.5 .1 Post-Test Error Analysis........................ 94

5.5 .2 êResults....................................... ê 94

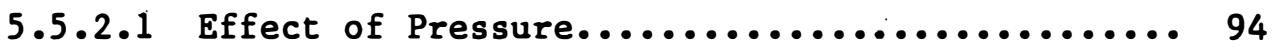

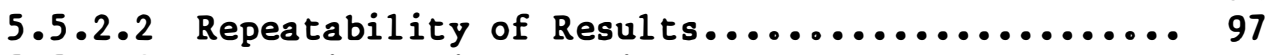

5.5.2.3 Comparison with Previous Data............... 98

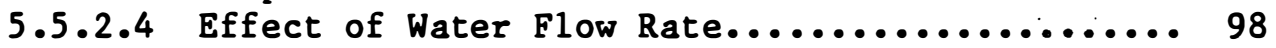

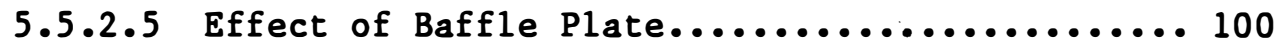

5.5.2.6 Effect of Bubble Injection................. 100

5.5.2.7 Total Fraction of Oxygen Desorbed............ 103

5.5.3 Potential Improvements in Accuracy of Measurement....... 103

5.5.4 Impact of Predeaeration on OC-OTEC Power Consumption.... 103

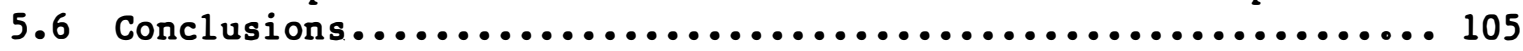

5.7 Applicability of Test Results to NPPE.................... 106

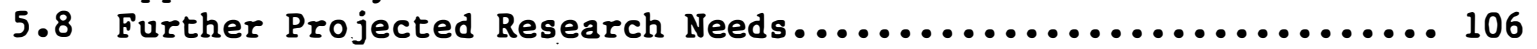

5.9 Total Gas Release.................................... 108

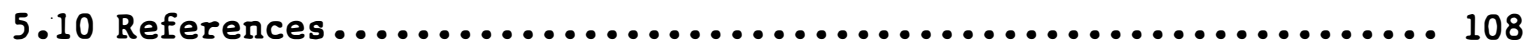

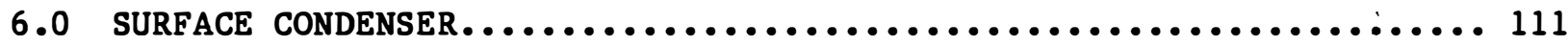

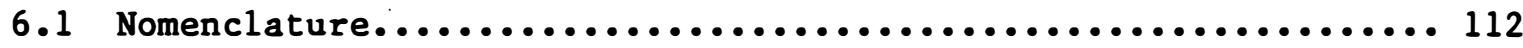

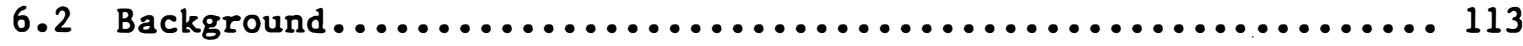

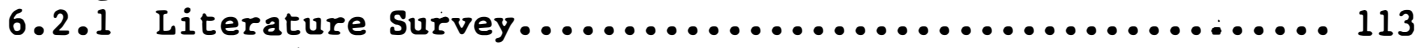

6.2 .2 Specific Objectives of Tests...................... 114

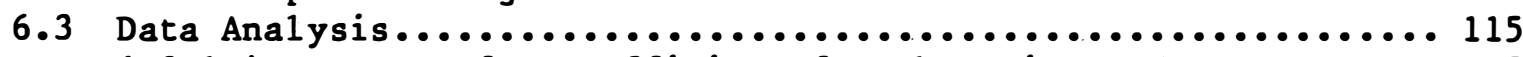

6.3.1 êHeat-Transfer Coefficient for the Main Condenser....... 115

6.3.1.1 Determination of the Effective Steam-Side $\hat{e}$

Heat-Transfer Coefficient................. 115

6.3.1.2 Determination of the Water-Side Heat-Transfer

Coefficient........................... 116 
TABLE OF CONTENTS (Continued)

6.3.2 êThermal Effectiveness of the Vent Condenser........... 116

6.3.3 Detailed Performance-Prediction Method................ 117

6.3.3.1 Algorithm for Performance Prediction.......... 117

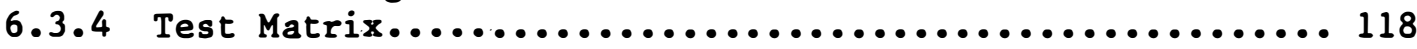

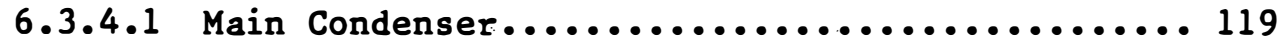

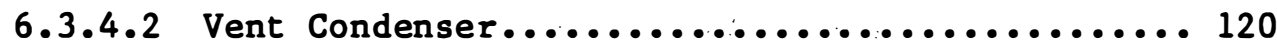

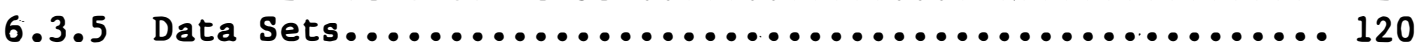

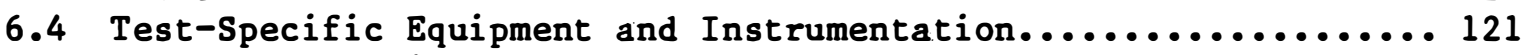

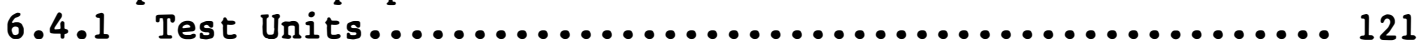

6.4.2 Specific Test Instrumentation.................... 123

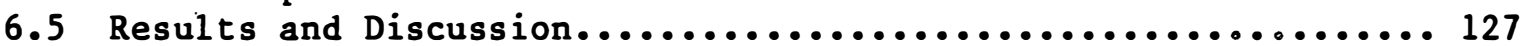

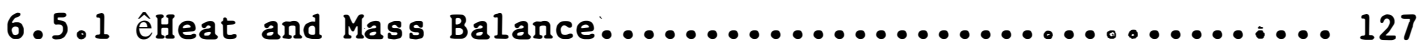

6.5 .2 Overall Performance of Main Condenser................ 130

6.5.2.1 Comparison of Steam-Side Coefficient with

Nusselt's Prediction...................... 131

6.5.2.2 Effects of Fraction of Steam Condensed........ 132

6.5.2.3 Effects of Inlet Gas Concentration........... 134

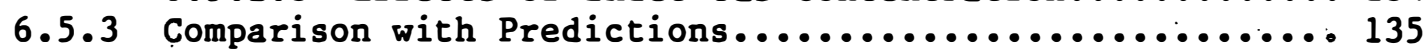

6.5.3.1 Detailed Analysis of Two Test Runs.......... 135

6.5.3.2 Comparison of Rate of Condensation.......... 137

6.5.3.3 Steam-Side Pressure Drop..................... 140

6.5.4 Overall. Performance of Vent Condenser................ 140

6.6 Conclusions...................................... 143

6.7 Application of Data to NPPE Design...................... 143

6.8 Further Research Needs................................ 144

6.9 References......................................... 144

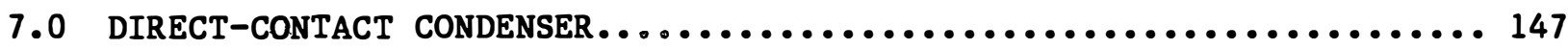

7.1 Nomenclature..................................... 148

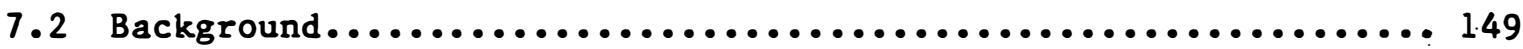

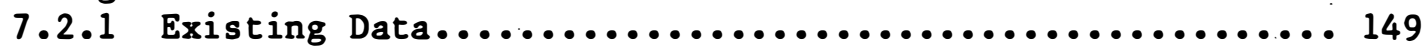

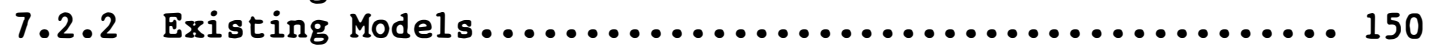

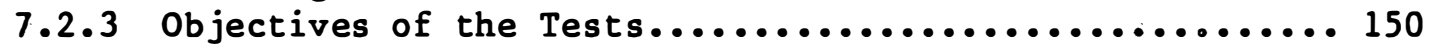

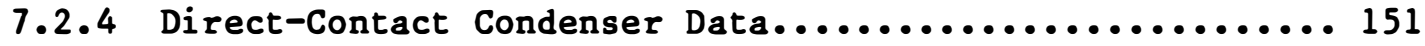

7.3 DCC Operation and Performance Parameters................. 151

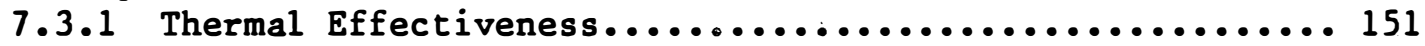

7.3 .2 Stage Jakob Number........................... 152

7.3 .3 Vent Ratio.................................. 152

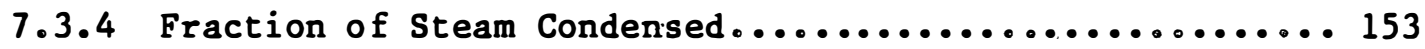

7.4 Test-Specific Equipment and Instrumentation.............. 153

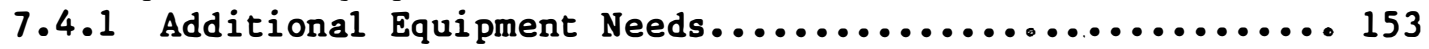

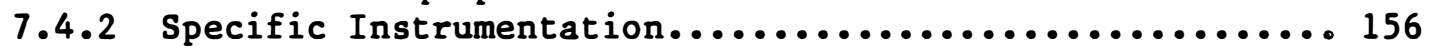

7.4.3 Specific Data Used for Performance Calculations......... 157

7.4.4 Error and Data Consistency....................... 160 


\section{TABLE OF CONTENTS (Continued)}

7.5 Test Results....................................... 163

7.5.1 Results for the First Stage (Cocurrent).............. 163

7.5.2 Results for the Second Stage (Countercurrent).......... 167

7.5.3 DCC Computer Models Validation for Seawater............ 169

7.5 .4 Overall Condenser Performance..................... 170

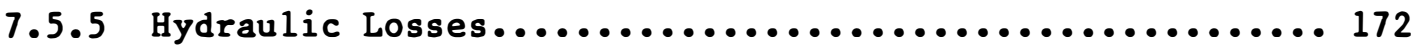

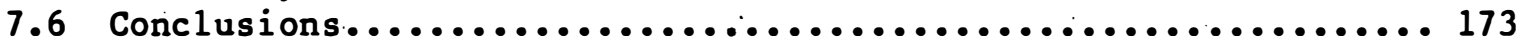

7.7 Impact of Results on NPPE System Design.................. 173

7.8 Further Research Needs.............................. 174

7.9 References....................................... 174

8.0 ÂCARBON DIOXIDE RELEASE FROM OCEAN THERMAL

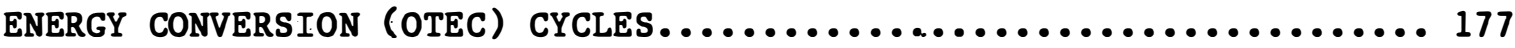

8.1 Nomenclature.................................... 178

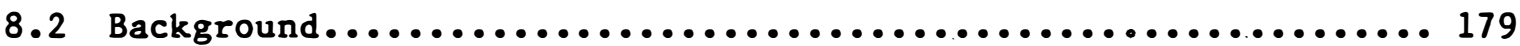

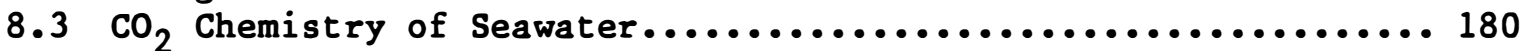

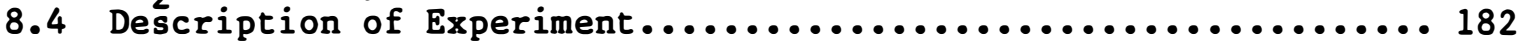

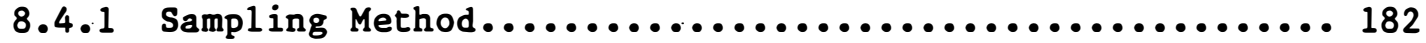

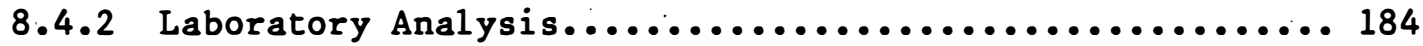

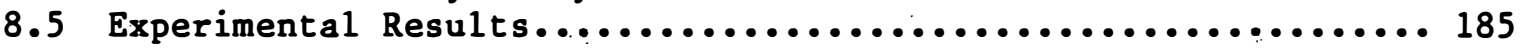

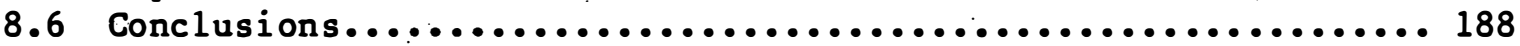

8.6 .1 Immediate $\mathrm{CO}_{2}$ Release......................... 188

8.6.2 Long-Term $\mathrm{CO}_{2}$ Release......................... 191

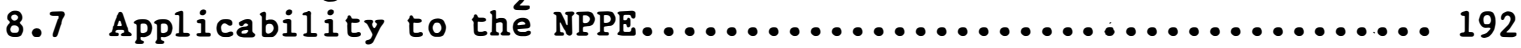

8.8 Further Research Needs............................. 192

8.9 References..................................... 192

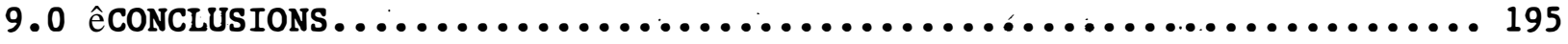

APPENDIX A: ERROR ANALYSIS.............................. 199

Nomenclature..................................... 200

A.1 Uncertainty in Primary Measurements..................... 202

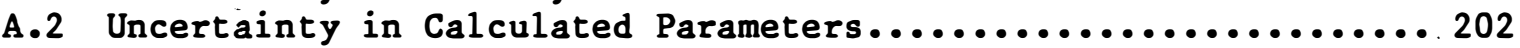

A.3 Calculation Methodology.............................. 202

A.4 References...................................... 204

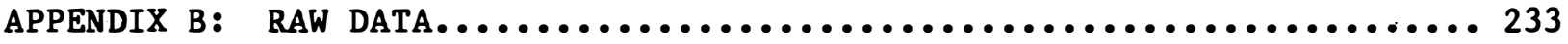

B.1 Experimental Data on Evaporator and Mist Eliminator..........235

B.2. Experimental Data on Surface Condenser.................... 243

B.3 Experimental Data on Direct-Contact Condenser............... 251

APPENDIX C: PHYSICAL PROPERTIES........................... 27.3

Nomenc lature......................................... 274

C.1 Physical Properties--Direct-Contact Condenser

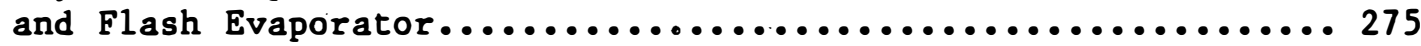




\title{
TABLE OF CONTENTS (Concluded)
}

\begin{abstract}
Page
C.2 Physical Properties--Surface Condenser................... 276

C.3 References....................................... 277
\end{abstract}

APPENDIX D: OXYGEN DESORPTION FROM WARM SEAWATER:

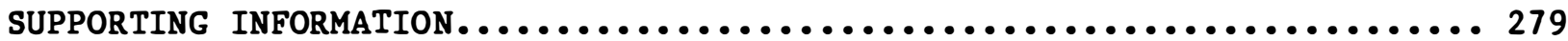

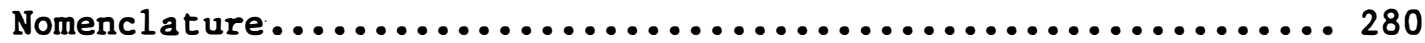

D.1 Thermodynamic Aspects of Dissolved Oxygen................. 281

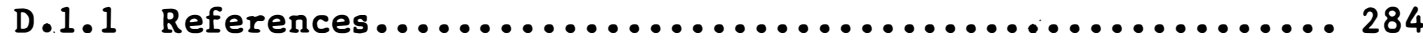

D.2 Uncertainty Analysis in Dissolved Oxygen Measurements........ 284

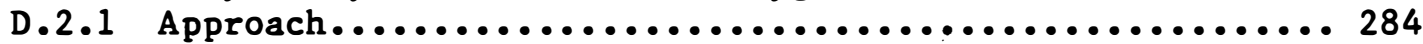

D.2.2 Error Elements.................................. 284

D.2.2.1 Uncertainty in Winkler Measurements.......... 284

D.2.2.2 Sensor-to-Sensor Error................... 286

D.2.2.3 Sensor Calibration Error.................. 286

D.2.2.4 Sensor Reading Error..................... 286

D.2.3 Error Propagation.............................. 287

D.2.4 Summary...................................... 287

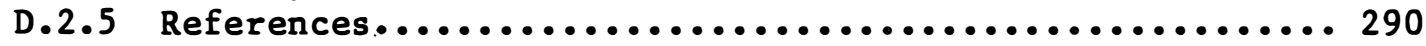

D.3 Methods of Improving Dissolved Oxygen Measurement Accuracy..... 290

D.3.1 References.................................... 291

D.4 Summary of Measured and Calculated Parameters for

Predeaeration Test................................... 292

APPENDIX E: OPERATION OF THE TEST APPARATUS AND LESSONS LEARNED........ 299

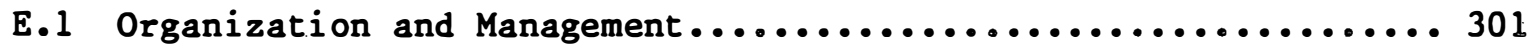

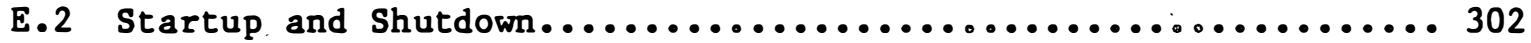

E.2.1 Startup................................... 302

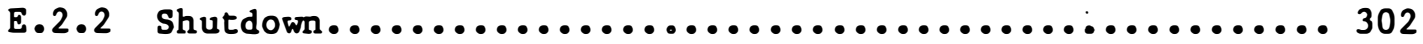

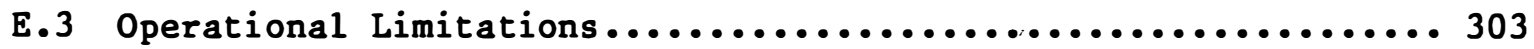

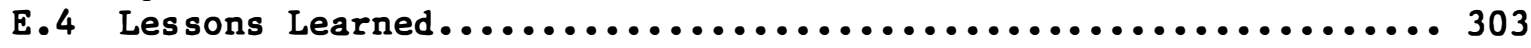

E.4.1 Improvements in Facility Operation................. 304

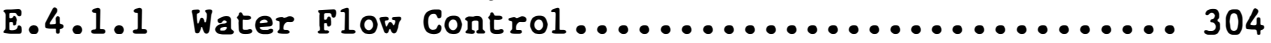

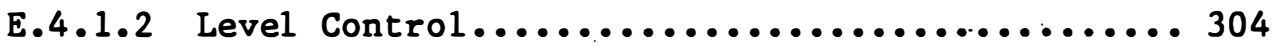

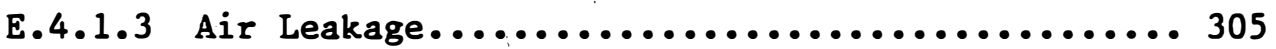

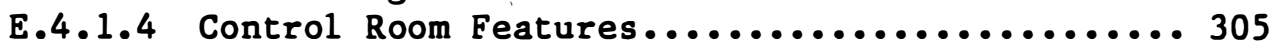

E.4.2 Improvements in Instrumentation.................. 306

E.4.3 Improvements in Test Procedures................... 307

E.5 References....................................... 307

APPENDIX F: IMPACT OF COMPONENT PERFORMANCE ON THE PERFORMANCE 


\section{LIST OF FIGURES}

$\underline{\text { Page }}$

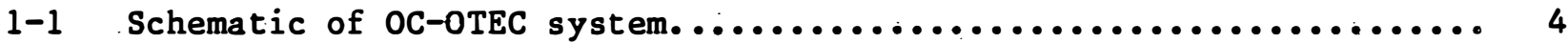

2-1a Elevation view of the Phase I HMTSTA....................... 13

2-1b Plan view of the Phase I HMTSTA........................... 14

2-2 Simplified schematic of NELH seawater supply system............ 16

2-3 HMTSTA evaporator vessel configuration.................... 18

2-4 First-stage surface condenser (plate-and-shel1, Rosenblad)

configuration used as main condenser......................... 19

2-5 Second-stage surface condenser (brazed-aluminum plate-fin, Trane) configuration used as vent condenser........................ 20

2-6 Elevation view of the Phase II HMTSTA...................... 22

2-7 Side-by-side direct-contact condenser configuration............. 23

2-8 Coaxial direct-contact condenser configuration................. 24

2-9 Cold-water flow loop configurations for the direct-contact condenser........................................... 25

2-10 Instrument locations in the Phase II HMTSTA.................. 27

3-1 Arrangement in SERI test cell for experiments with single-spout evaporator........................................... 46

3-2 Effectiveness with and without screens plotted as a function of fresh-water inlet velocity............................... 46

3-3 Photographs of spout evaporator with and without flashing........ 47

3-4 Photograph of plastic rubber screen assembly used for enhancement at the HMTSTA........................................ 53

3-5 Instrumentation employed for investigations of the HMTSTA evaporator......................................... 54

3-6 Heat balance for entire HMTSTA system...................... 56

3-7 Measurement consistency, seawater temperature difference.......... 56

3-8 Measurement consistency, seawater-to-steam temperature difference... 57

3-9 Evaporator chamber pressure inferred from temperature measurements vs. direct-pressure measurements........................ 57 


\section{LIST OF FIGURES (Continued)}

3-10 Influence of liquid loading on thermal effectiveness of seawater spout evaporator......................................

3-11 Influence of liquid loading on seawater multiple-spout evaporator; comparison with French data............................ 60

3-12 Influence of 1 iquid loading on fresh-water spout evaporator data in a confined enclosure..................................61

3-13 Influence of superheat on seawater spout evaporator............. 62

3-14 Influence of spout height on seawater spout evaporator.......... 63

3-15 Seawater evaporator, single 8-in. spout, postexperiment uncertainties.......................................... 64

3-16 Influence of liquid loading on seawater deaeration.............. 64

3-17 Measured spout pressure loss vs. dynamic pressure of seawater flowing through spout.................................. 65

4-1 Photograph of the mist eliminator........................ 76

4-2 Mist eliminator characterization......................... 77

5-1 Typical deaeration results of different experiments with fresh water and seawater.................................... 83

5-2 Schematic of warm seawater deaeration expérimental apparatus....... 87

5-3 Conical baffle plate installed in the deaeration chamber.......... 88

5-4 Bubble injection system................................ 89

5-5 Water sampling for dissolved oxygen measurements.............. 92

5-6 All data on warm seawater predeaerator oxygen desorption fraction as a function of pressure at various water flow rates obtained with baffle plate in place and no bubble injection.............. 95

5-7 All data on warm seawater predeaerator oxygen desorption fraction as a function of pressure at various water flow rates. obtained with no baffle plate and no bubble injection................... 96

5-8 Repeatability of data for, warm seawater oxygen desorption in predeaerator with baffle plate (obtained on $8 / 8-9 / 88) \ldots \ldots \ldots \ldots \ldots . . .97$

5-9 Repeatability of data for warm seawater oxygen desorption in predeaerator with no baffle plate (obtained on $8 / 10-11 / 88$ ). 


\section{LIST OF FIGURES (Continued)}

Page

5-10 Comparison of typical results of warm seawater oxygen desorption in barometric upcomer obtained in different studies.............. 99

5-11 Typical effect of bubble injection on warm seawater oxygen desorption (obtained at $25 \mathrm{~L} / \mathrm{s}$ with baffle plate on $6 / 29 / 88$ )...... 101

5-12 Increase in oxygen desorption from bubble injection (for data obtained at seawater flow rates of $25 \mathrm{~L} / \mathrm{s}$ and $50 \mathrm{~L} / \mathrm{s}$ with baffle

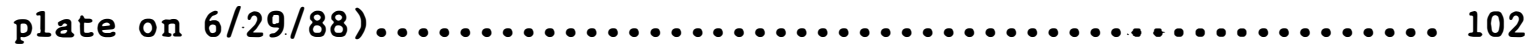

5-13 Combined warm seawater oxygen desorption in both evaporator and predeaeration chamber, as a function of predeaerator (evaporator) liquid loading........................................ 104

5-14 Schematic of a proposed predeaeration configuration for future tests using the net power-producing experiment (NPPE) apparatus..... 107

6-1 Instrumentation diagram for the main condenser................ 125

6-2 Instrumentation diagram for the vent condenser................126

6-3 Measurement consistency of calculated absolute temperature difference and measured differential temperature............... 127

6-4 Consistency of the main condenser heat balance................ 128

6-5 Comparison of evaporator and total (main + vent) condenser heat balances............................................ 129

6-6 Consistency of steam saturation temperature at the vent condenser inlet............................................... 129

6-7 Effects of water flow rate on overall heat-transfer coefficient, shown as a Wilson plot................................. 132

6-8 Effective steam-side coefficient as a function of fraction of steam condensed in main condenser............................. 133

6-9 Effective steam-side coefficient as a function of inlet gas concentration in main condenser.......................... 135

6-10 Water temperature profiles for the main condenser.............. 136

6-11 Profiles for the heat-flux ratio (actual to that assuming infinite mass-transfer coefficient) for the main condenser.........138

6-12 Comparison of calculated and experimentally measured total rates of condensation in main condenser........................ 138 


\section{LIST OF FIGURES (Continued)}

6-13 Comparison of calculated and experimentally measured rates of condensation for the cold-end section of main condenser........... 139

6-14 Comparison of calculated and experimentally measured rates of condensation for the mid-section of main condenser.............. 139

6-15 Comparison of calculated and experimentally measured rates of condensation for the warm-end section of main condenser........... 140

6-16 Comparison of calculated and experimentally measured steam-side pressure drop in main condenser............................ 141

6-17 Effects of refrigerant vapor superheat on thermal effectiveness of vent condenser....................................... 142

7-1 Location of instrumentation and types of measurements made in side-by-side configuration (similar to coaxial configuration)...... 157

7-2 Consistency of overall heat balance between heat lost by the evaporator and heat gained by the direct-contact condenser in both configurations......................................

7-3 Consistency of overall noncondensable gas mass flow rate exhausted through vacuum system as compared to calculated release assuming average $90 \%$ release of noncondensable gases from warm seawater and $100 \%$ release from cold seawater..........................

7-4 Consistency of overall thermal effectiveness calculated using differential temperature sensor data against that using differences of temperature measurements. $C$ is the average offset.............163

7-5 Consistency of vent ratio calculated based on overall inlet pressure against that using saturation pressure at inlet to first stage..... 163

7-6 Fresh-water results of percent condensed in first stage as a function of stage Jakob number obtained at the SERI OTEC laboratory and at the Seacoast Test Facility...........................165

7-7 Seawater results of percent condensed in first stage as a function of stage Jakob number for side-by-side and coaxial configurations....................................... 166

7-8 Measured gas pressure drop in first-stage (cocurrent) condenser as a function of stage steam loading.........................167

7-9 Range of variation in first-stage effectiveness resulting from changes in various input parameters......................... 168 
LIST OF FIGURES (Concluded)

Page

7-10 Seawater results of percent condensed in second stage as a function of stage Jakob number for side-by-side and coaxial configurations........................................ 169

7-11 Measured gas pressure drop in second stage as a function of stage steam loading......................................... 169

7-12 Overall performance of two direct-contact condenser stages in seawater for coaxial configuration....................... 171

7-13 Comparison of uncondensed steam exhausted from direct-contact condenser unit with respect to combined model predictions......... 172

8-1 Total concentration in the North Pacific Ocean

T., W. S. Broecker, and A. E. Bainbridge, 1981, "The Alkalinity and Total Carbon Dioxide Concentration in the World Oceans," SCOPE 16, Carbon edited by Bert Bolin, Chichester, England: John Wiley and Sons)................... 181

8-2 Sampling locations in the HMTSTA seawater supply system.......... 183

8-3 Carbon dioxide emission rates for electricity production.......... 190

8-4 Total $\mathrm{CO}_{2}$ concentration vs. depth near Oahu, Hawaii (Krock 1981).... 191

D-1 Temperature dependence of solubility of oxygen in water at equilibrium with atmospheric air.......................... 283

D-2 Pressure dependence of solubility of oxygen in seawater in equilibrium with air containing $20.95 \%$ oxygen................. 283

D-3 Fraction of oxygen desorbed at equilibrium from seawater as a function of total pressure................................ 283

F-1 Effect of heat-exchanger thermal effectiveness on net power........ 312

F-2 Effect of heat-exchanger head loss on net power............... 312

F-3 Effect of condenser gas-side pressure loss on net power........... 313

F-4 Effect of condenser temperature approach on net power............ 313

F-5 Effect of heat-exchanger gas release on net power.............. 314

F-6 Effect of predeaeration on net power........................... 315 


\section{LIST OF TABLES}

Page

2-1 General Specifications for the HMTSTA...................... 15

2-2 Characteristics of the NELH Seawater Supply System.............. 17

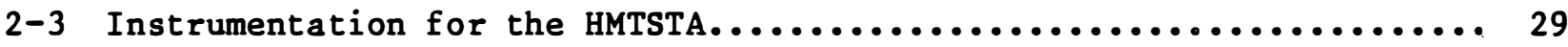

3-1 Evaporator Test Range................................. 51

3-2 Specifications for the HMTSTA Evaporator Vessel................ ê52

3-3 Evaporator Instrumentation.............................. 55

3-4 Design Conditions for the Spout Evaporator.................... 59

5-1 Warm Seawater Deaeration Test Parameters and Ranges.............. 85

6-1 Specifications for the Main (Rosenblad) Condenser................. 122

6-2 Specifications for the Vent (Trane Plate-Fin) Condenser...........123

6-3 Instrumentation for Surface-Condenser Experiments............... 124

6-4 Test Results for Wilson Plot Analysis....................... 131

6-5 Effects of Fraction of Steam Condensed...................... 133

6-6 Effects of Inlet Gas Concentration.......................... 134

6-7 Summary of Test Conditions to Evaluate Effects of Refrigerant

Vapor Superheat...................................... 142

6-8 Preliminary Specifications for the Test Unit.................. 144

7-1 Direct-Contact Condenser Configurations and Heights Tested......... 154

7-2 Range of Direct-Contact Condenser Parameters Tested at the Seacoast Test Facility..................................160

7-3 Direct-Contact Condenser Calculated Parameters--Error Summary........ 161

7-4 Measurement Consistency among Various Measurement and Calculation Methods for Direct-Contact Condenser Performance Parameters......... 164

7-5 Prediction Capabilities of Direct-Contact Condenser Models......... 170

7-6 Overall Water-Side Dynamic Loss Coefficients in Piping to Direct-Contact Condenser Stages............................. 172

8-1 Concentrations of the $\mathrm{CO}_{2}$ Species in Seawater, Representative $\hat{\mathrm{e}}$ Data for Seawater near Oahu, Hawaii (Krock 1981)................. 180 


\section{LIST OF TABLES (Concluded)}

8-2 Gas Content of Seawater near Oahu, Hawaii (Krock 1981).............181

8-3 Operating Conditions for the Evaporator and Condenser............ 182

8-4 Report of Total Dissolved Carbon Measurements and Calculated Properties........................................... 186

8-5 Results of $\mathrm{CO}_{2}$ Measurements in Warm and Cold Seawater Samples....... $187 \hat{\mathrm{e}}$

8-6 Projected Immediate $\mathrm{CO}_{2}$ Emissions from a Land-Based Open-Cycle OTEC Plant Using Direct-Contact Condensation................... 189

8-7 $\mathrm{CO}_{2}$ Emission Rates From Fossil Fuel-Fired Electric Power Plants...... 189 ê

A-1 Summary of Pretest Measurement Uncertainties................... 205

A-2 Derived Parameter Error Estimates for HMTSTA Component Tests:

Spout Evaporator.................................... 206

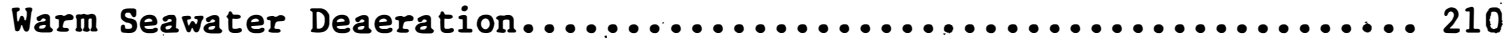

Surface Condenser..................................... 211

Direct-Contact Condenser............................... 219

B-1 Experimental Data for Evaporation of Seawater Using Vertical Spouts.. 236

B-2 Experimental Data for Pressure Loss in the Mist Eliminator.........239

B-3 Data Summary for Vent Condenser Tests........................ 244

B-4 Data Summary for Surface Condenser Tests, Main Condenser........... 248

B-5 Data Summary for Direct-Contact Condenser Tests................. 254

B-6 Effect of Principal Parameters on Cocurrent Stage................ 270

B-7 Effect of Principal Parameters on Countercurrent Stage...........271

D-1 Values of the Coefficients in Eq. D-2...................... 282

D-2 Comparison of Dissolved Oxygen Concentrations Measured with the Polarographic Instruments and by the Winkler Titration Method....... 285

D-3 Results of Uncertainty Analysis of Dissolved Oxygen Measurements..... 288

D-4 Data Table for Predeaeration Tests........................... 293 
CHAPTER 1.0

INTRODUCTION

Herbert J. Green

Solar Energy Research Institute 
This report presents the results of open-cycle ocean thermal energy conversion (OC-OTEC) experiments conducted in the Heat- and Mass-Transfer Scoping Test Apparatus (HMTSTA). The HMTSTA is the largest facility of its kind since the pioneering work in open-cycle done by Georges Claude between 1926 and 1933 . The experiments have provided seawater performance data for vertical spout flash evaporators, mist eliminators, predeaerators, and both surface and direct-contact condensers. Desalinated water was produced from seawater during condenser experiments. The data from these experiments are being used to. design a larger system experiment, the net power-producing experiment (NPPE), designed to produce net power for the first time using OC-OTEC technology.

\subsection{PRINCIPLES OF OPERATION IN AN OPEN-CYCLE SYSTEM}

Figure 1-1 shows a block diagram of a complete OC-OTEC system, including an evaporator, turbine/generator, condenser subsystem, and noncondensable gasremoval subsystem. In the open-cycle system, warm surface seawater at about $25^{\circ} \mathrm{C}\left(77^{\circ} \mathrm{F}\right)$ enters a vacuum chamber maintained at pressures around $2.7 \mathrm{kPa}$ ( $0.4 \mathrm{psi}$ ) absolute. Because this pressure is below the vapor pressure of water at $25^{\circ} \mathrm{C}$, part of the water boils in a flash-evaporative process. The remainder of the seawater, having been cooled by this evaporation, is discharged back to the ocean.

The steam is routed through a low-pressure turbine and then to a condenser, which establishes the low pressure at about $1.2 \mathrm{kPa}(0.2 \mathrm{psi})$ absolute. The turbine is coupled to a generator that produces electricity at a rate of about $70 \mathrm{~kW}$ per $\mathrm{kg} / \mathrm{s}$ of steam flow. A turbine exhaust diffuser can be used to recover some of the steam's kinetic energy and to increase system performance. A mist-removal device may be installed between the evaporator and the turbine to remove the water droplets carried by the wet steam. This device helps to protect the turbine from corrosion and erosion and, if surface condensers are used, it will prevent contamination of the fresh-water by-product by the seawater carryover (Bharathan and Penney 1983).

The condenser uses cold seawater at about $5^{\circ} \mathrm{C}\left(41^{\circ} \mathrm{F}\right)$ pumped from depths of up to $1000 \mathrm{~m}$ to condense the turbine exhaust steam and to maintain the low turbine outlet pressure. This condenser can be a direct-contact type, in which the seawater is mixed with the steam; or it can be a surface type, in which seawater is separated-from the steam by a metal surface. Surface condensers cost more than direct-contact condensers for the same efficiency. However, by preventing the cold seawater from contaminating the steam condensate, they provide desalinated water as a valuable by-product to the plant's output of electric power. Use of direct-contact condensers for desalinated water production requires operation in a closed-loop mode, as described in Chapter 7.

Most thermal power conversion systems require vent systems to remove small quantities of noncondensable (mainly oxygen and nitrogen) gas from the working fluid. In OC-OTEC, the steam contains a significantly higher percentage of this gas. One source for it is leakage from the atmosphere into the heatexchanger vacuum chambers. In addition, seawater contains small, but significant, quantities of gas in solution. When the seawater enters the lowpressure heat exchangers, a portion of the gas comes out of solution and enters the vacuum system. The desorbed gas, along with air leaking into the vacuum, accumulates in the condenser, blanketing the condensing surfaces and 


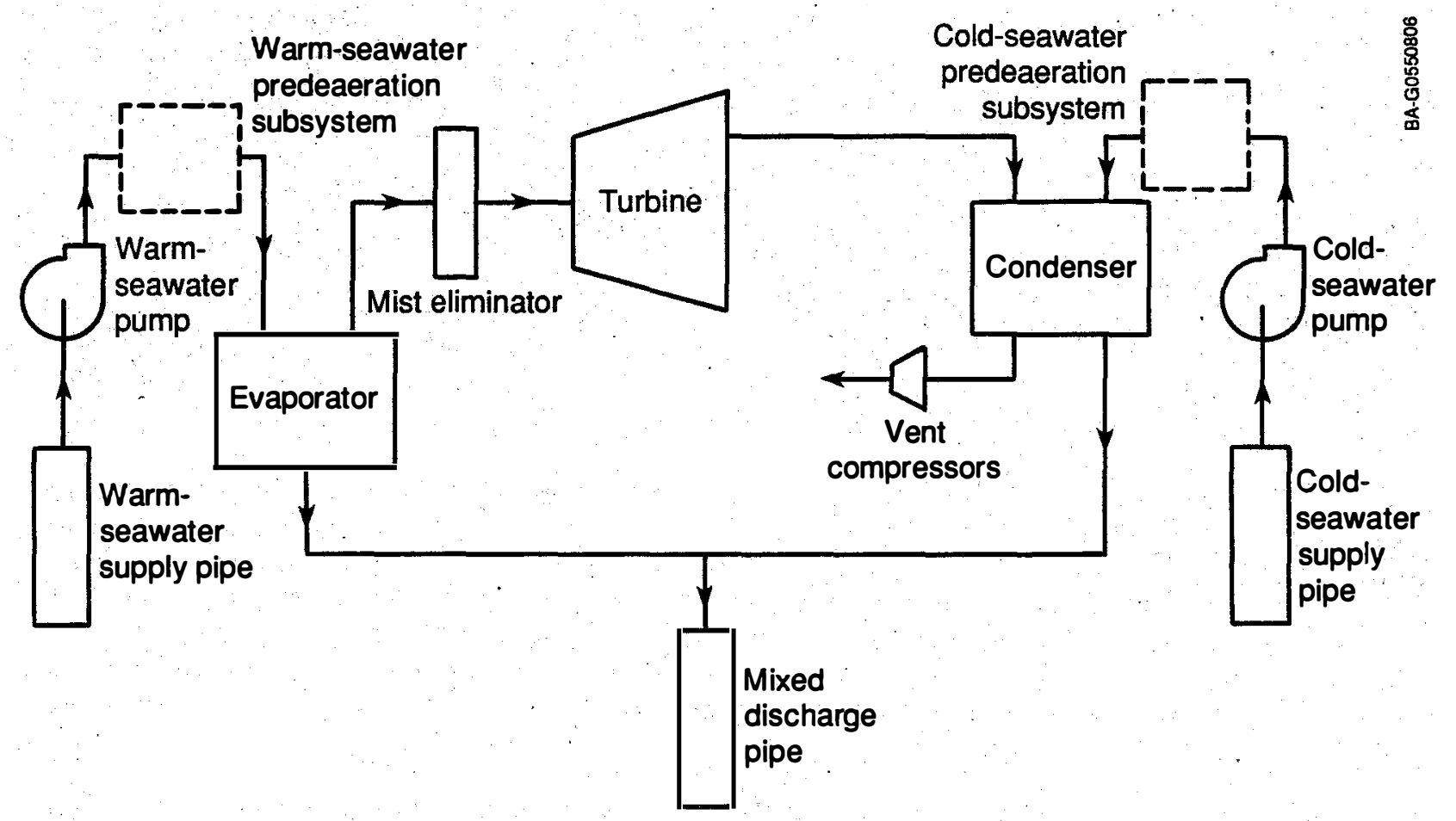

Figure 1-1. Schematic of OC-OTEC system

decreasing the heat-transfer performance. To maintain suitable operating pressures in the condenser of OC-OTEC systems, a sizable vent-compressor train is required to remove this gas.

In addition to these power system components, an OC-OTEC plant requires a seawater subsystem consisting of warm- and cold-water supply pipes, mixed-water discharge pipe, and seawater pumps. It also requires a vacuum containment structure to house the heat exchangers and, in some designs, the turbine.

Optional components of the system include two predeaerators, one in each of the cold- and warm-seawater inlet streams, located upstream of the heat exchangers and shown with dashed lines in Figure 1-1. Predeaerators remove a portion of dissolved, noncondensable gas from the water stream at a pressure higher than that in the vacuum chamber. Because the water-side pressure loss through passive predeaerators can be negligible, the passive predeaerators can reduce vent compressor power at no significant increase in parasitic pump power.

Part of the gross power produced by the generator is used to run the seawater pumps and the vent compressor. The remainder is the net power output of the plant. For large multimegawatt-sized plants, net power can be projected to be about $70 \%$ of the gross turbine output.

\subsection{OCEAN ENERGY TECHNOLOGY PROGRAM}

The HMTSTA experiments were funded by the Ocean Energy Technology Program of the U.S. Department of Energy (DOE). The long-range mission of this program 
is to develop ocean energy technology to a point at which the commercial sector can competently assess whether applications of the technology are viable energy-conversion alternatives, or supplements, to systems currently in use. Based on careful evaluation of past activities, the program's strategy is to focus on near-shore plants, both bottom mounted and land based, in the 2-15 $\mathrm{MW}$ range. A plant this size is practical for island applications. Furthermore, the size and the near-shore configuration reduce technical uncertainty. The technology developed for the 2-15 $\mathrm{MW}$ range is modularly applicable to larger plants (U.S. DOE 1985).

The projected long-range goal for capital costs of the total OTEC system is $\$ 3200 / \mathrm{kW}_{e}$. This translates into an estimated cost of service comparable to other power-generating options available. to the United States mainland Gulf and Atlantic coast regions, $14 \mathrm{c} / \mathrm{kWh}$. For the near term, research activities are focused on providing technical data sufficient for industry to design and install an OTEC system for about $\$ 7200 / \mathrm{kW}_{e} \cdot$. This approximates the estimated cost of service for oil-fired power generation in the perceived early-entry (island) market, 26c/kWh (U.S. DOE 1985).

A key technical objective of the program is to experimentally verify the validity of OC-OTEC heat- and mass-transfer predictions and power-generating techniques. To this end, the DOE has developed the Seacoast Test Facility (STF) located at the Natural Energy Laboratory of Hawaii (NELH): at Keahole Point, Kailua-Kona, Hawaii. The STF currently includes supply systems for both warm and cold seawater and the HMTSTA.

\subsection{PROGRESS OF OC-OTEC}

In 1978, DOE supported an investigation into the feasibility of OC-OTEC with a study by Westinghouse Corporation of a 100-MW floating plant (Westinghouse 1979.). Westinghouse's study indicated that the open-cycle system offers significant advantages over closed-cycle OTEC plants because it reduces or eliminates problems such as biofouling and corrosion of heat exchangers. They identified the principal uncertainties associated with the cycle and proposed additional research.

Since then, the two main laboratories currently involved in DOE's Ocean Energy Technology Program, the Solar Energy Research Institute (SERI) and Argonne National Laboratory (ANL), and their subcontractors have continued research on OC-OTEC. The research has had two main thrusts. First, computer-based models were developed to assist in analysis of system and component performance. Some characterize in detail such OC-OTEC components as spout evaporators, directcontact condensers, surface condensers, and seawater predeaerators (Ghiaasiaan and Wassel 1983; Bharathan, Parsons, and Althof 1988; Panchal and Bell 1984; Ghiaasiaan, Wassel, and Pesaran 1987). Others (Parsons, Bharathan, and Althof 1985; Block and Valenzuela 1985; Link and Shelpuk 1987) integrate less detailed component models to predict system performance.

Second, concurrently with the modeling effort, an experimental facility was constructed and operated at SERI to obtain operating data on OC-OTEC components. This facility, the Low-Temperature Heat- and Mass-Transfer Laboratory, uses fresh water for experimental testing of evaporators, condensers, and mist eliminators. Results have indicated that early predictions of component performance could be achieved or even surpassed by relatively simple and 
inexpensive components (Bharathan. and Penney 1984; Kreith 1987; Bharathan, Parsons, and Althof 1988). In preliminary tests conducted with smal1-diameter spouts using seawater, it was found that evaporator performance is approximately equal to performance achieved with fresh water (Larsen-Basse et al. 1985). On the other hand, when French researchers tested spouts with simulated seawater, they found that evaporator performance degraded slightly (Fournier 1985). Other tests indicated that predeaeration performance is significantly better with warm seawater than with fresh water (Krock and Zapka 1985). Finally, some tests of direct-contact condensers using seawater indicated that a high water-side effectiveness is readily achievable (Ridgway 1985).

\subsection{HITSTA EXPERIMENTS}

Construction of the HMTSTA greatly enhanced the ability of the Ocean Energy Technology Program to study the performance of OC-OTEC components using seawater. Although the apparatus is not large enough to resolve all of the associated heat- and mass-transfer issues, it has greatly increased the understanding of basic OC-OTEC heat- and mass-transfer processes. These tests were conducted jointly by researchers from SERI, ANL, the Pacific International Center for High Technology Research (PICHTR), and the University of Hawaii (UOH).

This report describes the first and second phases of tests conducted in the HMTSTA. For Phase I the HMTSTA combined a flash evaporator vessel with a twostage surface condenser. Surface condensers were selected because existing heat exchangers were available in the program's equipment inventory. It was judged that these heat exchangers could be modified and assembled into an operational apparatus in a short time and at relatively low cost compared to other options for a test apparatus. During Phase I experiments, prototypicalscale evaporator spouts were tested with seawater for the first time. Surface condensers were investigated under the critical conditions of subatmospheric pressure and high noncondensable gas content. The desalinated water produced in the surface condenser is believed to be the first produced using ocean thermal gradients. Predeaeration and mist-elimination configurations were studied in arrangements currently believed to be cost effective for largescale OC-OTEC plants.

Phase II addressed scoping experimental issues associated with a directcontact condenser (DCC) and confirmed the high performance seen in previous fresh-water tests. This second phase of tests required design and construction of a second vacuum vessel, seawater sump pit, and support tower. In addition to relocating and reconfiguring existing instrumentation, researchers installed new instruments and tied them into the data-acquisition system (DAS). Along with direct-contact-condenser tests, the gas content of the steam in the apparatus was characterized and the $\mathrm{CO}_{2}$ content was measured in the supply and discharge streams of both evaporator and direct-contact condenser.

The HMTSTA was a logical step in the progression from small-scale laboratory tests to large-scale system experiments. The results from the HMTSTA tests will be used to improve confidence in designing a larger-scale system experiment called the net power-producing experiment (NPPE). Current plans for the 
NPPE call for a gross power production level of at least $165 \mathrm{~kW}$ using $421 \mathrm{~kg} / \mathrm{s}(6500 \mathrm{gal} / \mathrm{min})$ of cold seawater and $620 \mathrm{~kg} / \mathrm{s}(9600 \mathrm{gal} / \mathrm{min})$ of warm seawater. The goal for net power production is at least $40 \mathrm{~kW}_{e}$ •

\subsection{ORGANIZATION OF THE REPORT}

This report is a compilation of work by eight authors. Federica Zangrando of SERI served as editor of the report, and the principal investigators provided chapters for their respective experiments.

A description of the HMTSTA system is given in Chapter 2 by Harold Link of SERI, who served as the field test engineer during Phase I and Phase II tests. Details of the apparatus, instrumentation, methods of operation, and lessons learned are included. These are not repeated in the chapters detailing component performance. The various organizations responsible for the HMTSTA design, construction, and operation are also noted.

Results of tests of flash evaporators and mist eliminators were written by Desikan Bharathan of SERI and are found in Chapters 3 and 4, respectively. Ahmad Pesaran of SERI provided the predeaerator test results in Chapter 5. Surface-condenser test results are described by C. B. Panchal of ANL in Chapter 6. Federica Zangrando served as the principal investigator for the direct-contact condenser experiments documented in Chapter 7 . Measurements of $\mathrm{CO}_{2}$ release from the HMTSTA are detailed in Chapter 8 by Herbert J. Green of SERI.

Appendices to the report include information on measurement uncertainty analysis, physical properties of seawater, and the impact of component performance on OTEC system performance. Tables of experimental data have been added as appendices if their length was too great for them to be included in the text.

Considerable effort was made to maintain consistency among chapters. However, because of the number of authors, some differences remain in the nomenclature used by different authors to denote the same physical quantities. Additionally, British units were used to calculate property functions for the surface condenser data (Appendix $C$ ) and the parameters were then converted to metric units. A nomenclature is provided at. the beginning of each chapter in which multiple parameters are presented; and these parameters are used consistently in the respective chapters, the associated data appendices, and in the calculations of measurement uncertainties related to the specific component under discussion (Appendix A).

\subsection{REFERENCES}

Bharathan, D., B. K. Parsons, and J. A. Althof, May 1988, Direct-Contact Condensers of Open-Cycle OTEC Applications: Model Validation with Freshwater Experiments for Structured Packings, SERI/TR-252-3108, Draft, Golden, CO: Solar Energy Research Institute.

Bharathan, D., and T. Penney, Dec. 1983, Mist Eliminators for Freshwater Production for Open-Cycle OTEC Systems, SERI/TR-252-1991, Golden, CO: Solar Energy Research Institute. 
Bharathan, D., and T. Penney, 1984, "Flash Evaporation from Turbulent Water Jets," Journal of Heat Transfer, Vol. 106, pp. 407-416.

Block, D. L., and J. A. Valenzuela, May 1985, Thermoeconomic Optimization of Open-Cycle OTEC Electricity and Water Production P1ants, SERI/STR-251-2603, Golden, CO: Solar' Energy Research Institute.

Fournier, T., 1985, "Open-Cycle Ocean Thermal Energy Conversion: Experimental Study of Flash Evaporation," Oceans ' 85 Conference Record, San Diego, CA: November 12-14, 1985, Vo1. 2, PP. 1222-1229.

Ghiaasiaan, S. M., and A. T. Wassel, 1983, "Inverted Vertical Spout Evaporators for Open Cycle Ocean Thermal Energy Conversion," Int. Comm. Heat and Mass Transfer, Vol. 10, Pp. 511-524.

Ghiaasiaan, S. M., A. T. Wassel, and A. A. Pesaran, 1987, "Gas Desorption from Seawater in OC-OTEC Barometric Upcomers," paper submitted for publication in the International Journal of Heat and Mass Transfer, Pergamon Press, Great Britain.

Kreith, F., 1987, "Heat Transfer Research for Ocean Thermal Energy Conversion," 1985 Max Jakob Memorial Award Lecture, presented at the opening session of the 2nd ASME-JSME Thermal Engineering Joint Conference, Honolulu, Hawaii, held March 22-27, 1987.

Krock, H. J., and M. J. Zapka, June 1985, "Open-Cycle OTEC Noncondensable Gas Exchange Characteristics,". Intersol '85, International Solar Energy Conference, Montreal, Canada.

Larsen-Basse, J., H. J. Krock, A. Sike, M. Zapka, and B. Shelpuk, 1985, "Open Cycle OTEC Experiments with Seawater--Early Results," presented at Oceans ' 85 Conference, San Diego, California, November.

Link, H. F., and B. G. Shelpuk, September 1987, Thermoeconomic Analysis of Land-Based, Open-Cycle OTEC, SERI Internal Report, SERI/TR-253-3077, Golden, CO: Solar Energy Research Institute.

Panchal, C. B., and K. J. Bell, 1984, "Theoretical Condensation in the Presence of Noncondensable Gases as Applied to Open-Cycle OTEC Condensers," ASME, presented at the 1984 Winter Annual Meeting, New Orleans, LA.

Parsons, B. K., D. Bharathan, and J. A. Althof, Sept. 1985, Thermodynamic Systems Analysis of the Open-Cycle Ocean Thermal Energy Conversion (OTEC), SERI/TR-25.2-2234, Golden, CO: Solar Energy Research Institute.

Ridgway, S. L., June 1985, "Direct-Contact Spray Condensers for Open-Cycle OTEC," InterSol '85 Conference Proceedings, held June 23-29 in Montreal, Canada: Vol. 3, PP. 1531-1535.

U.S. Department of Energy, 1985, Federal Ocean Energy Technology Program, Multi-Year Program P1an, FY 85-89, DOE/CH/10093-100, DE85016870.

Westinghouse Electric Corporation, March 5, 1979, 100 MWe OTEC Alternate Power Systems, Vol. 1: Technical Details, Lester, PA, Contract No. EG-77-C-05-1473 with U.S. Department of Energy. 
CHAPTER 2.0

EXPERIMENTAL APPARATUS AND INSTRUMENTATION

\author{
Harold Link \\ Solar Energy Research Institute
}


This chapter documents the equipment used.for all the component tests. It also describes the controls and instrumentation used in the system. Test-specific equipment and instrumentation that would not normally be used for operation of the system are described in more detail in the respective chapters on components. To conduct each series of tests, a minimum of components (seawater supply and discharge, evaporator, condenser, vacuum pump) must be operational to produce and condense the steam and to maintain the operating pressure. Therefore, system operating conditions were adjusted for each test to obtain the required conditions in the component under investigation.

\subsection{GENERAL LAYOUT AND EQUIPMENT}

The Phase I Heat- and Mass-Transfer Scoping Test Apparatus (HMTSTA) was configured primarily to permit testing of the open-cycle ocean thermal energy conversion (OC-OTEC) spout evaporator (Blake 1986). It uses warm and cold seawater and electrical power supplies at the Seacoast Test Facility (STF).

The major features of the Phase I apparatus included the following:

- An evaporator vessel suitable for conducting tests of evaporator spouts, warm-water predeaeration, and mist removal

- An evaporator supply/discharge tank located directly under the evaporator vessel

- A two-stage surface condenser system, the second stage of which uses a refrigerant to augment condensation capacity

- A vacuum compressor system to produce and maintain mechanically the subatmospheric pressures required for seawater evaporation

- Instruments and controls to monitor and adjust test conditions.

A more detailed description of the Phase I apparatus is provided in Section 2.1 of this chapter.

In Phase II, the HMTSTA was modified to test OC-OTEC direct-contact condensers. The direct-contact condenser used parts of Phase I hardware to generate steam and remove exhaust gases. Major features of the apparatus add-on include

- A vacuum vessel suitable for conducting side-by-side and coaxial experiments with two-stage direct-contact condensers

- A direct-contact condenser water supply/discharge tank located directly under the vacuum vessel

- Piping and a water-to-water heat exchanger to allow closed-loop operation

- An access and support tower for the direct-contact condenser vessel

- Modifications of steam flow paths from the evaporator and to the vacuum compressor system, and

- Instruments and controls to monitor and adjust test conditions. 


\subsubsection{Phase I}

Figures 2-1a and 2-1b show the side and top views of the Phase I apparatus. The evaporator vessel, evaporator supply/discharge tank below the evaporator, and main (first-stage) surface condenser are shown in Figure 2-1a with related piping. Besides the supply/discharge tank for the evaporator, Figure 2-1b shows a second supply/discharge tank that was used during Phase II in conjunction with direct-contact condenser experiments. The figure also shows the vent (second-stage) surface condenser and the vacuum system.

Table 2-1 provides the general specifications of the apparatus. The following subsections provide a more detailed description of each major component of the apparatus. Test-specific apparatus and instrumentation are described in more detail in the following chapters.

\subsubsection{Seawater Supply System}

The seawater supply system used for HMTSTA tests was modified extensively during the test period. At first, all cold and warm seawater was supplied through the "12-inch system," which consists of one 30-cm (12-in.) cold-water pipe and two $30-\mathrm{cm}\left(12-i n_{.}\right)$warm-water pipes. About four months into the Phase I tests, two new cold-water pipes were tied into the system. A 1-m (40-in.) pipe was constructed to supply cold seawater to the Hawaiian Ocean Science and Technology (HOST) Park and to future, larger-scale experiments at the Seacoast Test Facility. A $45-\mathrm{cm}$ (18-in.) pipe was also installed as a backup cold-water supply system.

The warm-water supply system was also upgraded with a pipe $70 \mathrm{~cm}$ (28 in.) in diameter whose primary purpose was to provide water to larger-scale experiments at the Seacoast Test Facility. Figure 2-2 shows schematically how these piping systems are interconnected. All seawater supplied to the HMTSTA flowed through the NELH header tanks. Additional information on these systems is provided elsewhere (Daniel 1989). Of primary concern in the operation of the HMTSTA was that water flows to all NELH customers be properly balanced; therefore, any major changes in HMTSTA water flows were coordinated through NELH.

Table 2-2 provides information on the capabilities of the NELH water-supply system as presently configured.

\subsubsection{Evaporator Vessel and Sump Tanks}

The evaporator vessel (Figure 2-3) is $1.07 \mathrm{~m}(3.5 \mathrm{ft}$ ) in diameter by $6.9 \mathrm{~m}$ $(22.5 \mathrm{ft}$ ) high. This aluminum vessel was modified for use in the HMTSTA to provide large openings for steam outlet, drainage of used seawater, and viewports. Both vessel diameter and warm-water flow rate restrict studies in this apparatus to three nominally configured spouts.

The height of the vessel is sufficient to permit simultaneous testing of predeaeration, evaporation, and mist removal. The mist eliminator was mounted $1 \mathrm{~m}(3.3 \mathrm{ft})$ below the steam outlet pipe and $2 \mathrm{~m}(6.6 \mathrm{ft})$ above the spout mounting plate, permitting testing of spouts as tall as $1.5 \mathrm{~m}(4.9 \mathrm{ft})$. The 2.7-m (9-ft) distance between the spout plate and the water inlet port in the bottom of the vessel facilitated a variety of predeaerator configurations. 


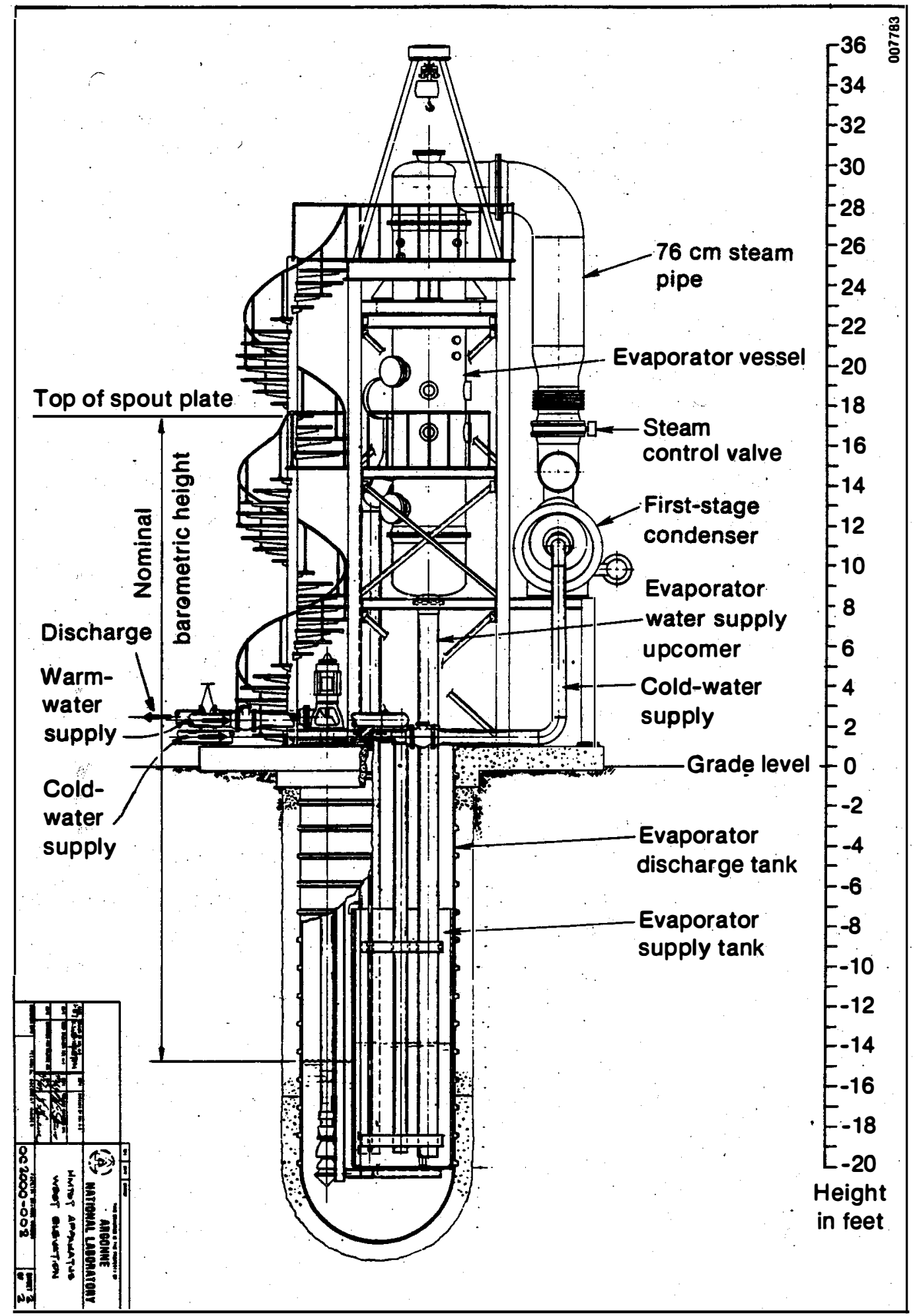

Figure 2-1a. Elevation view of the Phase I HMTSTA (taken from construction-type blueprints used for design and assembly at the HMTSTA) 


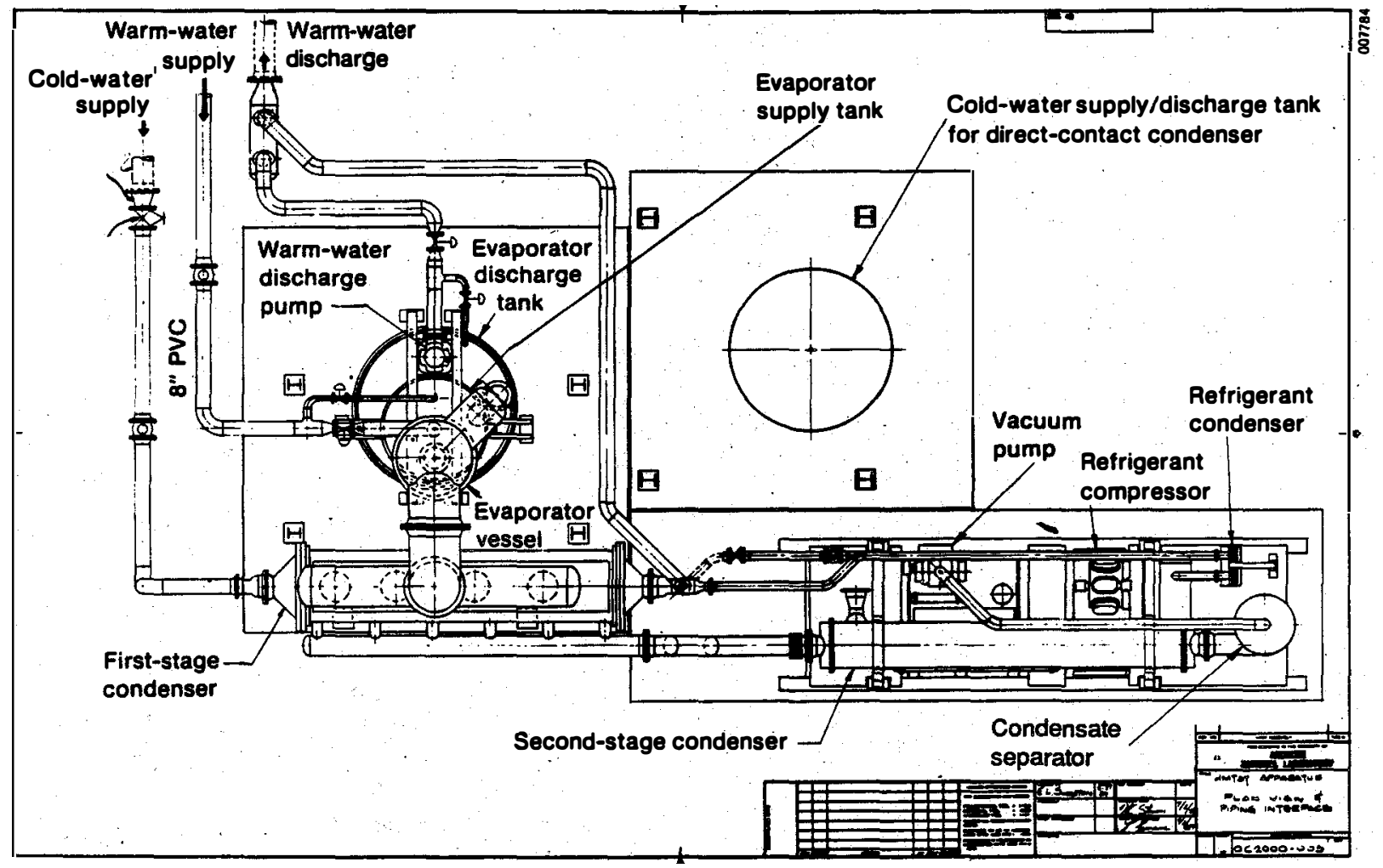

Figure 2-1b. Plan view of the Phase I HrTSTA.

(taken from construction-type blueprints used for design and assembly at the HMTSTA)

A partitioned supply/discharge sump (Figure 2-1b) was provided under the evaporator to control flow rates, establish barometric legs, and facilitate predeaeration studies. Because seawater predeaeration has been found to be sensitive to the process flow path (Krock and Zapka 1985), the HMTSTA was designed to minimize abrupt changes in direction and velocity of seawater in the upcomer (the pipe connecting the supply sump to the evaporator spouts). Water level in the supply sump was $10 \mathrm{~m}$ (33 ft) below the evaporator chamber. This distance allowed a full barometric leg to be free of flow-control valves or other devices that might affect predeaeration tests. Because the nominal evaporator pressure was only $2.3 \mathrm{kPa}$ ( 22 torr), this $10-\mathrm{m}$ ( $33-\mathrm{ft}$ ) leg balances the difference between atmospheric pressure at the surface of the supply pool and the low evaporator pressure at the outlet of the spout (see Figure 2-la).

Because the discharge sump is below grade, an axial-flow sump pump was used to discharge the water into the NELH water-disposal system. This disposal system discharged water. $2.4 \mathrm{~m}(8 \mathrm{ft})$ above sea level at a distance of about $90 \mathrm{~m}$ (300 ft) from the HMTSTA. 
Table 2-1. General Specifications for the HMTSTA

\begin{tabular}{|c|c|}
\hline Parameter & Value or Description \\
\hline Warm-water flow & $(1600 \mathrm{gal} / \mathrm{min})$ \\
\hline Warm-water temperature & $\left(75-81^{\circ} \mathrm{F}\right)$ \\
\hline Cold-water flow & $(1000 \mathrm{gal} / \mathrm{min})$ \\
\hline Cold-water temperature & $\left(43-45^{\circ} \mathrm{F}\right)$ \\
\hline Steam flow range & $(0.04-1.11 \mathrm{~b} / \mathrm{s})$ \\
\hline Minimum steam pressure & $(0.34$ psia) \\
\hline Maximum vacuum pump capacity & $(830 \mathrm{acfm})$ \\
\hline Nominal leak rate & $(2.2 \times 10-61 \mathrm{~b} / \mathrm{s})$ \\
\hline Insulation & $\begin{array}{l}\text { Evaporator, first-stage condenser, and connecting } \\
\text { steam pipe insulated with } 8-14 \mathrm{~cm} \text { of foam } \\
\text { insulation. }\end{array}$ \\
\hline & $\begin{array}{l}\text { Direct-contact condenser vessel and connecting } \\
\text { steam pipes insulated with } 2-5 \mathrm{~cm} \text { of foam } \\
\text { insulation. }\end{array}$ \\
\hline Access & $\begin{array}{l}\text { The support structure for the evaporator incorpo- } \\
\text { rates stairs, observation platforms, and an over- } \\
\text { head crane. }\end{array}$ \\
\hline & $\begin{array}{l}\text { The evaporator vessel can be entered by opening } \\
\text { full-diameter flanges at the top and bottom or via } \\
\text { a } 60-\mathrm{cm} \text { port just above the spout plate. }\end{array}$ \\
\hline & $\begin{array}{l}\text { The support structure for the direct-contact con- } \\
\text { denser incorporates straight stairs, observation } \\
\text { platforms and an overhead crane. The first level } \\
\text { direct-contact condenser planform is joined to the } \\
\text { existing first-level evaporator tower planform. - }\end{array}$ \\
\hline & $\begin{array}{l}\text { Access to the inside of the direct-contact con- } \\
\text { denser vessel is obtained by lifting the full- } \\
\text { diameter top head flange or by opening a 78-cm- } \\
\text { diameter side-mounted access port. }\end{array}$ \\
\hline & $\begin{array}{l}\text { Eight } 20-\mathrm{cm} \text {-diameter viewports give visual access } \\
\text { at two different levels. }\end{array}$ \\
\hline
\end{tabular}

Note: The seawater supply and discharge systems, the evaporator vessel, the evaporator supply/discharge tanks, the vacuum compressor system, and data acquisition system are the same for Phase II test as for Phase I tests. 


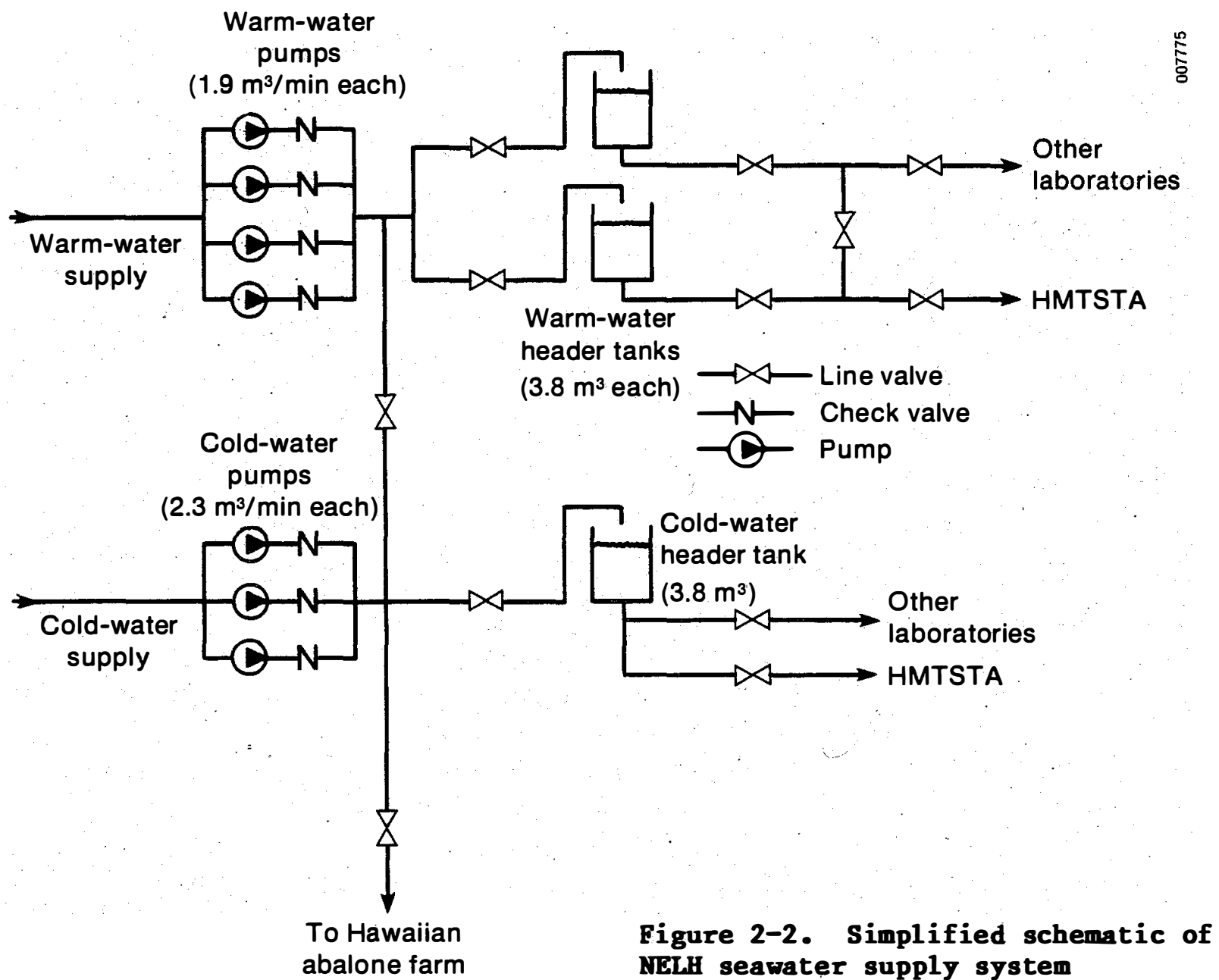

\subsubsection{Surface Condensers}

The Phase I HMTSTA is fitted with two surface condenser stages, a first-stage main condenser and a second-stage vent condenser. Both vessels were used in previous closed-cycle OTEC experiments by ANL. Major modifications to the main condenser included addition of a steam distribution manifold and partitions in the lower part of the vessel that permitted measurement of condensation rates in each of three horizontally adjacent sections. This crossflow, stainless-steel, main condenser (Figure 2-4), constructed of dimpled parallel plates welded into a plate-and-shell assembly, was rated at $1.1 \mathrm{MW}$ thermal for HMTSTA conditions.

The second-stage vent condenser, which received the gas exiting the first stage, was a brazed-aluminum plate-fin configuration (Figure 2-5) that was cooled by an R-12 charged refrigeration system. Use of zero-degree refrigerant instead of seawater in the vent condenser resulted in less steam being exhausted to the vacuum compressor system. Thus, conditions in the main condenser could be controlled over a wide range with a smaller compressor system than would otherwise be required. 
Table 2-2. Characteristics of the NELH Seawater Supply System

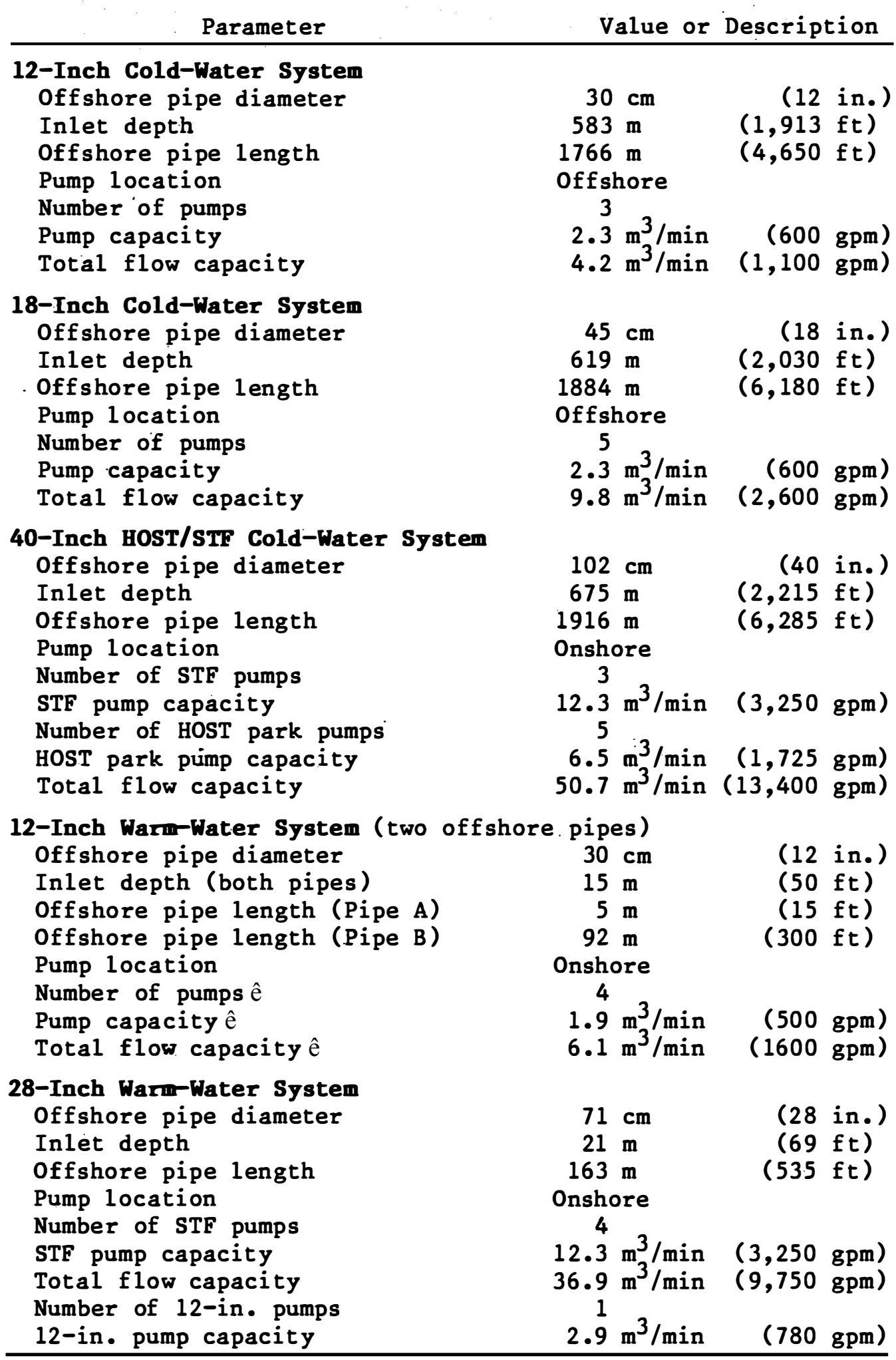

Note: Two of the STF pumps have been replaced with modified, submersible pumps originally specified for use in the 12-in. and 18-in. cold-water system. 


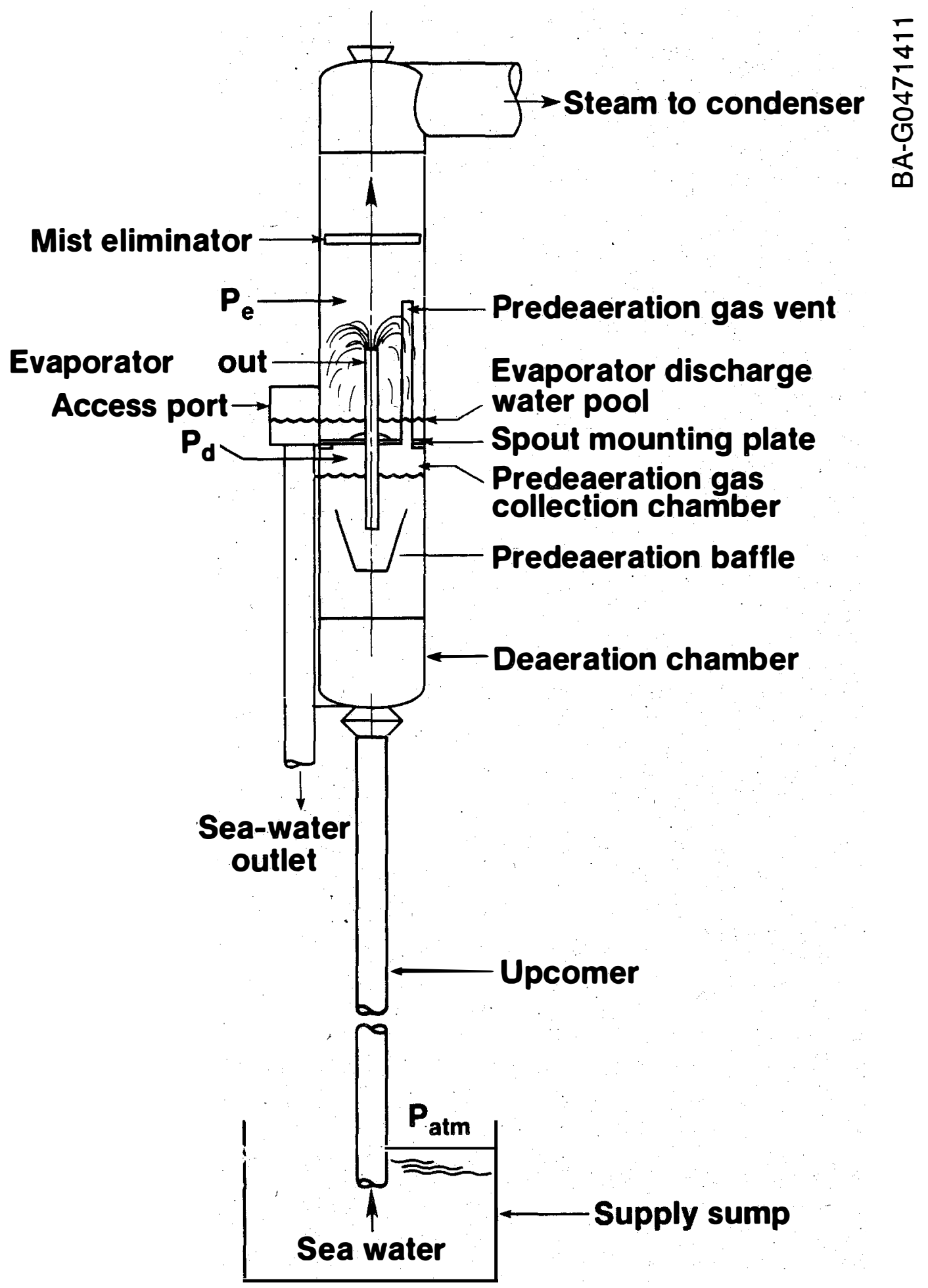

Figure 2-3. HMTSTA evaporator vessel configuration 


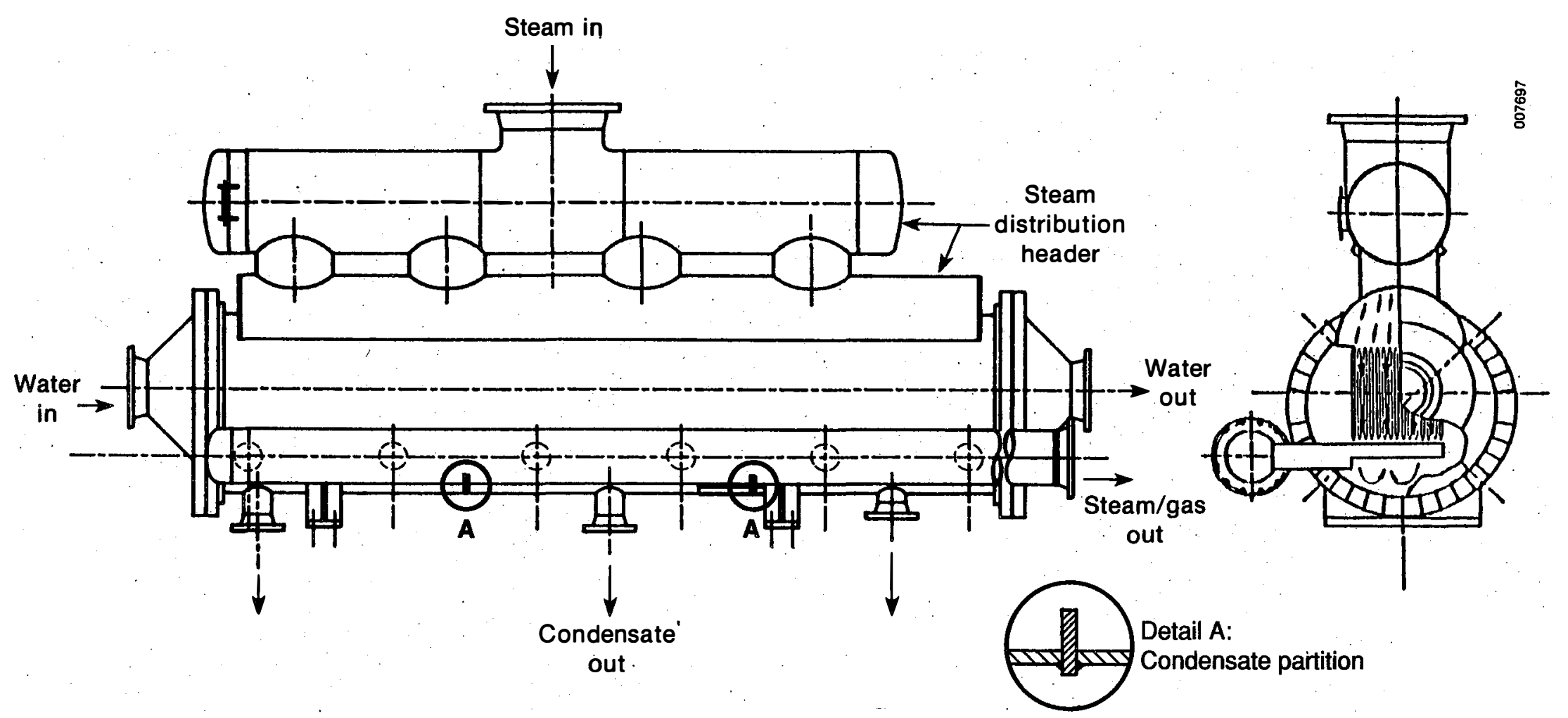

Figure 2-4. First-stage surface condenser (plate-and-shell, Rosenblad) configuration used as main condenser 

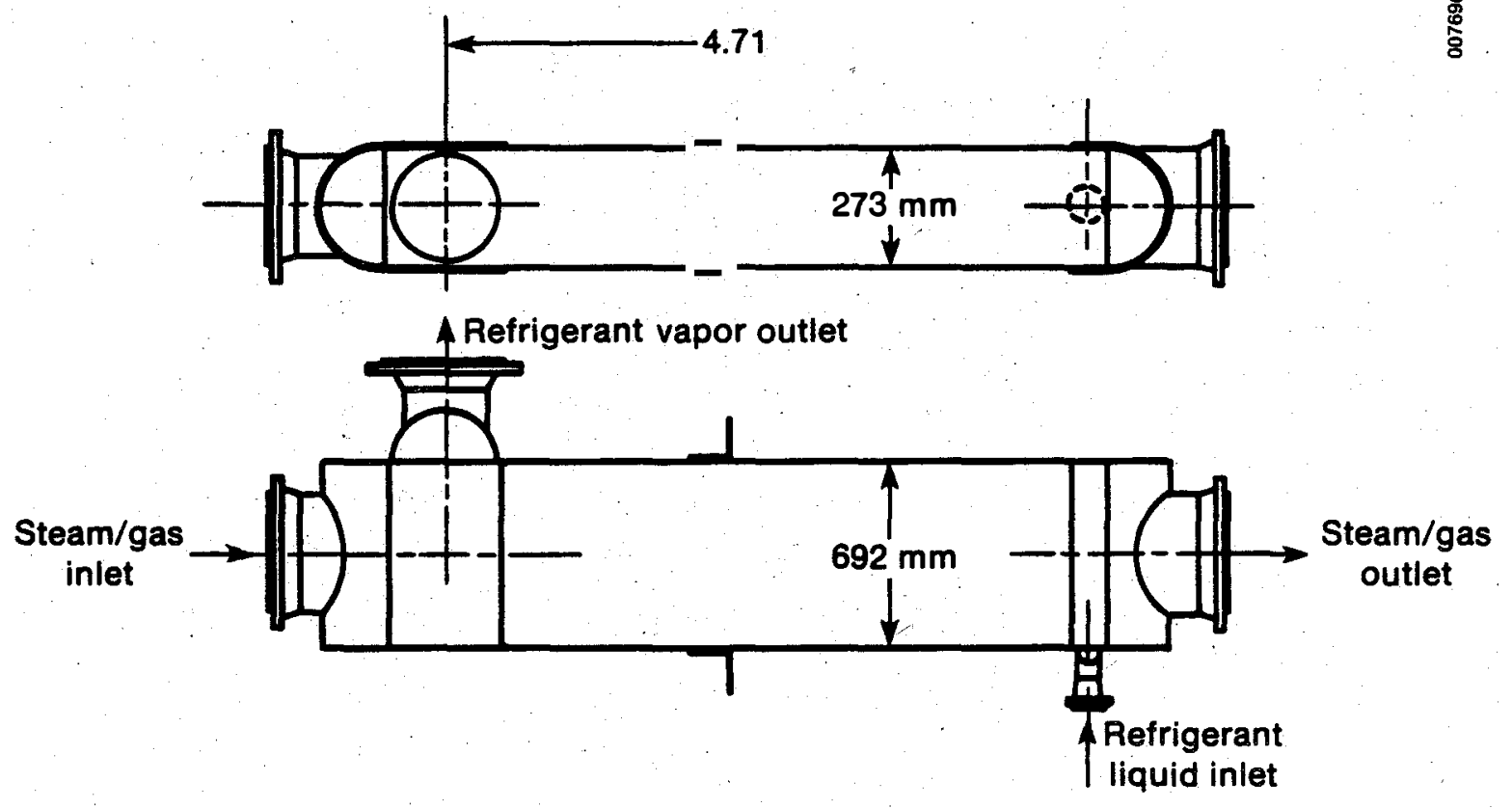

(a) External configuration of the test unit

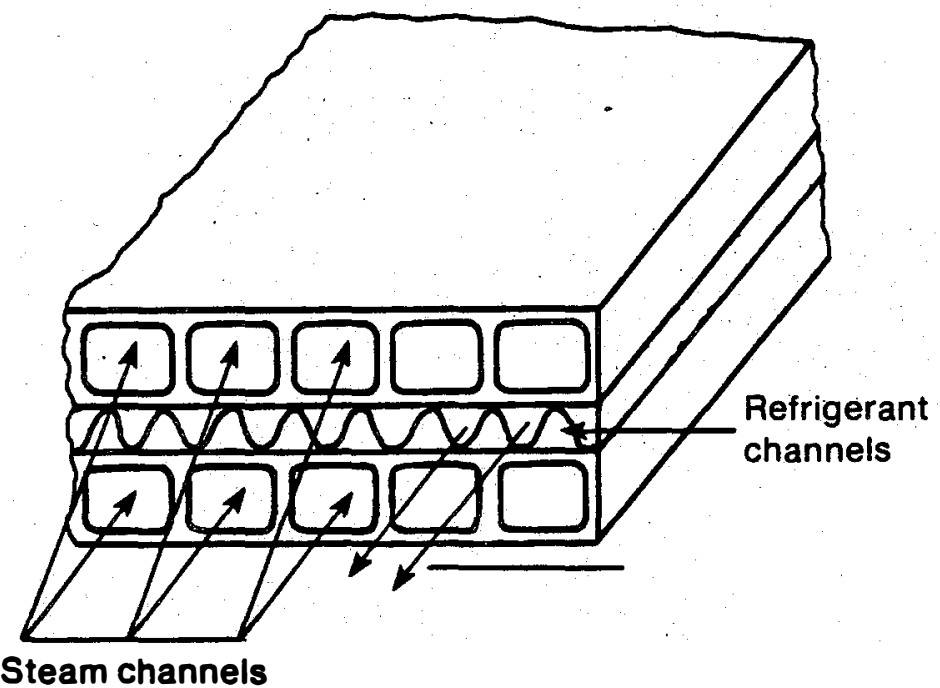

(b) Elemental section of plate-fin heat exchanger having straight, perforated refrigerant channels and extruded steam channels

Figure 2-5. Second-stage surface condenser (brazed-aluminum plate-fin, Trane) configuration used as vent condenser 
Each condenser was equipped with a receiver tank into which condensate drained. Both tanks. (which are under a partial vacuum) required automatically controlled pumps to discharge the condensate. Although condensate from the two condensers was normally discharged with the used seawater, fresh water from the first-stage condensate tank could also be directed through filters to an outlet to fill sample bottles.

\subsubsection{Auriliaries}

At the outlet of the second-stage condenser, uncondensed steam and noncondensable gases were piped to a three-stage vacuum compressor which compressed and vented them to the atmosphere. During initial tests of the apparatus, the blower-type first stage of the compressor system was slowed down and derated to $0.39 \mathrm{~m} / \mathrm{s}$ ( $830 \mathrm{acfm}$ ) at $2238 \mathrm{rpm}$, at inlet pressures of $1.3 \mathrm{kPa}$ (10 torr). These lower rates of flow better matched the capacity of the liquid-ring second and third compressor stages when noncondensable gas flow rates were high.

The refrigeration system supplied $R-12$-type refrigerant to the second-stage condenser and to a small heat exchanger in the vacuum pump loop (referred to as PSG-1) used to absorb heat of compression from the sealant water of the liquid-ring vacuum pump. Besides these two heat exchangers, the system featured a multicylinder reciprocating compressor, a plate-type refrigerant condenser, liquid and oil traps, and a receiver/reservoir. The plate-type refrigerant condenser exchanged heat from the refrigeration loop (cooling the vent condenser) to cold seawater. Controls' included "thermal" valves to control levels of liquid refrigerant in the heat exchangers, backpressure regulating valves to control pressure (and temperature) in the heat exchangers, shutoff valves, temperature and pressure indicators, and safety devices to automatically shut down the compressor in case of abnormal temperatures or pressures.

\subsubsection{Phase II Apparatus}

For Phase II tests, the first-stage surface condenser was disconnected from seawater and steam pipes and sealed off. A direct-contact condenser vessel was mounted on a steel tower adjacent to the evaporator tower (see Figure 2-1b). Steam and seawater connections to it were made as described below. Steam exiting from the direct-contact condenser was normally piped directly to the vacuum compressor. Provisions were made, but never used, to route steam through the second-stage surface condenser to provide a greater range of test conditions for the direct-contact condenser.

Figure 2-6 shows the side view of the direct-contact condenser section of the HMTSTA.

\subsubsection{Direct-Contact Condenser (DCC) Vessel}

The 1.8-m-diameter, steel, direct-contact condenser vessel provided sufficient volume to test two DCC configurations. Because the vessel resisted atmospheric loads, internal DCC stages could be constructed from lightweight transparent PVC shells. 


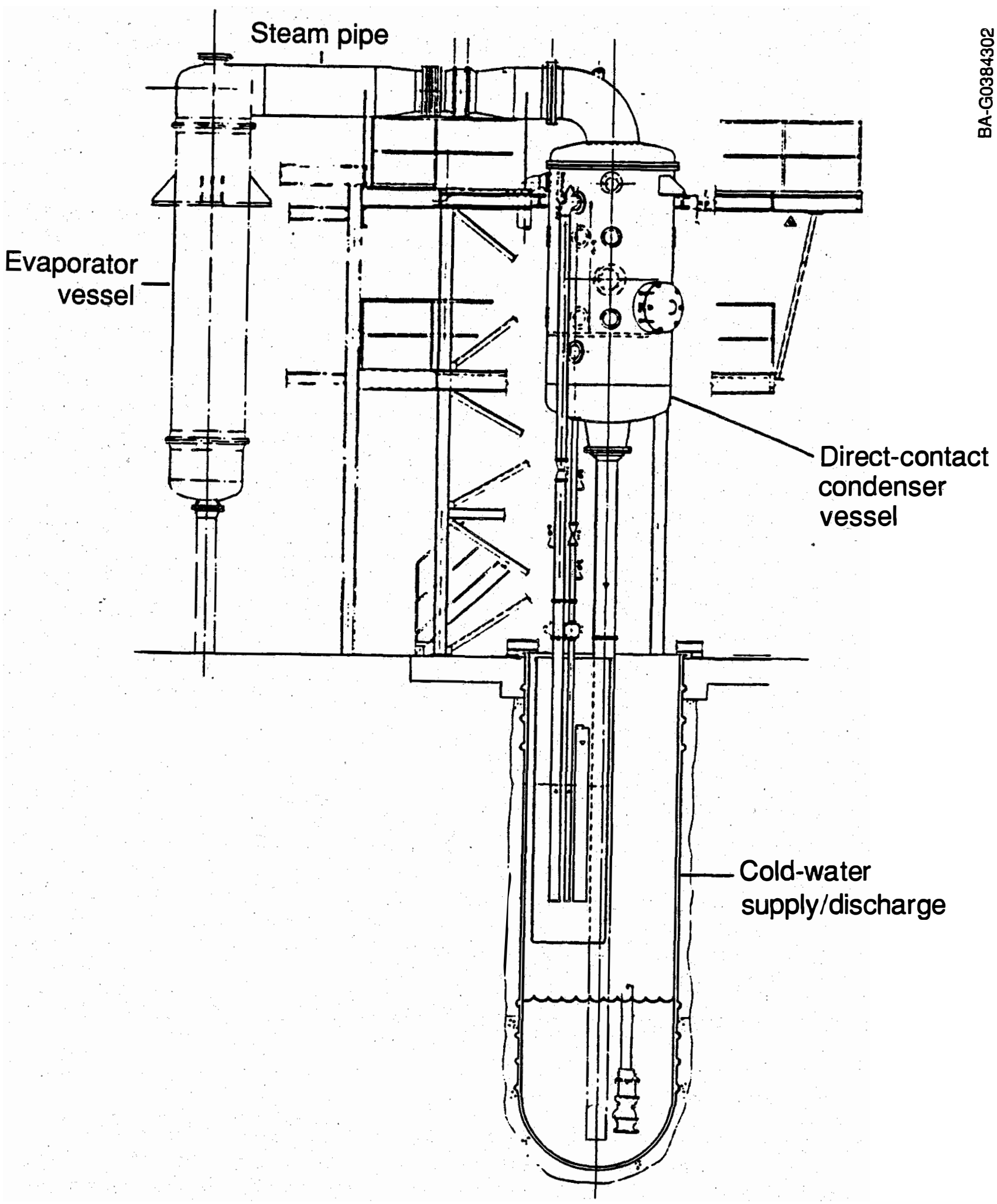

Figure 2-6. Elevation view of the Phase II HMTSTA 


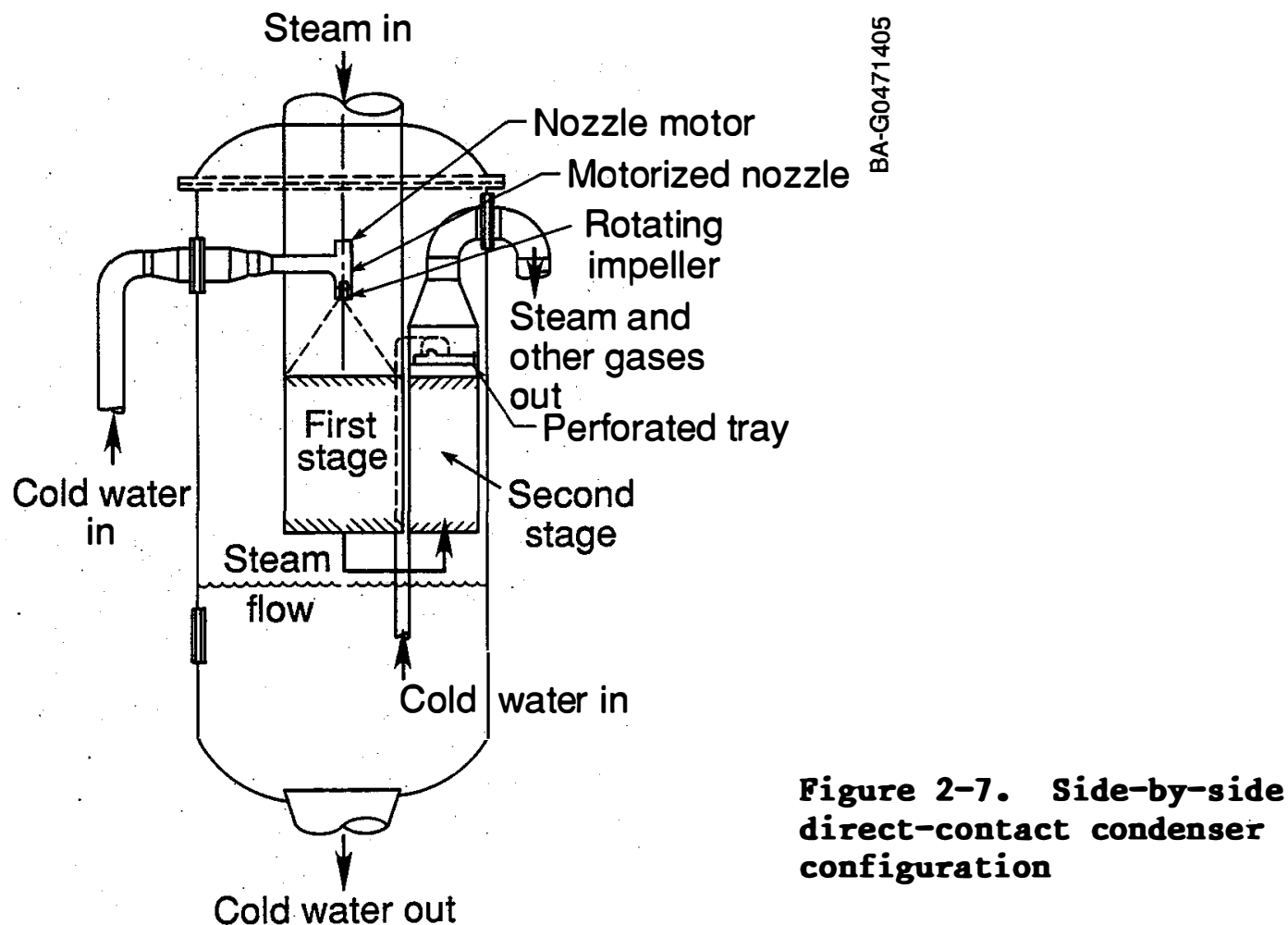

In the first DCC configuration the two cylindrical stages were arranged side by side (Figure 2-7). The arrangement only minimally disturbed the incoming steam flow in an effort to duplicate, to the greatest extent possible, test conditions in SERI's fresh-water laboratory. In the first stage, in which water and steam move downward cocurrently through structured packing, between $60 \%$ and $95 \%$ of the steam was condensed. Uncondensed s.team then traveled upward through the second stage against the falling water.

The first stage featured a hydraulically powered, adjustable-speed nozzle that could maintain even water distribution over the wide range of water flow rates that needed to be tested. This approach to water distribution is not recommended for systems in which flow rates do not vary significantly. A simple perforated plate provided excellent water distribution over the second stage. In this stage, four steam vents and a gap between the edge of the plate and the outside of the column allowed uncondensed steam and noncondensable gases to pass upward to the vacuum compressor passageway. Used water fell to a pool in the bottom of the vessel and was drained to an external sump in an arrangement similar to that of the evaporator sump.

In the second direct-contact condenser configuration, the stages were arranged coaxially (Figure 2-8). This arrangement provided condenser performance data of steam and water distribution for more prototypical OTEC plant layouts. The first stage was a $1.33-\mathrm{m}$-diameter hollow cylinder surrounding a $0.68-\mathrm{m}-$ diameter second stage. Although this configuration more efficiently used the available volume of the DCC vessel, incoming steam was subjected to sudden expansion and change in direction that might have resulted in maldistribution. 
Figure 2-8. Coarial direct-contact condenser configuration

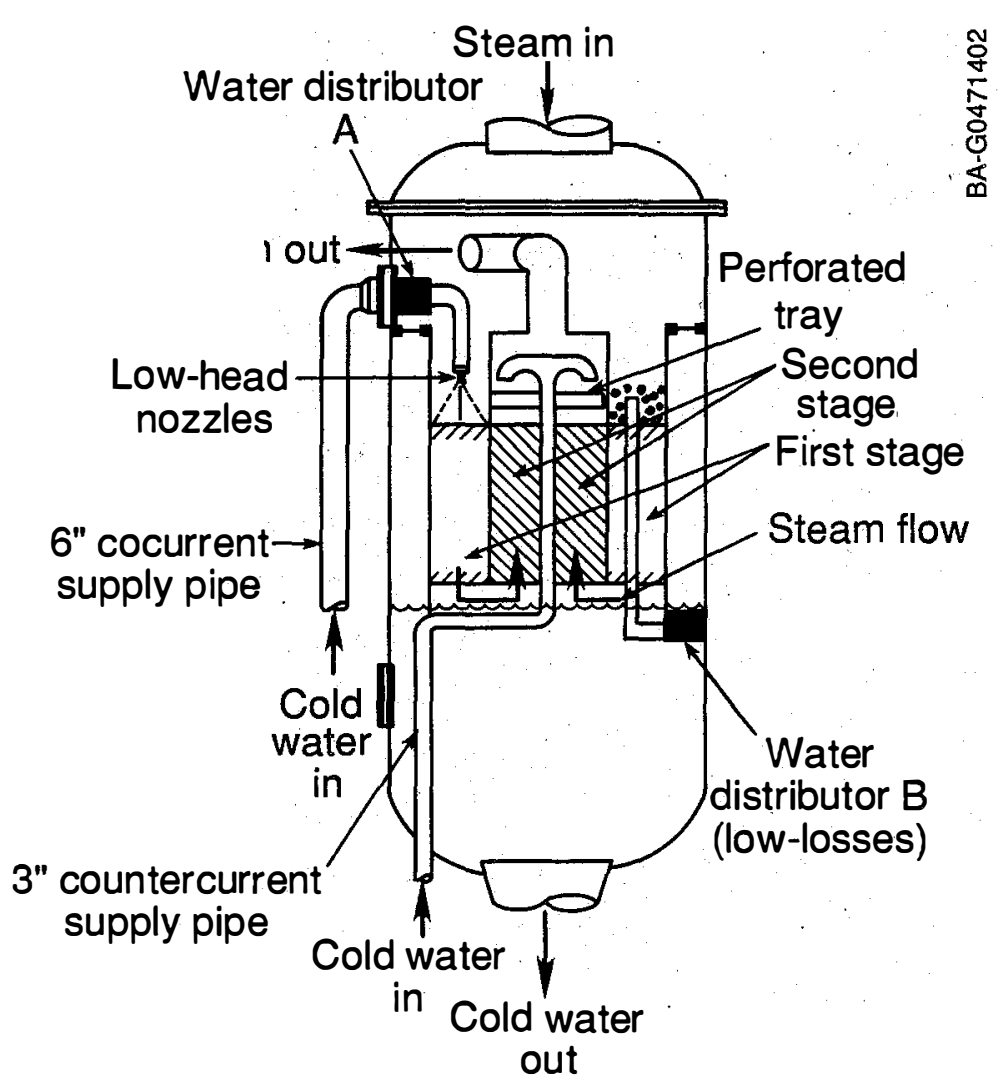

Two arrangements for water distribution were tested in the first stage of the coaxial configuration. In the first, 12 low-pressure nozzles distributed water over the annular flow area from water distributor $A$, in Figure 2-8, from a ring manifold located above the packing. In the second, the ring manifold was moved below the packing, and 12 pipes (previously used to supply the lowpressure nozzles) were directed upward through the packing (water distributor $B$ in Figure 2-8). The tops of the these pipes were left plain (i.e., without nozzles). The second stage of the coaxial configuration used a water distribution plate similar to that used in the side-by-side configuration.

A partitioned supply/discharge sump similar to the existing evaporator sump was provided under the direct-contact condenser vessel, to establish barometric legs for cold-water supply and drain. Because both DCC stages received water from a single supply sump, control valves in the upcomers provided the desired flow ratios. These valves were located as low as was practical in the upcomers and were left open as much as possible to minimize agitation and deaeration of the inlet cold water.

The discharge sump level (and, via the barometric leg, the discharge pool level in the DCC) was controlled by a differential-pressure level sensor that controlled a sump pump with variable-frequency drive. The pump discharged flow into the STF water-disposal system.

For specific tests, a batch of fluid could be circulated through the DCC stages in a closed loop. Latent heat of condensation absorbed by water in the loop was rejected to flow-through cold seawater in a surface-type, water-towater, plate heat exchanger (Figure 2-9). This arrangement permitted testing of the side-by-side DCC stages with fresh water and deaerated seawater. 


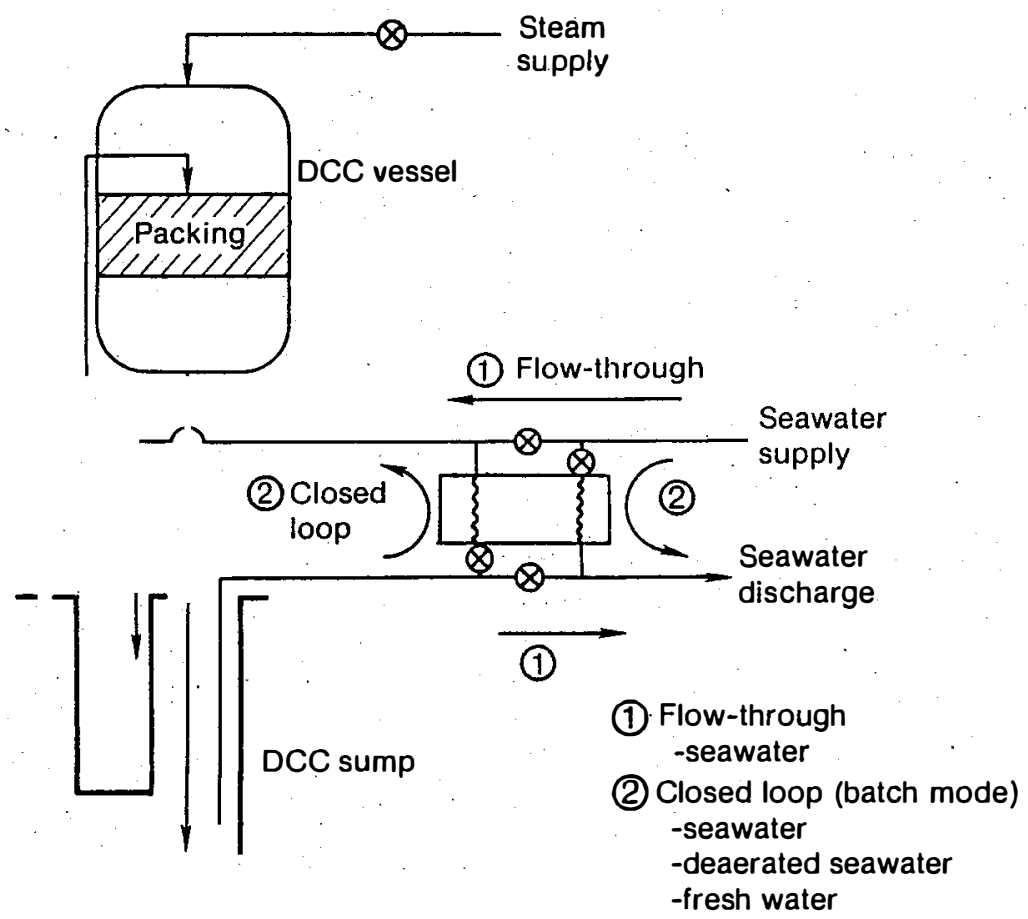

Figure 2-9. Cold-water flow loop configurations for the direct-contact condenser

\subsection{CONTROLS}

Primary controls in Phase I of the HMTSTA were

- Warm-water supply flow rate

- Warm-water discharge sump level

- Evaporator pressure

- Cold-water flow rate to the first-stage steam condenser (Rosenblad)

- Cold-water flow rate to the refrigerant condenser (auxiliary)

- Inlet pressure to the vacuum compressor.

In Phase II the same basic arrangement was maintained. However, the valves that had previously controlled flow to the first-stage surface condenser were relocated to control flow into either the DCC supply sump or the closed-loop heat exchanger. The cold-water flow to the refrigerant condenser could be provided after (in series) or parallel with the direct-contact condenser. Two controls were added for Phase II:

- Cold-water discharge sump level

- Cold-water flow to the second-stage condenser.

These controls were provided, in part, by valves operated remotely from the control room. Remotely operated valves typically were used to fine tune conditions. Coarse adjustments were achieved by manually adjusting valves locally. In the case of the cold-water discharge sump level, control was achieved by varying the speed of the discharge pump with a variable frequency drive (VFD). This VFD permitted pump speed to vary from 0 to $1800 \mathrm{rpm}$ so that discharge flow rates could be matched to supply flows without energy-wasting throttling valves. 
All control valves were butterfly type, ranging in size from $76 \mathrm{~mm}$ ( 3 in.) for flow to the second-stage condenser to $0.61 \mathrm{~m}$ ( $24 \mathrm{in.}$ ) for evaporator pressure. Two $38 \mathrm{~mm}$ ( 1.5 in.) globe-type throttling valves originally installed to control warm-water supply and discharge flows proved to be too small and were disconnected. The $0.61 \mathrm{~m}$ valve had an electric motor actuator, and the other valves were pneumatically controlled.

Feedback loops were provided for automatic control of three functions:

- Warm-water discharge sump level

- Evaporator pressure

- Cold-water discharge sump level.

Other controls included "thermal" valves, which controlled the flow rate of refrigerant to the second-stage surface condenser and to PSG-1 (to cool the liquid-ring compressor sealant). These valves closed down when the sensor indicated that the temperature of the refrigerant at the heat-exchanger outlet had cooled below a set point. This control matched the flow of refrigerant to the heat duty of the heat exchanger and prevented. liquid refrigerant from leaving the heat exchanger.

Backpressure regulators controlled the pressure in the two heat exchangers. By lowering the pressure in either, the operator could lower the refrigerant temperature. Usually the refrigerant was maintained at $0.5^{\circ} \mathrm{C}$ in the secondstage surface condenser and about $-10^{\circ} \mathrm{C}$ in PSG-1. These temperatures permitted maximum performance without frost buildup in the second-stage surface condenser.

\subsection{INSTRUMENTATION}

Figure 2-10 shows instrument locations for the various flow streams in the apparatus. A11 the instruments are 1isted in Table 2-3 together with their ranges and estimated accuracies. Sensor signals were conducted through shielded cables to appropriate signal-conditioning equipment and then to a DEC PDP 11/23+ minicomputer configured with 64 multiplexed analog-to-digital (A/D) channels. An external instrument box containing sensors that measured dissolved oxygen and conductivity was located at ground level. A second external instrument cabinet was used in Phase I to house the differential-temperature signal-conditioning cards. These cards were moved inside the instrument trailer during conversion to the Phase II configuration. The rest of the signal-conditioning instrumentation remained in the control trailer.

\subsubsection{Temperature Sensors}

The HMTSTA used platinum resistance temperature devices (RTDs) for all primary temperature measurements. Bimetal, dial-type thermometers were used in some cases, e.g., to measure the temperature of sealant water at the inlet to the liquid-ring compressor. Differential-temperature RTDs were connected in matched pairs to a single signal-conditioning card that provided a 10-Volt DC (VDC) output with a gain of $1.5^{\circ} \mathrm{C} / \mathrm{V}$. Absolute-temperature RTDs were connected to signal-conditioning cards that provided 0-5 VDC output with a gain of $20^{\circ} \mathrm{C} / \mathrm{V}$. All signal-conditioning cards were located in the instrument trailer and were connected to their RTDs using a four-wire configuration. 


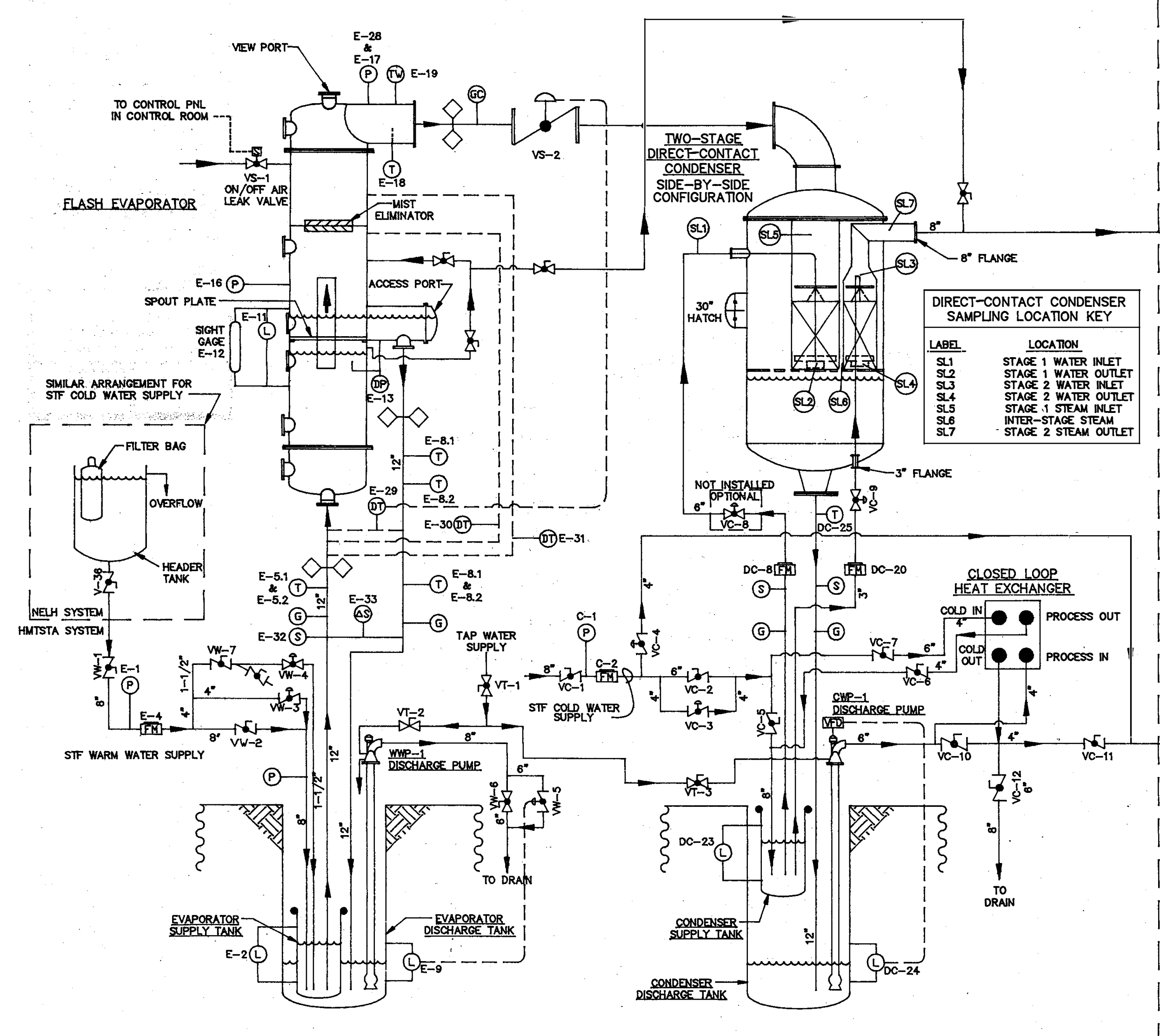

LEGEND

\begin{tabular}{|c|c|c|c|}
\hline & GAS COMPOSTITON & $\infty$ & GLOEE VAVE \\
\hline & GAS ANALISTSS & $\infty$ & $\begin{array}{l}\text { MANUNUY OPQRATED } \\
\text { BAL VNLVE }\end{array}$ \\
\hline & SALINTS & $N$ & CHECK VNVVE \\
\hline 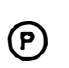 & PRESSURE & $\infty$ & $\begin{array}{l}\text { FOOW CONTROL VNVE } \\
\text { GLOEE PATIRRN }\end{array}$ \\
\hline & YQNOD LVVE INOICATOR & Lै & 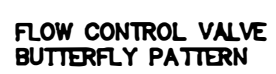 \\
\hline & DIFFEDENAL PRESSURE & $\sqrt{\omega}$ & $\begin{array}{l}\text { MANUNUY OPRRATD } \\
\text { BUTRRFY VALVE }\end{array}$ \\
\hline & 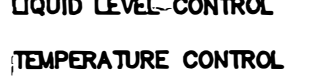 & $D 5$ & $\begin{array}{l}\text { MANUNYY OPERATDD } \\
\text { GLOEE VLLVE }\end{array}$ \\
\hline & WET GULB TEAPERA URE & & 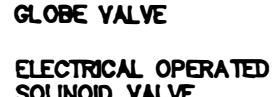 \\
\hline & DW METRR & $\bowtie$ & \\
\hline & $\begin{array}{l}\text { ROW STREM } \\
\text { ORIFCE }\end{array}$ & & \\
\hline
\end{tabular}

Figure 2-10.

Instrument locations in the Phase II HMTSTA

Note: This figure was taken from constructiontype blueprints used for design and assembly at of this figure. repeated. 


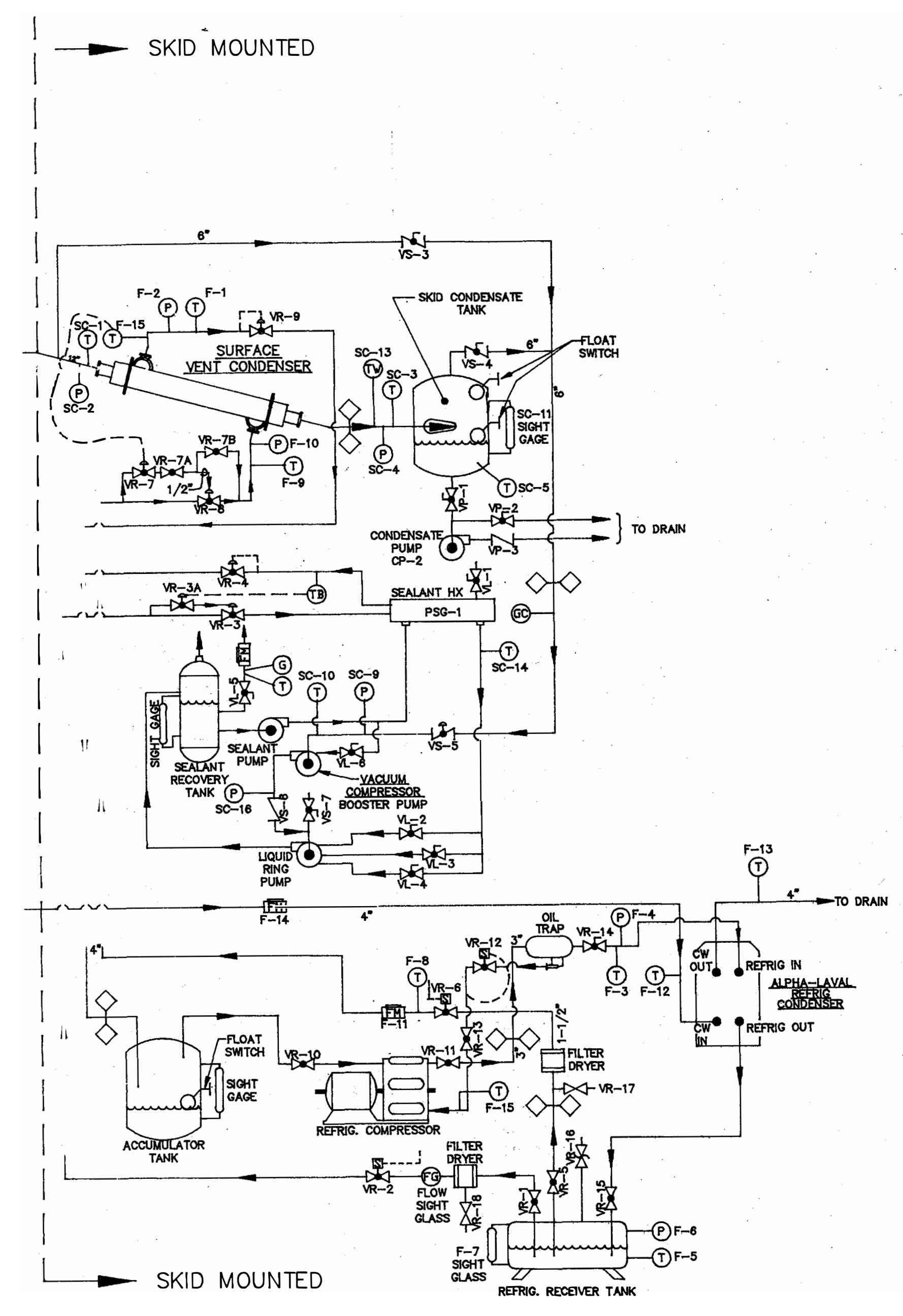

\section{LEGEND}

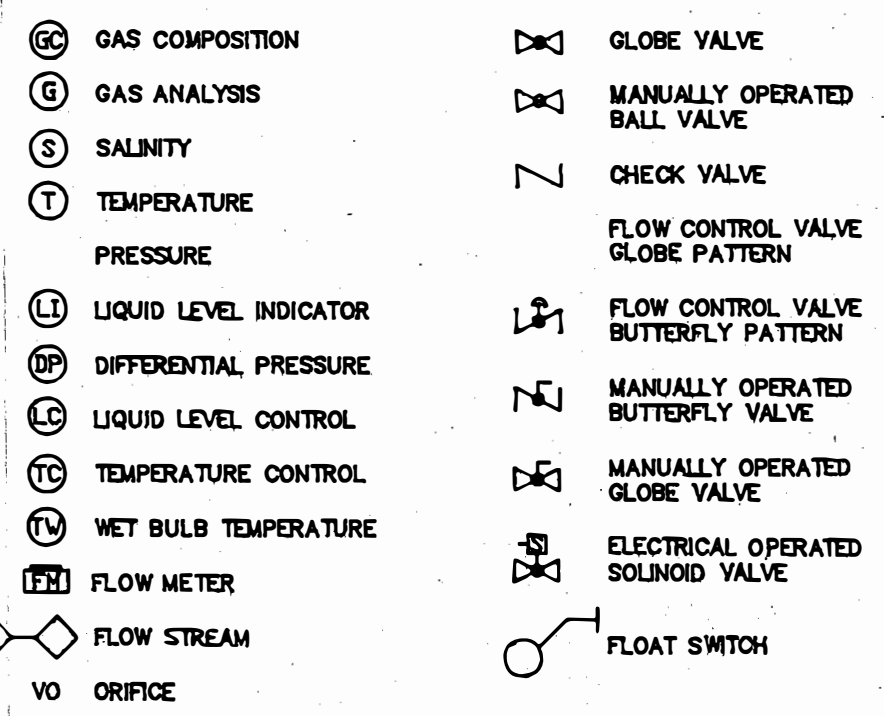

Figure 2-10. (Continued)

Instrument locations in the Phase II HMTSTA

Note: This figure was taken from constructiontype blueprints used for design and assembly at the HMISA. See other side for the remainder repeated.

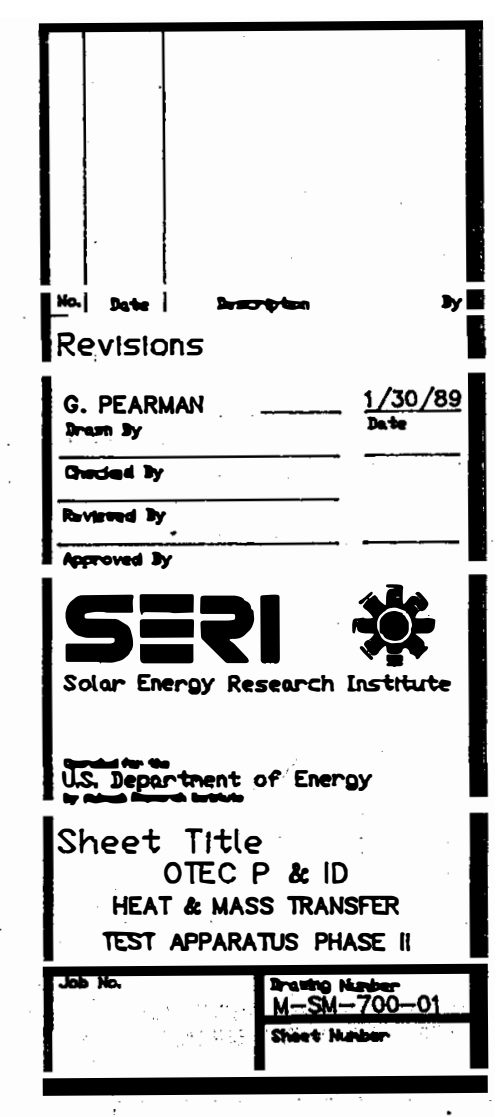


Table 2-3. Instrumentation for the HMTSTA

\begin{tabular}{|c|c|c|c|c|c|}
\hline Ref. No. & Function & Sensor Type & Location & Range & $\begin{array}{l}\text { Installed } \\
\text { Accuracy } \\
end{array}$ \\
\hline $\begin{array}{l}\text { E-1-P } \\
\text { E-2-L } \\
\text { E-3-LC } \\
\text { E-4-FM } \\
\text { E-5.1-T } \\
\text { E-5.2-T } \\
\text { E-8.1-T } \\
\text { E-8.2-T } \\
\text { E-9-L } \\
\text { E-10-LI } \\
\text { E-11-L } \\
\text { E-12-L } \\
\text { E-13-DP } \\
\text { E-14-T } \\
\text { E-15-TW } \\
\text { E-16-P } \\
\text { E-17-P } \\
\text { E-18-T } \\
\text { E-19-TW } \\
\text { E-20-T } \\
\text { E-21-P } \\
\text { E-22-DO } \\
\text { E-23-DO } \\
\text { E-24-DO } \\
\text { E-25-DP } \\
\text { E-26-DP } \\
\text { E-27-P } \\
\text { E-28-P } \\
\text { E-29.1-DT } \\
\text { E-29.2-DT } \\
\text { E-30-DT } \\
\text { E-31-DT } \\
\text { E-32-S } \\
\text { E-33-S } \\
\text { E-35-L }\end{array}$ & $\begin{array}{l}\text { Pressure } \\
\text { Water level } \\
\text { Water level } \\
\text { Flow rate } \\
\text { Temperature } \\
\text { Temperature } \\
\text { Temperature } \\
\text { Temperature } \\
\text { Water level } \\
\text { Water leve1 } \\
\text { Water leve1 } \\
\text { Water level } \\
\text { Delta-P } \\
\text { Temp, dry bulb } \\
\text { Temp, wet bulb } \\
\text { Pressure } \\
\text { Pressure } \\
\text { Temp, dry bulb } \\
\text { Temp, wet bulb } \\
\text { Temperature } \\
\text { Pressure, abs } \\
\text { Dissolved } 0_{2} \\
\text { Dissolved } 0_{2} \\
\text { Dissolved } 0_{2} \\
\text { Delta P } \\
\text { Delta P } \\
\text { Pressure, abs } \\
\text { Pressure, abs } \\
\text { Delta T } \\
\text { Delta T } \\
\text { Delta T } \\
\text { Delta T } \\
\text { Salinity } \\
\text { Salinity } \\
\text { Water level }\end{array}$ & $\begin{array}{l}\text { Strain gauge } \\
\text { Capacitance } \\
\text { Ultrasonic } \\
\text { Vortex } \\
\text { RTD } \\
\text { RTD } \\
\text { RTD } \\
\text { RTD } \\
\text { Capacitance } \\
\text { Ultrasonic } \\
\text { Capacitance } \\
\text { Sight glass } \\
\text { Strain gauge } \\
\text { RTD } \\
\text { RTD } \\
\text { Capacitance } \\
\text { Capacitance } \\
\text { RTD } \\
\text { RTD } \\
\text { RTD } \\
\text { Strain-gauge } \\
\text { Polarographic } \\
\text { Polarographic } \\
\text { Polarographic } \\
\text { Capacitance } \\
\text { Capacitance } \\
\text { Capacitance } \\
\text { Capacitance } \\
\text { RTD } \\
\text { RTD } \\
\text { RTD } \\
\text { RTD } \\
\text { Conductivity } \\
\text { Conductivity } \\
\text { Sight glass }\end{array}$ & $\begin{array}{l}\text { Warm water supply } \\
\text { Inlet tank } \\
\text { Inlet tank } \\
\text { Warm water in } \\
\text { Warm water in } \\
\text { Warm water in } \\
\text { Warm water out } \\
\text { Warm water out } \\
\text { Out let tank } \\
\text { Outlet tank } \\
\text { Evaporator } \\
\text { Evaporator } \\
\text { Evaporator spout } \\
\text { Steam, evaporator } \\
\text { Steam, evaporator } \\
\text { Steam, evaporator } \\
\text { Steam, mist elim. } \\
\text { Steam, mist elim. } \\
\text { Steam, mist elim. } \\
\text { Ambient } \\
\text { Ambient } \\
\text { Pred. water in } \\
\text { Evap. water in } \\
\text { Water out } \\
\text { Across pred. baff } 1 \text { e } \\
\text { Across mist elim. } \\
\text { Predeaerator } \\
\text { Evaporator } \\
\text { Water in - water out } \\
\text { Water in - water out } \\
\text { Water in - wb evap } \\
\text { Water in - wb stm mst el } \\
\text { Water in } \\
\text { Prct diff: wi-wo } \\
\text { Predeaerator }\end{array}$ & $\begin{array}{l}0-207 \mathrm{kPa} \\
0-2.4 \mathrm{~m} \\
\text { No } 1 \text { onger installed } \\
19-184 \mathrm{~kg} / \mathrm{s} \\
(-100)-260^{\circ} \mathrm{C} \\
(-100)-260^{\circ} \mathrm{C} \\
(-100)-260^{\circ} \mathrm{C} \\
(-100)-260^{\circ} \mathrm{C} \\
0-2.4 \mathrm{~m} \\
\text { No } 1 \text { onger installed } \\
0-2.4 \mathrm{~m} \\
0-1.2 \mathrm{~m} \\
0-34.5 \mathrm{kPa} \\
\text { No } 1 \text { onger installed } \\
\text { Never installed } \\
0-6.2 \mathrm{kPa} \\
\text { No } 1 \text { onger installed } \\
(100)-260^{\circ} \mathrm{C} \\
\text { Never insta1led } \\
\text { Never installed } \\
0-101 \mathrm{kPa} \\
0-20 \mathrm{ppm} \\
0-20 \mathrm{ppm} \\
0-20 \mathrm{ppm} \\
0-2 \mathrm{kPa} \\
0-600 \mathrm{~Pa} \\
0-45 \mathrm{kPa} \\
0-110 \mathrm{kPa} \\
0-30^{\circ} \mathrm{C} \\
0-30^{\circ} \mathrm{C} \\
\text { No } 10 \mathrm{nger} \text { installed }^{+} \\
0-30^{\circ} \mathrm{C} \\
30-37 \mathrm{ppt} \\
340 \mathrm{ppm} \\
0-1 \mathrm{~m}\end{array}$ & $\begin{array}{l}\text { (Absolute Value) } \\
\pm 0.9 \mathrm{kPa} \\
\pm 6.4 \mathrm{~mm} \\
\pm 1.7 \mathrm{~kg} / \mathrm{s} \\
\pm 0.26^{\circ} \mathrm{C} \\
\pm 0.26^{\circ} \mathrm{C} \\
\pm 0.26^{\circ} \mathrm{C} \\
\pm 0.26^{\circ} \mathrm{C} \\
\pm 6.4 \mathrm{~mm} \\
+6.4 \mathrm{~mm} \\
\pm 5 \mathrm{~mm} \\
\pm 0.3 \mathrm{kPa}\end{array}$ \\
\hline
\end{tabular}


Table 2-3. Instrumentation for the HMTSTA (Continued)

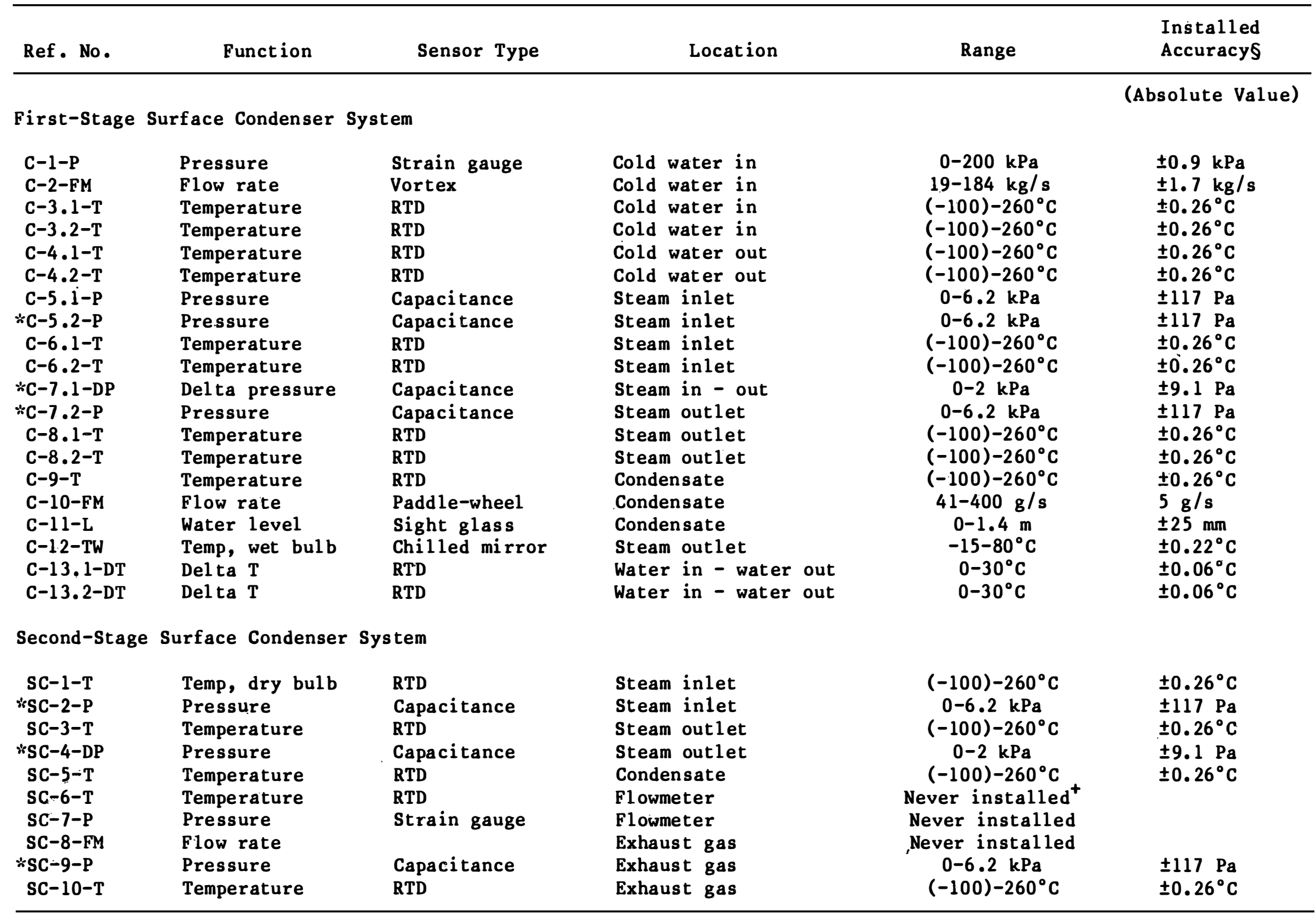


Table 2-3. Instrumentation for the HMTSTA (Continued)

\begin{tabular}{|c|c|c|c|c|c|}
\hline Ref. No. & Function & Sensor Type & Location & Range & $\begin{array}{l}\text { Installed } \\
\text { Accuracy }\end{array}$ \\
\hline $\begin{array}{l}\text { SC-11-L } \\
\text { SC-12-FM } \\
\text { SC-13-TW } \\
\text { SC-14-T } \\
\text { SC-15-TW }\end{array}$ & $\begin{array}{l}\text { Level } \\
\text { Flow rate } \\
\text { Temp, wet bulb } \\
\text { Temperature } \\
\text { Temp, wet bulb }\end{array}$ & $\begin{array}{l}\text { Sight glass } \\
\text { Turbine } \\
\text { Chilled mirror } \\
\text { Dial gauge } \\
\text { RTD }\end{array}$ & $\begin{array}{l}\text { Separator } \\
\text { Condensate } \\
\text { Steam outlet } \\
\text { Liq. ring coolant } \\
\text { Exhaust gas }\end{array}$ & $\begin{array}{c}0-25 \mathrm{~cm} \\
\text { Never installed } \\
-15-80^{\circ} \mathrm{C} \\
\text { Not connected } \\
\text { Never installed }\end{array}$ & $\begin{array}{l}\text { (Absolute Value) } \\
\pm 25 \mathrm{~mm} \\
\pm 0.22^{\circ} \mathrm{C} \\
\pm 0.2^{\circ} \mathrm{C}\end{array}$ \\
\hline \multicolumn{6}{|c|}{ Refrigerant System } \\
\hline $\begin{array}{l}\text { F-1-T } \\
\text { F-2-P } \\
\text { F-3-T } \\
\text { F-4-P } \\
\text { F-5-T } \\
\text { F-6-P } \\
\text { F-7-L } \\
\text { F-8-T } \\
\text { F-9-T } \\
\text { F-10-P } \\
\text { F-11-FM } \\
\text { F-12-T } \\
\text { F-13-T } \\
\text { F-14-FM }\end{array}$ & $\begin{array}{l}\text { Temperature } \\
\text { Pressure } \\
\text { Temperature } \\
\text { Pressure } \\
\text { Temperature } \\
\text { Pressure } \\
\text { Refrig. level } \\
\text { Temperature } \\
\text { Temperature } \\
\text { Pressure } \\
\text { Flow rate } \\
\text { Temperature } \\
\text { Temperature } \\
\text { Flow rate }\end{array}$ & $\begin{array}{l}\text { RTD } \\
\text { Strain gauge } \\
\text { RTD } \\
\text { Strain gauge } \\
\text { RTD } \\
\text { Strain gauge } \\
\text { Sight glass } \\
\text { RTD } \\
\text { RTD } \\
\text { Strain gauge } \\
\text { Vortex } \\
\text { RTD } \\
\text { RTD } \\
\text { Vortex }\end{array}$ & $\begin{array}{l}\text { Boiling vapor } \\
\text { Boiling vapor } \\
\text { Compressed vapor } \\
\text { Compressed vapor } \\
\text { Condensed } 1 \text { iquid } \\
\text { Receiver tank } \\
\text { Receiver tank } \\
\text { Liquid in } \\
\text { Vapor/1iquid } \\
\text { Vapor/liquid } \\
\text { Vapor } \\
\text { Cold water in } \\
\text { Cold water out } \\
\text { Cold water in }\end{array}$ & $\begin{array}{c}(-100)-260^{\circ} \mathrm{C} \\
0-1380 \mathrm{kPa} \\
(-100)-260^{\circ} \mathrm{C} \\
0-2070 \mathrm{kPa} \\
(-100)-260^{\circ} \mathrm{C} \\
0-2070 \mathrm{kPa} \\
0-30 \mathrm{~cm} \\
(-100)-260^{\circ} \mathrm{C} \\
(-100)-260^{\circ} \mathrm{C} \\
0-1380 \mathrm{kPa} \\
0-2.91 / \mathrm{s} \\
(-100)-260^{\circ} \mathrm{C} \\
(-100)-260^{\circ} \mathrm{C} \\
1.9-18.4 \mathrm{~kg} / \mathrm{s}\end{array}$ & $\begin{array}{l} \pm 0.26^{\circ} \mathrm{C} \\
\pm 12 \mathrm{kPa} \\
\pm 0.26^{\circ} \mathrm{C} \\
\pm 18 \mathrm{kPa} \\
\pm 0.26^{\circ} \mathrm{C} \\
\pm 18 \mathrm{kPa} \\
\pm 2 \mathrm{~mm} \\
\pm 0.26^{\circ} \mathrm{C} \\
\pm 0.26{ }^{\circ} \mathrm{C} \\
\pm 12 \mathrm{kPa} \\
0.021 / \mathrm{s} \\
\pm 0.26^{\circ} \mathrm{C} \\
\pm 0.26^{\circ} \mathrm{C}\end{array}$ \\
\hline \multicolumn{6}{|c|}{ First-Stage Direct-Contact Condenser } \\
\hline $\begin{array}{l}\text { DC-1-T } \\
\text { DC-2-DT } \\
\text { DC-3-DT } \\
\text { DC-4-T } \\
\text { DC-5-DT } \\
\text { DC-6-P } \\
\text { DC-7-DP } \\
\text { DC-8-FM } \\
\text { DC-9-DO } \\
\text { DC-10-D0 } \\
\text { DC-11-S } \\
\text { DC-12-S }\end{array}$ & $\begin{array}{l}\text { Temperature } \\
\text { Delta T } \\
\text { Delta T } \\
\text { Temperature } \\
\text { Delta T } \\
\text { Pressure } \\
\text { Delta P } \\
\text { Flow rate } \\
\text { Dissolved } 0_{2} \\
\text { Dissolved } 0_{2} \\
\text { Salinity } \\
\text { Salinity }\end{array}$ & $\begin{array}{l}\text { RTD } \\
\text { RTD } \\
\text { RTD } \\
\text { RTD } \\
\text { RTD } \\
\text { Capacitance } \\
\text { Capaci tance } \\
\text { Magnetic } \\
\text { Polarographic } \\
\text { Polarographic } \\
\text { Conductivity } \\
\text { Conductivity }\end{array}$ & $\begin{array}{l}\text { Water inlet } \\
\text { Water in - water out } \\
\text { Steam in - water in } \\
\text { Steam inlet } \\
\text { Steam in - steam out } \\
\text { Steam inlet } \\
\text { Steam in - steam out } \\
\text { Water } \\
\text { Water in } \\
\text { Water out } \\
\text { Water in } \\
\text { Prct diff: wi-wo }\end{array}$ & $\begin{array}{c}(-100)-260^{\circ} \mathrm{C} \\
0-30^{\circ} \mathrm{C} \\
0-30^{\circ} \mathrm{C} \\
(-100)-260^{\circ} \mathrm{C} \\
0-30^{\circ} \mathrm{C} \\
0-6.2 \mathrm{kPa} \\
0-250 \mathrm{~Pa} \\
0.3-9 \mathrm{~m} / \mathrm{s} \\
0-20 \mathrm{ppm} \\
0-20 \mathrm{ppm} \\
30-37 \mathrm{ppt} \\
340 \mathrm{ppm}\end{array}$ & $\begin{array}{l} \pm 0.26^{\circ} \mathrm{C} \\
\pm 0.06^{\circ} \mathrm{C} \\
\pm 0.06^{\circ} \mathrm{C} \\
\pm 0.26^{\circ} \mathrm{C} \\
\pm 0.06^{\circ} \mathrm{C} \\
\pm 117 \mathrm{~Pa} \\
\pm 9.1 \mathrm{~Pa} \\
\pm 0.01 \mathrm{~m} / \mathrm{s} \\
\pm 0.28 \mathrm{ppm} \\
\pm 0.28 \mathrm{ppm} \\
\pm 0.01 \mathrm{ppt} \\
\pm 18 \mathrm{ppm}\end{array}$ \\
\hline
\end{tabular}


Table 2-3. Instrumentation for the HMrSTA (Concluded)

\begin{tabular}{|c|c|c|c|c|c|}
\hline Ref • No. & Function & Sensor Type & Location & Range & $\begin{array}{l}\text { Installed } \\
\text { Accuracy } \$\end{array}$ \\
\hline \multicolumn{5}{|c|}{ Second-Stage Direct-Contact Condenser } & (Absolute Value) \\
\hline $\begin{array}{l}\text { DC-13-T } \\
\text { DC-14-DT } \\
\text { DC-15-T } \\
\text { DC-16-DT } \\
\text { DC-17-DT } \\
\text { DC-18-P } \\
\text { DC-19-DP } \\
\text { DC-20-FM } \\
\text { DC-21-D0 } \\
\text { DC-22-S }\end{array}$ & $\begin{array}{l}\text { Temperature } \\
\text { Delta T } \\
\text { Temperature } \\
\text { Delta T } \\
\text { Delta T } \\
\text { Pressure } \\
\text { Delta P } \\
\text { Flow rate } \\
\text { Dissolved } \mathrm{O}_{2} \\
\text { Salinity }\end{array}$ & $\begin{array}{l}\text { RTD } \\
\text { RTD } \\
\text { RTD } \\
\text { RTD } \\
\text { RTD } \\
\text { Capacitance } \\
\text { Capacitance } \\
\text { Magnetic } \\
\text { Polarographic } \\
\text { Conductivity }\end{array}$ & $\begin{array}{l}\text { Water inlet } \\
\text { Water in - water out } \\
\text { Steam outlet } \\
\text { Steam out - water in } \\
\text { Steam in - steam out } \\
\text { Steam inlet } \\
\text { Steam in - steam out } \\
\text { Water } \\
\text { Water out } \\
\text { Prct diff: wi-wo }\end{array}$ & $\begin{array}{c}(-100)-260^{\circ} \mathrm{C} \\
0-30^{\circ} \mathrm{C} \\
(-100)-260^{\circ} \mathrm{C} \\
0-30^{\circ} \mathrm{C} \\
0-30^{\circ} \mathrm{C} \\
0-6.2 \mathrm{kPa} \\
0-250 \mathrm{~Pa} \\
0.3-9 \mathrm{~m} / \mathrm{s} \\
0-20 \mathrm{ppm} \\
340 \mathrm{ppm}\end{array}$ & $\begin{array}{l} \pm 0.26^{\circ} \mathrm{C} \\
\pm 0.06^{\circ} \mathrm{C} \\
\pm 0.26^{\circ} \mathrm{C} \\
\pm 0.06^{\circ} \mathrm{C} \\
\pm 0.06^{\circ} \mathrm{C} \\
\pm 117 \mathrm{~Pa} \\
\pm 9.1 \mathrm{~Pa} \\
\pm 0.01 \mathrm{~m} / \mathrm{s} \\
\pm 0.28 \mathrm{ppm} \\
\pm 18 \mathrm{ppm}\end{array}$ \\
\hline \multicolumn{6}{|c|}{ General Direct-Contact Condenser } \\
\hline $\begin{array}{l}\text { DC-23-L } \\
\text { DC-24-L } \\
\text { DC-25-L } \\
\text { DC-26-T } \\
\text { DC-27-T }\end{array}$ & $\begin{array}{l}\text { Water level } \\
\text { Water level } \\
\text { Water level } \\
\text { Temperature } \\
\text { Temperature }\end{array}$ & $\begin{array}{l}\text { Capacitance } \\
\text { Sight glass } \\
\text { Capacitance } \\
\text { RTD } \\
\text { RTD }\end{array}$ & $\begin{array}{l}\text { Inlet tank } \\
\text { Condenser } \\
\text { Outlet tank } \\
\text { Closed loop seawtr in } \\
\text { Closed loop seawtr out }\end{array}$ & $\begin{array}{c}0-8 \mathrm{~m} \\
0-2 \mathrm{~m} \\
0-8 \mathrm{~m} \\
(-100)-260^{\circ} \mathrm{C} \\
(-100)-260^{\circ} \mathrm{C}\end{array}$ & $\begin{array}{l} \pm 6.4 \mathrm{~mm} \\
\pm 5 \mathrm{~mm} \\
\pm 6.4 \mathrm{~mm} \\
\pm 0.26^{\circ} \mathrm{C} \\
\pm 0.26^{\circ} \mathrm{C}\end{array}$ \\
\hline
\end{tabular}

*These pressure transducers were installed part way through the Phase I tests. The initial tests were performed using Sensotec strain gauge transducers with a 0-3.4 kPa range.

tInstruments that are "no longer installed" have either been replaced by orher instruments or were not functional and redundant were available. Instruments "never installed" are redundant and the alternate instrumentation is more accurate.

SInstalled accuracy estimates are taken from the test plan (Parsons et al. 1989). Values for the pressure sensors have been updated. 
Condensation dew-point hygrometers were used to measure wet-bulb temperature of steam in the surface condenser. In the evaporator and direct-contact condenser, steam saturation temperature was measured with RTDs covered with a wick that was partially immersed in a fresh-water reservoir.

\subsubsection{Pressure Sensors}

Primary pressure measurements were provided by diaphragm-type capacitance sensors that provided a 4-20 mA signal proportional to either absolute or differential pressures. This current signal was converted to a nominal 1-5 VDC signal using $250-0 \mathrm{hm}$ precision resistors located in the instrument trailer.

Some pressure measurements were made using diaphragm-type strain-gauge pressure sensors from a different manufacturer (Sensotec). Most of the pressure sensors originally installed in the apparatus were of this type. However, reliability problems led to their replacement with the capacitance-type sensors (Rosemount). The remaining strain-gauge-type sensors were connected to signal-conditioning cards in the instrument trailer using a four-wire configuration.

Atmospheric pressure was monitored with a strain-gauge pressure sensor (Cole-Parmer) with digital readout.

\subsubsection{Flocmeters}

Two types of flowmeters were used to measure seawater flows. Vortex-shedding meters measured warm-water flow, total cold-water flow, cold-water flow to the refrigerant condenser, and refrigerant flow to the second-stage surface condenser. These meters provided a 4-20 mA signal to resistors located in the instrument trailer which provided a nominal 1-5 VDC output. In Phase I, these flowmeters were connected to signal-conditioning cards that provided a 0-5 VDC out put.

The second type of seawater flowmeter, a magnetic-type, nonintrusive meter, was used to measure cold-water flows in the vertical upcomers supplying the two direct-contact condenser stages. These devices also provided a 4-20 mA signal that was converted to a 1-5 VDC signal with resistors.

A paddle-wheel flowmeter measured condensate flow from the first-stage condenser into the condensate collection tank. It used a signal-conditioning unit located in the instrument trailer that converted pulses from the paddle wheel to a 0-5 VDC signal.

Flow rate of steam and noncondensable gas out of the condenser was measured using the vacuum compressor as described in section 2.3.6.

Other flows were measured using rotometers of various sizes. They measured flow rate of sample water through the dissolved oxygen sensors and noncondensable gas flow rate out of the liquid-ring compressor.

Two Annubar pressure flow sensors were installed in the warm and cold seawater lines and were used to check readings of the main seawater flowmeters. 


\subsubsection{Level Indicators}

Level indicators were used to monitor liquid levels in the supply and discharge sumps of the evaporator and the direct-contact condenser, as well as in the evaporator, the predeaerator chamber, the condensate collection tanks, and the refrigerant reservoir. The level sensors in the supply and discharge sumps used an "air-bubble" type arrangement in which compressed air was bled through a tube into the lower portion of each sump. Flow rate of air in the tube was maintained at $3.9 \times 10^{-6} \mathrm{~m}^{3} / \mathrm{s}(0.5 \mathrm{scfh})$, which was low enough to prevent significant pressure loss through the tube but high enough to ensure that a steady stream of bubbles was emitted from the end of the tube. The pressure sensor (located at ground level) sensed the pressure in the tube, which was directly proportional to water level above the tube outlet. Bubbles were contained in a $76-\mathrm{mm}$ (3-in.) pipe to minimize the change in dissolved gas concentration of the process water. This bubble-type level sensor proved to be significantly more reliable than the immersion-type pressure sensors originally installed in the evaporator supply and discharge sumps. Problems occurred with the immersion-type sensors because of poor protection of the electrical signal and overpressurization when water levels above the sensors exceeded allowable limits $(4 \mathrm{~m})$.

Water levels in the evaporator and condensate tanks were measured by differential pressure sensors, which used gas pressure above the liquid surface as reference. As long as care was taken to prevent water from entering the dry (steam) legs of the sensors, they provided reliable indications of water level.

Water level in the predeaeration chamber was to be measured with a capacitance-type liquid level indicator. This sensor never provided reliable readings and was not used for tests. Instead a sight glass was used.

Ultrasonic sensors were installed in the evaporator supply and discharge sumps and later in the second-stage condensate collection tank. Excessive internal reflections apparently prevented these sensors from providing reliable level indications.

Sight gauges were used for all of the levels listed above except the supply and discharge sumps. These gauges provided reliable readings in the evaporator vessel but could not be connected to the computer data-acquisition system. Sight gauges on the condensate collection tanks and the refrigerant reservoir did not provide accurate readings because ambient heating caused bubbles to form in the liquid.

\subsubsection{Dissolved Oxygen Sensors}

Three polarographic dissolved-oxygen sensors measured oxygen content in the warm and cold seawater flows. Samples were extracted from supply and discharge pipes and from collection pans under each of the direct-contact condenser stages. These sample streams were plumbed to a sampling pump or pumps and then to the dissolved oxygen sensors. Downstream of the sensors, rotometers measured sampling flow rate.

The 0-1 VDC output from the dissolved oxygen sensors was converted to a 4-20 mA signal for transmission to the instrument trailer. Current resistors 
then converted it to a 1-5 VDC signal. The intermediate conversion to a current signal was required because the $0-1 \mathrm{~V}$ signal was not strong enough to drive the $A / D$ converters on the main data-acquisition computer or other recording instruments.

\subsubsection{Exhaust Gas F1ow}

The booster compressor, a blower-type, constant-displacement machine, was used to determine the vent rate of the condensers. The compressor's volumetric capacity was determined by measuring gas flow into the compressor using a rotometer with a throttling valve between the rotometer and the compressor. Although a "constant-displacement" compressor's volumetric throughput is theoretically independent of inlet pressure or compression ratio, the actual throughput is reduced from a constant value as inlet pressure decreases below a threshold (or compression ratio increases) because of backleakage and other effects. In the low-pressure region, the volumetric flow rate determined in-situ can be expressed as

$$
\dot{\mathrm{V}}=0.313+0.1 \mathrm{P}_{\text {in }}-0.032 \mathrm{P}_{\text {in }}{ }^{2}
$$

$$
\begin{array}{r}
\text { for } \mathrm{P}_{\text {in }}<1.5 \mathrm{kPa} \text {, while } \dot{\mathrm{V}}=0.39 \mathrm{~m}^{3} / \mathrm{s} \text { for } \mathrm{P}_{\text {in }} \geq 1.5 \mathrm{kPa} \text {, or } \\
\dot{\mathrm{V}}=0.4428-0.01577\left(\mathrm{P}_{\text {out }} / \mathrm{P}_{\text {in }}\right)
\end{array}
$$

where

$$
\begin{aligned}
\mathrm{P}_{\text {in }} & =\text { compressor inlet pressure }(\mathrm{kPa}) \\
\mathrm{P}_{\text {out }} & =\text { booster compressor outlet pressure }(\mathrm{kPa}) \hat{\mathrm{e}} \\
\dot{\mathrm{V}} & =\text { compressor volumetric flow }\left(\mathrm{m}^{3} / \mathrm{s}\right) \hat{\mathrm{e}}
\end{aligned}
$$

The volumetric flow through the booster compressor is composed of (1) noncondensable gases released from the warm and cold seawater, (2) the ambient air leaking into the system, and (3) the part of the steam that remains uncondensed and is exhausted. The ambient leak contributed less than $2 \%$ to the total flow, and is discussed in section 2.3.8. The quantity of uncondensed steam can be calculated from a measurement of saturation temperature and total pressure at the condenser outlet.

It was originally intended to measure the composition of the gas streams at different locations in the system in order to observe the quantity of dissolved gases released from the seawater streams. Unfortunately, University of Hawaii personnel could not perform these measurements using their mass spectrometer until all the heat exchanger tests were completed. Therefore, a redundant measurement of gas flow in and out of each component was not available.

The overall amount of noncondensable gas released in all the heat exchangers was calculated by subtracting the system's ambient leak and the uncondensed steam flow from the overall volumetric flow rate. Specific calculations are described in the respective chapters.

Lack of a redundant measurement of noncondensable gas flow at various stations introduced higher-than-desired uncertainties in calculation of gas mass 
fractions in and out of the heat exchangers. However, the impact of the uncertainty did not significantly affect the overall performance of the heat exchangers, as discussed in the respective chapters and in Appendix $A$.

\subsubsection{Data Acquisition System (DAS)}

The Data Acquisition System (DAS) was used to monitor and record the 0-5 VDC signals (or 0-10 VDC signals from the differential temperature sensors) from the various sensors described above. A PDP $11 / 23+$ computer was the primary tool for these purposes. Sixty-four channels of data were multiplexed to a pair of A/D converter cards. Software written for these experiments used the digital signals to calculate test conditions in engineering units. The conversions from raw digital inputs to engineering units used coefficients for slope and offset that were based on sensor calibrations. The computer could either display all 64 channels of data or 10 channels of data with additional calculated parameters such as heat load, thermal effectiveness, and heattransfer coefficients. Upon operator command, the computer stored data in files that included average readings, standard deviations of readings, and "trends" (the slope of a least-squares linear curve fit of the most recent data). The last parameters provided the principal investigator with measures of signal scatter and steadiness of test conditions. This analysis was conducted on sets of data taken over approximately $1.5 \mathrm{~min}$. and continuously updated. Each set consists of 30 data points per sensor, and each data point consists of $100 \mathrm{~A} / \mathrm{D}$ conversions. Selected data were also recorded on a 15-channel strip chart recorder.

A desktop PC-compatible computer was used to perform real-time analysis of test conditions. A commercially available spreadsheet program on the PC provided the operator with a versatile format for data analysis. He could determine component operating conditions and performance levels based on different combinations of sensors and, should significant differences appear, he could determine which sensors were likely to be malfunctioning. Using the program's graphing capability, he could plot test results and determine whether performance trends were being adequately characterized or whether additional data points were required.

\subsubsection{System Leak Rate}

Leak rate in the HMTSTA system, excluding the vacuum pump, was determined by measuring the rate of vacuum decay when water flows were stopped and the vacuum system was turned off. Typical system pressure at the start of the leak test was around $4 \mathrm{kPa}$, well above the saturation pressure of the warmest seawater; therefore little evaporation could occur from the water surfaces in the supply pipes and from the wet walls. The fluid in the supply and discharge pipes isolated the HMTSTA equipment from the open sumps, and a check valve near the inlet to the 1 iquid ring isolated the equipment at the other end. An additional isolation valve near the vacuum system was used during the early tests but was found to be redundant.

Initially, the leak rate was determined by observing the decay of system pressure overnight. The pressure vs. time curve was found to be 1 inear, except for a brief initial period of a few minutes. The slope gives a measure of the mass flow rate of ambient air into the system, if the volume of the system is known. Estimates of the volume were made from individual component dimensions 
and gave a total isolated volume of $14 \mathrm{~m}^{3}$ for Phase I and $19 \mathrm{~m}^{3}$ for Phase II equipment. This volume increases slightly overnight because the level of water in the vertical pipes drops as the pressure increases.

Based on the overnight results, leak checks were performed routinely after a test day by observing the decay rate in $30 \mathrm{~min}$. This time frame is sufficient to observe the linear dependence while the volume remains essentially constant. A rapid rise in system pressure indicated when a major leak existed, at which time tests would be suspended until the leak was found and fixed. Leaks were inspected by visual, auditory, soap-bubble or tracer-gas methods.

The nominal leak rate expected for the HMTSTA was $1 \mathrm{mg} / \mathrm{s}$. Instead, the actual leak rate could not be reduced readily below about $20 \mathrm{mg} / \mathrm{s}$. This value represents typically less than $2 \%$ of the noncondensable gases exhausting through the vacuum system, even at the lowest flow rates of seawater tested.

The leak rate measured during these tests was compared to a leak rate calculated from a mass balance using heat exchanger and vent compressor data when the system was in operation. To within the uncertainty in noncondensable-gas mass flow, the measured and calculated leak rates were in fair agreement during all tests reported here except for the surface condenser tests. Comparisons with gas composition and release tests conducted during the second part of 1989 also showed good agreement.

\subsection{OPERATION OF THE TEST APPARATUS}

The multi-institutional nature of the HMTSTA tests required the establishment of facility management procedures and operational guidelines, described in Appendix E.: A detailed operation and maintenance manual (Link 1989) documented step"by step the proper startup and shutdown procedures to be followed by the facility operator. These procedures are also summarized in Appendix E.

During operation of such a large and complex test facility, valuable lessons were learned regarding operational aspects, facility layout, and test procedures. This information will greatly aid in improving operation of the NPPE and of other future OTEC facilities. Lessons learned and recommendations based on that information are also summarized in Appendix E.

The following sections describe those operational aspects that directly bear on discussions of data collected and performance predictions presented in the following chapters.

\subsubsection{Setting of Test Conditions}

Test conditions were typically specified by the principal investigator (PI) in terms of warm- and cold-water flow rates, evaporator water temperature change, and condenser outlet conditions. HMTSTA controls permitted the operator to achieve and maintain these test conditions within the limitations of the apparatus (as described in Section 2.4.2). All Phase I and Phase II tests specified that steady-state conditions were to be obtained before recording data. Thus, water and steam temperatures were allowed to equilibrate for at least 10 minutes before data sets were recorded. In addition, the operator 
checked a variety of parameters to ensure that key instruments were operating satisfactorily. The following checks were typical of those conducted during test operations.

\subsubsection{Sensor Consistency}

Redundant flow, temperature, and pressure sensors provided checks of the proper operation of key sensors. Measured temperature differences were compared to calculated differences between absolute temperature sensor readings. Measured steam pressure differences were similarly compared to absolute pressure measurements. Because in most locations steam was in a saturated condition, the saturation temperature associated with the local steam pressure could be compared to the wet-bulb steam temperature measurement. These values were monitored by the operator during the experiments.

\subsubsection{Heat Balance}

The heat load in the evaporator (the product of water mass flow, specific heat, and temperature change) was compared to the heat load in the condenser. Typically the two heat loads differed by no more than $5 \%$. If larger differences appeared, the operator investigated the possibility that at least one flowmeter or temperature sensor was malfunctioning. Redundant absolute and differential temperature sensors helped considerably to identify malfunctioning sensors. In general, flowneters performed quite consistently.

\subsubsection{Stability and Limitations of the Facility}

In general, the facility operated with a high level of stability. Water levels in the evaporator and direct-contact condenser were the only parameters that required active control loops. Under normal operating conditions (flash-down temperature differences greater than $2^{\circ} \mathrm{C}$ ), steam generation rate could be established by proper positioning of the main steam valve between the evaporator and the condenser. Once this valve was positioned, the apparatus would quickly achieve steady-state condition and remain in steady state.

The most significant exception to this general stability was the refrigerantcooled second-stage surface condenser. Although a variety of techniques and some equipment modifications were tried, it was not possible to maintain a constant flow of refrigerant to this device. At best, flows could be held to within $25 \%$ of nominal conditions, but fluctuations in the refrigerant compressor output prevented better control. Of greater consequence was the inability to achieve and maintain a low refrigerant superheat at the out let of the condenser. At low refrigerant flows, all the refrigerant would boil and the outlet superheat would typically exceed $5^{\circ} \mathrm{C}$. As refrigerant flow was gradually increased, superheat would remain unchanged until liquid refrigerant appeared at the outlet of the condenser. At that point superheat would suddenly diminish to zero. This reduced the range of conditions over which the first-stage surface condenser could be tested, and it made analysis of secondstage condenser performance more difficult, as described in Chapter 6 .

Another limitation of the facility was the size of the evaporator vessel. Its small diameter relative to the evaporator spout spray pattern resulted in small spray-wall interactions in most tests and high spray-wall interactions in multiple-spout and high liquid loading tests. These interactions limited 
the ability to compare single vs. multiple spout performance, as described in Chapter 3 .

\subsubsection{Calibrations}

As described above, calibration coefficients were used to convert voltage measurements at the PDP computer A/D boards to engineering units of temperature, pressure, and so on. These coefficients were determined from calibration curves supplied by the manufacturer for factory-calibrated instruments including the pressure transducers, flowneters, and the chilled-mirror wetbulb hygrometers. Differential temperature sensors were calibrated at the SERI Metrology Laboratory. Absolute temperature sensors and level indicators were calibrated on site.

Absolute temperature sensors were calibrated at two temperatures: $0^{\circ} \mathrm{C}$ in an ice bath and about $27^{\circ} \mathrm{C}$ in a room-temperature copper block. Precision quartz probes originally used as reference temperature indicators were replaced in Phase II tests with thermistor probes. The thermistor probes were supplied by a special low-amperage controller to minimize self-heating errors.

Level sensors were calibrated against steel tape measurements. The volume flow through the vacuum system was calibrated once, as described in Section 2.3.6.

Calibrations were performed as specified by the PIs. Typically, at the beginning of each new test series, transducers critical for the planned tests were recalibrated. All sensors were calibrated before the beginning of evaporator tests (as part of the acceptance test procedures). Absolute temperature sensors were recalibrated once during evaporator tests. Dissolved oxygen sensors were refurbished before deaeration tests and recalibrated daily during those tests. Absolute temperature sensors, condensate tank level sensors, and the first-stage condensate flowmeter were recalibrated before the surface condenser tests. All gas pressure, absolute temperature, and differential temperature sensors were recalibrated before Phase II tests. Flowneters for the DCC stages were calibrated at the factory. Absolute temperature sensors were recalibrated once during those tests.

\subsection{REFERENUCES}

Blake, F. A., June 1986, OTEC Experimental Equipment Specification, SERI/MR-250-2961, Golden, Co: Solar Energy Research Institute.

Daniel, T. H, 1989, "New Seawater Delivery Systems at the Natural Energy Laboratory of Hawaii," presented at ASME International Solar Energy Conference, San Diego, CA, 2-4 April.

Krock, H. J., and M. J. Zapka, June 1985, "Open-Cycle OTEC Noncondensable Gas Exchange Characteristics," presented at Intersol '85, International Solar Energy Conference, Montreal, Canada.

Link, H., 1989, Operations Manual for the Heat- and Mass-Transfer Scoping Test Apparatus (HMTSTA), unpublished working document, Golden, CO: Solar Energy Research Institute. 
Parsons, B. K., H. F. Link, D. Bharathan, A. A. Pesaran, F. Zangrando, and C. B. Panchal, April 1989, Test Plan for the Heat- and Mass-Transfer Scoping Test Apparatus: Phase I and Phase II Tests, Internal Program Report, SERI/PR-253-3385, Golden, CO: Solar Energy Research Institute. 
CHAPTER 3.0

EVAPORATOR TESTS

Desikan Bharathan

Solar Energy Research Institute 


\subsection{NOMENCLATURE}

Abbrev. Description

Units

$\mathrm{C}_{\mathrm{i}}$ mass concentration of dissolved nonconderisable gases in the incoming seawater

$C_{\text {io }}$ mass concentration of the dissolved noncondensable gases in the outgoing seawater

D vessel diameter

m

spout diameter

m

$F_{r} \quad$ fraction of dissolved gases released in evaporator vessel

G

superficial steam loading

$\mathrm{kg} / \mathrm{m}^{2} \mathrm{~s}$

spout height

m

K hydraulic loss coefficient

L superficial liquid loading

$\Delta \mathrm{p} \quad$ pressure loss

$\mathrm{kg} / \mathrm{m}^{2} \mathrm{~s}$

$\mathrm{kPa}$

$q$ dynamic pressure

$\mathrm{kPa}$

S interspout spacing

m

$\Delta \mathrm{T}$

temperature difference

${ }^{\circ} \mathrm{C}$

$T_{w i}$

warm seawater inlet temperature

${ }^{\circ} \mathrm{C}$

warm seawater outlet temperature

${ }^{\circ} \mathrm{C}$

seawater temperature in equilibrium with steam $\hat{e}$

${ }^{\circ} \mathrm{C}$

$\varepsilon$

evaporator thermal effectiveness 


\subsection{BACKGROUND}

The mechanism by which steam is generated in an OC-OTEC system is called direct-contact or "flash" evaporation. This process occurs when warm seawater is introduced into the evaporator at a pressure lower than the vapor pressure that corresponds to the liquid inlet temperature, and steam is produced by the combined actions of boiling and surface evaporation. Flash evaporation is usually. quite violent as a result of the explosive growth of vapor bubbles from nucleation sites in the liquid. The growth of these bubbles shatters the liquid continuum and yields a wide range of droplet sizes. Because of the irregular geometry of the interface, it is practically impossible to define or measure the surface area from which evaporation takes place. Heat transfer in flash evaporation, therefore, cannot be described in terms of a conventional heat-transfer coefficient. To quantify the process and present experimental data, another parameter is introduced: effectiveness $(\varepsilon)$. The effectiveness of flash evaporation is defined as the ratio of the temperature difference between the inlet and outlet liquid streams to the temperature difference between the inlet 1 iquid stream and the vapor temperature corresponding to the chamber saturation pressure. This definition is similar to that for the effectiveness of a conventional heat exchanger, because it is the ratio of the temperature difference actually achieved to the maximum temperature difference the rmodynamically available.

Maa (1967) performed evaporation experiments from laminar jets of various liquids and described the mechanism of heat transfer as occurring in two steps: the transfer from the bulk of the liquid to the interface at an intermediate temperature, followed by molecular mass transfer from the interface to the vapor. The overall transfer rate is governed by molecular transport within the 1 iquid and the differential rate of molecular crossings at the interface. For seawater at $25^{\circ} \mathrm{C}$, interfacial heat-transfer resistance is extremely small compared with the resistance in the liquid. A freshly exposed interface cools from the bulk temperature to the vapor temperature in less than a millisecond, an amount of time a hundredfold shorter than the typical liquid residence time in the flash chamber. The accompanying growth of a thermal boundary layer on the liquid side, where the major temperature gradient resides, penetrates a distance of only 5-12 $\mu \mathrm{m}$. Because this thickness is small compared with the typical thickness of the liquid layer, flash evaporation can be treated as a surface phenomenon, with the first surface losing its potential for evaporation extremely quickly. For effective flash evaporation it is therefore imperative that a large interfacial area be available and that fresh surfaces continually be created.

\subsubsection{Experimental Investigations}

For laminar jets, heat transport on the liquid side is governed by molecular diffusion, whereas for turbulent jets, enhanced heat transport may be expected because of increased mixing caused by eddies in addition to molecular diffusion. Reports on experimental investigation of flash evaporation from turbulent jets are $f e w$, and in most cases the jets are "shattered" into discontinuous fragments and droplets. Brown and York (1962) proposed flash evaporation as a method for producing a fine spray of liquid droplets for aerosol applications. Balitskiy and Shurchkova (1969) observed in experimental studies of flash evaporation from $15-\mathrm{cm}-10$ ng water jets with diameters of 1,3 , and $5 \mathrm{~mm}$ that for a liquid superheat of more than $7^{\circ} \mathrm{C}$, the emerging 
jets shattered into a spray of droplets. Miyatake et al. (1981) studied flash evaporation from cylindrical water jets $3.5,5.0$, and $8.2 \mathrm{~mm}$ in diameter and 12,25 , and $25 \mathrm{~cm}$ in length, respectively, and with exit Reynolds numbers ranging from 66,000 to 155,000 . Photographs of increased jet shattering with increasing superheat were presented. Mills et al. (1982) presented data for evaporation from 4-mm-diameter circular turbulent water jets 95, 133, and $171 \mathrm{~mm}$ in length. In their experiments, they took precautions to maintain a coherent jet and to prevent jet shattering due to cavitation. For a jet Reynolds number in the range 3,000 to 25,000, the average Stanton number for these jets was found to be 3 to 11 times larger than those predicted based on laminar flow, suggesting that turbulent transport played a major role.

As was described in a previous review paper (Bharathan et al. 1984), three different geometries initially contended for the choice of evaporator in opencycle OTEC plants: open-channel flow, falling films, and falling jets. The open-channel flow design is not highly effective because the exposed interfacial area is limited, and boiling is suppressed by the hydrostatic pressure of the liquid. The two main. shortcomings of the falling-film evaporators are that, as a result of the explosive growth of vapor bubbles, coherent films cannot be maintained and the liquid distribution manifold obstructs the escape of vapor. Falling jets were investigated under OTEC conditions by Green et al. (1981), Kreith et al. (1982), and Bharathan and Penney (1984) for countercurrent vapor flow, and by Sam and Patel (1982) for crosscurrent vapor flow. It was observed that the jets shatter into a spray of droplets when they enter the evaporator. Green et al. (1981) measured an evaporator effectiveness of 0.7 to 0.8 with deaerated water in countercurrent flow, while for crosscurrent flow an effectiveness of nearly 0.95 was achieved (Sam and Patel 1982). In both cases, the influences of initial water superheat and water flow rate were minimal. The differences between these results are ascribed to losses incurred while vapor passes through the water distribution manifold in the countercurrent experiments and to the high initial air content of water in the experiments of Sam and Patel (1982).

In early 1983, experiments were performed at the Solar Energy Research Institute (SERI) on evaporation from a turbulent planar water jet. Bharathan and Penney (1984) found that the evaporation effectiveness of the jet was independent of initial jet thickness, indicating that once the jet shatters into droplets its initial thickness becomes irrelevant. These results confirmed the contention that evaporation is primarily controlled by the available interfacial surface area and the rate at which these surfaces are renewed. Following up on this hypothesis, screens were inserted in the jet to enhance its breakup. With four screens to help the jet's shattering process and renew the vapor liquid interfaces, an effectiveness approaching 1.0 was observed. Although extremely high effectiveness could be achieved by using screens in falling jets, the falling-jet geometry requires a complex manifold liquid distribution system that results in additional vapor pressure losses and increases the required evaporator size.

On the basis of these attempts to configure an effective OTEC flash evaporation geometry, it was concluded that high evaporation. effectiveness can be achieved regardless of the inlet geometry provided that the liquid jet is broken up, large interfacial areas are exposed, and the vapor-liquid interfaces are continuously renewed. Thus, the design of an effective evaporator focused on the liquid distribution manifold to achieve low losses in liquid 
and vapor pressure. This led to the development of an innovative design in which water is introduced into the evaporator through multiple vertical tubes that minimize pressure losses. Early work by Nisolle (1947) on OTEC evaporators described a variety of vertical tubes and slots of differing diameters and spacings to achieve effective seawater evaporation. This design, called the vertical spout evaporator, offers simple liquid distribution system, easy vapor separation with minimal obstructions in the vapor path, low liquid pressure loss $(0.5-0.7 \mathrm{~m})$, and the potential for a modular evaporator design not dependent on plant size.

Extensive experiments using fresh water were performed with vertical spout evaporators at SERI in 1983 and 1984. The arrangement in the test cell for these experiments with a single-spout evaporator is shown in Figure 3-1. The arrangement of the screens is shown in Figure 3-2, along with a plot of the effectiveness with and without screens as a function of water inlet velocity. In all of these tests, the heat flux from the jet was maintained at $210 \mathrm{~kW}$. The spout effectiveness measured in these tests varied between 0.90 and 0.97 with a liquid-side pressure drop of $0.7 \mathrm{~m}$ (spout height plus kinetic energy loss), somewhat less than for planar jets.

Photographs of the spout evaporator are shown in Figure 3-3 with and without flashing. The bright image at the center of each photograph is water exiting the top of the vertical spout. Case "a" shows that wi thout evaporation, the water jet exists smoothly and distributes itself as an axisymmetric sheet. When evaporation starts, bubbles begin to emerge from the spout and grow on the falling liquid sheet. Bubbles on the order of $10 \mathrm{~cm}$ in diameter can be seen at a heat $f l u x$ of $100 \mathrm{~kW}$ (case "b"). As the evaporation rate is further increased, the jet becomes more violent, vapor escapes from bursting bubbles, and explosive growth of the vapor shatters the jet into fragments and droplets. Most of the liquid escaping upward falls back on the incoming liquid and the coherent liquid sheet is totally destroyed, becoming a spray of droplets (case "c"). The only disadvantage observed so far is that, because of its inherently low liquid-side pressure loss, the spout configuration is prone to water surges that could result from sea-level fluctuations for a floating OTEC plant. Hydraulic studies indicate that this is not a problem for shore-based installations.

The experimental work described in this report investigated seawater evaporation from the vertical spout geometry for the OC-OTEC evaporator. Chapter 2 describes the equipment used for these tests. Figure 2-3 is a schematic of the evaporator vessel. Both the surface and the direct-contact condensers (Figures 2-5 through 2-8) were used to condense the steam produced.

The spectrum and quantity of liquid droplets carried over by the steam that is produced in the evaporator will be discussed in Chapter 4, which deals with the mist eliminator. It is the function of the mist eliminator to 1 imit the carryover to the levels required for the turbine equipment and the desalinated water composition. These requirements do not affect the geometry or performance of the evaporator, except for clearance above the spouts. 


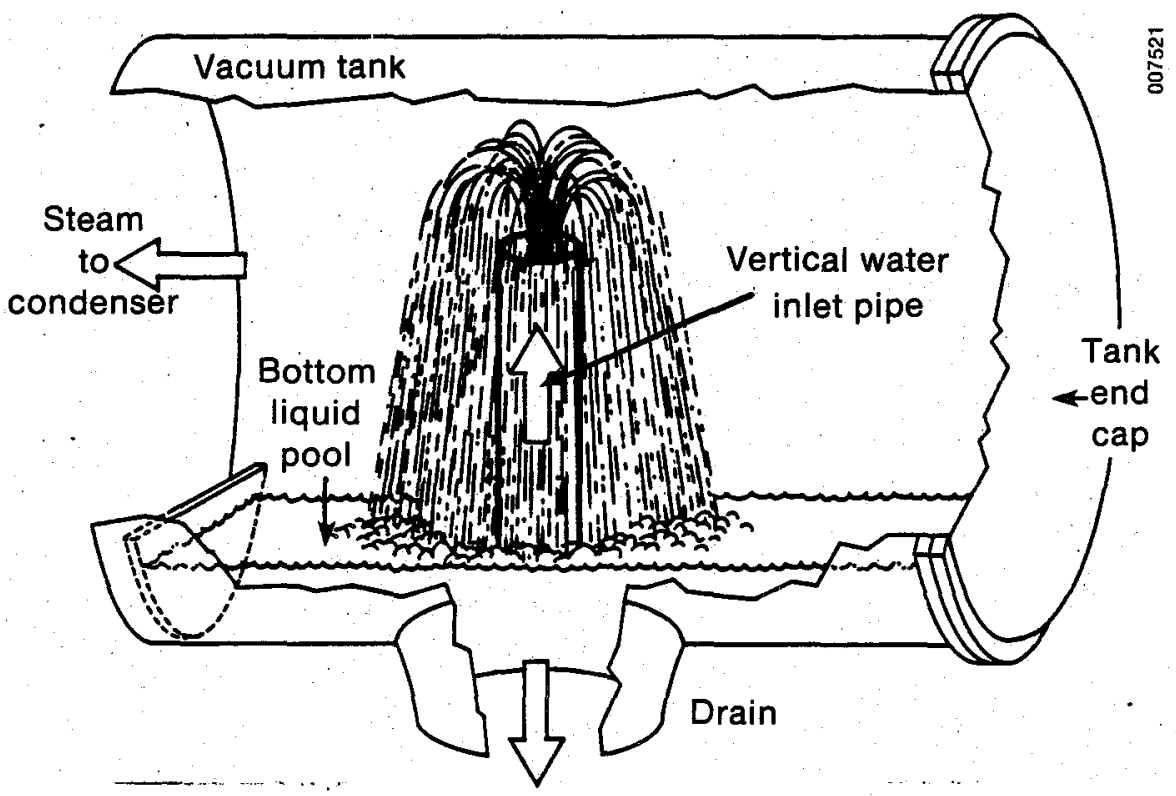

Figure 3-1. Arrangement in SERI test cell for experiments with single-spout evaporator
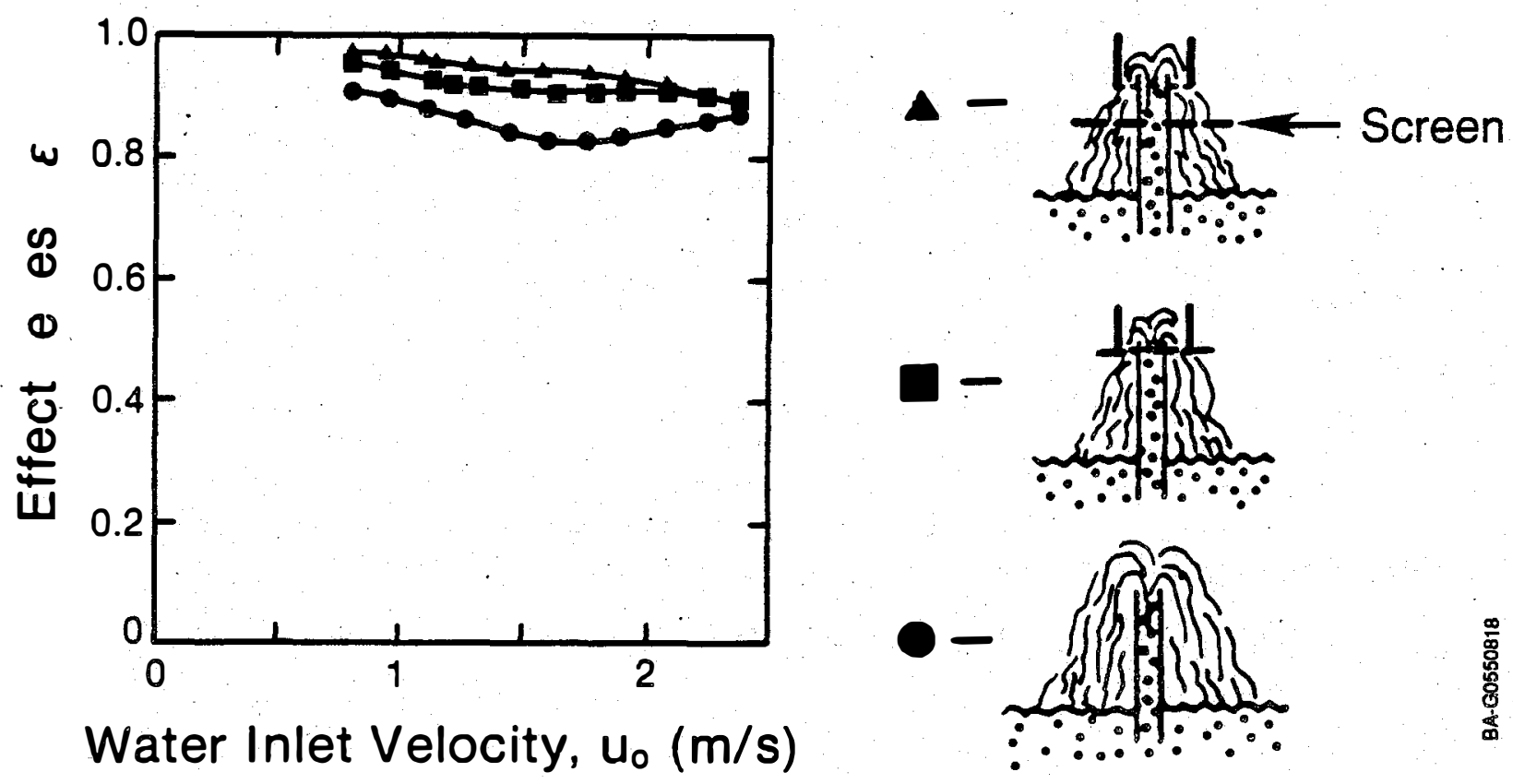

Figure 3-2. Effectiveness with and without screens plotted as a function of fresh-water inlet velocity 


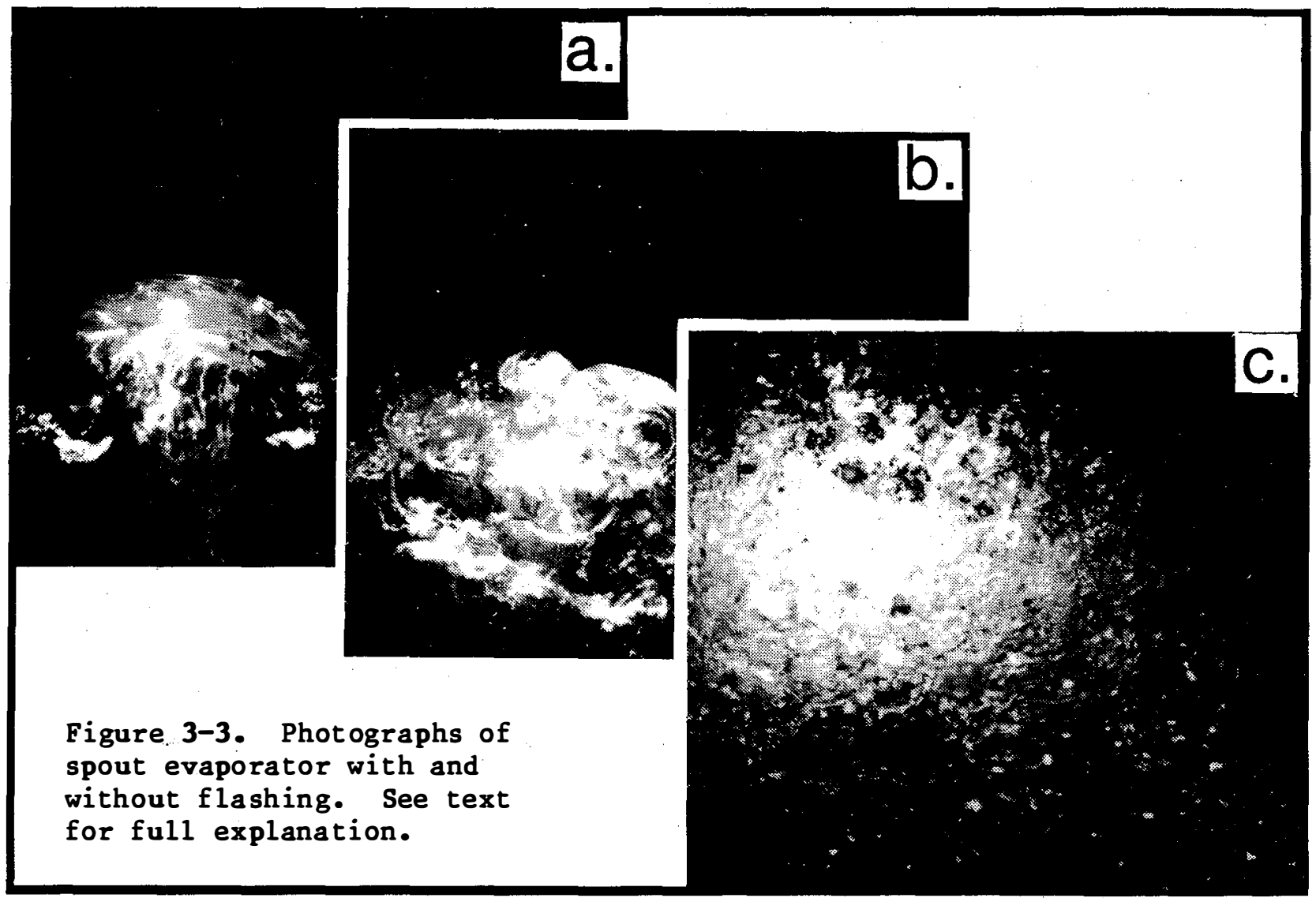

\subsubsection{Analytical Methods}

Analytical modeling of heat transport in coherent unshattered turbulent jets is complicated by the effect of turbulent mixing, the distribution of the effective eddy mixing across the jet, and the decay of turbulence downstream Theofanous, House, and Brumfield (1976) presented the only reported attempt to model turbulent transport in jets to include all these effects; they assumed the variation of eddy mixing across the jet to follow the Levich model (1962) and the decay of turbulence downstream to follow the decay of homogeneous turbulence behind a grid. However, they assumed heat and mass transport to occur in a fully developed situation. A review of this approach by Mills et al. (1982) indicated that the transport process cannot be treated in a fully developed sense and must be treated as an entrance region problem. Further, they indicated that available experimental data for mass transfer into turbulent coherent jets support neither the Levich theory nor the approach of Theofanus, House, and Brumfield.

Modeling of evaporation from turbulent jets that are shattered by the escape of vapor has been further complicated by the associated exposure of new surfaces and the resulting increases in the interfacial area caused by a spectrum of droplets. Heertjes and deNie (1966) reported on experimental and analytical efforts to quantify the mechanism of mass transfer to drops during formation, release, and coalescence. Mass and heat transfer during the period of formation can be substantial. Once formed, the droplets undergo internal 
circulation and vibrations during free fall. The ratio of an effective diffusion rate to the molecular diffusion rate may lie in the range of 1 to 4 for circulating drops, but it may be 10 or more for oscillating drops (Heertjes and deNie 1966).

It is clear that accurate predictions of flash evaporation from turbulent jets require adequate data on variations of effective thermal diffusivity in the regions of major temperature gradients within the jet and effective exposed interfacial area with downstream distance. Such a data base is not available.

An attempt to model evaporation from falling turbulent water sheets was reported by Bharathan and Penney (1984). Using simplifying assumptions, the effect of turbulent mixing was captured using an effective multiplier for the thermal diffusivity; the increased surface area for the shattered jet was taken to be what it would be if the jet were distributed in uniform droplets. The model indicated that evaporation was 1 iquid-side controlled. For shattered jets, resistance time and jet thickness were not the relevant correlating parameters. Surface renewals were shown to be effective in enhancing evaporation.

Nihous (1989) and Ghiaasiaan et al. (1989) attempted to simplify modeling through use of an effective mean droplet diameter for shattered sprays. Predictions using a semiempirical model showed reasonable agreement with experimental data. However, it should be noted that heat and mass transfer occurring during droplet formation can be substantial, as Heertjes and deNie (1966) reported.

\subsubsection{Objectives}

The specific objective of the scoping tests undertaken was to establish thermal and hydraulic performances of spout evaporator geometry using seawater over a limited range of spout diameter, height, superheat, and water flow rates directly applicable to the design of the Heat- and Mass-Transfer Experimental Apparatus/net power-producing experiment (HMTEA/NPPE) facility.

The evaporator tests at the HMTSTA were intended to investigate the performance of spout evaporators using seawater. Spout evaporators have been identified as one of the promising flash evaporator configurations. Considerable fresh-water data exist for spouts $0.13 \mathrm{~m}$ ( 5 in.) in diameter and $0.5 \mathrm{~m}$ (20 in.) high (Bharathan and Penney 1984). The seawater tests were aimed at generating seawater data comparable to the existing fresh-water results, as well as to obtain an initial set of data using seawater.

\subsection{EVAPORATOR PERFORMANCE PARAMETERS}

The evaporator performance is quantified in terms of its thermal performance as well as its hydraulic and mass-transfer behaviors. For performance measures that are complex and difficult to characterize, qualitative observations are made and reported.

For the evaporator tests, the following performance parameters are characterized as functions of independent variables discussed latex: 
- Thermal effectiveness, $\varepsilon$

- Water pressure loss

- Fraction of dissolved gas released, $F_{r}$

- Water droplet carryover

- Operational performance stability.

\subsubsection{Thermal Effectiveness}

Thermal effectiveness $(\varepsilon)$ for the evaporator is defined as

where

$$
\varepsilon=\frac{\left(T_{w i}-T_{w o}\right)}{\left(T_{w i}-T_{w}^{*}\right)},
$$

$$
\begin{aligned}
\mathrm{T}_{w i}= & \text { warm-water inlet temperature }\left({ }^{\circ} \mathrm{C}\right) \\
\mathrm{T}_{\text {wo }}= & \text { warm-water outlet (discharge) temperature }\left({ }^{\circ} \mathrm{C}\right) \\
\mathrm{T}_{\mathrm{w}} *= & \text { seawater temperature in equilibrium with the steam exiting from the } \\
& \text { evaporator }\left({ }^{\circ} \mathrm{C}\right) \text {. (Saturation temperature of seawater is about } \\
& 0.3^{\circ} \mathrm{C} \text { higher than the saturation temperature of fresh water at a } \\
& \text { nominal evaporator pressure of } 2.9 \mathrm{kPa} .)
\end{aligned}
$$

An effectiveness value of unity implies that the steam leaving the evaporator is in equilibrium with the discharge water. Fresh-water results with simple spouts exhibited a variation in $\varepsilon$ in a range of 0.85 to 0.95 (Bharathan and Penney 1984). With some types of special geometries to enhance evaporation, an effectiveness as high as 0.98 has been achieved.

\subsubsection{Water Pressure Loss}

The water pressure loss, which reflects the parasitic power required to operate the evaporator, consists of additive components caused by the spout height, entrance and exit losses, and frictional losses within the spout. This pressure loss was measured directly by a differential pressure transducer that senses pressures in the evaporator water supply pool below the predeaerator and the evaporator discharge pool (See Figure 2-3). The water pressure loss is expressed in Pascals and the water head loss in meters, using the appropriate seawater density and gravitational acceleration. The effective loss coefficient for the spouts is the pressure loss normalized by the superficial water dynamic pressure.

\subsubsection{Fraction of Dissolved Noncondensable Gas. Released}

Because oxygen and nitrogen make up more than $98 \%$ of the total readily released noncondensable gas dissolved in seawater, the most straightforward method of determining release of noncondensable gas would be to measure the concentration of these two gases in both the inlet and outlet water flows. The

*A large quantity of $\mathrm{CO}_{2}$ is present in seawater. However, most of this $\mathrm{CO}_{2}$ is chemically bonded to radicals in seawater and is not readily desorbed in the OC-OTEC heat exchanger, as discussed in Chapter 8. 
fraction of noncondensable gas release, $F_{r}$, could then be calculated from the equation

$$
F_{r}=\frac{c_{i i}-c_{i o}}{c_{i i}}
$$

where

$$
\begin{aligned}
c_{i i}= & \text { dissolved noncondensable gas content of water at the evaporator spout } \\
& \text { inlet (ppm by wt) } \\
C_{i o}= & \text { dissolved noncondensable gas content of evaporator discharge water } \\
& \text { (ppm by wt). }
\end{aligned}
$$

Accurate and rugged sensors are available for measuring dissolved oxygen content on line, but no such sensors exist for dissolved nitrogen measurements. Thus, fraction of total noncondensable gas released was estimated by measuring only the dissolved oxygen content (see Chapter 5). This approach was sufficiently accurate for online measurements because

- The diffusivities of nitrogen and oxygen in water are similar $\left(3.11 \times 10^{-9} \mathrm{~m}^{2} / \mathrm{s}\right.$ and $2.17 \times 10^{-9} \mathrm{~m}^{2} / \mathrm{s}$, respectively).

- Under conditions of low pressure and low noncondensable gas content in the evaporator, the equilibrium concentrations of dissolved nitrogen and oxygen are both virtually zero.

As a check on these assumptions, samples of inlet and outlet water to the evaporator were collected under steady-state operation for selected tests. These samples were then analyzed for dissolved oxygen, dissolved nitrogen, and total dissolved gas content (as well as for inorganic mineral ions) under controlled laboratory conditions. On the basis of measurements of dissolved gas levels in the sample, total gas released in the evaporator was determined using Eq. 3-2. To refine analyses, the total gas release fraction was then compared to the oxygen release fraction as measured by online instruments.

\subsubsection{Spout Flow Stability}

The potential for a flow instability problem exists because of the nature of two-phase flow in the spout(s). Release of noncondensable gas may contribute to any instability. No prior observation of or data about this behavior at OTEC conditions has been reported in the literature. During the limited tests with single and multiple spouts, no flow instabilities were observed.

\subsubsection{Independent Parameters}

Table 3-1 1ists the test series and the independent parameters studied in these evaporator scoping tests. In each series the effect of one parameter was investigated while the others were maintained constant at (or very near) the nominal value. One additional series of tests to ascertain the influence of enhancing screens placed around the spout was also conducted. 
Table 3-1. Evaporator Test Range

\begin{tabular}{|c|c|c|c|c|}
\hline $\begin{array}{l}\text { Test } \\
\text { Series }\end{array}$ & $\begin{array}{l}\text { Independent } \\
\text { Parameter }\end{array}$ & Units & $\begin{array}{l}\text { Nominal } \\
\text { Value }\end{array}$ & $\begin{array}{l}\text { Test } \\
\text { Range }\end{array}$ \\
\hline$E-101$ & $\begin{array}{c}\text { Temperature driving } \\
\text { potential }\end{array}$ & ${ }^{\circ} \mathrm{C}$ & 3.0 & $1.00-5.00$ \\
\hline $\begin{array}{l}E-102 \\
E-103 \\
E-104 \\
E-105\end{array}$ & $\begin{array}{l}\text { Seawater velocity } \\
\text { Spout height } \\
\text { Spout diameter } \\
\text { Number of spouts }\end{array}$ & $\begin{array}{c}\mathrm{m} / \mathrm{s} \\
\mathrm{m} \\
\mathrm{m} \\
--\end{array}$ & $\begin{array}{c}2.0 \\
0.50 \\
0.13 \\
1\end{array}$ & $\begin{array}{c}0.75-4.00 \\
0.30-0.80 \\
0.13-0.25 \\
1-3\end{array}$ \\
\hline
\end{tabular}

\subsection{TEST-SPECIFIC EQUIPMENT AND INSTRUMENTATION}

\subsubsection{Apparatus}

The evaporator vessel (Figure 2-3) is $1.07 \mathrm{~m}(3.5 \mathrm{ft}$ ) in diameter by about $6.9 \mathrm{~m}(22.5 \mathrm{ft})$ high. It is large enough in diameter to permit testing of single spouts without significant interference between the spout water spray pattern and the walls of the vessel. When three spouts were tested in the vessel, a significant amount of the water spray made contact with the vessel walls.

Both vessel diameter and available warm-water flow rate limited studies in this apparatus to three spouts in the diameter range indicated in Table 3-1.

The vessel .is tall enough to permit simultaneous testing of predeaeration, evaporation,.. and mist removal. The mist eliminator was mounted $1 \mathrm{~m}$ below the steam outlet pipe to reduce this outlet's influence on steam velocity distribution. The clearance of $2 \mathrm{~m}$ between the mist eliminator and the spout mounting plate permitted testing of spouts as tall as $1.5 \mathrm{~m}$. The 2.7-m (9-ft) distance between the spout plate and the water inlet port in the bottom of the vessel facilitated a variety of predeaerator configurations, as described in Chapter 5 .

Table 3-2 summarizes the major features of the evaporator vessel. Additional details about the facility may be found in Chapter 2 .

For enhancing screens, a set of plastic rubber screens was fabricated as shown in the accompanying photograph (Figure 3-4). This screen assembly was designed to slip over a 0.2-m-diameter spout for the single series of tests on enhancement at high liquid loading.

Figure 3-5 illustrates the basic set of instruments used in the evaporator. The measurements included water and steam temperatures and steam pressures within the chamber. Table 3-3 provides a summary of the measured quantities, including their uncertainties and redundancies. Various instruments other than those listed in Table 3-3 were also used throughout the apparatus to measure pressure, temperature, flow rate, and level, as described in Chapter 2. 
Table 3-2. Specifications for the HMTSTA Evaporator Vessel

\begin{tabular}{|c|c|}
\hline Parameter & Value or Description \\
\hline $\begin{array}{l}\text { Water supply and } \\
\text { discharge fittings }\end{array}$ & $30.5-\mathrm{cm}(12-\mathrm{in}$.$) pipe flanges$ \\
\hline Steam outlet pipe & 76-cm- (30-in.)-diameter pipe \\
\hline Spout mounting plate & $\begin{array}{l}1.07 \mathrm{~m}(42 \mathrm{in.}) \text { diameter, } 38 \mathrm{~mm}(1.5 \\
\text { in.) thick, located } 3.1 \mathrm{~m}(10 \mathrm{ft}) \text { below } \\
\text { the bottom of the steam outlet pipe }\end{array}$ \\
\hline Mist eliminator mounting & $\begin{array}{l}8 \text { each, } 5 \mathrm{~cm} \times 5 \mathrm{~cm}(2 \text { in. } \times 2 \text { in. }) \text {, } \\
\text { with a } 1.4-\mathrm{cm}-(9 / 16-\mathrm{in} .) \text {-diameter hole } \\
\text { located } 2 \mathrm{~m}(6.6 \mathrm{ft}) \text { above the spout } \\
\text { mounting plate }\end{array}$ \\
\hline Lighting and view ports & $\begin{array}{l}1 \text { each, } 30-\mathrm{cm}-\left(12-\mathrm{in}_{0}\right)-\text { diameter port, } \\
\text { at the top of the evaporator vessel }\end{array}$ \\
\hline
\end{tabular}

Not all of the instruments functioned as anticipated during the series of tests. Specific problems were encountered with the temperature probes and absolute pressure transducers in the evaporator vessel. Investigations revealed that the problems were traceable to salt spray affecting the electrical connectors of the temperature probes and causing corrosion in pressure transducer diaphragms. By monitoring the instruments and maintaining and using backup instrumentation, researchers were able to proceed with the test and quantitatively interpret the experimental data.

\subsubsection{Measurement Consistency}

To ascertain consistency in the measurements, crossplots of redundant measurements were made.

Figure 3-6 illustrates the heat balance for the entire HMTSTA system in the Phase I configuration. The heat per unit time absorbed by the two condenser stages was plotted vs. the heat per unit time released from the evaporator through steam production. The apparatus is capable of a thermal transfer rate of up to $1.25 \mathrm{MW}$. In general, the heat absorbed by the condenser followed that released by the evaporator; however, it was nominally $3 \%$ to $5 \%$ higher. Ambient heat loads may explain this discrepancy. The uncertainty of the calculated heat loss and gain was estimated to be between $3 \%$ and $7 \%$, as described in Appendix A. Thus, within experimental uncertainty, the agreement was excellent.

Figure 3-7 shows the water temperature difference derived from absolute temperature measurements crossplotted vs. differential temperature measurements. Uncertainties in these measurements are also indicated in this figure and Table 3-3. As can be seen in Figure 3-7, the agreement between the redundant measurements was much better than the estimated error bands. 


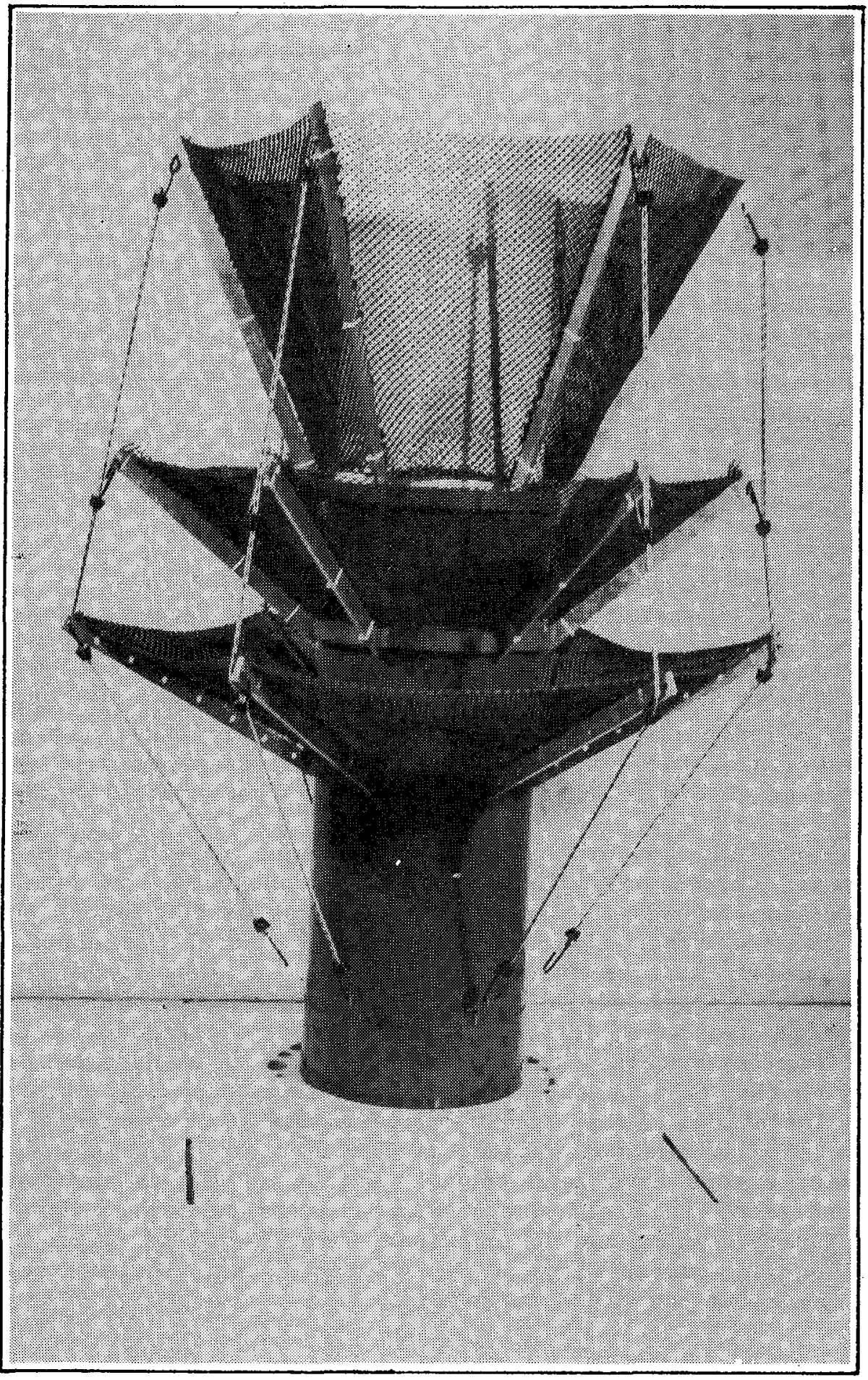

Figure 3-4. Photograph of plastic rubber screen assembly used for enhancement at the HMTSTA 
Measurements

6 - Temperature

3 - Differential temperature

2 - Absolute pressures

1 - Differential pressure

Note: numbers in parentheses represent numbers of instruments used in the measurements.

$T_{\infty}$ - dry bulb temperature

$T_{\text {wwi }}$ - warm॰water inlet temperature

$\mathrm{T}_{\text {wwo }}$ - warmowater outlet temperature

$\Delta T$ - differential temperature

p - pressure

$\Delta p$ - differential pressure

(1)

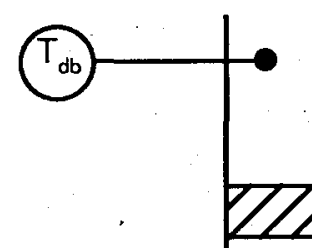

(1)
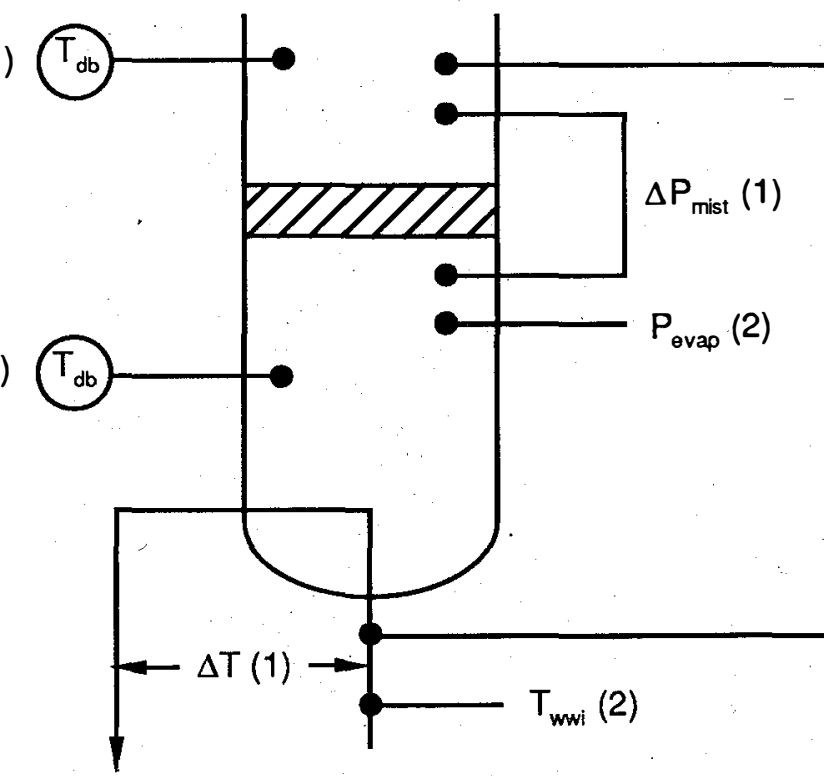

$\overline{0}$
$\frac{0}{0}$
$\frac{0}{0}$
$\frac{1}{\mathbf{\Sigma}}$

$\Delta T_{\text {ww-me }}(2)$

\section{Figure 3-5. Instrumentation employed for} investigations of the HMTSTA evaporator

A similar plot of water-to-steam temperature difference is shown in Figure 3-8. In a range of $2^{\circ}$ to $7^{\circ} \mathrm{C}$ temperature difference, the agreement is good. For lower $\Delta \mathrm{Ts}$, the absolute temperature measurements yield smaller $\Delta \mathrm{Ts}$, mostly because of errors in measurements arising from ambient radiation.

Figure 3-9 crossplots evaporator chamber pressure inferred from temperature measurements vs. direct pressure measurements. Most of the data points fall on the parity line. However, deviations as large as $100 \mathrm{~Pa}$ can be seen for a set of data points. This discrepancy arose as a result of errors in temperature and pressure measurements as described in Appendix A. Early test results indicated larger deviations. Salt water spray in the temperature measuring system and zero drifts in the pressure transducers caused these deviations. For later tests, the connectors for RTD measurements were better protected from the environment, and more stable pressure transducers were acquired and installed. These improvements in the instrumentation resulted in better consistency in the measurements. Satisfactory solutions for the pressure transducer errors have been found. Drifts in RTD calibrations for temperature measurement in field use remain a major concern. More stable and reliable temperature data can be obtained through use of super-stable thermistors. Improved reliability of measurements over longer time intervals remains desirable for the field operation. 
Table 3-3. Evaporator Instrumentation

\begin{tabular}{|c|c|c|c|c|}
\hline Quantity & Sensor & $\begin{array}{l}\text { Cond itioning } \\
\text { Instrument }\end{array}$ & Uncertainty & Redundancy \\
\hline $\begin{array}{l}\text { 1. Warm water inlet } \\
\text { temperature }\end{array}$ & RTD & $\begin{array}{l}\text { Sensotec } \\
\text { temperature } \\
\text { transmitter }\end{array}$ & $0.26^{\circ} \mathrm{C}$ & 2 \\
\hline $\begin{array}{l}\text { 2. Warm water outlet } \\
\text { temperature }\end{array}$ & RTD & $\begin{array}{l}\text { Sensotec } \\
\text { temperature } \\
\text { transmitter }\end{array}$ & $0.26^{\circ} \mathrm{C}$ & 2 \\
\hline $\begin{array}{l}\text { 3. Steam temperature } \\
\text { in the evaporator } \\
\text { chamber }\end{array}$ & RTD & $\begin{array}{l}\text { Sensotec } \\
\text { temperature } \\
\text { transmitter }\end{array}$ & $0.26^{\circ} \mathrm{C}$ & None \\
\hline $\begin{array}{l}\text { 4. Steam temperature } \\
\text { above mist } \\
\text { eliminator }\end{array}$ & RTD & $\begin{array}{l}\text { Sensotec } \\
\text { temperature } \\
\text { transmitter }\end{array}$ & $0.06^{\circ} \mathrm{C}$ & None \\
\hline $\begin{array}{l}\text { 5. Differential } \\
\text { temperature, warm } \\
\text { water inlet to } \\
\text { outlet }\end{array}$ & RTD & $\begin{array}{c}\text { YSI } \\
\text { differential } \\
\text { temperature } \\
\text { transmitter }\end{array}$ & $0.06^{\circ} \mathrm{C}$ & None \\
\hline $\begin{array}{l}\text { 6. Differential } \\
\text { temperature, water } \\
\text { inlet to steam } \\
\text { above mist } \\
\text { eliminator }\end{array}$ & RTD & $\begin{array}{c}\text { YSI } \\
\text { differential } \\
\text { temperature } \\
\text { transmitter }\end{array}$ & $0.06^{\circ} \mathrm{C}$ & 2 \\
\hline $\begin{array}{l}\text { 7. Pressure in the } \\
\text { evaporator }\end{array}$ & Diaphragm & $\begin{array}{l}\text { Ros emount } \\
\text { (low range) }\end{array}$ & $117 \mathrm{~Pa}$ & None \\
\hline $\begin{array}{l}\text { 8. Pressure in the } \\
\text { evaporator }\end{array}$ & Diaphragm & $\begin{array}{l}\text { Rosemount } \\
\text { (high range) }\end{array}$ & $540 \cdot \mathrm{Pa}$ & None \\
\hline $\begin{array}{l}\text { 9. Pressure drop in } \\
\text { mist eliminator }\end{array}$ & Diaphragm & Rosemount & $19: 1 \mathrm{~Pa}$ & None \\
\hline
\end{tabular}


Figure 3-6. Heat balance for entire HMTSTA system

Figure 3-7. Measurement consistency, seawater temperature difference
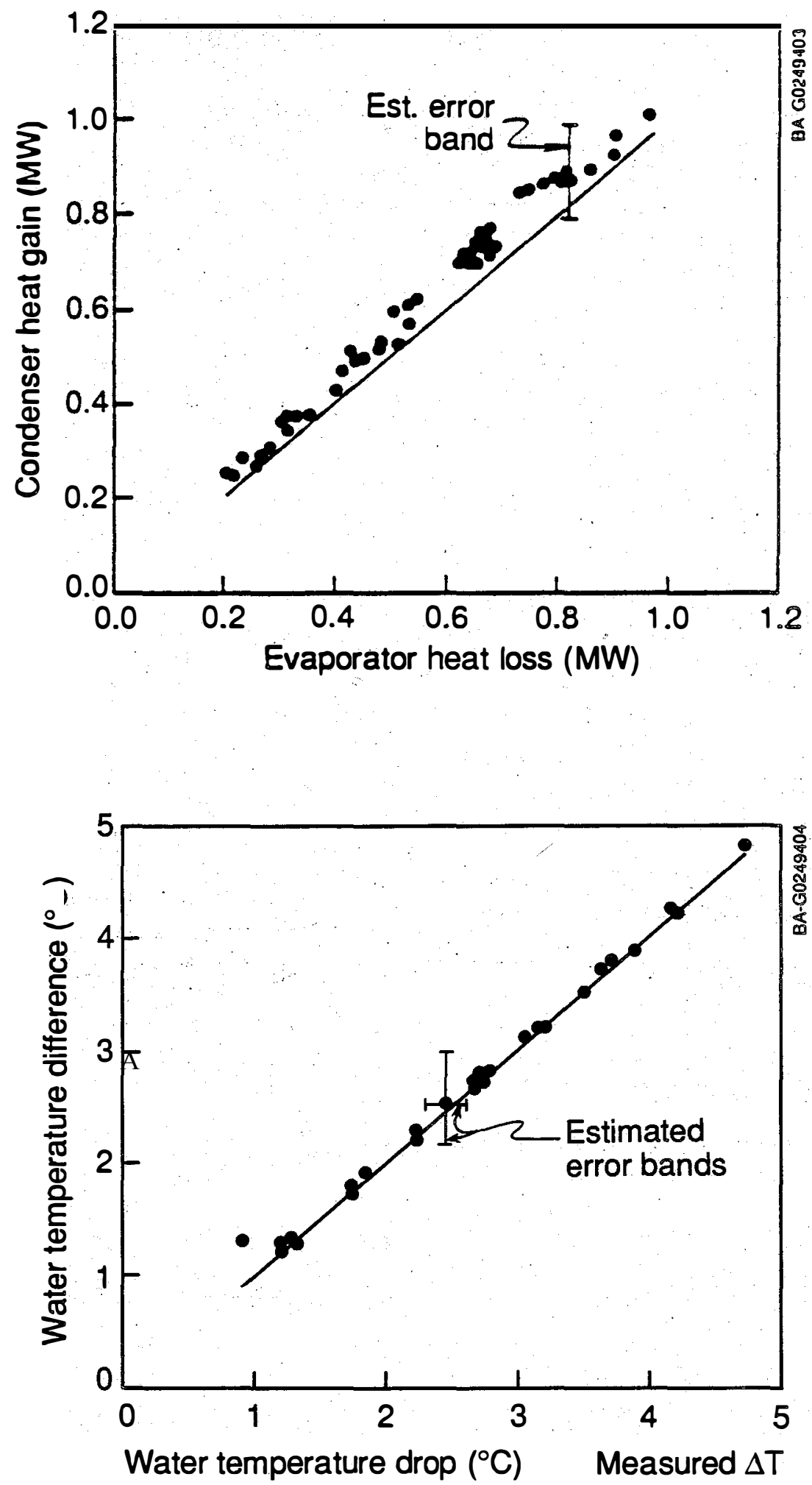

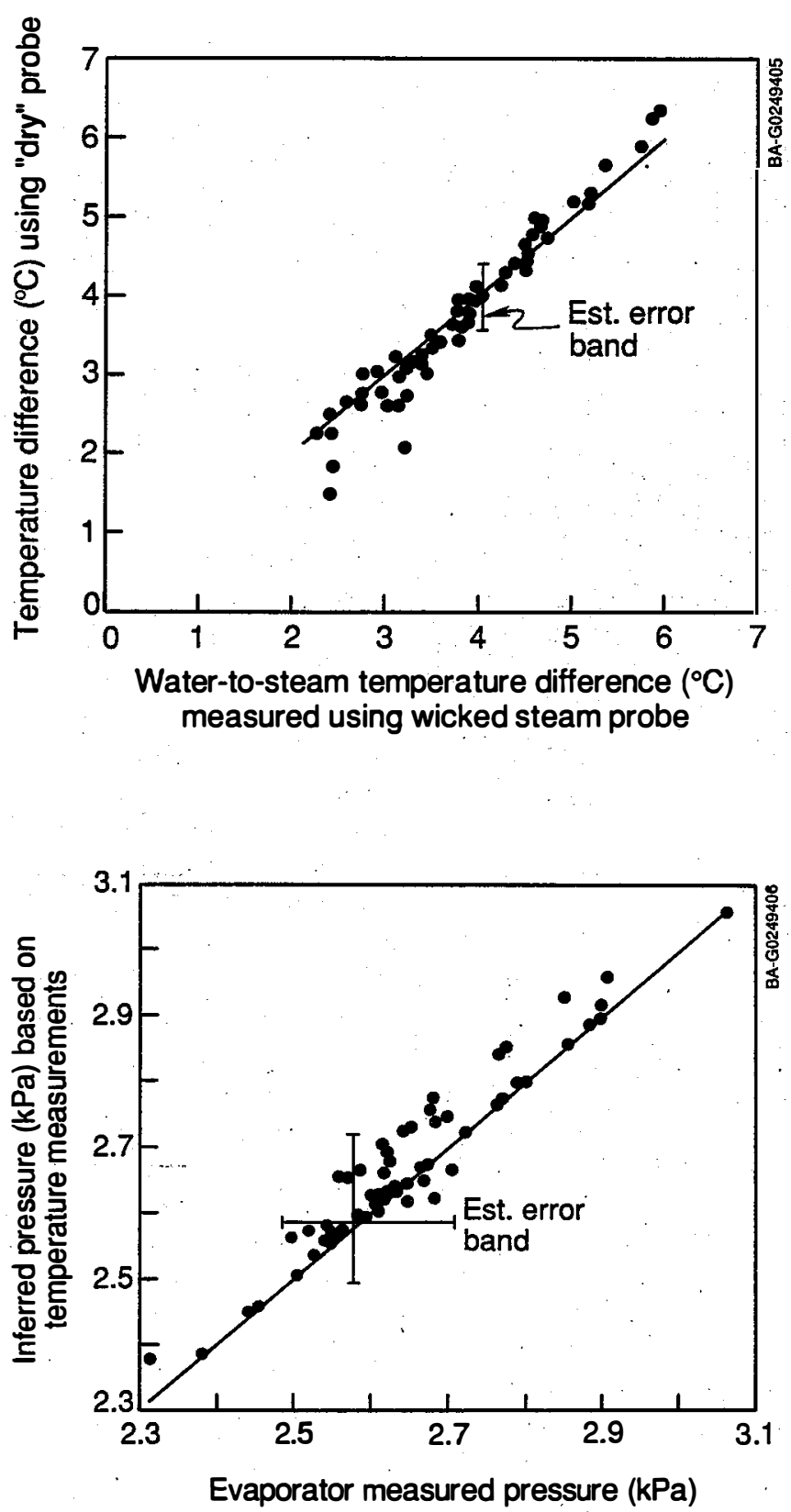

Figure 3-8.

Measurement consistency, seawater-to-steam temperature difference
Figure 3-9.

Evaporator chamber pressure inferred from temperature measurements vs. directpressure measurements

\subsection{SEAWATER EVAPORATOR RESULTS}

\subsubsection{Thermal Performance}

The evaporator thermal performance is a complex function of the geometric and flow parameters. The geometric parameters are spout diameter $d$, spout height $h$, vessel diameter $D$, and interspout spacing $S$ in the case of multiple spouts. Flow parameters include the spout velocity and the degree of superheat. For large power plants, which may incorporate a field of spouts, the evaporator may be compared to conventional countercurrent cooling towers. In a cooling tower, the purpose of evaporation is to cool the incoming water, whereas in the OTEC evaporator, the evaporated steam is the final product. However, both 
devices operate on the same basic principle. Usually the cooling-tower operation is described with the operating liquid loading, $\mathrm{L}\left(\mathrm{kg} / \mathrm{m}^{2} \mathrm{~s}\right)$, and the gas loading, G $\left(\mathrm{kg} / \mathrm{m}^{2} \mathrm{~s}\right)$ as the major parameters. These loadings, defined as mass flow rate per unit planform area, represent operating capacities and are directly relevant to OTEC evaporators that use a multiple field of spouts.

The evaporator results presented here describe thermal performance as a function of evaporator superheat (the denominator of Eq. 3-1), spout height, and overall liquid loading. Experimental results indicate that, in general, thermal effectiveness increases with increasing superheat and height and with decreasing liquid loadings.

Figure 3-10 illustrates the influence of liquid loading on thermal effectiveness of the evaporator. It includes measurements made with single spouts $0.13,0.20$, and $0.25 \mathrm{~m}$ in diameter and a set of three spouts $0.11 \mathrm{~m}$ in diameter arranged symmetrically in the vessel. All data are for nominal design conditions of $3^{\circ} \mathrm{C}$ water temperature drop ${ }^{*}$ and $0.46 \mathrm{~m}$ spout height. Table $3-4$ displays the liquid and steam loadings at design conditions for these spouts corresponding to a spout liquid velocity of $2 \mathrm{~m} / \mathrm{s}$, and steam dynamic pressures. All spouts exhibited decreasing effectiveness with increasing 1 iquid loading. The data for the smallest single spout tested lie in the range of $10<\mathrm{L}<40 \mathrm{~kg} / \mathrm{m}^{2} \mathrm{~s}$ and show 1ittle variation. Data for the $0.20-\mathrm{m}-$ diameter spout lie in the range of $40<L<90 \mathrm{~kg} / \mathrm{m}^{2} \mathrm{~s}$ and the effectiveness decreases from nearly 0.95 down to 0.8 with increasing L. Data for the largest spout cover $50<L<110 \mathrm{~kg} / \mathrm{m}^{2} \mathrm{~s}$ and follow the trend exhibited by data for the other single spouts, within the error margin. . Data for a larger spout merge well with data for a smaller spout as liquid loadings and spout diameter increase. This trend indicates that for single spouts, effectiveness is a function of overall liquid loading and is independent of the spout diameter over the range of tested diameters.

Figure 3-10. Influence of liquid loading on thermal effectiveness of seawater spout evaporator

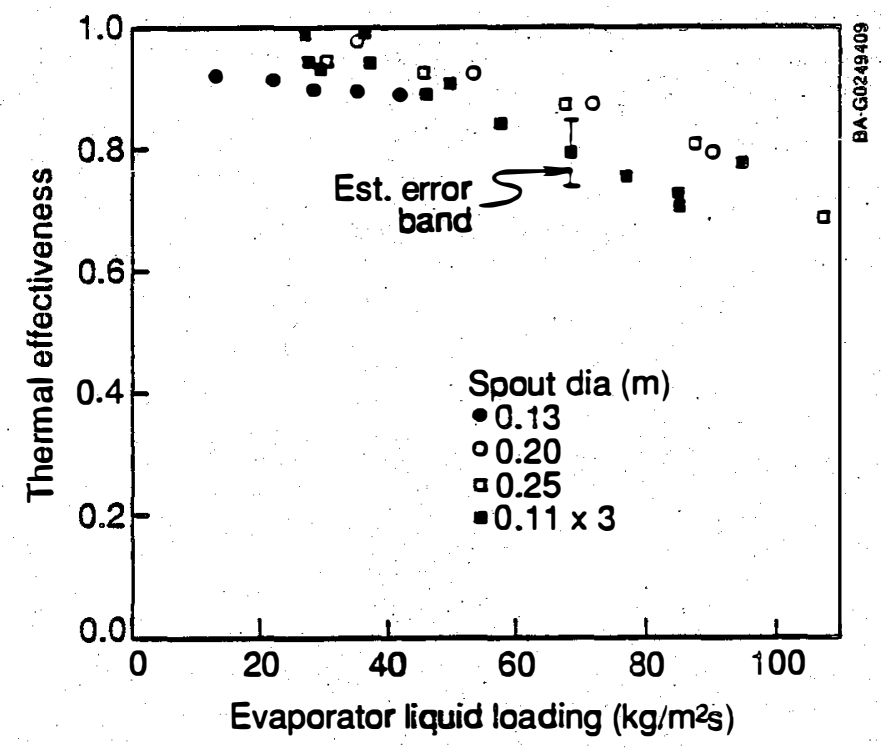

* The water temperature drop was easier to control than was the superheat parameter for all tests reported. 
Table 3-4. Design Conditions for the Spout Evaporator*

\begin{tabular}{ccccc}
\hline $\begin{array}{c}\text { Spout } \\
\text { Diameter } \\
(\mathrm{m})\end{array}$ & $\begin{array}{c}\text { Design } \\
\text { Liquid } \\
\text { Flow } \\
(\mathrm{kg} / \mathrm{s})\end{array}$ & $\begin{array}{c}\text { Liquid } \\
\text { Loading } \\
\left(\mathrm{kg} / \mathrm{m}^{2} \mathrm{~s}\right)\end{array}$ & $\begin{array}{c}\text { Steam } \\
\text { Loading } \\
\left(\mathrm{kg} / \mathrm{m}^{2} \mathrm{~s}\right)\end{array}$ & $\begin{array}{c}\text { Steam } \\
\text { Dynamic } \\
\text { Pressure } \\
(\mathrm{Pa})\end{array}$ \\
\hline 0.13 & 26 & 30 & 0.146 & 0.53 \\
0.20 & 66 & 74 & 0.36 & 3.2 \\
0.25 & 104 & 116 & 0.56 & 7.9 \\
$3 \times 0.11$ & 63 & 71 & 0.34 & 2.9 \\
\hline *Assumes nominal water inlet temperature of $26^{\circ} \mathrm{C}$, steam \\
outlet temperature of $22.7^{\circ} \mathrm{C}$ and an \\
effectiveness of unity.
\end{tabular}

The data for multiple spouts cover a range $30<L<85 \mathrm{~kg} / \mathrm{m}^{2} \mathrm{~s}$ and show decreasing effectiveness with increasing liquid loading. The multiple spouts were less effective than single spouts at the same liquid loading. This decrease in the effectiveness of multiple spouts may have arisen from interference among spouts and between spout and vessel wall. The spread of liquid at the spout exit level appeared to block ready escape of steam generated from below. Significant pressure loss, which prevents effective evaporation, may occur at this constriction.

A comparison of current multiple-spout evaporation data with prior data obtained using multiple spouts of similar configuration is shown in Figure 3-11. Nisolle (1947) conducted seawater evaporation tests using 19, 38, and 175 spouts of varied cross sections with equivalent diameters of 0.07 , 0.10 , and $0.03 \mathrm{~m}$, respectively. Nisolle's evaporation vessel was of comparable diameter to the HMTSTA apparatus. His data, when converted to a thermal effectiveness and an effective liquid loagding, yield an effectiveness of about 0.8 at a loading of nominally $50 \mathrm{~kg} / \mathrm{m}^{2} \mathrm{~s}$, as shown in Figure 3-11. Fournier (1985), using three spouts $0.03 \mathrm{~m}$ in diameter in a vessel $0.19 \mathrm{~m}$ in diameter, obtained effectiveness in the range of 0.8 to 0.9 over a liquid loading range of 35 to $65 \mathrm{~kg} / \mathrm{m}^{2}$ s using fresh and simulated seawater. Considering the number of spouts used by Nisolle, the liquid stream emerging from one spout interacted much more with the liquid streams emerging from the surrounding spouts; unlike in Fournier's investigation, wall interactions may have been more significant. However, the results obtained at these three very different laboratories (two in France, one in the United States) with different working fluids are in good agreement, given the measurement uncertainty.

Regardless of the nature of spout-to-spout or spout-to-wall interactions, all reported data merged to form a unique variation of $\varepsilon$ with $\mathrm{L}$, with $\varepsilon$ decreasing gradually as L increases. For multiple spouts, the two-phase flow field of droplets and steam resembled a field of rain of droplets. A global parameter such as the liquid loading, L, describes the field effectively. This parameter is commonly used by engineers to describe the operation of a cooling tower or other gas-liquid contacting devices in the chemical industry. For the present application, when $\varepsilon$ was plotted vs. the liquid loading, all the data merged. Any other description of the independent variable, e.g., spout 


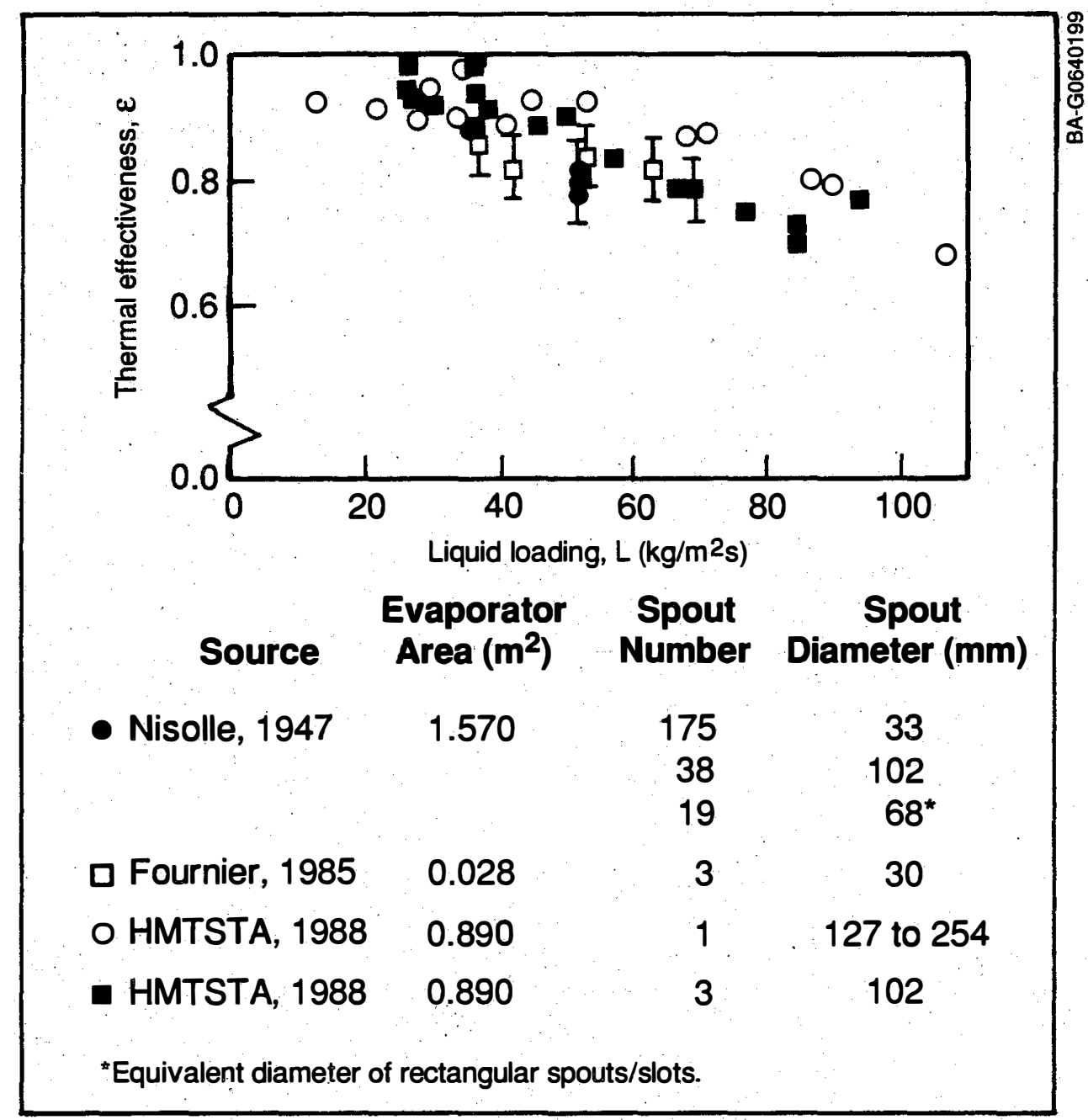

Figure 3-11. Influence of liquid loading on seawater multiple-spout evaporator; comparison with French data

exit velocity, does not provide a comprehensive description such as that provided by the liquid loading. On the basis of the entire data set presented in Figure 3-11, the influences of spout-to-spout and spout-to-wall interactions appear to be equivalent. In all experiments, no instability of flow among multiple spouts was reported.

Figure 3-12 shows earlier data trends obtained using fresh water at SERI. Two sets of. variations of effectiveness vs. liquid loading are shown. These data were obtained using a spout $0.13 \mathrm{~m}$ in diameter enclosed within a $0.56-\mathrm{m}-$ diameter cylinder. Because of the confinement, appropriate definitions of liquid and steam loadings were possible. The lower set of data was obtained using a simple straight spout; the upper set of data used a set of three screens below the spout for enhancement. In both cases the nominal water temperature drop at the design liquid loading was $2.2^{\circ} \mathrm{C}$, and the spout height was 


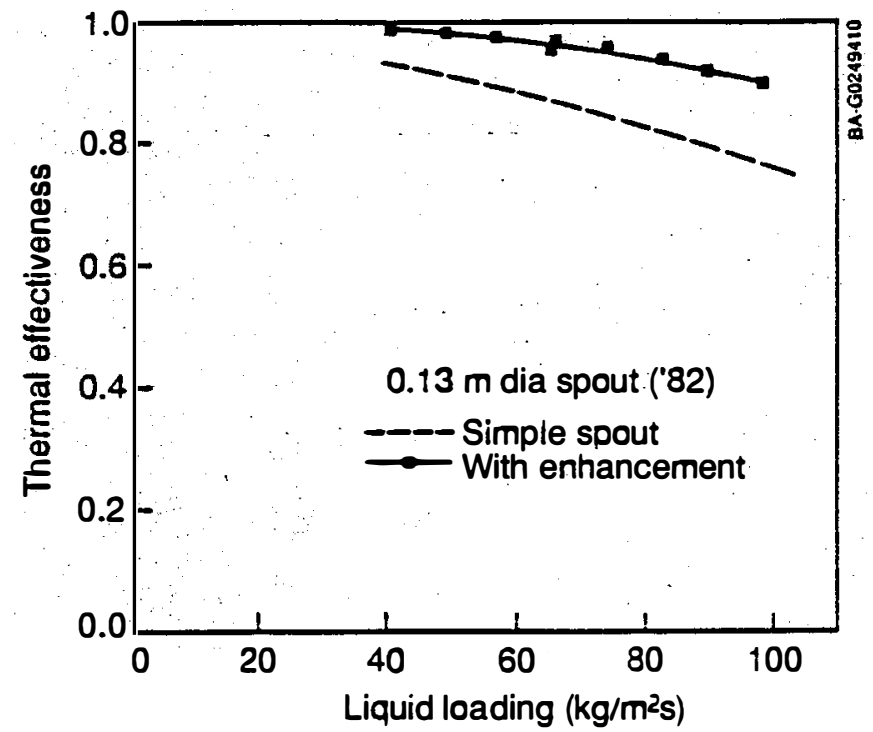

Figure 3-12.

Influence of liquid loading on fresh-water spout evaporator data in a confined enclosure

$0.5 \mathrm{~m}$. Both sets of data exhibit decreasing effectiveness with increasing loading. The trend obtained for the single spout using seawater (Figure 3-10) was identical to that using fresh water. The data obtained with the $0.13-\mathrm{m}$ spout in fresh-water tests (dashed line in Figure 3-12) can be superposed onto the data obtained in seawater with the single spouts (shown in Figure 3-10), resulting in the same recorded effectiveness for fixed liquid loading, within experimental uncertainties. The observed behaviors of fresh water and seawater under evaporation using vertical spouts are the same within experimental uncertainty.

When geometry, liquid loading, and superheat were similar, both fresh water and seawater yielded the same effectiveness for evaporation. Influences of additional nucleation sites which may be present in the seawater and of release of dissolved gases were not observable within experimental uncertainty.

With enhancement, the freshwater results indicated that effectiveness may be increased by as much as $17 \%$ at a high liquid loading of nearly $100 \mathrm{~kg} / \mathrm{m}^{2} \mathrm{~s}$. Strategically placing simple screens in the free fall of exiting water enhanced the likelihood of obtaining high thermal effectiveness at high evaporator liquid loadings.

A series of experiments using enhancement was conducted with seawater. Figure 3-4 shows a photograph of the screens used in an effort to enhance evaporation. No significant enhancement of thermal effectiveness resulting from the presence of screens was observed in seawater. In seawater, the presence of foam around the evaporating jets mitigated or nullified the influence of enhancement.

The influence of superheat on evaporator performance is shown in Figure 3-13. Data for single spouts $0.13 \mathrm{~m}$ and $0.20 \mathrm{~m}$ in diameter and for multiple spouts are included. The liquid loadings for these data sets were 30,74 , and 71 $\mathrm{kg} / \mathrm{m}^{2} \mathrm{~s}$, respectively. All spout heights were nominally $0.46 \mathrm{~m}$. 
Figure 3-13.

Influence of superheat on seawater spout evaporator

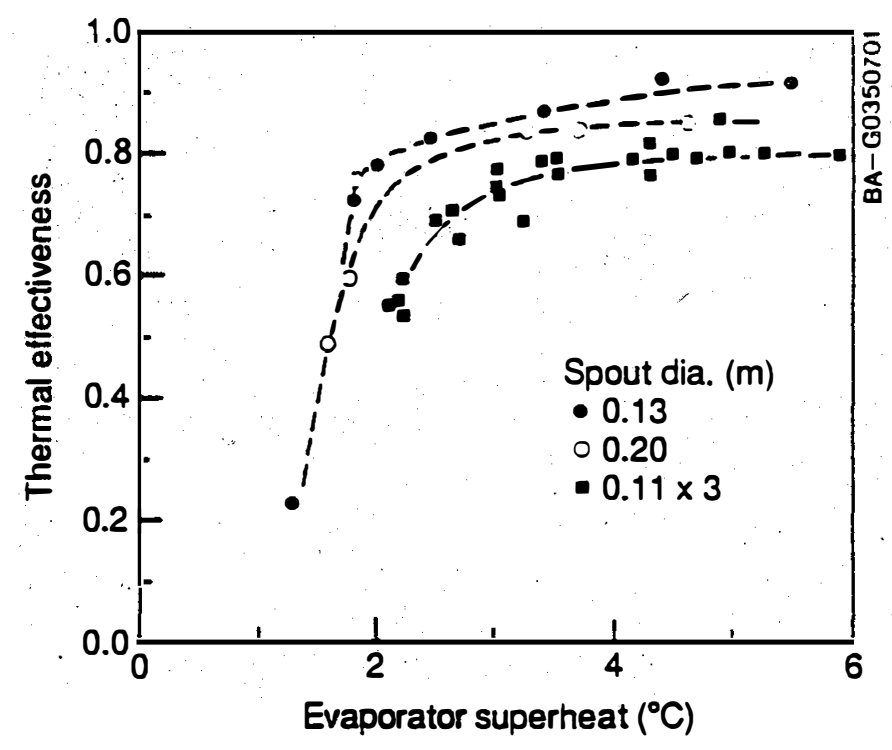

The data for each geometry showed an increasing effectiveness with increasing superheat. A rather sharp increase occurred as the superheat was raised from about $1^{\circ} \mathrm{C}$ to about $2^{\circ} \mathrm{C}$. The effectiveness increased dramatically because of the increased shattering of the exiting jet from the spout. At low superheats, escaping steam from the jet caused large bubbles to appear on the jet interface. However, the evaporation rate was not sufficient to alter the jet significantly from the geometry it displayed when no evaporation took place. The exposed surface area remained low and unaltered, resulting in low effectiveness.

As superheat was increased, the escaping steam tended to break up the jet, causing more surface area to be available for evaporation. This in turn increased the quantity of generated steam. An "avalanche" effect was observed as the superheat was gradually increased to initiate jet breakup. For superheats above a threshold level for jet breakup, the increase in effectiveness with increasing superheat was gradual. The jet geometry remained shattered and appeared visually similar.

For all single spouts, the variation of effectiveness with superheat was similar; lower values of effectiveness were obtained at higher liquid loadings. The multiple spouts again exhibited the familiar trend of effectiveness with superheat, but they yielded lower effectiveness than did single spouts at corresponding 1 iquid loadings.

The influence of spout height on the effectiveness of the evaporator is shown in Figure 3-14. Data are included for single spouts 0.13 and $0.20 \mathrm{~m}$ in diameter and for multiple spouts. The liquid loadings for these sets of data are 30,74 , and $71 \mathrm{~kg} / \mathrm{m}^{2} \mathrm{~s}$, respectively. The water temperature drop was maintained at nominally $3^{\circ} \mathrm{C}$ for all the data in this figure.

Al1 the data exhibited a rather gradual increase in effectiveness with increasing spout height. The smallest spout, operating at low liquid loadings, showed almost no variation with increasing height. The entire data set, when extrapolated to a spout height of zero, yielded finite intercepts, 


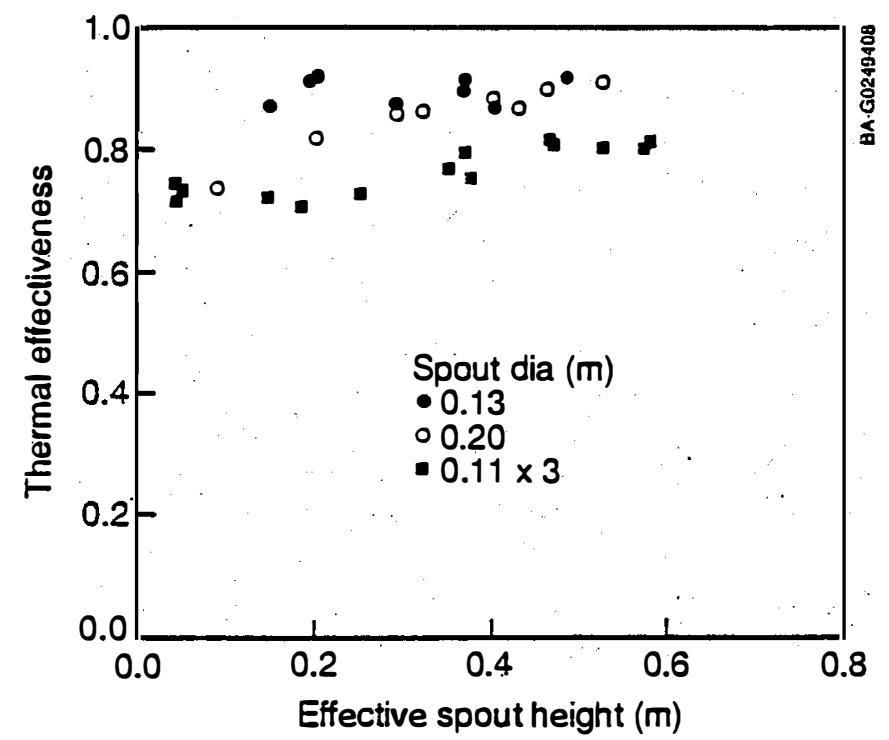

Figure 3-14.

Influence of spout height on seawater spout evaporator

corresponding to effectiveness value in the range of 0.6 to 0.9 . This intercept may be interpreted to be the extent of evaporation occurring in the area directly above the spout exit plane. A substantial amount of steam was generated there. The liquid was thrown upward against gravity in the vertical spout configuration and fell back upon itself to enhance jet shattering. Significant shattering in this region results in major steam production occurring here. The kinetic energy of the exiting jet effectively enhanced evaporation by creating substantial interfacial area directly above the spout.

The remaining $10 \%$ to $40 \%$ of the steam was generated in the area below the spout. In this freefall area, the droplet residence time is proportional to the square root of the height h. Evaporation from the droplets is controlled by 1 iquid-side thermal diffusion, because probabilities for collision among droplets and surface removals are minimal. The thermal diffusion process is typically proportional to the square root of the residence time. Thus, dependence of $\varepsilon$ on the residence time as the square root of time or as the fourth root of height may be expected. The observed influence of height on $\varepsilon$ was minimal, as expected, because of the small range of heights investigated and the weak functional dependence on height. The effectiveness reached nearly its asymptotic value for spout heights of 0.4 to $0.6 \mathrm{~m}$. Additional spout heights above $0.6 \mathrm{~m}$ are not beneficial considering the penalty associated with the water pumping loss.

Additional evaporator test data were collected during investigations of the direct-contact condensers (see Chapter 7 ). These data were obtained over five months under repeated operating conditions using the $0.20-\mathrm{m}-\mathrm{diameter}$ spout. They were used to establish postexperimental uncertainties of inferred thermal effectiveness. Figure 3-15 illustrates the measured variation of $\varepsilon$ vs. L over a 1 iquid loading range of 17 to $51 \mathrm{~kg} / \mathrm{m}^{2} \mathrm{~s}$ and indicates statistically inferred estimates of errors for a confidence level of $95 \%$. The largest inferred error was estimated to be \pm 0.03 for thermal effectiveness. This uncertainty is comparable to but somewhat smaller than the preexperimental estimate of \pm 0.07 described in Appendix A. 


\subsubsection{Release of Dissolved Gases}

The release of dissolved gases from the warm water as it flowed through the HMTSTA apparatus, including the predeaerator chamber below the evaporator and the evaporator itself, was estimated by measuring levels of dissolved oxygen in the incoming and outgoing water. More detailed studies of deaeration are reported in Chapter 5; the data presented here are to be considered preliminary estimates on $1 \mathrm{y}$. Measuring instrumentation for determination of gas release from warm seawater did not always perform satisfactorily during tests of the evaporator. However, an approximate rate of gas release could be estimated. Figure 3-16 shows the percentage of gas released vs. overall evaporator liquid loading. Because the diameters of the predearation chamber and the evaporation chamber are the same, this liquid loading also represents the predeaerator loading. These results are of the same magnitude as those described in Chapter 5, at the end of Section 5.5.2. Despite large scatter in the data, a general trend toward decreasing gas release with increased loading is observed in Figure 3-16. At a typical loading range between 50 and $100 \mathrm{~kg} / \mathrm{m}^{2} \mathrm{~s}$, a gas release between $70 \%$ and $50 \%$ may be projected.

\subsubsection{Spout Hydraulics}

Except for the largest single spout tested, all spouts were fitted with a bell-mouthed entry on the bottom to reduce pressure losses from liquid entrance. The spout tubes were nominally $1.75 \mathrm{~m} \mathrm{long}$, including the length of the bell-mouthed entry. Measured liquid pressure losses for flow through the spout were used to calculate the overall loss coefficient $K$, the ratio of measured pressure losses and dynamic pressure in the spout. Contributions from entrance, exit, and frictional losses were included.

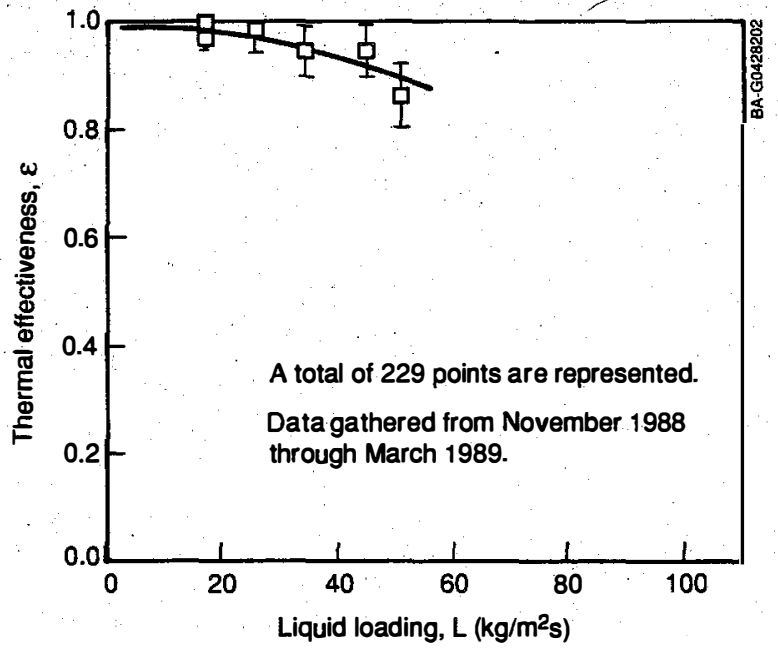

Figure 3-15. Seawater evaporator, single 8-in. spout, postexperiment uncertainties

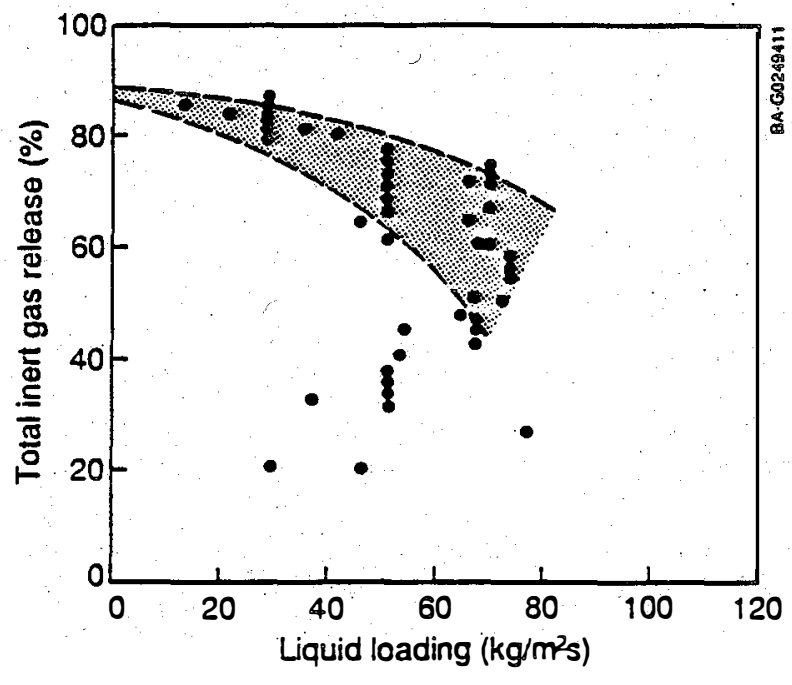

Figure 3-16. Influence of liquid loading on seawater deaeration 
Figure 3-17 illustrates the measured hydraulic pressure loss vs. the dynamic pressure of the liquid flowing through the spout. Data for all tested single and multiple spouts are included. Because the discharge configuration remains unchanged for all the tests with different spout configurations, the data are plotted as a function of the dynamic pressure in the discharge pipe. A linear variation of $\Delta p$ with the dynamic pressure is seen. The plotted loss includes the hydraulic loss in the spout as well as in a portion of the discharge pipe. Based on the slopes of the variation and the geometrical parameters for the tested configurations, the spout loss coefficient is deduced.

The data shown in Figure 3-17 were also analyzed to yield a hydraulic loss coefficient based on the dynamic pressure in the various spouts. For the spouts with bell-mouthed entries, the reduced data yielded a loss coefficient of $1.9( \pm 0.1)$. The absence of a bell-mouthed entry increased this coefficient to a value of $3.0( \pm 0.1)$. Single-phase flow calculations yield an estimate for the loss coefficient of 1.4 for the former case. The measured higher values suggest that increased frictional loss and end losses may arise from a two-phase bubbly flow through the spout with a finite void fraction.

Spent water from the evaporator was drained through a $0.30-m$ (12-in.) pipe with a dogleg turn. Hydraulic data yielded an overall loss coefficient for the drainage system of $6.1( \pm 0.2)$. Single-phase calculations yielded an estimate for this coefficient of approximately 4.0. Substantially increased losses in the drainpipe occurred because of the foamy, bubbly flow of the spent water. Proper design of the drainage system should lessen the overall hydraulic loss in the evaporator.

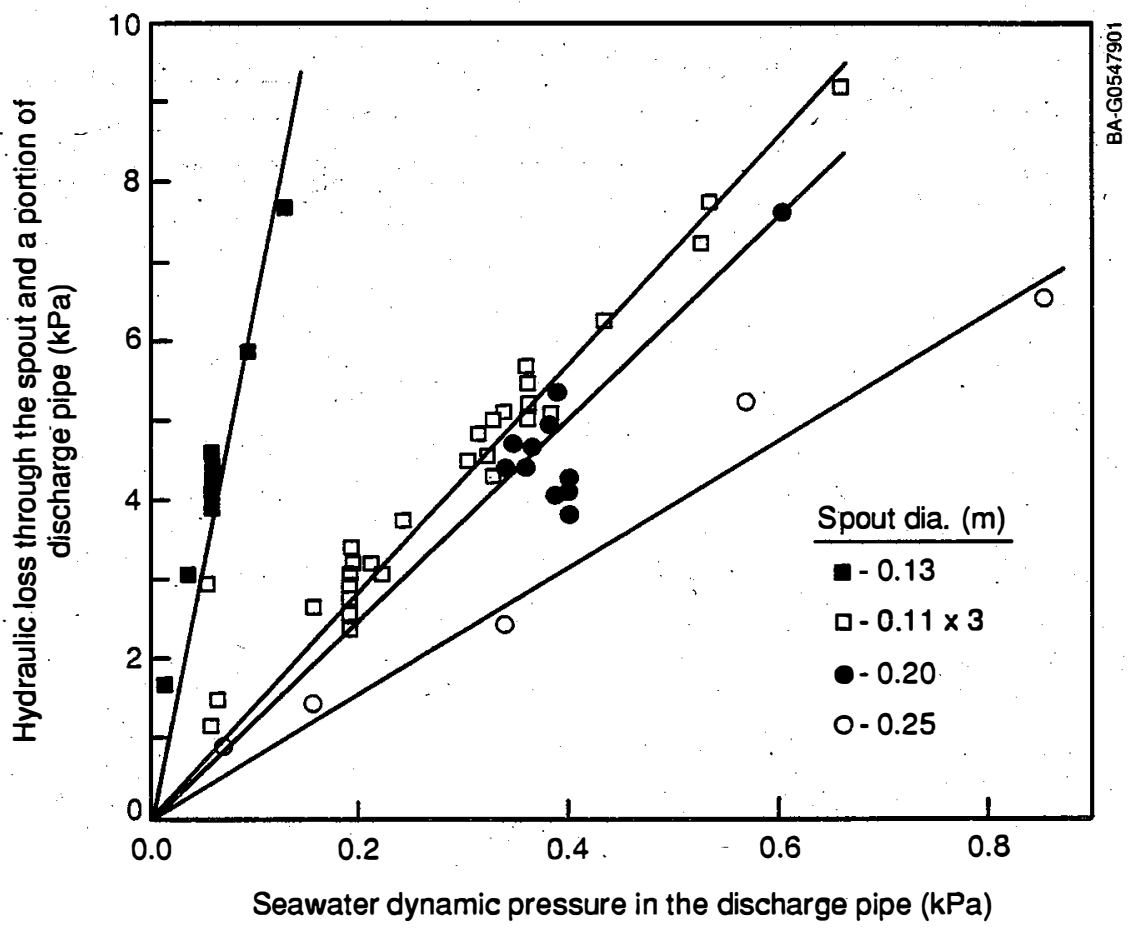

Figure 3-17.

Measured spout pressure loss vs. dynamic pressure of seawater flowing through spout 


\subsection{CONCLUSIONS}

Most scoping tests on the evaporator as outlined in the test plan (Parsons et a1. 1989) were completed during February and March 1988. Despite some operational problems with the instrumentation, significant results were obtained. The following conclusions may be drawn from the seawater results:

1. Liquid loading, superheat, and spout height determine seawater thermal performance for spout evaporators, both the three single spouts and the set of multiple spouts.

2. For the tested spout diameters, the single-spout data merge together to yield a unique variation of thermal effectiveness with liquid loading.

3. Within experimental uncertainty, spout effectiveness vs. 1iquid loading is the same for seawater and fresh water.

4. Superheats above $2^{\circ} \mathrm{C}$ are required to achieve high effectiveness using simple single spouts.

5. A spout height of $0.5 \mathrm{~m}$ is adequate to achieve high evaporator effectiveness.

6. Effectiveness of multiple spouts was lower than that of single spouts requiring slightly lower liquid loadings to obtain the same thermal effectiveness. The present data are consistent with data reported in the iterature. This reduction may arise from spout-to-spout or spout-to-wall interactions.

7. For all multiple-spout data, the overall liquid loading offers the most useful description for the independent variable to express dependence of the thermal effectiveness.

8. Multiple spouts exhibited no water or steam flow instabilities.

\subsection{APPLICABILITY OF TEST RESULTS TO THE NET POWER-PRODUCING EXPERIYIFNT (NPPE)}

The experiments were conducted using spouts up to $0.25 \mathrm{~m}$ in diameter at seawater flow rates of up to $100 \mathrm{~kg} / \mathrm{s}$. NPPE requires a warm seawater flow rate of $620 \mathrm{~kg} / \mathrm{s}$ to yield a steam flow rate of $3.5 \mathrm{~kg} / \mathrm{s}$. To achieve the NPPE goal of $40 \mathrm{~kW}$, evaporator effectiveness greater than 0.85 should be sought for the design. To minimize technical risk, spout diameters within the tested range reported here should be adopted for the NPPE. Such a diameter selection dictates the use of multiple spouts for the NPPE. To ascertain effectiveness values greater than 0.85 , based on the multiple-spout data presented in Figure 3-11, evaporator liquid loading should be kept below $50 \mathrm{~kg} / \mathrm{m}^{2} \mathrm{~s}$. The above discussions pertain to how the HMTSTA data apply to the selection of design conditions for the NPPE. 
Precaution is also called for in these areas:

- Hydraulic losses through the spouts that are greater than the single-phase flow predictions must be taken into account in the evaluation of parasitic power consumption.

- Manifolds for distribution of the warm seawater among multiple spouts must be carefully designed to ensure uniform liquid distribution among the spouts.

- Spouts must be distributed evenly throughout the evaporator vessel to ensure uniform steam flow to the turbine inlet.

- The water manifold must be designed to ensure that no trapped pockets of liberated noncondensable gases accumulate to cause unsteady flows.

- An adequately large and hydraulically smooth drain system must be provided to discharge the bubbly spent warm seawater effectively.

- A noncondensable release fraction of $100 \%$ from the evaporator warm seawater should be assumed when sizing the vacuum exhaust system to ensure adequate capacity for their removal.

- A mist eliminator (described in Chapter 4) must be considered for the NPPE, to ensure minimal carryover of seawater droplets with the steam supplied to the turbine.

- A minimum vertical clearance of at least $2 \mathrm{~m}$ must be provided between the spout exit plane and the mist eliminator, depending on the chosen liquid loading, to allow for gravitational settling and to prevent significant carryover of droplets. At a chosen liquid loading of less than $50 \mathrm{~kg} / \mathrm{m}^{2} \mathrm{~s}$, the steam velocity approaching the mist eliminator is less than $15 \mathrm{~m} / \mathrm{s}$. Such low steam velocity allows gravitational settling of seawater droplets greater than $1.5 \mathrm{~mm}$ in diameter (Bharathan and Penney 1983) over the specified minimum clearance of $2 \mathrm{~m}$.

Evaporation from the seawater is complicated by the formation of rivulets and droplets caused by steam escape and shattering. Available analytical models are empirical in nature and do not provide performance projections for new configurations of evaporators using multiple spouts. Cautious use of available test data and prudent judgment are required to minimize risk in the design and development of the evaporator for the NPPE.

\subsection{FURTHER RESEARCH NEEDS}

Further research on evaporation should be directed toward minimizing the required planform area for handling a given liquid or steam flow.. Such research, however, should be carried out on a larger-scale apparatus, such as the heat exchangers for the NPPE, to enhance our understanding of the influence of increased loadings, multiple spout interactions, and methods of enhancement. 


\subsection{REFERENCES}

Balitskiy, S. A., and Y. A. Shurchkova, 1969, "Flashing of a Superheated Liquid Under Vacuum," Heat Transfer--Soviet Research, Vo1. 1, No. 3, pp. 106-109.

Bharathan, D., and T. Penney, Dec. 1983, Mist Eliminators for Freshwater Production from Open-Cycle OTEC Systems, SERI/TR-252-1991, Golden, CO: Solar Energy Research Institute.

Bharathan, D., and T. Penney, 1984, "Flash Evaporation from Turbulent Water Jets," ASME Journal of Heat Transfer, Vo1. 106, Pp. 407-416.

Bharathan, D., F. Kreith, D. Schlepp, and W. L. Owens, 1984, "Heat and Mass Transfer in Open-Cycle OTEC Systems," Heat Transfer Engineering, Vo1. 5, No. 1-2, pp. 17-30.

Brown, R., and J. L. York, 1962, "Sprays Formed by Flashing Liquid Jets," AIChE Journal, Vol. 8, No. 2, pp. 149-153.

Fournier, T., 1985, "Open-Cycle Ocean Thermal Energy Conversion: Experimental Study of Flash Evaporation," Oceans '85 Conference Record, San Diego, CA: November 12-14, 1985, Vol. 2, PP. 1222-122.9.

Ghiaasiaan, S. M., A. T. Wassel, G. C. Nihous, and L. Vega, Nov. 1989, "A Semi-Empirical Model for OC-OTEC Spout Flash Evaporator," Proc. of the International Conference on Ocean Energy Recovery, Am. Soc. of Civil Engineers, Honolulu, HI.

Green, H. J., D. A. O1son, D. Bharathan, and D. H. Johnson, June 1981, Measured Performance of Falling-Jet Flash Evaporators, SERI/TP-631-1270, Golden, CO: Solar Energy Research Institute.

Heertjes, P. M., and L. H. deNie, 1966, "The Mechanism of Mass Transfer During Formation, Release, and Coalescence of Drops, Part I--Mass Transfer to Drops Formed at a Moderate Speed," Chemical Engineering Science, Vol. 21, pp. 755-768.

Kreith, F., D. A. Olson, D. Bharathan, and H. J. Green, Nov. 1982, A Study of Falling Jet Flash Evaporators, SERI/TP-252-1415, Golden, CO: Solar Energy Research Institute.

Levich, V. G., 1962, Physicochemical Hydrodynamics, Prentice-Hall, N.J., pp. 689-699.

Maa, J. R., 1967, "Evaporation Coefficient of Liquids," Industrial and Engineering Chemistry Fundamentals, Vol. 6, No. 4 pp. 504-518.

Mills, A. F., S. Kim, T. Leininger, S. Ofer, and A. Pesaran, 1982, "Heat and Mass Transport in Turbulent Liquid Jets," International Journal of Heat and Mass Transfer, Vol. 25, No. 6, pp. 889-897.

Miyatake, 0., T. Tomimura, Y. Ide, and T. Fumii, 1981, "An Experimental Study of Spray Flash Evaporation," Desalination, Vol. 36, Pp. 113-128. 
Nihous, G. C., 1989, "A Semi-Empirical Analysis of Spout Evaporators for OpenCycle Ocean Thermal Energy Conversion," ASME paper 89-HT-4, Am. Soc. of Mech. Engineers, New York, NY.

Nisolle, M. L., 1947, "Utilisation de 1'Energie Thermique des Mers (Les Problèmes de Fonctionnement)," Societé des Ingenieurs Civils de France: Paris, pp. 796-825.

Parsons, B. K., H. F. Link, D. Bharathan, A. Pesaran, F. Zangrando, and C. B. Panchal, April 1989, Test Plan for the Heat- and Mass-Transfer Scoping Test Apparatus: Phase I and Phase II Tests, Internal Program Report, SERI/PR-253-3385, Golden, CO: Solar Energy Research Institute.

Sam, R. G., and B. R. Patel, Oct. 1982, Open Cycle Ocean Thermal Energy Conversion Evaporator/Condenser Test Program Data Report, TN340, Hanover, NH: Creare $R \& D$, Inc.

Theofanous, T. G., R. N. House, and L. K. Brumfield, 1976, "Turbulent Mass Transfer at Free, Gas-Liquid Interfaces, With Applications to Open-Channel, Bubble, and Jet Flows," International Journal of Heat and Mass Transfer, Vol. 19, No. 6, pp. 613-624. 
CHAPTER 4.0

\title{
MIST ELIMINATOR TESTS
}

\author{
Desikan Bharathan \\ Solar Energy Research Institute
}




\subsection{BACKGROUND}

An attractive by-product of the OC-OTEC system is fresh water, which can be obtained from condensation of the steam produced in the evaporator if the steam contains only small amounts of entrained seawater droplets. This is accomplished by using a mist eliminator. An opęn-cycle plant can yield a specific water production of about 900 to $1600 \mathrm{~m} / \mathrm{day}$ per $\mathrm{MW}$ net $(0.24$ to $0.42 \mathrm{million}$ gal/day), depending on the design and operating conditions (Bharathan, Kreith, and Owens 1983).

In OC-OTEC steam generation, evaporator feed (sea) water is often carried over with the steam in the form of droplets of various sizes. Detrimental effects of this liquid carryover are threefold:

- The droplets impinge on the rotating turbine blades, causing the blades to erode.

- The droplets deposited on the various internal surfaces may evaporate further, leaving a residue of dissolved solids and highly concentrated brine, which may lead to corrosion.

- The seawater droplets carried to the condenser mix with the condensate, causing it to have an unacceptably high salt content.

To mitigate the problems of liquid carryover, the use of suitable mist eliminators in the steam flow path ahead of the turbine is often advocated (Westinghouse 1979).

Because the temperature of the steam upstream of the turbine is $10 \mathrm{w}\left(\sim 20^{\circ} \mathrm{C}\right)$, the corresponding saturation pressure is only $2340 \mathrm{~Pa}$ and the specific volume is about $60 \mathrm{~m} / \mathrm{kg}$. The volumetric flow of the steam upstream of the turbine may range from 750 to $1000 \mathrm{~m}^{3} / \mathrm{s}$ per $\mathrm{MW}$ of gross power extracted. The temperature drop across the turbine is about $10^{\circ} \mathrm{C}$. To prevent excessive parasitic power loss in the steam cycle, the pressure and temperature drop across the mist eliminator must be severely limited. The need to handle large volumetric steam flow with minimal pressure loss requires strict performance guidelines for the mist eliminator.

The performance of a mist eliminator can be specified as follows: 1iquid collection efficiency, pressure loss, maximum allowable vapor velocity (to prevent liquid reentrainment), and minimum size of removed droplets. In general, these requirements are interdependent; therefore, choosing a suitable mist eliminator based on any one criterion is not realistic. The performance of the mist eliminator does not impose operational restrictions on the evaporator except on the allowable steam velocity, if the planform areas must be the same, and the vertical clearance required between the tops of the spouts and the mist eliminator.

This chapter reports on the experimentally evaluated performance of a mist eliminator with chevron-shaped passages, selected based on prior studies conducted at SERI (Bharathan and Penney 1983). The measurements were limited to characterizing pressure loss as a function of steam dynamic pressure. Available experimental data and methodology for prediction of collection efficiencies allowed accurate estimation of the droplet removal efficiency of the chosen design. Analysis of the steam condensate, i.e., desalinated water, 
from the surface condenser indicated that the chosen mist eliminator limited the droplet carryover effectively, as projected.

\subsubsection{Available Experimental Data}

Eliminating droplets with diameters ranging from 10 to 3,000 microns can be adequately accomplished using gravitational settling, centrifugal separation, and inertial impaction. Inertial impaction devices are most frequently used in the industry because they require relatively little volume and a short vapor path. These devices are obstructions placed in the vapor path to divert the flow; the liquid particles tend to be carried by their momentum to the obstruction walls where they collect and drain in the form of layer droplets.

Early investigations of mist eliminators for OTEC applications were conducted by Bharathan and Penney (1983). Four different wire-mesh pads and a chevrontype mist eliminator were characterized in terms of a vapor pressure coefficient. Droplet removal efficiencies were calculated based upon analytical methodologies proposed by Katz (1959). Because of the susceptibility for reentrainment from wire-mesh pads at low steam velocities and the low pressure-loss penalties of chevron-type mist eliminators, Bharathan and Penney recommended the use of chevron-type mist eliminators for OC-OTEC application.

More recent measurements of the collection efficiencies of chevron-type mist eliminators indicated that they can effectively remove droplets up to $40 \mu \mathrm{m}$ in diameter (Monat, McNulty, and Michelson 1986). In an accompanying study by McNulty, Monat, and Hansen (1987), eighteen different commercially available mist eliminators were experimentally evaluated for hydraulic performance, collection efficiency, and tendency for reentrainment. Simple examples for design selection were also provided.

\subsubsection{Existing Models}

Katz (1959) provided methods to estimate collection efficiency and pressure loss of both wire-mesh and chevron-type mist eliminators. See Bharathan and Penney (1983) for a brief summary of the methodology. The prediction methods are suitable for initial estimation of the performance. Threshold minimum droplet diameter for removal may be predicted within $\pm 50 \%$ of the size, and pressure loss within $\pm 25 \%$.

Based on the available literature and prior studies, selection of a mist eliminator to achieve a specified performance is straightforward. Thus, the scope of the present set of experiments was limited to verifying the hydraulic loss characteristics of a chosen design.

\subsubsection{Specific Objectives}

The specific objectives of the tests conducted on the mist eliminator were

- To verify the pressure-loss characteristics of a chosen commercially available mist-eliminator design

- To verify its effectiveness in droplet removal by analyzing the chloride and total dissolved solid (TDS) content of the condensed steam. 


\subsection{DEFINITION OF THE GOVERNING PARAMETERS}

\subsubsection{Pressure-Loss Coefficient}

The pressure-loss coefficient, $K$, is expressed as

$$
\mathrm{K}=2 \Delta \mathrm{p} / \rho \mathrm{v}^{2}
$$

where $\Delta p$ is the pressure loss across the mist eliminator $(\mathrm{Pa})$, $\rho$ is the steam density $\left(\mathrm{kg} / \mathrm{m}^{3}\right)$,

$v$ is the steam velocity $(\mathrm{m} / \mathrm{s})$.

Typical value for steam density at OC-OTEC condition $1 \mathrm{~s}(1 / 60) \mathrm{kg} / \mathrm{m}^{3}$, and typical steam velocity may range from 10 to $30 \mathrm{~m} / \mathrm{s}$.

\subsubsection{Efficiency of Droplet Removal}

The efficiency of droplet removal is expressed as the fraction of droplets removed to their total number present upstream of the eliminator. Removal efficiency is strongly dependent on droplet size, steam velocity, and the turning angle the steam undergoes in a chevron-type mist eliminator. Measurement of the collection efficiency requires sophisticated and expensive instrumentation, such as the laser interferometer used by Monat, McNulty, and Michelson (1986). No attempt to measure collection efficiency was made in the experiments reported here.

\subsection{EQUIPMENT AND INSTRUMENTATION}

\subsubsection{Equipment}

The mist eliminator chosen to be tested was a chevron-type, Flexi-chevron Type VIII, made of 304 stainless steel with $25-\mathrm{mm}$ (1-in.) spacing between passages. This article was chosen after careful review of a variety of available designs and of data in the literature to yield low pressure losses as well as good mist-removal efficiency. A photograph of the eliminator is shown in Figure 4-1.

The mist eliminator was placed horizontally $1.3 \mathrm{~m}$ above the spout exit. A larger separation height of 2 to $3 \mathrm{~m}$ is desirable for passive gravitational settling of water droplets of diameters down to $1.5 \mathrm{~mm}$ and for steam velocities of up to $30 \mathrm{~m} / \mathrm{s}$ (Bharathan and Penney 1983). However, construction considerations of the evaporator chamber limited the height at which the mist eliminator could be placed. This limited separation distance often resulted in larger water droplets carried into the mist eliminator at high evaporator liquid loadings, large superheats, and short spout heights, and frequently the mist eliminator was flooded.

\subsubsection{Instrumentation}

The equipment and instrumentation used in this set of experiments are described in Chapter 3 on evaporator tests (Section 3.4). No other additional instrumentation was used. Desalinated water samples were sent to an independent analytical laboratory to analyze and quantify the chloride and TDS content. Pressure loss measurements were performed using the differential 


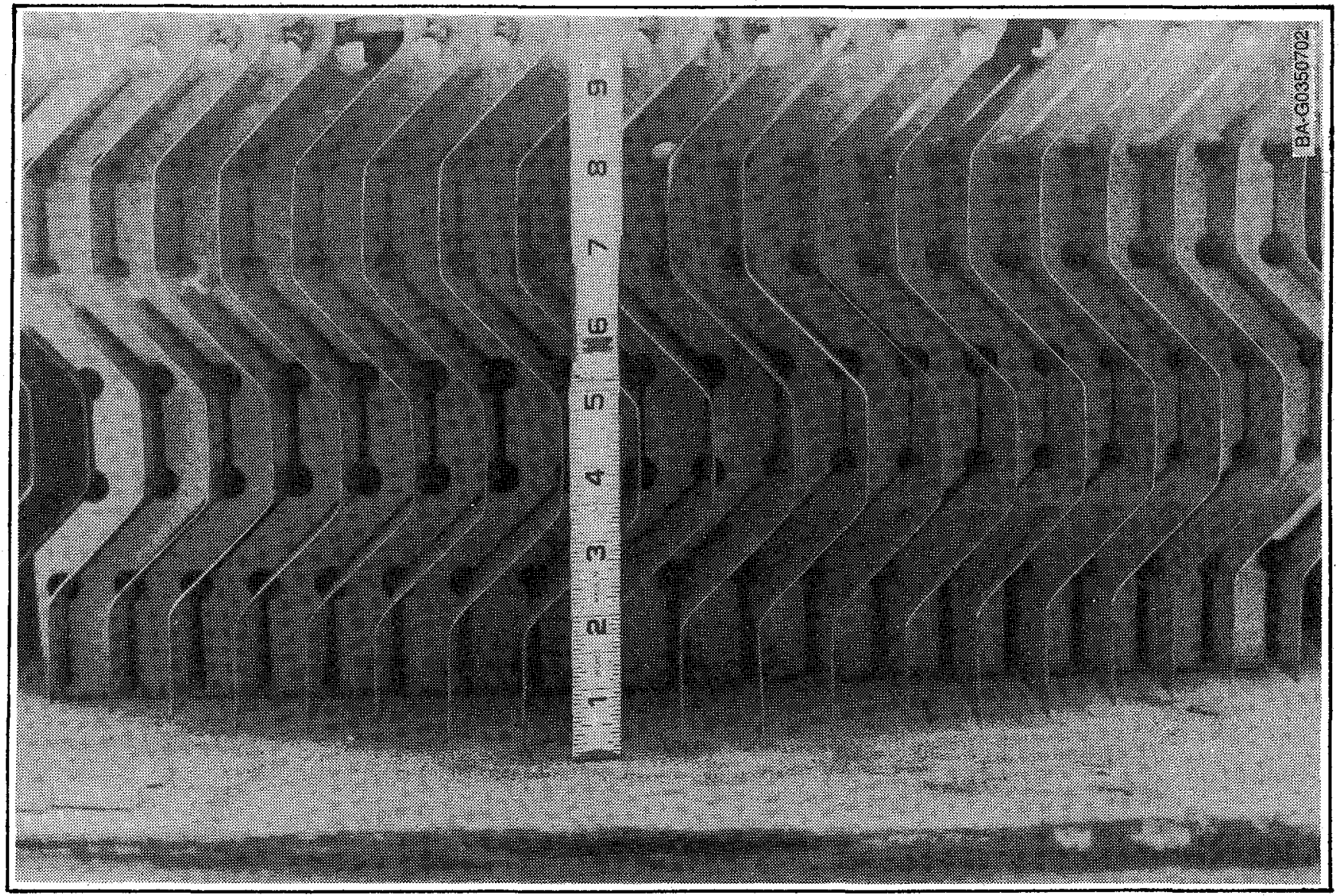

Figure 4-1. Photograph of the mist eliminator

pressure transducer, $\Delta \mathrm{p}_{\mathrm{mist}}$, as shown in Figure 3-5. Steam dynamic pressure was inferred from the temperature and pressure measurements made in the evaporator.

\subsection{RESULTS}

Figure 4-2 shows the measured mist-eliminator pressure 1oss plotted against the steam dynamic pressure at the inlet of the mist eliminator. The data show large scatter. At low levels of dynamic pressure, the measurements tend to congregate around a straight line with a slope of nominally 4. The value of the slope is the hydraulic loss coefficient for the stainless steel mist eliminator. Other data often lie considerably above this line. There occurs a substantial increase in the eliminator pressure loss whenever the incoming steam carries a large droplet load. This increase was observed to occur at high evaporator liquid loadings, high superheats, and low evaporator spout heights. This increase was a result of the limited separation height of the eliminator above the spout, and can be significantly reduced if this height can be increased to 2 or $3 \mathrm{~m}$ (Bharathan and Penney 1983). 


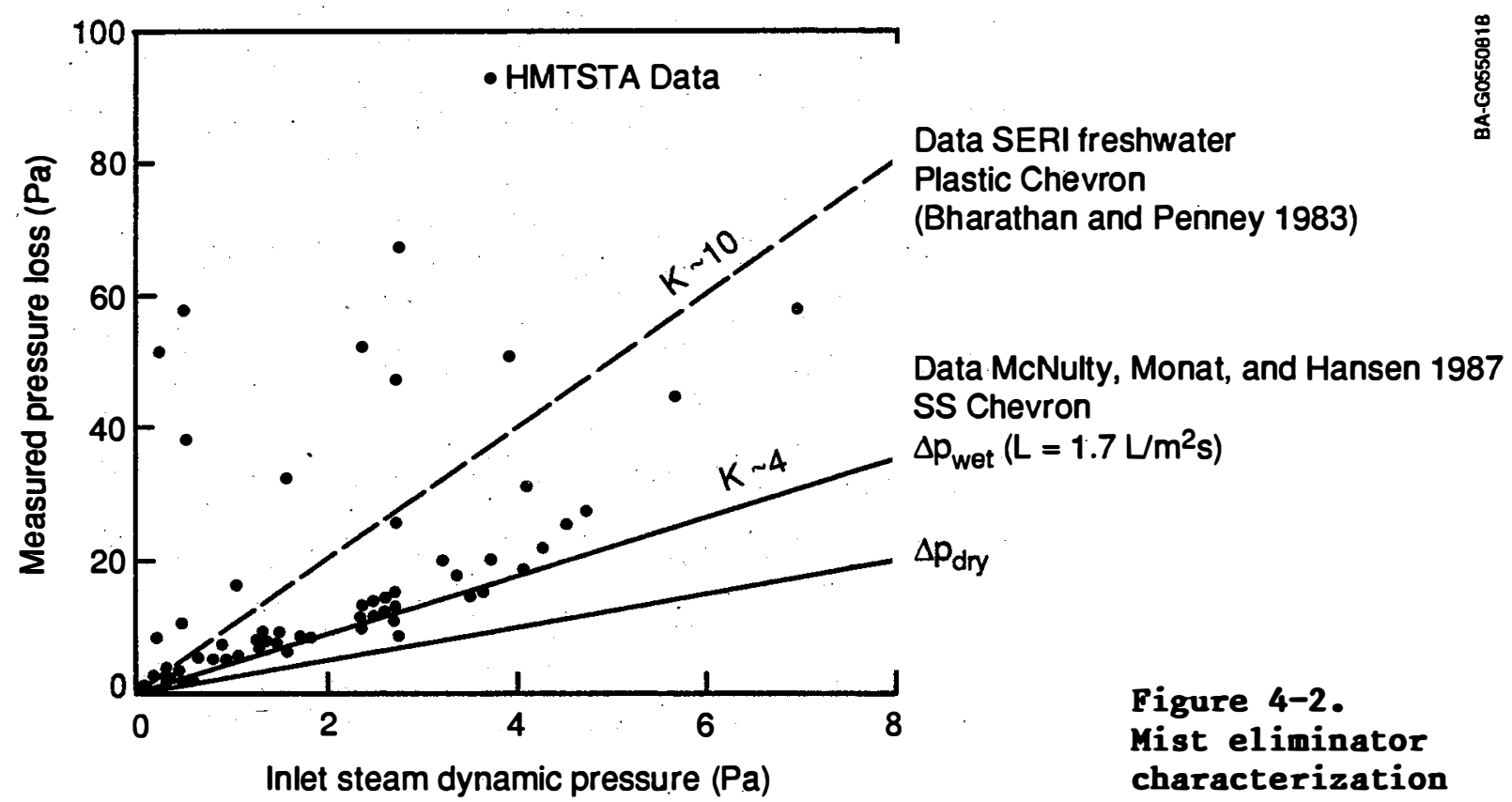

For comparison, prior results of measured pressure losses are also included in Figure 4-2. Earlier fresh-water data generated at SERI, using an eliminator of similar design but made with thick polyethylene sheets, yielded a straightline variation of pressure loss with steam dynamic pressure with a slope of about 10 (Bharathan and Penney 1983). Using thinner stainless steel sheets in the current test article resulted in a significant reduction in this slope. The thinner sheets allowed for reduced entrance and exit losses in the pas sages.

Measurements of pressure loss for the present eliminator using an air/water system as presented by McNulty, Monat, and Hansen (1987) are also included. Wet conditions occur when water droplets are entrained with the gas. Under wet conditions, the pressure loss variation that they measured lies close to the present measurements, when the eliminator is not overloaded. This agreement between prior measurements and our current data lends credibility to the measured loss characteristics of the mist eliminator.

The significance of the present results is that effective mist elimination can be achieved with relatively low pressure-loss penalties, with the loss coefficient approaching 4 .

The capability of the mist eliminator to remove droplets from the gas stream was not directly measured, but it was inferred from the chloride and TDS content of the condensate. Analysis of the condensate showed that its chloride and TDS content were 1.0 and $23 \mathrm{mg} / \mathrm{L}$, respectively. Allowable levels of chloride and TDS content for public water supplies are 250 and $500 \mathrm{mg} / \mathrm{L}$, respectively. The droplet removal efficiency is thus well above the needs for acceptable desalinated water quality. It should be noted here that these results were obtained at low steam flow rates. At higher steam loadings, the carryover increases. Available data in the literature (Katz 1959; Monat, McNulty, and Michelson 1986) can be effectively used to establish the maximum 
steam loadings at which effective droplet removal efficiency can be maintained. Calculations indicate that effective removal can be maintained for inlet steam velocities of up to $30 \mathrm{~m} / \mathrm{s}$ (Katz 1959; Monat, McNulty, and Michelson 1986).'

\subsection{CONCLUSIONS}

The chosen mist eliminator performed as expected, yielding a pressure-loss coefficient of 4 and removing more than enough droplets to result in a desalinated water quality well above acceptable levels.

\subsection{APPLICABILITY OF TEST RESULTS TO NET POWER-PRODUCING EXPERIMENT (NPPE)}

Adequate data and published methodology exist to accurately predict the performance of mist eliminators. Prior measurements indicate that droplet diameter may range from 10 to 3,000 microns at the source, i.e., the evaporator spout. Clear-cut specifications of droplet carryover requirements with respect to the turbine and desalinated water quality will allow straightforward selection of a suitable commercially available mist eliminator for the NPPE.

\subsection{FURTHER RESEARCH NEEDS}

No further research needs are identified with respect to mist-eliminator performance for OC-OTEC applications.

\subsection{REFERENCES}

Bharathan, D. and T. Penney, Dec.-1983, Mist Eliminators for Freshwater Production from Open-Cycle OTEC Systems, SERI/TR-252-1991, Golden, CO: Solar Energy Research Institute.

Bharathan, D., F. Kreith, and W. L. Owens, Jan. 1983, An Overview of Heat and Mass Transfer in Open-Cycle OTEC Systems, SERI/TP-254-1854, Golden, CO: Solar Energy Research Institute.

Katz, E. J., 1959, A Study of Initial Mist Collectors, M.S. Thesis, University Park: Pennsylvania State University.

McNulty, K. J., J. P. Monat, and 0. V. Hansen, May 1987, "Performance of Commercial Chevron Mist Eliminators," Chemical Engineering Progress, pp. 48-55.

Monat, J. P., K. J. McNulty, and I. S. Michelson, Dec. 1986, "Accurate Evaluation of Chevron Mist Eliminators," Chemical Engineering Progress, pp. 32-39.

Westinghouse Electric Corporation, Mar. 1979, 100-MW OTEC Alternate Power Systems, final report to U.S. DOE under Contract EG-77-C-05-1473, Vol. 1 . 
CHAPTER 5.0

\section{OXYGEN DESORPTION FROM WARM SEAWATER}

Ahmad A. Pesaran

Solar Energy Research Institute 


\subsection{NOMENCLATURE}

Abbrev. Description

Units

$\mathrm{C}_{\text {eq }}$ equilibrium concentration of dissolved noncondensable gases in water

$\mathrm{mg} / \mathrm{L}$

$C_{\text {in }}$ dissolved noncondensable gas concentration of water in the supply pipe

$\mathrm{mg} / \mathrm{L}$

$\mathrm{C}_{\text {spout dissolved noncondensable gas concentration of water at }}$ the spout inlet leaving the predeaerator

$\mathrm{mg} / \mathrm{L}$

$\mathrm{C}_{\text {out }}$

dissolved noncondensable gas concentration of evaporator discharge water

$\mathrm{mg} / \mathrm{L}$

Feq $_{\text {eq }}$

fraction of gas desorbed when water is at equilibrium conditions

Fod

fraction of gas desorbed in the predeaeration chamber

Fev

$E_{t}$

fraction of gas desorbed in the evaporator chamber

Ed

total fraction of gas desorbed from the warm seawater

deaeration effectiveness (Eq. 5-4)

$\mathbf{P}$

predeaerator pressure

$\mathrm{kPa}$ 


\subsection{BAGKGROUND}

\subsubsection{Introduction}

Seawater contains dissolved gases (mostly oxygen and nitrogen, and some carbon dioxide), bubbles, and suspended particles. As the seawater moves into the low-pressure OC-OTEC system environment, it becomes supersaturated (see Section D.1 of Appendix D). Therefore, dissolved gases can be desorbed from the water stream, especially in the presence of nucleation sites (bubbles and suspended particles). Release of these noncondensable gases in the evaporator and condensers can degrade condenser performance (Kreith and Bharathan 1988). More importantly, to maintain the vacuum levels in the heat exchangers, additional pumping power is required to remove the noncondensable gases. These effects are estimated to decrease the net power production of an OC-OTEC plant by up to 15\%. (Block and Valenzuela 1985). It is possible to remove part of the noncondensable gases from seawater before they enter the evaporator or condensers by a predeaeration scheme with low parasitic power losses. To determine how much gas desorbs at various stages of an OC-OTEC system, experimental data are needed. In this chapter, a distinction is made between deaeration and predeaeration. "Deaeration". is total release of noncondensable gases in the evaporator and condenser. "Predeaeration" is the removal of noncondensable gases from the seawater before it enters the evaporator or condenser. Total deaeration rates measured during the tests reported here are generally in agreement with those calculated and described in the specific chapters on heat exchanger performance, within experimental errors. The following sections will concentrate on results obtained on predeaeration of the warm seawater.

\subsubsection{Previous Experimental Work}

This section briefly summarizes recent OTEC deaeration experimental investigations. Because of difficulties in measuring nitrogen concentrations, experiments were typically. conducted by monitoring levels of oxygen release and inferring overall gas release from this measurement. Oxygen release level is defined as

\section{(initial concentration - final concentration) initial concentration}

Lindenmuth, Liu, and Poquette (1982) investigated gas desorption in a barometric upcomer using fresh water (with flow rates of about 2.8 to $13.7 \mathrm{~kg} / \mathrm{s}$ ). They found a small dissolved oxygen release (less than $8 \%$ ) using filtered tap water, and an increase of deaeration levels with decreasing water flow rates. Golshani and Chen (1981) investigated deaeration of fresh water in a barometric upcomer and a packed column (with flow rates of 1.5 to $3.5 \mathrm{~kg} / \mathrm{s}$ ). They found less than a $20 \%$ dissolved oxygen release in the upcomer, and an increase in oxygen release with an increase in water flow rate. The dependency of gas release on water flow rate was different in the two experiments, possibly because of differences in experimental setups and water sampling techniques.

Krock and Zapka (1981) studied the deaeration of fresh water and seawater in a packed column, an upcomer, and a debubbler (with water flow rates of 1.2 to $5 \mathrm{~kg} / \mathrm{s}$ ). In most of their experiments, dissolved oxygen measurements were used to estimate the level of deaeration. Dissolved nitrogen measurements 
were performed only in a limited number of experiments using a gas chromatograph. They found that up to $80 \%$ of dissolved gases in warm seawater can be desorbed. They also found that deaeration levels are higher in surface seawater than in deep seawater, possibly because of the presence of a larger number of nucleation sites in the surface seawater. Only small differences existed between deaeration levels of deep seawater and fresh water. Deaeration levels were found to be practically insensitive to water flow rate. They recommended oxygen as a good indicator for total gas exchange for surface seawater, but not for deep seawater.

Later, Zapka (1988) studied deaeration of fresh and recirculated seawater (with flow rates of 0.5 to $1.3 \mathrm{~kg} / \mathrm{s}$ ) in a packed column, a barometric deaerator, and a debubbler. He also studied reinjection of air in a downcomer. He found the dissolved oxygen release level in seawater to be between $10 \%$ and $20 \%$ in the deaerator. In his experiments, oxygen release level increased with the decrease of flow rate. The oxygen release level was increased to $80 \%-90 \%$ upon injection of air bubbles.

Figure 5-1 shows typical results of these experiments (Lindenmuth, Liu, and Poquette 1982; Golshani and Chen 1981; Krock and Zapka 1981; Zapka 1988). In all of these studies the level of oxygen release increased as the pressure decreased. The dissolved oxygen was measured either by a Winkler titration method or by a polarographic dissolved oxygen sensor. These studies addressed many questions and raised others. Some of the data were conflicting, and the dependency of the deaeration level on flow rate, flow path, and the configuration of the test facilities remained unclear. Most of these experiments were performed in small-scale test loops not typical of OTEC test facilities.

\subsubsection{Existing Models}

A mathematical model developed prior to the tests (Ghiaasiaan, Wassel, and Pesaran 1990) analyzed the desorption process of dissolved oxygen, nitrogen, and carbon dioxide in the barometric upcomers of an OTEC plant. Their model considered the growth of bubbles caused by gas mass transfer, evaporation, and decrease of hydrostatic pressure in the upcomers. Growth of bubbles that originated in ocean surface layers and/or formed in the upcomers was considered. Heterogeneous nucleation at pipe wall crevices and on suspended particles, as well as bubble coalescence, were considered. The model predicted that gas desorption would increase with decrease in pressure, decrease in seawater flow rate, increase in concentration of nucleation sites, and decrease in degree of bubble coalescence.

\subsubsection{Scope of the Present Work}

Previous experimental and analytical studies on gas desorption in OTEC upcomers agree that (1) gas desorption rate increases with decrease of pressure and. (2) presence of nucleation sites enhances gas desorption rates. However, these studies show conflicting trends on dependency of gas release rate on the water flow rate.

The objectives of this study, gas desorption tests with warm water in the Heat- and Mass-Transfer Scoping Test Apparatus (HMTSTA), were to learn the following: 


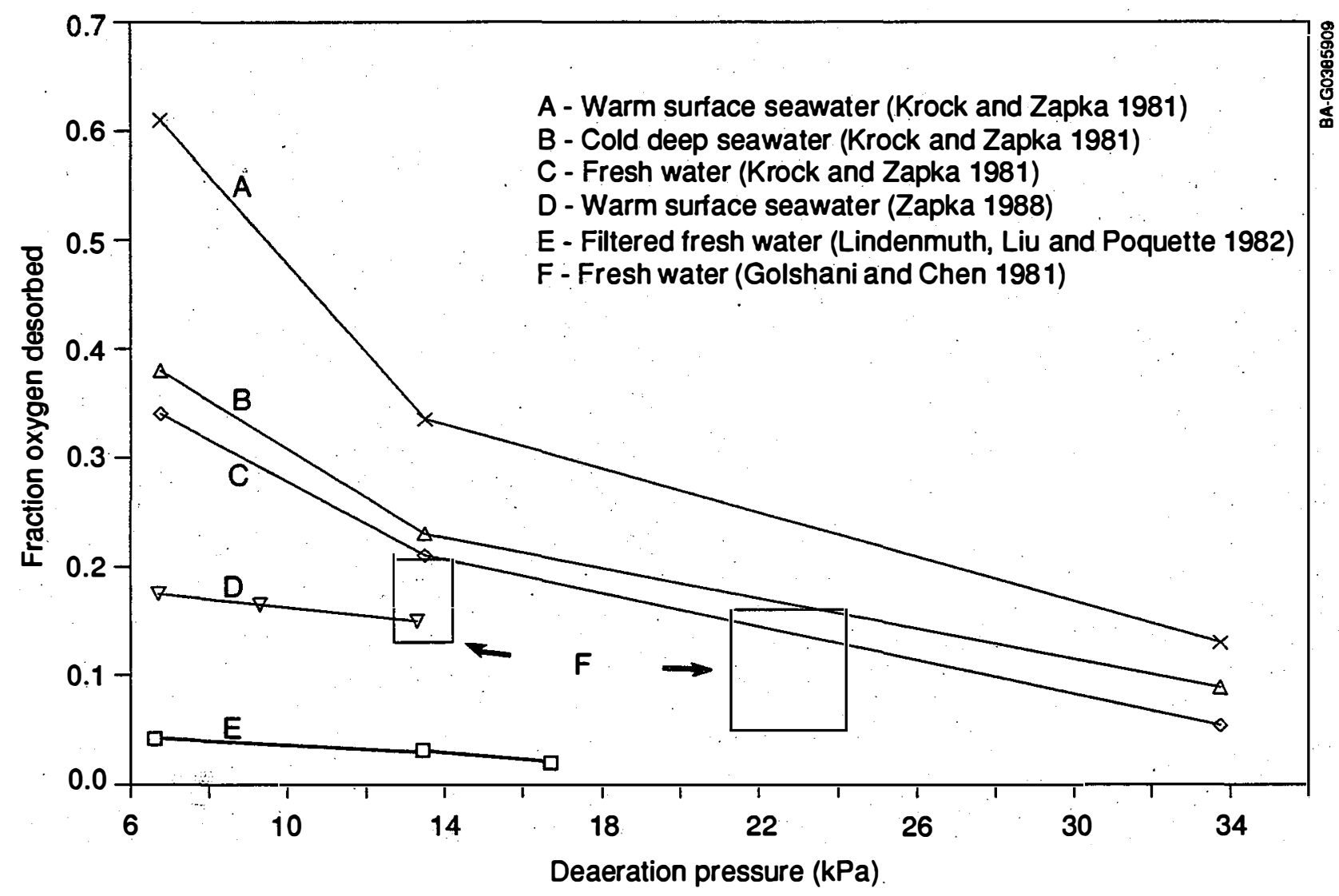

Figure 5-1. Typical deaeration results of different experiments with fresh water and seawater

- How much gas was desorbed in a prototypical OTEC experiment with typical OC-OTEC operating conditions

- The dependency of gas desorption on water flow rate

- The effect of the presence of a baffle plate on gas desorption

- The effect of bubble injection on gas desorption.

This chapter presents the results of gas desorption tests conducted with warm surface seawater in the evaporator and predeaerator (Figure 2-3) during the summer of 1988.

\subsection{DEFINITION OF PERFORMANCE AND TEST PARAMETERS}

The deaeration tests were intended to investigate how much gas is desorbed from warm seawater in the predeaerator and evaporator chambers as a function of parameters typical in OC-OTEC operation. Previous studies have shown that the deaeration process depends on deaeration pressure, water flow rate, flowpath geometry, and presence of nucleation sites. These tests were performed in a laboratory-scale experiment with water flow rates of 0.5 to $14 \mathrm{~kg} / \mathrm{s}$. Here, tests with larger flow rates of 20 to $80 \mathrm{~kg} / \mathrm{s}$ were conducted in a larger-scale apparatus, the HMTSTA, to examine the previous results. For the deaeration tests the major performance parameter, fraction of gases desorbed, was characterized as a function of independent parameters discussed later. 


\subsubsection{Performance Parameters}

The fractions of noncondensable gases desorbed were calculated from the following equations:

$$
\begin{aligned}
& F_{\text {pd }}=\left(c_{\text {in }}-c_{\text {spout }}\right) / c_{\text {in }} \\
& F_{\text {ev }}=\left(c_{\text {spout }}-c_{\text {out }}\right) / c_{\text {spout }} \\
& F_{t}=\left(c_{\text {in }}-c_{\text {out }}\right) / c_{\text {in }}
\end{aligned}
$$

These definitions are commonly used in the literature (Lindenmuth, Liu, and Poquette 1982; Golshani and Chen 1981; Krock and Zapka 1981; Ghiaasiaan, Wassel, and Pesaran 1990) and indicate what fraction of incoming dissolved gases is desorbed in a desired process.

To determine the fractions of all gases desorbed, knowledge was needed of dissolved oxygen, nitrogen, and carbon dioxide contents. However, as will be discussed in Section 5.4, only oxygen was measured; the fraction of other gases desorbed can be inferred from the oxygen measurement.

Note that other parameters occasionally used to describe predeaerator performance are "fraction of equilibrium gas desorbed," "deaeration effectiveness," or "normalized deaeration," accounting for the small quantity of gas that would remain dissolved in the solution under equilibrium with the partial pressure of gas in the bubbles in the seawater. The deaeration effectiveness for the predeaerator is defined as

$$
E_{p d}=\left(C_{\text {in }}-C_{\text {spout }}\right) /\left(C_{\text {in }}-C_{\text {eq }}\right) \cdot
$$

If "fraction of gas desorbed at equilibrium" is defined as

$$
F_{\text {eq }}=\left(c_{\text {in }}-c_{\text {eq }}\right) / c_{\text {in }},
$$

then it can be shown, by combining Eqs. 5-1 and 5-5, that the deaeration effectiveness or fraction of equilibrium gas desorbed in the predeaerator is

$$
E_{p d}=F_{p d} / F_{\text {eq }}
$$

An additional performance parameter in the predeaerator is the water-side pressure loss resulting from any predeaeration enhancement scheme. This pressure loss was determined by comparing measurements of evaporator spout pressure loss taken both with and without the enhancement device in position.

\subsubsection{Test Parameters}

Table 5-1 1ists the independent parameters studied in these deaeration scoping tests. The test matrices were constructed on the basis of trends predicted by the mathematical model of Ghiaasiaan, Wassel, and Pesaran (1990). Predeaeration pressure in Table 5-1 is the pressure of the liberated gases in the predeaeration chamber. As predeaeration pressure increases, the amount of gas desorbed is expected to decrease. This pressure is related to the evaporator pressure, flow rate, and flow-path geometry. It was not possible to cover the entire range of predeaerator pressure over the entire range of flow rates 
because the flow rate from the open sump into the evaporator upcomer (see Figure 2-3) is influenced by the pressure in the evaporator vessel.

Water flow rate in Table 5-1 is the rate of warm water through the predeaerator chamber of constant horizontal area. The mathematical model suggests that as water flow rate increases, the fraction of gas desorbed decreases. However, previously published experimental data show conflicting trends when compared with the model and with each other (Lindenmuth, Liu, and Poquette 1982; Golshani and Chen 1981; Krock and Zapka 1981; Zapka 1988; Ghiaasiaan, Wassel, and Pesaran 1990).

Table 5-1. Warm Seawater Deaeration Test Parameters and Ranges

\begin{tabular}{|c|c|c|c|}
\hline $\begin{array}{l}\text { Test } \\
\text { Series }\end{array}$ & $\begin{array}{l}\text { Independent } \\
\text { Parameters }\end{array}$ & $\begin{array}{l}\text { Nominal } \\
\text { Value }\end{array}$ & $\begin{array}{l}\text { Test } \\
\text { Range }\end{array}$ \\
\hline$D W-101$ & $\begin{array}{l}\text { Predeaerator } \\
\text { pressure }\end{array}$ & $15 \mathrm{kPa}$ & $8-35 \mathrm{kPa}$ \\
\hline DW-102 & Water flow rate & $20 \mathrm{~L} / \mathrm{s}$ & $20-80 \mathrm{~L} / \mathrm{s}$ \\
\hline DW-103 & Flow-path geometry & No baffle & With baffle \\
\hline DW-104 & $\begin{array}{l}\text { Nucleation seeding } \\
\text { by bubble injection }\end{array}$ & None & $\begin{array}{l}\text { With and } \\
\text { without }\end{array}$ \\
\hline
\end{tabular}

Previous experiments also indicate a dependence of the fraction of gas released on the flow-path geometry. The objective in the tests reported here was to have minimum obstructions between the warm-water supply tank and the evaporator spout, i.e., a straight supply pipe with no valves or other obstructions. To evaluate the effect of other flow-path geometries on the predeaeration processes, a conical baffle plate (see Section 5.4) was installed for some of the predeaeration tests. This baffle plate was expected to enhance predeaeration by causing the bubbles to separate at the free water surface that formed in the predeaeration chamber beneath the spout plate and by reducing bubble entrainment in the spout.

An increase in the number of nucleation sites can increase the fraction of gas desorbed (Lindenmuth, Liu, and Poquette 1982; Zapka 1988; Ghiaasiaan, Wassel, and Pesaran 1990). Bubble seeding can provide nucleation sites throughout the volume of the flow. This parameter was tested by injecting nitrogen gas bubbles in the middle of the evaporator supply pipe (upcomer) via four porous tubes (see Section 5.4 for details). Previous investigators (Lindenmuth, Liu, and Poquette 1982; Zapka 1988) injected air, but nitrogen was selected for injection in this study because it would not interfere with the dissolved oxygen measurement. In addition, the presence of nitrogen was not expected to affect the oxygen desorption rate. Only the effect of increased nucleation sites on oxygen release was determined; nitrogen release was not studied because nitrogen measurement was unavailable at the time of these experiments. For this phase of scoping studies, no plan existed to measure bubble sizes and number densities with sophisticated instruments. Observation was considered sufficient. 


\subsection{TEST-SPECIFIC EQUIPMENT AND INSTRUMENTATION}

A general description of the experimental apparatus appears in Chapter 2 . The gas desorption tests with warm seawater were conducted in the evaporator/ predeaerator vessel. Beneath the spout plate of the evaporator, the noncondensable gases, released because of low pressures, were trapped. This configuration is similar to that proposed for predeaerators in OC-OTEC plants, where trapped gases are vented outside of the evaporator through a compressor. In the HMTSTA, a vent line allowed trapped gases to be vented either into the evaporator chamber or into the vent compressor for direct removal. Here, the volume under the spout plate is referred to as the "predeaeration chamber." Figure 5-2 shows a schematic of the apparatus for warm seawater predeaeration experiments. Spouts with a diameter of $0.25 \mathrm{~m}$ (10 in.) and heights of 0.5 and $0.25 \mathrm{~m}$ above the spout plate were used.

\subsubsection{Hardware}

A transparent acrylic pipe was installed as part of the upcomer just below the bottom of the evaporator vessel to make the flow visible. The pipe was $0.30 \mathrm{~m}$. (12 in.) in diameter and $1.5 \mathrm{~m}$ ( $5 \mathrm{ft}$ ) long.

A conical baffle plate (shown schematically in Figure 5-2 and pictured in Figure 5-3) was fabricated and installed in the predeaeration chamber for some of the tests. This was done so that the effect of change in flow-path geometry on the gas desorption process could be evaluated (Section 5.3.2).

To inject nitrogen gas bubbles in the upcomer, a system consisting of gas cylinders, pressure regulators, a flowmeter, and four porous tubes was installed next to the upcomer. Figure 5-4 shows the bubble injection system schematically. The purpose of the loop was to inject gas bubbles to investigate their effect on the gas desorption rate.

A tap on the spout plate was connected to the evaporator chamber with a vent tube. To regulate the rate of gas vented to the evaporator chamber from the predeaeration chamber, two options (orifice plates and an external regulating valve) were tried. During experiments it was found that the vent rate could be controlled more easily using the external valve. The desired predeaeration pressure was obtained mainly by adjusting the evaporator pressure at specified flow rates.

\subsubsection{Instrumentation}

\subsubsection{Introduction}

To characterize the deaeration process, the following major measurements were made:

- Warm-water flow rate

- Water temperatures, inlet to and outlet from the evaporation/deaeration vessel

- Pressure in the predeaeration chamber

- Pressure in the evaporator chamber 


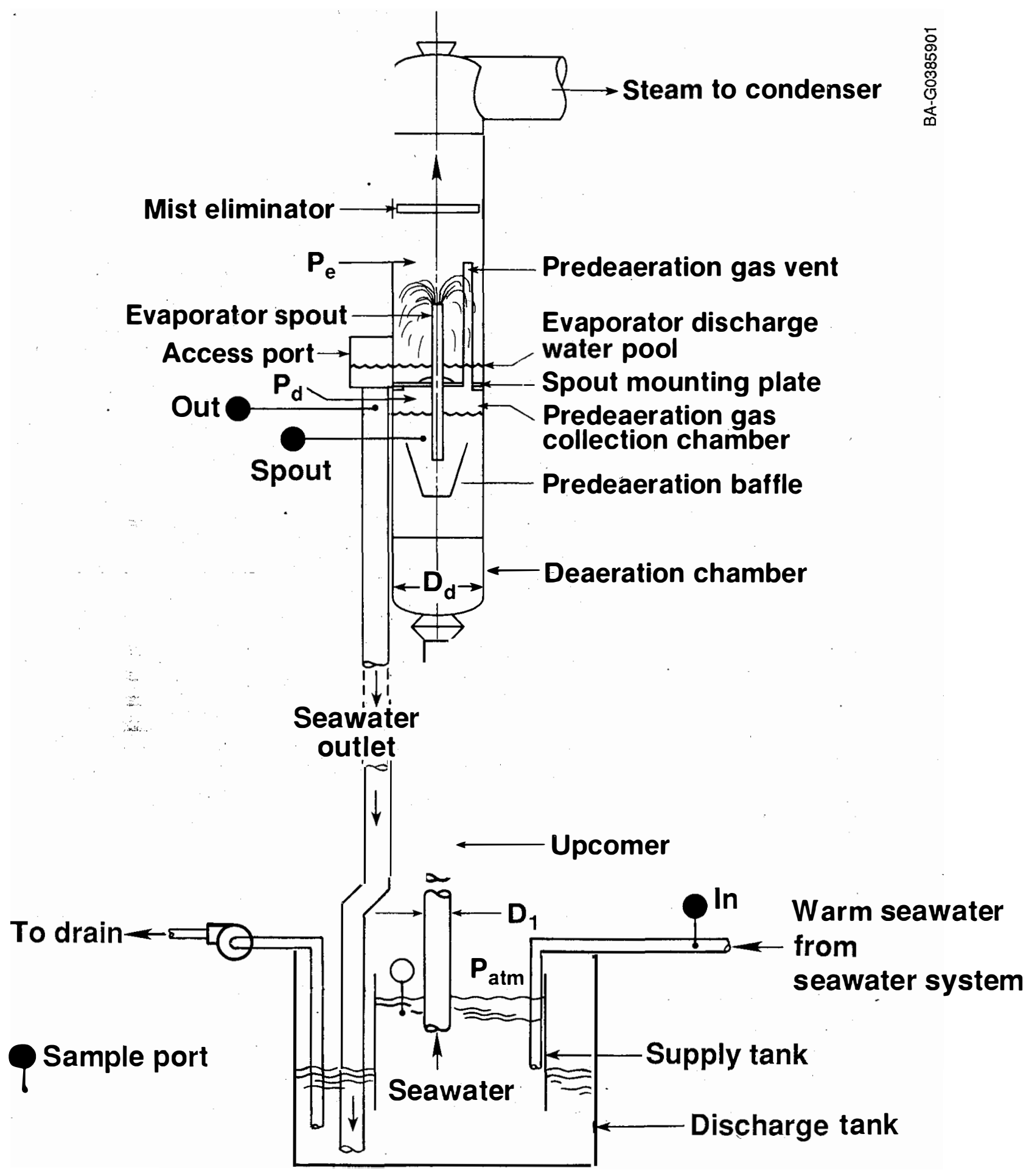

Figure 5-2. Schematic of warm seawater deaeration experimental apparatus 
Figure 5-3. Conical baffle plate installed in the deaeration chamber

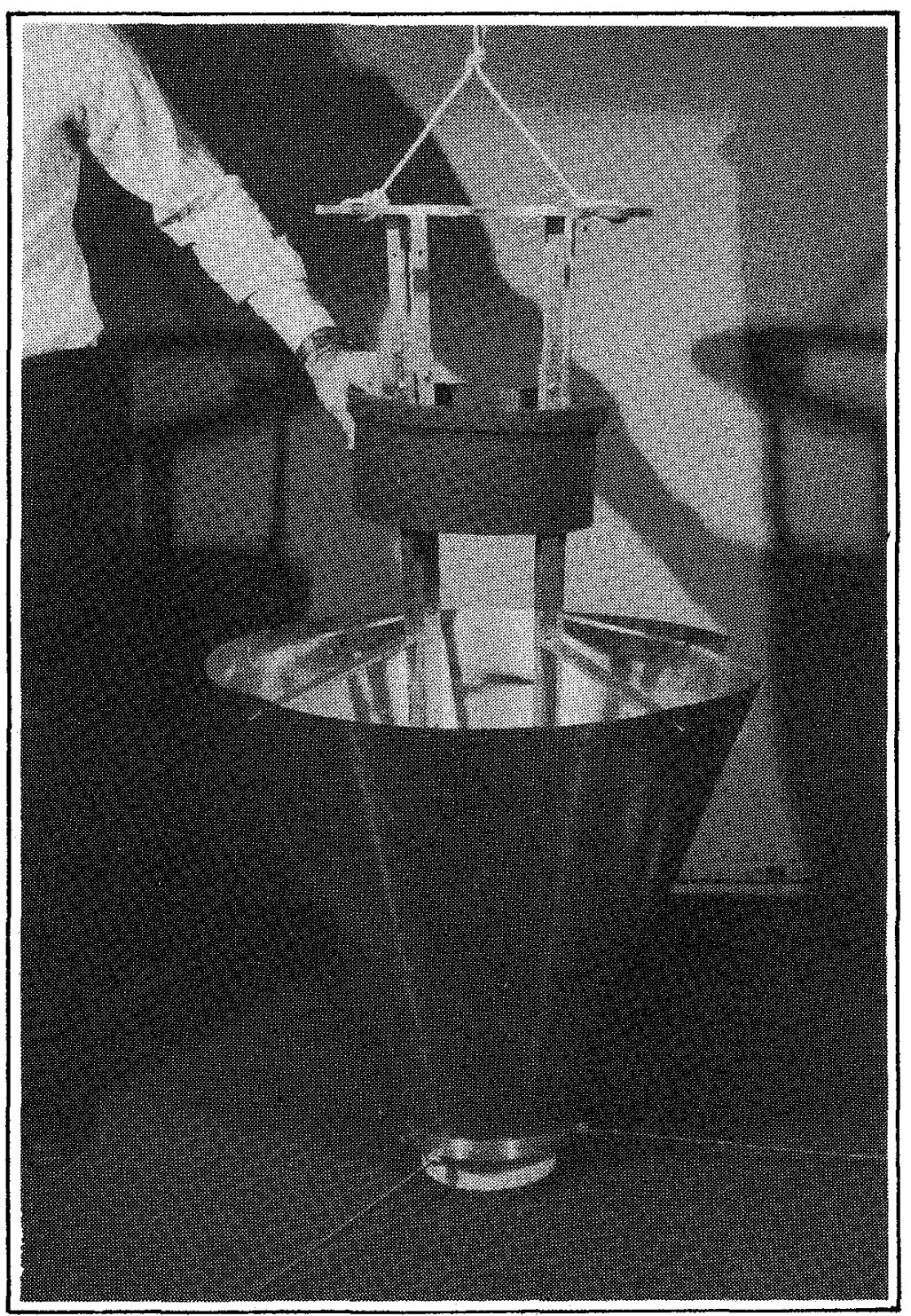

- Pressure increase caused by any predeaeration enhancements

- Dissolved oxygen concentrations of water at three locations:

- the inlet to the upcomer

- the entrance to the spout (exit of the predeaeration chamber)

- the outlet from the evaporator discharge pipe.

Most of the instruments needed for these measurements are general to HMTSTA and are described in Chapter 2. Only oxygen measurement was specific to these tests. The dissolved oxygen (D.O.) concentrations were measured with Clarktype membrane-covered polarographic sensors.

\subsubsection{Oxygen as Indicator Gas}

More than $98 \%$ of the dissolved gases in warm surface seawater is oxygen and nitrogen; the other $2 \%$ is mainly free (i.e., molecular) carbon dioxide (Krock 1981) with minute amounts of other inert gases (Sverdrup, Johnson, and Fleming 


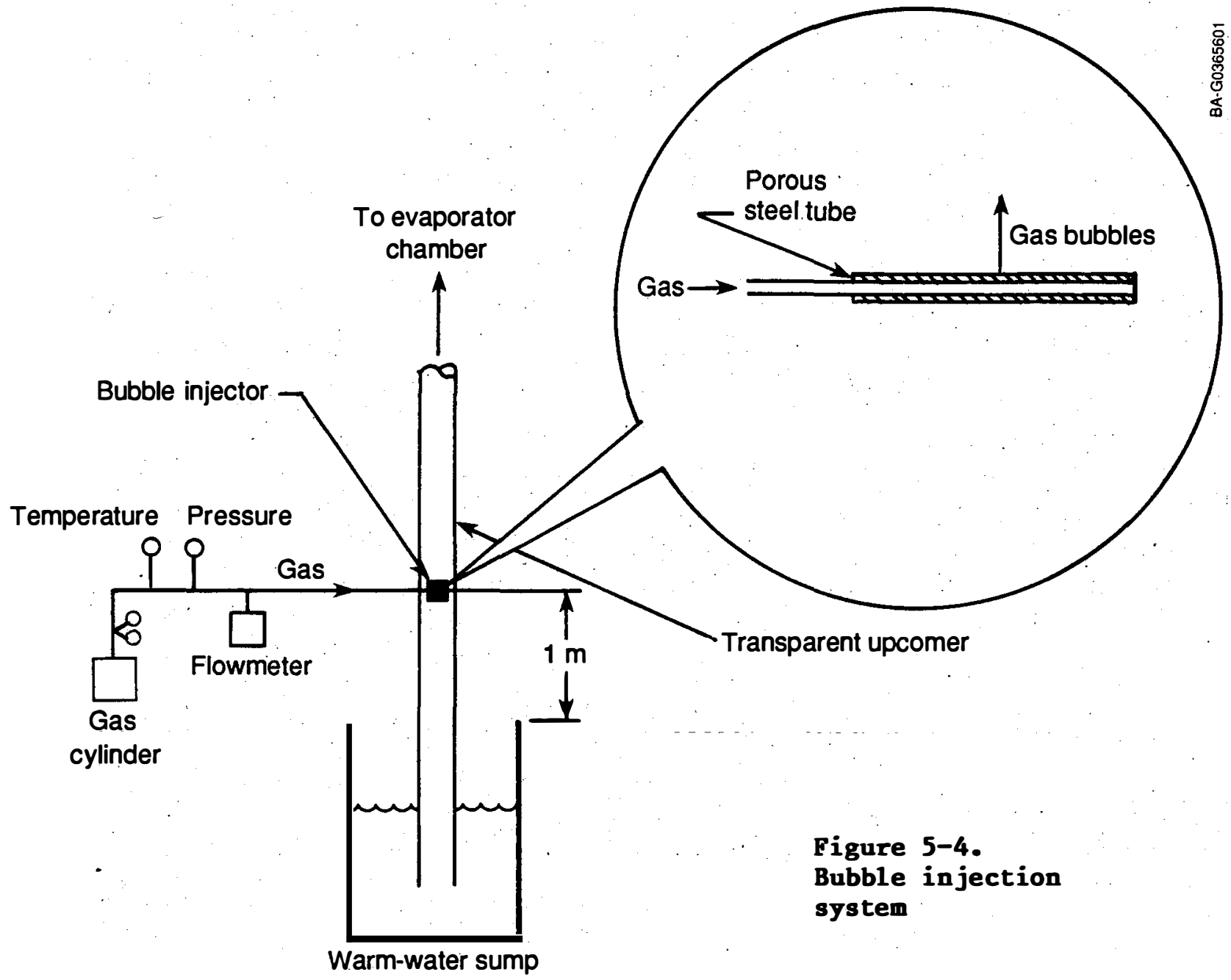

1942). Measurements near the experimental site, Keahole Point in Hawaii, showed the concentration of dissolved oxygen in warm surface seawater to be about $6.8 \pm 0.3 \mathrm{mg} / \mathrm{L}$, the concentration of nitrogen to be about $11.2 \pm 0.8 \mathrm{mg} / \mathrm{L}$, and the concentration of free carbon dioxide to be about $0.34 \mathrm{mg} / \mathrm{L}$ (Krock 1981).

Because the amount of carbon dioxide release was expected to be small (about $2 \%$ of oxygen and nitrogen content) it was not measured. Later tests, described in Chapter 8, showed that the level of carbon dioxide release was less than $4 \%$ of the oxygen and nitrogen content; therefore, the amount of carbon dioxide release can in fact be neglected relative to other gases when calculating a mass balance of gas released from warm seawater.

Of the two major remaining gases, oxygen was selected over nitrogen to be measured as an estimate of deaeration level from warm surface seawater. The reasons were the following:

- Relatively accurate and online sensors are available to measure dissolved oxygen; no such sensors exist to measure dissolved nitrogen. 
- The dissolved nitrogen content can be measured only with gas analyzers (gas chromatographs/mass spectrometers), which were not available at the time of the experiments.

- Measuring the overall dissolved gas content using aerometers, which measure total amount of dissolved gases in a solution, proved to be time consuming and inaccurate (Krock and Zapka 1981).

- The overall mass-exchange coefficient for nitrogen in seawater is similar to that for oxygen (Zapka 1988); i.e., the two gases are desorbed at about the same rate.

- Previous experiments (Krock and Zapka 1981) showed that the fraction of nitrogen released from surface seawater was within $20 \%$ of the fraction of oxygen released.

For this study, only dissolved oxygen was measured to estimate deaeration levels from surface seawater in the evaporator and predeaerator. Based on available data, dissolved nitrogen and oxygen were assumed to be released at the same rate. Release of dissolved carbon dioxide was assumed to be negligible, which was confirmed later.

\subsubsection{Measurements of Dissolved Oxygen (D.0.)}

Because of their ruggedness, precision, and online measurement capability, Clark-type membrane-covered polarographic sensors were used to measure $D .0$. content of seawater. In this device and other similar ones, a thin permeable membrane stretched over the sensor isolates the sensor electrodes from the environment, but allows oxygen to pass from the sample water. Oxygen is reduced at a cathode immersed in an electrolyte solution. A current proportional to the concentration of the oxygen in the water is produced that is then converted to D.O. concentrations. Because both temperature and salinity affect the dissolved oxygen content (Appendix D, Section D.1), sensors (YSI model 5739) and meters (YSI model 58) were selected that had circuitry for temperature and salinity compensation.

All available commercial flow-through Clark-type oxygen sensors are designed for atmospheric and high-pressure applications. Golshani and Chen (1981) found that under vacuum conditions such as those found in OTEC, the Clark-type sensors gave erroneous results. At low pressures, the distance between the membrane and the cathode was altered, and this affected the performance. To use D.O. sensors, the water had to be brought to atmospheric conditions by extraction using batch sampling techniques (Lindenmuth, Liu, and Poquette 1982; Golshani and Chen 1981; Krock and Zapka 1981) or continuous sampling methods (Krock 1981). In another method, Lindenmuth, Liu, and Poquette (1982) stopped the flow, brought the system to atmospheric conditions, and then inserted a D.O. sensor for measurement, a method not reliable and not practical for operation in the HMTSTA.

Zapka (1988) has reviewed various sampling procedures in detail. Batch sampling techniques were criticized because of contamination with atmospheric oxygen and sampling time effect. Therefore, a continuous sampling method similar to the one recommended by Zapka (1988) was adopted for onl ine measurement of seawater D.O. content for this study. 
In these tests, to bring sample water to the D.0. sensors at atmospheric pressure, water samples were withdrawn from desired locations in the vacuum vessel using sampling tubes and pumps. The sensors were located at ground level so that the water head in the tubes kept the pumps from working too hard against the vacuum, eliminating cavitation. This sampling method provided online measurement capability. The samples were drawn from the inlet seawater supply pipe (referred to here as "In"), the inlet water to the spout just before the water leaves the predeaeration chamber ("Spout"), and the outlet water from the evaporator vessel ("Out"). Figure 5-2 shows the location of the sampling ports.

At the beginning of the tests, the three D.0. sensors were calibrated according to the manufacturer's recommendations (Yellow Springs. Instruments Company 1987). Then the performance and accuracy of the sensors and meters were checked with oxygen-depleted fresh water and a humid mixture of oxygen and nitrogen containing $4.99 \%$ or $11.5 \%$ oxygen. It was found that under these controlled conditions, measurements of the D.O. instruments were satisfactory within the manufacturer's specifications, and the variation from one sensor to another was less than $0.2 \mathrm{mg} / \mathrm{L}$ as expected (i.e.;. about a $1 \%$ full-scale error or $3 \%-8 \%$ error in the measured values).

Plexiglas containers were fabricated to hold the D.0. sensors for flow-through measurements. Because a polarographic D.O. sensor consumes oxygen, sufficient fluid (at a velocity of about $0.3 \mathrm{~m} / \mathrm{s}$ ) must pass over the membrane to prevent oxygen starvation, which causes an erroneous lower reading. The suggested velocity was obtained by passing about 3.8 to $7.6 \mathrm{~L} / \mathrm{min}$ of water through each sensor holder to provide proper and stable operation of the sensors.

The accuracy of the sensor measurements was also checked with the standard chemical analysis technique, the Winkler titration method. The same seawater was passed through the sensor holders connected in series, and the D.O. concentration was measured with each of the three sensors. Simultaneous measurements of the D.O. concentrations of two or three different samples of this water were made using the Winkler method. Table D-2 of Appendix D shows comparison results. With these in-series measurements, no discernible effect of oxygen consumption by sensors was detected. Values measured by polarographic instruments were within $\pm 0.48 \mathrm{mg} / \mathrm{L}$ of values obtained by the Winkler method. This value is the maximum difference between the sensor reading and the Winkler-method results, as shown on column $L$ of Table D-2. This is equivalent to a maximum difference of $7 \%$. The overall combined error estimate has a mean of $\pm 0.35 \mathrm{mg} / \mathrm{L}$ (see Eq. D-16). An uncertainty analysis is documented in Section D.2 of Appendix D.

Originally, the plan was to use separate sensors to measure the D.0. concentration of seawater from each sample line. This arrangement would have provided simultaneous measurements of the D.O. concentrations and, thus, online calculation of the amount of oxygen released in the predeaerator and evaporator. However, during field operation of the sensors it was found that the discrepancy between readings of the sensors measuring the same seawater sample was about $\pm 0.4 \mathrm{mg} / \mathrm{L}$, causing an extra $6 \%$ random error in calculating the fraction of oxygen released. Therefore, all three D.O. sensors were used to measure the same seawater sample, from In, Spout, or Out, as shown in Figure 5-5. Readings from sensors for a particular seawater sample were averaged to provide a value with more confidence. This approach was more dependable; 
Figure 5-5. Water sampling for dissolved oxygen measurements

\section{Dissolved oxygen meters and sensors}

Water sample location

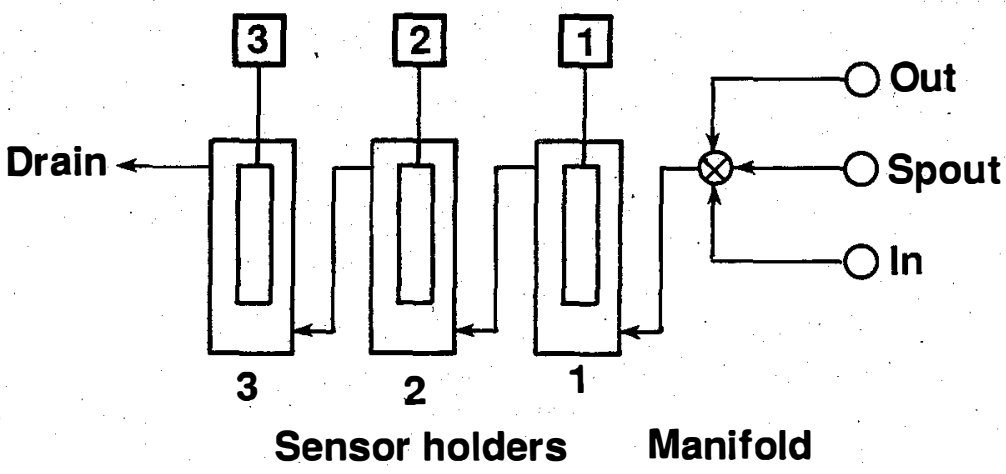

and it was proved necessary when halfway through the testing period, one of the sensors malfunctioned and was removed for repair, and only the other two sensors were used. The effect of averaging the readings of two sensors rather than three was to increase the element of random error. All of the data were analyzed based on the results of two D.O. sensors.

\subsubsection{Experimental Procedure}

After the desired steady-state operating condition outlined in Chapter 2 was achieved, gas desorption data were collected as follows:

A water sample from one of three sampling ports, e.g., In, was passed through the three D.O. sensor holders, and, after steady state was reached, data were recorded. Then a water supply from another sampling port, e.g., Spout, was connected to the D.O. sensor holders, and data were recorded after the 1 ines were purged with new sample water. The same procedure was repeated for the third sampling port, e.g., Out. Then operating parameters were adjusted for another set of conditions, and the above steps were repeated. These measurements were made in a time span on the order of minutes.

\subsubsection{Experimental Experience}

After some preliminary tests, a few problems were encountered. During the tests, a significant number of bubbles was observed in the Spout and Out seawater sampling lines. Most were bubbles entrained with the seawater flowing into the sampling lines. Bubbles were alșo generated at flow obstructions and impeller pumps in the sampling lines. Some were reabsorbed at high pressures in the sampling lines and increased the dissolved oxygen readings. In addition, bubbles passing through the D.O. sensors caused unstable readings. Sometimes the pumps cavitated at their impeller and generated unwanted bubbles. The D.O. sensors tended to drift from day to day. Even with filters in the sample water lines, small sand particles and other debris in the warm seawater were carried to the D.O. sensors and gradually eroded the surfaces of D.0. membranes, affecting $D .0$. readings. The following activities were undertaken to resolve these problems. 
Examination of the impeller pumps revealed that a few leaks around the impeller seal were the major reason for the cavitation. The problem was solved by using a better sealant and tightening the seal components, although some cavitation at the pumps still remained. In another attempt, the impeller pumps were replaced with a peristaltic pump (Masterflex Model 07459-30) that did not have an impeller and thus did not cavitate. Although the peristaltic pump had a maximum-rated capacity near $1 \mathrm{~L} / \mathrm{min}$, it did not deliver a sufficient amount of flow rate to the D.O. sensors because of low backpressure. Thus, the impeller pumps were reinstalled for the tests. The number of flow obstructions (such as bends and valves) was reduced. The sensors had to be air calibrated every day to overcome the problem of drifting. In a few instances, a D.O. sensor could not be calibrated and its membrane had to be replaced. The membranes were replaced weekly to avoid the problem of erosion caused by debris in the seawater.

To resolve the problem with bubbles, two solutions existed: reabsorbing all the bubbles, e.g., by compression, or removing the bubbles, e.g., by separation before they entered the D.O. sensor holders. Because of its ease of installation and effectiveness, a "bubble separator" was used to remove the entrained bubbles from the sample lines before D.0. measurement. The device acted like a settling chamber: the bubbles were exposed to a free surface and released before the water entered the D.0. sensors. A drawback of the method was that only the dissolved amount of oxygen in the "debubbled" solution was measured; the total amount of oxygen in the original sample water was not measured. (The total oxygen content consists of both dissolved oxygen in solution and gaseous oxygen in bubbles.) The D.0. measurements of debubbled water gave a measure of how much oxygen was desorbed from seawater, and not how much gas was released or separated from the seawater in the predeaeration chamber. Here, a distinction has been made between desorbed oxygen (that transferred from the water into bubbles surrounded by water), and released oxygen (that physically separated from the seawater into the gaseous phase at the top of the predeaeration chamber). Because in the tests bubbles were observed being carried by the seawater through the spouts to the evaporator, the actual amount of oxygen released or separated in the predeaerator was less than the amount of oxygen desorbed from seawater. The results reported in the next section represent the upper boundary of the amount of oxygen desorbed from seawater. To measure total amount of gas released in the predeaeration chamber, another method to measure the volume and composition of released gas needs to be implemented in future tests.

Although the above efforts resolved some of the problems, the dissolved oxygen measurements still had shortcomings: the repeatability of measurements from day to day was not always satisfactory; the D.O. instruments drifted; and at times the water flow rate through the D.0. sensors was not sufficient, causing a lower D.0. content reading. As a result, a large scatter exists in the data ( see Section D.2 of Appendix D).

\subsection{RESULTS AND DISCUSSION}

Discussion in this section includes post-test error analysis and typical results obtained; effects of pressure, water flow rate, flow-path geometry, and bubble injection; potential ways to improve the measurements; and the potential effect of predeaeration of warm seawater before it enters the evaporator on the power consumption of an OC-OTEC plant. 


\subsubsection{Post-Test Error Analysis}

Water samples were periodically collected from the sample 1 ines, and dissolved oxygen was measured, the Winkler method having been used to verify and calibrate the D.0. sensors. Results in Table D-2 of Appendix D show that the sensor-measured values are within $0.48 \mathrm{mg} / \mathrm{L}$ (maximum value in column $\mathrm{L}$ of Table D-2) of the Winkler-measured values, which is worse than predicted from pretest error analysis.

A post-test uncertainty analysis was performed (see Section D.2 of Appendix D) to estimate the overall uncertainty in the fraction of oxygen desorbed. Errors from analysis and seawater sampling for the Winkler method, sensor calibration, sensor-to-sensor variations, and sensor fluctuations were estimated and propagated into an estimation of fraction of oxygen desorbed. To estimate the uncertainty in the calculated fraction of oxygen desorbed, the root-sum-square model (ANSI/ASME 1985) was applied to the bias and random errors, giving a confidence level of 95\%. The magnitude of the overall average uncertainty in the fraction of oxygen desorbed was found to be 0.14 (unit = fraction of oxygen desorbed). This uncertainty accounts for absolute values of the fraction of oxygen desorbed obtained over two months of testing. Two error bands are shown on some of the graphs in the next sections. One shows the absolute error, and the other shows only the error caused by random reading of sensors. If data are obtained during a short period (e.g., two hours), they can be compared on a relative basis. In that case, the calibration and bias errors do not need to be considered, as is discussed in Section D.2 of Appendix D.

\subsubsection{Results}

Section D.4 of Appendix D provides results of deaeration tests in tabular form. In all of the tests, the temperature of incoming warm seawater was about $26.5^{\circ} \pm 0.5^{\circ} \mathrm{C}$. Data presented here are based on the date or the flowpath configuration. Data grouped on a given date can be compared more confidently, because the calibration and other bias errors for two hours of testing did not change and can be ignored for relative comparison.

Also shown in some of the figures in this section is the fraction of oxygen gas desorbed at equilibrium (Eq. 5-5). The equilibrium value is the upper 1 imit of how much oxygen can be desorbed at a given pressure. The equilibrium level was obtained, assuming water at $26.5^{\circ} \mathrm{C}$, inlet dissolved-oxygen content of $6.6 \mathrm{mg} / \mathrm{L}$, and oxygen fraction of 0.2095 in the air in equilibrium with water (see Section D.1 of Appendix D).

\subsubsection{Effect of Pressure}

Figures 5-6 and 5-7 show all the data sets obtained with and without the baffle plate in the chamber, respectively. The graphs show the fraction of oxygen gas desorbed (Eq. 5-1) in the predeaerator chamber as a function of pressure at various water flow rates. Even with the scatter of the data, a general trend can be seen from these two figures: the fraction of oxygen desorbed in the predeaerator chamber increases with decreasing chamber pressure. To show this observation more clearly, the data for two different tests are given in Figure 5-8. Bubble injection data are not included in these two 


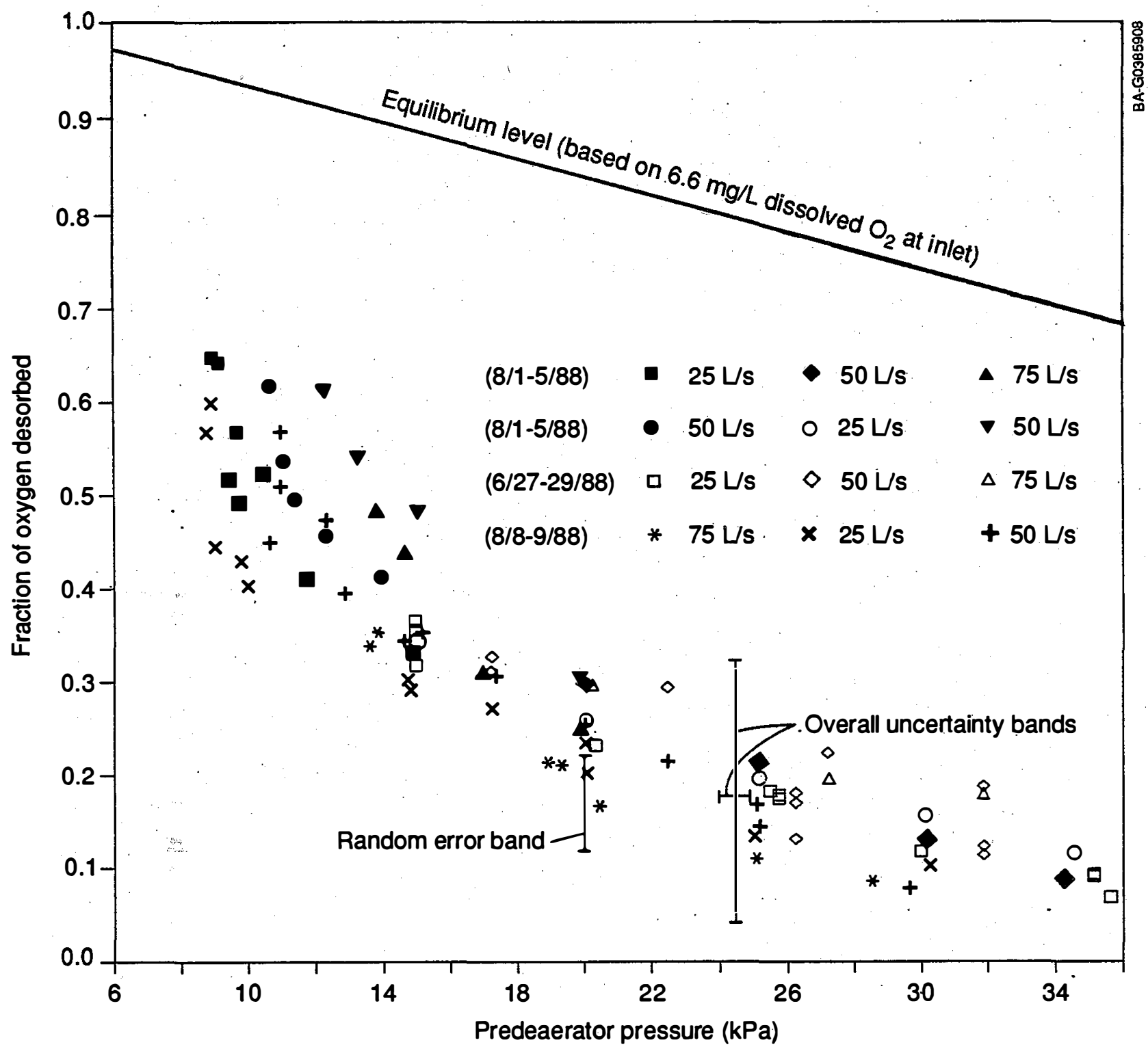

Figure 5-6. All data on warm seawater predeaerator oxygen desorption fraction as a function of pressure at various water flow rates obtained with baffle plate in place and no bubble injection

figures. A large scatter on the absolute values of the results can be seen. Overall, about. $10 \%$ to $60 \%$ of oxygen in the warm seawater can come out of solution in the predeaerator at pressures between 9 and $35 \mathrm{kPa}$.

The data in Figure 5-8 were obtained with the baffle plate installed in the chamber. For relative comparison of the data points obtained on the same day for a given water flow rate, only the random error of sensors needs to be considered. The fraction of oxygen desorbed in the predeaerator $\left(F_{p d}\right)$ depends 


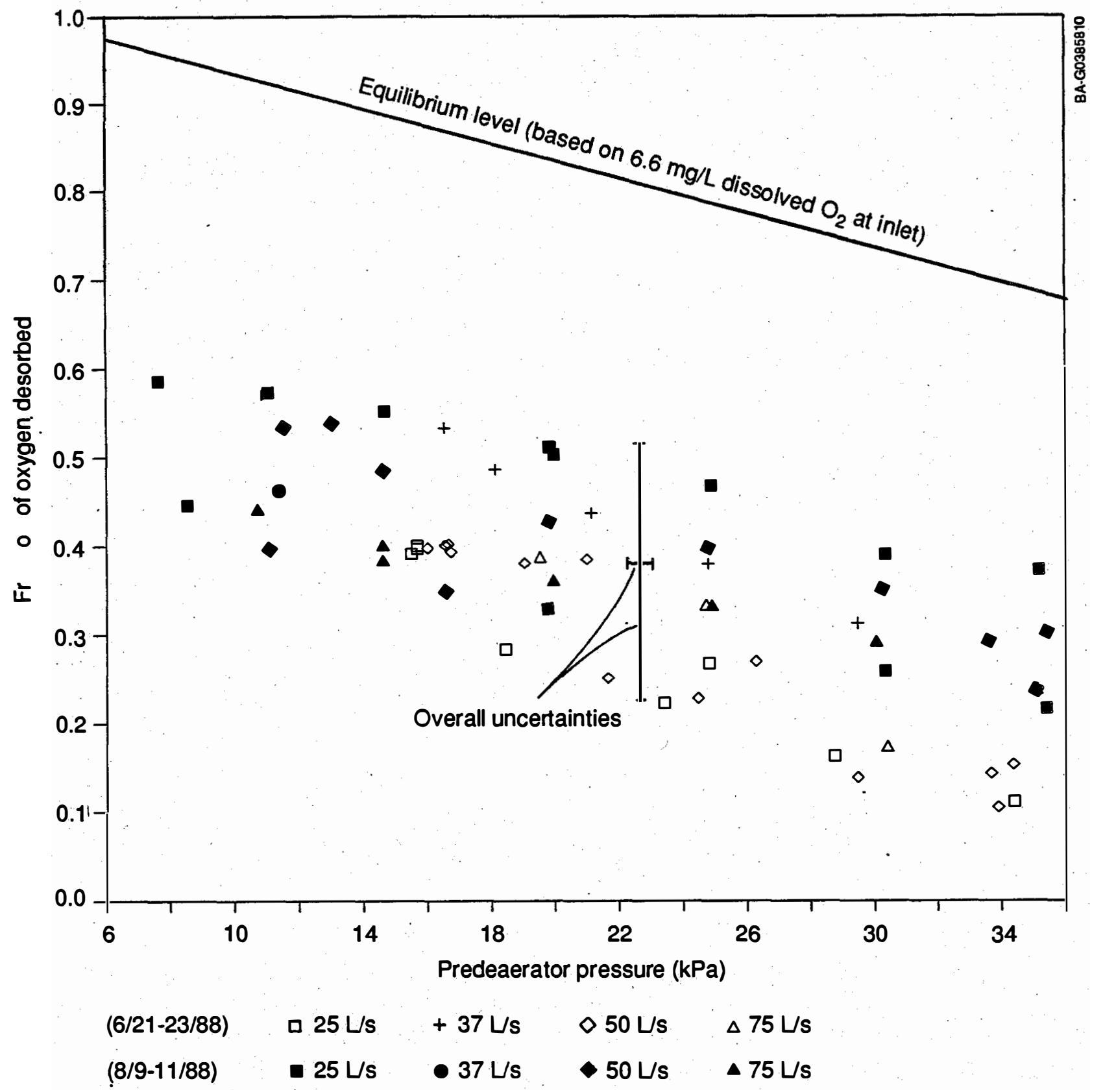

Figure 5-7. All data on warm seawater predeaerator oxygen desorption fraction as a function of pressure at various water flow rates obtained with no baffle plate and no bubble injection 


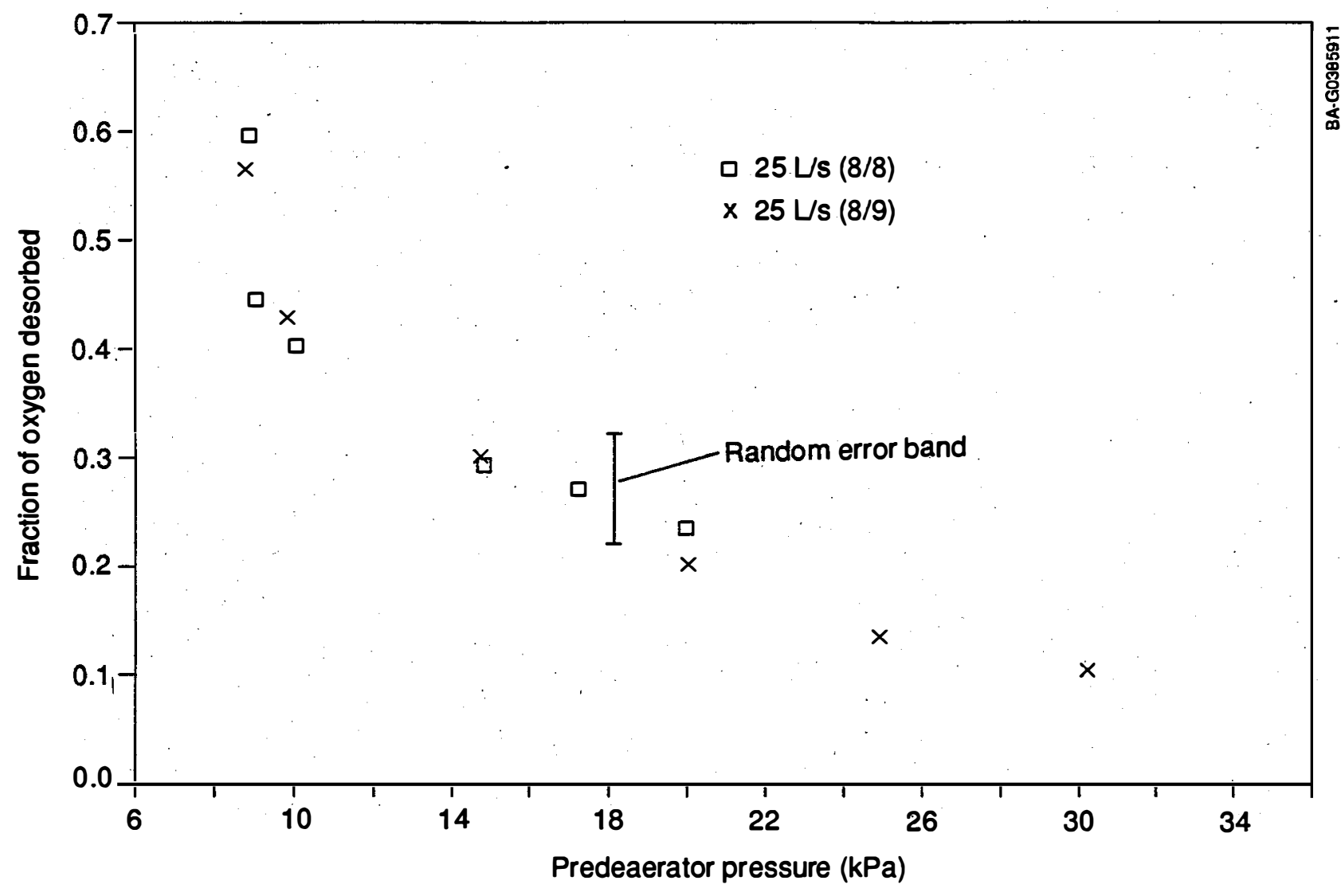

Figure 5-8. Repeatability of data for warm seawater oxygen desorption in predeaerator with baffle plate (obtained on $8 / 8-9 / 88$ )

rather strongly on predeaeration chamber pressure, and it increases with decreasing predeaerator pressure. This was expected because as pressure decreases, seawater becomes increasingly supersaturated with oxygen and releases its dissolved oxygen. Previous investigators observed the same trend (Lindenmuth, Liu, and Poquette 1982; Golshani and Chen 1981; Krock and Zapka 1981; Zapka 1988). Other data sets also show the same trend: an increase of the fraction of oxygen desorbed with decreasing pressure.

\subsubsection{Repeatability of Results}

Figure 5-8 also shows the repeatability of the data obtained in two consecutive days for the same operating conditions. Some of the other data sets also show good repeatability. However, this repeatability did not hold for all the data sets. For example, Figure 5-9 shows a case in which, at the same water flow rate, a large difference (about 50\%) existed between results for two different days. This difference was mostly attributed to drift in D.O. sensors and to changes in sample water conditions (e.g., flow rate through sensors and bubble content). It is also possible that the quality (size and number density of bubbles and nucleation sites) of incoming seawater had changed because of a change in surf and weather conditions such as rainfall that affected the rate at which oxygen desorbs. Because the seawater quality was not measured during the tests, the contribution of change in water quality on fraction of gas desorbed cannot be estimated. 


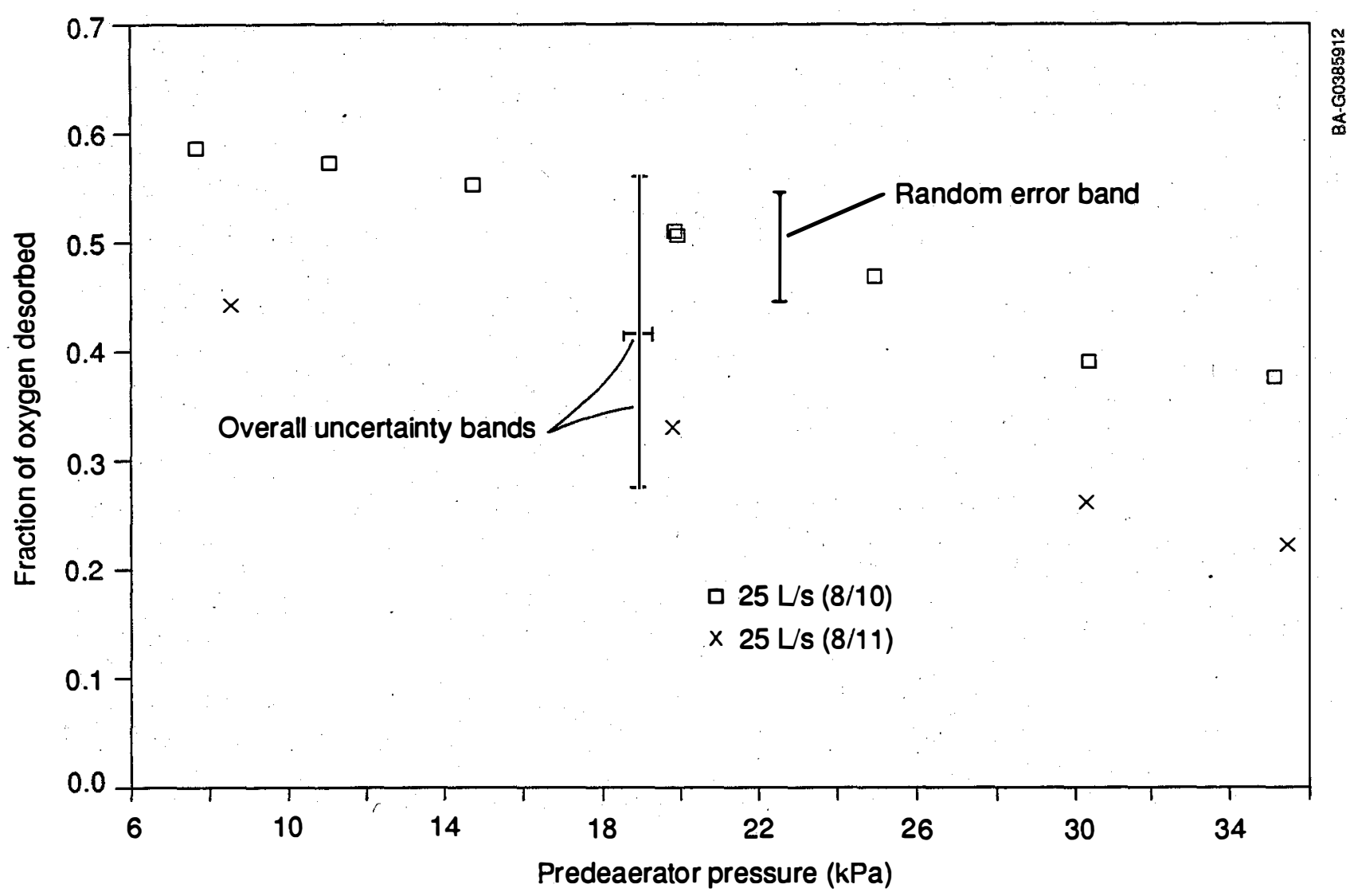

Figure 5-9. Repeatability of data for warm seawater oxygen desorption in predeaerator with no baffle plate (obtained on $8 / 10-11 / 88$ ). Compare to Figure 5-8.

\subsubsection{Comparison with Previous Data}

Figure 5-10 compares deaeration data obtained in this study with previous warm seawater deaeration data for upcomer water velocities around $0.5 \pm 0.1 \mathrm{~m} / \mathrm{s}$. The deaeration levels of this study are somewhat higher than those of Krock and Zapka (1981) and much higher than those of Zapka (1988). Zapka (1988) used seawater brought by truck to storage tanks for conducting the experiment. Because the seawater was reused several times during the experiments, it is possible that the number density of bubbles and nucleation sites in the seawater were reduced through settling and atmospheric exposure, which could account for lower desorption rates.

\subsubsection{Effect of Water Flow Rate}

Most of the experiments performed and the data in Figures 5-6 and 5-7 and in Section D.4 of Appendix D show that a functional dependence of the fraction of oxygen released in the predeaerator with seawater flow rate cannot be determined, for the following reasons. 


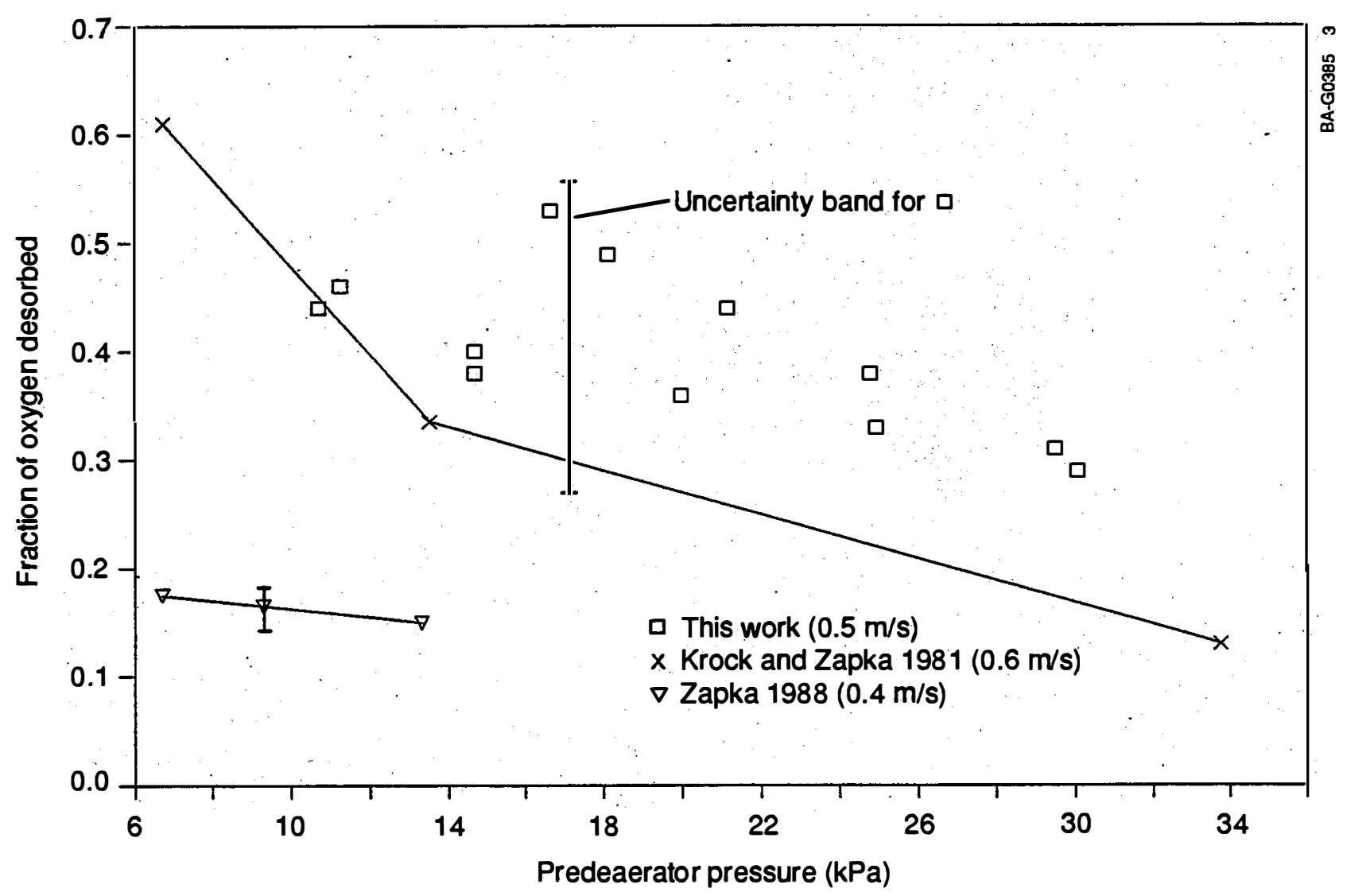

Figure 5-10. Comparison of typical results of warm seawater orygen desorption in barometric upcomer obtained in different studies (no error band was given in Krock and Zapka [1981])

When water flow rate decreases, the residence time in the deaeration chamber increases and the dissolved gases have more time to desorb from the solution. Thus, the fraction of gas released increases. However, in the HMTSTA the decrease in flow rate was obtained by closing a valve in the supply pipe upstream of the supply tank (see Figure 5-2). Closing of the valve caused cavitation, and larger bubbles were generated. These bubbles were easily separated in the large supply tank, which is open to the atmosphere and well agitated. Thus at the lower flow rates the supply tank itself acted as a deaerator, stripping the seawater of some noncondensable gas and causing fewer bubbles to enter the upcomer and the deaeration chamber in the evaporator vessel. The gas desorption from seawater is governed by nucleation and bubble-growth phenomena. As the amount of bubbles and nucleation sites in the incoming seawater decreases, less gas is desorbed and thus the fraction of gas released decreases, as predicted by the deaeration model (Ghiaasiaan, Wassel, and Pesaran 1990).

Change in water flow rate in the HMTSTA configuration caused change in both residence time and in number density of bubbles entering the upcomer. These effects had two opposing impacts on the fraction of oxygen released: one increased the fraction of oxygen released, and the other decreased it. 
Therefore, the fraction of gas released depended not on the flow rate, but on the effects of the flow rate control mechanism." Also, no effort other than visual observation was made to measure the bubble density, so the separate effects of residence time and bubble density could not be determined. Finally, scatter in the data added more uncertainty to the dependence of fraction of oxygen released on the water flow rate.

To obtain the dependence of gas desorption water flow rate, future experiments should be designed so that change in water flow rate does not change the bubble density of the entering water and so that separate effects of bubble density and residence time can be measured. The effect of bubble injection directly into the upcomer just upstream of the deaeration chamber is discussed in Section 5.5.2.6.

\subsubsection{Effect of Baffle Plate}

The effect of the baffle plate on flow-path geometry (which in turn affects oxygen desorption) can be determined by comparing the data in Figures 5-6 and 5-7. Given the uncertainty in the data, no discernible change in gas desorption resulted from the presence of this particular baffle plate. It was expected that it would enhance the gas desorption in the predeaeration chamber by preventing the bubbly seawater from entering the spout directly and by providing a means to expose and separate bubbles at the free water surface. However, the bubbles were carried by the seawater to the spout and did not separate at the surface because of high seawater velocity. Data with less scatter and uncertainty and other baffle plate configurations are needed to examine the effect of the baffle plate.

The pressure drop across the predeaeration baffle plate was also measured to determine whether the baffle increased the water-side pressure losses. This was done by comparing measurements of evaporator spout pressure loss taken with and without the baffle plate in position. No discernible difference in pressure loss could be seen at water flow rates of 25,37 , and $50 \mathrm{~L} / \mathrm{s}$. At flows of $75 \mathrm{~L} / \mathrm{s}$, however, the baffle plate added about a 1-kPa additional pressure loss, or $10 \%$ of the combined static and dynamic pressure loss through the spout.

\subsubsection{Effect of Bubble Injection}

The effect of bubble injection can be seen from Figures 5-11 and 5-12. Figure 5-11 shows the fraction of oxygen desorbed as a function of pressure at various bubble injection rates. High injection is when $150 \mathrm{~cm} / \mathrm{min}$ of nitrogen was fed into each of four bubble injectors. Low injection is when $40 \mathrm{~cm} / \mathrm{min}$ of nitrogen gas was injected into each of four bubble injectors. The bubbles were injected into a section of the upcomer where its pressure was about $65 \mathrm{kPa}$. The quantity of gas injected into the flow stream was only a

*At the operating conditions of these experiments, the impacts of flow rate and bubble density were predicted to be of the same magnitude using the deaeration model (Ghiaasiaan et al. 1990). Thus the two effects could not be resolved separately. 
small fraction (less than $1 \%$ ) of the gas content in the water. That is, the net addition of noncondensable gases was small. Also, for the purpose of investigation, gas from an external source was injected. In an OC-OTEC plant; part of the noncondensable gas removed from the evaporator and condenser by the vacuum pump may be reinjected into the upcomer at the appropriate pressure, so there would be no net addition of noncondensable gases from external sources other than seawater.

During the tests, it was observed that more bubbles were generated with high injection than with low injection. The size of bubbles released from the injectors was observed to range from 0.1 to $3 \mathrm{~mm}$. The individual bubble size and number density were not measured. According to a deaeration model (Ghiaasiaan, Wassel, and Pesaran 1990), gas desorption rate from water increases with an increase in the number density of bubbles in the water or with a decrease in bubble sizes.

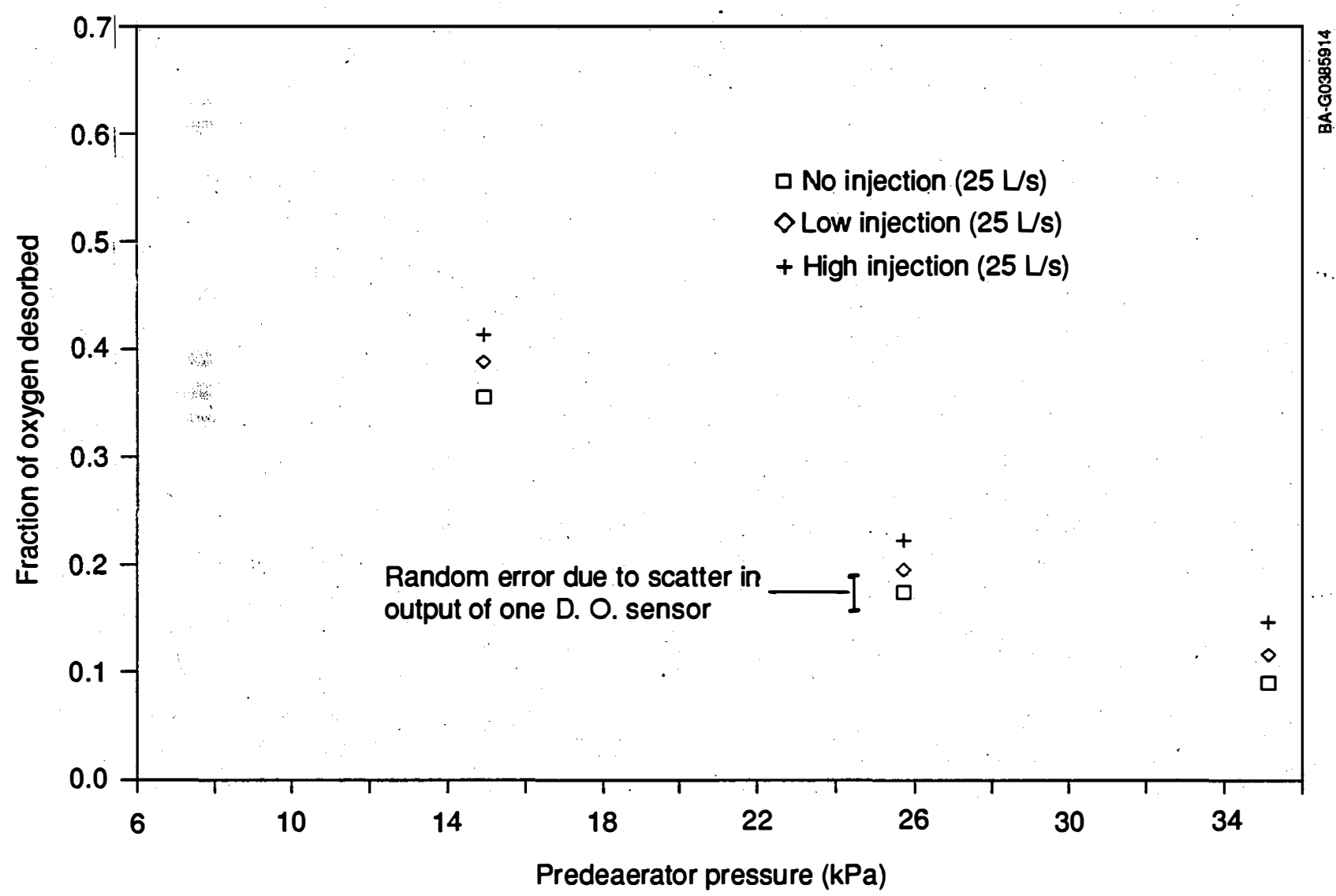

Figure 5-11. Typical effect of bubble injection on warm seawater oxygen desorption (obtained at $25 \mathrm{~L} / \mathrm{s}$ with baffle plate on 6/29/88) 


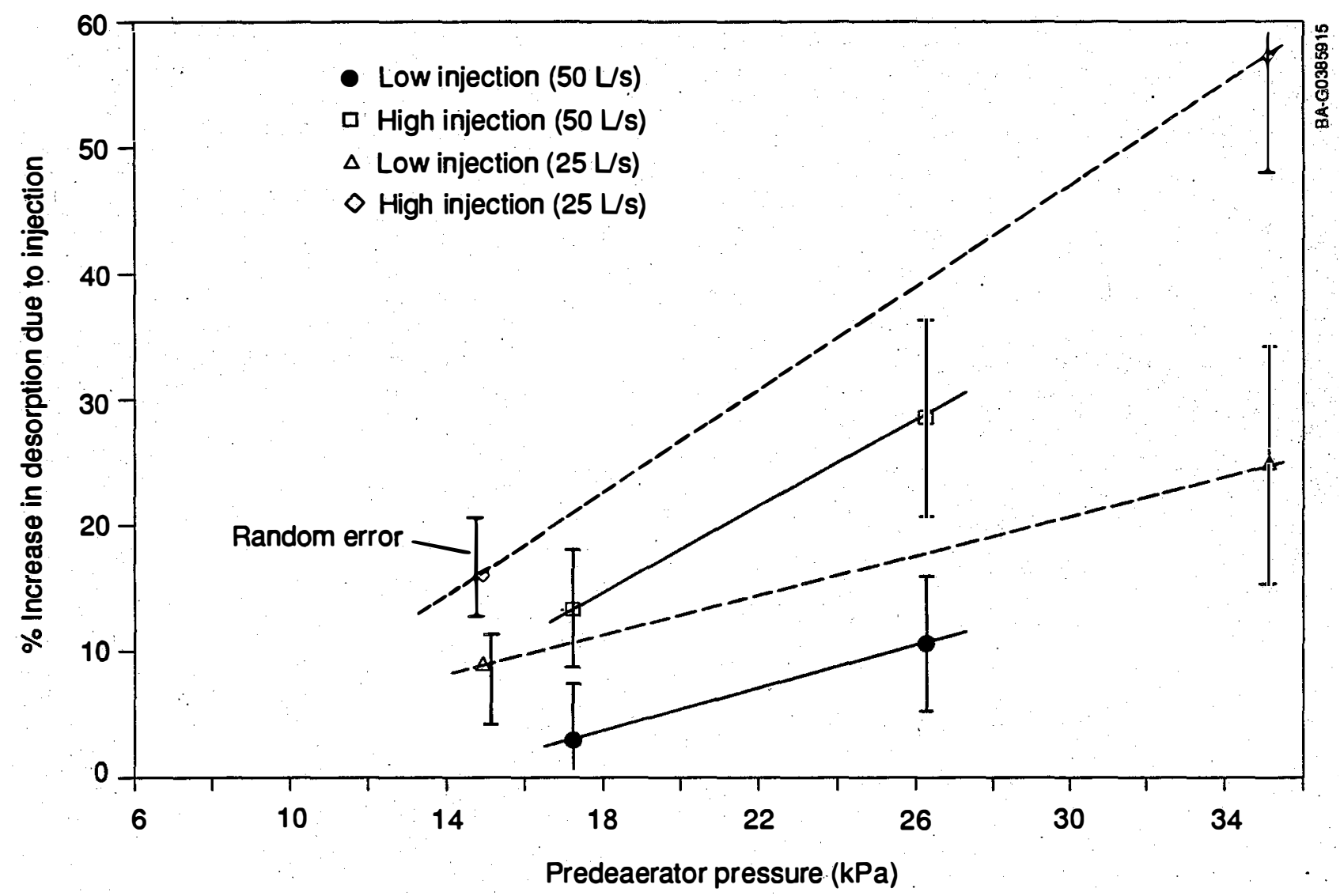
Figure 5-12. Increase in orygen desorption from bubble injection (for data obtained at seawater flow rates of $25 \mathrm{~L} / \mathrm{s}$ and $50 \mathrm{~L} / \mathrm{s}$ with baffle plate on $6 / 29 / 88$ )

If the absolute values of the data presented in Figure $5-11$ are compared, taking into account their overall uncertainty, discernible differences are not evident between the results with and without injection. However, comparis on should be done on a relative basis for the short period of time (less than two hours) in which the data were obtained with and without bubble injection. Furthermore, the results of only one D.0. sensor are presented in Figure 5-11, to eliminate sensor-to-sensor random error. On a relative basis, it can be seen that more oxygen was desorbed when bubbles were injected.

To demonstrate the validity of the above conclusion, results from Figure 5-11 are replotted in Figure 5-12 as a percentage increase in the fraction of oxygen desorbed as a result of injection, which is defined as

$$
\frac{\left(F_{p d} \text { with injection }\right)-\left(F_{p d} \text { with no injection }\right)}{\left(F_{p d} \text { with no injection }\right)}
$$

Figure 5-12 shows the percentage of increase in the fraction of oxygen desorbed from injection as a function of flow rate and pressure and injection rates. The error bands shown on this figure were obtained by propagating the random error of $0.05 \mathrm{mg} / \mathrm{L}$ from the sensor reading into the calculation of the 
percentage of increase using the method discussed in Section D.2 of Appendix D. Figure 5-12 shows that bubble injection. increases the oxygen desorption rate and that the effect is larger at higher predeaerator pressures. At the high injection rate, the oxygen desorption level has increased by $20 \%$ to $60 \%$. The increase in oxygen desorption level from seawater upon bubble injection has been observed by others (Lindenmuth, Liu, and Poquette 1982; Zapka 1988) in small-scale experiments.

Bubble seeding (and gas reinjection) can enhance oxygen and possibly nitrogen release from seawater in the predeaerator. It may have a potential in OC-OTEC power plants to increase the amount of noncondensable gases removed from the predeaerator before they enter the evaporator. The range of optimum bubble size, number, density, gas flow rate, pressure at which gas should be injected, and effect of bubble injection on production of net power for an OTEC plant should be investigated in future experiments.

\subsubsection{Total Fraction of Oxygen Desorbed}

Figure 5-13 shows the total fraction of gas desorbed from the warm seawater in the system as a function of evaporator pressure at various water loadings (i.e., seawater mass flow rate divided by the cross-sectional area of the predeaeration chamber). The fraction of oxygen desorbed increased with a decrease in pressure. Depending on the evaporator pressure, $45 \%$ to $95 \%$ of the dissolved oxygen was desorbed from the warm seawater. The typical operating pressure of an OC-OTEC evaporator is about 2.4 to $2.7 \mathrm{kPa}$. At this pressure range, the tests showed that $75 \%$ to $95 \%$ of the dissolved oxygen can be released in the evaporator. At these typical values, the pressure in the predeaeration chamber ranged from 10 to $12 \mathrm{kPa}$, and the fraction of oxygen desorbed from seawater in the predeaeration chamber was about 0.4 to 0.6 .

\subsubsection{Potential Improvements in Accuracy of Measurement}

To improve results for measurement of the dissolved oxygen and to obtain reliable online data, the following recommendations are made (see Section D.3 of Appendix D for details):

- Replace the Clark-type sensors with "balanced electrode reaction" sensors, which are insensitive to the flow rate.

- Use peristaltic pumps for delivering water to the sensors to avoid cavitation in the 1 ines.

- Frequently calibrate sensors against the Winkler method to establish accuracy and stability with time.

\subsubsection{Impact of Predeaeration on OC-OTEC Power Consumption}

As was discussed in Section 5.2, noncondensable gases must be removed from OC-OTEC heat exchangers (evaporator and condenser) to maintain the vacuum levels required for their operation. The power required to remove these gases reduces the net power production of the plant. Link and Shelpuk (1987) and Block and Valenzuela (1985) estimated that the amount of power typically needed to remove noncondensable gases is between $10 \%$ and $15 \%$ of the net power produced by an OC-OTEC plant. If noncondensable gases are removed before they enter heat exchangers, e.g., at predeaerators, then less noncondensable 


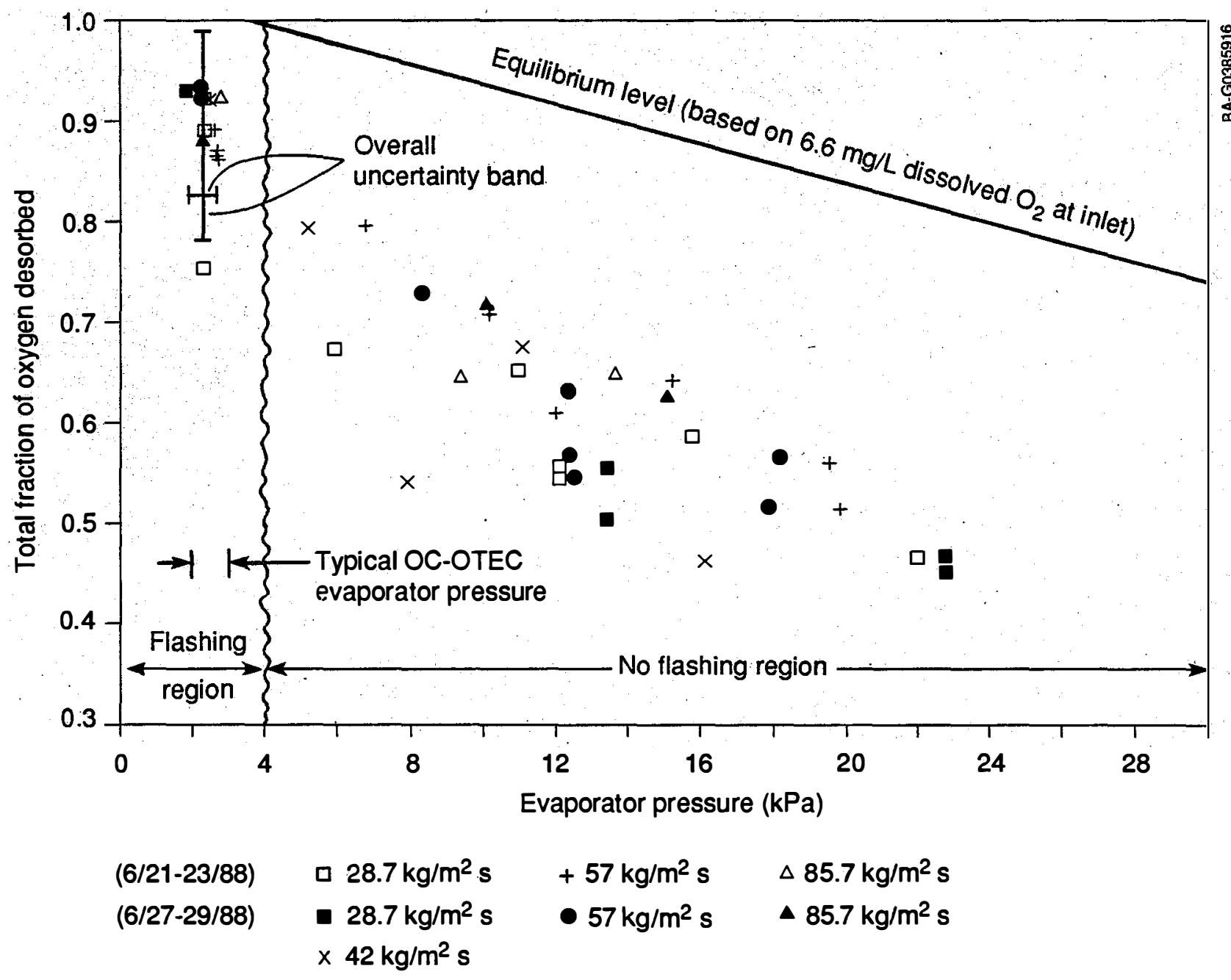

Figure 5-13. Combined warm seawater orygen desorption
in both evaporator and predeaeration chamber, as a
function of predeaerator (evaporator) liquid loading

pumping power is needed, because gases are removed at pressures higher than exchanger pressures. To estimate typical reduction in power using a predeaeration scheme, an OC-OTEC system simulation model (Link and Shelpuk 1987) is used here.

A polynomial equation is used to predict the fraction of incoming gases (oxygen and nitrogen) that will be released in the predeaerator at various pressures. Using the root-mean-square method, a polynomial was fit to all the points of the predeaeration data obtained with no baffle plate shown in Figure 5-7:

$$
\mathrm{F}_{\mathrm{pd}}=0.653-0.0167 \mathrm{P}+1.17 \times 10^{-4} \mathrm{P}^{2} .
$$

In simulating a single-stage predeaeration scheme in the system model, without including hydraulic losses, it was found that relative to the no-predeaeration baseline, the power to remove noncondensable gases decreased by $25 \%$ when 
predeaerating at $10 \mathrm{kPa}$ (see Appendix F). Accounting for uncertainty in the oxygen desorption data, this decrease can be $25 \% \pm 8 \%$.

The experimental data obtained in this study may be used in OC-OTEC system simulation models, as shown, to give a preliminary indication of how much pumping power to remove noncondensable gases could be saved with different predeaeration schemes. A predeaeration scheme may consist of a bubble eliminator (debubbler) installed just in front of the evaporator to remove bubbles containing desorbed gases from the water fed to the evaporator. Such a device is effective in removing desorbed gases, as was observed from measurements made in this study with the bubble separator device or with debubblers of previous studies (Krock and Zapka 1981; Zapka 1988). Such debubblers are settling chambers that reduce the velocity of water compared with the rising velocity of bubbles and separate bubbles from water. Recent tests in the HMTSTA by S. Ridgway (see Section 5.9) have shown that fine-mesh screens can filter small deaerated bubbles from passing seawater, thereby permitting a more compact predeaerator chamber. Such fine-mesh screens can be installed in the debubbler to reduce its required length. Trade-offs between energy savings and capital costs associated with the predeaerator schemes should be made to evaluate the quantitative benefits of predeaeration schemes.

\subsection{CONCLUSIONS}

Scoping tests on warm seawater deaeration as outlined in the HMTSTA test plan (Parsons et al. 1989) were obtained between June and August 1988. The tests provide the first set of data from a large-scale OC-OTEC experiment. From the tests and analysis the following observations can be made:

- The observed fraction of oxygen desorbed in the predeaeration chamber ranged from 0.07 to 0.6 for a predeaerator pressure range of 9 to $35 \mathrm{kPa}$.

- The scatter in data was large because of difficulties and uncertainties in field measurements of the dissolved oxygen concentration of seawater.

- The fraction of oxygen desorbed from seawater decreased with increasing predeaeration-stage pressure, as previous investigators observed. A correlation between fraction of gas released and pressure was provided for use by engineers and designers.

- The dependence of the fraction of oxygen desorbed with water flow rate could not be determined because change in flow rate caused two effects: changes in residence time and entering bubble density. These effects had opposing impacts on the fraction of oxygen desorbed and could not be separated.

- The oxygen desorption rate in the predeaerator was increased by $20 \%$ to $60 \%$ upon injection of bubbles in the upcomer.

- Given the uncertainty in the data, the installed conical baffle plate did not have any effects on oxygen desorption levels.

- Observation showed that oxygen was desorbed from seawater in the predeaeration chamber as bubbles. Tests showed that oxygen was desorbed from the seawater but was not completely released in the predeaerator, and bubbles containing desorbed oxygen were carried into the evaporator. The tests showed that the bubbles could be separated from the water effectively in a bubble separatior. 
- At a typical OC-OTEC evaporator pressure of $2.4 \mathrm{kPa}, 75 \%$ to $95 \%$ of dissolved oxygen content was desorbed from the warm seawater in the predeaerator and evaporator combined.

- Using the desorption rates measured in the tests and applying them in a system simulation model, a single-stage predeaeration scheme may reduce the amount of pumping power required to remove noncondensable gases by about $25 \% \pm 8 \%$. This would increase the net power output of an OC-OTEC plant by about $2 \%$ to $3 \%$.

\subsection{APPLICABILITY OF TEST RESULTS TO NPPE}

To select the capacity of a vacuum compression system for the OTEC net powerproducing experiment (NPPE), one needs to know the amount of noncondensable gases that should be removed from the system. Noncondensable gases enter the system as releases from warm surface seawater and cold deep seawater and via air leaks. The NPPE design calls for a warm seawater flow rate of $620 \mathrm{~kg} / \mathrm{s}$ (9600 gpm). The total concentration of all noncondensable gases in the warm seawater near the experiment site is about $19 \mathrm{mg} / \mathrm{L}$ (see Section 5.4.2.2). Results show that $75 \%$ to $95 \%$ of dissolved oxygen content is released from the warm seawater and must be pumped out. Chapter 8 shows that about $100 \%$ of the free carbon dioxide is desorbed, but this component is a small fraction of the total noncondensable gases. Therefore, assuming that the rate at which nitrogen and carbon dioxide are desorbed from the warm seawater is the same as the rate measured for oxygen, then about 14 to $17 \mathrm{~g} / \mathrm{s}$ of noncondensable gases will be released from the warm seawater in the NPPE evaporator. Predeaeration could remove about 8 to $11 \mathrm{~g} / \mathrm{s}$ of these gases at a higher pressure than the evaporator pressure. The vacuum pump for NPPE should be sized to accommodate the maximum predicted release, as well as release from cold seawater and air leaks.

Using the oxygen-desorption test results in a system model by simulating NPPE conditions, it can be shown that a warm seawater predeaeration strategy.could reduce vacuum pumping power and capacity, and thus size, of the NPPE compressor by as much. as $20 \%$ and increase its net power production by about $5.5 \mathrm{~kW}$, not counting hydraulic losses. (The analysis is based on a projected four-stage compressor with efficiency of $60 \%$, steam inlet temperature of $6^{\circ} \mathrm{C}$, compressor inlet pressure of $1.23 \mathrm{kPa}$, and $47 \%$ gas release at a pressure of $11.3 \mathrm{kPa}$ in the predeaerator.) Because the expected amount of increase in net power production is small, predeaerators will not be included in the initial NPPE apparatus. However, predeaeration experiments will be considered after power production is characterized to properly quantify the potential impact of predeaeration on large-scale systems. A relatively simple approach to performing warm seawater deaeration experiments at the NPPE is proposed in the next section.

\subsection{FURTHER PROJECTED RESEARCH NEEDS}

Although the gain in net power for OC-OTEC plants is relatively small--a few percent potential increase--predeaeration can provide incremental gains. Therefore, attention should be directed to this topic when OC-OTEC technology has been characterized at a system level. To obtain the dependence of warm seawater gas desorption on water flow rate for design purposes, system model simulations, and deaeration model verifications, experiments should be 
designed that separate the effects of residence time and entering bubble density when flow rate changes. Effects of different baffle designs also should be investigated. In addition, more dependable and more accurate dissolvedoxygen sensors or other measurement techniques should be used. A "balanced electrode reaction" sensor, which is flow rate insensitive, is recommended for use, rather than Clark-type sensors. The sensor should be calibrated frequently using the Winkler method to establish accuracy and stability with time.

Future tests should be conducted on deaeration of cold deep seawater, as well as surface warm seawater, and should measure the desorption not only of oxygen but also of nitrogen and carbon dioxide. Gas analyzers such as gas chromatographs and mass spectrometers are necessary to measure the nitrogen and carbon dioxide content of the gas. Techniques to measure total gas release, such as volumetric measurements and bubble density and bubble size and distributions, are also recommended. The accuracy of the results obtained in future experiments should be established with a rigorous error analysis.

Although the baseline NPPE is configured without predeaeration, that capability could be added easily at a later time. The proposed predeaerator, shown in Figure 5-14, would be outside the main vacuum vessel (evaporator and condenser) on the warm and cold seawater supply pipes between the supply pumps and vacuum vessels. The predeaerator would be a bubble separator consisting of a fiberglass pipe $2.4 \mathrm{~m}(8 \mathrm{ft})$ in diameter and $6.1 \mathrm{~m}(20 \mathrm{ft})$ 1ong. These pipes were previously used for studies of large cold-water pipes, are currently in stock at the Seacoast Test Facility, and would withstand the vacuum pressure required for this application. The purpose of fine-mesh screens in the bubble separator is to filter the deaerated bubbles as discussed in Section 5.5.4. The arrangement shown in Figure 5-14 allows tests both with and without predeaeration.

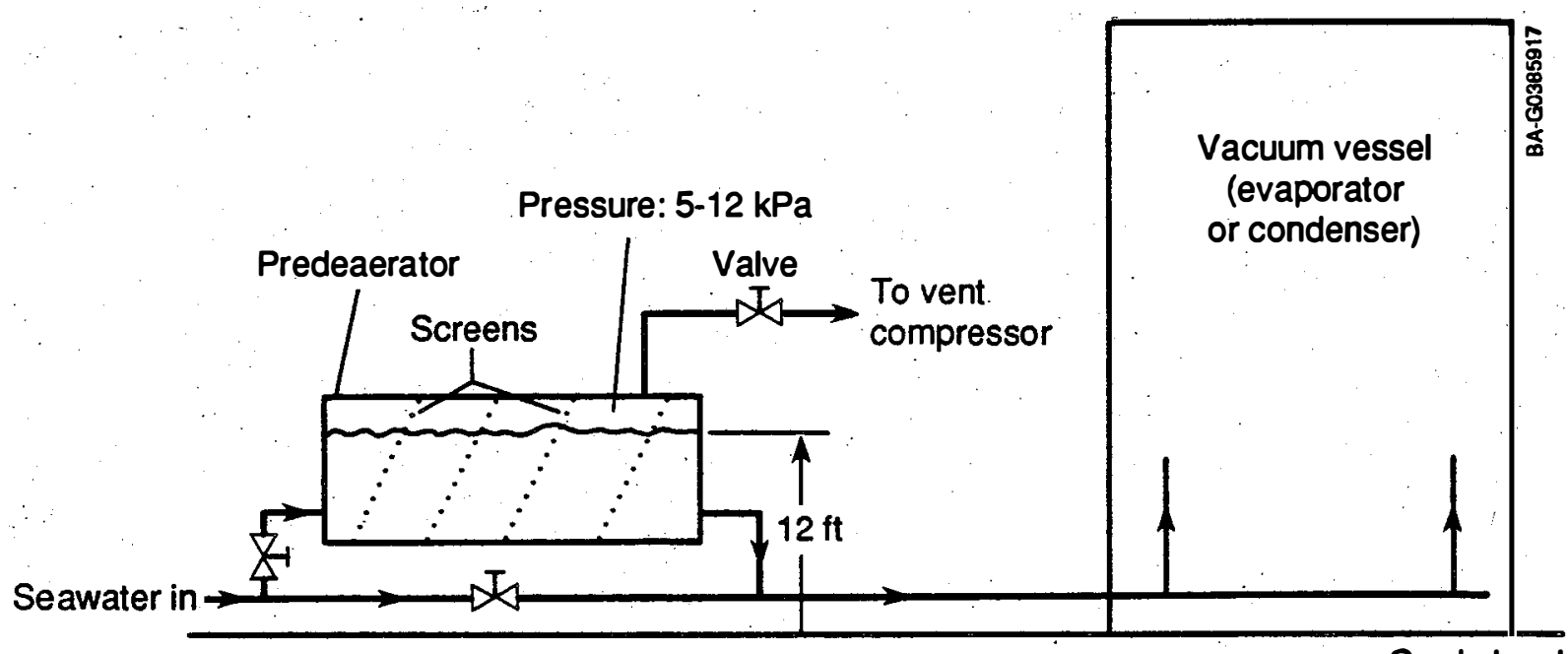

Grade level

Figure 5-14. Schematic of a proposed predeaeration configuration for future tests using the net power-producing experiment (NPPE) apparatus 


\subsection{TOTAL GAS RELEASE}

The previous sections presented the results of oxygen desorption tests in the evaporator and predeaerator conducted in the summer of 1988. This section summarizes results of some exploratory tests of total gas release from warm seawater conducted in the HMTSTA evaporator and predeaerator during the summer of 1989 (S. Ridgway 1989).

In the exploratory tests, rather than measuring the dissolved oxygen content, the total amount of noncondensable gases released from warm seawater was measured with a positive-displacement domestic-type gas meter (Sprague Model 250) attached to the exhaust of the vacuum pumping system. The capacity of the unit is $2.2 \times 10^{-3} \mathrm{~m}^{3} / \mathrm{s}$ (275 CFH at $0.5 \mathrm{in}$. water column), providing 0.11 cubic feet per revolution. The accumulated gas flow over a reference time period was checked against a Dwyer rotometer of $3.1 \times 10^{-3} \mathrm{~m}^{3} / \mathrm{s}$ (400 SCFH) capacity. It was found that under normal evaporator operating pressure (about $2.7 \mathrm{kPa}$ ), about $90 \%$ of dissolved gases are released at different water flow rates. This is consistent with the results obtained with oxygen desorption tests conducted in summer 1988 (see Figure 5-13).

Limited numbers of tests were conducted to measure total gas release at pressures above steam saturation pressures in the evaporator and the predeaerator. It was found that fraction of total gas released was a function of pressure, number of entering gas bubbles, flow-path configuration, and water residence time, consistent with the oxygen desorption tests of the summer of 1988 (see Section 5.5). Ridgway found that the desorbed gas bubbles in the predeaerator can be effectively separated from the water by 270 -mesh stainless steel screen baffles. The fine-mesh screen filtered the small deaerated bubbles from passing seawater going into the evaporator; the gas bubbles were released in the predeaeration chamber. At a warm seawater 1 iquid loading of $34 \mathrm{~kg} / \mathrm{m}^{2} \mathrm{~s}$, near the current NPPE evaporator design loading, $51 \%$ of the dissolved gases were released in the predeaerator at about $9.5 \mathrm{kPa}$. This pressure is too low to enter the third stage of the proposed NPPE vacuum system, but it gives an estimate of the range of predeaeration to be expected. This value is about $10 \%$ to $20 \%$ higher than was observed during the oxygen desorption tests. At smaller liquid loadings (near $17 \mathrm{~kg} / \mathrm{m}^{2} \mathrm{~s}$ ) the quantity of gas released from the warm water amounted to about $80 \%-90 \%$ at pressures from 4 to $11 \mathrm{kPa}$. Similar tests with cold seawater flowing through the evaporator vessel indicated a release on the order of $60 \%$. The higher fraction of gas released in the later tests is attributed to the effect of the screen mesh. A rigorous error analysis has not been conducted for these exploratory tests; however, preliminary results confirm the existence of techniques suitable for removing gas bubbles from the seawater. Therefore, predeaeration should continue to be considered one of the viable techniques of incrementally improving the overall commercial OC-OTEC system performance, with potential to decrease by about $10 \%$ the system's parasitic losses (see Appendix F).

\subsection{REFERENCES}

ANSI/ASME PTC 19.1-1985, 1986, Measurement Uncertainty, supplement to ASME Instrument and Apparatus Performance Test Codes, New York, NY: American Society of Mechanical Engineers. 
Block, D. L., and Valenzuela, J. A., 1985, Thermoeconomic Optimization of OC-OTEC Electricity and Water Production Plants, SERI/STR-251-2603, Golden, CO: Solar Energy Research Institute.

Ghiaasiaan, S. M., A. T. Wassel, and A. A. Pesaran, 1990, "Gas Desorption from Seawater in OC-OTEC Barometric Upcomers," Journal of Solar Energy Engineering, Vol. 112, Pp. 204-215.

Golshani, A., and F. C. Chen, 1981, Ocean Thermal Energy Conversion Gas Desorption Studies, Vol. 1: Deaeration in a Packed Column and a Barometric Intake System, ORNL/TM-7438/V2, Oak Ridge, TN: Oak Ridge National Laboratory.

Kreith, F., and D. Bharathan, 1988, "Heat Transfer Research for Ocean Thermal Energy Conversion," Journal of Heat Transfer, Vol. 110, No. 2, Pp. 5-22.

Krock, H. J., 1981, Gas Analyses of Water Samples for OTEC Program, J.K.K. Look Laboratory, Technical Report No. 51, University of Hawaii at Manoa.

Krock, H. J., and M. J. Zapka, 1981, "Gas Evolution in Open-Cycle OTEC," Proceedings of 5th Symposium of OMAE, Tokyo, Japan: American Society of Mechanical Engineers, Vol. 2, Pp. 613-618.

Lindenmuth, W., H. Liu, and G. Poquette, 1982, Seawater Deaeration in OC-OTEC Risers, Report 8031-1, Hydronautics, Inc.

Link, H. F., and B. Shelpuk, 1987, Thermoeconomic Analysis of Land-Based OpenCycle OTEC, SERI/TR-253-3077 (draft), Golden, CO: Solar Energy Research Institute.

Parsons, B. K., H. F. Link, D. Bharathan, A. A. Pesaran, F. Zangrando, and C. B. Panchal, 1989, Test Plan for the Heat- and Mass-Transfer Scoping Test Apparatus: Phase I and Phase II Tests, Internal Program Report, SERI/PR-2533385, Golden, C0: Solar Energy Research Institute.

Ridgway, S., 1989, Personal Communication.

Sverdrup, H. U., M. W. Johnson, and R. H. Fleming, 1942, The Oceans, New York: Prentice-Ha11, Pp. 186-210.

Yel low Springs Instruments, 1987, Instruction Manual, YSI Model 58 Dissolved Oxygen Meter, Item No. 069387, Yellow Springs, OH: Yellow Springs Inst ruments Co., Inc.

Zapka, M. J., 1988, Gas Exchange in Seawater with Special Emphasis on OC-OTEC, Ph.D. Dissertation, Manoa: University of Hawaii. 
CHAPTER 6.0

SURFACE CONDENSER*

C. B. Panchal

Argonne National Laboratory

*Work supported by the U.S. Department of Energy, Assistant Secretary for Conservation and Renewable Energy, Office of Utility Technologies, Wind/Hydro/ Ocean Division, under Contract W-31-109-Eng-38. 


\subsection{NOMENCLATURE}

\begin{tabular}{|c|c|c|}
\hline Abbrev. & Description & Units \\
\hline Ao $\hat{e}$ & reference heat transfer area & $\mathrm{m}^{2}$ \\
\hline$c_{p}$ & specific heat & $\mathrm{kJ} / \mathrm{kg} \cdot \mathrm{K}$ \\
\hline$\varepsilon_{\mathrm{vc}}$ & $\begin{array}{l}\text { steam-side thermal effectiveness of vent condenser } \\
(\mathrm{Eq} \cdot 6-6)\end{array}$ & \\
\hline h & enthalpy & $\mathrm{kJ} / \mathrm{kg}$ \\
\hline hs & effective steam-side coefficient & $\mathrm{kW} / \mathrm{m}^{2} \mathrm{~K} \hat{\mathrm{e}}$ \\
\hline hen & $\begin{array}{l}\text { condensate coefficient calculated using the Nusselt } \\
\text { analysis }\end{array}$ & $\mathrm{kW} / \mathrm{m}^{2} \mathrm{Kê}$ \\
\hline hw1 & $\begin{array}{l}\text { water-side heat-transfer coefficient calculated using } \\
\text { Eq. 6-5 }\end{array}$ & $\mathrm{kW} / \mathrm{m}^{2} \mathrm{~K} \hat{\mathrm{e}}$ \\
\hline $\mathrm{hw2}$ & $\begin{array}{l}\text { water-side heat-transfer coefficient calculated using } \\
\text { the present data }\end{array}$ & $\mathrm{kW} / \mathrm{m}^{2} \mathrm{Ke}$ \\
\hline m & mass flow rate & $\mathrm{kg} / \mathrm{s}$ \\
\hline$q$ & rate of heat transfer & $\mathbf{k W}$ \\
\hline Rw & wall resistance & $\mathrm{K} \mathrm{m}^{2} / \mathrm{kW} \mathrm{ê}$ \\
\hline $\mathrm{T}$ & temperature & ${ }^{\circ} \mathrm{C}$ \\
\hline$\Delta \mathrm{Tm}$ & mean temperature difference (Eq. 6-3) & \\
\hline Uo & overall heat-transfer coefficient. & $\mathrm{kW} / \mathrm{m}^{2} \mathrm{~K}$ \\
\hline \multicolumn{3}{|c|}{ Dimensionless Numbers } \\
\hline Nu & Nusselt number & \\
\hline $\operatorname{Pr}$ & Prandt 1 number & \\
\hline $\operatorname{Re}$ & Reynolds number & \\
\hline
\end{tabular}

\section{Subscript}

c

condenser

e

evaporator

i inlet

1 1iquid

- outlet

$r$ refrigerant

s saturation

v vapor

w

water 


\subsection{BACKGROUND}

Two types of condensers can be used for the open cycle. In the direct-contact condenser, which is described in Chapter 7 , the steam condenses directly on the seawater and the two fluids are mixed. In the surface condenser, the seawater remains separated from the steam by a surface, and desalinated water is produced as a direct by-product of the OC-OTEC process.

The experimental results presented in this section are a part of the overall research approach for the development of the open-cycle surface condenser. The technical approach is summarized as follows:

- Development of performance prediction methods

- Development of scoping experiments using Heat- and Mass-Transfer Scoping Test Apparatus (HMTSTA) existing condensers

- Refinement of performance prediction methods

- Design of test unit for net power-producing experiment (NPPE) with prototypical flow geometry

- Design of experiments using HMTSTA and NPPE

- Verification of performance prediction methods

- Development of design criteria.

The overall goal of the research program is to develop design criteria that can be used for the open-cycle surface condenser. Necessary design tools in the form of performance correlations, calculation algorithms, and experimental data bases will be developed. In this section the experimental data obtained using the existing condenser test units are discussed, and the results are compared with theoretical predictions.

\subsubsection{Literature Survey}

The analysis of condensation of low-pressure steam in the presence of noncondensable gases is documented in the open literature (Schrodt 1973; Krishna and Panchal 1977; Price and Bell 1974). Since the original analysis

f Colburn and Hougen (1934), many researchers have conducted theoretical and experimental analyses in an effort to understand the effects noncondensable gases have on the rate of condensation. The problem can be divided into two design issues: (1) local calculation of the heat and mass fluxes and (2) integration of heat- and mass-balance equations over the heat-transfer surface. For a prototypical condenser geometry, the overall performance prediction could be significantly affected by the spatial distribution of the gases and the assumption used for calculating the inlet steam flow distribution. The steam flow, on the other hand, is affected by perturbation in the pressure distribution caused by pressure drop, local fluxes of heat and mass, inlet configuration, and location of the vent system. These parameters themselves interact and impose a difficult design problem.

Past work in research and development has been mostly devoted to power plant condensers. In addition, design tools have been developed (Bell and Ghaly 1972; Porter and Jeffreys 1963; McNaught 1986) for sizing process condensers for multicomponent systems. Recently, Webb and Magnall (1988) discussed design 
guidelines for vacuum condensers of shell-and-tube configurations. In most commercial applications, the venting power requirement is relatively low, and the major consideration is the condensing capacity of the heat exchanger. The open-cycle condenser must be designed with a low margin of design variables because of the need to balance the cold water requirement, vacuum pumping power, and turbine backpressure. A condenser that is overdesigned would consume excess cold water, and an inefficient or too-small condenser would elevate the steam inlet pressure or increase the vacuum pump power or both.

Existing design methods generally are restricted to shell-and-tube condensers, and no experimental data are available to validate them for OTEC conditions. In the Westinghouse design study (1979) of a 100-MWe floating plant, a tube-bundle configuration was used for the surface condenser. They used the point-wise calculation method discussed by Barsness (1963), which is based on the overall heat-transfer calculation for a shell-and-tube heat exchanger. It is developed for sizing power plant condensers; therefore, a large uncertainty is introduced by applying such design methods to OTEC conditions. In the Creare R\&D, Inc., study for SERI (Block and Valenzuela 1985) a modular tubebundle design approach was used. To maintain high steam velocity, they used a reducing flow area bundle in cross-flow configuration. The Creare study assumed minimum effects of the noncondensable gases on the condenser size. That analysis was extended by Panchal and Bell (1984) to the plate-fin condenser geometry for open-cycle application. It had been suggested that a condenser configuration with a defined steam path should be considered for OTEC applications. The study discussed a plate-fin condenser that can provide flexibility and low-cost design options.

\subsubsection{Specific Objectives of Tests}

The major objectives for the experimental program reported here were to obtain surface condenser performance data for OTEC conditions using existing test units and to determine the uncertainty in the performance prediction methods.

The surface condenser units are made up of a main condenser (see Figure 2-4) that uses cold seawater to condense on the order of $80 \%-90 \%$ of the incoming steam, and a vent condenser (see Figure 2-5) that concentrates the noncondensable gases by condensing a large fraction of the leftover steam from the main unit. This unit used refrigerant $R-12$ as the working fluid.

The specific experimental objectives were as follows:

- Determine overall performance for the main condenser.

- Measure local and total rate of condensation and compare with theoretical predictions.

- Determine thermal effectiveness of the vent condenser.

- Compare measured and predicted thermal effectiveness for the vent condenser.

- Use the experimental data to design the NPPE test unit with prototypical flow channels. 


\subsection{DATA ANALYSIS}

A general approach for the thermal design of surface condensers consists of an overall performance calculation and a detailed design method. The overall performance calculation method is used to determine the initial size of the condenser. This method could be based on either the heat-transfer coefficient or on thermal effectiveness. The current data analysis used the overall heat-transfer concept for the main condenser and thermal effectiveness for the vent condenser. This approach reflected the criterion of condensation of $90 \%$ to $95 \%$ of the incoming steam in the main condenser, and the bringing down of the steam saturation temperature to the lowest possible value in the vent condenser. Also, it was selected because the effects of noncondensable gases are less severe in the main condenser than in the vent condenser.

The presence of noncondensable gases makes it necessary to adopt a computerbased performance calculation method to develop the final design specification. The spatial distribution of the local steam saturation temperature and the mass-transfer resistance caused by the presence of gases can easily be incorporated in such methods. One major objective is to develop a performance calculation method that. can be verified using the overall and local measurements. In this experimental program, the total and local rates of condensation were measured for the main condenser, in addition to inlet and outlet conditions.

\subsubsection{Heat-Transfer Coefficient for the Main Condenser}

The average overall heat-transfer coefficient is defined as follows:

$$
\text { Uo }=\mathrm{q}_{\dot{\mathrm{w}}} / \mathrm{AO}_{\mathrm{O}} \Delta \mathrm{Tm}
$$

where the water-side rate of heat transfer is calculated as follows:

$$
q_{w}=m_{w} C_{p}\left(T_{w o}-T_{w i}\right)
$$

where water temperatures are average values of two temperature sensors.

The mean temperature difference is calculated using the following equation:

$$
\Delta \operatorname{Tm}=\frac{\left(T_{s i}-T_{w o}\right)-\left(T_{s o}-T_{w i}\right) \hat{e}}{\ln \left[\left(T_{s i}-T_{w o}\right) /\left(T_{s o}-T_{w i}\right)\right]}
$$

where $\mathrm{T}_{\text {si }}, \mathrm{T}_{\text {so }} \quad \begin{aligned} & \text { steam saturation temperatures; calculated for inlet and outlet } \\ & \text { conditions of pressure and gas concentration }\end{aligned}$

$\mathrm{T}_{\text {wi }}, \mathrm{T}_{\text {wo }} \quad$ = water inlet and outlet temperatures; measured.

6.3.1.1 Determination of the Effective Steam-Side Heat-Transfer Coefficient

The steam-side heat-transfer coefficient is determined by subtracting the water-side and wall resistances as shown below.

$$
h s=\frac{1}{\left(1 / U_{0}-1 / h_{w}-R_{w}\right)}
$$


It was assumed that during the test period, the biofouling deposit would be negligible. Experimental data have shown that negligible biofouling buildup occurs for deep-ocean cold water. The condenser surface was examined several times during the experiments, and no fouling deposit was visible. The wall resistance is calculated using wall thickness and thermal conductivity.

\subsubsection{Determination of the Water-Side Heat-Transfer Coefficient}

The main condenser unit was tested as an ammonia evaporator at Argonne National Laboratory ( $A N L$ ), where a series of tests were conducted to determine the water-side heat-transfer coefficient using the Wilson plot technique. The data are unpublished except for the overall performance results (Panchal et al. 1981), which provide the following correlation:

$$
\mathrm{Nu}=0.221 \mathrm{Re} 0.68 \mathrm{Pr} 0.333 . \hat{\mathrm{e}}
$$

The heat-transfer measurement error is $\pm 2 \%$ and the curve-fitting error on these data is $\pm 8.5 \%$.

It is difficult to obtain a meaningful Wilson plot for conditions in which distribution of noncondensable gases might affect the effective steam-side coefficient as the water flow rate changes. However, the above correlation can be checked by changing the water flow for a steam-side condition of low inlet gas concentration and a relatively low fraction of steam condensed.

\subsubsection{Thermal Effectiveness of the Vent Condenser}

The main function of the vent condenser is to reduce the steam-to-gas ratio (i.e., saturation temperature) for the exiting steam/gas mixture. Therefore, the overall performance is expressed by the steam-side thermal effectiveness as shown below:

$$
\varepsilon_{v c}=\frac{T_{s i}-T_{s o}}{T_{s i}-T_{s r}}
$$

where

$$
\begin{aligned}
& \mathrm{T}_{\text {si }}= \begin{array}{l}
\text { steam saturation temperature; calculated using inlet } \\
\text { conditions of pressure and gas concentration }
\end{array} \\
& \mathrm{T}_{\text {so }}= \text { steam saturation temperature at outlet; measured } \\
& \mathrm{T}_{\mathbf{s r}}=\begin{array}{l}
\text { average boiling temperature of refrigerant; calculated } \\
\text { using the average pressure. }
\end{array}
\end{aligned}
$$

As may be seen from the above equation, determination of the thermal effectiveness depends upon an accurate measurement or calculation of inlet and outlet steam-saturation temperatures. In the current analysis, the dewpoint temperature measurement at the outlet is a key parameter. Using this measurement, the steam concentration is calculated; the gas mass flow rate is calculated using the vacuum-pump capacity. The rate of condensation is calculated using the refrigerant-side heat balance as shown below.

$$
q_{r}=m_{r}\left(h_{v o}-h_{1 i}\right)
$$


where

$m_{r} \quad=$ refrigerant mass flow rate; measured

$h_{\text {vo }}=$ enthalpy of vapor at outlet; calculated

$\mathrm{h}_{1 \mathrm{i}}=$ enthalpy of liquid at inlet; calculated.

\subsubsection{Detailed Performance-Prediction Method}

The analysis used to predict the condenser performance is elsewhere (Panchal and Bell 1984), and for the sake of brevity it is not discussed here. The performance-prediction method is based on the Colburn analysis, and the literature correlations are used for the heat- and mass-transfer coefficients. The steam/gas mixture flow is in general laminar; the Reynolds number at inlet is in the range 1000-2000. The mass-transfer coefficient is calculated using the heat-transfer correlation of sieder and Tate as reported in Bird, Stewart, and Lightfoot (1981) and applying the heat- and mass-transfer analogy. Rose (1981) has identified limitations for the analogy caused by the mass flux normal to the interface. However, the uncertainty is within acceptable limits for the purpose of design. The algorithm used to calculate the rate of condensation for the cross-flow condenser is summarized below in terms of calculating steps.

\subsubsection{Algorithm for Performance Prediction}

1. Read geometry parameters for main condenser.

2. Read inlet conditions for a given test run.

3. Calculate necessary geometry parameters, i.e, heat transfer and flow area.....

4. Calculate water-side heat-transfer coefficient and pressure drop.

5. Divide condenser into $\mathbf{N}$ horizontal and $M$ vertical increments.

6. Calculate inlet steam flow distribution for $\mathbf{N}$ increments as follows:

Start integration from water inlet increment.

Assume average condensate coefficient.

Calculate condensate coefficient and hence overall Uo.

Calculate rate of condensation for given increment.

Calculate water temperature for next increment.

Integrate along condenser length.

Calculate steam flow for each increment proportional to rate of condensation.

7. Start integration from water inlet and top point.

8. Calculate heat- and mass-transfer coefficients and condensate coefficient using the Nusselt analysis. Steam-side heat-transfer coefficient is calculated using laminar flow between parallel plates. Mass-transfer coefficient is calculated assuming analogy. 
9. Determine interfacial temperature iteratively by applying heat and mass continuity at the interface.

10. Calculate local heat- and mass-transfer rates.

11. Calculate conditions for next increment, i.e., vertically down for steam side and horizontally for water side.

12. Integrate vertically.

13. Iterate (repeat from step 7) for corrected water-side temperature; i.e., average of inlet and calculated outlet.

14. ê Continue integration along water-flow direction, i.e., horizontally by following steps 7-13 for each horizontal increment.

15. Complete integration over whole condenser area.

16. Calculate average outlet steam flow using outlet values for horizontal increments.

17. Compare each value against average steam flow and calculate difference.

18. Apply difference calculated in step 17 to assumed inlet steam flow. This step is based on an assumption that inlet steam distribution is governed by the pressure drop to the entrance of a uniformly distributed vent system. This assumption should apply when the steam-side pressure drop across the condenser is small. On the other hand, when the condenser steam-side pressure drop is higher than are entrance losses to the vent system, the iteration should be based on balancing the steam-side pressure drop. The current analysis can handle both of these boundary conditions.

19. êfter correcting inlet steam distribution, start integration from water inlet and top point of condenser.

20. Iterate on steam flow distribution until local steam flow agrees with an average value within given tolerance.

21. Calculate outlet conditions.

For the vent condenser, the algorithm can be simplified because of the countercurrent flow configuration. The local heat- and mass-flux calculations are integrated along the condenser length. The refrigerant-side heat transfer is calculated using the analysis (Rose 1981) extended from the vertical to the horizontal configuration of the test unit. For the superheated vapor flow region, an appropriate correlation is used to calculate the single-phase heat-transfer correlation. However, a comparison of the experimental data with predictions has not yet been carried out. The initial set of experiments presented some difficulties in controlling operating conditions, as discussed in Chapter 2. A full analysis will be carried out after the experiments are repeated with appropriate system modification.

\subsubsection{Test Matrix}

The HMTSTA test plan (Parsons et al. 1989) discusses the test matrix in detail. Some changes were made to the original test matrix to accommodate the capacity of the apparatus and component or subsystem performance. For certain series of experiments, it was necessary to repeat the measurements because of problems associated with operating conditions or instrumentation or both. 
Situations in which that was necessary are pointed out below. Moreover, several series of experiments were conducted toward the end of the test schedule. It was possible to use a large number of data sets; however, it was necessary to eliminate some of them because of relatively large measurement uncertainties. The data sets used for the performance analysis are documented in Section B.2 of Appendix B.

\subsubsection{Main Condenser}

In the HMTSTA test plan (Parsons et al. 1989) the following variables were included for the experimental investigation.

1. Inlet steam velocity 7 to $21 \mathrm{~m} / \mathrm{s}$ (23 to $68 \mathrm{ft} / \mathrm{s})$

2. Fraction of steam condensed 0.7 to 0.9

3. Distribution of water and steam temperatures by varying water flow rate in the distribution range of 20 to $58 \mathrm{~kg} / \mathrm{s}$

4. Inlet gas concentration $0.2 \%$ to $1 \%$ by weight by varying warm-water flow and flash-down temperature.

Using these guidelines, three series of tests were planned as summarized below. All measured parameters, along with test run identification, are documented in Section B.2 of Appendix B.

Test Series 1: Water Flow Rate Is Variable.

In this series of tests, the cold-water rate was varied in the range of available seawater flow rate at NELH. This series provided data that can be used to validate the ANL heat-transfer coefficient for the water side and that will aid in study of the effects of temperature distribution for cross-flow configuration. It was not possible to maintain the fraction of steam condensed to 0.7 or lower for this series of tests, and some tests were repeated to try to get a low value of fraction of steam condensed in the main unit. The objective was to keep the effects of noncondensable gases at a minimum to enable verification of the water-side heat-transfer coefficient.

Test Series 2: Fraction of Steam Condensed in Main Condenser Is Variable.

The objective of this series of tests was to determine the effects of outlet steam conditions on the condenser performance. The test data should provide an optimum value for fraction of steam that can be condensed without significant reduction in the performance of the main condenser. In the original plan, the fraction of steam to be condensed in the main condenser was 0.7 to 0.9. It was not possible to achieve the low value, and the maximum value of fraction of steam condensed was about 0.99. However, the condenser pressure was high, indicating significant reduction in performance at a high fraction of steam condensed.

Test Series 3: Inlet Gas Concentration Is Variable.

In the original plan, it was proposed to control the inlet gas concentration by changing the warm-water flow and flash-down temperature. Low water flow rate and high flash-down temperature should generate less noncondensable gases 
than high water flow with low flash-down at the same rate of steam generation. Because more air leaked in during surface-condenser experiments than was originally expected, a large variation in the inlet gas concentration was not possible. Nevertheless, the results provide the data base for the open-cycle range of conditions.

\subsubsection{Vent Condenser}

The HMTSTA test plan (Parsons et al. 1989) showed the following parameters as primary variables:

1. Steam inlet velocity 5 to $68 \mathrm{~m} / \mathrm{s}$ ( 15 to $225 \mathrm{ft} / \mathrm{s}$ )

2. Inlet gas concentration $1.7 \%$ to $5.9 \%$ by weight

3. Outlet steam-to-gas ratio 2.3 to 5 by weight.

Using these guidelines, the following three series of test were conducted. (See Section B.2 of Appendix B for the detailed data and test-run identification.) It was quite difficult to maintain desired test conditions for the vent condenser. Controlling the R-12 outlet vapor superheat was the major problem for many test runs as described in Chapter.2, Section 2.4.2. Some experiments were repeated in an attempt to achieve necessary test conditions, but they could not be maintained for all runs included in the plan.

Test Series 1: Inlet Steam Velocity Is Variable.

In this series of tests, the steam mass flow rate at the inlet of the fixedgeometry condenser stage was varied while keeping other conditions constant, e.g., inlet and outlet steam saturation temperatures.' The independent variable was the refrigerant boiling temperature.

Test Series 2: Outlet Steam Saturation Temperature Is Variable.

Maintaining inlet steam conditions relatively constant (i.e., steam mass flow and saturation temperature), the outlet steam saturation was varied by controlling refrigerant boiling temperature. It was not possible to cover the proposed saturation temperature range of $7^{\circ}$ to $12^{\circ} \mathrm{C}$. Control of other parameters was again difficult for this series of tests.

Test Series 3: Inlet Steam Saturation Temperature Is Variable.

This series of tests was quite difficult to run, and only preliminary sets of data were obtained. With only limited useful data, it would be difficult to quantify the effects of the primary variable.

\subsubsection{Data Sets}

The experimental data resulting from the test series discussed above are shown in Section B.2 of Appendix B. Al1 measured parameters are included in the appendix. Intermediate parameters and the final results are also shown. The basic information included in the data set is summarized below.

1. Data file

2. Test no.
Data file used for a particular run

Test number with reference to test matrix 
3. Measured parameters

4. Calculated parameters

5. $R$ indication
Al1 necessary parameters in engineering units Calculated results shown on figures Repeated test run.

The 1 ist of measured parameters is shown below:

Flow rates--Coolant, refrigerant, condensate (total and local from three sections of main condenser)

Temperature--Coolant inlet and outlet (two sensors), delta-T, steam inlet and outlet, refrigerant inlet and outlet

Dewpoint--steam inlet (for only a few runs) and outlet for vent condenser

Wet bulb--outlet of main condenser temperature (for only a few runs)

Pressure--steam inlet and differential-P for both condensers, at inlet to the vacuum pump, downstream of expansion valve, refrigerant inlet and outlet.

The intermediate calculated parameters are

Gas flow rate--using vacuum pump inlet conditions and pump capacity

Steam flow rate--using main and vent condenser heat balances and calculated exhaust steam flow rate

Steam temperature--using measured total pressure and calculated gas concentration.

Calculated results are

Heat-transfer coefficient--using governing equations described above

Thermal effectiveness--using governing equation described above

Heat balances--using energy-balance equations

Fraction of steam condensed--using heat and mass balances.

Most of the main condenser experiments were carried out in May 1988. All necessary instruments were calibrated before starting the surface-condenser experiments. One series of experiments was carried out in June 1988, and remaining and repeat runs were completed during July 1988. All vent-condenser experiments were conducted in July 1988. Some vent-condenser experiments were done earlier; however, it was difficult to control operating conditions, and these results are not included.

\subsection{TEST-SPECIFIC EQUIPMENT AND INSTRUMENTATION}

\subsubsection{Test Units}

In the present test plan, measurement of the overall performance was the major objective. Therefore, a minimum of internal instruments was provided in the surface-condenser test units to determine the local rate of condensation and the distribution of noncondensable gases. The test units used in the HMTSTA 
were the Rosenblad dimpled-plate heat exchanger as main condenser and the Trane brazed-aluminum heat exchanger as vent condenser as described in Chapter 2. Originally designed for closed-cycle OTEC applications as ammonia condensers and evaporators, they were modified for open-cycle flow conditions and for integration into the HMTSTA system. The main condenser was operated under prototypical conditions; however, the vent unit was cooled by the refrigerant. This arrangement increased condensing capacity at open-cycle steam pressures by restricting the capacity for cold water.

Figure 2-4 in Chapter 2 shows the overall configuration of the Rosenblad heat exchanger. It consists of dimpled parallel plates welded into a plate-andshell assembly to provide steam and water channels in a cross-flow configuration. Table 6-1 gives the general specifications of the heat exchanger. Shrouds were installed to direct steam flow along the parallel-plate flow channels, and large inlet nozzles required for low-pressure steam flow were installed. In addition, the steam header was installed to minimize uneven steam flow. An appropriately sized and uniformly distributed vent system was necessary to prevent the buildup of noncondensable gases. At the bottom of the unit, condensate was separated and collected at each of three equally spaced sections. Each section was partitioned, so that the rate of condensation for the warm, middle, and cold ends of the condenser could be separately measured. The uncondensed steam/gas mixture from the main condenser flowed into a space from which it was drawn out through six equally spaced 152-mm (6-in.) outlet nozzles. It should be noted that the two outer surfaces were exposed to the stagnant steam/gas mixture; therefore, they were not included in the heat-transfer calculations.

Table 6-1. Specifications for the Main (Rosenblad) Condenser

\begin{tabular}{lll}
\hline \multicolumn{1}{c}{ Parameters } & \multicolumn{1}{c}{ Value } \\
\hline Plate material & AL-6X & Stainless steel \\
Heat-transfer area & $88 \mathrm{~m}^{2}$ & $\left(947 \mathrm{ft}^{2}\right)$ \\
Number of water flow channels & 16 & $\left(1.167 \mathrm{ft}^{2}\right)$ \\
Water flow area & $0.108 \mathrm{~m}^{2}$ & $\left(13.53 \mathrm{ft}^{2}\right)$ \\
Steam flow area & $1.26 \mathrm{~m}^{2}$ & $(0.0625 \mathrm{in.})$ \\
Wall thickness & $1.58 \mathrm{~mm}$ & $(8 \mathrm{Btu} / \mathrm{h} \mathrm{ft} \mathrm{F)}$ \\
Wall conductivity & $13.8 \mathrm{~W} / \mathrm{m} \mathrm{K}$ & $(15.6 \mathrm{ft})$ \\
Effective length & $4.76 \mathrm{~m}$ & $(1.89 \mathrm{ft})$ \\
Effective height & $0.58 \mathrm{~m}$ & \\
\hline
\end{tabular}

The Trane brazed-aluminum heat exchanger was tested as a vent condenser. Figure 2-5 in Chapter 2 shows overall and sectional views of the test unit. The condenser was cooled by boiling refrigerant $R-12$ on the $f$ inned side, and steam condensation took place in the extruded channels. There are 9 extrusion channels, each with 21 flow channels; see Table 6-2 for details of geometry. The steam/gas mixture entered through the $305-\mathrm{mm}$ (12-in.) inlet nozzle into a rectangular inlet section. The mixture then flowed through individual flow channels. Refrigerant R-12 at about $5 \%$ to $8 \%$ mass quality entered from a 51-mm (2-in.) inlet nozzle, and made a $90^{\circ}$ turn through individually arranged 
finned flow channels. Slightly superheated refrigerant vapor exited from the 203-mm (8-in.) outlet nozzle. This flow arrangement gave countercurrent flow between steam/gas mixture and refrigerant. The condenser was installed with a slight inclination to improve drainage of condensate.

Table 6-2. Specifications for the Vent (Trane Plate-Fin) Condenser

\begin{tabular}{lll}
\hline \multicolumn{1}{c}{ Parameters } & \multicolumn{1}{c}{ Value } \\
\hline Plate material & AL 3003 & \\
Heat-transfer area & $49 \mathrm{~m}^{2}$ & \\
Number of steam flow channels & 82 & $\left(527 \mathrm{ft}^{2}\right)$ \\
Refrigerant flow area & $0.036 \mathrm{~m}^{2}$ & $\left(0.392 \mathrm{ft}^{2}\right)$ \\
Steam flow area & $0.09 .3 \mathrm{~m}^{2}$ & $\left(0.998 \mathrm{ft}^{2}\right)$ \\
Steam channel size & $28.6 \times 19 \mathrm{~mm}$ & $(1.125 \mathrm{x} \mathrm{0.7.5} \mathrm{in.)}$ \\
Steam equivalent diameter & $24.3 \mathrm{~mm}$ & $(0.958 \mathrm{in.})$ \\
Wall thickness & $2.9 \mathrm{~mm}$ & $(0.114 \mathrm{in.})$ \\
Wall conductivity & $160 \mathrm{~W} / \mathrm{m} \mathrm{K}$ & $(92.5 \mathrm{Btu} / \mathrm{hr} \mathrm{ft} \mathrm{F)}$ \\
Effective length & $4.70 \mathrm{~m}$ & $(15.45 \mathrm{ft})$ \\
Effective width & $0.546 \mathrm{~m}$ & $(21.5 \mathrm{in.})$ \\
\hline
\end{tabular}

\subsubsection{Specific Test Instrumentation}

As mentioned above, both test units were instrumented to measure overall performance. Table 6-3 1ists the instruments used for the surface-condenser data analysis. Figures $6-1$ and $6-2$ show their locations. Wherever possible, multiple sensors were installed to improve measurement accuracy and redundancy. Temperature, pressure, and condensate flowmeter sensors were calibrated just before the first phase of surface-condenser experiments. For absolute temperature sensors, two-point calibration was carried out: at ice point $\left(0^{\circ} \mathrm{C}\right)$ and at gallium triple point $\left(29.972^{\circ} \mathrm{C}\right)$. The quartz temperature was used as a secondary reference to check ice- and gallium-point temperatures. Periodic checks of absolute temperature sensors were performed as described in Chapter 2. For low-pressure sensors, an NBS-traceable mechanical gauge was used to check the sensor calibration. In general, they agreed within the uncertainty shown in Table 6-3. Water and R-12 flowmeters are factory calibrated; however, the electronic signal-conditioning system was calibrated in place. For refrigerant pressure sensors, the factory calibration was used, because no reference pressure measurement was available at the site.

In general, most instruments performed well during the initial surfacecondenser experiment. One of the two delta-T sensors gave unreliable readings; however, the other was in good condition and was used for comparison with temperature differences calculated using absolute temperature measurements. Figure 6-3 presents the results for the majority of experiments and shows that both readings agree within the measurement accuracy shown in Table 6-3. Therefore, absolute temperature measurements (average of two units at inlet and outlet each) are used for the main-condenser analysis. The water flowmeter could not be independently checked; however, at low flow rates, it agreed within $1 \%$ with another flowmeter connected in series. The condensate 
Table 6-3. Instrumentation for Surface-Condenser Experiments

\begin{tabular}{|c|c|c|c|c|c|}
\hline $\begin{array}{l}\text { Measured } \\
\text { Parameter }\end{array}$ & Sensor* & Range & Error & Value & $\begin{array}{l}\text { No. of } \\
\text { Sensors }\end{array}$ \\
\hline \multicolumn{6}{|l|}{ MAIN CONDENSER } \\
\hline Water inlet, ${ }^{\circ} \mathrm{C}$ & RTD & $0-100$ & 0.26 & 7.5 & 2 \\
\hline Water outlet, ${ }^{\circ} \mathrm{C}$ & RTD & $0-100$ & 0.26 & 11.5 & 2 \\
\hline Water delta-T, ${ }^{\circ} \mathrm{C}$ & RTD & $0-30$ & 0.06 & 4.0 & 2 \\
\hline Inlet steam temp., ${ }^{\circ} \mathrm{C}$ & RTD & $0-100$ & 0.26 & 13.0 & 2 \\
\hline Outlet steam temp., ${ }^{\circ} \mathrm{C}$ & RTD & $0-100$ & 0.26 & 12.5 & 2 \\
\hline Condensate temp., ${ }^{\circ} \mathrm{C}$ & RTD & $0-100$ & 0.26 & 10.0 & 1 \\
\hline Steam pressure, kPa & Cap & $0-6.2$ & 0.117 & 1.5 & 2 \\
\hline Steam delta-P, $\mathrm{Pa}$ & Cap & $0-2000$ & 9.1 & $<10$ & 2 \\
\hline Water flow rate, $1 / \mathrm{s}$ & Vortex & $19-184$ & 1.7 & 45 & 1 \\
\hline Condensate flow, $\mathrm{ml} / \mathrm{s}$ & $\begin{array}{l}\text { Paddle } \\
\text { wheel }\end{array}$ & $41-400$ & 5 & 350 & 1 \\
\hline \multicolumn{6}{|l|}{ VENT CONDENSER } \\
\hline Inlet steam temp., ${ }^{\circ} \mathrm{C}$ & RTD & $0-100$ & 0.26 & 12.5 & 1 \\
\hline Outlet steam temp., ${ }^{\circ} \mathrm{C}$ & RTD & $0-100$ & 0.26 & 8.5 & 1 \\
\hline $\begin{array}{l}\text { Inlet steam dewpoint, }{ }^{\circ} \mathrm{C} \\
\text { Chilled mirror }\end{array}$ & RTD & $0-50$ & 0.22 & 12.5 & 1 \\
\hline $\begin{array}{l}\text { Outlet steam dewpoint, }{ }^{\circ} \mathrm{C} \\
\text { Chilled mirror }\end{array}$ & RTD & $0-50$ & 0.22 & 10.0 & 1 \\
\hline Condensate temp., ${ }^{\circ} \mathrm{C}$ & RTD & $0-100$ & 0.26 & 10.0 & 1 \\
\hline Inlet pressure, $\mathrm{kPa}$ & Cap & $0-6.2$ & 0.117 & 1.5 & 1 \\
\hline Delta-P, Pa & Cap & $0-2000$ & 9.1 & $<50$ & 1 \\
\hline Inlet $\mathrm{R}-12$ temp., ${ }^{\circ} \mathrm{C}$ & RTD & $0-100$ & 0.26 & 7.0 & 1 \\
\hline Outlet R-12 temp., ${ }^{\circ} \mathrm{C}$ & RTD & $0-100$ & 0.26 & 7.5 & 1 \\
\hline Inlet $\mathrm{R}-12$ pressure, $\mathrm{kPa}$ & SG & $0-1380$ & 12 & 400 & 1 \\
\hline Outlet $\mathrm{R}-12$ pressure, $\mathrm{kPa}$ & SG & $0-1380$ & 12 & 390 & 1 \\
\hline $\mathrm{R}-12$ Flow rate, $1 / \mathrm{s}$ & Vortex & $0-2.9$ & 0.02 & 0.5 & 1 \\
\hline
\end{tabular}

*RTD: Resistance temperature device; SG: Strain gauge;

Cap: Capacitance measurement

flowmeter was calibrated by volume measurement and corresponding receivertank calibration. As a backup, a differential pressure-drop sensor was installed to measure change in condensate level in the receiver. It gave the total rate of condensation. In the latter part of the test plan, especially during vent-condenser experiments, the condensate flowmeter was unreliable, and the level measurement method was used.

For the vent condenser, refrigerant flow rate and steam dewpoint measurements are important parameters for the data analysis. For a limited number of test runs both dewpoint cells, steam inlet and outlet, were-functional. For the remaining runs, the inlet saturation temperature was calculated using the local pressure and gas concentration. It was compared with wet-bulb temperature measurement for the steam outlet of the main condenser at the hot-end side. The outlet dewpoint measurement was used for vent-condenser data analysis and to calculate the noncondensable gas flow rate using the vacuumpump capacity. 


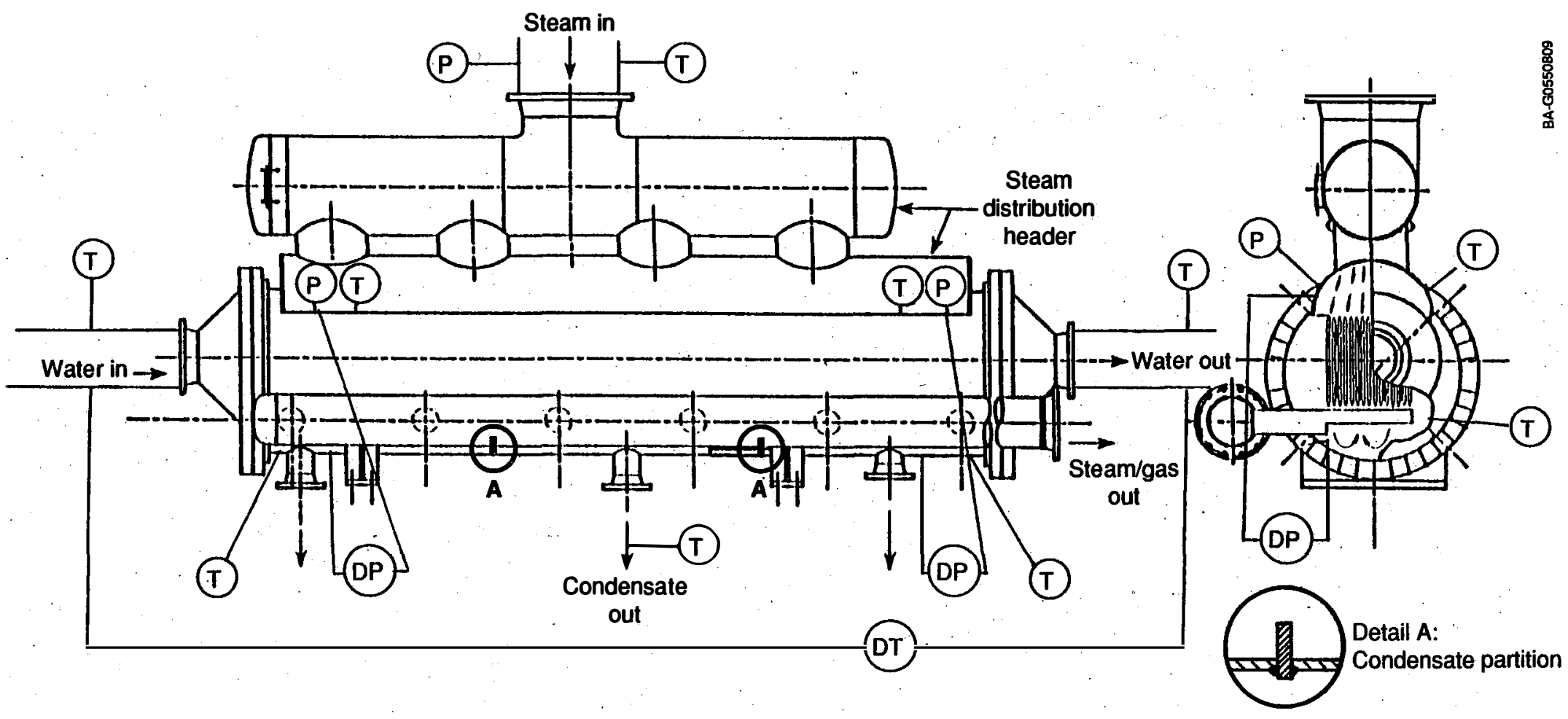

Figure 6-1. Instrumentation diagram for the main condenser 


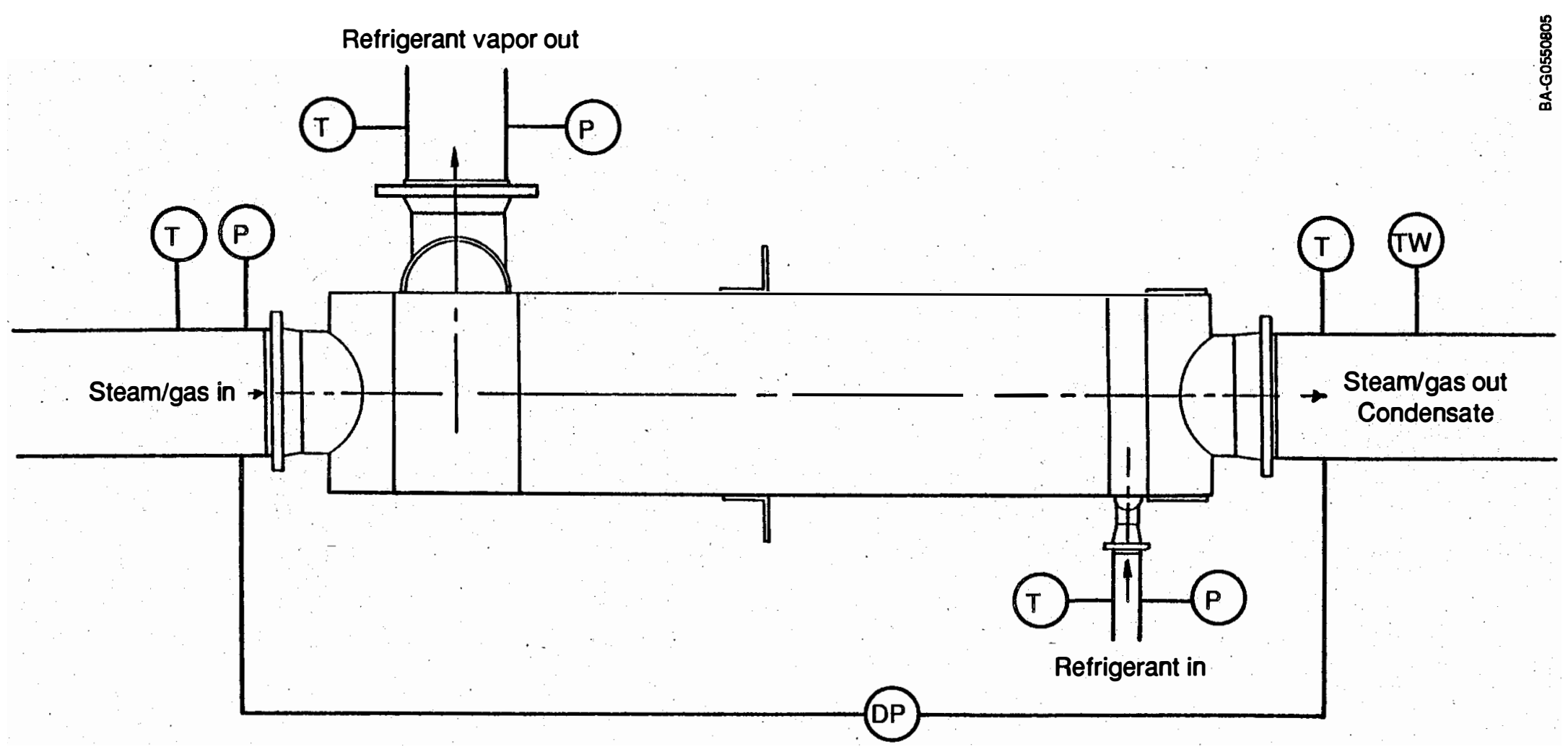

Figure 6-2. Instrumentation diagram for the vent condenser 


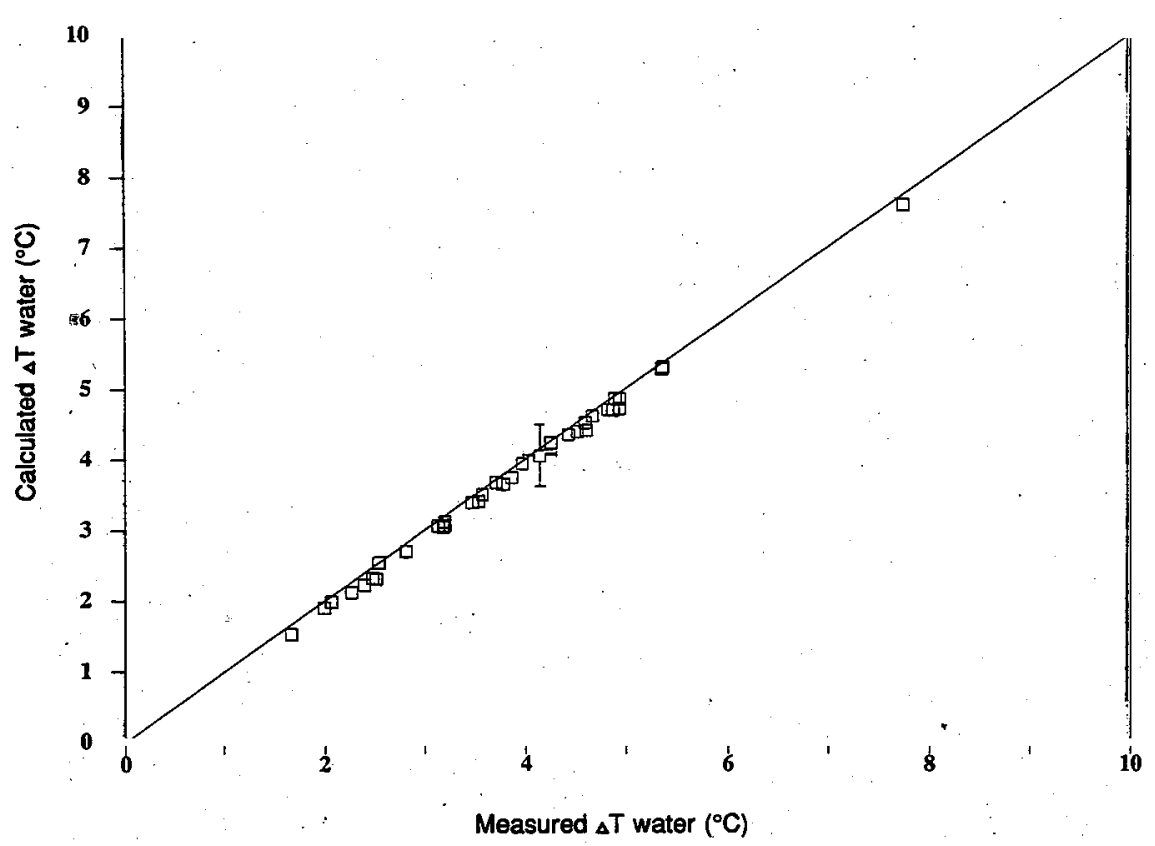

Figure 6-3. Measurement consistency of calculated absolute temperature difference and measured differential temperature

\subsection{RESULTS AND DISCUSSION}

\subsubsection{Heat and Mass Balance}

Necessary equations for the heat and mass balances were discussed in the previous section. The procedure is summarized below.

\section{Main Condenser}

- Determine water-side heat balance, using absolute temperature (average of two sensors at inlet and outlet) measurements.

- Determine steam-side heat balance, using experimentally measured rate of condensation.

- Compare with evaporator heat balance, using absolute temperature measurements.

Vent Condenser

- Determine refrigerant-side heat balance.

- Determine steam-side heat balance.

Because the rate of condensation was not measured accurately, the steam-side heat balance was determined from an alternative method for the second item above. The revised method, used inlet and outlet steam saturation temperatures, provided accurate mass flow rate for noncondensable gases was known.

Figure 6-4 compares the water- and steam-side heat balances. The two methods of calculating the rate of heat transfer agreed within about $5 \%$ for most test runs. In conclusion, the heat balance for the main condenser was within instrument measurement errors. Figure 6-5 compares the heat released from the 
Figure 6-4.

Consistency of the main condenser heat balance ${ }^{1}$

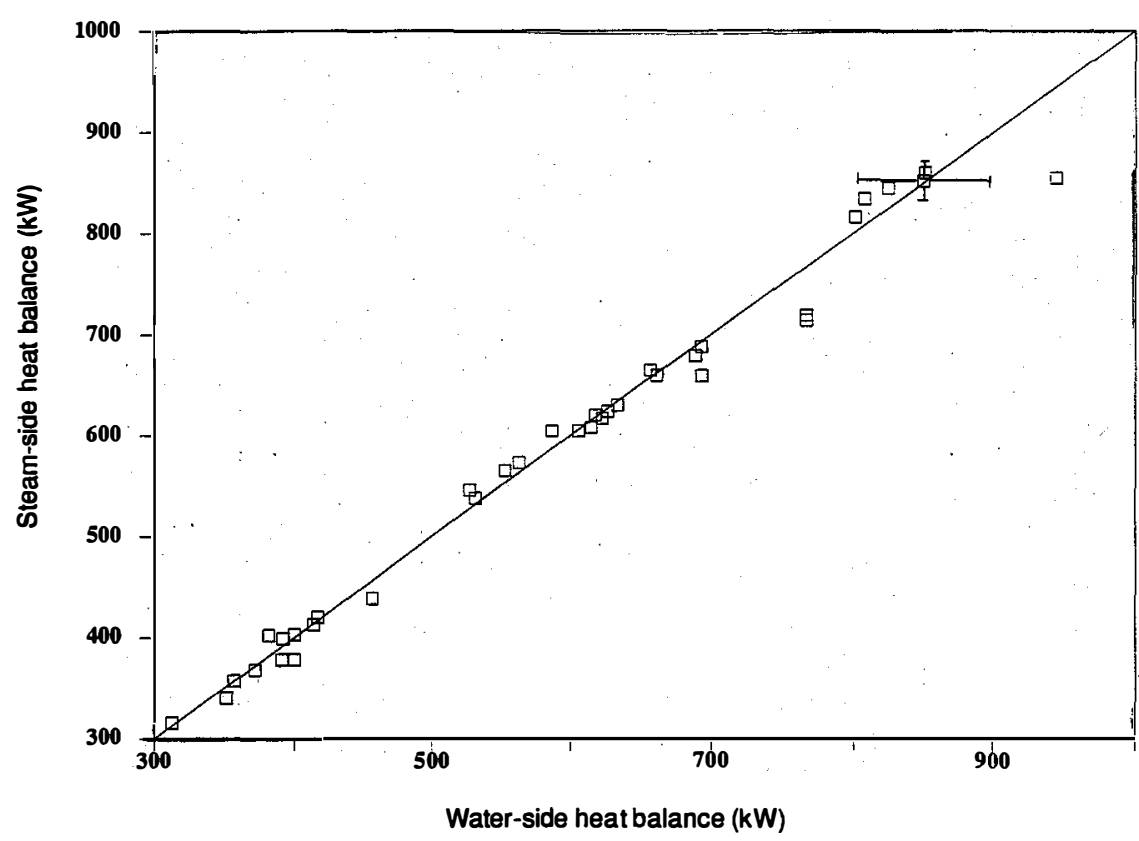

evaporator per unit time with the total absorbed by both condensers. In general, about $1 \%$ of steam is exhausted by the vacuum pump, and it 1 s not included in Figure 6-5. Note that the calculated heat-transfer rate in the condenser was consistently higher than that in the evaporator. It can be argued that the condenser system gains some heat from the atmosphere. However, during the initial tests, refrigerant temperature was kept relatively low, approximately $-10^{\circ} \mathrm{C}$. As a result, condensate in the vent condenser was being frozen during a test run, resulting in higher values for the refrigerant heat balance. In later tests the problem was corrected and the agreement improved (Figure 6-5).

It was not possible to cross check the heat balance for the vent condenser primarily because of the difficulties in maintaining a constant flow of refrigerant to this unit, as described in Section 2.4.2. Thus, an unknown level of uncertainty was introduced for calculation of the steam mass flow at the inlet of the second stage. The steam flow rate calculated using the evaporator and main condenser heat balances gave a large error because less than $10 \%$ of steam generated in the evaporator and not condensed in the main (first-stage) condenser flowed to the vent (second-stage) condenser. The inlet steam flow for the vent condenser is calculated using the outlet steam partial pressure (through measured dewpoint), the gas flow rate, and the rate of condensation calculated using the $\mathrm{R}-12$ heat balance. This method gave consistent results. Moreover, the calculated inlet saturation temperature agreed with the measured wet-bulb temperature at the main condenser outlet within an average of about $0.5^{\circ} \mathrm{C}$, as shown in Figure 6-6. These measurements were taken during vent-condenser experiments. The wet-bulb temperature measurement was higher than were the values, partly because of the 

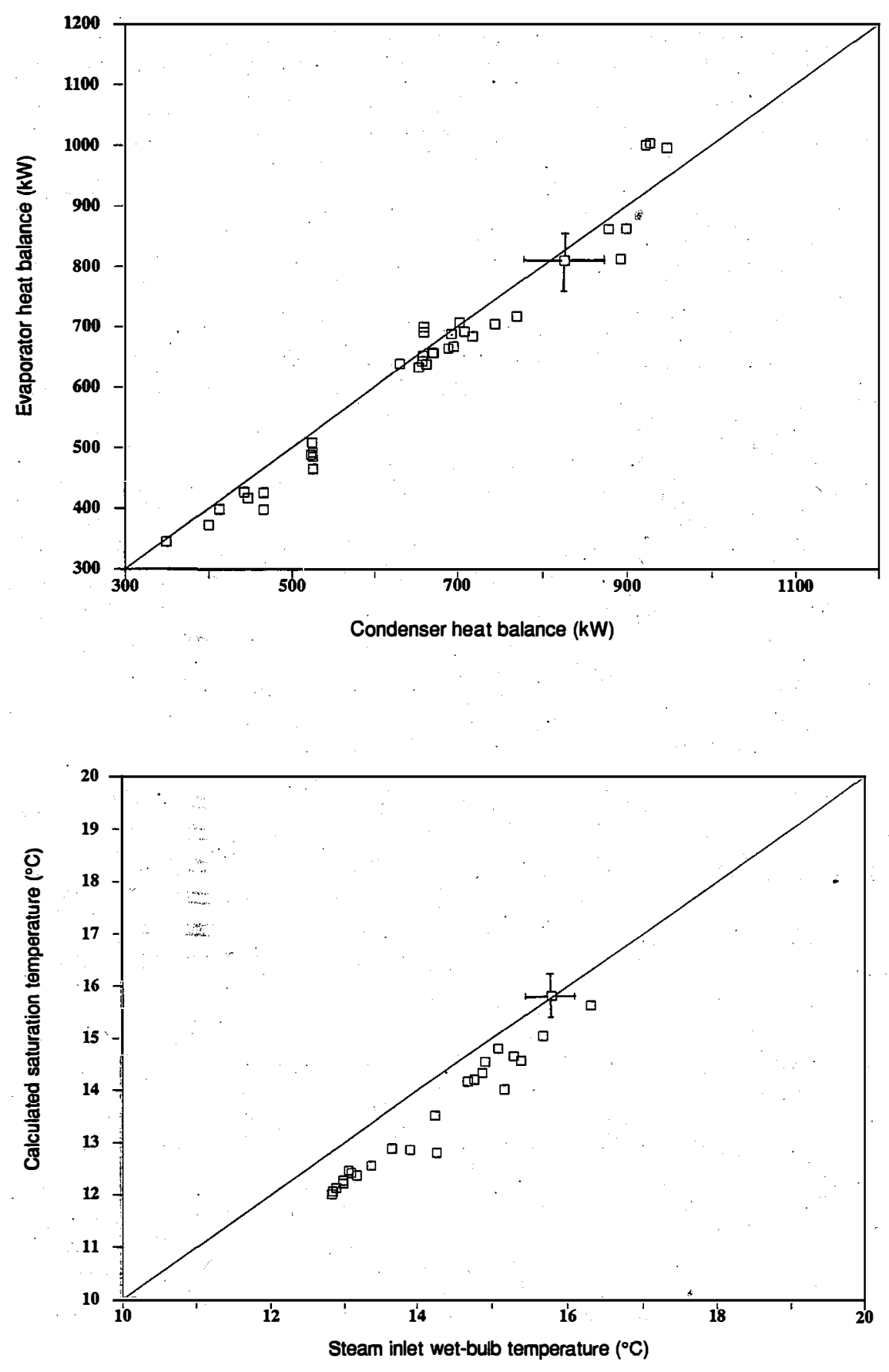

Figure 6-5. Comparison of evaporator and total (main + vent) condenser heat balances
Figure 6-6. Consistency of steam saturation temperature at the vent condenser inlet

steam-side pressure drop between the main condenser and vent condenser (i.e., outlet manifolding of the main condenser). The results in Figure 6-6 show that the saturation steam temperature calculated using the method described above is within the expected range of uncertainty of $\pm 0.2^{\circ}$ to $\pm 0.3^{\circ} \mathrm{C}$. 
Because of the problem discussed above, the mass balance for steam cannot be checked by direct measurements. However, a good agreement between the waterand steam-side heat balances for the main condenser, and acceptable heat balance for the total system, indicate that the overall steam balance should be acceptable for the data analysis. The flow rate of the noncondensable gases (separate from the quantity of uncondensed steam) was not measured directly. The following three methods can be used to calculate the total gas flow rate.

\section{Using vacuum pump capacity:}

The total noncondensable gas flow rate (that released from warm water plus air in-leakage) can be calculated using vent outlet dewpoint (saturation) temperature, pressure at inlet to vacuum pump, and volumetric flow capacity of vacuum pump. Assuming 100\% release of gases (nitrogen and oxygen) from the warm water, the air in-leakage is calculated by taking the difference. This assumed release is within the error band of the measured release described in Chapter 5. A constant pump capacity of $0.39 \mathrm{~m}^{3}$ ( 830 ACFM) was used for surface-condenser data analysis. Later, the volumetric flow capacity was determined as a function of inlet pressure. However, for surface-condenser experiments, the pressure to the inlet of the vacuum pump did not change significantly, and no pressure correction was used.

2. Using warm-water gas-release data and static air in-leakage:

In this method, the gas flow rate can be calculated using the rate at which gas is released from the warm water or assuming $100 \%$ gas release, and by determining the air in-leakage under static conditions, as described in Chapter 2, Section 2.3.8.

3. Using dewpoint (saturation) temperatures and rate of condensation for vent condenser:

By using the inlet and outlet steam saturation temperatures and the rate of condensation for the vent condenser, it is possible to calculate the gas flow rate. As was mentioned above, the rate of condensation was not directly measured, and dewpoints at both inlet and outlet of the vent condenser were not available for all test runs. Therefore, this method was not used in the data analysis.

In general, the rate of gas flow calculated by the first method was higher than that calculated by the second. It varied between $10 \%$ and $70 \%$ depending upon warm water flow rate, system pressure, and whether the vent condenser was used; no systematic trend was found. In the surface condenser analysis, method 1 was used to calculate the total gas flow rate. The uncertainty in the gas flow rate has an effect on the outlet saturation temperature for the main condenser that is of the same order as the error on dewpoint measurement.

\subsubsection{Overall Performance of Main Condenser}

Table 6-4 shows the results of three sets of experiments in which the water flow rate was varied. The second set is a repeat of the first with a lower fraction of steam condensed. It was difficult to maintain the same fraction of steam condensed, because the water flow rate was varied. The results show 
$\mathrm{TP}-3561$

Table 6-4. Test Results for Wilson Plot Analysis

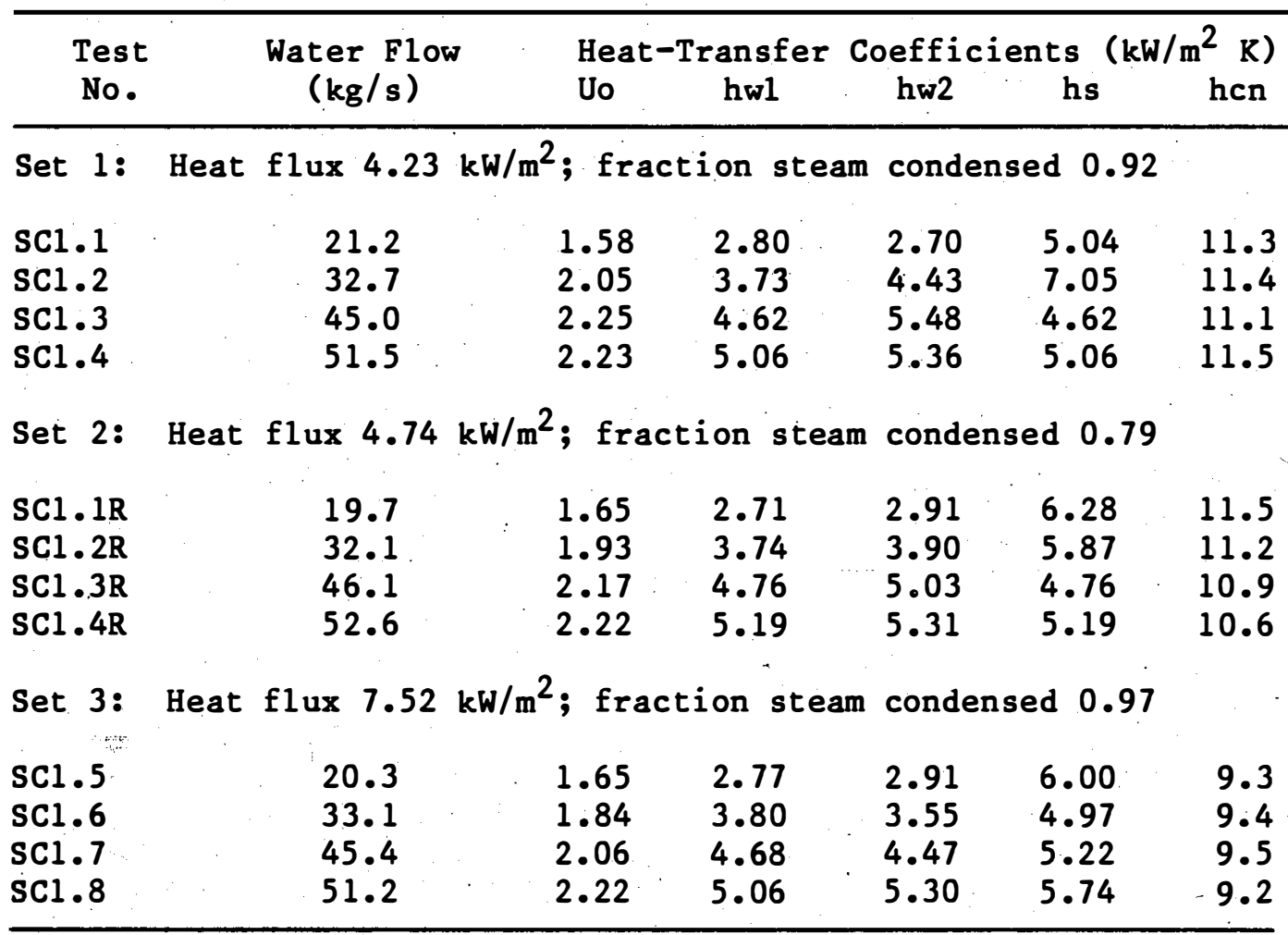

that the effective steam-side heat-transfer coefficient remained similar for a given series of tests. The data are shown in the form of a Wilson plot in Figure 6-7. The water-side coefficient was calculated using the Wilson plot analysis for these data and is shown in Table 6-4. For sets 1, 2, and 3, the agreements between the calculated values of hwl, calculated using Eq. 6-4, and hw2, calculated using the present data, were about $12 \%, 5 \%$, and $5 \%$, respectively. The difference is larger for set 1 than for the other two sets. That can be explained on the basis of the Wilson plot data shown in Figure 6-7. The data for set 1 (squares) do not follow the linear correlation, indicating that the steam-side coefficient did not remain constant when the water flow rate was varied.

The results of these three sets of experiments suggest that the water-side coefficient calculated using the correlation of Eq. 6-5 is acceptable with an uncertainty in the range of $5 \%$ to $10 \%$. As was mentioned earlier, the effective steam-side coefficient is calculated by subtracting the water-side and wall resistances.

\subsubsection{Comparison of Steam-Side Coefficient with Nusselt's Prediction}

To determine the overall effects of noncondensable gases, the effective steamside coefficient is compared with the condensate coefficient calculated using the Nusselt prediction method. The results in Table 6-4 show that the masstransfer resistance reduced the average steam-side coefficient to about 0.42 to 0.65 of the Nusselt predictions for the three sets of experiments used for 


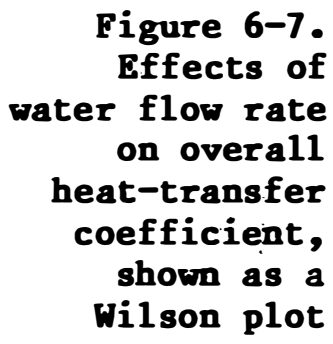

Figure 6-7.

overall

heat-transfer

shown as a

Wilson plot

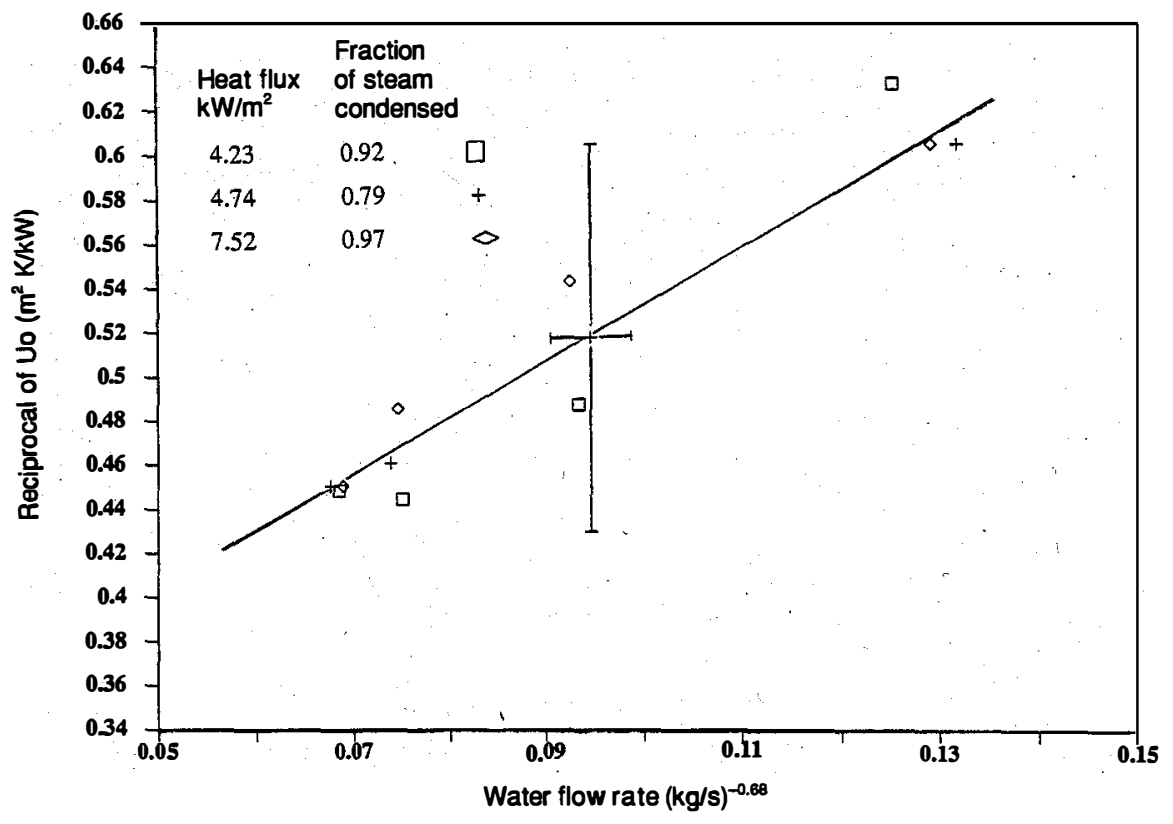

the Wilson-plot analysis. For a fraction of steam condensed less than 0.85 , assumption of an infinite mass-transfer coefficient would give a somewhat high rate of condensation, but the calculation for the condenser area could be within design uncertainties. It should be noted, however, that a large fraction of steam leaves the condenser when less than 0.8 of incoming steam is condensed in the main condenser. Therefore, a uniformly distributed vent system like the one used for this experiment should be designed.

The current test unit has parallel plates; therefore, the overall performance is relatively low. The open-cycle surface condenser will have to be designed for enhancement (area and/or heat transfer) on both sides. Current data for the steam-side coefficient should not be used for finned or some other kind of enhanced surfaces. It can be shown that the effective fin efficiency for the condensation process could be significantly low as a result of variation in the effective heat-transfer coefficient along the fin surface. The effects of steam-side enhancement (axial or spiral grooves) have not been studied for condensation in the presence of noncondensable gases.

\subsubsection{Effects of Fraction of Steam Condensed}

As the fraction of incoming steam condensed in the main condenser is increased, the effects of noncondensable gases should become significant. Table 6-5 shows how the inlet pressure into the condenser increases with increased fraction of steam condensed for three water flow rates. The corresponding decrease in the effective steam-side coefficient is shown in Figure 6-8. Note that for the highest fraction of steam condensed, the vent condenser was inactivated by turning off $R-12$ flow.

The condenser backpressure increased rapidly as the fraction of incoming steam condensed was increased above about 0.85 (Table 6-5.) The effective steamside coefficient dropped sharply for a high fraction of steam condensed in the main condenser. The water flow rate seems to have had a relatively small effect on the test results; three sets of data presented in Figure 6-8 show comparable steam-side behavior. 
Table 6-5. Effects of Fraction of Steam Condensed

\begin{tabular}{|c|c|c|c|c|c|c|c|}
\hline $\begin{array}{l}\text { Test } \\
\text { No. }\end{array}$ & $\begin{array}{l}\text { Heat } \\
Q_{e}\end{array}$ & $\begin{array}{c}\text { Balance } \\
Q_{C}\end{array}$ & $Q_{r}^{k W}$ & $\begin{array}{l}\text { Fraction } \\
\text { Steam } \\
\text { Condensed }\end{array}$ & $\begin{array}{l}\text { Steam Inlet } \\
\text { Pressure } \\
(\mathrm{kPa})\end{array}$ & $\begin{array}{c}\text { Uo } \\
\left(\mathrm{kW} /{ }^{2} \mathrm{~K}\right)\end{array}$ & $\begin{array}{c}\mathrm{hs} \\
\left(\mathrm{kW} / \mathrm{m}^{2} \mathrm{k}\right)\end{array}$ \\
\hline Set 1: & \multicolumn{7}{|c|}{ Water flow $44 \mathrm{~kg} / \mathrm{s}$} \\
\hline $\begin{array}{l}S C 2.1 R \\
S C 2.2 R \\
S C 2.3 R \\
S C 2.4 R\end{array}$ & $\begin{array}{l}683 \\
690 \\
699 \\
687\end{array}$ & $\begin{array}{l}532 \\
553 \\
606 \\
693\end{array}$ & $\begin{array}{r}185 \\
107 \\
54 \\
2\end{array}$ & $\begin{array}{l}0.74 \\
0.83 \\
0.91 \\
0.98\end{array}$ & $\begin{array}{l}1.53 \\
1.56 \\
1.63 \\
2.06\end{array}$ & $\begin{array}{l}2.23 \\
2.12 \\
2.00 \\
1.30\end{array}$ & $\begin{array}{l}6.53 \\
5.60 \\
4.78 \\
2.10\end{array}$ \\
\hline Set 2: & \multicolumn{7}{|c|}{ Water flow $32 \mathrm{~kg} / \mathrm{s}$} \\
\hline $\begin{array}{l}S C 2.5 R \\
S C 2.6 R \\
S C 2.7 R \\
S C 2.8 R\end{array}$ & $\begin{array}{l}727 \\
723 \\
723 \\
734\end{array}$ & $\begin{array}{l}533 \\
563 \\
588 \\
683\end{array}$ & $\begin{array}{r}144 \\
107 \\
70 \\
2\end{array}$ & $\begin{array}{l}0.78 \\
0.85 \\
0.88 \\
0.98\end{array}$ & $\begin{array}{l}1.63 \\
1.68 \\
1.74 \\
2.15\end{array}$ & $\begin{array}{l}1.65 \\
1.87 \\
1.79 \\
1.25\end{array}$ & $\begin{array}{l}5.83 \\
5.24 \\
4.60 \\
2.16\end{array}$ \\
\hline Set 3: & \multicolumn{7}{|c|}{ Water flow $55 \mathrm{~kg} / \mathrm{s}$} \\
\hline $\begin{array}{l}\text { sc2.9 } \\
\text { sc2. } 10 \\
\text { sc2.11 }\end{array}$ & $\begin{array}{r}1000 \\
1003 \\
995\end{array}$ & $\begin{array}{l}767 \\
808 \\
945\end{array}$ & $\begin{array}{r}155 \\
119 \\
2\end{array}$ & $\begin{array}{l}0.83 \\
0.87 \\
0.98\end{array}$ & $\begin{array}{l}1.65 \\
1.73 \\
2.26\end{array}$ & $\begin{array}{l}2.38 \\
2.24 \\
1.52\end{array}$ & $\begin{array}{l}6.44 \\
5.52 \\
2.53\end{array}$ \\
\hline
\end{tabular}

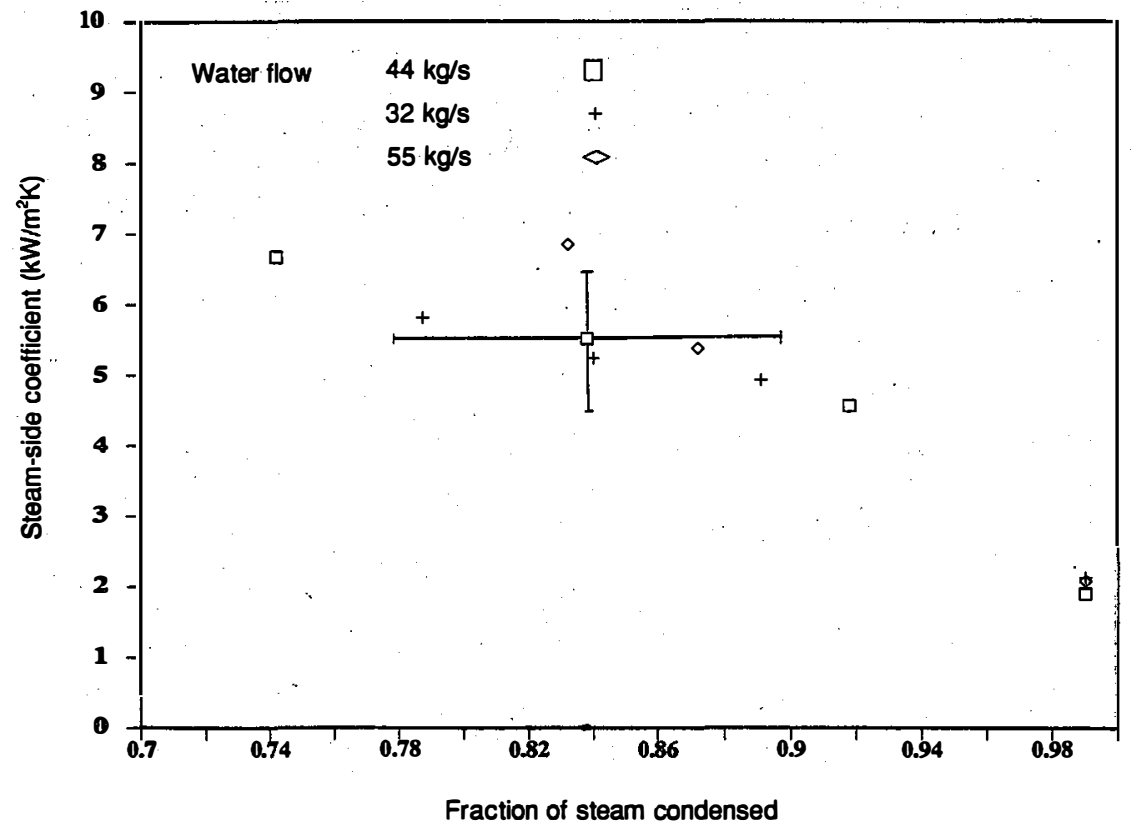

Figure 6-8. Effective steam-side coefficient as a function of fraction of steam condensed in main condenser 
This series of tests demonstrated that the current test unit, with no enhancement and no cross-flow configuration, should not be operated for a fraction of steam condensed greater than about 0.8 to maintain an appropriate open-cycle condenser pressure. The inlet cold-water temperature for these tests was about $8.5^{\circ} \mathrm{C}$. Therefore, necessary corrections should be made before applying the test data directly to the NPPE, where the nominal inlet cold-seawater temperature is expected to be $6.1^{\circ} \mathrm{C}$.

\subsubsection{Effects of Inlet Gas Concentration}

The nominal inlet gas concentration in the open-cycle power system is expected to be in the range of $0.3 \%$ to $0.5 \%$ by weight. However, in these experiments, the inlet gas concentrations were mostly higher than normal, perhaps because of air in-leakage. This series of tests shows the effects of inlet gas concentration on the main performance. Table 6-6 summarizes the test results, and the steam-side effective heat-transfer coefficient is plotted as a function of inlet gas concentration in Figure 6-9.

The last two columns of Table 6-6 show the effective steam-side coefficient and the average coefficient predicted by the Nusselt analysis assuming condensation of pure steam. As discussed earlier, the difference in these two sets of values represents the effects of mass-transfer resistance. The results show that the effective steam-side coefficient drops sharply for inlet

Table 6-6. Effects of Inlet Gas Concentration

\begin{tabular}{|c|c|c|c|c|c|c|c|}
\hline $\begin{array}{l}\text { Test } \\
\text { No. }\end{array}$ & \multicolumn{2}{|c|}{$\begin{array}{c}\text { Gas Concentration } \\
\text { Inlet Outlet } \\
\text { ( } \% \text { by wt) }\end{array}$} & \multicolumn{2}{|c|}{$\begin{array}{l}\text { Saturation } \\
\text { Temperature }\end{array}$} & \multicolumn{3}{|c|}{$\begin{array}{l}\text { Heat-Transfer Coefficient } \\
\qquad\left(\mathrm{kW} / \mathrm{m}^{2} \mathrm{~K}\right)\end{array}$} \\
\hline et 1 : & \multicolumn{7}{|c|}{ Water flow rate $45 \mathrm{~kg} / \mathrm{s}$; heat flux $10 \mathrm{~kW} / \mathrm{m}^{2}$; fraction 0.95} \\
\hline $\begin{array}{l}\mathrm{SC} 3.1 \\
\operatorname{sC} 3.2 \\
\operatorname{sC} 3.3 \\
\operatorname{sC} 3.4\end{array}$ & $\begin{array}{l}0.55 \\
0.47 \\
0.32 \\
0.21\end{array}$ & $\begin{array}{l}7.09 \\
6.85 \\
7.96 \\
5.46\end{array}$ & $\begin{array}{l}15.88 \\
16.45 \\
15.73 \\
14.71\end{array}$ & $\begin{array}{l}15.31 \\
15.87 \\
15.02 \\
14.26\end{array}$ & $\begin{array}{l}1.85 \\
1.81 \\
2.11 \\
2.22\end{array}$ & $\begin{array}{l}4.02 \\
3.89 \\
5.44 \\
6.28\end{array}$ & $\begin{array}{l}8.7 \\
8.7 \\
8.6 \\
8.8\end{array}$ \\
\hline et 2: & \multicolumn{7}{|c|}{ Water flow rate $45 \mathrm{~kg} / \mathrm{s}$; heat flux $5 \mathrm{~kW} / \mathrm{m}^{2}$; fraction 0.89} \\
\hline $\begin{array}{l}\operatorname{sc} 3.5 \\
\operatorname{sc} 3.6 \\
\operatorname{sc} 3.7 \\
\operatorname{sc} 3.8\end{array}$ & $\begin{array}{l}1.37 \\
0.88 \\
0.66 \\
0.56\end{array}$ & $\begin{array}{l}9.13 \\
9.95 \\
5.29 \\
4.53\end{array}$ & $\begin{array}{l}12.28 \\
11.79 \\
11.42 \\
11.34\end{array}$ & $\begin{array}{l}11.54 \\
10.91 \\
11.01 \\
11.00\end{array}$ & $\begin{array}{l}1.58 \\
1.67 \\
1.82 \\
2.01\end{array}$ & $\begin{array}{l}2.98 \\
3.31 \\
3.95 \\
4.97\end{array}$ & $\begin{array}{l}11.0 \\
11.2 \\
10.6 \\
10.9\end{array}$ \\
\hline et 3 : & \multicolumn{7}{|c|}{ Water flow rate $44 \mathrm{~kg} / \mathrm{s}$; heat flux $5 \mathrm{~kW} / \mathrm{m}^{2}$; fraction 0.86} \\
\hline $\begin{array}{l}\text { SC3.5R } \\
\text { SC3.6R } \\
\text { SC3.7R } \\
\text { SC3.8R }\end{array}$ & $\begin{array}{l}1.02 \\
0.71 \\
0.57 \\
0.47\end{array}$ & $\begin{array}{l}6.94 \\
5.34 \\
4.12 \\
3.02\end{array}$ & $\begin{array}{l}12.74 \\
12.39 \\
12.33 \\
12.10\end{array}$ & $\begin{array}{l}12.30 \\
12.08 \\
12.18 \\
12.01\end{array}$ & $\begin{array}{l}1.70 \\
1.82 \\
1.86 \\
1.99\end{array}$ & $\begin{array}{l}3.43 \\
3.94 \\
4.09 \\
4.84\end{array}$ & $\begin{array}{l}11.3 \\
10.9 \\
11.0 \\
10.5\end{array}$ \\
\hline
\end{tabular}




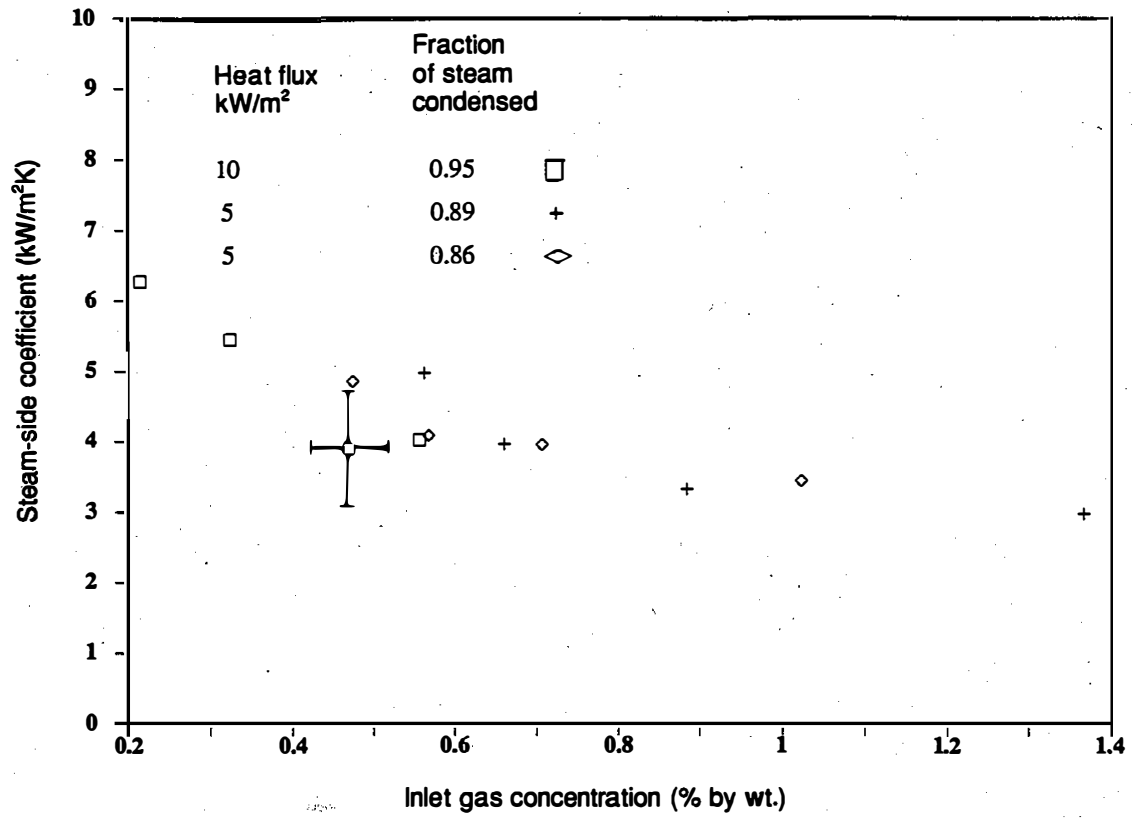

Figure 6-9. Effective steam-side coefficient as. a function of inlet gas concentration in main condenser

gas concentration greater than 0.2 by weight. Therefore, the fraction of steam condensed in the main condenser should be kept low--even at low inlet gas concentration--to design the condenser using the Nusselt prediction method. In addition, the vent system should be similar to that in the present design to allow for uniform exiting of the remaining steam and gas mixture.

\subsubsection{Comparison with Predictions}

In general, the open-cycle surface condenser will be designed by integrating the local heat- and mass-balance equations for a given set of geometry parameters of the condenser. Therefore, comparison of the experimental rate of condensation and outlet conditions with theoretical predictions-including axial variations-is an important step. It was mentioned earlier that the rate of condensation for the main unit was measured at three axial points; and outlet conditions, i.e., pressure and temperature, were also measured. The experimentally measured parameters were directly compared with the theoretical predictions. The analysis used to predict the surface condenser's performance was described earlier.

\subsubsection{Detailed Analysis of Two Test Runs}

To understand the theoretical analysis, the results for two test runs, including predicted temperature and local heat-flux profiles, are discussed in detail. Figure 6-10 shows inlet/outlet conditions and predicted parameters for test runs $\mathrm{SCl} .5$ and $\mathrm{SCl} .8$, which had 1 ow and high water flow rates. Note that the total and local rates of condensation were measured separately; therefore, they may or may not agree. Analysis predicted $2 \%$ and $5 \%$ higher rates of condensation, respectively. The local rates of condensation from three sections were predicted within acceptable uncertainties. The predicted rate of condensation for the cold-end section was $8 \%$ to $10 \%$ higher than were 


\section{Test Run SC1.5}

Water Flow: $20.3 \mathrm{~kg} / \mathrm{s}$

Steam Temperature: $16.9^{\circ} \mathrm{C}$

Water Inlet

\begin{tabular}{l|rrrr|r}
7.33 & 10.72 & 12.94 & 14.33 & 15.28 & 15.61 \\
7.33 & 10.44 & 12.56 & 14.00 & 15.00 & 15.33 \\
7.33 & 10.06 & 12.00 & 13.67 & 14.72 & 15.11 \\
7.33 & 9.44 & 11.28 & 12.78 & 13.94 & 14.39
\end{tabular}

Test Run SC1.8

Water Flow: $51.2 \mathrm{~kg} / \mathrm{s}$

Steam Temperature: $12.7^{\circ} \mathrm{C}$

Water Inlet

\begin{tabular}{l|llll|r}
7.17 & 8.44 & 9.39 & 10.17 & 10.72 & 11.00 \\
7.17 & 8.22 & 9.11 & 9.83 & 10.44 & 10.67 \\
7.17 & 8.11 & 8.89 & 9.56 & 10.11 & 10.39 \\
7.17 & 7.78 & 8.39 & 8.94 & 9.44 & 9.67
\end{tabular}

\begin{tabular}{llccccc}
\hline $\begin{array}{c}\text { Rate of } \\
\begin{array}{c}\text { Condensation } \\
(\mathbf{m L} / \mathbf{s})\end{array}\end{array}$ & $\begin{array}{c}\text { Cold } \\
\text { End }\end{array}$ & $\begin{array}{c}\text { Mid- } \\
\text { Section }\end{array}$ & $\begin{array}{c}\text { Warm } \\
\text { End }\end{array}$ & $\begin{array}{c}\text { Cold } \\
\text { End }\end{array}$ & $\begin{array}{c}\text { Mid- } \\
\text { Sectlon }\end{array}$ & $\begin{array}{c}\text { Warm } \\
\text { End }\end{array}$ \\
\hline Local & & & & & & \\
Experimental & 116 & 87 & 50 & 104 & 88 & 63 \\
Predicted & 129 & 80 & 47 & 112 & 87 & 67 \\
Total & & & & & & \\
Experimental & 253 & & & 252 & \\
Predicted & 256 & & & 266 & \\
\hline
\end{tabular}

Figure 6-10. Water temperature profiles for the main condenser 
the experimentally measured values. The rates of condensation for the other two sections were predicted within $5 \%$. Note that the rate of condensation for the cold end for test run $\mathrm{SCl} .5$ was about 2.7 times that for the warm end; this is because of the larger change in the cold water temperature than that for test run $\mathrm{SCl} .8$, for which the value is about 1.7 .

Figure 6-10 shows the distribution of water temperature for the two test runs discussed above in the form of tabulated numbers. The results clearly indicate the spatial variation of the water temperature and steam-side conditions. Therefore, a two-dimensional integration must be carried out to obtain an accurate calculation of the axial rate of condensation and the effects of uniform vs. nonuniform venting systems. Note that the coolant temperature shows a gradient at the outlet, which makes the cross flow less efficient than the countercurrent flow in terms of thermal effectiveness and proper use of cold water. A multipass condenser generally corrects this problem.

Figure 6-11 shows the distribution of the heat-flux ratio, which is defined as the ratio of actual heat flux to that with an infinite mass-transfer coefficient. It implies that the interface temperature is the same as the bulk saturation temperature. The ratio represents a quantitative parameter for reduction in the temperature driving force caused by mass-transfer resistance. A very low value of this ratio in a specified region of the condenser indicates that noncondensable gases have built up as a result of low steam flow caused by improper venting or inlet steam distribution. Again, the multipass condenser should facilitate uniform inlet steam distribution and minimize possible buildup of noncondensable gases. In the main condenser, the heat-flux ratio is high if the fraction of incoming gas is kept low. However, it is essential to predict the performance by integrating the heat- and mass-balance equation as discussed above. In that case uncertainty in the calculation of the mass-transfer coefficient would have an insignificant effect on the prediction of overall performance.

\subsubsection{Comparison of Rate of Condensation}

In Figure 6-12, the measured rate of condensation for all test runs is compared with predictions. In most cases the predicted rate of condensation was within about $5 \%$. In general, the rate was somewhat higher than that in the experimental results. It is difficult to determine the exact parameter that might give a higher predicted rate of condensation. Figure 6-12 includes results from all test runs, with wide variations in water flow, heat flux, steam pressure, and inlet saturation temperature. Other parameters, e.g., fraction of steam condensed, water inlet temperature, and inlet gas concentration, could not be varied over a wide range because of naturally limiting conditions.

Figures 6-13, 6-14, and 6-15 show the local rates of condensation for the cold end, midsection, and warm end of the condenser, respectively. Most data points lie within $5 \%$ uncertainty bands. In general, the predicted rate of condensation for the cold-end section was somewhat higher than were the experimentally measured values. The opposite is true for the midsection, while the warm-end section shows scatter of the data points on both sides of the curve. 
Test Run SC1.5

Water Flow: $20.3 \mathrm{~kg} / \mathrm{s}$

Steam Temperature: $16.9^{\circ} \mathrm{C}$

Water Inlet

\begin{tabular}{|lllll|}
\hline 0.99 & 0.99 & 0.99 & 0.99 & 0.99 \\
0.97 & 0.98 & 0.98 & 0.98 & 0.98 \\
0.92 & 0.94 & 0.96 & 0.97 & 0.97 \\
0.85 & 0.90 & 0.93 & 0.95 & 0.96 \\
0.70 & 0.77 & 0.83 & 0.87 & 0.91 \\
\hline
\end{tabular}

Test Run SC1.8

Water Flow: $51.2 \mathrm{~kg} / \mathrm{s}$

Steam Temperature: $12.7^{\circ} \mathrm{C}$

Water Inlet

\begin{tabular}{|lllll|}
\hline 0.98 & 0.98 & 0.98 & 0.98 & 0.98 \\
0.95 & 0.95 & 0.95 & 0.96 & 0.97 \\
0.88 & 0.90 & 0.92 & 0.93 & 0.94 \\
0.82 & 0.85 & 0.87 & 0.89 & 0.91 \\
0.64 & 0.68 & 0.71 & 0.75 & 0.78 \\
\hline
\end{tabular}

Figure 6-11. Profiles for the heat-flux ratio (actual to that assuming infinite mass-transfer coefficient) for the main condenser

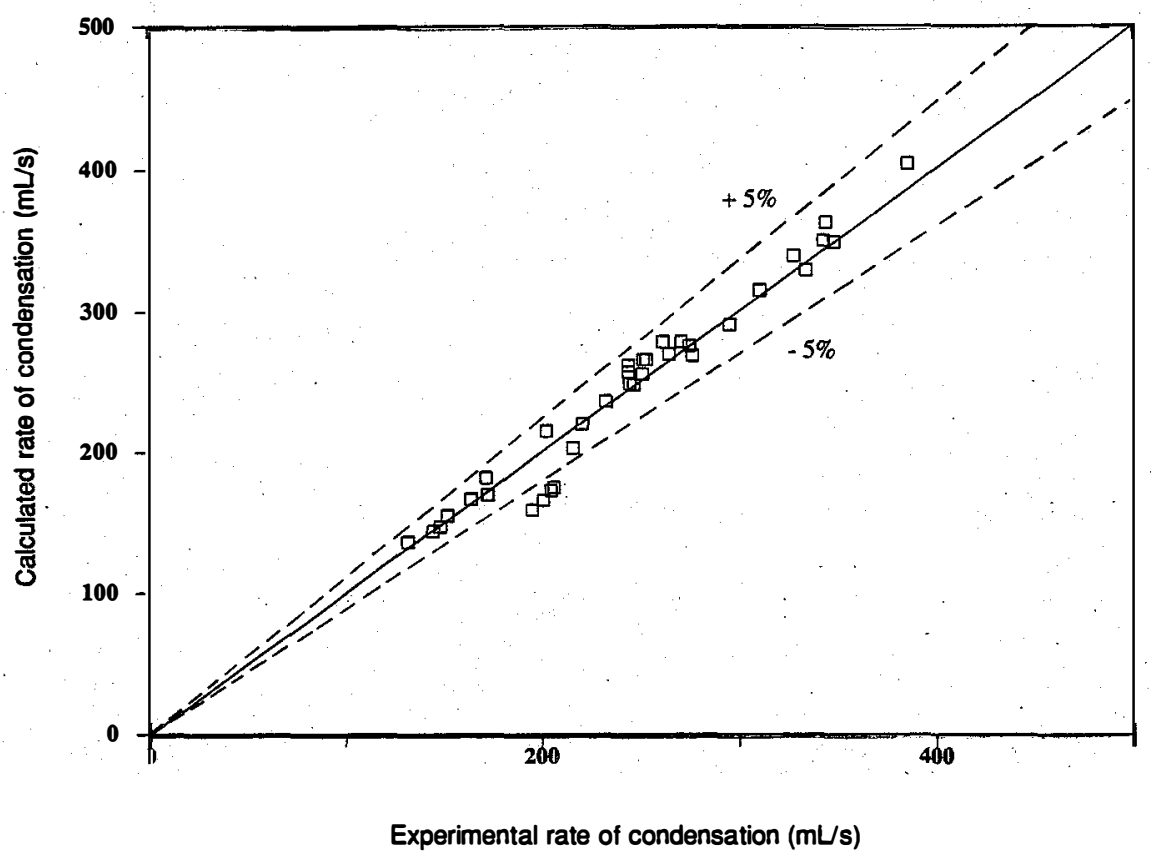

Figure 6-12. Comparison of calculated and experimentally measured total rates of condensation in main condenser 

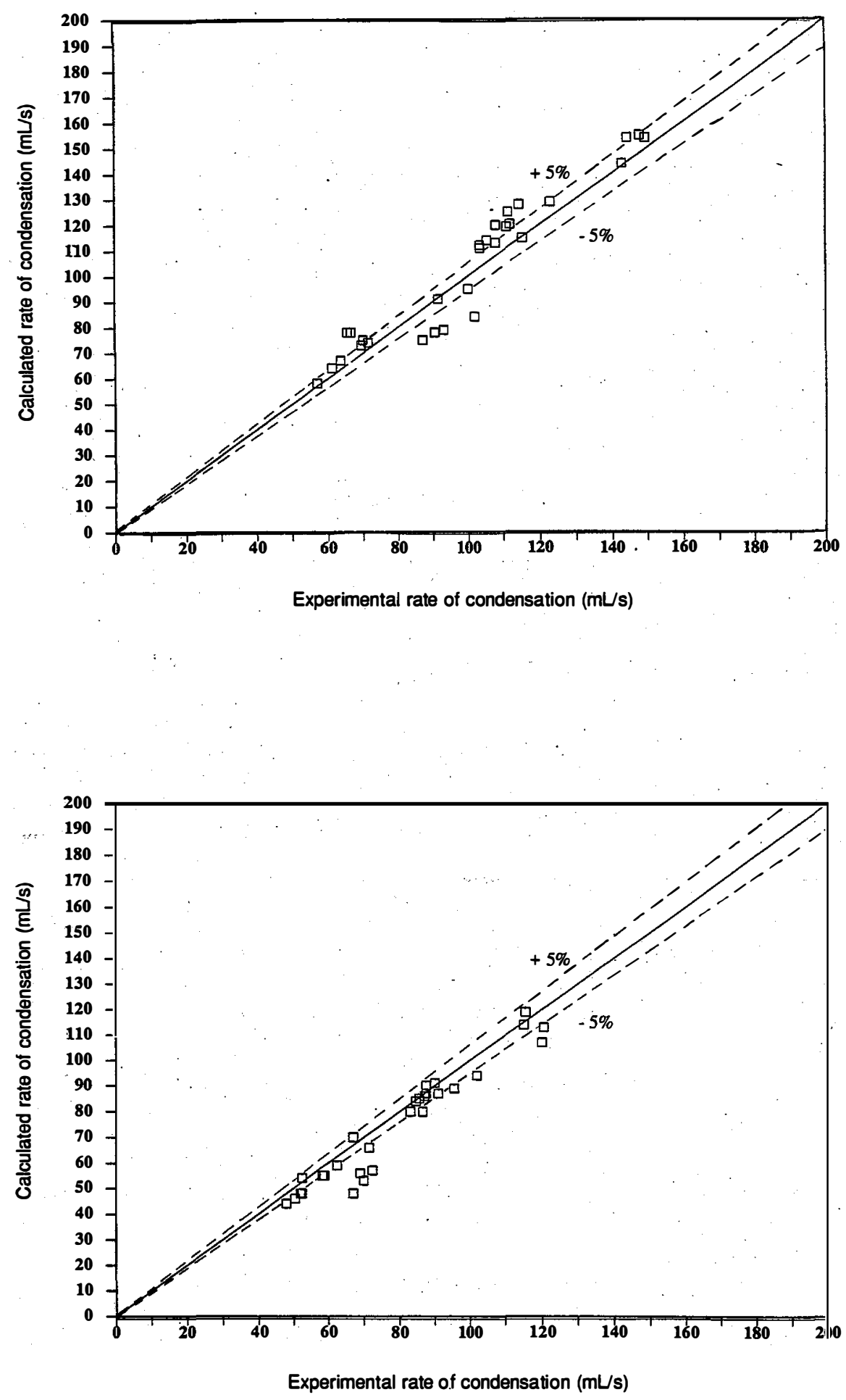

Figure 6-13. Comparison of calculated and experimentally measured rates of condensation for the cold-end section of main condenser
Figure 6-14. Comparison of calculated and experimentally measured rates of condensation for the mid-section of main condenser 
Figure 6-15. Comparison of calculated and experimentally measured rates of condensation for the warm-end section of main condenser

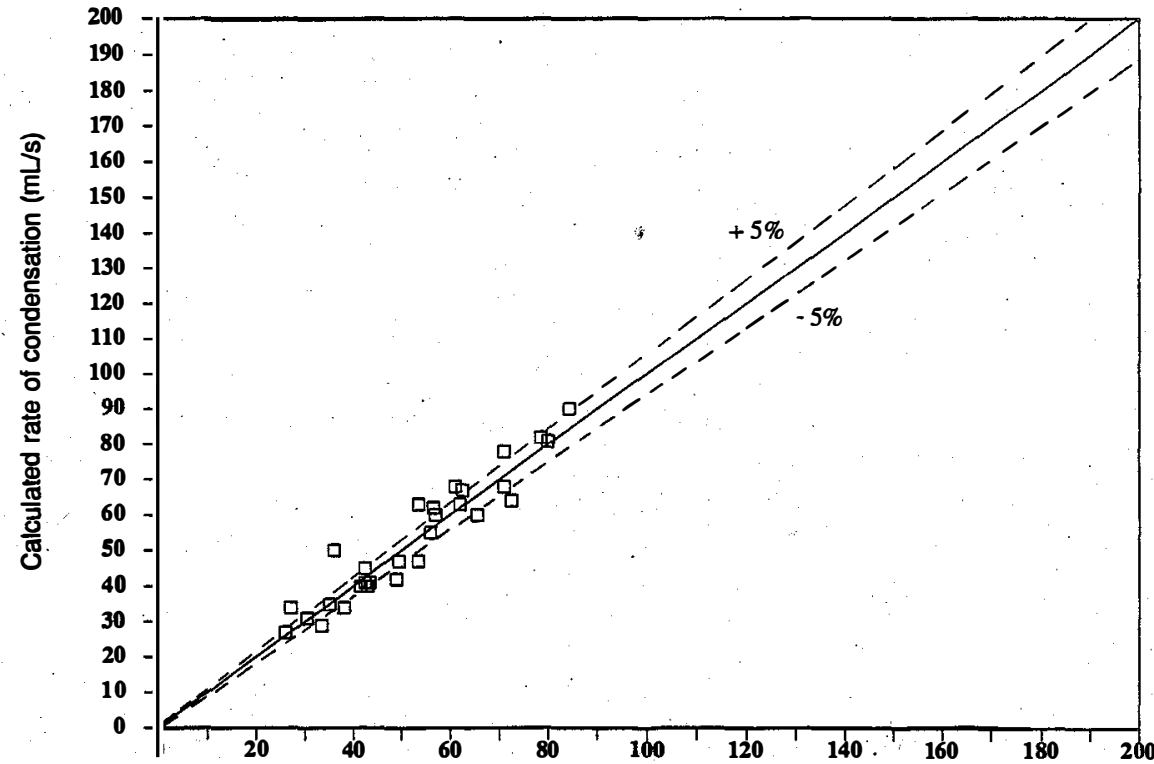

Experimental rate of condensation $(\mathrm{mL} / \mathrm{s}$ )

The key test of the analysis is whether it can predict the variation in the rate of condensation along the length of the condenser. The prediction is directly related to the method of calculating inlet steam distribution, taking into account the uniform venting system. A comparison of the rates of condensation for the three sections indicates that the analysis is able to predict the performance of the cross-flow condenser. However, the heattransfer surface of the present test unit is not enhanced, and the fraction of steam condensed was kept low. Therefore, the analysis cannot easily be extended to those conditions without further validation of the prediction methods. Nonetheless, the experimental data and the analysis provide key technical information that can be used for designing a prototypical surface condenser for the NPPE or another integrated open-cycle power system.

\subsubsection{Steam-Side Pressure Drop}

As was mentioned earlier, the steam-side pressure drop for the main condenser was small. Figure 6-16 shows data for all test runs and predicted values as a function of inlet steam mass flow rate. The experimental measurements indicated a slight gain in pressure (negative experimental pressure drop); however, although positive, the predicted pressure drop is relatively small and is within the uncertainty of the differential pressure measurement. For the purpose of practical design, the steam-side pressure drop for the main condenser can be neglected.

\subsubsection{Overall Performance of Vent Condenser}

The overall performance of the vent condenser is evaluated in terms of thermal effectiveness. In this approach, an average value of inlet and outlet saturation temperature for the refrigerant $\mathrm{R}-12$ is used. However, the outlet 


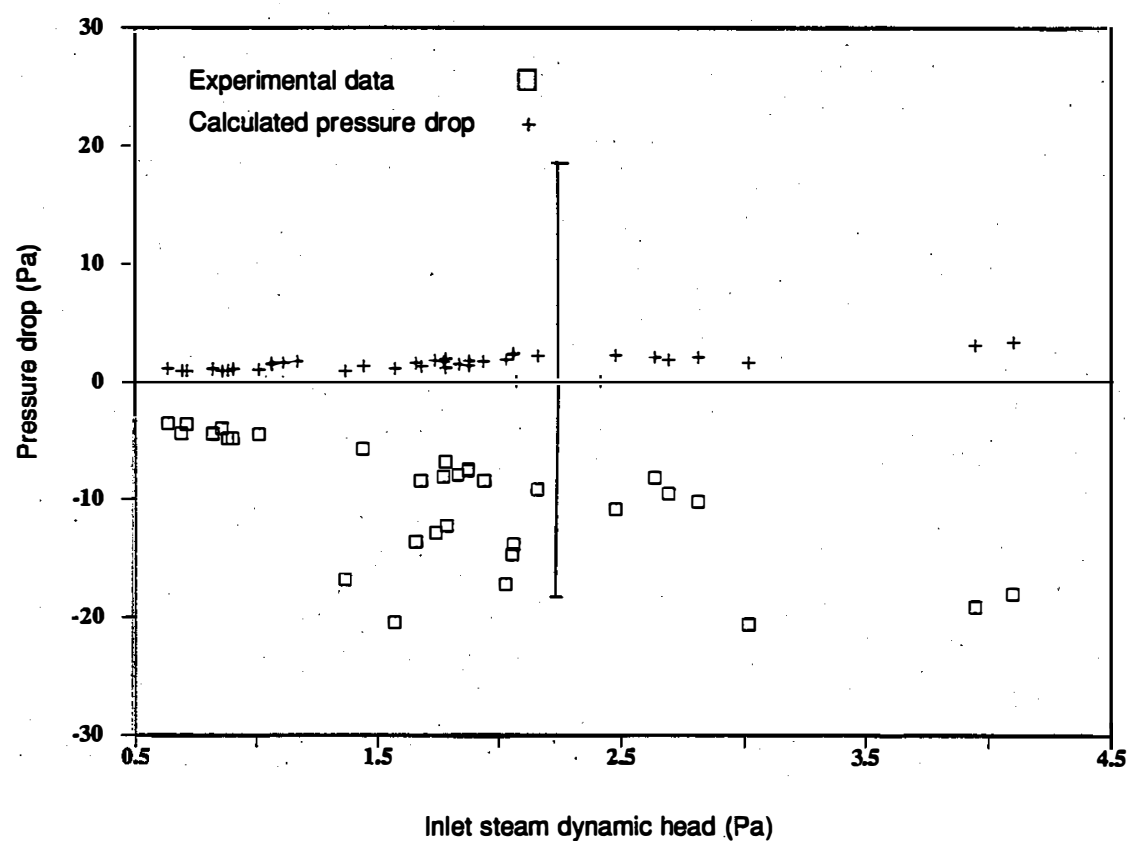

Figure 6-16. Comparison of calculated and experimentally measured steam-side pressure drop in main condenser

refrigerant vapor was superheated for most experiments. As a result, the thermal effectiveness was lower than researchers had originally predicted. The vapor superheat was calculated by taking the difference of refrigerant saturation temperature (calculated using measured pressure at the outlet) and out let vapor temperature. Figure 6-17 shows the effects of refrigerant vapor superheat on the thermal effectiveness. The test data points selected for this plot have other parameters (e.g., inlet and outlet saturations) that remained relatively constant. Table 6-7 summarizes the test conditions.

At vapor superheat below about $1^{\circ} \mathrm{C}$, thermal effectiveness was in the expected above about $5^{\circ} \mathrm{C}$. For most vent-condenser test runs, the vapor superheat was high. Therefore, the effects of test parameters on the performance cannot be quantitatively determined using the present set of data. Attempts were made to control the refrigerant conditions; however, it was difficult to control the vapor superheat with the present control system.

In general, the following observations should be considered regarding the vent experiments:

- For most test runs, the inlet dewpoint sensor did not function properly. As a result, the gas mass balance calculated using the vacuum pump capacity cannot be cross checked.

- The rate of condensation was not measured directly. Therefore, the rate of heat transfer, was based on heat balance on the refrigerant side.

- The condensation flowmeter for the main condenser was not functional during these tests, and strip-chart recorder output was used to calculate the overall steam mass balance. 


\section{Figure 6-17. Effects of refrigerant vapor superbeat on thermal effectiveness of vent condenser}

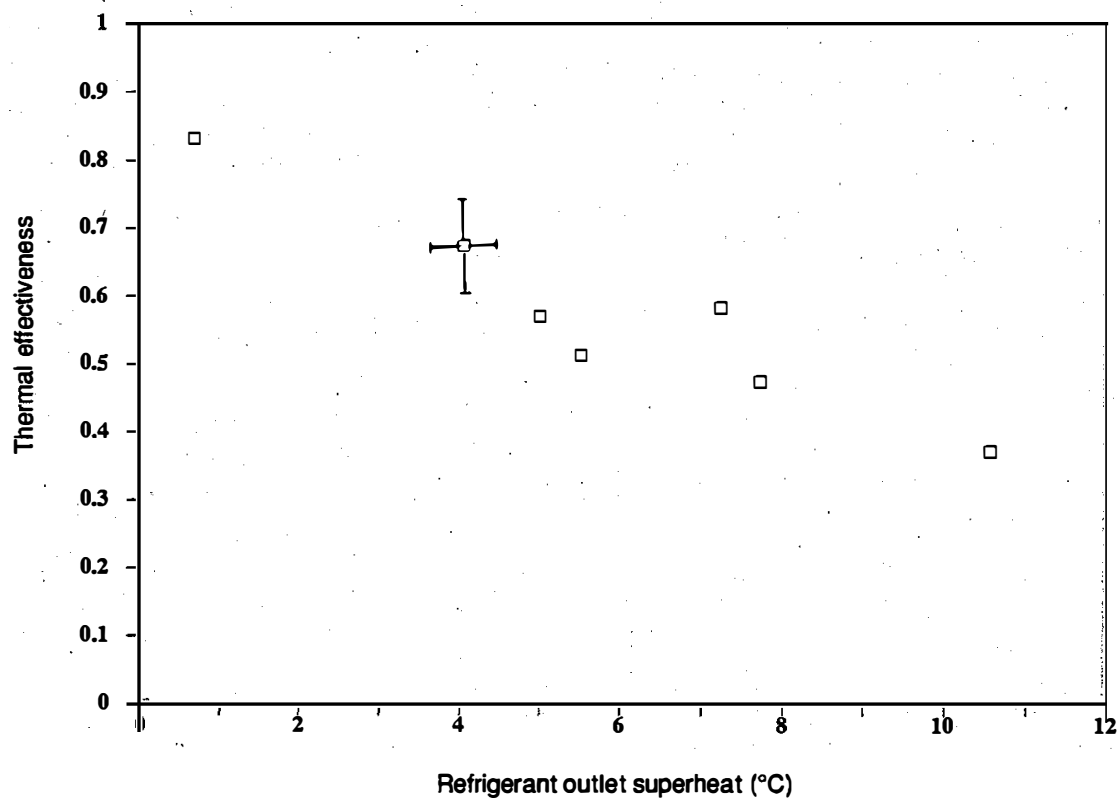

Table 6-7. Summary of Test Conditions to Evaluate Effects of Refrigerant Vapor Superheat

\begin{tabular}{lccccc}
\hline $\begin{array}{l}\text { Test } \\
\text { No. }\end{array}$ & $\begin{array}{c}\text { Refrigerant } \\
\text { Heat } \\
\text { Balance } \\
(\mathrm{kw})\end{array}$ & $\begin{array}{c}\text { Steam Saturation } \\
\text { Temperature } \\
\text { Inlet }\end{array}$ & $\begin{array}{c}\text { Refrigerant } \\
\text { Oapor } \\
\left({ }^{\circ} \mathrm{C}\right)\end{array}$ & $\begin{array}{c}\text { Steam-Side } \\
\text { Superheat } \\
\left({ }^{\circ} \mathrm{C}\right)\end{array}$ & $\begin{array}{c}\text { Thermal } \\
\text { Effectiveness }\end{array}$ \\
\hline SC5.2 & 82 & 12.42 & 8.76 & 7.25 & 0.58 \\
SC5.3 & 76 & 12.28 & 8.84 & 10.57 & 0.37 \\
SC5.4 & 63 & 12.47 & 9.66 & 4.06 & 0.67 \\
SC6.1 & 61 & 12.38 & 8.56 & 0.69 & 0.83 \\
SC6.2 & 60 & 12.07 & 9.07 & 7.73 & 0.47 \\
SC6.3 & 48 & 12.23 & 9.93 & 5.54 & 0.51 \\
SC6.3R & 55 & 12.14 & 9.64 & 5.03 & 0.57 \\
\hline
\end{tabular}

Although it was difficult to maintain low refrigerant-vapor superheat and required steam-side conditions, experiments were conducted to determine the qualitative effects of key parameters. The major parameters studied were inlet steam velocity and steam saturation temperature at inlet and outlet (i.e., gas concentration). Because of higher values of the refrigerant vapor superheat and corresponding lower refrigerant-side heat-transfer coefficient, the thermal effectiveness was relatively insensitive to the change in parameters. The results are not presented here because no definite conclusion can be drawn for the quantitative effects of test parameters. However, the raw data are included in Appendix $B$ for future reference and possible use of the data for reanalyzing them using a better method. The existing methods for calculating the refrigerant-side heat-transfer coefficient are not adequate 
for accurately calculating the steam-side coefficient, especially for conditions under which the vent condenser was operated in the HMTSTA. In conclusion, the vent condenser provided the service by maintaining the steam/gas mixture mass flow within the vacuum pump capacity and allowed researchers to control test conditions for the main condenser. However, a better method of analyzing the test data is required because of the problem of controlling test conditions.

\subsection{CONCLUSIONS}

- The test data for the main condenser validated the prediction method for the cross-flow configuration for unenhanced parallel-plate condenser geometry.

- The distributed vent system used for the main condenser seems to have maintained uniform distribution of steam without causing buildup of noncondensable gas in a confined area of the condenser.

- The vent condenser performed poorly. Difficulty associated with controlling the refrigeration system may have caused or significantly contributed to the poor performance.

- The gas-side mass balance was difficult to cross check; therefore, a large uncertainty could exist in calculations of the noncondensable gas concentration. The effects of this uncertainty probably had minimal effect on the analysis of the main condenser because the fraction of noncondensable gas is small in this stage. Instead, the vent-condenser data analysis needs an accurate calculation of the gas flow rate, because noncondensable gases are concentrated in this stage.

- The steam-side pressure drop measured for the main and vent condensers is small.

\subsection{APPLICATION OF DATA TO NPPE DESIGN}

In NPPE design guidelines, $10 \%$ of the total steam generated in the evaporator would be condensed in the surface condenser to produce desalinated water. But power consumption for desalinated water production will not be incorporated in the calculation of net power. Current experimental data and the theoretical analysis are being used to generate design specifications for the test unit to be used in the NPPE system, which may first be tested in the HMTSTA. Major design specifications for the test unit are summarized in Table 6-8. The test unit contains the prototypical flow channel and multipass configurations. Such configurations should be of low cost and should provide an efficient surface condenser for OTEC applications.

The current analysis is used to predict the thermal performance of this test unit. In addition, a uniformly distributed vent system similar to that installed for the main condenser will be used. It is, however, necessary to extend the analysis to the multipass system and the finned surface. The condensation process in the presence of noncondensable gases on the finned surface is complicated by temperature distribution in the fin, and it is thus difficult to calculate effective fin efficiency. Analysis for the multipass condenser configuration requires an iterative computational method to match water temperatures between passes. 
Table 6-8. Preliminary Specifications for the Test Unit

\begin{tabular}{ll}
\hline Parameters & \multicolumn{1}{c}{ Value } \\
\hline $\begin{array}{l}\text { Material } \\
\text { Water channel }\end{array}$ & $\begin{array}{l}\text { Aluminum AL-6061 } \\
\text { Extruded (12.7 or 16-mm square }\end{array}$ \\
channels with rounded corners) & Finned surface with varying fin \\
Steam channel & \\
density for 3 passes & Brazing \\
Assembly method & 3 \\
Number of water passes & $1.5-2.5 \mathrm{~m}$ \\
Length & $1.8-2.7 \mathrm{~m}$ \\
Height &
\end{tabular}

\subsection{FURTHER RESEARCH NEEDS}

It is recommended that analysis for the surface condenser be validated for finned and/or enhanced steam-side and for a multipass flow configuration on water-side. It may be possible to integrate main and vent condensers if a multipass condenser is used.

If additional tests are considered for the vent condenser, they should be planned with the following modifications to the HMTSTA equipment:

- Necessary system modifications should be made so that the refrigeration system can be operated at vapor superheat of less than $1^{\circ} \mathrm{C}$. Alternatively, the system could be modified to operate the vent condenser with recirculating fresh-water coolant. Fresh water in turn could be cooled with either cold seawater or refrigerant $R-12$.

- Temperature sensors should be installed along the condenser's length. If possible, wet-bulb or dewpoint sensors should be installed at two or three locations to determine the axial rate of condensation. Uncertainty in the analysis could be significantly reduced if the axial saturation temperature for the steam/gas mixture were known.

- Necessary steps should be taken to obtain accurate gas and steam mass balances.

The Colburn analysis should be validated for the laminar flow conditions. Specifically, the effective heat- and mass-transfer approach should be experimentally validated.

\subsection{REFERANCES}

Barsness, E. J., 1963, Calculation of the Performance of Surface Condensers by Digital Computers, ASME Paper 63-PWR-2.

Bell, K. J., and M. A. Ghaly, 1972, "An Approximate Generalized Design Method for Multicomponent/Partial Condensers," AIChE Symposium Series, Vol. 69, p. 72 . 
Bird, R. B., W. E. Stewart, and E. N. Lightfoot, 1960, Transport Phenomena, New York: John Wiley and Sons, Inc., p. 398.

Block, D. L., and J. A. Valenzuela, 1985, Thermoeconomic Optimization of OC-OTEC Electricity and Water Production P1dnts, SERI/STR-251-2603, Golden, CO: Solar Energy Research Institute.

Colburn, A. P., and 0. A. Hougen, 1934, "Design of Cooler Condensers for Mixtures of Vapors and Noncondensing Gases," Ind. Eng. Chem., Vol. 26, p. 1178.

Krishna, R., and C. B. Panchal, 1977, "Condensation of a Binary Vapour Mixture in the Presence of an Inert Gas," Chem. Eng. Sci., Vol. 32, p. 741.

McNaught, J. M.,. 1986, "An Assessment of Design Methods for Condensation of Vapors from Noncondensing Gases," in Heat Exchanger Source Book, edited by J. W. Palen, New York: Hemisphere Publishing Corporation.

Panchal, C. B., and K. J. Bell, 1984, Theoretical Analysis of Condensation in the Presence of Noncondensable Gases as Applied to Open-Cycle OTEC Condensers, ASME Paper 84-WA/So1-27.

Panchal, C. B., Hillis, D., Seren, L., Yung, D., Lorenz, J., Thomas, A., and Sather, N., 1981, "Heat Exchanger Tests at Argonne National Laboratory," Proceedings of the 8th Ocean Energy Conference, Washingtion, DC, June 7-11, 1981, pp. 319-327.

Parsons, B. K., H. F. Link, D. Bharathan, A. A. Pesaran, F. Zangrando, and C. B. Panchal, April 1989, Test Plan for the Heat- and Mass- Transfer Scoping Test Apparatus: Phase I and Phase II Tests, Internal Program Report, SERI/SP-253-3385, Golden, CO: Solar Energy Research Institute.

Porter, K. E., and G. V. Jeffreys, 1963, "The Design of Cooler-Condensers for the Condensation of Binary Vapours in the Presence of a Non-Condensable Gas," Trans. Inst. Chem. Eng., Vol. 41, p. 126.

Price, B. C., and K. J. Bell, 1974, "Design of Binary Vapour Condensers Using the Colburn-Drew Equation," AIChE Sysmposium Series, Vol. 70, p. 163.

Rose, J. W., 1981, "Condensation in the Presence of Noncondensing Gases," in Power Condenser Heat Transfer Technology, edited by P. Marto and R. Nunn, New York: Hemisphere Publishing Corporation.

Schrodt, J. T., 1973, "Simultaneous Heat and Mass Transfer from Multicomponent Condensing Vapor-Gas Systems," AIChE Journal, Vol. 19, No. 4, p. 753.

Webb, D. R., and K. Magna11, 1988, "A New Approach to Design of Vacuum Condensers," Proceedings of the Second UK National Conference on Heat Transfer, London: Mechanical Engineering Publication, p. 949.

Westinghouse Electric Corporation, Mar. 1979, 100 MWe Alternate Power Systems (final report), ORO-1473-T1, Lester, PA: Westinghouse Electric Corp. 
CHAPTER 7.0

DIRECT-CONTACT CONDENSER

\author{
F. Zangrando \\ Solar Energy Research Institute
}




\subsection{NOMENCLATURE}

\begin{tabular}{|c|c|c|}
\hline Abbrev. & Description & Units \\
\hline$c_{p}$ & specific heat & $\mathrm{kW} / \mathrm{mK}$ \\
\hline $\mathrm{F}$ & fraction of steam condensed & \\
\hline G & steam loading & $\mathrm{kg} / \mathrm{m}^{2} \mathrm{~s}$ \\
\hline $\mathrm{Ja}$ & Jakob number $(\mathrm{Eq}, 7-2)$ & \\
\hline $\mathrm{h}_{\mathrm{fg}_{\mathrm{g}}}$ & latent heat & $\mathrm{kJ} / \mathrm{kgK}$ \\
\hline$L$ & liquid loading & $\mathrm{kg} / \mathrm{m}^{2} \mathrm{~s}$ \\
\hline M & mass venting ratio (Eq. $7-4$ ) & \\
\hline MW & molecular weight & \\
\hline m & mass flow rate & $\mathrm{kg} / \mathrm{s}$ \\
\hline $\mathbf{P}$ & pressure & \\
\hline $\mathbf{R}$ & universal gas constant & $\mathrm{kJ} / \mathrm{kgK}$ \\
\hline $\mathrm{T}$ & temperature & \\
\hline $\mathrm{V}$ & vent ratio (Eq. 7-3) & \\
\hline Q & volumetric flow rate & $\mathrm{m}^{3} / \mathrm{s}$ \\
\hline $\mathrm{x}_{\mathbf{i}}$ & mass fraction of noncondensable gas (inerts) & \\
\hline$\varepsilon$ & $\begin{array}{l}\text { thermal effectiveness (Eq. 7-1) } \\
\text { pressure drop across condenser stage }\end{array}$ & $P_{a}$ \\
\hline
\end{tabular}

\section{Subscripts}

$\begin{array}{ll}\text { CW } & \text { cold water } \\ \text { FW } & \text { fresh water } \\ \text { g } & \text { gas mixture } \\ \text { i } & \text { in; inerts } \\ 0 & \text { out } \\ \text { s } & \text { steam } \\ \text { sat } & \text { saturation } \\ \text { SW } & \text { seawater } \\ \text { WW } & \text { warm water } \\ \text { w } & \text { water, seawater } \\ * & \text { equilibrium value for seawater } \\ 1 & \text { first stage } \\ 2 & \text { second stage } \\ \text { exh } & \text { exhaust }\end{array}$




\subsection{BACKGROUND}

The direct-contact condenser (DCC) is a chamber in which the steam emanating from the turbine is exposed directly to cold seawater for condensation. The seawater is distributed over packing material that has a large surface area per unit volume so that the steam encounters a large seawater surface on which to condense. The condensate flows out of the chamber with the warmed seawater. The noncondensable gases, introduced with the steam and liberated from the cold seawater, are exhausted to ambient through a vacuum pump system.

Extensive work has been carried out at SERI to develop a DCC for OC-OTEC applications using structured packing. The main advantage of the DCC is its ability to handle large quantities of low-density steam and noncondensable gases in a compact volume and without a large pressure drop. Random and structured packings have been used in industry, primarily as gas/liquid contacting devices for mass transfer in chemical-processing industrial applications.

In typical OC-OTEC operating conditions, cold seawater enters the chamber at about $6^{\circ} \mathrm{C}$, and the saturation temperature of. the incoming steam is about $12^{\circ} \mathrm{C}$. Because the steam is exposed directly to the seawater, the seawater exits at a temperature that is very close to the steam inlet saturation temperature (the difference is on the order of $0.5^{\circ} \mathrm{C}$ ). The noncondensable gases released from the warm seawater in the evaporator amount to approximately $19 \mathrm{ppm}$ (see Chapter 5); and a small quantity of additional gas is introduced by system leaks. These two sources account for a noncondensable-gas concentration in the steam of about $0.3 \%$ by weight. In addition, most of the noncondensable gases present in the cold seawater (about $19 \mathrm{ppm}$ of the cold seawater) also come out of solution during the condensation process. All these gases must be pumped out of the condenser to maintain operating pressure; their proportion in the exhaust flow is generally $40 \%$ to $70 \%$, depending on operating conditions. The tests were conducted over a broad test matrix typical of potential OC-OTEC operating conditions.

\subsubsection{Existing Data}

Literature about direct-contact condensation is limited. No comprehensive treatments are available for direct-contact applications to design and analyze industrial and power systems, as are available for surface condensers. The most common techniques used by industry in direct-contact gas to liquid heattransfer processes are the liquid-spray column and the baffle-plate column. Methods of designing these devices and comparisons of their performance are given by Fair $(1961,1972)$. Thermal effectiveness attained has been in the range 0.6 to 0.7 , generally with large pressure drops through the condenser.

Packed columns have been used in industry for applications that require high heat and mass transfer in small volumes. Until recently, the columns were packed with randomly distributed structures such as $\mathrm{Pall}$ rings and Berl saddles that served to distribute the liquid and resulted in complex flow

patterns with associated large pressure losses. More recently, structured packings have been introduced, especially for use in industrial cooling towers. In the structured packings, the liquid is distributed over an ordered series of inclined sheets made of plastic, metal, or wire mesh. Although the cost per unit volume of structured packings is somewhat higher than the cost 
of the more traditional packings, they yield a low ratio of pressure drop to heat- or mass-transfer coefficient per unit volume (Bravo, Rocha, and Fair 1985, 1986).

An intensive program to test direct-contact condensation was initiated at SERI in 1983. Tests conducted with a multitude of both random and structured packings using fresh water (Bharathan, Parsons, and Althof 1988) have yielded valuable information on how these devices operate in the low-pressure, highnoncondensable-gases environment typical of OTEC conditions. Structured packings were found to provide very high thermal effectiveness, up to 0.93 , for contactor heights less than $1 \mathrm{~m}$. With low pressure drops, they routinely yielded more than $98 \%$ condensation of the steam. These are the packings of choice for OC-OTEC applications.

\subsubsection{Existing Models}

Detailed computer models were developed at SERI (Bharathan, Parsons, and Althof 1988), and laboratory data using fresh water were used to extensively validate the models over a broad range of parameters typical of potential OC-OTEC applications. These models are one-dimensional, steady-state analytical models that calculate the heat-, mass-, and momentum-transfer processes occurring in a condenser with structured packing, in both cocurrent and countercurrent flows. The models are based on the heat- and mass-transfer analogy (Colburn and Hougen 1934) and employ established correlations for heat transfer, mass transfer, turbulent water film flow over an inclined plane, and gas flow friction. The evolution of noncondensable gases from the water film is treated as a diffusional process.

The cocurrent model integrates the process differential equations in the direction of gas and liquid flow. In the countercurrent condenser, the liquid enters at the top and the gas mixture enters at the bottom. The countercurrent model integrates through the process equations by marching from bottom to top, using calculated conditions for the water outlet temperature at the bottom. The integration is repeated using efficient iteration schemes until the calculated water conditions at the top of the countercurrent condenser match the specified inlet water conditions. These models are written in Turbo-Pascal language and can be used on standard IBM or compatible personal computers.

These condenser models were modified to predict DCC performance with seawater. A new set of physical properties for seawater was incorporated, as discussed in Section C.1 of Appendix $C$, and the calculation of temperature at the interface between seawater and gas mixture was modified. The heat-transfer calculations maintain consistent temperatures in the liquid and gas phases separately, while the mass-transfer calculation considers the equilibrium saturation pressure for seawater.

\subsubsection{Objectives of the Tests}

The specific objectives of tests reported in this chapter were to (1) estab1 ish the seawater performance of DCCs operating at OC-OTEC conditions, (2) quantify the effect of principal parameters influencing component performance, (3) validate the DCC computer models, and (4) generate data for use in the design of a net power-producing experiment (NPPE) in which net power 
will be produced for the first time using OC-OTEC technology. These objectives were met successfully, and the results are summarized here.

\subsubsection{Direct-Contact Condenser Data}

The DCC tests reported here were conducted from December 1988 to May 1989 using the Phase II configuration of the HMTSTA system (see Chapter 2). Data collected are shown in Section B.3 of Appendix B, which includes nomenclature describing the symbols used for the data column. These labels are also used in the discussion below. Each line entry represents a data point, identified by the date and a subset number. Each data point ( 1 ine) refers to one set of conditions at steady state. Several conditions were tested each day. Many parameters and redundant data collected during the tests are not shown in these summary data tables. However, all performance parameters can be calculated using the values shown therein.

For reference; the data presented were obtained during tests conducted during the following periods:

- $12 / 1 / 88-2 / 27 / 89$ ( side-by-side)

- $3 / 2 / 89-3 / 17 / 89$ and 4/13/89-4/27/89 (coaxial).

Some discrepancies were noted among the early data, and several tests were repeated. Therefore, not all the data collected before January 1989 are shown in the appendix. The data tables note cases in which two temperature sensors were used to obtain the required temperature difference because of difficulties with the differential temperature sensors.

\subsection{OPERATION AND PERFORMANCE PARAMETERS}

The performance of each of the two DCC stages (see Figures 2-7 and 2-8) is a complex function of liquid and steam loading, inlet noncondensable-gas concentration, gas release from the cold seawater, saturation temperature, exhaust pressure, and geometry (Bharathan, Parsons, and Althof 1988). Two parameters used to describe the thermal performance of each stage are the thermal effectiveness and the Jakob number; these parameters can also be applied to the overall condenser performance by selecting average water temperatures. The overall exhaust performance of the condenser unit can be described by the vent ratio. The hydraulic losses incurred providing water to the condenser are described by overall hydraulic-loss coefficients that incorporate all losses in the supply and discharge pipes, as configured at the HMTSTA.

\subsubsection{Thermal Effectiveness}

The thermal effectiveness of each stage compares the temperature difference observed in the seawater as it passes through that stage with the total available temperature driving potential, and is expressed as

$$
\varepsilon=\frac{T_{w o}-T_{w i}}{T_{s i}^{\dagger}-T_{w i}} .
$$

Here, $\mathrm{T}_{s i}^{*}$ is the seawater temperature (if operating with seawater) that is in equilibrium with the steam entering each stage. At typical condenser 
pressures, this effective temperature is $0.28^{\circ} \mathrm{C}$ higher than the corresponding fresh-water saturation temperature. The theoretical limit $\varepsilon=1$ represents ideal use of the temperature driving potential, in the absence of noncondensable gas. Note that, at given inlet conditions, the temperature driving potential is larger when operating with seawater than when operating with fresh water. The overall thermal effectiveness is expressed in the same form as Eq. 7-1, using the average water temperature rise in the two stages and the inlet steam temperature into the first stage.

\subsubsection{Stage Jakob Number}

The Jakob number describes the minimum amount of water needed to condense the desired amount of incoming steam, given a certain driving potential:

$$
\mathrm{Ja}=\frac{L C_{p w}\left(T_{s i \hat{i}}-T_{w i}\right)}{G h_{f g}}
$$

Typically, it is desired to condense only $80 \%-90 \%$ of the steam in the first (cocurrent) stage, and the remainder in the second stage. Therefore Ja is less than one, while $\mathrm{Ja}_{2}$ is greater than one. If either stage were to be used alone, the theoretical limit of $\mathrm{Ja}_{1}$ would be 1.0 .

\subsubsection{Vent Ratio}

When noncondensable gases are introduced into the system by leaks and by desorption from the process water, a venting system must be used to remove them and maintain the operating pressure. Under these conditions, a quantity of steam must also be exhausted with the noncondensable gas. This is typically $50 \%$ or more of the total exhausted gas. The vent ratio compares the ideal volumetric flow out of the condenser to the actual quantity of gas removed. The ideal (smallest) volumetric flow rate requires both a condenser with zero pressure losses and one in which the steam reaches the minimum possible partial pressure (the saturation pressure at the inlet water temperature). This provides the highest noncondensable gas partial pressure at the outlet. For calculation of the ideal and actual volumetric flow rates, the total static pressure at the outlet of the condenser can be expressed in terms of the total static pressure at the inlet of the condenser minus the total pressure drop incurred in the condenser stages. The partial pressure of noncondensable gases can be expressed in terms of this overall outlet pressure minus the saturation pressure of the steam at the outlet of the condenser. This gives the ideal and actual flow rates as

$$
\begin{aligned}
& Q_{\text {ideal }}=\frac{\mathrm{m}_{\text {io,2 }} \mathrm{R}\left(\mathrm{T}_{\mathrm{wi}, 2}+273.15\right)}{\left[\mathrm{P}_{\mathrm{in}, 1}-\mathrm{P}_{\text {sat }}\left(\mathrm{T}_{\mathrm{wi}, 2}\right)\right] \mathrm{MW}}, \\
& Q_{\text {real }}=\frac{m_{\text {io,2 }} R\left(T_{\text {so,2 }}+273.15\right)}{\left[P_{\text {in } 11}-\Sigma \Delta P-P_{\text {sat }}\left(T_{\text {so }, 2}\right)\right] M W_{i}}, \hat{e}
\end{aligned}
$$

giving the vent ratio as

$$
V=\frac{Q_{\text {ideal }}}{Q_{\text {real }}}=\frac{P_{i, 1}-\Sigma \Delta P-P_{s a t}\left(T_{s o, 2}\right)}{P_{i, 1}-P_{s a t}\left(T_{w i, 2}\right)} \frac{\left(T_{w i, 2}+273.15\right)}{\left(T_{s o, 2}+273.15\right)}
$$


The ideal case is recovered when both $\Sigma \Delta \mathrm{P}=0$ and $\mathrm{T}_{\mathrm{so}, 2}=\mathrm{T}_{w i, 2}$, giving $\mathrm{V}=1$; real condensers operate at $V<1$, implying that more steam is exhausted with the noncondensable gases than the theoretical minimum. This volumetric performance parameter is typically used to size positive-displacement vacuum systems operating at the low pressures encountered in OC-OTEC applications. It can readily be converted to mass flow rates as

$$
M=V\left(\frac{T_{s o, 2}}{T_{w i, 2}}\right) \frac{P_{s a t}\left(T_{w i, 2}\right)}{P_{s a t}\left(T_{s o, 2}\right)},
$$

which is more commonly used for conventional power-plant vent systems.

\subsubsection{Fraction of Steam Condensed}

The fraction of steam mass condensed in each stage is the product $\varepsilon \times \mathrm{Ja}$ calculated for that stage:

$$
F=\frac{L C_{p w} \Delta T_{C W}}{G_{f g}}
$$

where the appropriate values of 1 iquid and steam loading and temperature rise are used for each stage. The overall fraction condensed is expressed as $\left[F_{1}+\right.$ $\left.\left(1-F_{1}\right) F_{2}\right]$.

\subsection{TEST-SPECIFIC EQUIPMENT AND INSTRUNENTATION}

The following sections summarize the equipment and instrumentation specifically required for tests on the DCC or special operating procedures for other components needed to provide the inlet conditions required. These items were mentioned in Chapter 2.

\subsubsection{Additional Equipment Needs}

During the DCC tests, a single evaporator spout was used with a diameter of either 0.20 or $0.25 \mathrm{~m}$, depending on steam conditions required. Steam flow from the evaporator ranged up to $0.5 \mathrm{~kg} / \mathrm{s}$. Desorption of noncondensable gases (mainly oxygen and nitrogen released from the warm seawater) is a function of warm-water flow rate at a constant evaporator pressure. Production of steam is a function of warm-water flow rate and water temperature difference in and out of the evaporator. Therefore, the ratio of these two quantities is an inverse function of the temperature difference between the incoming and outgoing warm seawater, independent of the warm-water flow. At nominal evaporator conditions, a typical value for the noncondensable-gas inlet concentration is $0.33 \%$, unless gas is purposefully injected into the evaporator or a large leak is present. Warm-water flow rate and evaporator chamber pressure can be set independently to provide the required steam and noncondensable gases. The desired pressure at the inlet to the DCC is set by adjusting the pressure drop through a butterfly valve in the steam duct between the evaporator and the inlet to the condenser. 
In the first (cocurrent) stage, the steam flows vertically down, in the same direction as and in direct contact with the cold seawater. In the second (countercurrent) stage, steam remaining from the first stage is condensed by flowing upward in a direction opposite to the flow of cold seawater. Both stages contain commercially available structured packing which is made of corrugated, slanted sheets of plastic that present a triangular cross section to the seawater and steam (Bharathan, Parsons, and Althof 1988; Parsons et al. 1989). The Munters CF-25060 structured packing used at the HMTSTA has an effective surface area per unit volume of $98 \mathrm{~m}^{2} / \mathrm{m}^{3}$. The packing is composed of stacked $0.15-\mathrm{m}-\mathrm{high}$ sections. Each is rotated in the horizontal plane with respect to the others to have a different flow channel orientation in each section.

Two configurations were tested for the DCC assembly: one with two small stages side by side and one with larger coaxial stages. The first geometry was selected because it enabled tests with seawater that were closely related to the tests conducted at SERI with fresh water; the second was selected because it used all the steam available from the evaporator in a configuration that may be more representative of larger OTEC systems. These two configurations are shown in Figures $2-7$ and 2-8 of Chapter 2.

The packing planform areas of the first (cocurrent) stage are $0.43 \mathrm{~m}^{2}$ and $1.02 \mathrm{~m}^{2}$ for the side-by-side and coaxial configurations, respectively; the packing planform areas for the second (countercurrent) stage are $0.15 \mathrm{~m}^{2}$ and $0.34 \mathrm{~m}^{2}$, respectively. The structured packing heights tested and the overall freefall heights are shown in Table 7-1. The freefall height includes the height above the packing, in which water is distributed over the packing, and the height below it, in which the uncondensed steam from the first stage turns around and enters the second stage. Visual observation of these areas shows that the water flow is broken up into droplets or thin filaments.

Several systems of water distribution were tested for the cocurrent stage, which requires good water distribution with minimal blockage of the steam flow path. In the side-by-side configuration, by varying the rotational speed of vanes inside a motorized nozzle, horizontal spread of the seawater over the

Table 7-1. Direct-Contact Condenser Configurations and Heights Tested

\begin{tabular}{llcccc}
\hline \multicolumn{2}{c}{ Stage } & \multicolumn{2}{c}{ First } & (Cocurrent) & \multicolumn{2}{c}{ Second (Countercurrent) } \\
\hline Symbol & Type & $\begin{array}{c}\text { Packing } \\
\text { Height } \\
\text { (m) }\end{array}$ & $\begin{array}{c}\text { Freefall } \\
\text { Height } \\
\text { (m) }\end{array}$ & $\begin{array}{c}\text { Packing } \\
\text { Height } \\
\text { (m) }\end{array}$ & $\begin{array}{c}\text { Freefal1 } \\
\text { Height } \\
\text { (m) }\end{array}$ \\
\hline & Side-by-side (SS) & 0.91 & 1.63 & 0.91 & 1.22 \\
C & SS (fresh water on1y) & 0.61 & 1.63. & 0.61 & 0.92 \\
+ & SS & 0.61 & 1.16 & 0.61 & 0.92 \\
$\#$ & Coaxial (CX) & 0.61 & 1.02 & 0.61 & 1.04 \\
+ S & CX & 0.61 & 1.02 & 0.91 & 1.35 \\
SS (at SERI, fresh) & 0.61 & 1.24 & 0.61 & 0.91 \\
\hline
\end{tabular}


packing planform area was obtained. This distribution system is not at all typical of potential OTEC applications. However, a broad range of flow rates could be tested by adjusting the spray pattern for each flow rate to control the evenness of the seawater distribution at the top of the packing. A more typical distribution system (water distributor A in Figure 2-8) was used for the coaxial configuration. Here, 12 Munters nozzles (Dek-Spray, B turbolators 76- $\mathrm{mm}$ diameter) were used, equally spaced around the annular condenser stage and centered on the packing. The spray area for each nozzle was about $0.33 \mathrm{~m} \times 0.33 \mathrm{~m}$, providing for some overlap in the spray areas. These two systems provided both the needed geometrical flexibility for all tests envisioned, and good water distribution, but at the expense of high hydraulic losses. Note that in both systems, the cold seawater reached a height $0.7 \mathrm{~m}$ above the top of the packing before descending into the distribution nozzles. Once the tests requiring large variations of flow rate were completed, a more representative water distribution system with lower hydraulic losses was tested, as will be described later.

Quantitative measurements of the water distribution pattern were made at the SERI laboratory before the distributors were shipped to Hawaii, and they were not repeated on site. Visual observation was used to qualitatively characterize the spreading at the HMTSTA. In a "good" water distribution, the seawater on top covers the entire packing and the seawater exiting at the bottom is evenly distributed over the whole planform area of the stage. In a "poor" water distribution, the water on top only covers part of the packing, but it still exits fairly evenly from the entire bottom of the stage, having been spread out by the packing itself. "No" distribution means that the motorized nozzle was off and the seawater simply was discharged from a vertical $0.1-\mathrm{m}$-diameter pipe onto an area $0.74 \mathrm{~m}$ in diameter, with the packing providing the only spreading.

The last cocurrent water distribution system tested, shown at the right in Figure $2-8$, consists of 12 vertical pipes $51 \mathrm{~mm}$ in diameter that pass through the packing and discharge the cold seawater $0.15 \mathrm{~m}$ above the top of the packing. The same annular water distributor used with the 12 nozzles was relocated below the condenser stages and supplied the pipes.. The spray pattern from the top of these vertical pipes does not resemble qualitatively that from the evaporator spout, because the water is not shattered by the flashing process. Apparently, however, release of noncondensable gases from the cold seawater causes it to spread farther horizontally than it would in a conventional fountain. The area coverage for each pipe had a diameter of about $0.33 \mathrm{~m}$. This vertical pipe distributor is simpler and it provided pressure losses two to three times lower than those observed in the other configurations tested.

Water distribution to the countercurrent condenser stage is straightforward under all flow rates, because so little gas is left flowing out of it. As is shown in Figures 2-7 and 2-8, the water distribution system consists of a supply pipe discharging onto a perforated water tray which contains a few vertical vents. The system provides excellent water distribution just above the packing, with small hydraulic losses.

Three water types were tested at the HMTSTA. The mode of operation is shown schematically in Figure 2-9 in Chapter 2. In open-1oop operation, "normal" seawater was received directly from the Natural Energy Laboratory of Hawaii 
(NELH), piped through the equipment, and discharged. In addition, fresh water and deaerated seawater were tested while operating in a closed-loop mode (Parsons et al. 1989). In this mode, the desired fluid is stored in the supply and discharge sumps and recirculated through the condenser vessel. Continued exposure to the low pressure in the DCC deaerates the closed-loop fluid to near-equilibrium concentrations of noncondensable gases within about an hour. In the closed-loop mode, the heat of condensation is transferred to the cold, external seawater flow using a secondary plate heat exchanger. This is a commercial unit, Tranter Superchanger UX-216-HP-164, with 164 titanium plates and $60.7-\mathrm{m}^{2}$ heat-transfer area, rated at $633 \mathrm{~kW}$ th exchanged. Closedloop fluid was circulated on one side up to $0.022 \mathrm{~m}^{3} / \mathrm{s}$, while up to $0.025 \mathrm{~m}^{3} / \mathrm{s}$ of cold seawater from NELH flowed through the other side and was discharged.

The maximum heat exchange capability of the Tranter unit is equivalent to condensation of $0.26 \mathrm{~kg} / \mathrm{s}$ of steam; therefore, the tests in closed-loop mode were only conducted in the side-by-side configuration. The fresh water produced was drained continuously out of the sumps and discarded to maintain constant operating levels.

\subsubsection{Specific Instrumentation -}

The DCC test instrumentation is shown schematically in Figure 7-1 for the side-by-side configuration; it is situated virtually at the same position for the coaxial configuration. It consists primarily of matched RTD probes for differential temperature measurements, diaphragm capacitance transducers for absolute and differential pressures as well as liquid levels, and magnetic and vortex-shedding flowmeters for liquid flows (Parsons et al. 1989). This instrumentation is supplemented by other HMTSTA operational instrumentation, as described in Chapter 2. Al1 test instrumentation was calibrated at the SERI Metrology Laboratory or by the manufacturer just before the side-by-side tests and recalibrated in the same manner during the coaxial tests. A concerted effort was made throughout the test period to verify that all instrumentation was working properly, to compare redundant measurements, and to maintain a regular schedule for recalibration.

The differential temperature and differential pressure sensors were monitored at the beginning of each day, while the chamber pressure was maintained above the saturation pressure and with fluid flowing through the chamber, to obtain the zero shift for that particular set of data. Typically, observed drift in the temperature difference was on the order of $10 \mathrm{mK}$ and remained steady; in contrast, the pressure difference drifted up to $\pm 25 \mathrm{~Pa}$ over a 24-hour period. During the coaxial tests the differential pressure sensors were monitored periodically each day to minimize this effect. Similar difficulties with differential pressure measurements. at such low ranges were found in the SERI laboratory, where environmental conditions are far less rigorous than at the STF.

The parameter $\mathrm{T}_{\mathrm{i}} \stackrel{*}{\text {, }}$ referred to for the sake of brevity as steam temperature, is measured using RTDs covered with wicks. These wicks are wetted with fresh water; therefore these sensors measure the fresh-water temperature that is in equilibrium with the incoming steam (wet-bulb temperature). When the tests are conducted with seawater, the output of the steam sensors must be corrected 


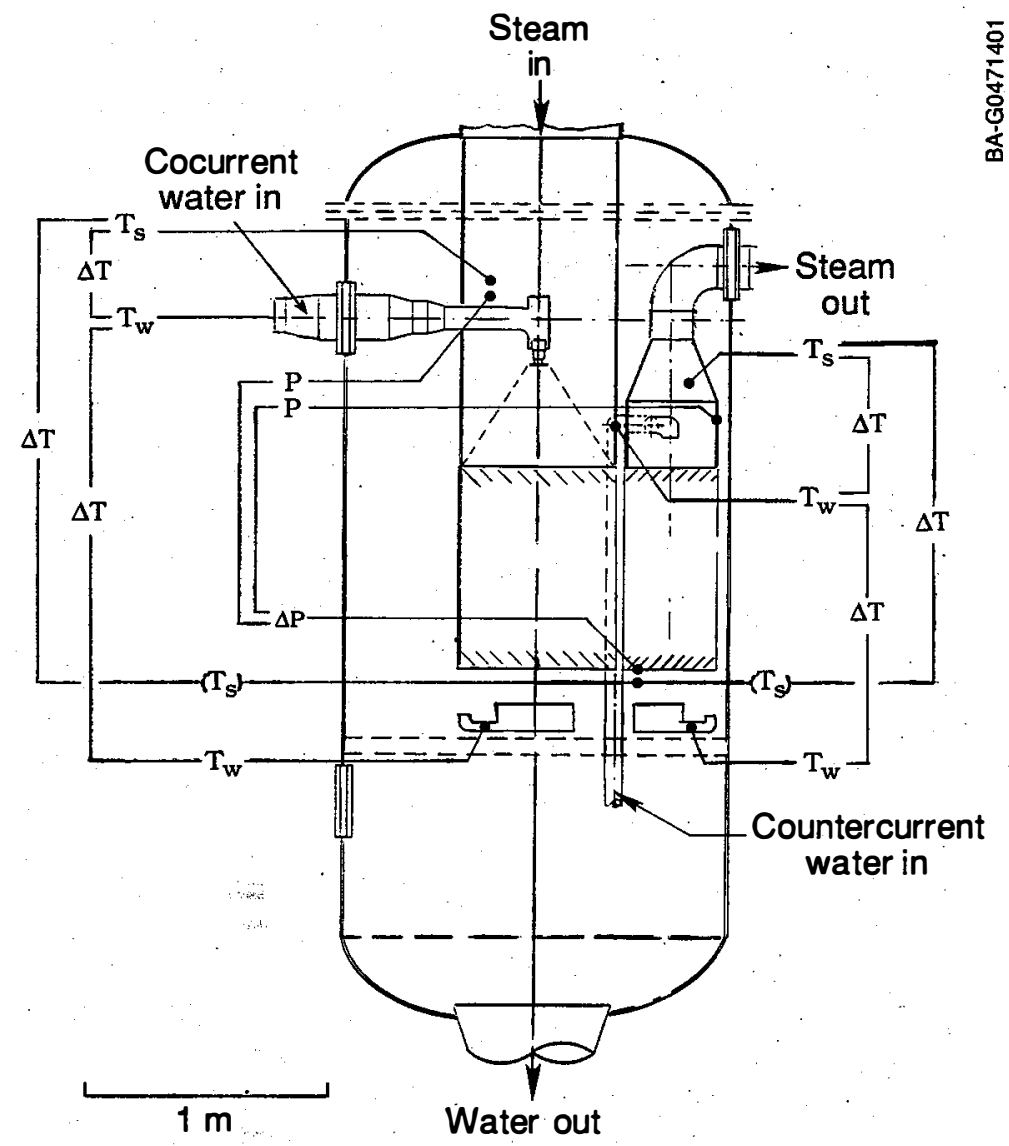

Figure 7-1. Location of instrumentation and types of measurements made in side-by-side configuration (similar to coarial configuration)

by applying a boiling-point-elevation correction. In the data analysis performed, this correction is applied to the data as a constant $0.280^{\circ} \mathrm{C}$. The actual saturation pressure for each point is not recalculated because

$$
\Delta \mathrm{T}_{\text {elevation }}=+0.280^{\circ} \mathrm{C} \pm 0.005^{\circ} \mathrm{C} \text { for } 1.15 \mathrm{kPa}<\mathrm{P}<1.6 \mathrm{kPa}
$$

and the variation over the tested range is so small that it does not contribute appreciably to the expected error. Note that if the water wetting the wicks were to be contaminated with seawater, as appears to have happened in some of the early tests, then the temperature displayed by the sensor would already be the equilibrium temperature with respect to seawater, and the boiling-point-elevation correction should not be applied to the data. If it were applied in this case (as was done for all data collected) this would give an effectiveness lower than the actual value by about 0.05 .

\subsubsection{Specific Data Used for Performance Calculations}

Al1 performance parameters were calculated using data obtained from differential temperature sensors specifically installed to measure the required values. These data are shown in Section B.3 of Appendix B. For example, the effectiveness (Eq. 7-1) of the first stage uses the differential temperature between cold water in and out of this stage temperature between incoming steam and incoming water $\Delta T_{\text {si,wi,l }}$ at the 
top of this stage. In some of the earlier sets of data, the differential temperature sensors were not operating properly. In those cases, temperature sensor data were used to calculate the performance parameters, as is indicated in the legend for the data tables.

Similarly, calculations for the second stage use $\Delta \mathrm{T}_{\mathrm{CW}}, 2$ for the numerator and $\left(\Delta \mathrm{T}_{\text {so,wi, }}+\Delta \mathrm{T}_{\text {si,so, }}\right)$ in the denominator. This is the sum of the temperature differences between water and steam at the top of the countercurrent stage and between the steam temperature in and out of the stage. All differential temperature readings are corrected for sensor zero offset, which is recorded as the first data file of each day. The depression of the seawater saturation conditions is incorporated as a constant in the denominator (see Section 7.4.2).

The Ja (Eq. 7-2) for each stage is calculated on the basis of water flow rate data measured for each cold-water stream and from the data obtained with the differential temperature sensors described above. Physical properties are calculated at an average stage temperature using the functions shown in Section C.1 of Appendix C.

The composition of the seawater assumed in the calculations is based on analyses of samples collected offshore near the STF (Krock 1981). Total mass fraction of noncondensable gases in the warm seawater is assumed to be $18.8 \mathrm{ppm}$, and for the cold seawater it is $19.4 \mathrm{ppm}$. Because of difficulties with the equipment, the intended redundant measurement by mass spectrometry of gas composition at various locations in the system could not be performed by University of Hawaii personnel at the same time as the DCC tests were being conducted. Therefore, the calculations for the DCC assume a constant $90 \%$ release from the warm seawater and a constant $100 \%$ release from the cold seawater at OTEC operating conditions. The first value is in agreement with test results reported in Chapter 5, and the second with later tests using the mass spectrometer that are yet unreported.

For the DCC analysis, the mass fraction of noncondensable gases coming into the condenser stages is calculated from the exhaust mass flow rate of steam and noncondensable gas plus or minus the appropriate quantities condensed or released in each stage. This can be cross-checked by calculating the release from the evaporator, but the previous method was found to give more consistent results.

The mass and composition of the gas exhausted from the condenser unit is

$$
\begin{gathered}
m_{\text {so, } 2}=Q_{\text {exh }} P_{\text {exh }} \frac{P_{\text {sat }}\left(T_{\text {so, }}\right)}{P_{0,2}} \frac{M W_{s}}{R T_{\text {exh }}} \\
m_{i 0,2}=Q_{\text {exh }} P_{\text {exh }}\left[1-\frac{P_{\text {sat }}\left(T_{\text {so }, 2}\right)}{P_{0,2}}\right] \frac{M W_{i}}{R T_{\text {exh }}} .
\end{gathered}
$$

$\mathrm{T}_{\text {so, } 2}$ is calculated from the incoming seawater temperature and the temperature difference between seawater and steam at the top of the second stage $\left(\Delta \mathrm{T}_{w i, s o, 2}+\mathrm{T}_{\text {wi,2 }}\right)$. This value of outlet steam temperature agrees with the absolute measurement of $\mathrm{T}_{\text {so, } 2}$ within the error estimate (discussed below). 
The total pressure at the same location is calculated from inlet pressure to the first stage $P_{i, 1}$ and overall pressure drop $\left(\Delta \mathrm{P}_{1}+\Delta \mathrm{P}_{2}\right)$. This choice is made because $P_{i, 1}$ can be compared to $P_{\text {sat }}\left(T_{s i, 1}\right)$, and this comparison has resulted in excellent agreement. Instead, $\mathrm{P}_{0,2}$ cannot be compared against any other redundant measurement using a different principle for the measurement. The exhaust flow rate is calculated using $P_{\text {exh }}$ and the vacuum system calibration function described in Chapter 2, Section 2.3.6.

The mass flow rate of steam entering the DCC is calculated from exhaust conditions and heat balance as

$$
\mathrm{m}_{\mathrm{si}, 1}=\left(\mathrm{m}_{\mathrm{so}, 2}+\frac{\mathrm{m}_{\mathrm{CW}, 2} \mathrm{C}_{\mathrm{pw}} \Delta \mathrm{T}_{\mathrm{CW}, 2}}{\mathrm{~h}_{\mathrm{fg}}}\right)+\frac{\mathrm{m}_{\mathrm{CW}, 1} \mathrm{C}_{\mathrm{pw}} \Delta \mathrm{T}_{\mathrm{CW}, 1}}{\mathrm{~h}_{\mathrm{fg}}}
$$

The term in parentheses is the mass flow rate of steam at the inlet of the second stage, $\mathrm{m}_{\mathrm{si}, 2}$.

The mass fraction of noncondensables at the inlet to the first stage is calculated as

$$
x_{i, 1}=\frac{m_{i i, 1}}{m_{s i, 1}+m_{i i, 1}} \approx \frac{0.9\left(18.8 \times 10^{-6}\right) m_{W W}+1 e a k}{m_{s i, 1}}
$$

The numerator is the mass of noncondensable gases at the inlet to the first stage, $\mathrm{m}_{\mathrm{i} i, 1^{-}}$. This term is so small in comparison to the mass of steam from the turbine that it has been ignored in the denominator. $x_{i i}$ has also been calculated from the total noncondensable gas exhausted, minus all released from the two cold seawater streams, and the values found from these two calculations agree well, within the uncertainty of the calculations. Notice that $90 \%$ release from warm seawater is assumed in Eq. 7-10.

For the second stage, the mass fraction of noncondensables at the inlet is calculated as

$$
x_{i i, 2}=\frac{m_{i, 2}}{m_{s i, 2}+m_{i, 2}}-\frac{\left(m_{i o, 2}-\left(19.4 \times 10^{-6}\right) m_{C W, 2}\right)}{\left(m_{s i, 2}+m_{i, 2}\right)}
$$

where the numerator is the mass of noncondensable gases at the inlet to the second stage, $\mathrm{m}_{\mathrm{i}, 2}$, also used in the denominator. Note that for cold seawater, $100 \%$ release of noncondensables is assumed.

Table 7-2 summarizes the ranges of each parameter for the first and second stages, as tested. The test matrices selected were broad enough to amply cover the potential OC-OTEC range and the parameters expected to be used in the NPPE. Symbols representing the data are given in Table 7-1 and they are used consistently in the figures of this chapter, unless otherwise stated. 
Table 7-2. Range of Direct-Contact Condenser Parameters Tested at the Seacoast Test Facility

\begin{tabular}{|c|c|c|}
\hline & Min. & Max. \\
\hline $\begin{array}{l}\text { Area cocurrent }\left(\mathrm{m}^{2}\right) \\
\text { Area countercurrent }\left(\mathrm{m}^{2}\right) \hat{\mathrm{e}}\end{array}$ & $\begin{array}{l}0.426 \\
0.146\end{array}$ & $\begin{array}{l}1.021 \\
0.343\end{array}$ \\
\hline $\begin{array}{l}\text { First Stage } \\
\text { Steam loading }\left(\mathrm{kg} / \mathrm{m}^{2} \mathrm{~s}\right) \\
\text { Noncondensable-gas inlet (\%) } \\
\left.\text { Liquid loading ( } \mathrm{kg} / \mathrm{m}^{2} \mathrm{~s}\right) \\
\text { T steam in }\left({ }^{\circ} \mathrm{C}\right) \\
\text { T water in }\left({ }^{\circ} \mathrm{C}\right) \\
\text { Jakob number }\end{array}$ & $\begin{array}{r}0.28 \\
0.27 \\
16.89 \\
11.57 \\
5.83 \\
0.73\end{array}$ & $\begin{array}{r}0.61 \\
0.42 \\
40.50 \\
17.46 \\
6.58 \\
1.35\end{array}$ \\
\hline $\begin{array}{l}\text { Second Stage } \\
\text { Steam loading }\left(\mathrm{kg} / \mathrm{m}^{2} \mathrm{~s}\right) \\
\text { Noncondensable-gas inlet (\%) } \\
\left.\text { Liquid loading ( } \mathrm{kg} / \mathrm{m}^{2} \mathrm{~s}\right) \\
\text { T steam in }\left({ }^{\circ} \mathrm{C}\right) \\
\text { T water in }\left({ }^{\circ} \mathrm{C}\right) \\
\text { Jakob number }\end{array}$ & $\begin{array}{l}0.05 \\
0.87 \\
7.70 \\
9.51 \\
5.60 \\
1.01\end{array}$ & $\begin{array}{r}0.50 \\
4.90 \\
47.50 \\
18.00 \\
6.66 \\
6.67\end{array}$ \\
\hline $\begin{array}{l}\text { Overall heat exchanged ( } \mathrm{kW}) \\
\text { Overall } \% \text { condensed }\end{array}$ & $\begin{array}{l}317 \\
97.76\end{array}$ & $\begin{array}{l}1248 \\
99.69\end{array}$ \\
\hline
\end{tabular}

\subsubsection{Error and Data Consistency}

An extensive error analysis conducted before the tests is documented in the test plan (Parsons et al. 1989) and summarized in Table A-2 of Appendix A, including sample calculations. These pretest estimates, summarized in Table 7-3, have been compared with a post-test analysis and with redundant sensors measurements to assess and verify the accuracy of the data collected. Where appropriate, the least-squares error band estimates are shown on the graphs, along with the value of the standard deviation of the collected data. In most cases, the data have shown excellent consistency and variations smaller than the documented error estimates. If discrepancies were found, the tests were repeated or the cases are noted in the text. Overall, the data collected provide confidence for engineering design of the NPPE heat exchangers.

Figure 7-2 shows the consistency of the heat balance performed on the system by comparing the calculated values of heat rates (using evaporator and condenser instrumentation), the appropriate error bands in the ranges tested, and the standard deviation of all data shown in this plot. The estimated heatbalance error for the evaporator is about twice that for the DCC, because the temperature difference in the evaporator is about half that in the DCC. Note that a consistent bias appears at the higher heat rates, as in previous Phase I tests. This bias arises from ambient heat input (the evaporator operates near ambient temperature but the condenser is well below ambient). 
Table 7-3. Direct-Contact Condenser Calculated Parameters--Error Summary

\begin{tabular}{lccc}
\hline Parameter & $\begin{array}{c}\text { First Stage } \\
( \pm \%)\end{array}$ & $\begin{array}{c}\text { Second Stage } \\
( \pm \%)\end{array}$ & $\begin{array}{c}\text { Overali } \\
( \pm \%)\end{array}$ \\
\hline Jakob number & 1.7 & 3.1 & - \\
Effectiveness $(\Delta \mathrm{T})$ & 1.4 & 1.3 & 1.4 \\
Effectiveness (T-T) & 5.0 & 5.0 & 6.2 \\
Fraction condensed & 1.7 & 2.6 & 1.5 \\
Steam loading & 1.8 & 3.0 & - \\
Liquid loading & 1.5 & 2.7 & - \\
Vent ratio & - & - & \\
Additional Parameters ( $\pm \%)$ & $8-11$ & \\
Steam temperature (based on pressure) & \\
Interstage steam T (various methods) & $2-5$ & \\
Noncondensable gases in steam & 13 & \\
Overall heat balance : & 3.7 & \\
\hline
\end{tabular}

It is negligible in the side-by-side tests, where only a small inner part of the DCC vessel is used for the stages. Because of this bias, the heat rates in the condenser stages (instead of the evaporator) are used to calculate the amount of steam produced and condensed. The calculated heat rates fall within approximately $\pm 5 \%$, that is, the standard deviation is $\sigma= \pm 3.7 \%$.

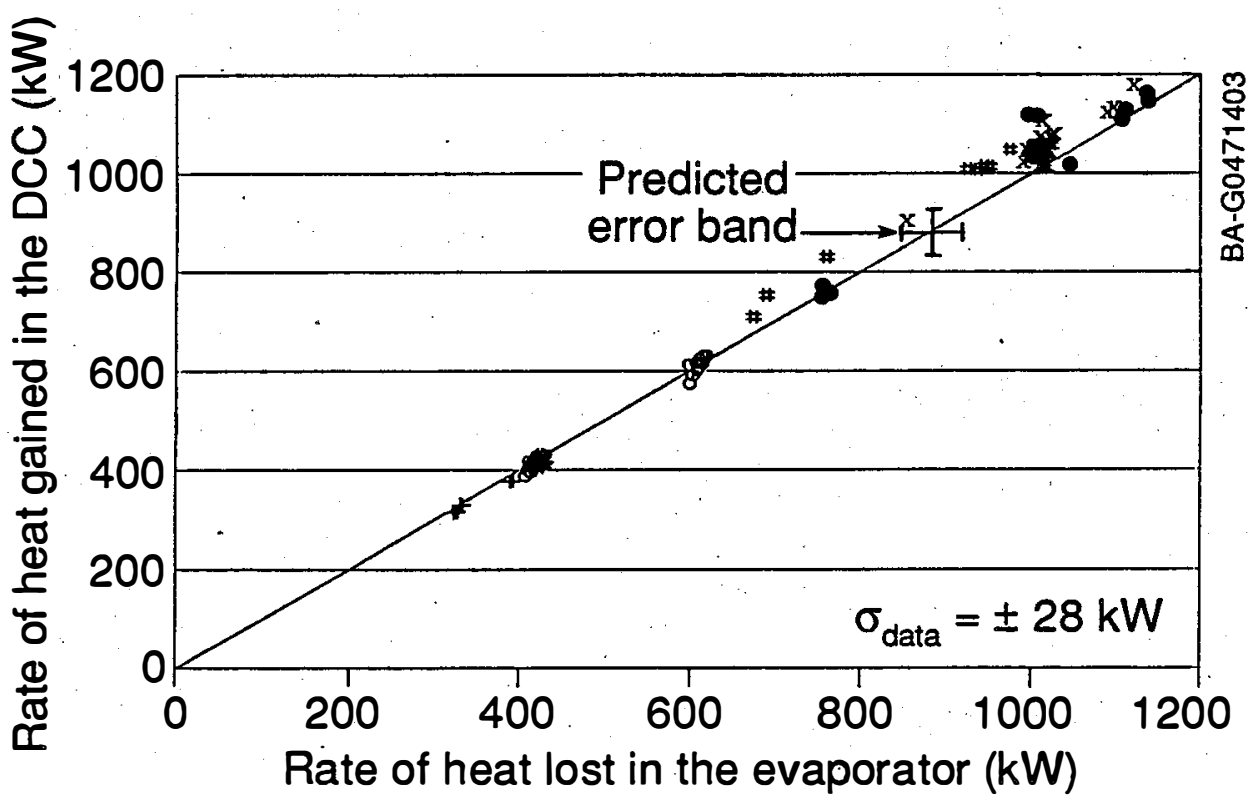

Figure 7-2. Consistency of overall heat balance between heat lost by the evaporator and heat gained by the direct-contact condenser in both configurations 
Calculations of exhaust gas composition (Eqs. 7-7 and 7-8) show reasonable consistency with calculated rates of noncondensable gas release on the basis of deaeration tests (Chapter 5) and recent results of gas analysis. Leakage rates were monitored regularly and amounted to 20 to $40 \mathrm{mg} / \mathrm{s}$, rising occasionally as high as $200 \mathrm{mg} / \mathrm{s}$. Even at the highest leak rate, the leak accounts for less than $5 \%$ of the noncondensable flow through the condenser. The method of monitoring leaks is described in Chapter 2, Section 2.3.8.

Figure 7-3 shows that noncondensable gas exhausted is within $20 \%$ of the total content of noncondensable gases released from the seawater streams. During side-by-side tests when small flows were used, the rate of gas release was virtually 100\%. During coaxial tests at higher flow rates, the average combined rate of gas release from both streams was about $85 \%$.

A consistency analysis was performed during and after the tests. Figures 7-4 and 7-5 illustrate consistency of the two most important performance parameters for the DCC unit, the thermal effectiveness and the vent ratio. Note that the effectiveness calculated using temperature measurements is actually higher than that calculated using differential temperature sensors. Therefore, those results discussed in the next sections that are based on differential temperature measurements may be conservative. Note also the excellent agreement between vent ratios calculated on the basis of inlet pressure measurement as compared to inlet steam temperature measurement. This results from the agreement between $P_{s a t}\left(T_{s i, 1}\right)$ and $P_{i, 1}$. The agreement in $V$ indicates that the large error band assigned to the vent ratio is also a very conservative value.

Similar analyses for other important parameters have been based on redundant measurements and a statistically significant sample of data. A few are summarized in Table 7-4. The last two columns refer to the offset of the correlation from mean values and the standard deviation of the correlation. These are representative of the various redundant measurements and calculations not shown in the table.

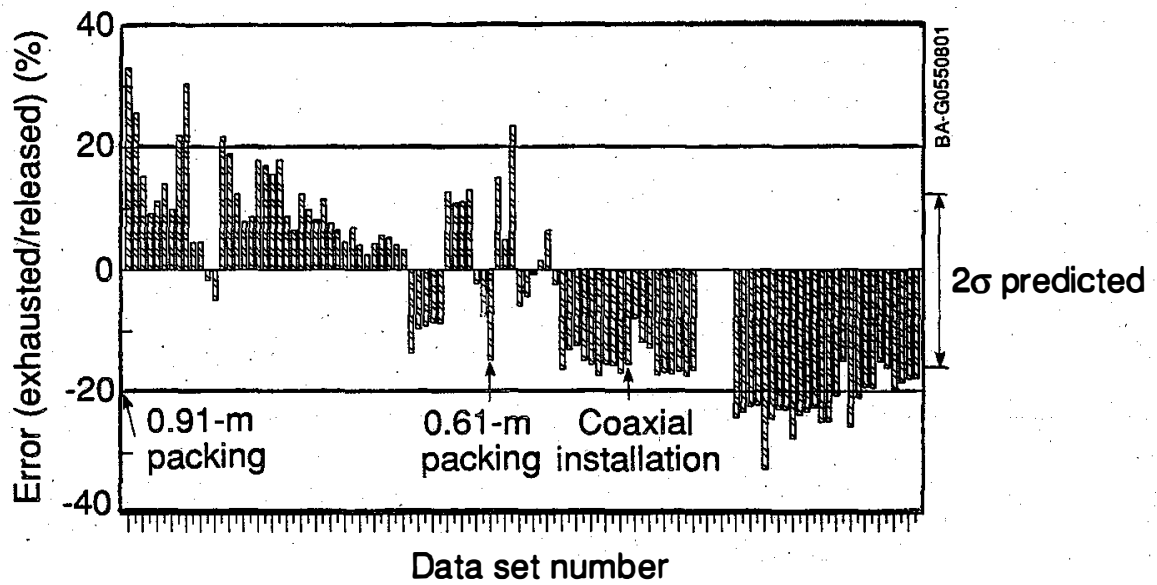

Figure 7-3. Consistency of overall noncondensable gas mass flow rate exhausted through vacuum system as compared to calculated release assuming average 907 release of noncondensable gases from warm seawater and 1007 release from cold seawater 


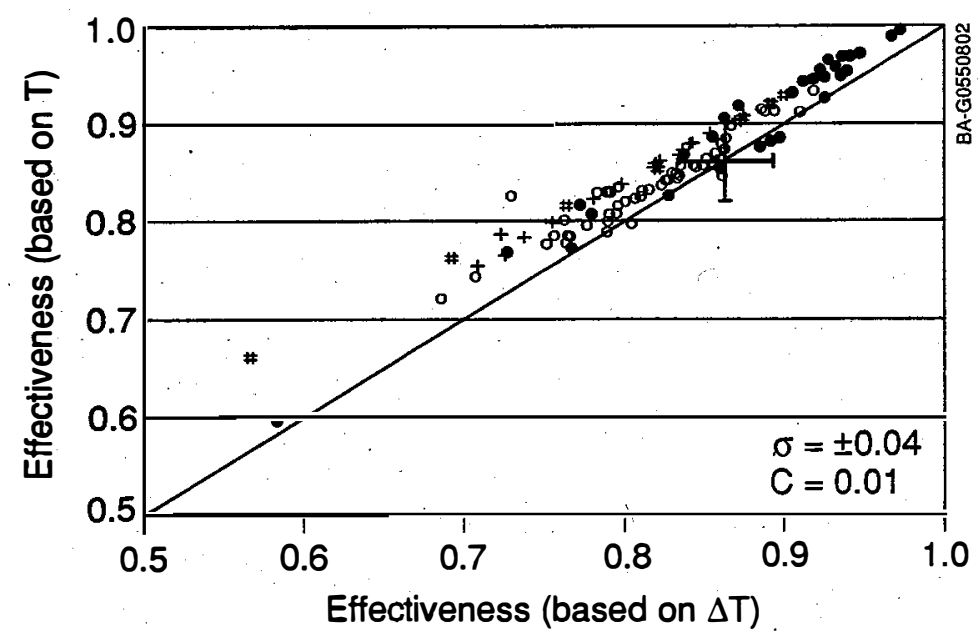

Figure 7-4.

Consistency of overall

thermal effectiveness

calculated using

differential temperature

sensor data against

that using differences

of temperature measurements.

$C$ is the average offset.

\subsection{TEST RESULTS}

This section describes the results obtained during the DCC tests. First- and second-stage results are differentiated for clarity of presentation and because model validation must be performed separately for each stage. At the end of the section, the results of the combined stages are discussed in the context of the NPPE.

\subsubsection{Results for the First Stage (Cocurrent)}

Before presenting seawater data, a comparison is made between results obtained in the SERI laboratory and the HMTSTA using the same type of packing and fresh water. This is to verify that differences in geometry between the two condensers do not affect the results. Figure 7-6 shows the percent of the incoming steam mass that is condensed in the first stage as a function of stage Jakob number. The theoretical limit is the asymptote where $\varepsilon_{1}=1.0$. Note that the Jakob number range of interest is from 0.8 to about 0.9 , because

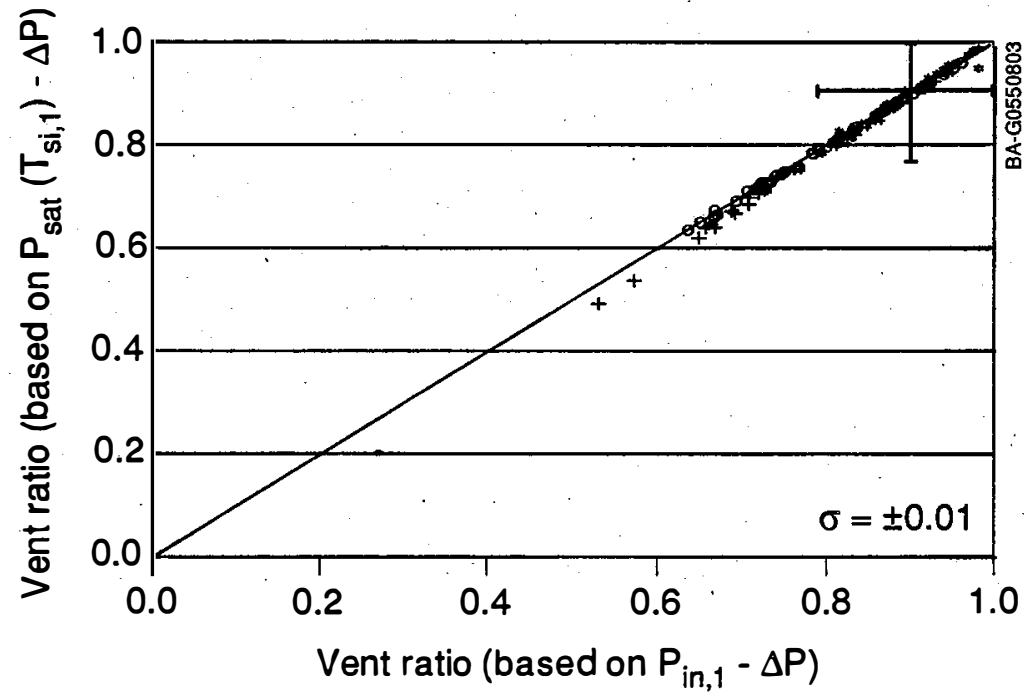

Figure 7-5. Consistency of vent ratio calculated based on overall inlet pressure against that using saturation pressure at inlet to first stage 
Table 7-4. Measurement Consistency among Various Measurement and Calculation Methods for Direct-Contact Condenser Performance Parameters

\begin{tabular}{|c|c|c|c|c|c|}
\hline Parameter & $\begin{array}{l}\text { First Measurement/ } \\
\text { Calculation } \\
\text { (Independent) }\end{array}$ & $\begin{array}{l}\text { Second Measurement/ } \\
\text { Cal culation } \\
\text { (Dependent) }\end{array}$ & $\begin{array}{l}\text { Typical } \\
\text { Value }\end{array}$ & $\begin{array}{l}\text { Offset of } \\
\text { Dependent } \\
\text { Value }\end{array}$ & $\begin{array}{l}\text { Standard } \\
\text { Deviation }\end{array}$ \\
\hline $\begin{array}{l}\text { Overall thermal } \\
\text { effectiveness (Eq. 7-1) }\end{array}$ & $\begin{array}{l}\text { Based on differential. } \\
\text { temperatures }\end{array}$ & $\begin{array}{l}\text { Based on difference } \\
\text { of two temperatures }\end{array}$ & 0.86 & +0.01 & \pm 0.04 \\
\hline Vent rat io (Eq. 7-3) & $\begin{array}{l}\text { Based on absolute } \\
\text { inlet pressure and } \\
\text { overall pressure } \\
\text { differences }\end{array}$ & $\begin{array}{l}\text { Based on inlet } \\
\text { saturation pressure } \\
\text { and overall pressure } \\
\text { differences }\end{array}$ & 0.90 & 0 & \pm 0.01 \\
\hline Overall pressure drop & $\begin{array}{l}\text { Based on differential } \\
\text { pressures }\end{array}$ & $\begin{array}{l}\text { Based on absolute } \\
\text { inlet and outlet } \\
\text { pressures }\end{array}$ & $100 \mathrm{~Pa}$ & $+30 \mathrm{~Pa}$ & $\pm 32 \mathrm{~Pa}$ \\
\hline $\begin{array}{l}\text { Interstage steam } \\
\text { saturation temperature }\end{array}$ & $\begin{array}{l}\text { Based on first-stage inlet } \\
T_{s} \text { and differential } \\
\text { temperatures }\end{array}$ & $\begin{array}{l}\text { Based on second- } \\
\text { stage out let and } \\
\text { differential } \\
\text { temperatures }\end{array}$ & $12^{\circ} \mathrm{C}$ & $+0.4^{\circ} \mathrm{C}$ & $\pm 0.44^{\circ} \mathrm{C}$ \\
\hline $\begin{array}{l}\text { Outlet steam } \\
\text { saturation temperature }\end{array}$ & Measured & $\begin{array}{l}\text { Based on inlet } \mathrm{T}_{\mathrm{s}} \\
\text { minus different ial } \\
\text { temperatures }\end{array}$ & $6.0^{\circ} \mathrm{C}$ & $-0.1^{\circ} \mathrm{C}$ & $\pm 0.06^{\circ} \mathrm{C}$ \\
\hline
\end{tabular}




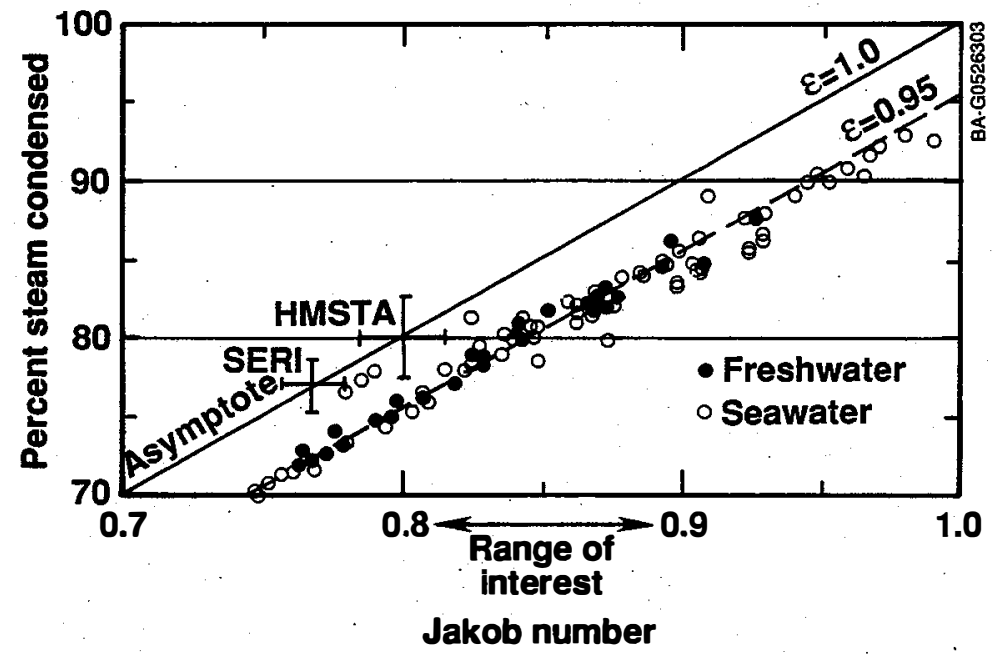

of stage Jakob number obtained at the SERI OTEC laboratory and at the Seacoast Test Facility

it is not intended that the first stage condense all the incoming steam. Most of the data are shown for a steam loading near $G_{1} \sim 0.4 \mathrm{~kg} / \mathrm{m}^{2} \mathrm{~s}$, and at values near $\mathrm{X}_{\mathrm{i}, 1}=0.33 \%$ for noncondensable-gas concentration. The HMTSTA data are right on top of the SERI data. The error bands show the calculated leastsquares error predicted for the two facilities.

A 1 ine of constant effectiveness is shown at $\varepsilon_{1}=0.95$, which fits the data well; this value is typical for the first stage at $G_{1} \sim 0.4 \mathrm{~kg} / \mathrm{m}^{2} \mathrm{~s}$. Similar comparisons using fresh water at other parameter settings confirm the repeatability of the fresh-water results between the two test facilities. The planform area of the condenser stages used in the SERI laboratory is smaller than at the HMTSTA; the environments are different; and specific water distribution systems are also different, although both provide qualitatively good distribution. Because the data show such good agreement, it appears that these parameters are not very important in the ranges tested, rendering the extensive data set obtained at SERI applicable to other conditions.

Figure 7-7 shows the same kind of data obtained when operating with seawater at the HMTSTA, in both side-by-side and coaxial configurations, at all the heights shown in Table 7-1, and with all the water distributors tested. The data include all tested parameters over the range of steam loading and noncondensable-gas content, and show excellent repeatability over the broad test range. Variations in the input parameters result only in differences that are within the error bands; therefore, they are difficult to separate. The lines shown represent constant stage effectiveness from 0.85 to the theoretical limit of 1.0 .

All coaxial data show a higher effectiveness $\left(\varepsilon_{1} \sim 0.95\right)$ than the side-by-side data $\left(\varepsilon_{1} \sim 0.90\right)$, although both show very high effectiveness. The reason for this difference is not known, but it may result from contamination of the fresh water used for the wicks on the steam sensors during the side-by-side tests. This would decrease the calculated value of the effectiveness by about 0.05 compared to the actual value. This difference in calculated effectiveness stems from the difference in driving potential (the denominator in Eq. 7-1) if the wicks were contaminated (see Section 7.4.2). The calculated difference is virtually the same as that observed between the side-by-side and coaxial data presented in Figure 7-7. 
Figure 7-7.

Seawater results of percent condensed in first stage as

a function of

stage Jakob number

for side-by-side

and coarial

configurations

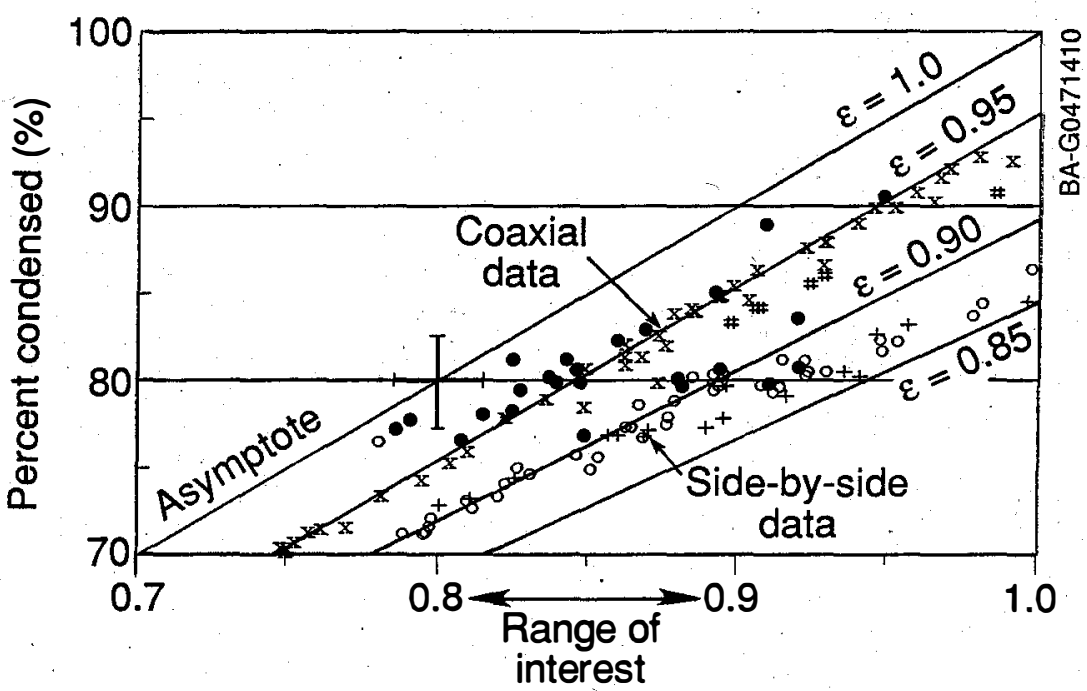

First-stage Jakob number

The coaxial data at $G_{1} \sim 0.4 \mathrm{~kg} / \mathrm{m}^{2} \mathrm{~s}$ (symbol $\mathrm{x}$ ) fall virtually on the line of constant effectiveness $\varepsilon_{1}=0.95$, as did the fresh-water results shown in Figure 7-6. Therefore, given the same operating parameters $\left(\mathrm{G}_{1}, \mathrm{Ja} \mathrm{J}_{1}\right)$, the seawater and fresh-water results are indistinguishable. These results might be so similar because the heat capacity and temperature driving potential tend to compensate for each other. Assuming a constant $\mathrm{G}_{1}$ and $\mathrm{Ja}_{1}$, the 1 iquid loading required in fresh water and seawater is essentially the same,

$$
\frac{\mathrm{L}_{\mathrm{FW}} \quad \mathrm{C}_{\mathrm{p}, \mathrm{SW}}}{\mathrm{L}_{\mathrm{SW}} \quad \mathrm{C}_{\mathrm{p}, \mathrm{FW}}} \cdot \frac{\mathrm{T}_{\mathrm{si}}-\mathrm{T}_{\mathrm{wi}}+0.28}{\mathrm{~T}_{\mathrm{si}}-\mathrm{T}_{\mathrm{wi}}}=\frac{4.0}{4.2} \cdot \frac{6.28}{6.0}=1.05,
$$

providing for virtually the same environment in the structured packing. Despite the different mechanisms of noncondensable-gas release in fresh water and seawater, this difference cannot be resolved in the data.

The gas pressure drop in the first stage remains below $50 \mathrm{~Pa}$ over the tested range, and is only a weak function of steam loading, up to $G_{1} \sim 0.6 \mathrm{~kg} / \mathrm{m}^{2} \mathrm{~s}$ (see Figure 7-8). This results in a drop of the steam saturation temperature through the first stage of about $0.5^{\circ} \mathrm{C}$. At the outlet of the first stage the noncondensable gases are only slightly concentrated $\left(x_{i i, 2}\right.$ is about $\left.1 \%-5 \%\right)$.

The freefall length of the cocurrent stage does not show a measurable effect. Results obtained with the computer model (see below) predict that, at lengths even shorter than those tested, the steam has virtually reached equilibrium conditions, and that the seawater exits at a temperature slightly higher than the saturation temperature, as expected.

Tests were conducted with deaerated seawater while operating the condenser in closed-10op mode. At $G_{1} \sim 0.4 \mathrm{~kg} / \mathrm{m}^{2} \mathrm{~s}$, the deaerated case showed only slightly better thermal effectiveness than the "normal" case. The improvement is about 0.03 in first-stage effectiveness, which is within the error band. 


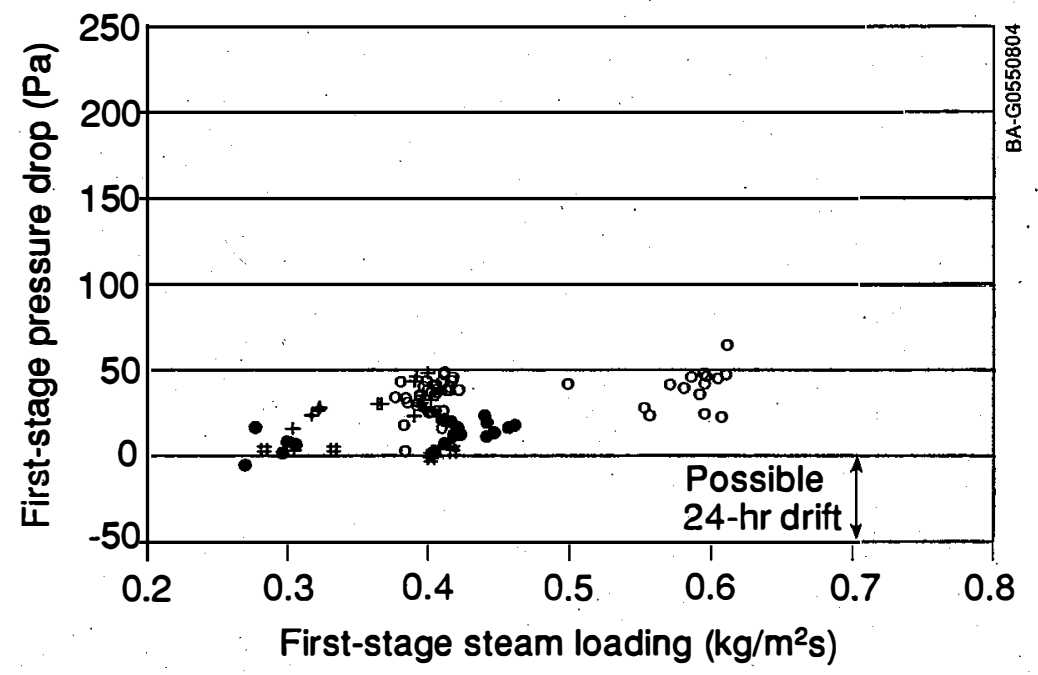

Figure 7-8. Measured gas pressure drop in first-stage (cocurrent) condenser as a function of stage steam loading

Tests were also conducted with qualitatively "poor" water distribution, which reduced the effectiveness by about 0.07 . When no attempt to distribute the water was made, the minimum effectiveness observed was 0.55 . Although ê operating with no water distribution is not suggested, it is encouraging that the worst-case limit for the DCC first stage with structured packing is in the range of best performances by many other condensers and geometries.

Tests conducted to identify the effects of water type, cold seawater deaeration, inlet noncondensable-gas mass fraction, steam loading, and packing length all showed results that indicated very small changes in first-stage effectiveness. It is difficult to present comparative test data, because the effects to be analyzed result in performance variations of the same order as those caused by slight changes in operating parameters. They also fall within the experimental uncertainty. HMTSTA system conditions could not be held precisely constant during all these tests. Therefore, for ease of presentation, the data were compared to model predictions (validation of the models is discussed below), and these predictions are used in Figure 7-9 to display the small effects of the parameters under study. The curves were generated using the cocurrent DCC computer model at constant inlet water and steam conditions, at the average values tested. For $\mathrm{Ja}_{1}=0.85$ all the different conditions change the effectiveness by no more than 0.1 . The largest effect is caused by changes in steam loading, from 0.1 to $0.6 \mathrm{~kg} / \mathrm{m}^{2} \mathrm{~s}$; highest effectiveness is obtained for the lowest steam loading, and increased sensitivity to this parameter is seen for the higher $G_{1}$. The next largest effect is caused by changes in noncondensable-gas inlet concentration. This suggests that deaeration in the evaporator would improve performance slightly if most of the noncondensable gases can be removed. Packing length has no effect in the range shown. Deaerated cold seawater behaves identically to fresh water and very similarly to "normal" seawater at low inlet noncondensable-gas concentration, suggesting that cold-water deaeration has little potential impact on performance of the first stage.

\subsubsection{Results for the Second Stage (Countercurrent)}

The second stage condenses the steam coming out of the first stage and concentrates the noncondensable gases to near the maximum permissible. This stage also shows. similar performance whether it operates in fresh water or 
Figure 7-9. Range of variation in first-stage effectiveness resulting from changes in various input parameters

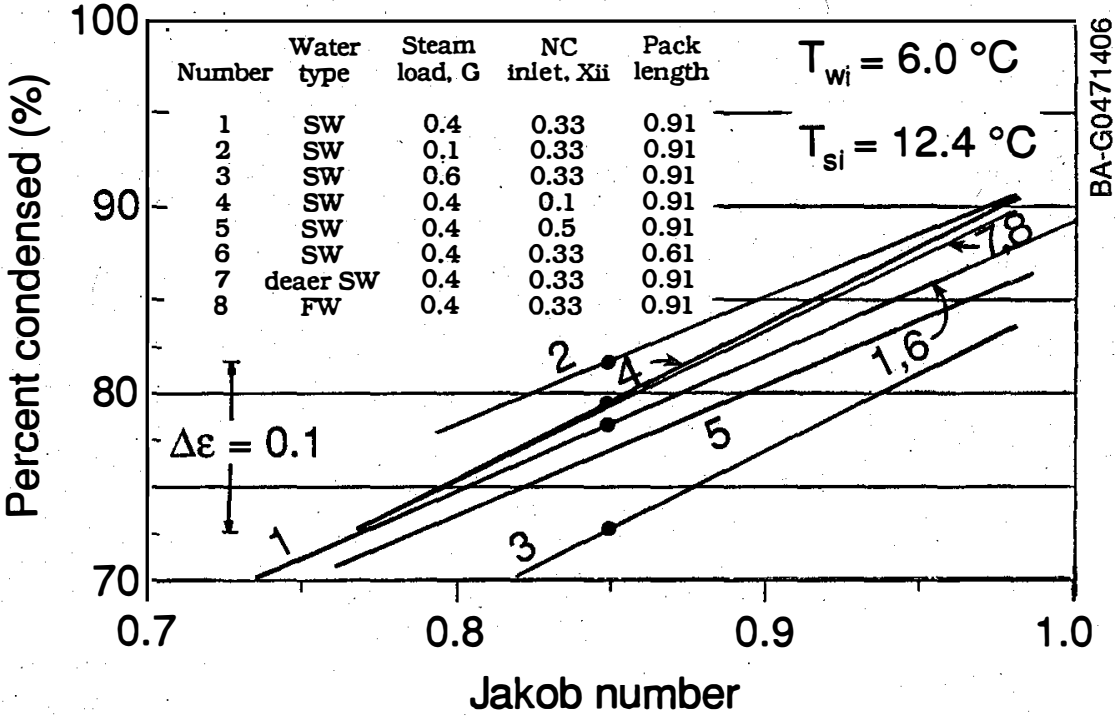

seawater. In fresh-water operation (Bharathan, Parsons, and Al thof 1988), the countercurrent condenser can be characterized by a constant $98 \%$ condensed at any $\mathrm{Ja}_{2}>1$. Therefore, the effectiveness of this stage is inversely proportional to $\mathrm{Ja}_{2}$.

Comparisons of data obtained at SERI and at the HMTSTA. show excellent agreement. Figure 7-10 shows all seawater data collected for $\mathrm{Ja}_{2}<2$ and for broad ranges of $G_{2}$ and $x_{i i, 2^{*}}$. The dashed lines approximate the slight dependence of the data on noncondensable-gas inlet concentration for $\mathrm{X}_{\mathrm{i} i, 2} \sim 1 \%$ and $3 \%$. The theoretical limit of $\mathrm{Ja}_{2}$ is one, if noncondensable gases are not present. Countercurrent condensation is an efficient process because the steam encounters colder water as it proceeds through the stage. Typically for operation with seawater, the second stage condenses from $95 \%$ to $98 \%$ of the incoming steam. Therefore, the practical range of interest for $\mathrm{Ja}_{2}$ can be maintained at about 1.1 to 1.2. Note that side-by-side and coaxial data are very close for the second stage.

A conservative assumption for seawater is to take a constant $95 \%$ condensed. An effectiveness of 0.85 is readily obtained with seawater for $\mathrm{Ja}_{2}$ at about 1.1. Because this stage must process only a fraction of the steam that enters the first stage, it is smaller than the first stage, and it uses less water; therefore its impact on overall effectiveness of the DCC is small.

The gas pressure drop is almost a quadratic function of the stem loading of the stage. It can be maintained below $50 \mathrm{~Pa}$ for $\mathrm{G}_{2}<0.3 \mathrm{~kg} / \mathrm{m}^{2} \mathrm{~s}$, but climbs rapidly at higher loadings (see Figure 7-11). The approach temperature between steam outlet and water inlet $\Delta \mathrm{T}_{\mathrm{so}}, \mathrm{wi}, 2$ is $1 \mathrm{ow}$, about $0.5^{\circ} \mathrm{C}$, as can be seen in section B.3 of Appendix B. In fact this difference can be negative (down to $-0.28^{\circ} \mathrm{C}$ ) when operating with seawater because of the depression of the partial pressure. The outlet condition determines how much steam must be exhausted with the noncondensable gases. Typically, the noncondensable gases are concentrated in this stage and are exhausted at $40 \%$ to $70 \%$ concentration. 


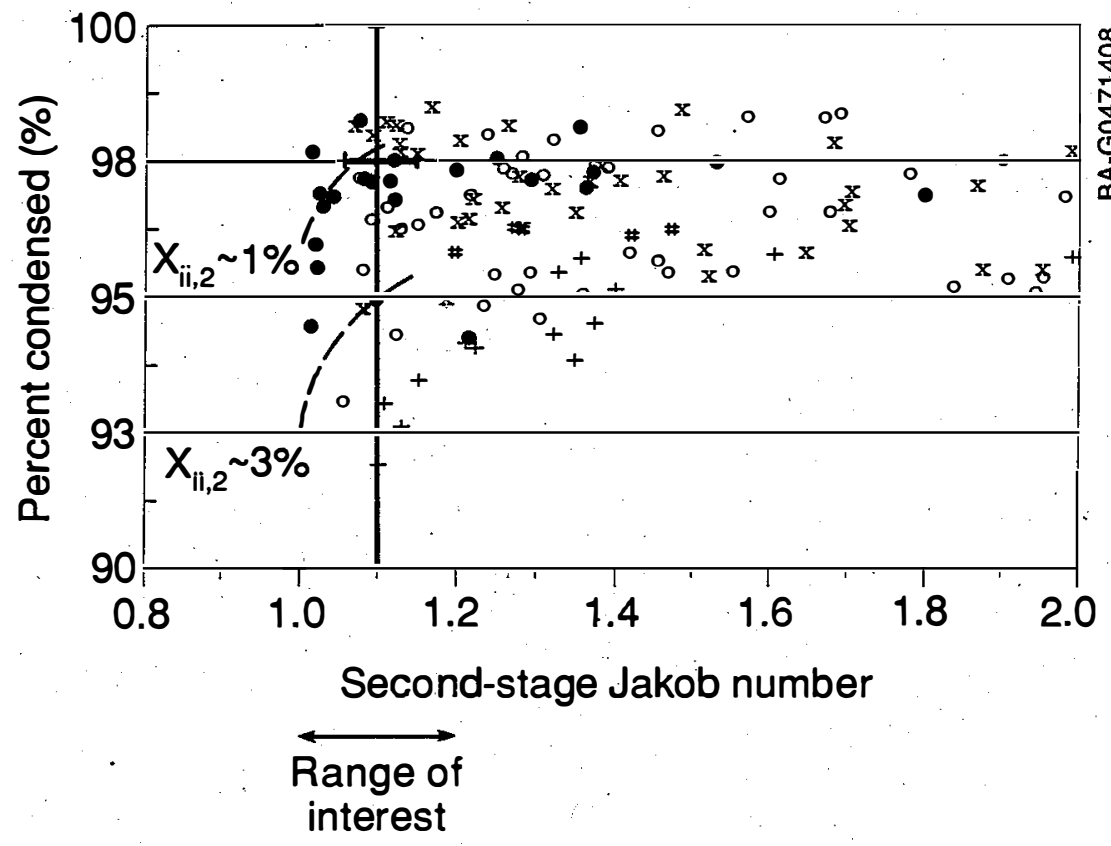

Figure 7-10. Seawater results of percent condensed in second stage as a function of stage Jakob number for side-byside and coarial configurations

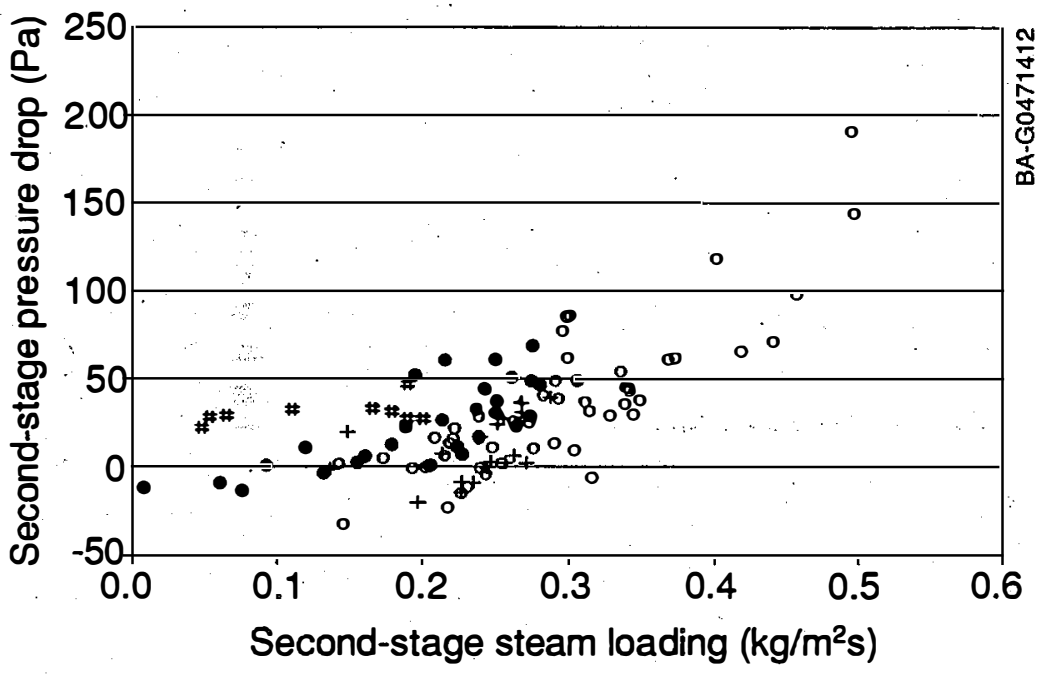

Figure 7-11. Measured gas pressure drop in second stage as a function of stage steam loading

\subsubsection{Computer Models Validation for Seawater}

The data collected at the STF were compared to the predictions obtained from the models for each stage. The following modifications were made to the existing models (Bharathan, Parsons, and Althof 1988):

- Inclusion of seawater physical properties

- Calculation of seawater saturation temperature and pressure

- Modification of the mass-transfer equations to account for the equilibrium saturation pressure for seawater as compared to the equilibrium value for fresh water. This requires maintaining separate, consistent definitions of sensible heat in the liquid and vapor. 
- Modification of the local gas friction coefficient in the Darcy-Weisbach equation--see Eqs. 2-38 and 2-39 in Bharathan, Parsons, and Althof (1988)-which is expressed here as $f=0.171+3+\left(92.7 / \mathrm{Re}_{g}\right)$. The factor of three accounts for the additional losses incurred in a stack of packing consisting of $0.15-\mathrm{m}$ sections, instead of the $0.3-\mathrm{m}$ sections used in the SERI freshwater tests.

The predictions of both models followed all the significant trends observed in the experiments with seawater. Comparison of the model predictions with all data collected yields prediction capabilities as summarized in Table 7-5. The predictions are not quite as good as they were for the fresh-water tests at SERI, mostly because the error bands are larger for the data obtained at the HMTSTA. However, they are quite satisfactory for engineering design purposes.

Table 7-5. Prediction Capabilities of Direct-Contact Condenser Models

\begin{tabular}{cccc}
\hline Stage & Parameter & $\begin{array}{c}\text { Average } \\
\text { Deviation } \\
\text { (model to data) }\end{array}$ & $\begin{array}{c}\text { Standard } \\
\text { Deviation }\end{array}$ \\
\hline Cocurrent & Percent condensed & $-0.7 \%$ & $\pm 2.8 \%$ \\
Countercurrent & Pressure drop & $18 \mathrm{~Pa}$ & $\pm 7.4 \mathrm{~Pa}$ \\
& Percent condensed & $0.3 \%$ & $\pm 1.0 \%$ \\
& Pressure drop & $19 \mathrm{~Pa}$ & $\pm 41 \mathrm{~Pa}$ \\
\hline
\end{tabular}

\subsubsection{Overall Condenser Performance}

The data showing the combined effect of the first and second condenser stages with the fixed area ratio of 3:1 originally selected for the HMTSTA are shown in Figure 7-12 for all gas and noncondensable-gas loadings tested in the coaxial configuration. Most of the points are taken at $G_{1} \cong 0.4-0.47 \mathrm{~kg} / \mathrm{m}^{2} \mathrm{~s}$, but several are at higher steam loading. The symbols used in this figure identify the range of condenser inlet steam temperature. An ideal condenser would operate at the upper right corner of the graph, where both performance parameters have a value of one. A real condenser can operate within $10 \%$ of this thermodynamic limit.

An increasing value of $V$ represents a reduction in steam exhausted with the noncondensable gases, implying lower exhaust power consumption. An increasing value of thermal effectiveness represents a reduction of cold seawater use, implying lower seawater pumping power. Exhaust and seawater pumping power account for the majority of parasitic power losses in the system. Therefore, the minimum system parasitic losses occur when the system operates at the upper right corner (the ideal performance limit). Constant system parasitic losses can be represented by a set of curves that encircle this corner, as shown by the dashed 1 ines in Figure 7-12. The exact shape of the curves depends on the specific performance of other system components, but they tend to be oval as shown. Curves that are farther away from the upper right corner imply larger overall parasitic losses, thus less output of net power from the 
system. By adjusting geometric and operating parameters of the condenser stages, the condenser can be designed to operate at any point along one of these parasitic curves, which would result in the same system parasitic losses. Thus system analysis must give the appropriate selection of condenser operating conditions for a specific system and application. Therefore, several combinations of parameters can provide thermal effectiveness near 0.86 , for vent ratios near 0.9 . These values were selected based on system modeling as nominal points for design of the NPPE before the seawater tests were conducted. Further system analysis based on the recent results obtained with seawater can be used to refine the selection of nominal operating parameters during the NPPE design effort, if necessary.

The overall results are insensitive to the steam inlet temperature for the range shown in Figure 7-12. This implies that it is possible to adjust the operational parameters between the two stages so that the same overall behavior is observed while obtaining the required inlet steam temperature.

Figure 7-13 compares the prediction of the models to the calculated quantity of steam exhausted from the DCC unit, in terms of percent steam mass uncondensed. The overall prediction is obtained by combining the predictions for each stage, using the appropriate inlet conditions for each. Given the small quantity of steam that remains uncondensed (generally much less than $1 \%)$, the agreement between the models and all the data collected is remarkable. Note that neither the data nor the models can resolve such small absolute values. For any type of condenser operating at these low pressures, it is not possible to measure the required quantities with accuracy sufficient to resolve these differences in mass flow rates.

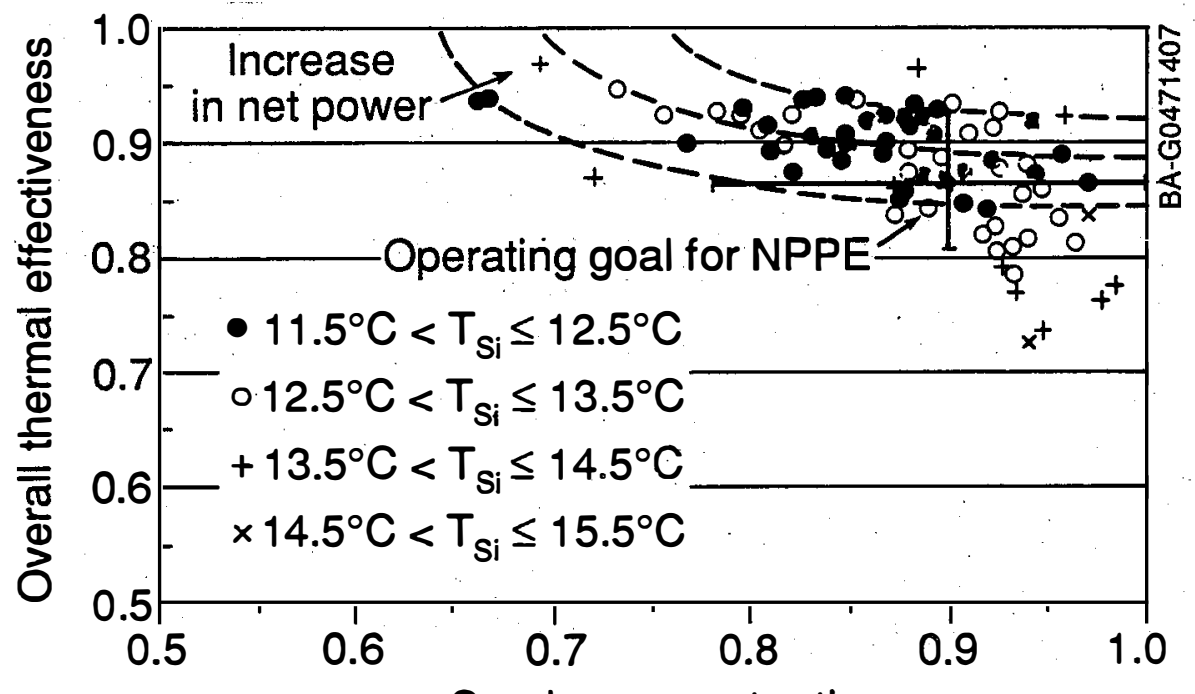

Condenser vent ratio
Figure 7-12. Overall performance of two direct-contact condenser stages in seawater for coarial configuration 
Figure 7-13. Comparison of uncondensed steam exhausted from direct-contact condenser unit with respect to combined model predictions

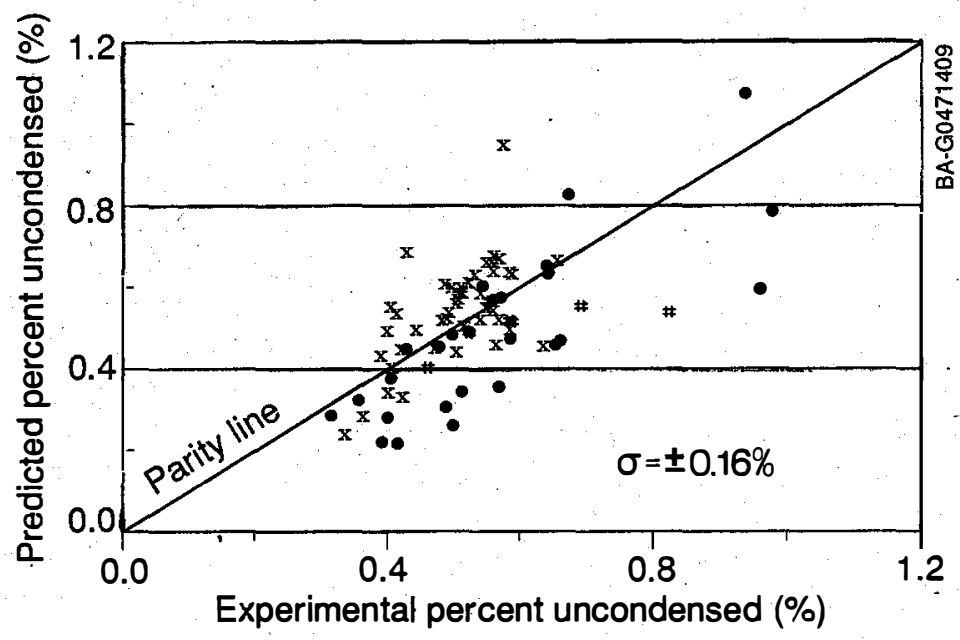

\subsubsection{Hydraulic Losses}

Components contributing to hydraulic losses in the supply and discharge water for the DCC stages include the piping and flow controls to and from the sumps, the distributors over the packing, and the heights required for the condensers. The static losses occur because of the free-fall height required for the condensers (see Table 7-1). The overall dynamic losses for the low-loss water distributors (vertical pipes and drip tray) are shown in Table 7-6 in terms of overall hydraulic loss coefficients (the ratio of head losses to the velocity head), which were calculated for nominal supply pipe diameters of

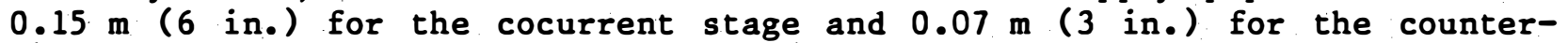
current stage, respectively. The predictions were made using standard frictional pressure loss calculations for the layout at the STF (Crane Co. 1985). In both cases, the dynamic losses measured for the DCC were lower than predicted.

Table 7-6. Overall Water-Side Dynamic Loss Coefficients in Piping to Direct-Contact Condenser Stages

\begin{tabular}{lcccc}
\hline \multicolumn{1}{c}{ Stage } & $\begin{array}{c}\text { Distribution } \\
\text { Type }\end{array}$ & $\begin{array}{c}\text { Measured } \\
\text { Coefficient }\end{array}$ & $\begin{array}{c}\text { Predicted } \\
\text { Coefficient }\end{array}$ & $\begin{array}{c}\text { Prediction } \\
\text { Error }\end{array}$ \\
\hline Cocurrent & $\begin{array}{c}\text { Spouting } \\
\text { vertical pipes }\end{array}$ & 3.7 & 4.6 & $26 \%$ \\
Countercurrent & Drip tray & 4.5 & 5.2 & $16 \%$ \\
\hline
\end{tabular}

Measurements of static heads at intermediate positions in the plping appeared to indicate that the losses were lower than expected in the upper parts of the piping (lower operating pressures). The lower parts appeared to show losses in line with predictions. A possible explanation is that the observed desorption of dissolved gases in the upper parts (near the low pressures of 
the DCC chamber) caused a pumping action similar to that of an airlift pump. The lift's effect may be larger than that of the increase in frictional losses, which are expected from the bulk-velocity increase in the two-phase flow region.

Overall, total hydraulic losses in the HMTSTA amounted to slightly more than the desired $2 \mathrm{~m}$ for NPPE nominal conditions; however, the losses encountered in the lower sections can readily be reduced by modifying the size or design of this piping.

\subsection{CONCLUSIONS}

Extensive tests of two DCC stages operating with seawater at typical OC-OTEC conditions were conducted between December 1988 and May 1989. They yielded a substantial data base over broad operating ranges suitable for OC-OTEC systems. The data showed excellent consistency and variations smaller than the predicted error estimates, giving confidence in the data collected. The data confirm earlier predictions of excellent thermal, exhaust, and hydraulic performance for the DCC. Overall thermal effectiveness above 0.9 has been shown consistently for vent ratios of 0.9 in the presence of high noncondensable-gas content. This indicates that the DCC unit can operate within $10 \%$ of the theoretical limits for cold-water use and venting requirements. Within experimental uncertainty, thermal performance in seawater and fresh-water operation cannot be distinguished. Total hydraulic losses equivalent to less than 2-m heads are easily attainable. Computer models describing the condensation process in the DCC stages accurately predict the process under a wide range of geometries and operating conditions.

In all cases, confidence in both data and computer model predictions is high and gives increased certainty regarding engineering design of direct-contact condensers for larger-scale OC-OTEC systems.

\subsection{IMPACT OF RESULTS ON NPPE SYSTEM DESIGN}

The results obtained at the STF for seawater generally matched or surpassed initial expectations. The only exception concerns the quantities of dissolved gases that are released from the water streams, about $85 \%-100 \%$. This can be addressed by designing the vent system to handle a larger-than-expected gas flow. The thermal performance of the DCC observed in the coaxial configuration is better than expected; this can be used to reduce the power required for water pumping or, for fixed cold-water flow, to decrease the inlet steam temperature to the condenser, giving the turbine a lower exhaust pressure and therefore a larger temperature difference for increased power output.

Exhaust venting requirements very near the theoretical limit were obtained. For sizing of a vacuum system, the limitations of prediction capabilities and data resolution can be alleviated by adding a precooler just before the vacuum system. This unit would consume very 1 ittle power and cold seawater but it would ensure that any steam that may not be condensed in the DCC is reduced to equilibrium level, because the precooler would condense at least $95 \%$ of the already very small quantity of steam potentially left over from the second stage. Additionally, this would compress the gas slightly because of the lower gas temperature in the precooler. 


\subsection{FURTHER RESEARCH NEEDS}

The data obtained at the STF with the DCC are sufficiently accurate and cover a sufficiently large range of possible OC-OTEC operating conditions that larger systems such as the NPPE or larger may be designed confidently. Additional tests in the larger system need to be conducted only over a restricted test matrix to confirm. that results obtained in the HMTSTA remain applicable. These tests are recommended because slightly different geometries of the steam passages and water distributors will be used in the larger systems, and the uniformity of these distribution systems needs to be tested. However, the HMTSTA data have shown that the performance of the DCC is not affected very strongly by steam or cold seawater maldistribution. Therefore only a small effect on performance is expected.

Some modifications of the area ratios, steam loadings, and water loadings tested in the HMTSTA will be needed to accommodate different configurations. The computer models are sufficiently accurate that parametric runs can be conducted to identify the most suitable configuration of each condenser stage for each particular application.

The packing material selected for these tests showed excellent performance. However, even more effective packings (e.g., gauze structured packing with even higher usable surface area per unit volume) have become commercial-ly available recently. An assessment of the potential gains might be undertaken with the existing computer models to ascertain whether measurable advantages are possible.

\subsection{REFERENCES}

Bharathan, D., B. K. Parsons, and J. A. Althof, May 1988, Direct-Contact Condensers for Open-Cycle OTEC Applications: Model Validation with FreshWater Experiments for Stuctured Packings, SERI/TR-253-3108, Golden, CO: Solar Energy Research Institute.

Bravo, J. L., J. A. Rocha, and J. R. Fair, Jan. 1985, "Mass Transfer in Gauze Packings," Hydrocarbon Processing, pp. 91-95.

Bravo, J. L., J. A. Rocha, and J. R. Fair, Mar. 1986, "Pressure Drop in Structures Packing," Hydrocarbon Processing, pp. 45-59.

Colburn, A. P., and O. A. Hougen, Nov. 1934, "Design of Cooler Condensers for Mixtures of Vapors with Noncondensing Gases," Industrial and Engineering Chemistry, Vol. 26, Pp. 1178-1182.

Crane Co.,, 1985, "Flow of Fluids through Valves, Fittings and Pipes," Engineering Division Technical Paper No. 410, New York: Crane Co.

Fair, J. R., Aug. 1961, "Design of Direct-Contact Gas Coolers,". Petroleum and Chemical Engineer, Vo1. 2, PP. 203-210. 
Fair, J. R., June 1972, "Designing Direct-Contact Coolers/Condensers," Chemical Engineering, Vol. 2, pp. 91-100. (See also "Process Heat Transfer by Direct Fluid Phase Contact," Chemical Engineering Progress Symposium series no. 118, Vol. 68, pp. 1-11, 1972.)

Krock, H. J., Dec. 1981, Gas Analysis of Water Samples for OTEC Program, Manoa: University of Hawaii Technical Report, No. 57.

Parsons, B. K., H. F. Link, D. Bharathan, A. A. Pesaran, F. Zangrando, and C. B. Pancha1, April 1989, Test Plan for the Heat- and Mass-Transfer Scoping Test Apparatus: Phase I and Phase II Tests, Internal Program Report, nintinn nes sor Golden, CO: Solar Energy Research Institute. 


\section{CHAPTER 8.0 \\ CARBON DIOXIDE RELEASE FROM \\ OCEAN THERMAL ENERGY CONVERSION (OTEC) CYCLES}

Herbert J. Green

Solar Energy Research Institute 


\subsection{NOMENCLATURE}

\begin{tabular}{|c|c|}
\hline Abbrev. & Description \\
\hline (g) & gas \\
\hline (s) & solute \\
\hline $\mathrm{DCO}_{2}$ & $\begin{array}{l}\text { dissolved } \mathrm{CO}_{2} \text { (also known as free } \mathrm{CO}_{2} \text { ), the sum of the } \\
\text { concentrations of dissolved molecular carbon dioxide, } \\
\mathrm{CO}_{2}(\mathrm{~s}) \text {, and carbonic acid, } \mathrm{H}_{2} \mathrm{CO}_{3}\end{array}$ \\
\hline $\mathrm{TCO}_{2}$ & $\begin{array}{l}\text { total } \mathrm{CO}_{2} \text {, the sum of the concentrations of all four } \mathrm{CO}_{2} \\
\text { species in seawater }\end{array}$ \\
\hline $\mathrm{PCO}_{2}$ & partial pressure of $\mathrm{CO}_{2}$ in seawater \\
\hline $\mathrm{STCO}_{2}$ & salinity-normalized $\mathrm{TCO}_{2}$ \\
\hline
\end{tabular}

\section{Units and Conversions}

$1 \mathrm{micromole} / \mathrm{kg}\left(\mathrm{CO}_{2}\right.$ in seawater $)=1 \mu \mathrm{M} / \mathrm{kg}=0.044 \mathrm{ppm}$

1 mole $\mathrm{CO}_{2}=44 \mathrm{~g}$ 


\subsection{BACKGROUND}

Emission of carbon dioxide $\left(\mathrm{CO}_{2}\right)$ from the combustion of fossil fuels and the resulting prospect of global warming are environmental issues that are drawing increasing attention from scientists and the public (Houghton and Woodwell 1989; Schneider 1989). Although renewable energy is being promated as a means of avoiding these emissions, OTEC is one renewable-energy technology that may release some ... However, the measured quantity released is a small fraction of that released by conventional power plants, as discussed in this chapter.

Three OTEC cycles are discussed in this chapter: closed cycle, open cycle, and hybrid cycle. In an open-cycle system, warm seawater is introduced into a chamber in which the pressure is below the seawater vapor pressure. Flash evaporation of the seawater produces steam, which then passes through a turbine. The steam is consumed either in a direct-contact condenser or in a surface condenser that produces desalinated water. In a closed-cycle system, a working fluid such as ammonia or Freon is circulated in a closed loop consisting of an evaporator, a turbine, a condenser, and a feed pump. Warm seawater provides heat to the evaporator, and cold seawater is used to cool the condenser. A hybrid-cycle system combines the flash evaporator of the open cycle with a closed-cycle loop. The steam flashed from warm seawater in the evaporator passes into a surface heat exchanger that is a combination steam condenser/ammonia evaporator. In this manner, the condensing steam provides heat to the closed-cycle loop and produces desalinated water (Panchal and Bell 1987).

Two types of $\mathrm{CO}_{2}$ release in OTEC cycles will be considered. First, there may be immediate release, i.e., any release from the OTEC plant itself that occurs during power generation. Second, there may be long-term release from the $\mathrm{CO}_{2}-$ rich cold seawater discharged from an OTEC plant. $\mathrm{CO}_{2}$ produced during plant construction or demolition will not be assessed in this chapter. Immediate release occurs in open-cycle or hybrid-cycle components such as flash evaporators and direct-contact condensers. In these components, seawater is exposed to subatmospheric pressures that promote outgassing of $\mathrm{CO}_{2}$ (as well as $\mathrm{N}_{2}$ and $\mathrm{O}_{2}$ ) from both warm and cold seawater. A closed-cycle plant, on the other hand, is expected to have no immediate $\mathrm{CO}_{2}$ release because the warm seawater passes through surface heat exchangers. Some immediate release is possible if these heat exchangers are at subatmospheric pressures, which may occur if they are installed at a height above sea level.

Experiments at the STF early in 1989 offered an opportunity to measure the $\mathrm{CO}_{2}$ release from open-cycle components under operating conditions considered prototypical for future open-cycle oTEC plants. The resulting data provide a basis for predicting immediate $\mathrm{CO}_{2}$ release from open and hybrid OTEC cycles. The Carbon Dioxide Research Group under $\mathrm{Dr}$. C. D. Keeling at the Scripps Institution of Oceanography (Scripps) in La Jolla, California, analyzed the $\mathrm{CO}_{2}$ content of the seawater samples taken for this study. Scripps has $10^{2}$ years' experience with the measurement of $\mathrm{CO}_{2}$ in seawater using a cryogenic extraction technique. This technique provides the high resolution and repeatability necessary to measure potentially small changes in $\mathrm{CO}_{2}$ content. Scripps has also developed reliable and well-documented sampling methods for remote locations. 


\subsection{CHEMISTRY OF SEAWATER}

Carbon dioxide in seawater participates in the following four reactions:

$$
\begin{aligned}
& \mathrm{CO}_{2}(\mathrm{~g})+\mathrm{H}_{2} \mathrm{O} \leftrightharpoons \mathrm{CO}_{2}(\mathrm{~s})+\mathrm{H}_{2} \mathrm{O} \\
& \mathrm{CO}_{2}(\mathrm{~s})+\mathrm{H}_{2} \mathrm{O} \leftrightharpoons \mathrm{H}_{2} \mathrm{CO}_{3} \\
& \mathrm{H}_{2} \mathrm{CO}_{3} \leftrightharpoons \mathrm{HCO}_{3}^{-}+\mathrm{H}^{+} \\
& \mathrm{HCO}_{3}^{-} \leftrightharpoons \mathrm{CO}_{3}^{-2}+\mathrm{H}^{+}
\end{aligned}
$$

where ( $g$ ) denotes gas and $(s)$ denotes solute.

Thorough treatments of this chemistry are available in numerous texts, including Riley and Chester (1971) and Sverdrup, Johnson, and Fleming (1970). Because very little carbonic acid is present in seawater, the concentrations of dissolved molecular carbon dioxide, $\mathrm{CO}_{2}(\mathrm{~s})$, and carbonic acid, $\mathrm{H}_{2} \mathrm{CO}_{3}$, are commonly added together. This sum will be called the dissolved $\mathrm{CO}_{2}$ or $\mathrm{DCO}_{2}$. "Free $\mathrm{CO}_{2}$ " is also a commonly used term for $\mathrm{DCO}_{2}$. The sum of $\mathrm{DCO}_{2}$ plus the bicarbonate ions, $\mathrm{HCO}_{3}^{-}$, and the carbonate ions, $\mathrm{CO}_{3}^{-2}$, will be called total $\mathrm{CO}_{2}$ or $\mathrm{TCO}_{2}$. The partial pressure of $\mathrm{CO}_{2}$ in the seawater will be called $\mathrm{PCO}_{2} \cdot$ Only the $\mathrm{DCO}_{2}$ contributes to the $\mathrm{PCO}_{2}$ in the seawater.

The relative concentrations of these species in seawater can be seen in Table 8-1, which gives representative data from Hawaiian waters. Most of the $\mathrm{CO}_{2}$ in seawater exists as bicarbonate ions, with only small concentrations of $\mathrm{DCO}_{2}$. The deep cold seawater used as the heat sink in OTEC cycles has about $20 \%$ more $\mathrm{TCO}_{2}$ than does the warm surface seawater. The higher $\mathrm{TCO}_{2}$ content partly results from the processes of respiration by marine animals and decomposition of organic matter that sinks into the ocean. In addition, this seawater was last in contact with the atmosphere in the polar regions. The cold temperatures there result in an increased solubility of $\mathrm{CO}_{2}$ compared to the warm surface seawater. The $\mathrm{TCO}_{2}$ concentration as a function of depth for the North Pacific Ocean is shown in Figure 8-1 (Takahashi, Broecker, and Bainbridge 1981). The depths of interest for supplying cold seawater to OTEC cycles are nominally between 0.5 and $1.0 \mathrm{~km}$. The natural geographic variability of $\mathrm{CO}_{2}$ content is apparent in these data. The surface seawater typically has a $\mathrm{PCO}_{2}$ near the atmospheric partial pressure of $\mathrm{CO}_{2}$, currently about $350 \mathrm{ppm}$. The $\mathrm{PCO}_{2}$ of cold seawater is between three and four times higher than that of surface seawater.

Table 8-1. Concentrations of the $\mathrm{CO}_{2}$ Species ip Seawater, Representative Data for Seawater near Oahu, Hawaii(a) (Rrock 1981)

\begin{tabular}{ccccc}
\hline $\begin{array}{c}\text { Sample Depth } \\
(\mathrm{m})\end{array}$ & $\begin{array}{c}\mathrm{TCO}_{2} \\
(\mu \mathrm{mole} / \mathrm{L})\end{array}$ & $\begin{array}{c}\mathrm{DCO}_{2} \\
(\mu \mathrm{mole} / \mathrm{L})\end{array}$ & $\begin{array}{c}\mathrm{HCO}_{3}^{-} \\
(\mu \mathrm{mole} / \mathrm{L})\end{array}$ & $\begin{array}{c}\mathrm{CO}_{3}{ }^{-2} \\
(\mu \mathrm{mole} / \mathrm{L})\end{array}$ \\
\hline 9 & 1912 & 7 & 1634 & 271 \\
687 & 2315 & 54 & 2203 & 58 \\
\hline
\end{tabular}

(a) Oahu OTEC-6; May 29, 1981; Site 2, Cast 3. 


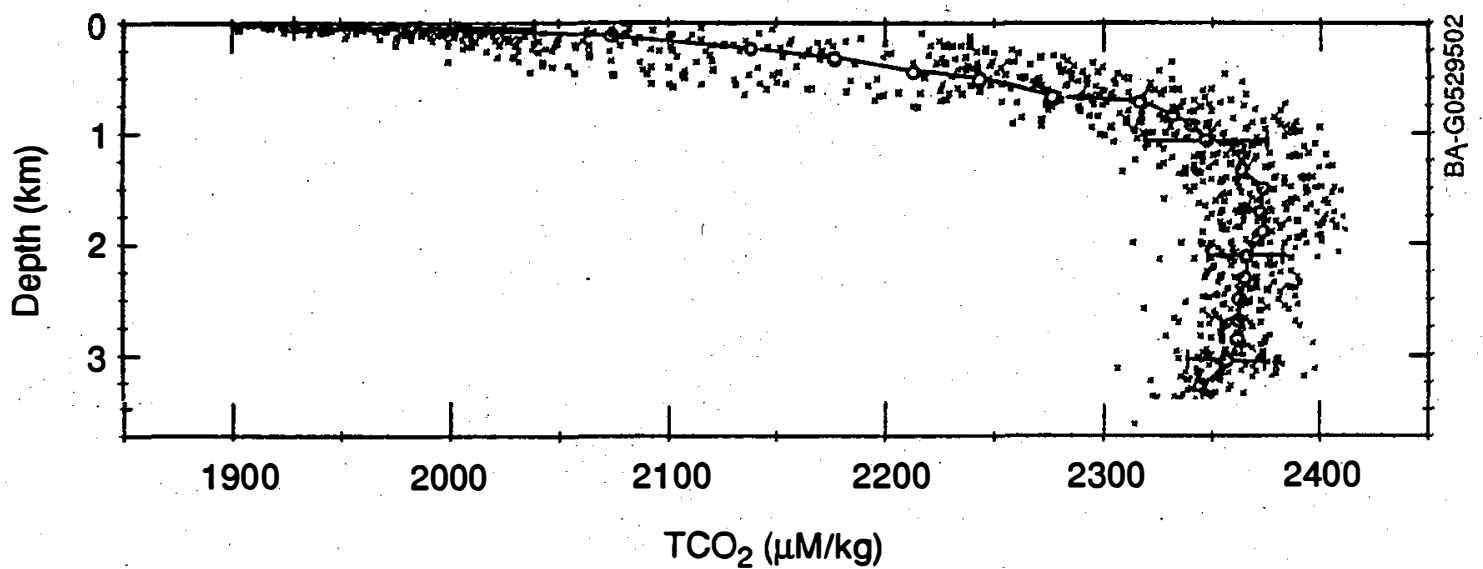

Figure 8-1. Total $\mathrm{CO}_{2}$ concentration in the North Pacific Ocean (Takahashi, T., W. S. Broecker, and A. E. Bainbridge, 1981, "The Alkalinity and Total Carbon Diozide Concentration in the World Oceans," SCOPE 16, Carbon Cycle Modelling, edited by Bert Bolin, Chichester, England: John Wiley and Sons)

Seawater contains significantly more $\mathrm{CO}_{2}$ than any other atmospheric gas (Table 8-2), but the seawater content of these gases is not indicative of the quantities that will be released under vacuum. The $\mathrm{CO}_{2}(\mathrm{~s})$ in seawater, along with the dissolved $\mathrm{N}_{2}$ and $\mathrm{O}_{2}$, should be readily released in the presence of subatmospheric pressures. The loss of $\mathrm{CO}_{2}(\mathrm{~s})$ creates a nonequilibrium condition in the seawater which causes bicarbonate to be converted to $\mathrm{CO}_{2}(\mathrm{~s})$ by the reactions noted above. The kinetics of the hydration of $\mathrm{CO}_{2}$ (reaction 8-2) are sufficiently slow that $\mathrm{CO}_{2}$ has a half life in seawater on the order of minutes. (Riley and Chester 1971). This would indicate that only a small fraction of the bicarbonate and carbonate ions will be converted to $\mathrm{CO}_{2}(\mathrm{~s})$ and released in the brief time required for seawater to pass through an open-cycle system. The seawater residence time in a direct-contact condenser is estimated to be between 1 and $2 \mathrm{~s}$, and its residence time in a flash evaporator is on the order of $1 \mathrm{~s}$. Previously, no data have been available to establish that the $\mathrm{CO}_{2}$ release was, in fact, limited to the $\mathrm{DCO}_{2} \cdot$ If a larger release of $\mathrm{CO}_{2}$ were possible, this would have created environmental impacts and would also have affected the size and power consumption of the compressor required to exhaust noncondensable gases from the condenser of an open-cycle system.

Table 8-2. Gas Content of Seawater near Oahu, Hawaii (Rrock 1981)

\begin{tabular}{lcccc}
\hline & $\begin{array}{c}\text { Sample } \\
\text { Depths } \\
(\mathrm{m})\end{array}$ & $\begin{array}{c}\text { Dissolved } \\
\mathrm{O}_{2} \\
(\mathrm{ppm})\end{array}$ & $\begin{array}{c}\text { Dissolved } \\
\mathrm{N}_{2} \\
(\mathrm{ppm})\end{array}$ & $\begin{array}{c}\text { Total Dissolved } \\
\mathrm{CO}_{2} \mathrm{TCO}_{2} \\
(\mathrm{ppm})\end{array}$ \\
\hline $\begin{array}{l}\text { Warm } \\
\text { Seawater }\end{array}$ & $27-50$ & 6.4 & 11.1 & 84.0 \\
$\begin{array}{l}\text { Cold } \\
\text { Seawater }\end{array}$ & $665-681$ & 1.1 & 14.4 & 102.0 \\
\hline
\end{tabular}

(1 $\mu \mathrm{mole} / \mathrm{kg} \mathrm{CO}$ CO$\left._{2}=0.044 \mathrm{ppm}\right)$ 


\subsection{DESCRIPTION OF EXPERIMENT}

\subsubsection{Sampling Method}

The $\mathrm{CO}_{2}$ released from the HMTSTA open-cycle evaporator and direct-contact condenser was measured by sampling the supply and discharge seawater from these components and performing laboratory analysis for $\mathrm{CO}_{2}$ content. The HMTSTA was maintained in steady-state operation while the samples were taken. The flash evaporator in the HMTSTA was configured with a single 20.3-cm-diameter vertical spout. The direct-contact condenser was in a two-stage configuration, as described in Chapter 7 . The operating conditions for both evaporator and condenser are shown in Table 8-3. The calculated steam flow rates, also shown in the table, agree to about 1\%; the last digit in parentheses is not significant. The configuration of these components and their operating conditions are both projected to be prototypical of future open-cycle OTEC power plants. Thus, the rate of $\mathrm{CO}_{2}$ release from these components should also be prototypical.

Table 8-3. Operating Conditions for the Evaporator and Condenser

\begin{tabular}{lccccc}
\hline & $\begin{array}{c}\text { Inlet } \\
\text { Temp } \\
\left({ }^{\circ} \mathrm{C}\right)\end{array}$ & $\begin{array}{c}\text { Outlet } \\
\text { Temp. } \\
\left({ }^{\circ} \mathrm{C}\right)\end{array}$ & $\begin{array}{c}\text { Seawater } \\
\text { Flow Rate } \\
(\mathrm{kg} / \mathrm{s})\end{array}$ & $\begin{array}{c}\text { Liquid } \\
\text { Loading } \\
\left(\mathrm{kg} / \mathrm{m}^{2} \mathrm{~s}\right)\end{array}$ & $\begin{array}{c}\text { Steam } \\
\text { Flow Rate } \\
(\mathrm{kg} / \mathrm{s})\end{array}$ \\
\hline $\begin{array}{l}\text { Flash } \\
\text { Evaporator }\end{array}$ & 24.9 & 21.2 & 28.9 & 32.2 & $0.17(4)$ \\
$\begin{array}{l}\text { Direct-Contact } \\
\text { Condenser }\end{array}$ & 6.5 & 13.8 & 15.0 & $24.3(1 \mathrm{st}$ stage) & $0.17(6)$ \\
\hline
\end{tabular}

Samples were taken from the inlet and discharge pipes of both the flash evaporator and direct-contact condenser (see Figure 8-2). Because the inlet and discharge pipes operate at less than ambient pressures, a peristaltic pump was used to draw the samples. This type of pump has a relatively gentle pumping action that avoids cavitation, which might promote gas desorption. It also has no rotating seals that might leak ambient air and contaminate the samples.

The supply system that delivers seawater to the experiment has three locations where the seawater is exposed to ambient air: a pump sump, a head tank, and the supply sumps integral to the HMTSTA shown in Figure 8-2. Because repeated exposure to ambient air was 1 ikely to alter the $\mathrm{CO}_{2}$ content of the seawater, samples of the source seawater were taken as it came from the ocean. Both the warm and the cold seawater were sampled in the pump station sump directly from the mouth of the offshore pipe (Figure 8-2). These samples were taken with a 3-L Niskin bottle, a standard device for collecting seawater samples for oceanographic study.

Duplicate samples were obtained at each location to provide a check on the sample integrity and on the repeatability of the measurements. Thus, 
12 samples were taken in all, 2 each from six locations. The second sample at a given location was taken immediately after the first. One hour and 40 minutes were required to take all 12 samples. The HMTSTA was maintained: in steady-state operation for this entire period. The seawater temperatures noted for the samples were those recorded by instruments at the HMTSTA.

Scripps provided a sampling kit with all the equipment required to preserve, seal, and ship the samples. Samples were stored in 1-L glass bottles sealed with greased stoppers. The bottles were filled from the bottom and deliberately overfilled by at least $0.5 \mathrm{~L}$ to flush out the liquid that was at the free surface in the bottle during filling. Each sample was treated with mercuric chloride to kill all biologic activity and then sealed. The 12 samples were shipped immediately to Scripps, where the analysis for $\mathrm{CO}_{2}$ was completed within nine days after the samples were taken.

A small airspace of about $5 \mathrm{cc}$ was left in each bottle. This airspace is required to allow thermal expansion and contraction of the sample and of the bottle without breaking the seal provided by the stopcock. Over time, this volume of air comes into $\mathrm{CO}_{2}$ equilibrium with the seawater sample, creating small errors in the measurements. However, calculations reveal that these errors are at least an order of magnitude smaller than the anticipated laboratory experimental errors.

The worst case is for the cold-water sump samples. The airspace in these samples originally had the ambient air $\mathrm{CO}_{2}$ partial pressure of $350 \mathrm{ppm}$. In equilibrium with the seawater sample, this partial pressure increased to match that of the seawater, $1134 \mathrm{ppm}$. This resulted in 7 micrograms of $\mathrm{CO}_{2}$ being released from the liter of seawater to the airspace. The change in $\mathrm{TCO}_{2}$ of the sample was $0.16 \mathrm{micromole} / \mathrm{kg}$. However, the anticipated systematic experimental error, noted below, is more than an order of magnitude greater than this change, in the $\mathrm{TCO}_{2}$. Similar calculations for the other samples show that they have even smaller changes in $\mathrm{TCO}_{2}$.

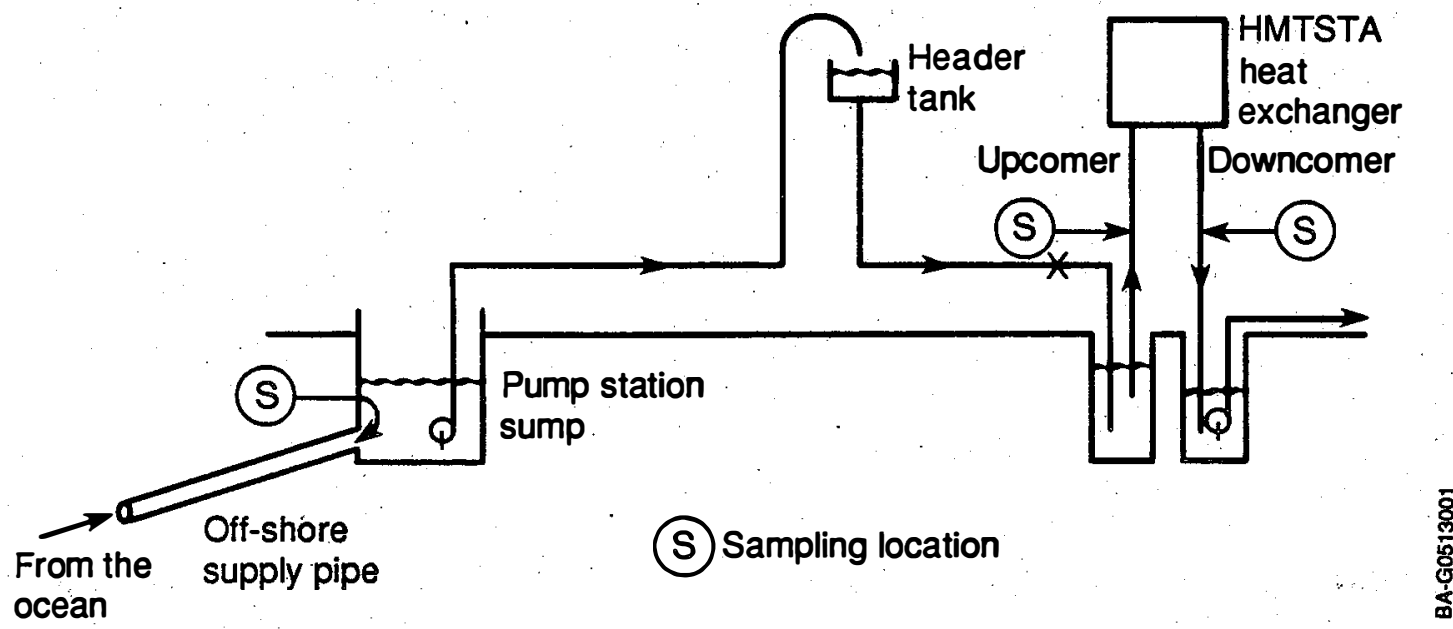

Figure 8-2. Sampling locations in the HMTSTA seawater supply system 


\subsubsection{Laboratory Analysis}

Upon receipt of the samples, Scripps inspected the bottles for any signs of leakage past the stopcocks. Measurement.s of $\mathrm{TCO}_{2}$, alkalinity, and salinity $\mathrm{e}$ were then made on each sample. The methods used are described below.

A cryogenic vacuum extraction technique was used to measure the $\mathrm{TCO}_{2}$. This method starts with the acidification of a known volume of seawater with phosphoric acid to convert the carbonate and bicarbonate ions to dissolved molecular carbon dioxide, $\mathrm{CO}_{2}(\mathrm{~s})$. All dissolved gases are then extracted from the sample under vacuum. The $\mathrm{CO}_{2}$ is captured in a liquid-nitrogen cold trap. Other desorbed noncondensable gases, $\mathrm{O}_{2}, \mathrm{~N}_{2}$, and $\mathrm{Ar}$, pass through this cold trap into the vacuum pump. $\mathrm{H}_{2} \mathrm{O}$ vapor is captured in an upstream dry-ice cold trap. The resulting sample of $\mathrm{CO}_{2}$ is further purified by repeated sequences of dry-ice and liquid-nitrogen cold traps to ensure that all water vapor and other gases have been removed. The sample is then introduced into a precision manometer of known volume in a temperature-controlled enclosure. Using a virial equation of state to account for nonideal gas behavior, the number of moles of $\mathrm{CO}_{2}$ is determined from the volume, temperature, and pressure. A high-precision mercury manometer is used as a primary pressure standard.

Scripps has demonstrated repeatability of $0.8 \mathrm{micromole} / \mathrm{kg}$ (one standard deviation) in the measurement of $\mathrm{TCO}_{2}$ in seawater. Given that the objective is to detect changes in $\mathrm{TCO}_{2}$, repeatability is the first concern. However, accuracy is of interest as well. Scripps estimates that the accuracy is within $\pm 2.0 \mathrm{micromole} / \mathrm{kg}$ based primarily on calibrations with measured quantities of carbonates.

The salinity was measured with a Hytech inductive salinometer. The measurements were made with reference to Wormley standard seawater. The repeatability of this measurement is $0.001 \mathrm{ppt}$ (one standard deviation), and the accuracy is $\pm 0.01 \mathrm{ppt}$.

Total alkalinity was measured via potentiometric acid titration. An aliquot of seawater was titrated with $\mathrm{HCl}$ to obtain a curve of voltage (measured with a glass electrode) vs. volume of added acid. This curve was analyzed with a nonlinear fitting routine to determine the endpoint. The repeatability of this measurement is estimated to be $\pm 1.5 \mathrm{microequivalent} / \mathrm{kg}$ (one standard deviation), and the accuracy is estimated to be $1.5 \mathrm{microequivalent} / \mathrm{kg}$.

Calculations of several additional parameters including $\mathrm{PCO}_{2}$ and $\mathrm{DCO}_{2}$ were made using the three measured parameters and appropriate thermodynamic constants. Finally, the $\mathrm{TCO}_{2}$ and the alkalinity were normalized to constant salinity and designated $\mathrm{STCO}_{2}$ and $\mathrm{SALK}$, respectively. $\mathrm{STCO}_{2}$ was calculated:

$$
\mathrm{sTCO}_{2}=\mathrm{TCO}_{2} \times\left(\mathrm{s}_{\text {initial }} / \mathrm{s}_{\mathrm{final}}\right)
$$

where

$$
\begin{aligned}
s_{\text {initial }} & =\text { initial salinity } \\
s_{\text {final }} & =\text { final salinity }
\end{aligned}
$$


This was done to remove changes in $\mathrm{TCO}_{2}$ resulting solely from subtraction or addition of pure water from or to the seawater during evaporation and condensation. SALK was calculated in the same manner. The warm-water samples were normalized against the warm-water sump salinity, and the cold-water samples were normalized against the cold-water sump salinity. Normalizing against the source seawater was convenient to show changes in $\mathrm{CO}_{2}$ content as the seawater flowed through the experiment. The full data set received from Scripps is presented in Table 8-4.

\subsection{EXPERIMENTAL RESULTS}

Upon initial inspection, Scripps discovered that one sample bottle, P3231, appeared to have an air leak past the stopcock. The leak was sealed and the sample was analyzed along with the others. That sample, from the cold-water sump, had a lower $\mathrm{CO}_{2}$ content than did the duplicate cold-water sump sample, indicating that some loss of $\mathrm{CO}_{2}$ may have occurred. Also, this pair of samples had a distinctly 1 arger residual (the difference between the pair of measurements) than did any other pair of samples. For these reasons, the data from the sample that leaked have not been included in the following results.

The data from the remaining 11 samples are shown in Table 8-5. For those five sampling locations where there are pairs of samples, the data have been averaged to give one set of data for each location. The standard deviation of the residuals for the pairs of $\mathrm{TCO}_{2}$ measurements was $1.15 \mathrm{micromole} / \mathrm{kg}$. This is a good result compared to the measurement repeatability of $0.8 \mathrm{micromole} / \mathrm{kg}$ noted above. The measurement repeatability reflects the random error in mea surements of identical samples, i.e., samples taken from the same Niskin bottle. The current data are expected to have some additional random error because the samples were taken from a flowing system and, thus, are not identical samples.

The values obtained for $\mathrm{TCO}_{2}$ and $\mathrm{DCO}_{2}$ in both the warm and cold seawater coming from the ocean are consistent with other sources of $\mathrm{CO}_{2}$ data previously noted in Tables 8-1 and 8-2 and in Figure 8-1. The warm seawater $\mathrm{PCO}_{2}$ is $326.7 \mathrm{ppm}$, just below the atmospheric partial pressure of $\mathrm{CO}_{2}$, which is about $350 \mathrm{ppm}$. The cold seawater $\mathrm{PCO}_{2}$ is more than three times higher at $1133.7 \mathrm{ppm}$. The values for $\mathrm{DCO}_{2}$ and $\mathrm{PCO}_{2}$ in the evaporator and condenser downcomers must not be considered to reflect the actual conditions in those components. The seawater just leaving the evaporator and condenser should be low in $\mathrm{DCO}_{2}$ if, in fact, some or all of the $\mathrm{CO}_{2}(\mathrm{~s})$ has been desorbed. The seawater would not be at equilibrium because of the slow reaction kinetics noted previously. Not enough time would have passed to allow the conversion of bicarbonate ions to replace the released $\mathrm{CO}_{2}(s)$. However, in the nine days between sampling and analysis, the samples would have come to equilibrium with a replenished content of $\mathrm{DCO}_{2}$.

Table 8-5 includes "calculated salinity" data, to be distinguished from the measured salinity reported in Table 8-4. This salinity was calculated from the operating conditions of the evaporator and condenser. Temperature changes and flow rates in these components were used to calculate the steam flow rate. This, in turn, was used to calculate a salinity change in the seawater passing through these components. The calculated salinities for the upcomers were assumed to be the same as for the sumps. This may not be strictly true, but it is a reasonable assumption because salinity changes in the seawater supplies are expected to be small. 
Table 8-4. Report of Total Dissolved Carbon Measurements and Calculated Properties(a)

\begin{tabular}{|c|c|c|c|c|c|c|c|c|c|}
\hline $\begin{array}{c}\text { Sample } \\
\text { No. }\end{array}$ & Source of Sample & $\begin{array}{c}\text { Temp. } \\
\left({ }^{\circ} \mathrm{C}\right)\end{array}$ & $\begin{array}{c}\text { Salinity } \\
(\mathrm{ppt})\end{array}$ & $\begin{array}{c}\mathrm{TCO}_{2} \\
\text { (micromole } \\
\text { per kg) }\end{array}$ & $\begin{array}{l}\text { Alkalinity } \\
\text { (microequiv } \\
\text { per } \mathrm{kg} \text { ) }\end{array}$ & $\begin{array}{l}\mathrm{PCO}_{2} \\
(\mathrm{ppm})\end{array}$ & $\begin{array}{c}\mathrm{DCO}_{2} \\
\text { (micromole } \\
\text { per } \mathrm{kg} \text { ) }\end{array}$ & $\begin{array}{c}\mathrm{sTCO}_{2}(\mathrm{~b}) \\
\text { (micromole } \\
\text { per kg) }\end{array}$ & $\begin{array}{c}\text { SALK } \\
\text { (microequiv } \\
\text { per } \mathrm{kg})\end{array}$ \\
\hline P3228 & Warm-water sump & 24.9 & 34.349 & 1929.92 & 2262.05 & 327.7 & 9.4 & 1928.6 & 2261.3 \\
\hline P3229 & Warm-water sump & 24.9 & 34.352 & 1927.37 & 2260.63 & 325.6 & 9.3 & & \\
\hline P3230 & Cold-water sump & 6.5 & 34.402 & 2320.13 & 2340.53 & 1133.7 & 56.2 & 2317.7 & 2338.9 \\
\hline P3231 & Cold-water sump & 6.5 & 34.390 & 2315.18 & 2337.19 & 1117.4 & 55.4 & & \\
\hline P3232 & Condenser upcomer & 6.5 & 34.310 & 2309.25 & 2337.15 & 1068.8 & 52.8 & 2314.6 & 2342.2 \\
\hline P3233 & Condenser upcomer & 6.5 & 34.304 & 2308.05 & 2335.10 & 1075.1 & 53.1 & & \\
\hline P3234 & Warm-water upcomer & 24.9 & 34.350 & 1931.45 & 2268.37 & 322.4 & 9.2 & 1931.1 & 2266.9 \\
\hline P3235 & Warm-water upcomer & 24.9 & 34.354 & 1930.99 & 2265.65 & 325.0 & 9.3 & & \\
\hline P3236 & Warm-water downcomer & 21.2 & 34.389 & 1929.80 & 2266.43 & 282.0 & 8.8 & 1927.5 & 2265.9 \\
\hline P3237 & Warm-water downcomer & 21.2 & 34.397 & 1929.98 & 2270.95 & 277.6 & 8.7 & & \\
\hline P3238 & Cold-water downcomer & 13.8 & 33.986 & 2227.20 & 2310.90 & 920.5 & 35.8 & 2255.3 & 2339.4 \\
\hline P3239 & Cold-water downcomer & 13.8 & 33.983 & 2229.42 & 2311.78 & 930.1 & 36.2 & & \\
\hline
\end{tabular}

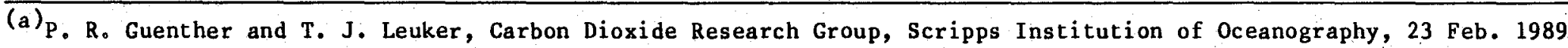

(b) Normalized with the measured salinity. 
Table 8-5. Results of $\mathrm{CO}_{2}$ Measurements in Warm' and Cold Seawater Samples

\begin{tabular}{|c|c|c|c|c|c|c|}
\hline Source of Sample & $\begin{array}{c}\text { Temperature } \\
\left({ }^{\circ} \mathrm{C}\right) \hat{\mathrm{e}}\end{array}$ & $\underset{\left.(\mu \mathrm{mole}\}_{\mathrm{kg}}\right)}{\mathrm{TCO}_{2}}$ & $\stackrel{\mathrm{DCO}_{2}}{(\mu \mathrm{mole} / \mathrm{kg}) \mathrm{e}}$ & $\begin{array}{l}\mathrm{PCO}_{2} \\
(\mathrm{ppm})\end{array}$ & $\begin{array}{l}\operatorname{sTCO}_{2}(\mathrm{~d}) \\
(\mu \mathrm{mole} / \mathrm{kg})\end{array}$ & $\begin{array}{c}\text { Calculated } \\
\text { Salinity } \\
\text { (ppt) }\end{array}$ \\
\hline Warm-water sump & 24.9 & 1928.6 & 9.4 & 326.7 & 1928.6 & 34.351 \\
\hline Evaporator upcomer & 24.9 & 1931.2 & 9.3 & 323.7 & 1931.2 & 34.351 \\
\hline Evaporator downcomer & 21.2 & 1929.9 & $8.8^{(c)}$ & $279.8^{(c)}$ & $1918.3^{(a)}$ & 34.559 \\
\hline Cold-water sump & 6.5 & 2320.1 & 56.2 & 1133.7 & 2320.1 & 34.402 \\
\hline Condenser upcomer & 6.5 & 2308.6 & 53.0 & 1072.0 & 2308.6 & 34.402 \\
\hline Condenser downcomer & 13.8 & 2228.3 & $36.0^{(c)}$ & $925.3^{(c)}$ & $2254.5^{(b)}$ & 34.003 \\
\hline
\end{tabular}

(a) Normalized to the salinity in the warm-water sump. $\hat{e}$

(b) Normalized to the salinity in the cold-water sump. $\hat{e}$

(c) These data may not reflect actual conditions in the experiment. $\hat{e}$

(d) Normalized with the calculated salinity. $\hat{e}$ 
There was not complete agreement between these two determinations of salinity. First, the measured salinity change in the evaporator is much smaller than the calculated change. Second, the measured salinity change between the coldwater sump and the condenser upcomer is unexpectedly large. It appears unlikely that condensation of atmospheric moisture could be the sole cause of this change in the cold seawater, because the resulting cold-seawater temperature rise would be large, about $1.7^{\circ} \mathrm{C}$. Note that the overall coldseawater salinity change, sump to downcomer, is essentially the same for the two methods. The $\mathrm{STCO}_{2}$ data noted in Table 8-5 have been normalized by the calculated salinity because this method indicates a larger $\mathrm{CO}_{2}$ release from the evaporator.

The data show a slight gain in $\mathrm{TCO}_{2}$ between the warm-water sump and the evaporator upcomer. However, the change is about the same size as the repeatability of the measurements. A gain in $\mathrm{TCO}_{2}$ is reasonable because the warm seawater is not saturated with $\mathrm{CO}_{2}$ and the seawater is exposed to ambient air in the supply system. In the flash evaporator itself, only a small drop in $\mathrm{STCO}_{2}, 12.9 \mathrm{micromole} / \mathrm{kg}$, occurs. This is $39 \%$ greater than the $9.3 \mathrm{micromole} / \mathrm{kg}$ of dissolved $\mathrm{CO}_{2}$ in the evaporator upcomer. This indicates that all of the $\mathrm{DCO}_{2}$ in the seawater was released and that a small additional quantity of $\mathrm{HCO}_{3}{ }^{-}, 3.6 \mathrm{micromole} / \mathrm{kg}$, was converted to $\mathrm{DCO}_{2}$ and released as well: This is consistent with the slow reaction kinetics noted previously.

There is a drop in $\mathrm{TCO}_{2}$ between the cold-water sump and the condenser upcomer. Some $\mathrm{CO}_{2}$ release to the atmosphere is expected because the cold seawater is supersaturated with $\mathrm{CO}_{2}$ and the open-air sumps and tanks in the supply system provide exposure to the atmosphere. The $\mathrm{TCO}_{2}$ may also be reduced because of condensation of atmospheric moisture, which dilutes the seawater. In the direct-contact condenser, there is a drop in $\mathrm{STCO}_{2}$ of $54.1 \mathrm{micromole} / \mathrm{kg}$. This is $2 \%$ greater than the $\mathrm{DCO}_{2}$ in the seawater coming into the condenser. This result is similar to that for warm seawater, although the quantity of $\mathrm{HCO}_{3}$ that is converted to $\mathrm{DCO}_{2}$ and subsequently released is smaller, $1.1 \mathrm{micromole} / \mathrm{kg}$.

\subsection{CONCLUSIONS}

\subsubsection{Immediate $\mathrm{CO}_{2}$ Release}

These experiments confirm that very 1 ittle $\mathrm{CO}_{2}$ is released in open-cycle oTEC evaporators and direct-contact condensers, even though the total $\mathrm{CO}_{2}$ content, $\mathrm{TCO}_{2}$, of seawater is high compared to that of other dissolved gases. As was expected, all of the $\mathrm{DCO}_{2}$ in the incoming seawater was released. There was, however, only a modest additional release of $\mathrm{CO}_{2}$. This confirms that the reaction kinetics for conversion of $\mathrm{HCO}_{3}{ }^{-}$to $\mathrm{CO}_{2}(\mathrm{~s})$ are sufficiently slow that very little $\mathrm{HCO}_{3}^{-}$is released from the seawater during its brief passage through these components.

With this data set, the $\mathrm{CO}_{2}$ emissions from future open-cycle OTEC plants can be estimated. Assumptions for seawater requirements for plants of commercial size are based on a" system model developed at SERI for a land-based 10-MW open-cycle plant. This model predicts that $5710 \mathrm{~kg} / \mathrm{s}-\mathrm{MW}$ of warm seawater and $2580 \mathrm{~kg} / \mathrm{s}-\mathrm{MW}$ of cold seawater will be needed for plant operation. The flow rates for a given plant may, of course, be different than these assumptions depending on many factors including the type of cycle, the available temperature difference, the length of the cold-water pipe, and so on. 
Future OTEC plants may or may not be designed with seawater supply systems that expose the seawater to the atmosphere, as was the case during the experiment. For this reason, the largest emissions from the data set have been used in these projections. For the warm seawater, the largest release of $\mathrm{CO}_{2}$ is between the evaporator upcomer and downcomer, $12.9 \mathrm{micromole} / \mathrm{kg}$. For the cold seawater, the release from the cold-water sump to the condenser downcomer has been used, $65.6 \mathrm{micromole} / \mathrm{kg}$. The resulting $\mathrm{CO}_{2}$ emission rate is $38.5 \mathrm{~g} \mathrm{CO}_{2} / \mathrm{kWh}$ for the plant, with most of the $\mathrm{CO}_{2}$ being released from the cold seawater (see Table 8-6).

Table 8-6. Projected Immediate $\mathrm{CO}_{2}$ Emissions from a Land-Based Open-Cycle OTEC Plant Using Direct-Contact Condensation

\begin{tabular}{lccc}
\hline & $\begin{array}{c}\mathrm{CO}_{2} \\
\text { Emissions } \\
(\mu \mathrm{mole} / \mathrm{kg})\end{array}$ & $\begin{array}{c}\text { Specific } \\
\text { Flow Rate } \\
(\mathrm{kg} / \mathrm{s}-\mathrm{MW})\end{array}$ & $\begin{array}{c}\mathrm{CO}_{2} \\
\text { Emission Rate } \\
\left(\mathrm{g} \mathrm{CO}_{2} / \mathrm{kWh}\right)\end{array}$ \\
\hline Warm seawater & 12.9 & 5710 & 11.7 \\
Cold seawater & 65.6 & 2580 & $\underline{26.8}$ \\
TOTAL & & & 38.5 \\
\hline
\end{tabular}

Marland (1983) has determined average $\mathrm{CO}_{2}$ emission rates from the burning of natural gas, fuel oil, and coal. The rates shown in Table 8-7 include $\mathrm{CO}_{2}$ emissions resulting from production of these fuels. For natural gas, the emissions during delivery to the consumer are included as well. For delivered fuel oil and coal, the $\mathrm{CO}_{2}$ emission rates are actually somewhat higher than those shown. These emissions are relatively constant for various heating values of the fuels.

Table 8-7. $\mathrm{CO}_{2}$ Emission Rates From Fossil Fuel-Fired Electric Power Plants

\begin{tabular}{|c|c|c|c|}
\hline Fuel. & $\begin{array}{l}\mathrm{CO}_{2} \text { Emission Rate ê } \\
\text { for Burning (b) } \\
\left(\mathrm{kg} \mathrm{CO} / 10^{9} \mathrm{~J}\right) \hat{e}\end{array}$ & $\begin{array}{l}\text { Plant } \\
\text { Heat Rate } \\
(\mathrm{kJ} / \mathrm{kWh})\end{array}$ & $\begin{array}{l}\mathrm{CO}_{2} \text { Emission } \mathrm{e} \\
\text { Rate for Power } \\
\text { Production } \\
\left(\mathrm{g} \mathrm{CO}_{2} / \mathrm{kWh}\right) \mathrm{e}\end{array}$ \\
\hline $\begin{array}{l}\text { Natural gas } \\
\text { (Delivered to the customer) }\end{array}$ & 60.0 & 8,865 & 531 \\
\hline $\begin{array}{l}\text { Fuel oil } \\
\text { (At the refinery) }\end{array}$ & 81.7 & 8,900 & 730 \\
\hline $\begin{array}{l}\text { Coal } \\
\text { (At the minehead) }\end{array}$ & 90.4 & 10,340 & 934 \\
\hline
\end{tabular}


$\mathrm{CO}_{2}$ emissions from fossil-fuel electric power plants vary with the heat rate of the individual plant. The Electric Power Research Institute (1986) gives nominal heat rates for current-technology power plants for each of the three types of fuel. These heat rates are presented in Table 8-7 along with the calculated $\mathrm{CO}_{2}$ emissions for the three fuels per kilowatt hour of electricity. The emissions from the fossil-fuel plants are substantially greater than are the projected emissions from an open-cycle OTEC plant. The OTEC emissions are only $7.3 \%$ of those from a gas-fired plant and $4.1 \%$ of those from a coal-fired plant.

The OTEC emission rates just mentioned apply to an open-cycle plant in which all of the condensation is direct contact. If the open-cycle plant is designed for coproduction of desalinated water as well as electricity, some or all of the cold seawater will be routed to a surface condenser or heat exchanger. This seawater will not be exposed to the low pressures of the direct-contact condenser and will release 1 ittle if any $\mathrm{CO}_{2}$. Thus, coproduction of electricity and desalinated water will reduce the $\mathrm{CO}_{2}$ emissions of an open-cycle plant. A hybrid-cycle plant has a flash evaporator that will produce $\mathrm{CO}_{2}$ emissions from the warm seawater. Assuming a similar specific flow rate, the emissions will be $11.7 \mathrm{~g} \mathrm{CO}_{2} / \mathrm{kWh}$, or $2.2 \%$ of the emissions of a gas-fired power plant. A closed-cycle plant is expected to have little or no immediate release of $\mathrm{CO}_{2}$ because both the warm and cold seawater pass through surface heat exchangers. A comparison of the $\mathrm{CO}_{2}$ emission rates for OTEC and fossil-fueled cycles is found in Figure 8-3.

The possibility that subatmospheric pressures can occur in surface heat exchangers located above sea level was noted earlier. This applies to any OTEC cycle with a surface heat exchanger: closed-cycle or hybrid-cycle systems, or open-cycle systems that have surface condensers for producing desalinated water. For example, a heat exchanger located $4.6 \mathrm{~m} \mathrm{(15} \mathrm{ft)} \mathrm{above}$ sea level might have pressures as $10 \mathrm{w}$ as $55 \mathrm{kPa}$ ( $8 \mathrm{psia}$ ). The actual pressure varies with many factors including elevation of the heat exchanger, flow rate, pump head and location, and throttling with valves. Subatmospheric pressures

Figure 8-3. Carbon diozide emission rates for electricity production

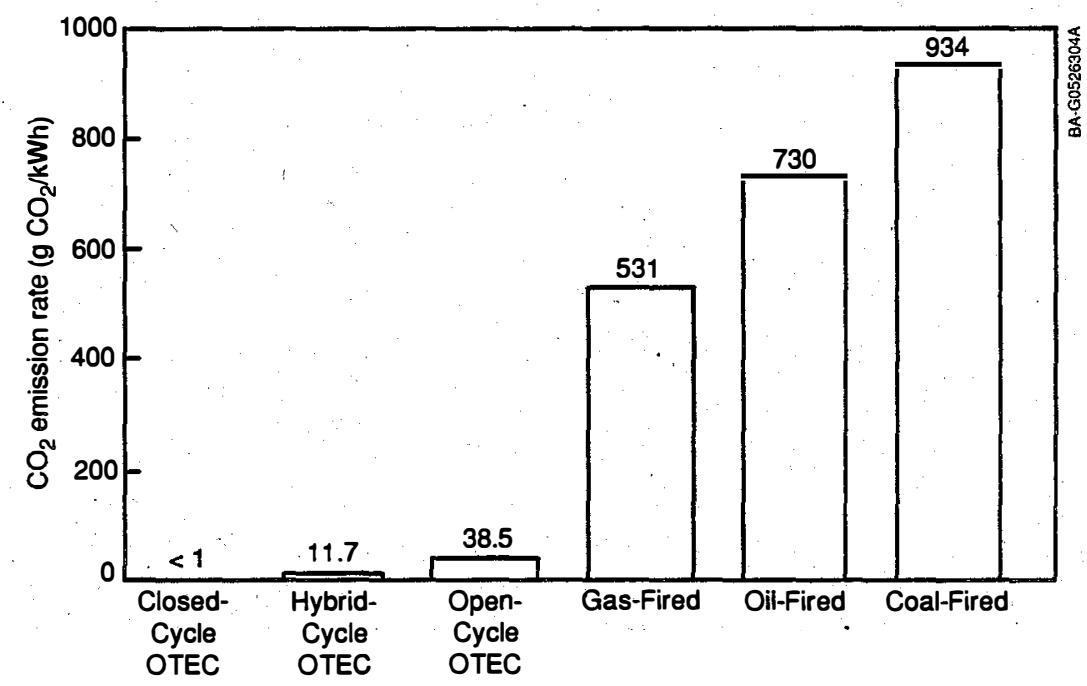


may encourage some release of dissolved gases into bubbles in the seawater. These bubbles may collect in high points in the heat exchanger or piping and require removal with a vacuum pump. This type of release is expected to be very small, especially if the heat-exchanger pressures are near atmospheric pressure. No release of this type was noted during operation of Mini-OTEC in 1979 (Owens and Trimble 1980).

In summary, all OTEC plants, whether closed cycle, hybrid cycle, or open cycle, will operate with significantly lower immediate $\mathrm{CO}_{2}$ emissions than fossil-fueled electric power plants. The immediate $\mathrm{CO}_{2}$ emissions generated by a land-based open-cycle plant will be 15 to 25 times smaller than those from fossil-fueled plants of equal size.

\subsubsection{Long-Term $\mathrm{CO}_{2}$ Release}

The cold seawater discharged to the ocean from any OTEC plant, whether open, hybrid, or closed cycle, will have a higher partial pressure of $\mathrm{CO}_{2}$ than the atmosphere, creating the possibility of long-term $\mathrm{CO}_{2}$ release. However, this release can be avoided by plant design that incorporates subsurface mixed discharge of the warm and cold seawater. This is illustrated in Figure 8-4, which shows the $\mathrm{CO}_{2}$ concentration vs. depth for seawater near Oahu, Hawaii. This site has $1910 \mathrm{micromole} / \mathrm{kg} \quad \mathrm{TCO}_{2}$ in the warm seawater and $2315 \mathrm{micromole} / \mathrm{kg}$ in the cold seawater at a depth of $700 \mathrm{~m}$. Based on the data in Table 8-5 and the specific flow rates in Table 8-6, an OC-OTEC plant at this site would produce a mixed discharge with $\mathrm{TCO}_{2}$ of 2007 . Seawater with the same $\mathrm{TCO}_{2}$ is found at a depth of $195 \mathrm{~m}$, as shown in Figure 8-4. Discharge at this depth or lower will result in no long-term $\mathrm{CO}_{2}$ release.

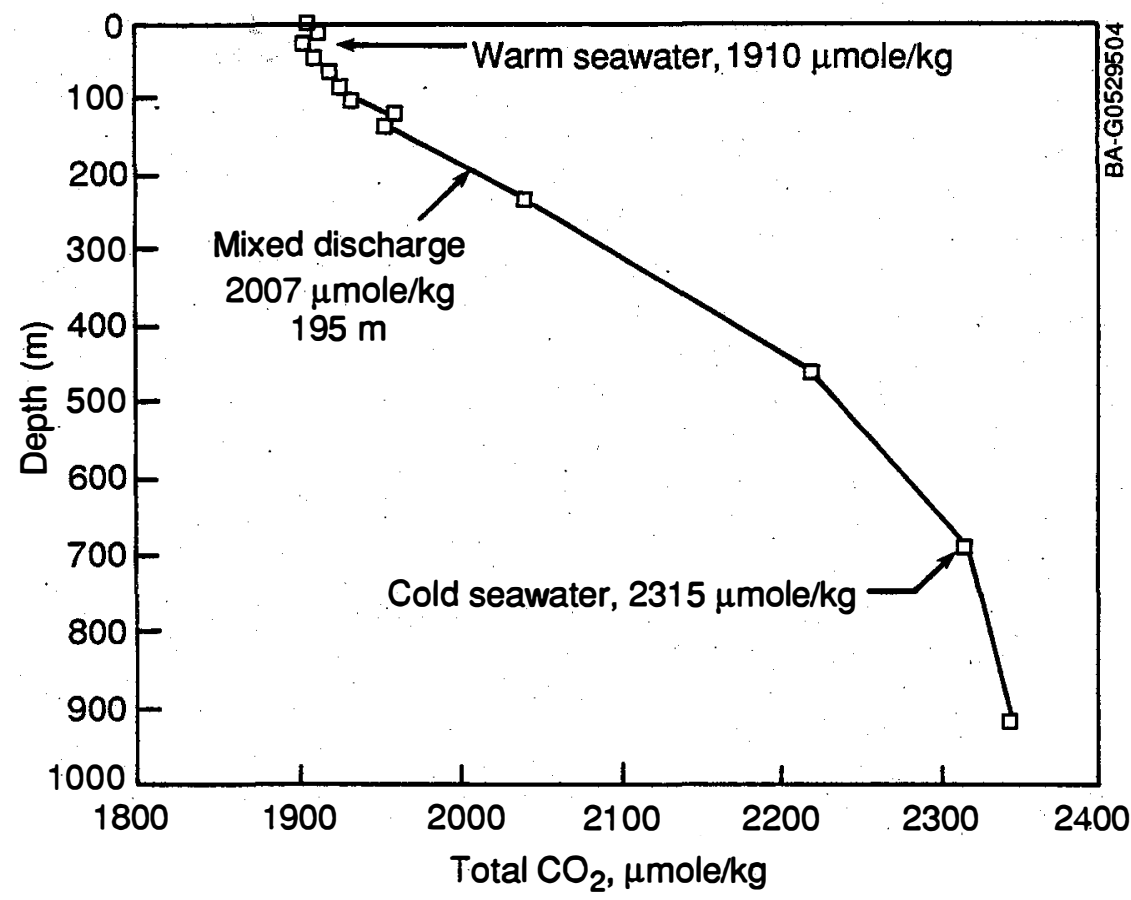

Figure 8-4. Total $\mathrm{CO}_{2}$ concentration vs. depth near Oahu, Hawaii (Rrock 1981) 
These depths are also below the surface mixed layer of the ocean in relatively stable layers that have virtually no contact with the atmosphere. The surface mixed layer has an average depth of only $75 \mathrm{~m}$, which varies with location and season (Riley and Chester 1971). Because the discharge is below the mixed layer, the ecology of the surface mixed layer is not disturbed, and the warm seawater supply temperature to the plant is not affected. Subsurface discharge also avoids adding nutrients from the cold seawater to the euphotic zone, where it could promote algae blooms. The euphotic zone is that part of the upper ocean which has adequate sunlight to support plant growth. This zone extends to a depth of at least $80 \mathrm{~m}$ (Sverdrup et al. 1970).

The cold seawater from an OTEC plant may be used for mariculture instead of being discharged directly into the ocean. This seawater will be low in oxygen and will likely require reaeration before it can be used to grow marine animals. Such use could result in extended exposure to the atmosphere and some long-term release of $\mathrm{CO}_{2}$. As for mariculture of marine plants, the cold seawater discharge will be directly usable. It still has a 1 arge $\mathrm{CO}_{2}$ content, as these data indicate. However, the excess $\mathrm{CO}_{2}$ is likely to be rapidly consumed by the cultured plants, thus limiting its release into the atmosphere.

\subsection{APPLICABILITY TO THE NPPE}

The results of this experiment should be directly applicable to the NPPE. The HMTSTA evaporator and direct-contact condenser are the prototypes for the NPPE evaporator and condenser in terms of both configuration and operating conditions. For the NPPE flow rates of $620 \mathrm{~kg} / \mathrm{s}$ warm seawater and $421 \mathrm{~kg} / \mathrm{s}$ cold seawater, the $\mathrm{CO}_{2}$ release will be $35.6 \mathrm{millimole} / \mathrm{s}$ or $1.57 \mathrm{~g} / \mathrm{s}$.

\subsection{FURTHER RESEARCH NEEDS}

Additional experiments are recommended to resolve the anomalies noted earlier between the measured and calculated salinities. Experiments under a variety of operating conditions in both the evaporator and the direct-contact. condenser would add confidence to the conclusions, which are based on a single operating point. Such experiments have been conducted using a mass spectrometer to characterize the contents of the steam and noncondensable gases in the HMTSTA. These data, obtained by researchers from the University of Hawaii, have not been documented at the time of writing. Further analysis and experiments will be necessary to quantify the long-term $\mathrm{CO}_{2}$ emissions from OTEC plant discharges and the emissions that will occur during plant construction and demolition.

\subsection{REFERENCES}

Electric Power Research Institute, 1986, Technical Assessment Guide, Volume 1: Electricity Supply--1986, P-4463-SR, Vo1. 1, Palo Alto, CA.

Houghton, R. A., and G. M. Woodwel1, 1989, "Global Climate Change," Scientific American, April, Vol. 260, No. 4.

Krock, H. J., 1981, Gas Analyses of Water Samples for OTEC Program, Technical Report No. 51, U HAWAII-LOOK LAB-81-4, Honolulu, HI: University of Hawaii, James K. K. Look Laboratory of Oceanographic Engineering, Department of Ocean Engineering. 
Marland, G., 1983, "Carbon Dioxide Emission Rates for Conventional and Synthetic Fuels," Energy, Vol. 8, No. 12, Pp: 981-992.

Owens, W. L., and L. C. Trimble, 1980, "Mini-OTEC Operational Results," Conference Proceedings, Seventh Ocean Energy Conference, CONF-800633, Vo1. 2, PP. 14.1.1-14.1.9, Washington, D.C.: U.S. Department of Energy.

Panchal, C. B., and K. J. Bel1, 1987, "Simultaneous Production of Desalinated Water and Power Using a Hybrid-Cycle Plant," Journal of Solar Energy Engineering, Vol. 109, May, PP. 156-160.

Riley, J. P., and R. Chester, 1971, Introduction to Marine Chemistry, London: Academic Press.

Schneider, S. H., 1989, "The Changing Climate," Scientific American, Vol. 261, No. 3 .

Sverdrup, H. U., M. W. Johnson, and R. H. Fleming, 1970, The Oceans, Englewood Cliffs, NJ: Prentiss-Hall, Inc.

Takahashi, T., W. S. Broecker, and A. E. Bainbridge, 1981, "The Alkalinity and Total Carbon Dioxide Concentration in the World Oceans," SCOPE 16, Carbon Cycle Modelling, edited by Bert Bolin, Chichester, England: John Wiley and S.ons. 
CHAPTER 9.0

CONCLUSIONS 
Tests conducted in the HMTSTA assessed the heat- and mass-transfer performance of all key open-cycle OTEC components except the turbine, using seawater as the working fluid. The results provide a sound technical basis for understanding and predicting with confidence the performance of these components at larger scales.

Tests on the spout evaporator concluded that the principal parameter affecting evaporator thermal effectiveness is the liquid loading, both for simple spouts and for multiple spouts. Within experimental uncertainty, the seawater and fresh-water results are the same. Superheat and spout height have less of an effect. Superheat above $2^{\circ} \mathrm{C}$. is required to achieve high thermal effectiveness using single spouts. A spout height of $0.5 \mathrm{~m}$ and spout diameter of $0.25 \mathrm{~m}$ are adequate. Multiple spouts show a lower effectiveness than single spouts, but both can be designed to attain thermal effectiveness of 0.9 or above, indicating that warm seawater requirements are within $10 \%$ of the theoretical minimum. No water or steam instabilities were observed.

Based on the available literature and prior studies, selection of a mist eliminator to achieve a specified performance is straightforward. Performance of a candidate mist eliminator was verified at the HMTSTA, yielding a low pressure-drop penalty and removing more than enough droplets from the steam to result in desalinated water quality well above standards for drinking water. A suitable commercially available mist eliminator can be selected when specifications are defined of droplet carryover requirements with respect to turbine operations.

Scoping tests on warm seawater predeaeration have shown that the fraction of oxygen desorbed ranges from 0.07 to 0.6 for predeaeration pressures between 9 and $35 \mathrm{kPa}$. The scatter of data was large because of difficulties and uncertainties in field measurements of dissolved oxygen concentration. These difficulties and changes in operating conditions did not allow conclusive definition of the dependence of desorption on seawater flow rate. Oxygen is observed to desorb from the seawater as bubbles, but these bubbles are not completely released in the passive predeaeration chamber and some are carried into the evaporator. However, the bubbles were shown to be easily removed from the water in a separator, indicating future directions in predeaeration methods. System model simulation predicts potential reduction of pumping power for gas removal by $25 \%$, resulting in a potential increase in system net power of about $2 \%$ if warm water predeaeration were incorporated. Total observed release of oxygen from the warm water was $75 \%$ to $95 \%$ of the dissolved content, implying that equivalent rates are to be expected for the overall noncondensable gas release from the warm seawater.

Results of surface condenser tests validated the computer model that predicts performance of a cross-flow, unenhanced parallel-plate condenser geometry. This geometry was used as the main condenser and showed small steam pressure drop and no observable buildup of noncondensable gas in confined areas of the main condenser. The vent condenser performed poorly, resulting in difficulties in calculation of the overall condenser mass balance. However, it is believed that uncertainties caused by difficulties with the vent condenser had minimal effects on the analysis of the main condenser. 
Data obtained with two direct-contact condenser stages using structured packings showed excellent consistency and confirmed earlier predictions of superior thermal, exhaust, and hydraulic performance for the DCC. Overall thermal effectiveness above 0.9 has been shown consistently for vent ratios of 0.9 in the presence of high noncondensable-gas content. This indicates that the DCC unit can operate with only $10 \%$ more than the theoretical minimum for cold water use and venting requirements. Within experimental uncertainty; thermal performance in seawater and fresh-water operation cannot be distinguished. Total hydraulic losses equivalent to less than $2-m$ heads are easily attainable. Computer models describing the condensation process in each of the DCC stages have been validated and accurately predict the process under a wide range of geometries and operating conditions.

Very 1ittle carbon dioxide is released during open-cycle OTEC system operation, although the amount released is virtually the total dissolved quantity. Immediate emission from open-cycle OTEC plants amounts to 15 to 25 times less than the emissions generated by fossil-fueled electric power plants. Longterm carbon dioxide release could be slightly higher and will depend on discharge design or types of downstream applications of the spent seawater.

Tests at the HMTSTA on heat exchanger components were conducted in the parameter range for NPPE operation. In all cases, the seawater test results confirm or surpass the performance obtained in fresh water and predicted by the analytical models for the components to be used in the NPPE. Valuable experience was also gained in operation of the HMTSTA test facility that will be reflected in improved design of the layout and operational procedures in the NPPE facility. There now exists a good basis to design the NPPE with confidence that the expected performance will be achieved. 
APPEADIX A

ERROR ANALYSIS 


\section{NOMENCLATURE}

Abbrev.

Description

Units

$\mathrm{C}_{\mathrm{p}}$

F

specific heat

$\mathrm{kJ} / \mathrm{kg}^{\circ} \mathrm{C}$

generic function

NA

$\Delta \mathrm{F}$

error on $F$

NA

i

integer from 1 to $n$

--

$Q_{\text {wW }}$

mass flow of warm seawater

$\mathrm{kg} / \mathrm{s}$

$\mathrm{X}$

generic variable

NA

$\Delta \mathrm{X}$

error on $X$

NA

$T_{w i}$

temperature of incoming seawater

${ }^{\circ} \mathrm{C}$

Two

temperature of outgoing seawater

${ }^{\circ} \mathrm{C}$

Note: The nomenclature used in Table A-2 follows the use selected by each principal investigator for the four main components tested: spout evaporator, warm-seawater deaerator, surface condenser, and directcontact condenser. The respective nomenclatures used for each component can be found at the beginning of each related chapter and its data appendix. 
This appendix presents summaries of primary instrument and derived performance parameter pretest error estimates. (An example of a derived performance parameter is evaporator effectiveness, Eq. 3-1, calculated from measured water and steam temperatures.) Actual errors from particular experiments are discussed in appropriate component sections.

The instrumentation error estimates (Table.A-1) combine all anticipated errors from instrumentation and signal conditioning specifications. The derived parameter error estimates (Table A-2) result from the instrumentation measurement errors and other values used in equations. This analysis was performed before the tests (Parsons et al. 1989) and is summarized here for completeness and because several values were updated from those presented in the test plan.

The error estimates are useful for

- assessing suitability of instrumentation and signal conditioning hardware prior to test

- assessing different methods of calculating a given performance parameter from alternative, redundant instrumentation

- providing an indicator of the quality of data obtained in a test.

Assessment of hardware suitability was performed during the HMTSTA design phase.

The results of alternative methods of calculating performance parameters are summarized in Table A-2 of this appendix. For example, evaporator effectiveness can be evaluated in three ways (second, third, and fourth block of Table A-2). Estimated maximum expected errors on the effectiveness parameter based on the three methods are $144 \%, 18 \%$, and $7 \%$. The error using differential sensors and steam pressure is estimated to be lowest. This kind of assessment allows the principal investigator to choose the most suitable type of data analysis.

By plotting two ways of calculating performance parameters against one another for a given test set, the quality of the data can be assessed. For example, see Figure 7-4, where two methods of calculating DCC overall thermal effectiveness are plotted. One standard deviation of the expected error estimates, from the analysis of Table A-2, is also plotted in the figure. If data deviate from the parity line by more than the error estimates, they are suspect, and results should be carefully examined and retesting considered. Conversely, data comparisons which fall inside the estimated error bands indicate that internal data are consistent and that no better refinement can be expected with the given instrumentation. Another source of data lying outside expected error bands is violation of assumptions in the equations--for example, assuming single-phase flow to calculate liquid velocities and head losses. The summary of derived parameter error estimates provides the tool for these types of comparisons. Actual comparisons are discussed in each of the component performance sections by the principal investigators. 


\section{A.1 UNCERTAINTY IN PRIMARY MEASUREMTIS}

Table A-1 lists the final results of the end-to-end pretest error estimates for all the instruments used in HMTSTA tests. The first column refers to the sections in the HMTSTA test plan (Parsons et al. 1989) that describe how the final number was obtained for each sensor. Several values shown here for pressure and differential pressure measurements have been updated from those shown in the test plan, based on more recent information from the sensor manufacturer.

\section{A. 2 UNCERTAINTY IN CALCULATED PARAMETERS}

Table A-2 lists the various methods of calculating the performance parameters based on a selection of primary measurements, the error contribution from each primary measurement, and the total root-mean-square (RMS) uncertainty for each calculation method.

The table is divided into blocks. Each block contains the calculated parameter, the equation used to determine this parameter, and its nominal value (top of each block). Below this is a short table describing the primary measurement, related property, or function calculation used in the equation, as appropriate. This short table also provides the nominal value of each primary quantity and its individual error contribution. The rightmost column provides the partial error contribution from each primary quantity to the performance parameter that is being calculated. The total uncertainty is shown as the last row of each block.

For each performance parameter that can be calculated by multiple methods, the method with highest uncertainty is presented first.

Table A-2 is divided into the four main components tested, and is presented in the same order as they appear in the text:

- Spout evaporator

- Warm-seawater deaeration

- Surface condenser

- Direct-contact condenser.

The terminology used in each block pertaining to the four above-mentioned components follows the use selected by each principal investigator. The respective nomenclature used for each component can be found at the beginning of each related chapter and its data appendix.

The primary quantities can also be identified by inspection of the equation used to calculate the performance parameter and by inspection of their units.

\section{A.3 CALCULATION METHODOLOGY}

This section describes the calculation method for the error analysis for derived component and system performance parameters (Parsons et al. 1989; Measurement Uncertainty Handbook 1980; ANSI/ASME 1986). Errors for the evaporator and direct-contact condenser are calculated at the design point for the planned net power-producing experiment (NPPE). Errors for the surface condenser experiments utilize data from Test Run 880706.008, run near the rated 
conditions of the main condenser. The individual instrument measurement errors are taken from the summary in Table A-1.

Assume the function $\quad F=f\left(x_{1}, x_{2}, \ldots, x_{n}\right)$

where $X_{i}$ is a primary instrument measurement parameter and $F$ is an arbitrary derived performance parameter.

Then

$$
\frac{\Delta F}{F}=\left[\sum_{i=1}^{n}\left(\frac{1}{F} \frac{\partial F}{\partial X_{i}} \Delta x_{i}\right)^{2}\right]^{1 / 2}
$$

$\Delta F / F$ is the resulting most probable fractional error in the derived parameter resulting from instrument measurement errors, $\Delta \mathrm{x}_{i} \cdot$

For the following summary tables (A-2) the error contribution of each parameter is the partial derivative, $\partial F / \partial X_{i}$, times the instrument measurement error divided by the performance parameter. The total probable error on a derived parameter is the root-mean-square (RMS) of the individual parameter contributions.

For example, the first block of Table A-2 describes the calculations for the evaporator heat load using a differential temperature measurement, where DT-ww $=T_{w i}-T_{w o}$ is the difference between incoming and outgoing warm-seawater temperatures, for a warm-water mass $f 10 \mathrm{w} Q_{w w}=51.7 \mathrm{~kg} / \mathrm{s}$, and specific heat of, the warm seawater $C_{p}$.

Function $F=$ Heat Load $=Q_{w w} C_{p}\left(T_{w i}-T_{w o}\right)$

$$
\begin{aligned}
& \frac{1}{F} \frac{\partial F}{\partial Q_{w w}}=\frac{1}{Q_{w w} C_{p}\left(T_{w i}-T_{w o}\right)} \cdot C_{p}\left(T_{w i}-T_{w o}\right)=\frac{1}{Q_{w w}}=\frac{1}{51.7}=0.0193 \\
& \frac{1}{F} \frac{\partial F}{\partial C_{p}}=\frac{1}{C_{p}}=\frac{1}{3.99}=0.2506 \\
& \frac{1}{F} \frac{\partial F}{\partial\left(T_{w i}-T_{w o}\right)}=\frac{1}{\left(T_{w i}-T_{w 0}\right)}=\frac{1}{3.50}=0.2857 \\
& \frac{\Delta F}{F}=\left\{\left(0.0193 * 1.7^{2}\right)+\left(0.2506 * 0.019^{2}\right)+\left(0.2857 * 0.056^{2}\right)\right\}^{1 / 2} \\
& =0.0369=3.69 \%
\end{aligned}
$$

Note that in cases in which the expected value is close to the calculated measurement error, the partial multiplier $1 / \mathrm{F} \partial \mathrm{F} / \partial \mathrm{X} i$ can be quite large, resulting in high percentage error of the derived parameter. 


\section{A.4 REFERENCES}

ANSI/ASME PTC 19.1-1985, 1986, Measurement Uncertainty, supplement to ASME Instrument and Apparatus Performance Test Codes, New York, NY: American Society of Mechanical Engineers.

Measurement Uncertainty Handbook, revised 1980, Research Triangle Park, NC: Instrument Society of America, 172 pp.

Parsons, B. K., H. F. Link, D. Bharathan, A. A. Pesaran, F. Zangrando, and C. B. Panchal, April 1989, Test Plan for the Heat- and Mass-Transfer Scoping Test Apparatus: Phase I and Phase II Tests, Internal Program Report, SERI/SP-253-3385, Golden, CO: Solar Energy Research Institute. 
Table A-1. Summary of Pretest Measurement Uncertainties

\begin{tabular}{|c|c|c|c|}
\hline Section* & Measurement & Error & $\% \mathrm{FS}$ \\
\hline $\begin{array}{c}\text { A.2.4 } \\
\text { A.2.4 } \\
\text { A.2.5 } \\
\text { A.2.6 } \\
\text { A.2.7 } \\
\text { A.2.8 } \\
\text { A.2.9 } \\
\text { A.2.10 } \\
\text { A.2.11 } \\
\text { A.2.12 } \\
\text { A.2.13 } \\
\text { A.2.14 } \\
\text { A.2.15 } \\
\text { A.2.16 } \\
\text { A.2.17 } \\
\text { A.2.18 } \\
\text { A.2.19 } \\
\text { A.2.20 } \\
\text { A.2.21 } \\
\text { A.2.22 } \\
\text { A.2.23 }\end{array}$ & $\begin{array}{l}\text { Absolute temperature (water) } \\
\text { Absolute temperature (steam) } \\
\text { Differential temperature (water) } \\
\text { Differential temperature (steam) } \\
\text { Absolute pressure (steam, evaporator) } \\
\text { Absolute pressure (water, supply; } \\
\text { coarse vacuum) } \\
\text { Absolute pressure (boiling refrigerant) } \\
\text { Absolute pressure (compressed } \\
\text { refrigerant } \\
\text { Absolute pressure (gas, predeaerator) } \\
\text { Pressure difference (predeaeration } \\
\text { baffle, DCc stages) } \\
\text { Pressure difference (mist eliminator) } \\
\text { Pressure difference (evaporator spout) } \\
\text { Flow rate (seawater, evaporator, and } \\
\text { lst-stage condenser) } \\
\text { Flow rate (seawater, 2nd-stage condenser) } \\
\text { Flow rate (condensate) } \\
\text { Flow rate (refrigerant) } \\
\text { Flow rate (exhaust gas) } \\
\text { Level (inlet, outlet tanks) } \\
\text { Level (predeaeration chamber) } \\
\text { Oxygen content (inlet water) } \\
\text { Salinity, absolute (inlet water) } \\
\text { Salinity, absolute (condensate) } \\
\text { Conductivity, ratio (inlet/outlet } \\
\text { warm water) } \\
\text { Absolute pressure (steam, } \\
\text { evaporator, condensers) } \\
\text { Level (discharge pool) } \\
\text { Flow rate (DCc stages) } \\
\text { Wet-bulb temperature (surface } \\
\text { condenser inlet and outlet) }\end{array}$ & $\begin{array}{c} \pm 0.255^{\circ} \mathrm{C} \\
\pm 0.259^{\circ} \mathrm{C} \\
\pm 0.056^{\circ} \mathrm{C} \\
\pm 0.060^{\circ} \mathrm{C} \\
\pm 26 \mathrm{~Pa} \\
\pm 0.9 \mathrm{kPa} \\
\pm 12.0 \mathrm{kPa} \\
\pm 18.0 \mathrm{kPa} \\
\pm 544 \mathrm{~Pa} \\
\pm 9.1 \mathrm{~Pa} \\
\pm 19.1 \mathrm{~Pa} \\
\pm 300 \mathrm{~Pa} \\
\pm 1.7 \mathrm{~kg} / \mathrm{s} \\
\pm 0.37 \mathrm{~kg} / \mathrm{s} \\
\pm 1.11 \mathrm{ml} / \mathrm{s} \\
\pm 0.024 \mathrm{\ell} / \mathrm{s} \\
\pm 0.06 \mathrm{~m} 3 / \mathrm{s} \\
\pm 6.4 \mathrm{~mm} \\
\pm 3.6 \mathrm{~cm} \\
\pm 0.28 \mathrm{Ppm} \\
\pm 10.6 \mathrm{Ppm} \\
\pm 44.6 \mathrm{Ppm} \\
\pm 18.3 \\
\pm 117 \mathrm{~Pa} \\
\pm 520 \mathrm{~Pa} \\
\pm 0.011 \mathrm{~m} / \mathrm{s} \\
\pm 0.22{ }^{\circ} \mathrm{C}\end{array}$ & $\begin{array}{l} \pm 0.87 \\
\pm 0.49 \\
\pm 3.6 \\
\pm 3.2 \\
\pm 0.87 \\
\pm 0.92 \\
\pm 0.80 \\
\pm 0.10 \\
\pm 0.8 \\
-- \\
\pm 0.26 \\
\pm 1.5 \\
\pm 0.15 \\
\pm 0.15 \\
\pm 0.15 \\
\pm 5.4 \\
\pm 1.9 \\
\pm 0.87 \\
\pm 0.58 \\
\pm 0.44\end{array}$ \\
\hline
\end{tabular}

* These are sections in the HMTSTA test plan (Parsons et al. 1989) that describe the details of how the final number was obtained. Several entries were updated (see next footnote).

‡Error recalculated from test plan estimates to include sensor six-month stability and temperature effect specifications. 
Table A-2. Derived Parameter Error Estimates for HMTSTA Component Tests: SPOUT EVAPORATOR

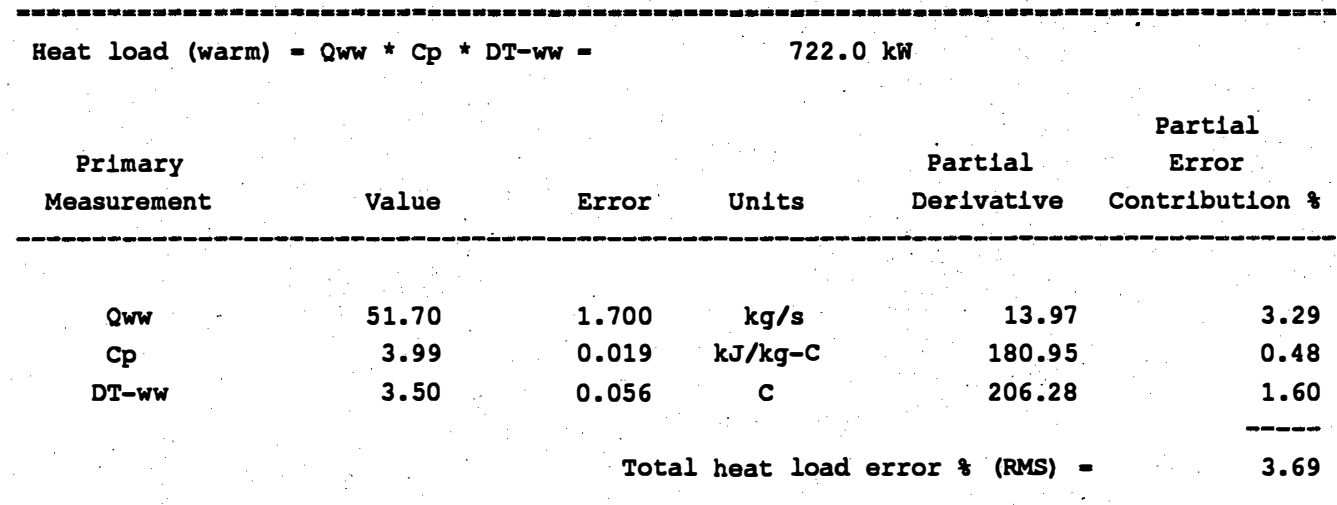

Effectiveness (method a) $=$ DT-Ww / [(Tw11+Tw12)/2 - Tsat (Pst-evap) ]

0.897

\begin{tabular}{|c|c|c|c|c|c|}
\hline $\begin{array}{c}\text { Prlmary } \\
\text { Measurement }\end{array}$ & Value & Error & Un1ts & $\begin{array}{c}\text { Partial } \\
\text { Derivative }\end{array}$ & $\begin{array}{c}\text { Partial } \\
\text { Error } \\
\text { Contribution }\end{array}$ \\
\hline DT-WW & 3.50 & 0.056 & c & 0.2562 & 1.60 \\
\hline Tw11 & 26.00 & 0.255 & c & 0.0104 & 0.29 \\
\hline Tw12 & 26.00 & 0.255 & C & 0.0104 & 0.29 \\
\hline saturated curve & Tsat $=4026$. & $8 / 118.478-$ & $\ln [$ (Pst-e & $-3.738) / 161$ & $75]\}-234.738+$ \\
\hline Pst-evap & 2612 & 900 & $\mathrm{~Pa}$ & - & \\
\hline Tsat (Pst-evap) & 22.10 & 5.639 & c & 0.2297 & 144.46 \\
\hline
\end{tabular}

Effectiveness (method b) $=$ DT-ww / [(Tw11+Tw12)/2 - Tsat (Pst evap) $]$

0.897

\begin{tabular}{cccccc}
$\begin{array}{c}\text { Primary } \\
\text { Measurement }\end{array}$ & Value & Error & Units & $\begin{array}{c}\text { Partial } \\
\text { Partial } \\
\text { Derlvative }\end{array} \begin{array}{c}\text { Error } \\
\text { Contribution }\end{array}$ \\
\hline DT-wW & 3.50 & 0.056 & C & 0.2562 & 1.60 \\
Tw11 & 26.00 & 0.255 & C & 0.0104 & 0.29 \\
Tw12 & 26.00 & 0.255 & C & 0.0104 & 0.29
\end{tabular}

saturated curve, Tsat $=4026.98 /(18.478-\ln [($ Pst evap -3.738$) / 161.75])-234.738+0.3$

Pst evap

Tsat (Pst evap)

2612

22.10
117
0.733

Pa

C

(b) error \& (RMS) =
18.78

$-18$.

$\mathrm{C}={ }^{\mathrm{O}} \mathrm{C}$ 
Table A-2. Derived Parameter Error Estimates for HMTSTA Component Tests: SPOUT EVAPORATOR (Continued)

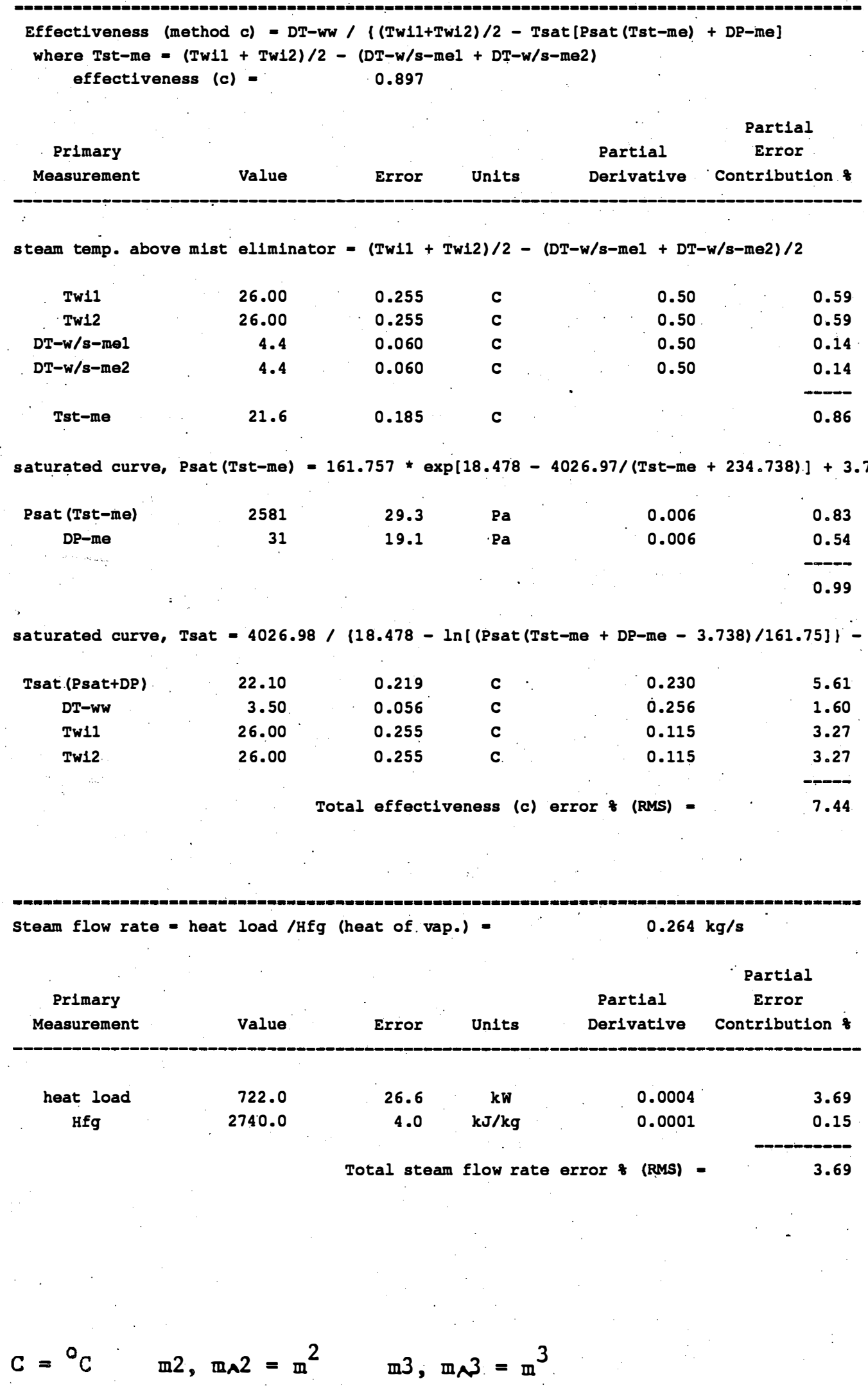


Table A-2. Derived Parameter Error Estimates for HMTSTA Component Tests: SPOUT EVAPORATOR (Continued)

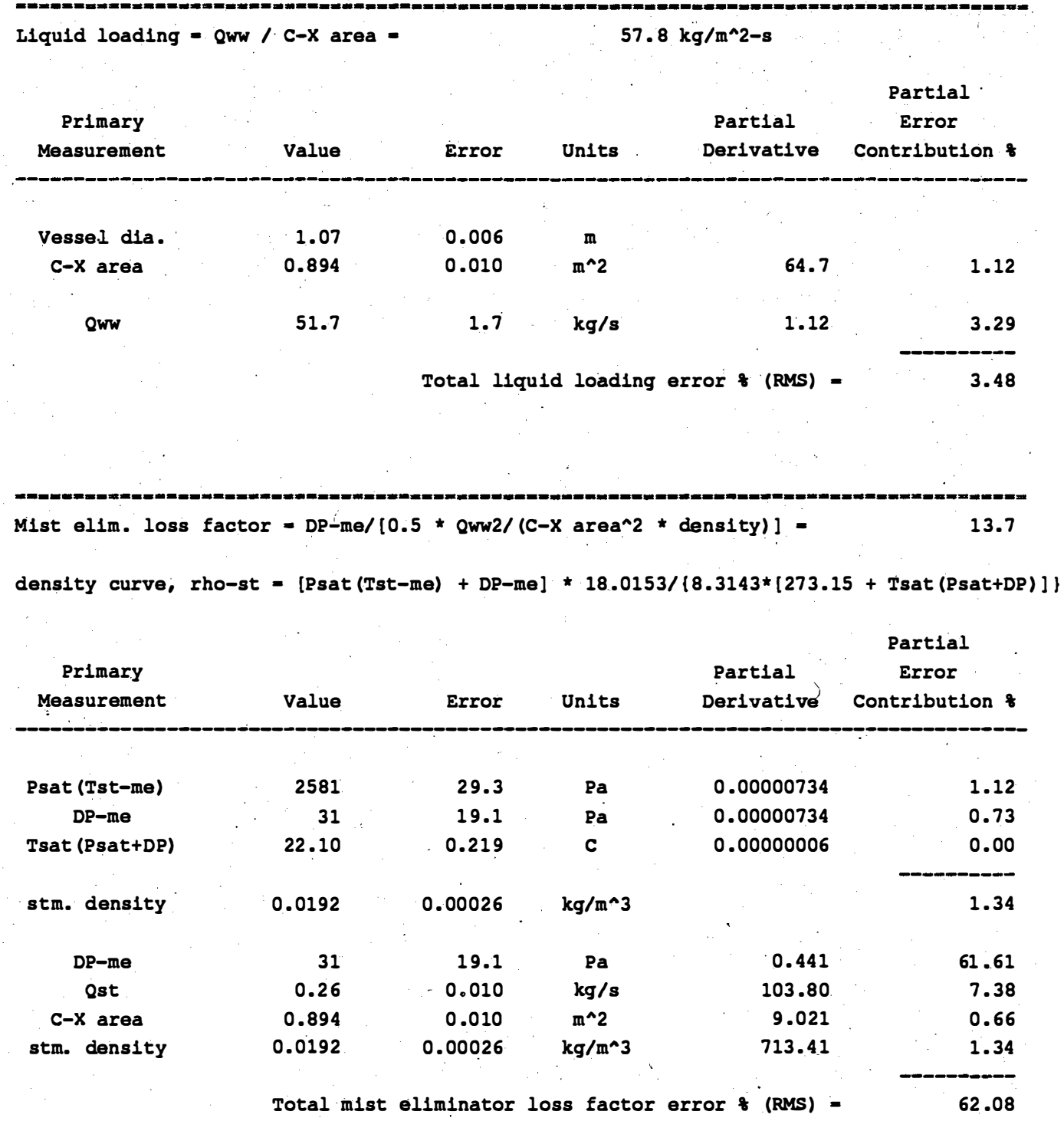

Mist ellm. exit mass flow liquid/mass flow steam - FCnd * Sc/(S1-SC) - 0.000023

\begin{tabular}{|c|c|c|c|c|c|c|}
\hline $\begin{array}{c}\text { Primary } \\
\text { Measurement }\end{array}$ & Value & Error & Units & & $\begin{array}{l}\text { Partial } \\
\text { Derivative }\end{array}$ & $\begin{array}{c}\text { Partial } \\
\text { Error } \\
\text { Contribution }\end{array}$ \\
\hline sc & 0.001 & 0.0446 & & ppt & 0.0232 & 4460.13 \\
\hline s1 & 34.5 & 0.0106 & & ppt & 0.000001 & 0.03 \\
\hline Fend & 0.8 & 0.0232 & & - & 0.000029 & 2.90 \\
\hline
\end{tabular}

$\mathrm{C}={ }^{\circ} \mathrm{C} \quad \mathrm{m} 2, \mathrm{~m}_{\wedge} 2=\mathrm{m}^{2} \quad \mathrm{~m} 3, \mathrm{~m}_{\mathrm{A}} 3=\mathrm{m}^{3}$ 


\section{Table A-2. Derived Parameter Error Estimates for HMTSTA Component Tests:} SPOUT EVAPORATOR (Concluded)

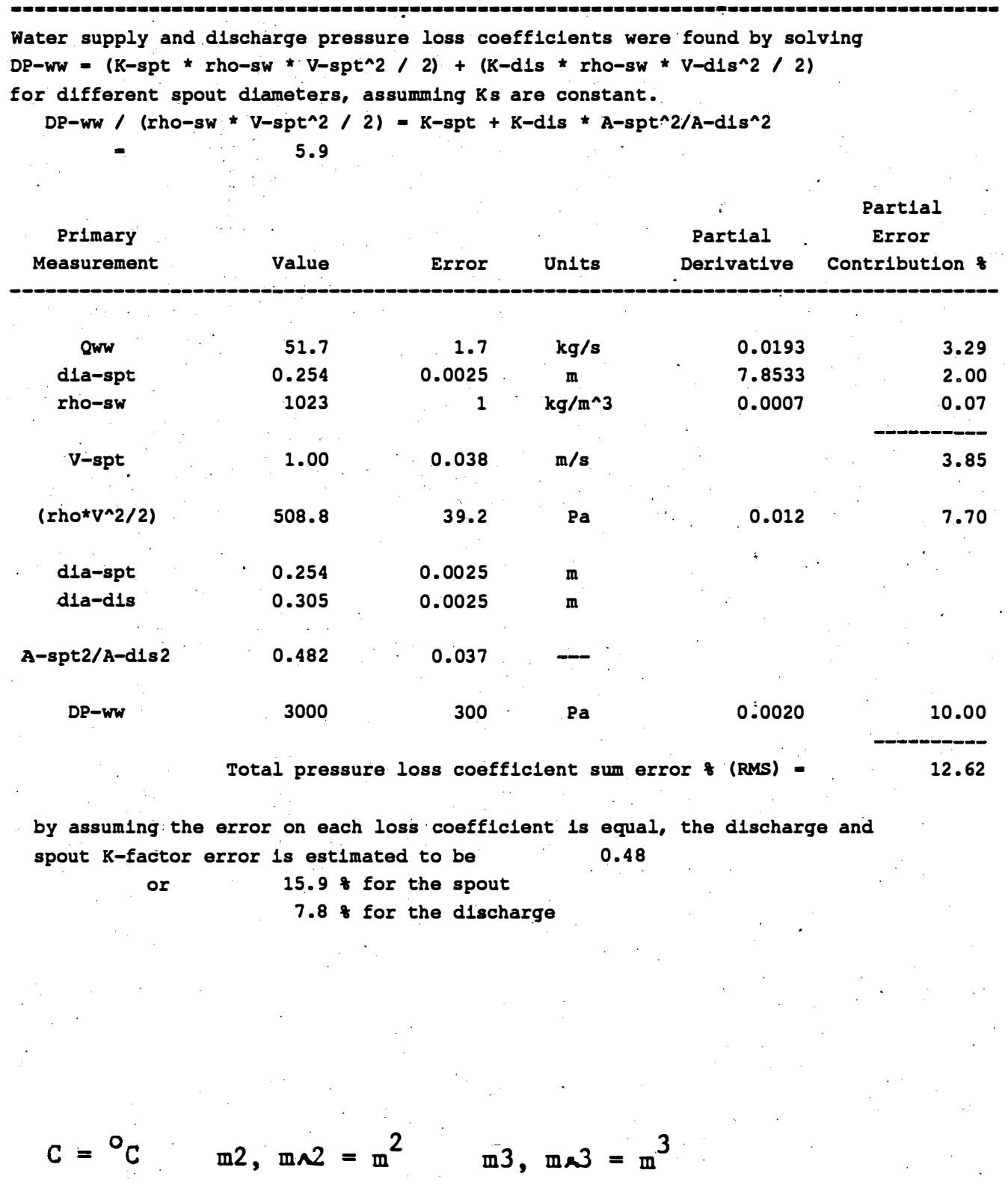


Table A-2. Derived Parameter Error Estimates for HMTSTA Component Tests: WARM SEAWATER DEAERATION

The errors for dissolyed oxygen online measurements are discussed extensively In Section D.2.4 of Appendix, D, and the derivation will not be repeated here. Warm seawater dissolved oxygen typical values and errors are sumarized here for completeness.

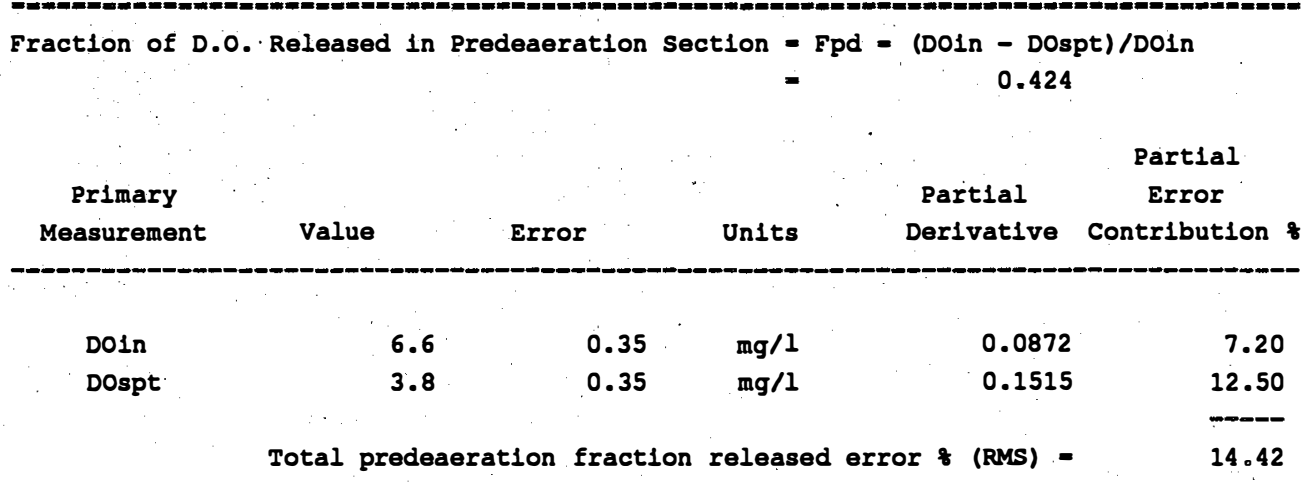

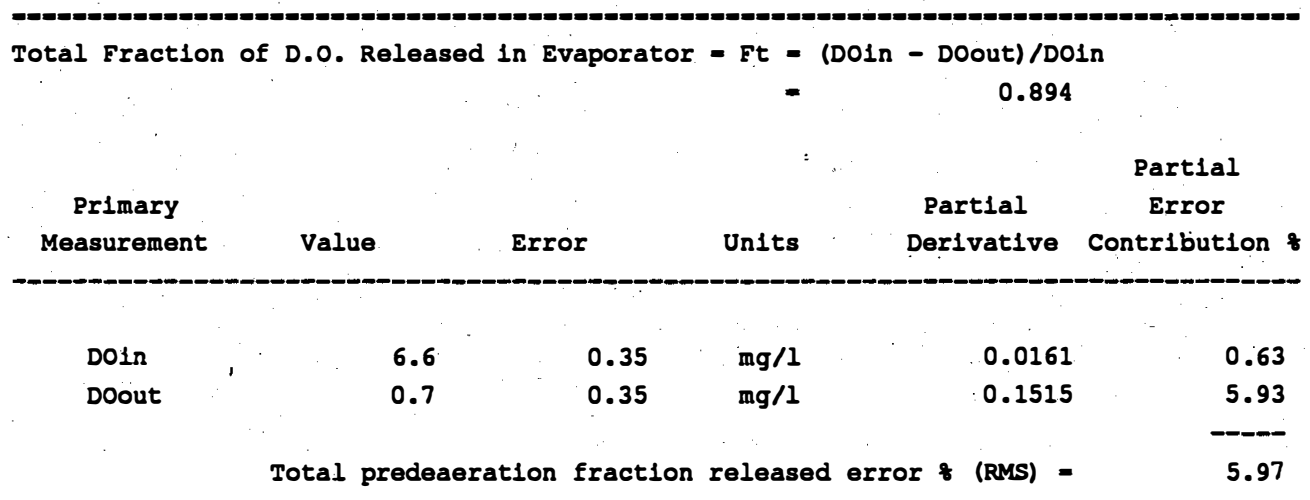


Table A-2. Derived Parameter Error Estimates for HMTSTA Component Tests: SURFACE CONDENSER

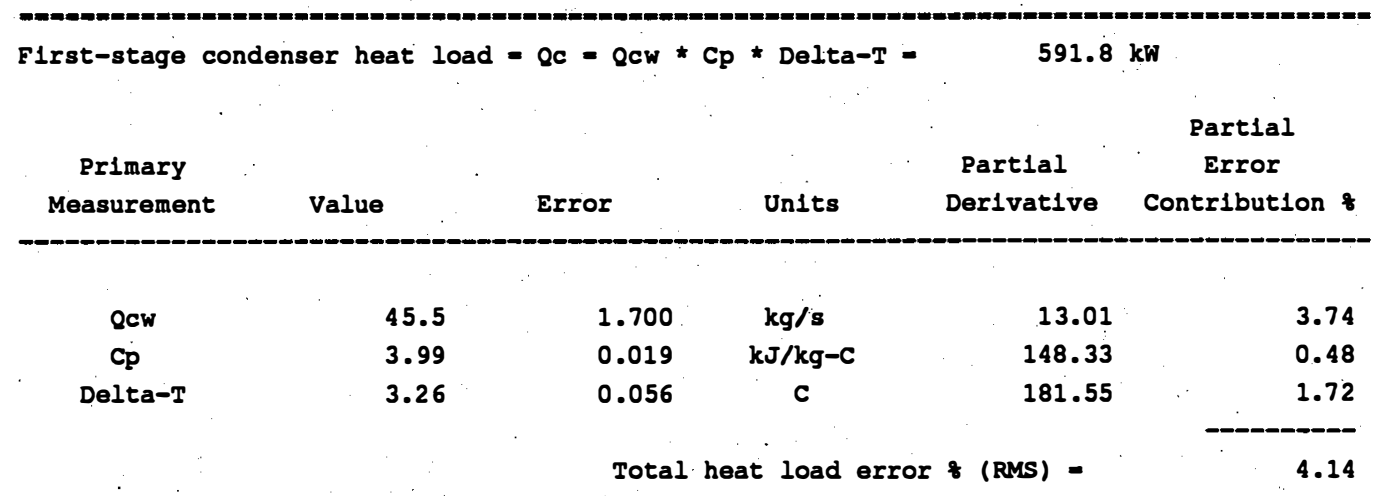

First-stage condenser heat load $=Q c w * C p *(T w 0, a v-T w 1, a v)$

$552.5 \mathrm{~kW}$

\begin{tabular}{|c|c|c|c|c|c|}
\hline $\begin{array}{l}\text { Primary } \\
\text { Measurement }\end{array}$ & Value & Error & Units & $\begin{array}{l}\text { Partial } \\
\text { Derivative }\end{array}$ & $\begin{array}{c}\text { Partial } \\
\text { Error } \\
\text { Contribution } \%\end{array}$ \\
\hline Twol & 11.73 & 0.255 & c & 0.5 & 1.09 \\
\hline Two2 & 11.65 & 0.255 & C & 0.5 & 1.09 \\
\hline Two,av & 11.69 & 0.1275 & c & 177.56 & 3.83 \\
\hline Tw11 & 8.55 & 0.255 & c & 0.5 & 1.49 \\
\hline Tw12 & 8.60 & 0.255 & c & 0.5 & 1.49 \\
\hline Tw1,av & 8.58 & 0.1803 & c & 177.56 & 5.41 \\
\hline Qcw & 44.5 & 1.700 & $\mathrm{~kg} / \mathrm{s}$ & 12.65 & 3.63 \\
\hline \multirow[t]{2}{*}{$C p$} & 3.99 & 0.019 & $\mathrm{~kJ} / \mathrm{kg}-\mathrm{C}$ & 141.11 & 0.45 \\
\hline & & Tọtal & at load e & $=\&$ (RMS) $=$ & 7.57 \\
\hline
\end{tabular}


Table A-2. Derived Parameter Error Estimates for HMTSTA Component Tests: SURFACE CONDENSER (Continued)

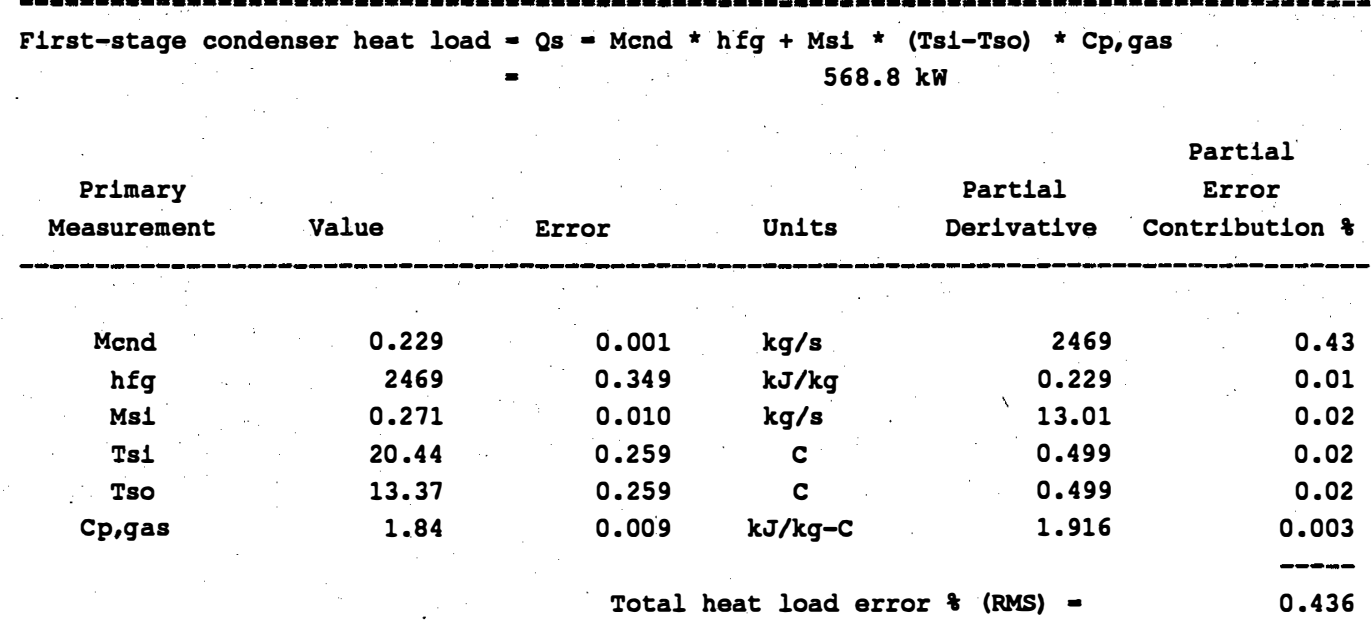

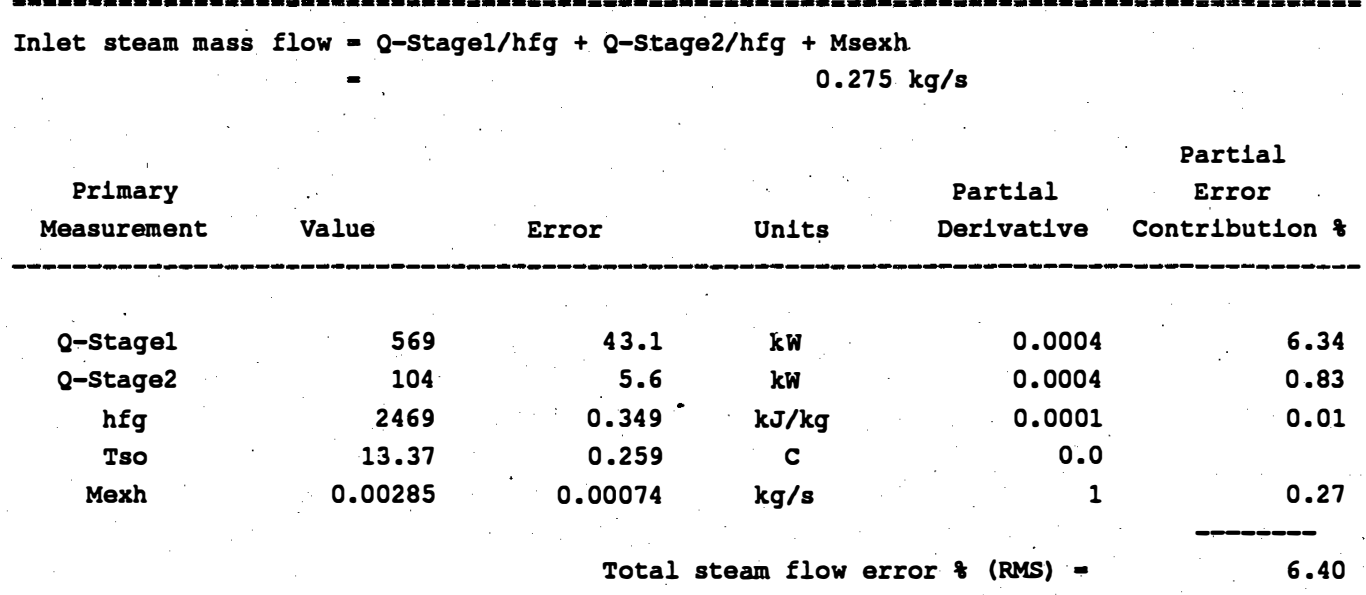

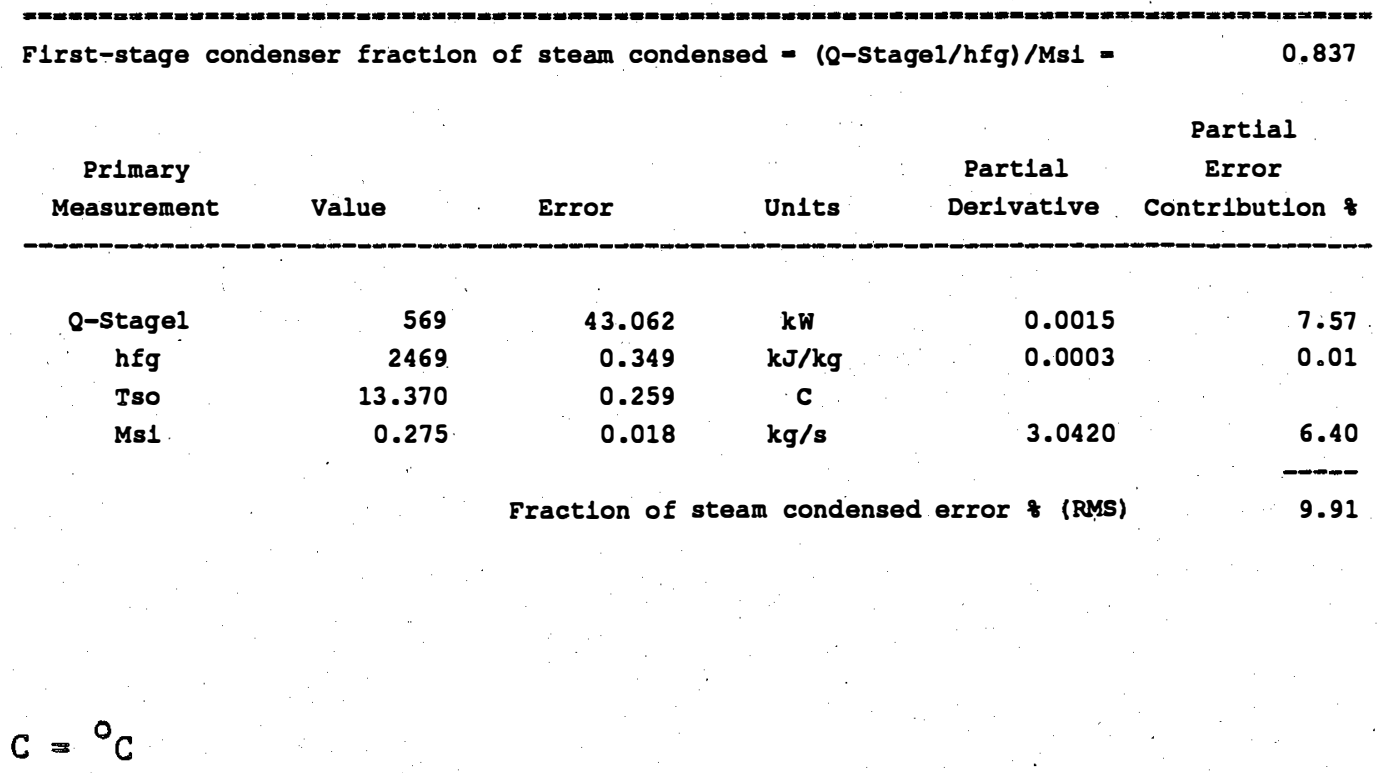


Table A-2. Derived Parameter Error Estimates for HMTSTA Component Tests: SURFACE CONDENSER (Continued)

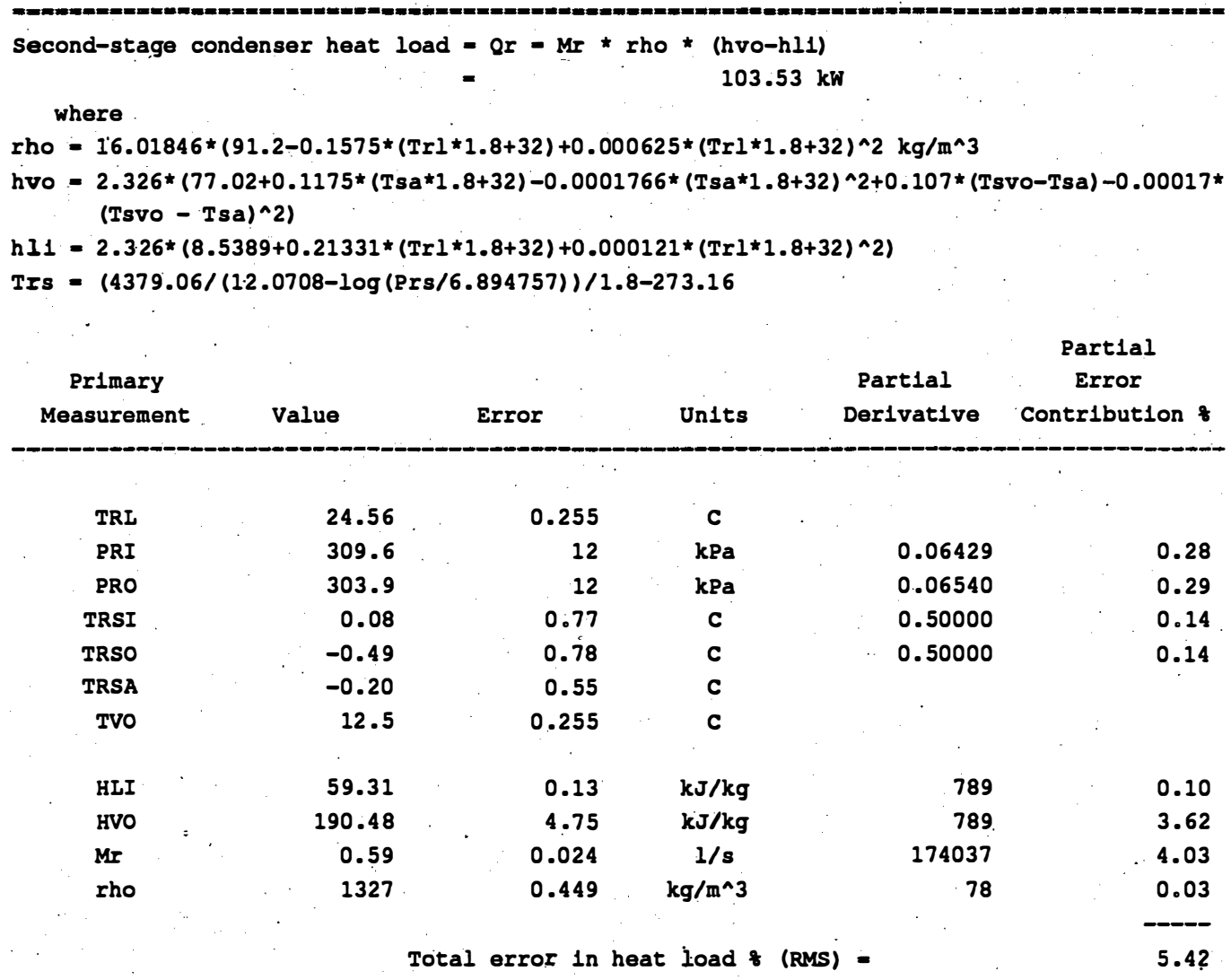

Inert gas flow rate $=\mathrm{Mg}$

$=29.2 *$ Qexh*Pexh/ (273.16+Texh)*(1-Ps (Tdeiw) /Pso2) $=$

$0.00149 \mathrm{~kg} / \mathrm{s}$

where PS (Tdew) $=133.322 * 10^{\wedge}(7.89182-2967.7731 /(378.4+($ TDEW* $1.8+32)))$

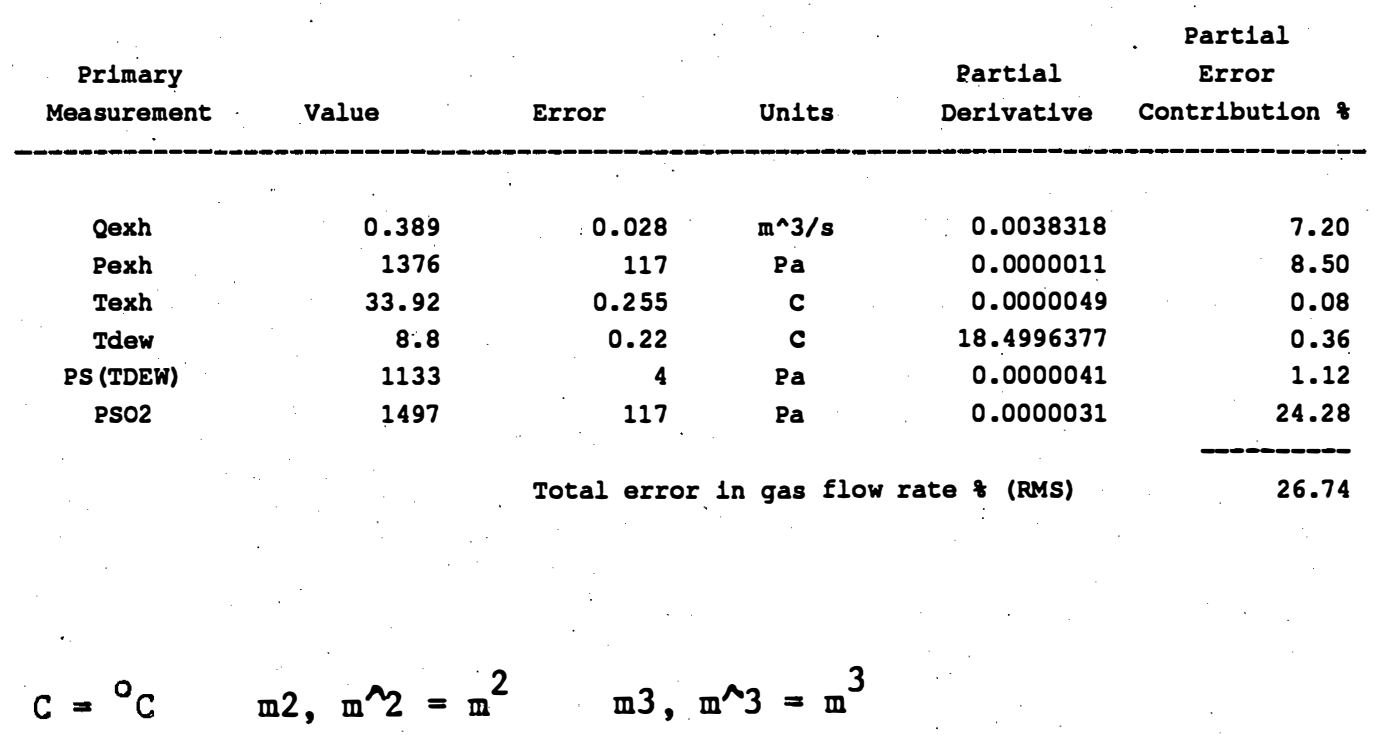


Table A-2. Derived Parameter Error Estimates for HMTSTA Component Tests: SURFACE CONDENSER (Continued)

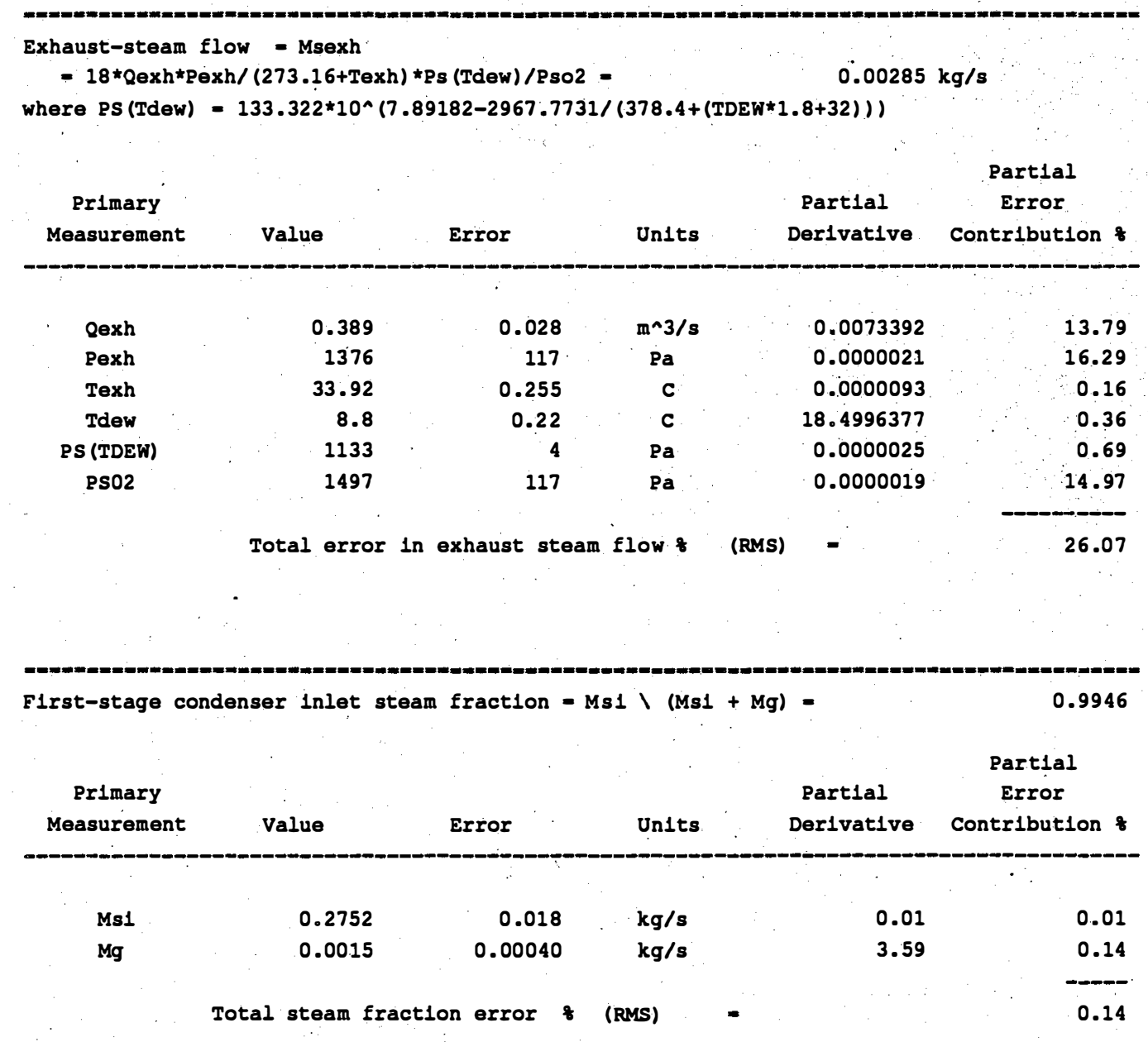

$\mathrm{C}={ }^{\circ} \mathrm{C} \quad \mathrm{m} 2, \mathrm{~m}^{\wedge} 2=\mathrm{m}^{2 \hat{\mathrm{e}}} \mathrm{m} 3, \mathrm{~m} \wedge 3=\mathrm{m}^{3 \hat{\mathrm{e}}}$ 
Table A-2. Derived Parameter Error Estimates for HMTSTA Component Tests: SURFACE CONDENSER (Continued)

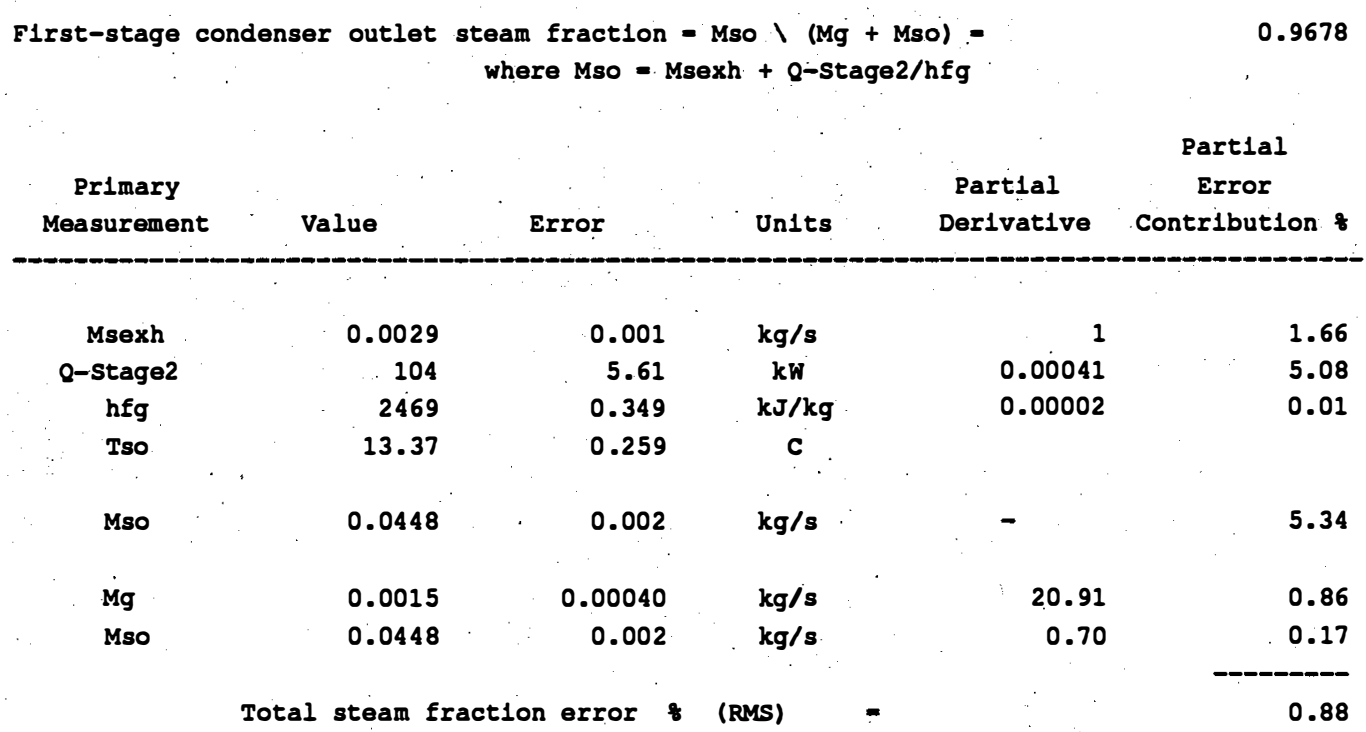
First-stage Inlet steam saturation temperature
$13.590 \mathrm{C}$

$T s 1=((2967.7731 /(7.89182-\operatorname{LOG} 10(P s 1 * Y s m 1 / 0.133322))-378.4)-32) / 1.8$

\begin{tabular}{|c|c|c|c|c|c|}
\hline Measurement & Value & Error & Units & $\begin{array}{l}\text { Partial } \\
\text { Derlvat1ve }\end{array}$ & $\begin{array}{c}\text { Partial } \\
\text { Error } \\
\text { Contribution }\end{array}$ \\
\hline$\therefore$. & & & & & $\therefore$ \\
\hline Ys1 & 0.9946 & 0.0014 & wt fren & 0.6190. & 0.089 \\
\hline Psic & 1.592 & 0.117 & $\mathrm{kPa}$ & 0.5 & 3.075 \\
\hline Psih & 1.531 & 0.117 & $\mathrm{kPa}$ & 0.5 & 3.75 \\
\hline Ysm1 & 0,9967 & 0.0009 & mole fren & 15.42515 & 0.101 \\
\hline Psia & 1.5615 & 0.0827 & $\mathbf{k P a}$ & 9.84555 & 5.994 \\
\hline
\end{tabular}

$C={ }^{\circ} \mathrm{C} \quad$ LOG10 $=$ LOG $_{10}$ 
Table A-2. Derived Parameter Error Estimates for HMTSTA Component Tests: SURFACE CONDENSER (Continued)

\begin{tabular}{|c|c|c|c|c|c|}
\hline $\begin{array}{c}\text { F1rst-stage ou } \\
\text { Tso = ( }(2967 \\
\text { Primary } \\
\text { Measurement }\end{array}$ & $\begin{array}{l}\text { steam satu } \\
31 /(7.89182- \\
\text { Value }\end{array}$ & $\begin{array}{l}\text { on temperat } \\
0 \text { (PsoYsmo) }\end{array}$ & $\begin{array}{l}e \\
133322) 1-37\end{array}$ & $\begin{array}{r}13.462 \\
4)-32) / 1.8\end{array}$ & $\begin{array}{l}\text { Partial } \\
\text { Error } \\
\text { Contribution \& }\end{array}$ \\
\hline . & & & & , & \\
\hline Yso & 0.9678 & 0.0085 & wt fren & 0.6320 & 0.548 \\
\hline Psic & 1.592. & 0.117 & $\mathrm{kPa}$ & 1 & 7.31 \\
\hline Psih & 1.531 & 0.117 & kPa & 1 & 7.55 \\
\hline Dpsc & -0.008 & 0.019 & kPa & 1 & \\
\hline Dpsh & -0.019 & 0.019 & kPa & 1 & \\
\hline Psoc & 1.600 & 0.117 & $\mathrm{kPa}$ & 0.5 & 3.71 \\
\hline Psoh & 1.550 & 0.117 & $\mathrm{kPa}$ & 0.5 & 3.71 \\
\hline Ysmo & 0.9799 & 0.0054 & mole fren & 15.672 & 0.63 \\
\hline Psoa & 1.575 & 0.0827 & kPa & 9.751 & 5.99. \\
\hline
\end{tabular}

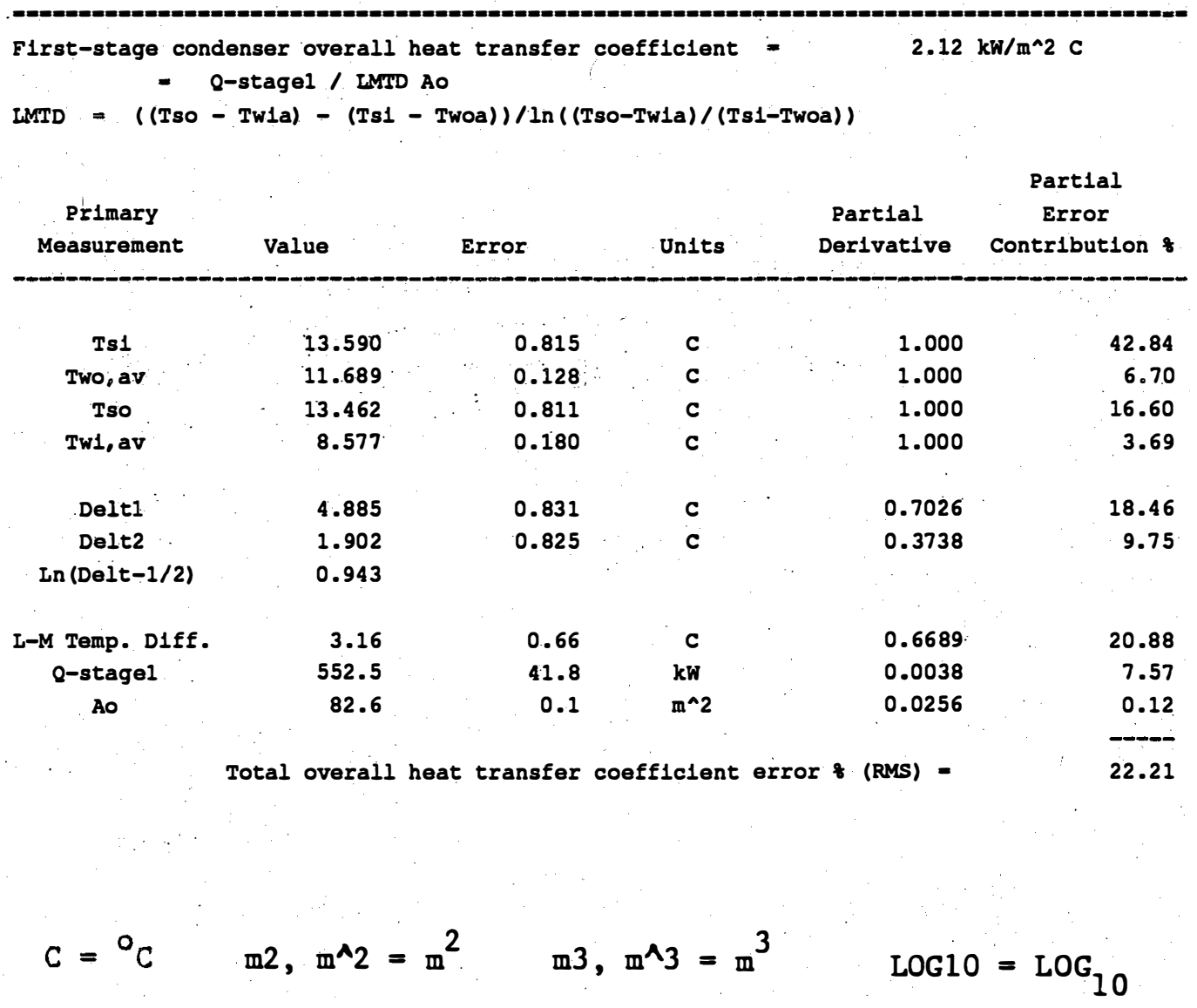


Table A-2. Derived Parameter Error Estimates for HMTSTA Component Tests: SURFACE CONDENSER (Continued)

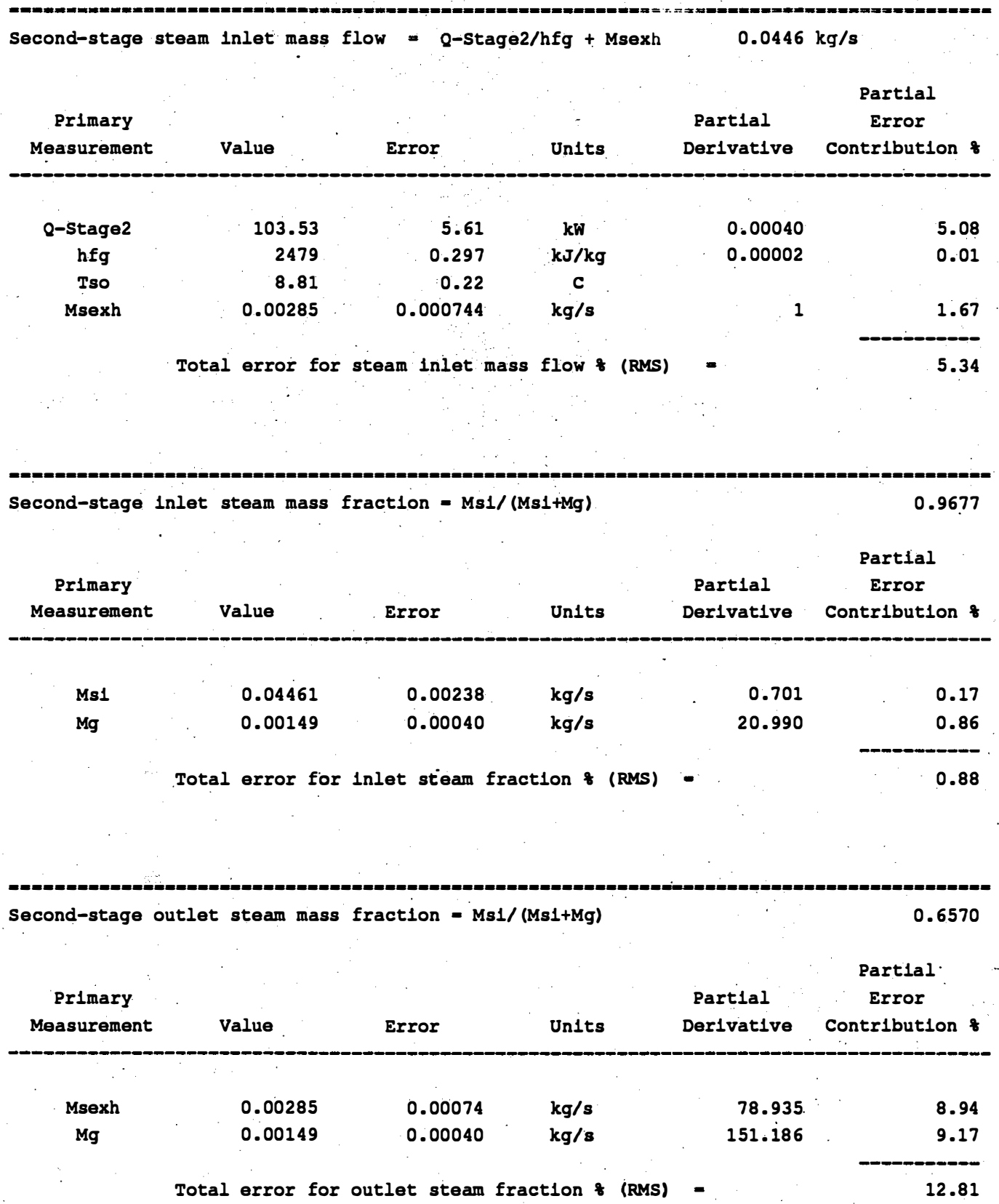

$c={ }^{\circ} \mathrm{C}$ 
Table A-2. Derived Parameter Error Estimates for HMTSTA Component Tests: SURFACE CONDENSER (Concluded)

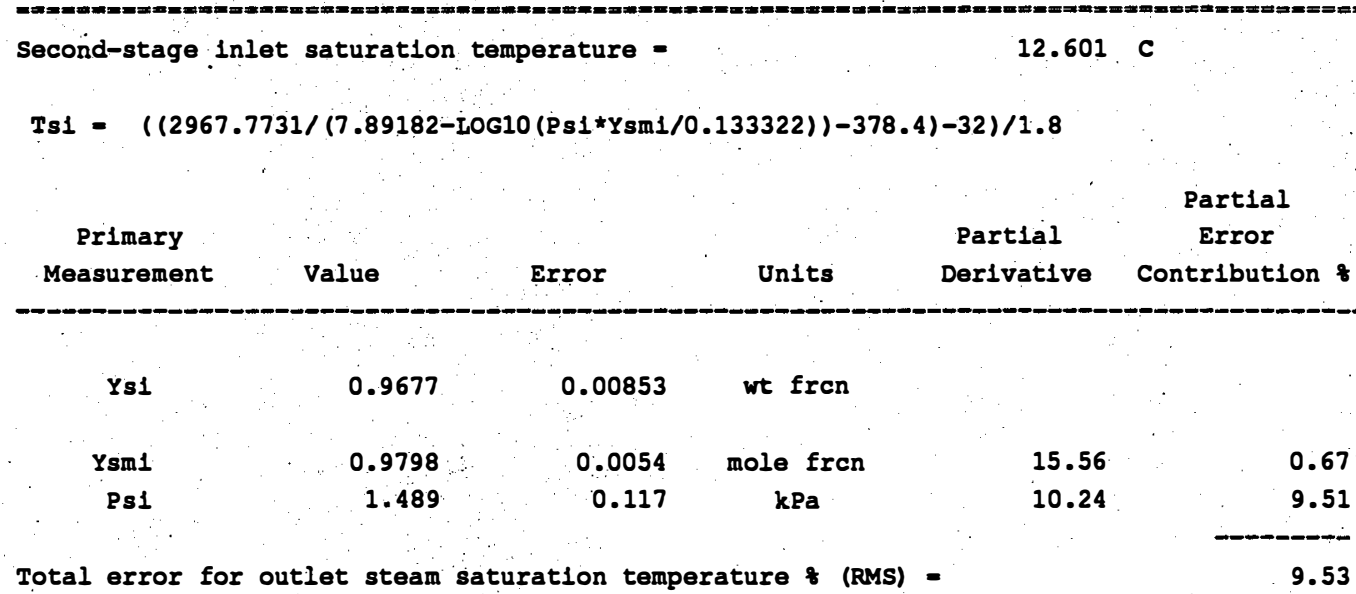

Total error for outlet steam saturation temperature of (RMS) =

9.53

Second-stage condenser thermal effectiveness =

0.30

- $(T s 1$ - Tso)/(Ts1 - Trsa)

\begin{tabular}{|c|c|c|c|c|c|}
\hline $\begin{array}{l}\text { Primary } \\
\text { Measurement }\end{array}$ & Value & Error & Units & $\begin{array}{l}\text { Partial } \\
\text { Derivative }\end{array}$ & $\begin{array}{c}\text { Error } \\
\text { Contribution } \%\end{array}$ \\
\hline Ts1 & 12.601 & 1.201 & C & 0.0550 & 22.27 \\
\hline Tso (Tdewo) & 8.806 & 0.220 & C & 0.0781 & 5.80 \\
\hline Trsa & -0.202 & 0.550 & C & 0.0232 & 4.30 \\
\hline
\end{tabular}

Second stage $R-12$ vapor superheat

- Tvo - Trso = $12.99 \mathrm{C}$

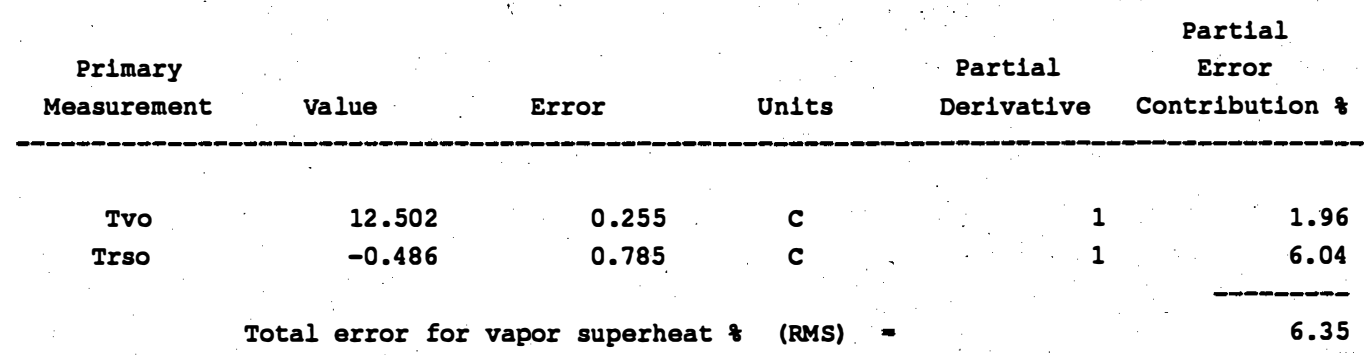

LOGIO $=$ LOG $_{10} \quad \mathrm{C}={ }^{\circ} \mathrm{C}$ 
Table A-2. Derived Parameter Error Estimates for HMTSTA Component Tests: DIRECT-CONTACT CONDENSER

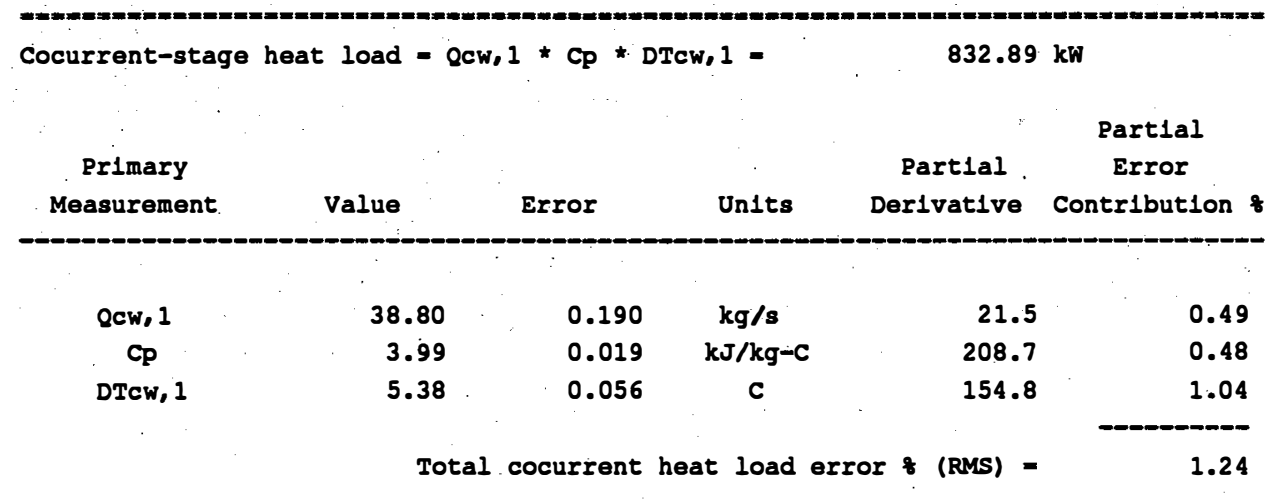

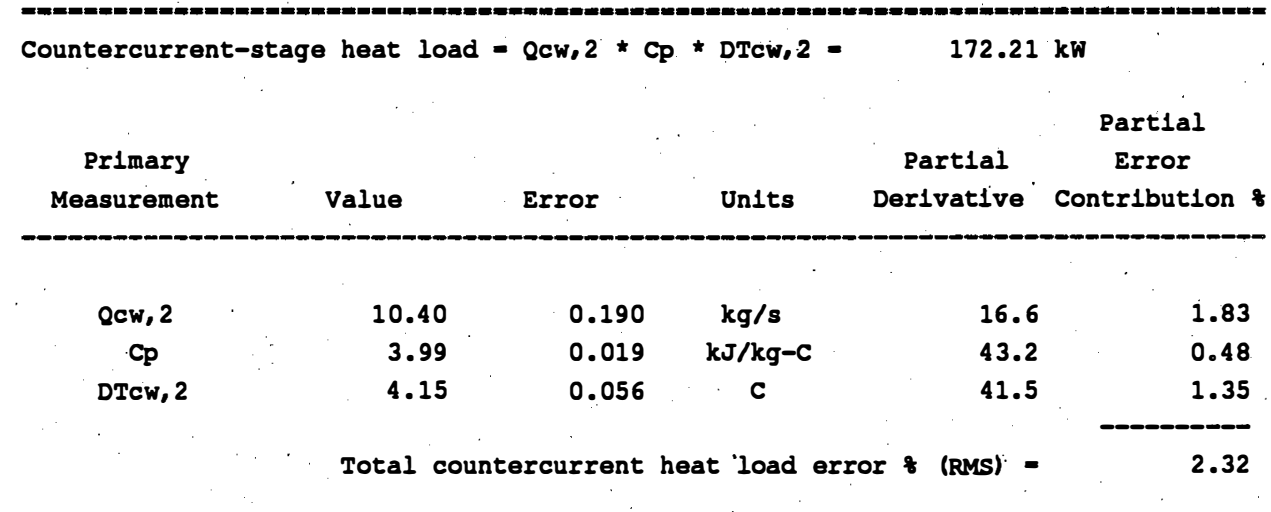

\begin{tabular}{|c|c|c|c|c|c|}
\hline \multirow{2}{*}{$\begin{array}{l}\text { Total heat load } \\
\text { Primary } \\
\text { Measurement }\end{array}$} & \multirow[t]{2}{*}{ lat load } & \multirow[b]{2}{*}{ Error } & \multirow[b]{2}{*}{ Units } & \multicolumn{2}{|c|}{$1005.10 \mathrm{~kW}$} \\
\hline & & & & $\begin{array}{c}\text { Partial } \\
\text { Derlvative }\end{array}$ & $\begin{array}{c}\text { Partial } \\
\text { Error } \\
\text { Contribution } \%\end{array}$ \\
\hline Heat load co & 832.9 & 10.37 & $\mathrm{~kW}$ & 1. & 1.03 \\
\hline Heat load cc & 172.2 & 4.00 & kw & 1. & 0.40 \\
\hline
\end{tabular}

$c={ }^{\circ} \mathrm{C}$ 
Table A-2. Derived Parameter Error Estimates for HMTSTA Component Tests: DIRECT-CONTACT CONDENSER (Continued)

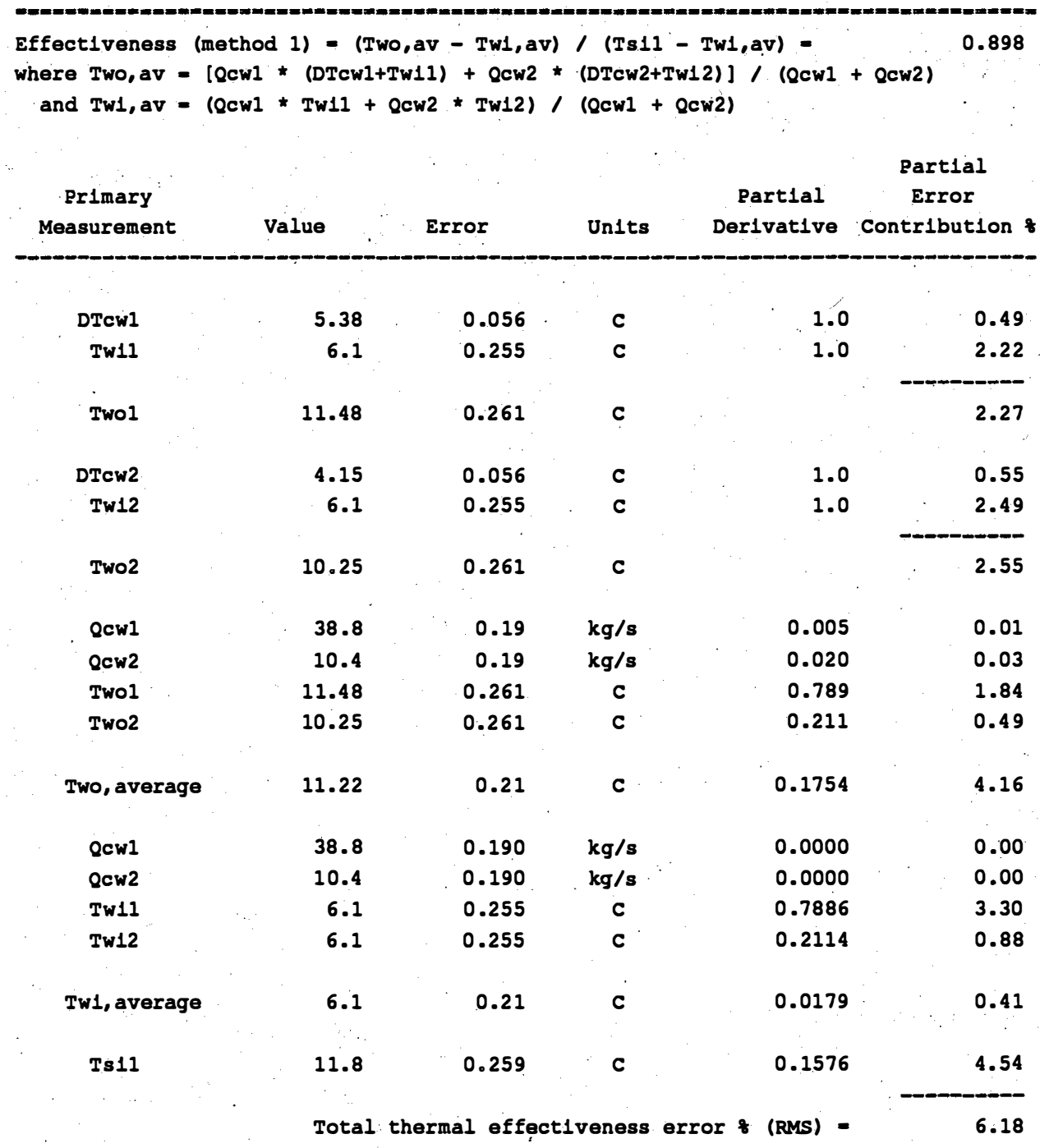

$\mathrm{C}={ }^{\circ} \mathrm{C}$ 
Table A-2. Derived Parameter Error Estimates for HMTSTA Component Tests: DIRECT-CONTACT CONDENSER (Continued)

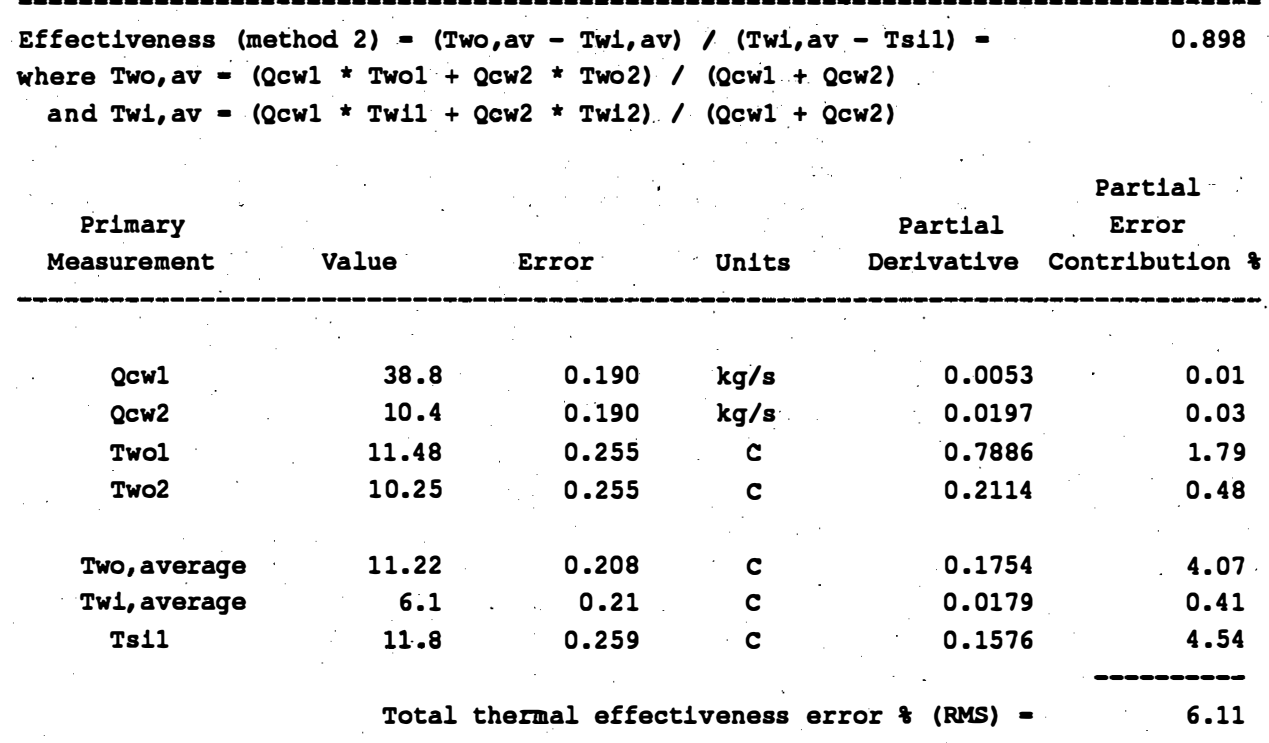

Effectiveness (method 3) - (QCW1 * DTcw1 + QcW2 * DTcW2) / (QCW1 + QcW2) / DTs1w11 0.898

\begin{tabular}{|c|c|c|c|c|c|}
\hline $\begin{array}{c}\text { Primary } \\
\text { Measurement }\end{array}$ & Value & Error & Un1ts & $\begin{array}{c}\text { Partlal } \\
\text { Derivat1ve }\end{array}$ & $\begin{array}{c}\text { Partial } \\
\text { Error } \\
\text { Contribution } \%\end{array}$ \\
\hline Qcw1 & 38.8 & 0.2 & $\mathrm{~kg} / \mathrm{s}$ & 0.0009 & 0.02 \\
\hline Qcw2 & 10.4 & 0.2 & $\mathrm{~kg} / \mathrm{s}$ & 0.0035 & 0.07 \\
\hline DTcw1 & 5.38 & 0.056 & C & 0.1384 & 0.86 \\
\hline DTcw2 & 4.15 & 0.056 & c & 0.0371 & 0.23 \\
\hline DTs1w11 & 5.70 & 0.060 & c & 0.1576 & 1.05 \\
\hline
\end{tabular}

$\mathrm{c}={ }^{\circ} \mathrm{C}$ 
Table A-2. Derived Parameter Error Estimates for HMTSTA Component Tests: DIRECT-CONTACT CONDENSER (Continued)

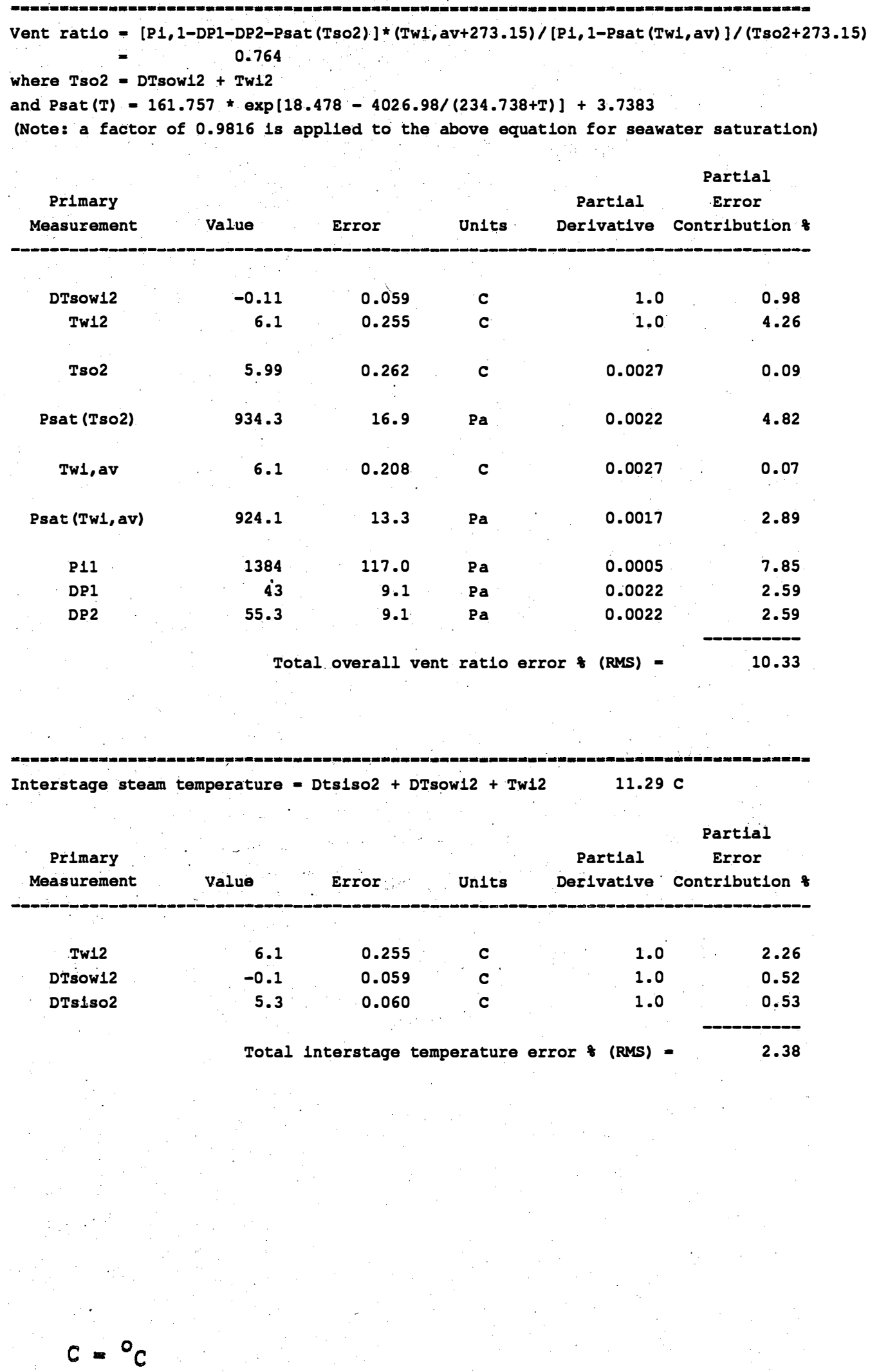


Table A-2. Derived Parameter Error Estimates for HMTSTA Component Tests: DIRECT-CONTACT CONDENSER (Continued)

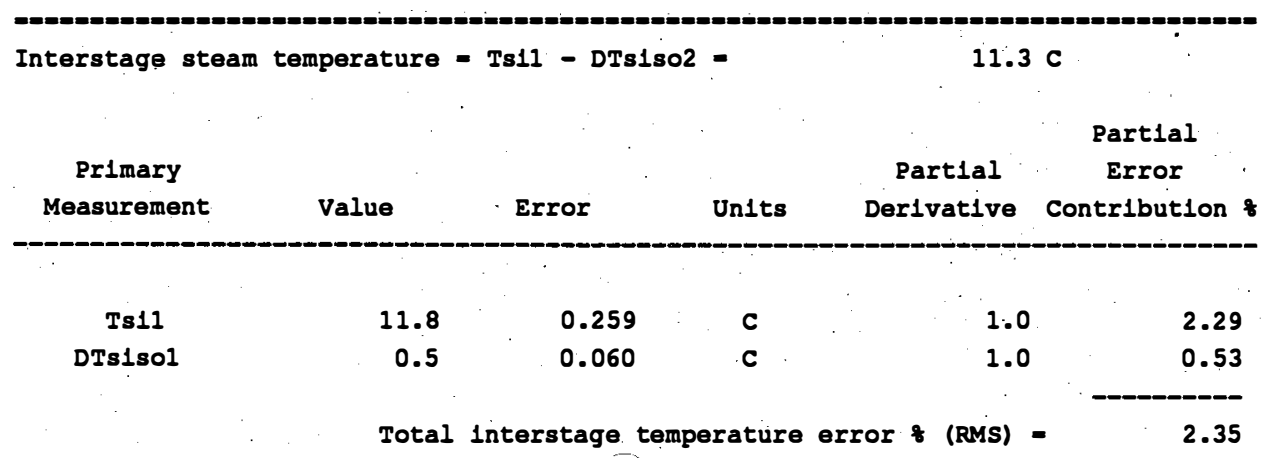

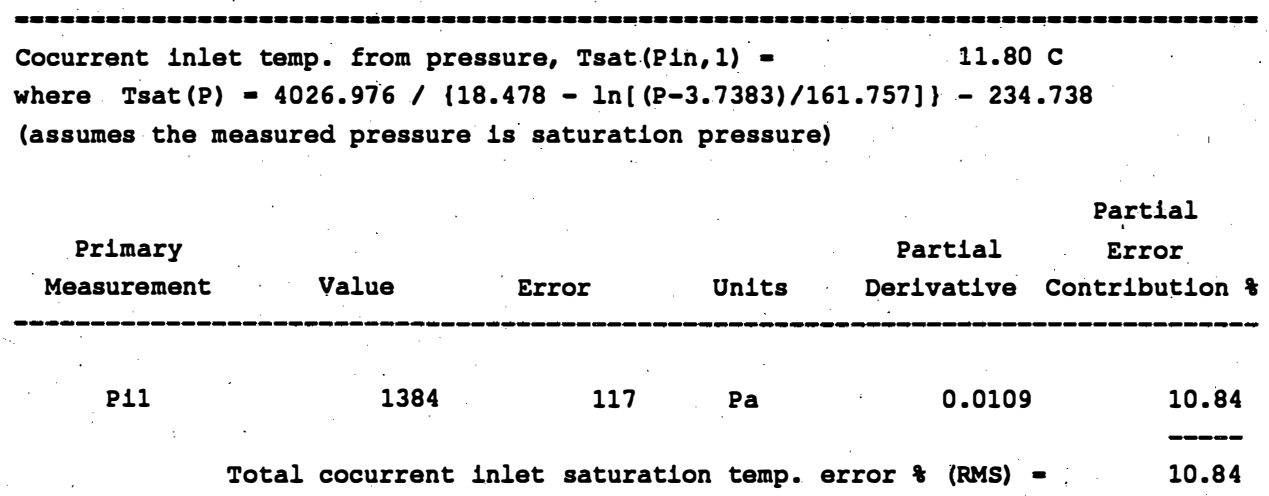

$\mathrm{C}={ }^{\circ} \mathrm{C}$ 
Table A-2. Derived Parameter Error Estimates for HMTSTA Component Tests: DIRECT-CONTACT CONDENSER (Continued)

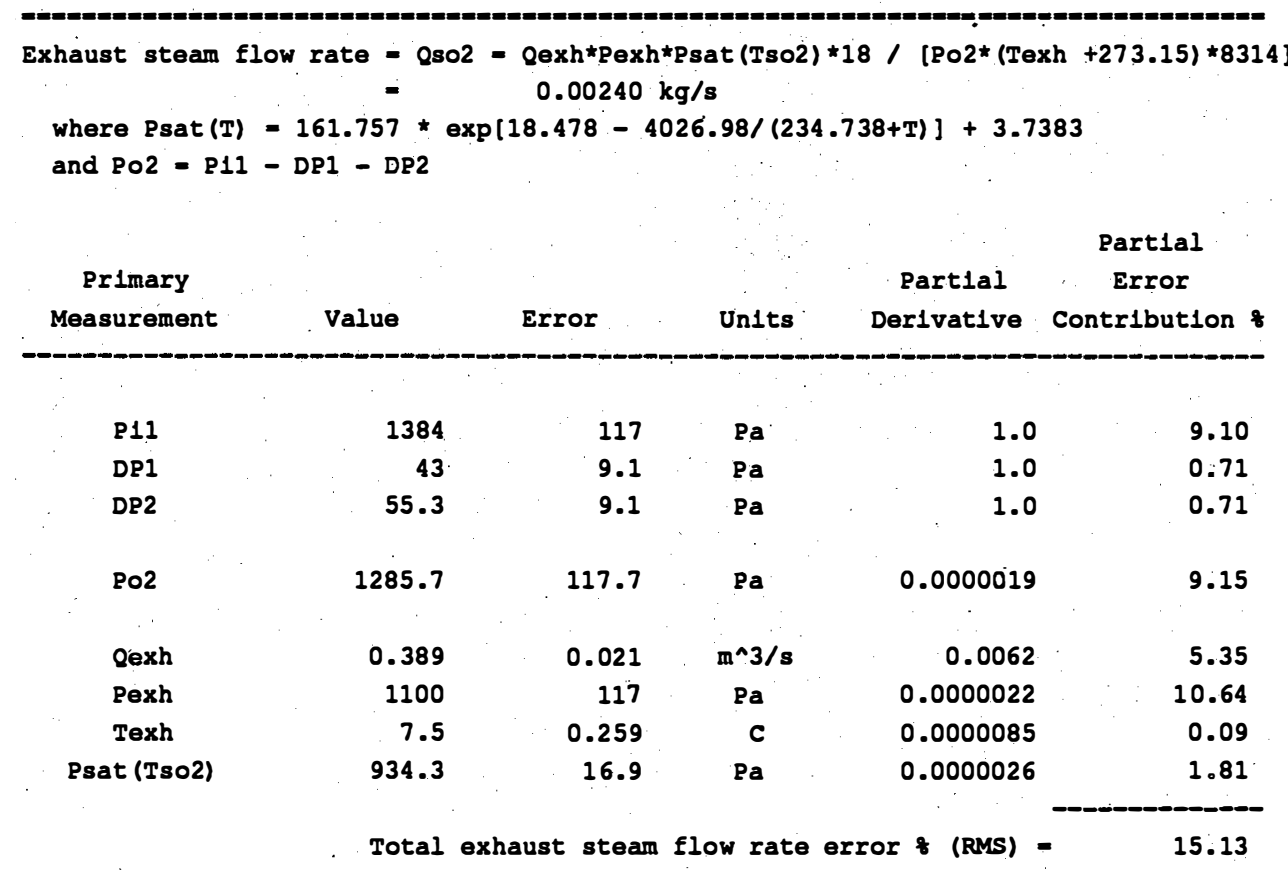

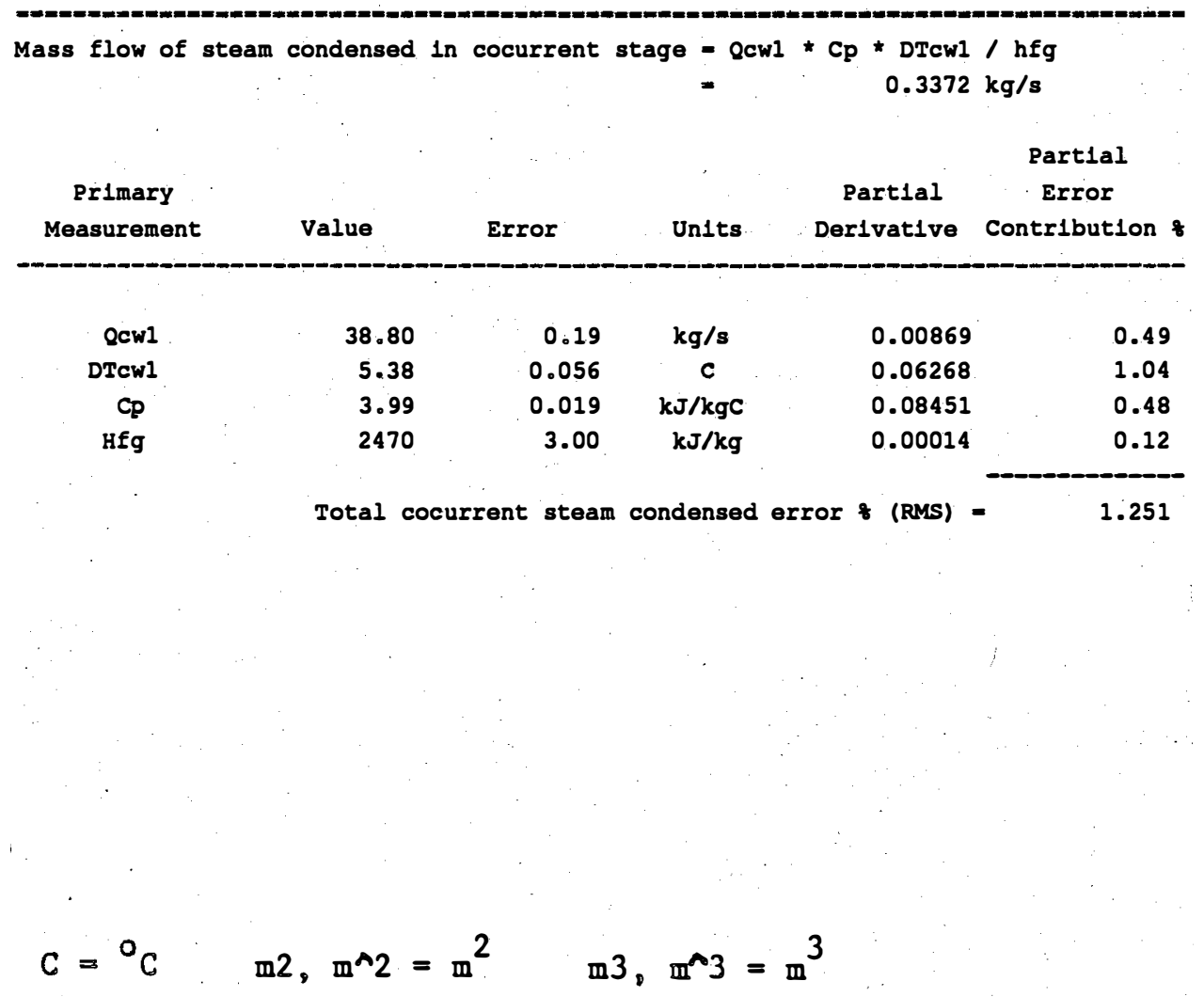


Table A-2. Derived Parameter Error Estimates for HMTSTA Component Tests: DIRECT-CONTACT CONDENSER (Continued)

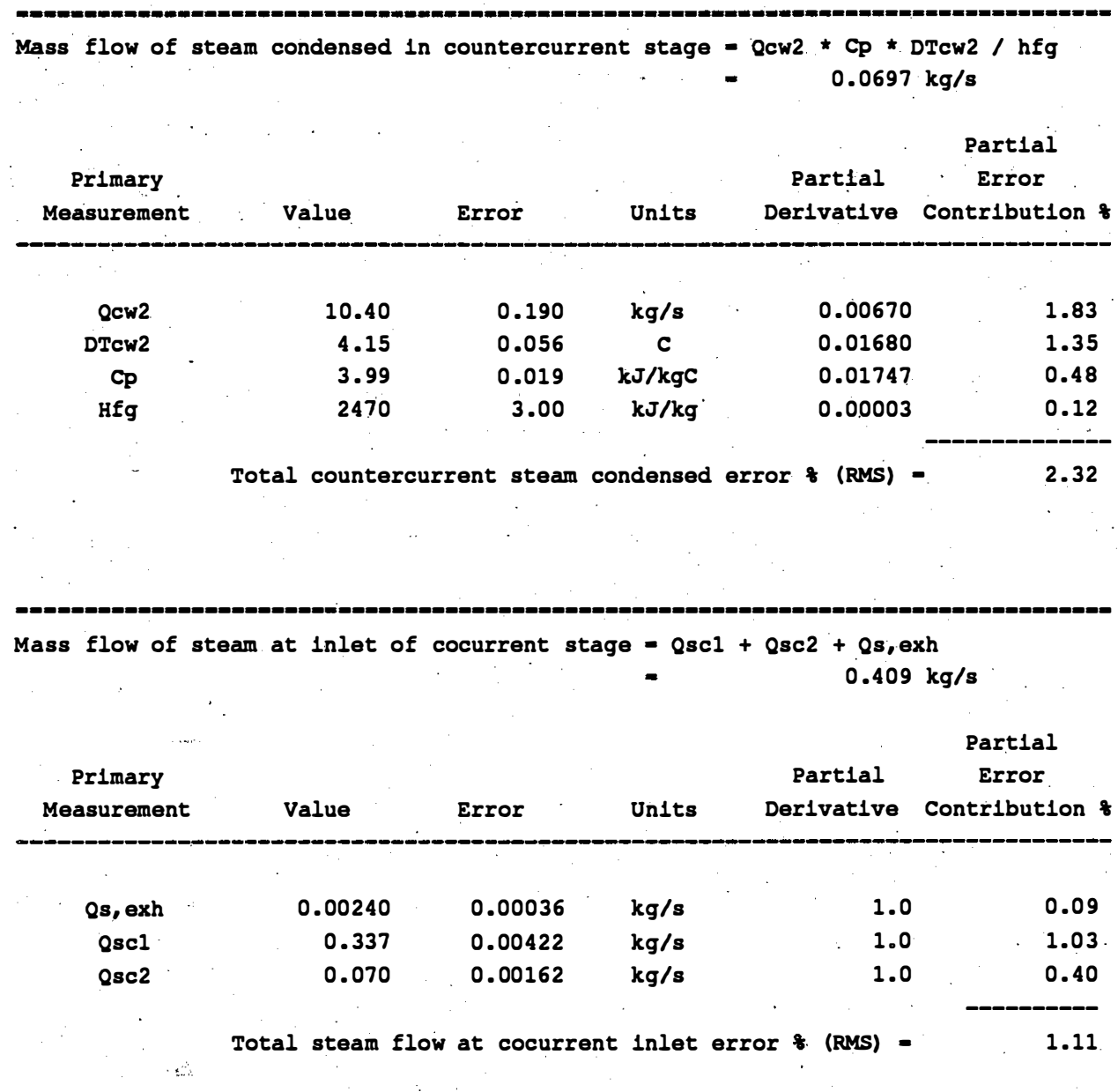

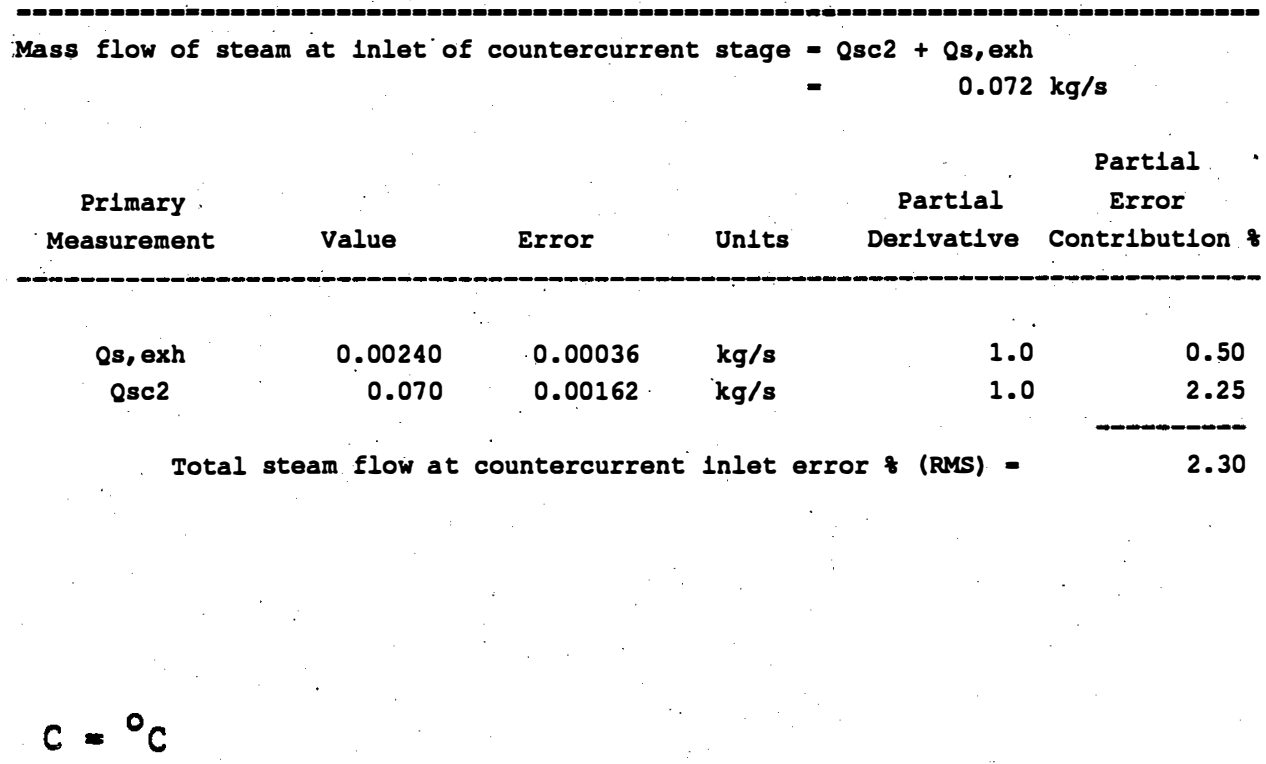


Table A-2. Derived Parameter Error Estimates for HMTSTA Component Tests: DIRECT-CONTACT CONDENSER (Continued)

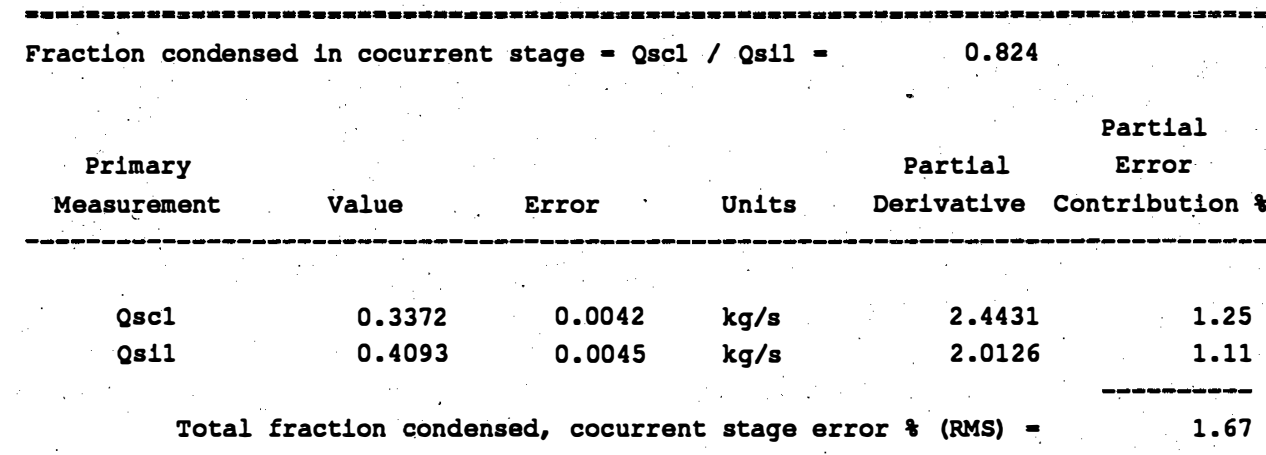

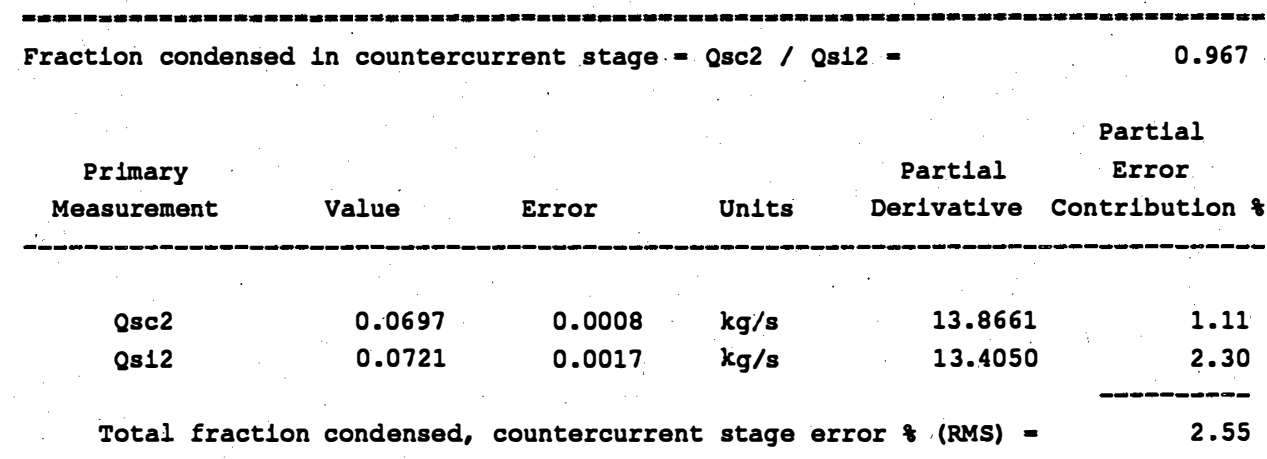

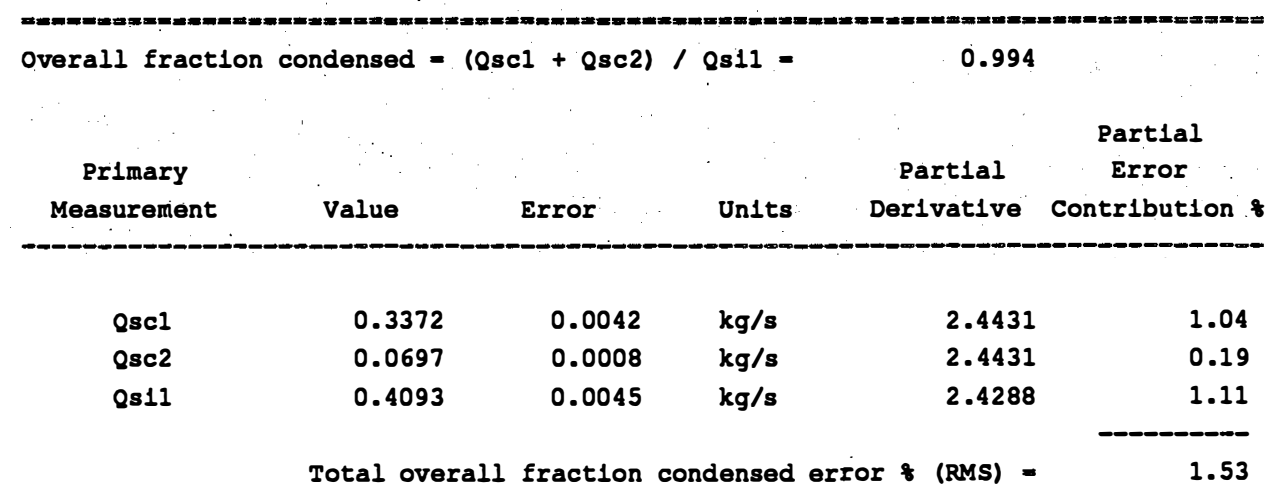


Table A-2. Derived Parameter Error Estimates for HMTSTA Component Tests: DIRECT-CONTACT CONDENSER (Continued)

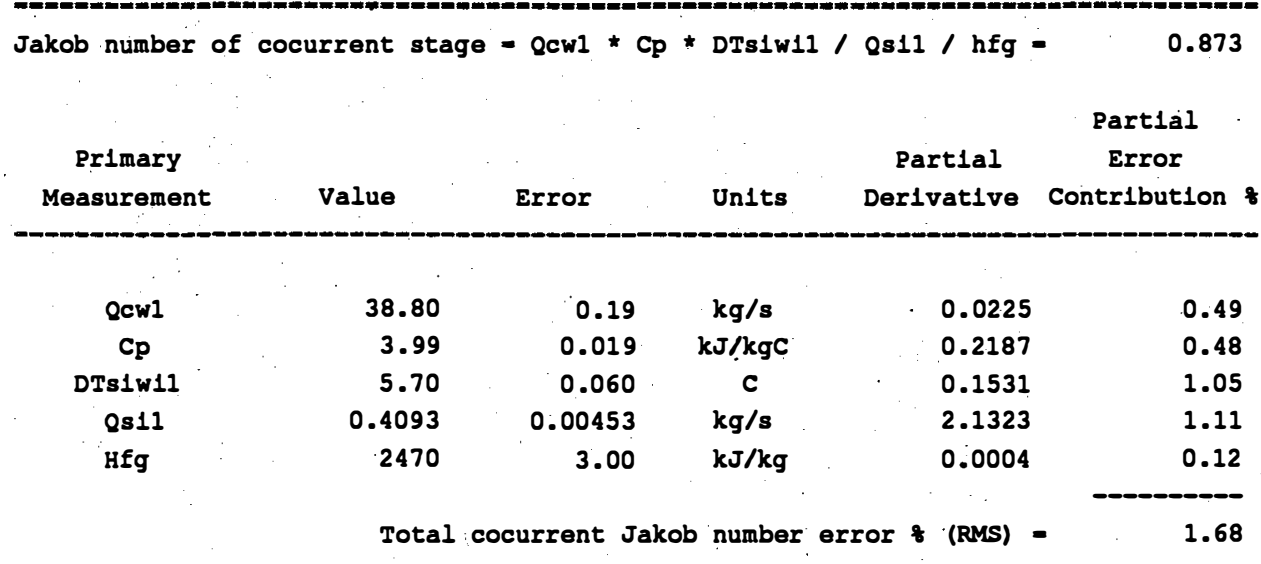

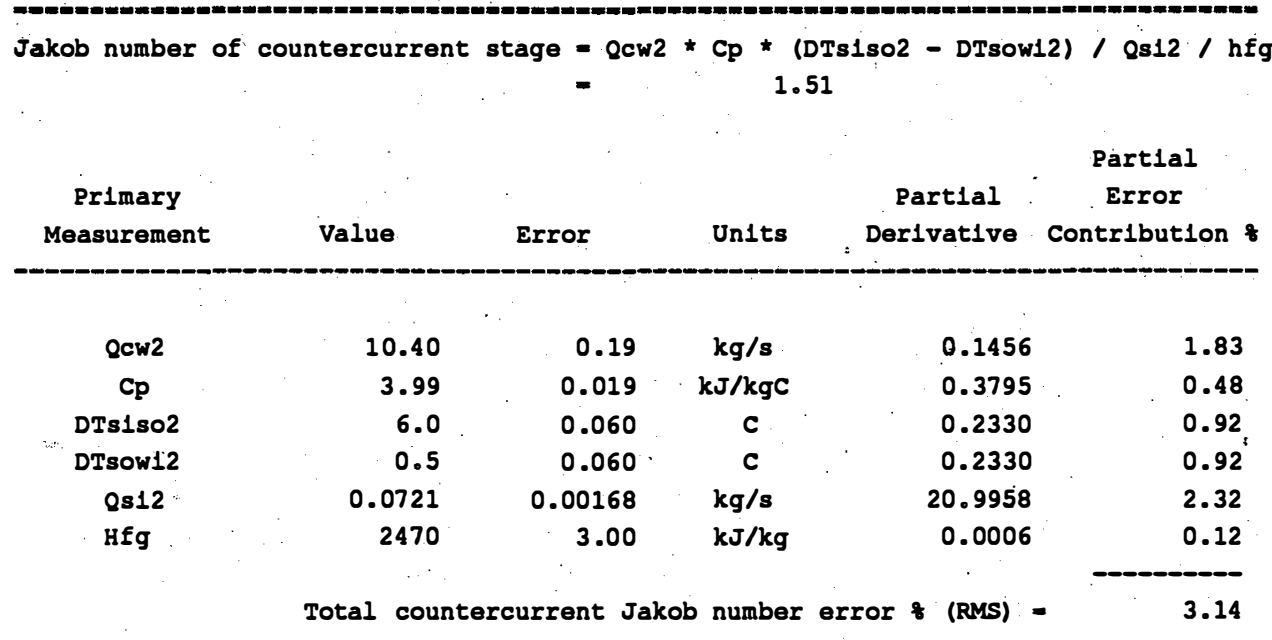

$C={ }^{0} \mathrm{C}$ 
Table A-2. Derived Parameter Error Estimates for HMTSTA Component Tests: DIRECT-CONTACT CONDENSER (Continued)

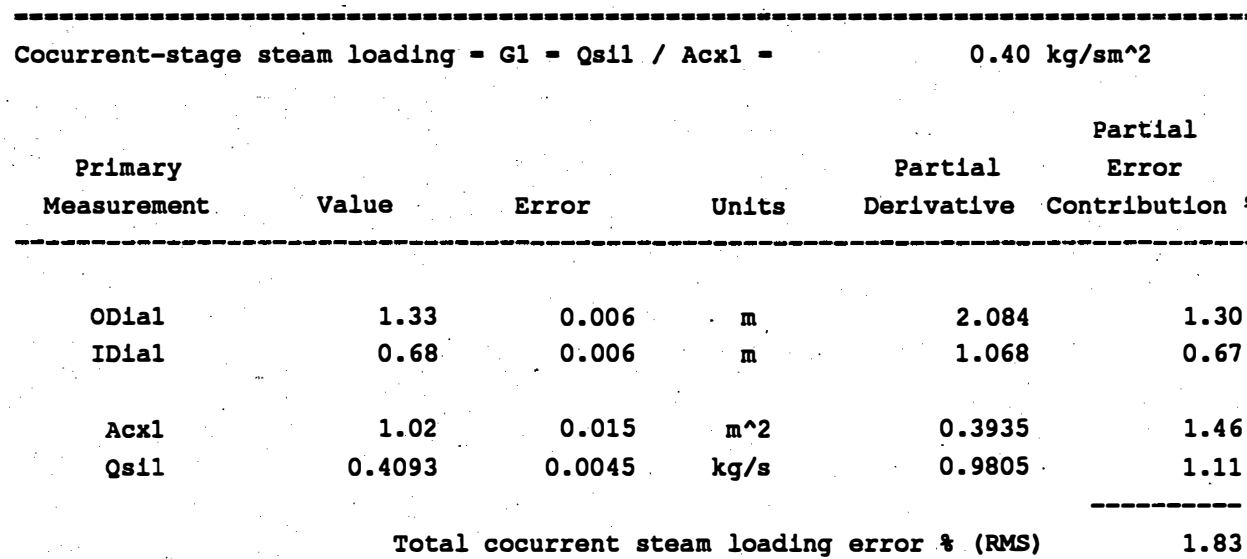

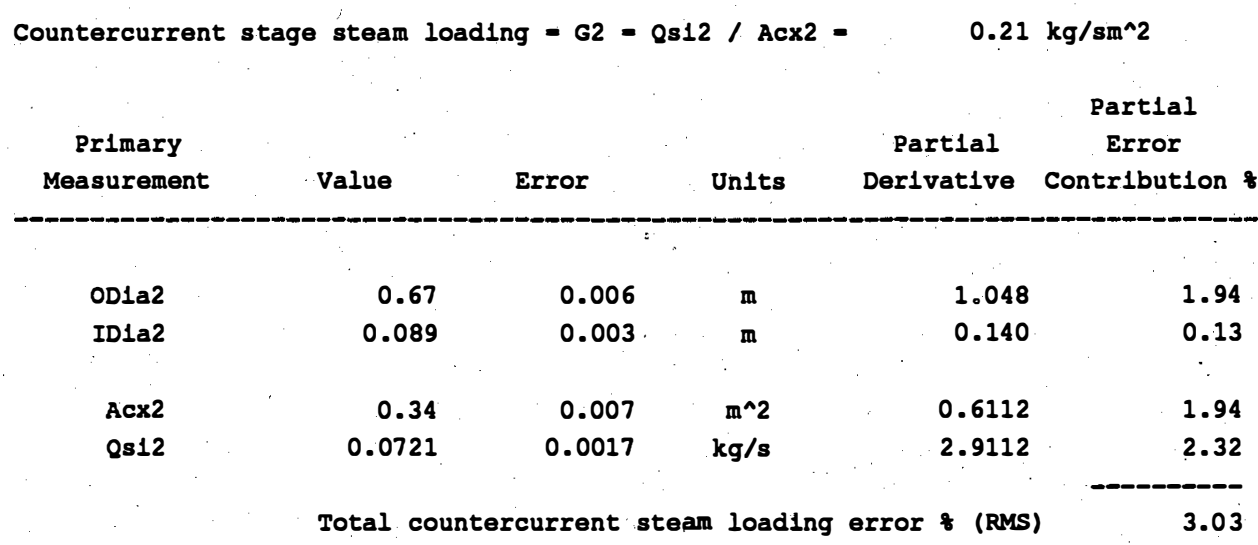

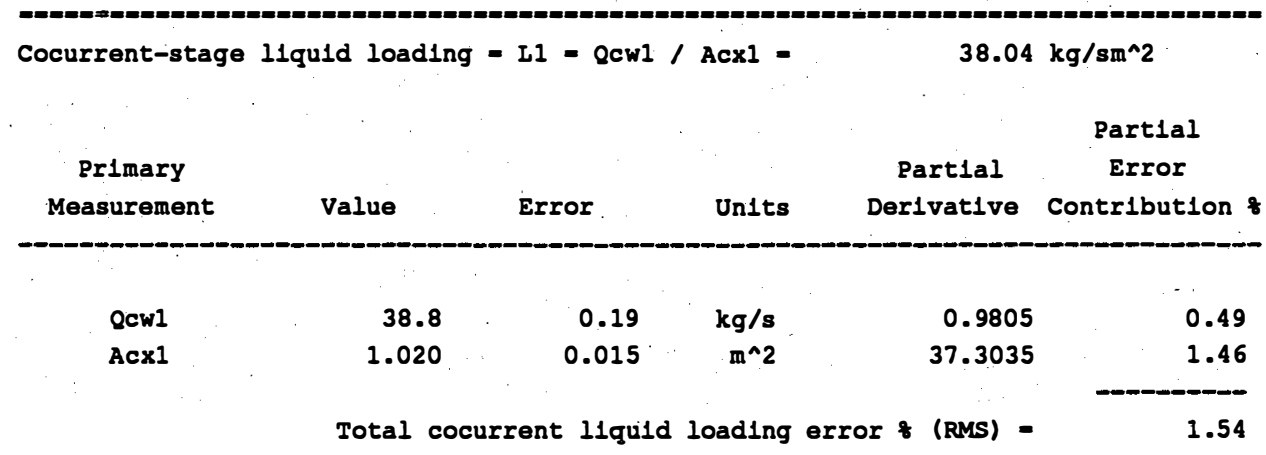

$\mathrm{m} 2, \mathrm{~m}^{\wedge} 2=\mathrm{m}^{2} \quad \mathrm{~m} 3, \mathrm{~m} \wedge 3=\mathrm{m}$ 
Table A-2. Derived Parameter Error Estimates for HMTSTA Component Tests: DIRECT-CONTACT CONDENSER (Continued)

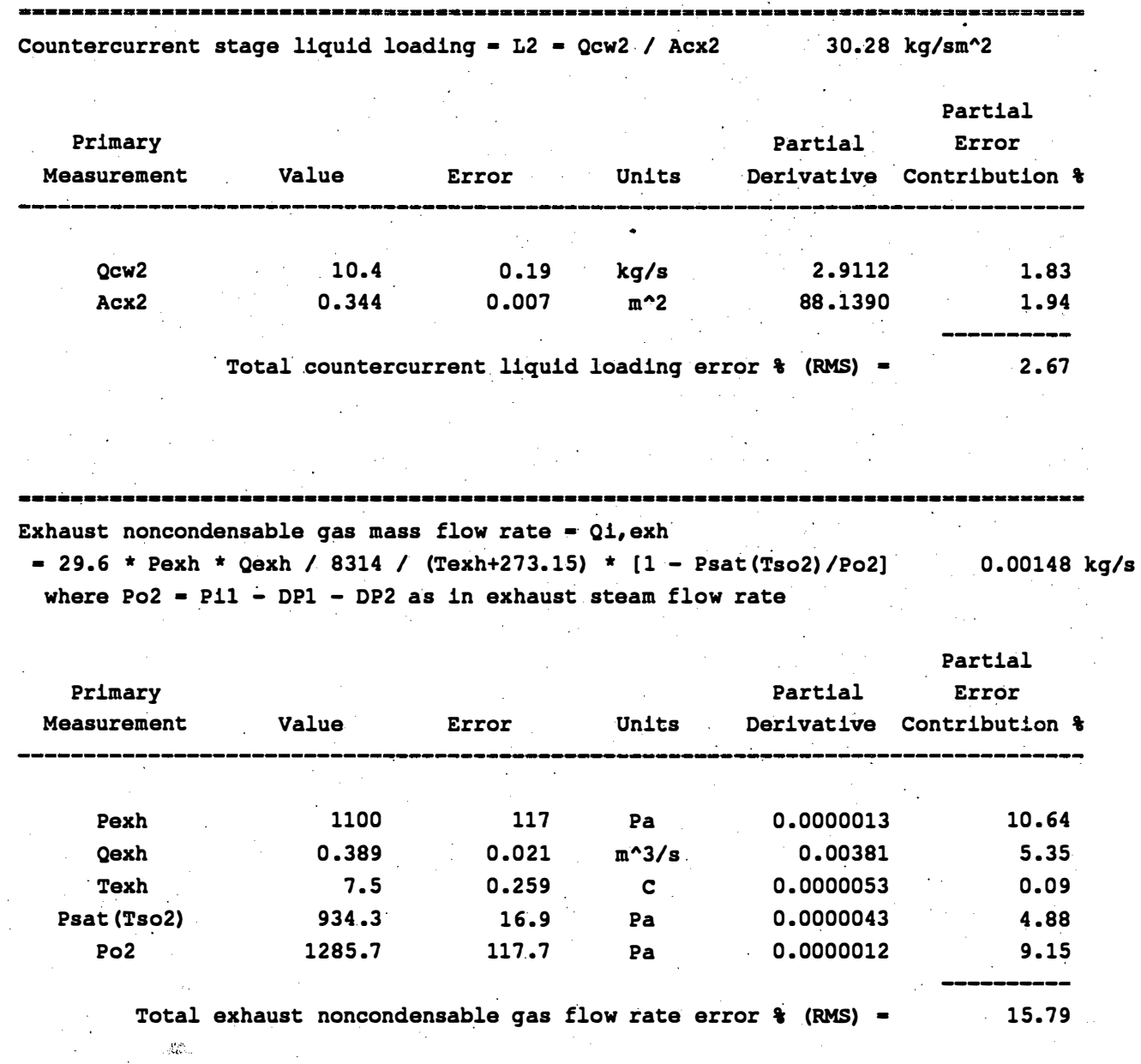

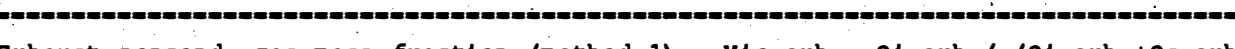

Exhaust noncond. gas mass fraction (method 1) $=x 10, e x h=01, e x h /(Q 1, e x h+Q s, e x h)$ 0.382

\begin{tabular}{|c|c|c|c|c|c|}
\hline $\begin{array}{c}\text { Primary } \\
\text { Measurement }\end{array}$ & Value & Error & Unlts & $\begin{array}{c}\text { Partial } \\
\text { Derivative }\end{array}$ & $\begin{array}{c}\text { Partial } \\
\text { Error } \\
\text { Contribution } 8\end{array}$ \\
\hline & & & & & \\
\hline $01, e \times h$ & 0.0015 & 0.0002 & $\mathrm{~kg} / \mathrm{s}$ & 159.17 & 9.8 \\
\hline$Q s, e x h$ & 0.0024 & 0.0004 & $\mathrm{~kg} / \mathrm{s}$ & 98.46 & 9.3 \\
\hline
\end{tabular}

$\mathrm{C}={ }^{\circ} \mathrm{C} \quad \mathrm{m} 2, \mathrm{~m}^{\wedge} 2=\mathrm{m}^{2} \quad \mathrm{~m} 3, \mathrm{~m}^{\wedge} 3=\mathrm{m}^{3}$ 


\section{Table A-2. Derived Parameter Error Estimates for HMTSTA Component Tests:} DIRECT-CONTACT CONDENSER (Continued)

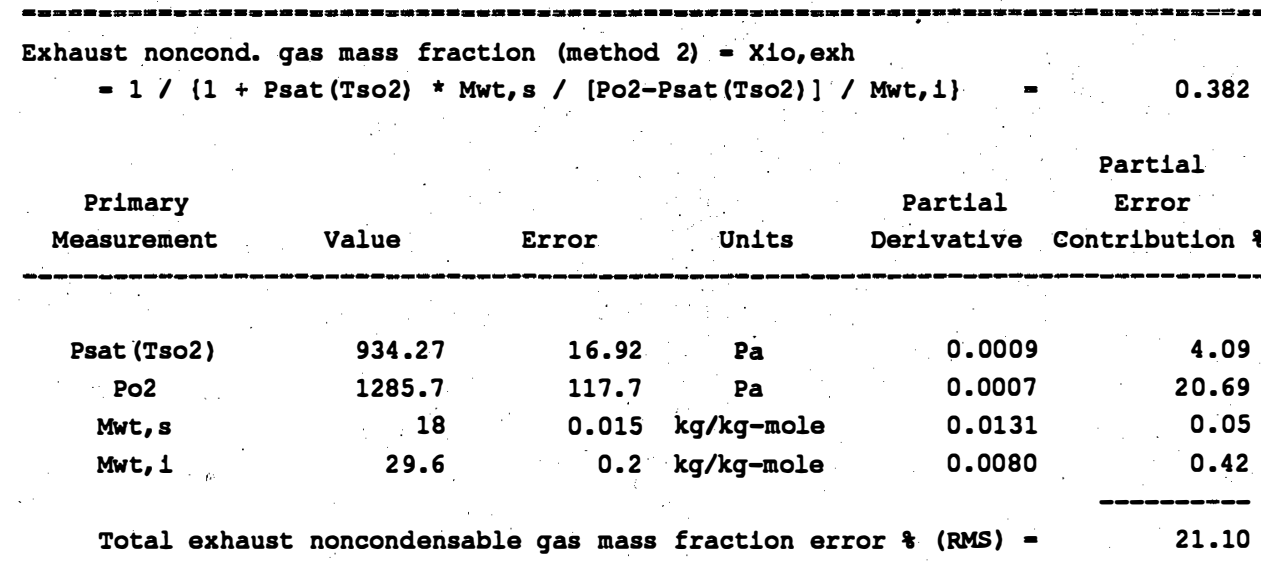

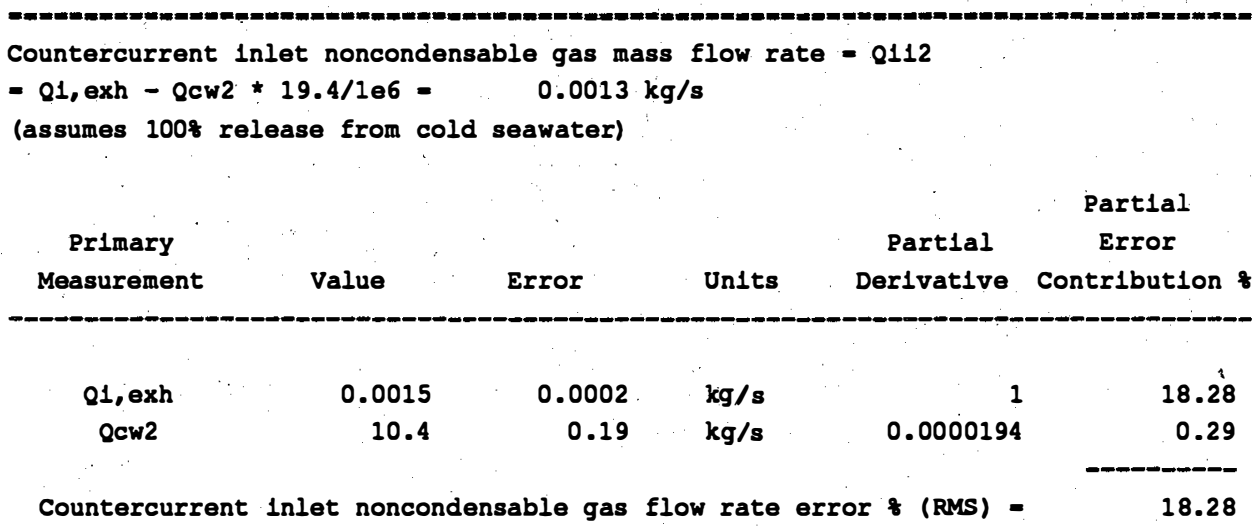

Countercurrent 1nlet noncond. gas mass fraction $=x_{11,2}=012 /(012+Q 312)$

$$
\text { - } 0.017
$$

\begin{tabular}{|c|c|c|c|c|c|}
\hline $\begin{array}{c}\text { Primary } \\
\text { Measurement }\end{array}$ & Value & Error & Units & $\begin{array}{c}\text { Partial } \\
\text { Derivative }\end{array}$ & $\begin{array}{c}\text { Partial } \\
\text { Error } \\
\text { Contribution }\end{array}$ \\
\hline Q12 & 0.0013 & 0.0002 & $\mathrm{~kg} / \mathrm{s}$ & 13.39 & 18.0 \\
\hline Qs12 & 0.0721 & 0.0017 & $\mathrm{~kg} / \mathrm{s}$ & 0.24 & 2.3 \\
\hline
\end{tabular}


Table A-2. Derived Parameter Error Estimates for HMTSTA Component Tests: DIRECT-CONTACT CONDENSER (Concluded)

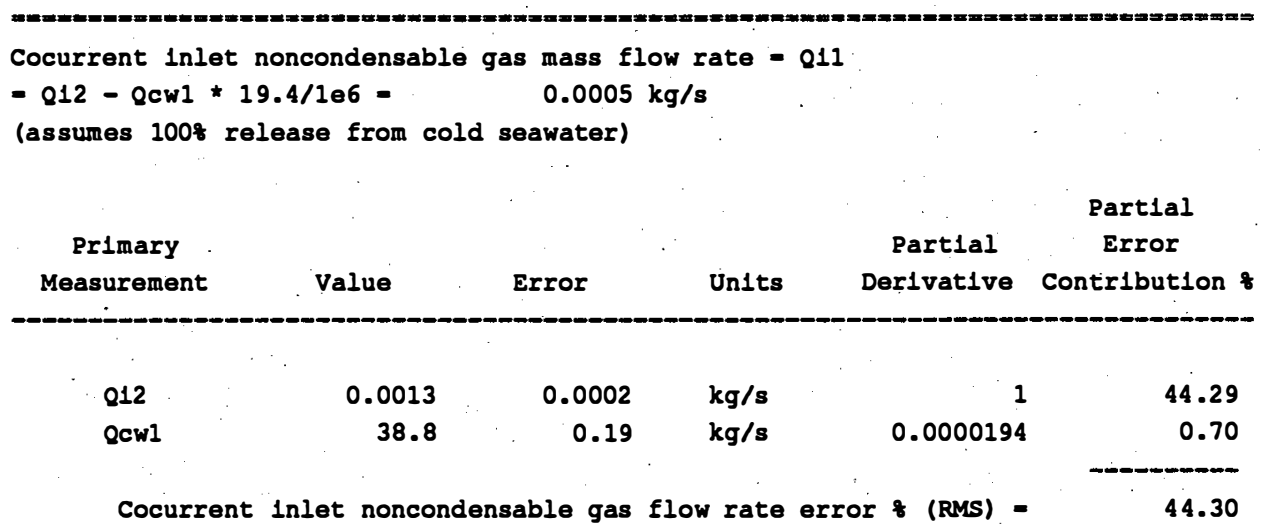

Cocurrent Inlet noncond. gas mass fraction $=x 11,1=011 /(011+Q s 11)$

$$
0.00129
$$

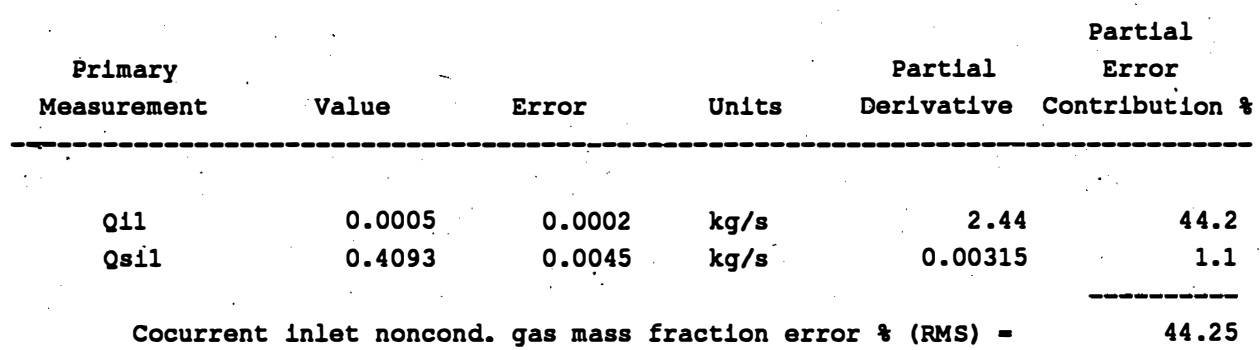


APPENDIX B

RAW DATA 
Nomenclatures are provided within each of the three sections of data. 


\section{B.1 EXPERIMIONTAL DATA ON EVAPORATOR AND MIST ELIMINATOR}

Table B-1 summarizes the experimental data gathered at the HMTSTA. Single spouts with diameters of $0.13,0.20$, and $0.25 \mathrm{~m}$ and a set of three spouts each $0.11 \mathrm{~m}$ in diameter were tested.

For the 10-in. spout, data with seawater flow variation only were obtained. Influences of spout height and superheat were not investigated.

Table B-1 contains nine columns. Column 1 represents a serial number. All data are sorted according to the major influencing parameter, such as 1 iquid loading, spout height, and superheat.

Column 2 represents an average seawater inlet temperature to the evaporator.

Column 3 represents the seawater liquid loading at the evaporator inlet; this parameter is defined as the inlet seawater mass flow rate divided by the evaporator chamber cross-sectional area, expressed as $\mathrm{kg} / \mathrm{m}^{2} \mathrm{~s}$.

Column 4 represents the evaporator chamber pressure, expressed in $\mathrm{kPa}$.

Column 5 represents the spout height, namely the distance between the water drain pool and the top of the vertical tube used as the spout.

Column 6 lists the superheat, expressed as the temperature difference between the inlet seawater and the exit seawater which would be in equilibrium at the imposed evaporator chamber pressure.

Column 7 shows an average measured temperature difference between inlet and exit seawater.

Column 8 lists thermal effectiveness.

Column 9 identifies which spout geometry was used for the tests. For further explanation, see footnotes.

Mist eliminator pressure-loss data are presented in the accompanying Table B-2. This table contains five columns whose headings adequately describe the data.

$$
C={ }^{\circ} \mathrm{C} \quad \mathrm{m} 2, \mathrm{~m}^{\wedge} 2=\mathrm{m}^{2} \quad \mathrm{~m} 3, \mathrm{~m}^{\wedge} 3=\mathrm{m}^{3}
$$


Table B-1. Experimental Data for Evaporation of Seawater Using Vertical Spouts*

\begin{tabular}{|c|c|c|c|c|c|c|c|c|}
\hline & Water & & & & & Water & & \\
\hline $\begin{array}{l}\text { Serlal } \\
\text { Number }\end{array}$ & $\begin{array}{c}\text { Inlet } \\
\text { Temperature } \\
\text { ( C) }\end{array}$ & $\begin{array}{l}\text { L1quid } \\
\text { Loading } \\
\text { (kg/m2s) }\end{array}$ & $\begin{array}{l}\text { Evaporator } \\
\text { Pressure } \\
\text { (kPa) }\end{array}$ & $\begin{array}{l}\text { Spout } \\
\text { Helght } \\
\text { (m) }\end{array}$ & $\begin{array}{l}\text { Super- } \\
\text { heat } \\
\text { (c) }\end{array}$ & $\begin{array}{c}\text { Temperature } \\
\text { Drop } \\
\text { ( C) }\end{array}$ & $\begin{array}{c}\text { Thermal } \\
\text { Effectiveness } \\
(--)\end{array}$ & $\begin{array}{l}\text { Spout } \\
\text { Identifier }^{b}\end{array}$ \\
\hline
\end{tabular}

Influence of Llquid Loading

\begin{tabular}{|c|c|c|c|c|c|c|c|c|}
\hline 1 & 25.80 & 27.3 & 2.77 & 0.59 & 2.72 & 2.69 & 0.99 & $3-\mathrm{L}$ \\
\hline 2 & 25.91 & 28.0 & 2.76 & 0.45 & 2.89 & 2.72 & 0.94 & $3-I$ \\
\hline 3 & 25.37 & 29.6 & 2.67 & 0.44 & 2.91 & 2.70 & 0.93 & $3-I$ \\
\hline 4 & 26.12 & 37.2 & 2.80 & 0.46 & 2.90 & 2.73 & 0.94 & $3-I$ \\
\hline 5 & 25.40 & 46.5 & 2.64 & 0.47 & 3.12 & 2.77 & 0.89 & $3-I$ \\
\hline 6 & 25.85 & 49.9 & 2.73 & 0.59 & 3.04 & 2.75 & 0.91 & $3-L$ \\
\hline 7 & 25.45 & 57.7 & 2.63 & 0.45 & 3.24 & 2.72 & 0.84 & $3-I$ \\
\hline 8 & 25.48 & 67.8 & 2.59 & 0.46 & 3.51 & 2.78 & 0.79 & $3-I$ \\
\hline 9 & 25.88 & 69.9 & 2.67 & 0.53 & 3.40 & 2.68 & 0.79 & $3-\mathrm{L}$ \\
\hline 10 & 25.59 & 77.0 & 2.59 & 0.46 & 3.62 & 2.73 & 0.75 & $3-I$ \\
\hline 11 & 25.88 & 84.8 & 2.62 & 0.34 & 3.72 & 2.68 & 0.72 & $3-I$ \\
\hline 12 & 25.89 & 85.1 & 2.62 & 0.48 & 3.72 & 2.71 & 0.73 & $3-I$ \\
\hline 13 & 25.74 & 85.4 & 2.57 & 0.46 & 3.90 & 2.75 & 0.70 & 3-L \\
\hline 14 & 25.85 & 94.9 & 2.65 & 0.46 & 3.52 & 2.73 & 0.78 & $3-I$ \\
\hline 15 & 25.61 & 30.9 & 2.70 & 0.48 & 2.95 & 2.79 & 0.94 & $10-\mathrm{L}$ \\
\hline 16 & 25.65 & 46.1 & 2.71 & 0.45 & 2.96 & 2.74 & 0.93 & $10-\mathrm{I}$ \\
\hline 17 & 25.71 & 68.0 & 2.70 & 0.47 & 3.08 & 2.69 . & 0.87 & $10-\mathrm{L}$ \\
\hline 18 & 25.77 & 88.0 & 2.65 & 0.45 & 3.42 & 2.75 & 0.81 & $10-\mathrm{L}$ \\
\hline 19 & 25.78 & 107.9 & 2.64 & 0.30 & 3.49 & 2.40 & 0.69 & $10-\mathrm{I}$ \\
\hline 20 & 25.63 & 36.4 & 2.73 & 0.42 & 2.78 & 2.70 & 0.97 & $8-L$ \\
\hline 21 & 25.64 & 36.5 & 2.74 & 0.60 & 2.77 & 2.71 & 0.98 & $8-I$ \\
\hline 22 & 25.62 & 54.1 & 2.70 & 0.43 & 2.97 & 2.72 & 0.92 & $8-I$ \\
\hline 23 & 25.63 & 72.2 & 2.68 & 0.41 & 3.13 & 2.71 & 0.87 & $8-I$ \\
\hline 24 & 25.61 & 90.7 & 2.62 & 0.42 & 3.43 & 2.71 & 0.79 & $8-I$ \\
\hline 25 & 25.82 & 13.8 & 2.68 & 0.47 & 3.31 & 3.046 & 0.92 & $5-I$ \\
\hline 26 & 25.51 & 22.4 & 2.62 & 0.47 & 3.37 & 3.073 & 0.91 & $5-I$ \\
\hline 27 & 25.48 & 29.0 & 2.63 & 0.47 & 3.29 & 2.953 & 0.90 & $5-L$ \\
\hline 28 & 25.63 & 35.8 & 2.64 & 0.47 & 3.36 & 3.004 & 0.89 & $5-I$ \\
\hline 29 & 25.52 & 42.3 & 2.61 & 0.47 & 3.42 & 3.037 & 0.89 & $5-I$ \\
\hline
\end{tabular}

Influence of Spout Helght

$\begin{array}{lllllllll}30 & 26.00 & 67.2 & 2.62 & 0.04 & 3.86 & 2.74 & 0.71 & 3-\mathrm{H} \\ 31 & 26.03 & 72.5 & 2.66 & 0.04 & 3.62 & 2.68 & 0.74 & 3-\mathrm{H} \\ 32 & 25.56 & 70.4 & 2.58 & 0.05 & 3.68 & 2.68 & 0.73 & 3-\mathrm{H} \\ 33 & 25.89 & 51.0 & 2.65 & 0.11 & 3.55 & 2.70 & 0.76 & 3-\mathrm{H} \\ 34 & 25.57 & 70.4 & 2.57 & 0.15 & 3.76 & 2.69 & 0.72 & 3-\mathrm{H} \\ 35 & 25.88 & 51.0 & 2.65 & 0.18 & 3.55 & 2.66 & 0.75 & 3-\mathrm{H} \\ 36 & 25.96 & 67.7 & 2.61 & 0.18 & 3.86 & 2.71 & 0.70 & 3-\mathrm{H} \\ 37 & 25.56 & 70.4 & 2.56 & 0.25 & 3.77 & 2.72 & 0.72 & 3-\mathrm{H} \\ 38 & 25.88 & 51.0 & 2.66 & 0.27 & 3.47 & 2.71 & 0.78 & 3-\mathrm{H} \\ 39 & 25.57 & 70.3 & 2.59 & 0.35 & 3.58 & 2.73 & 0.76 & 3-\mathrm{H} \\ 40 & 25.56 & 66.4 & 2.61 & 0.37 & 3.47 & 2.74 & 0.79 & 3-\mathrm{H}\end{array}$


Table B-1. Experimental Data for Evaporation of Seawater Using Vertical Spouts* (Continued)

\begin{tabular}{|c|c|c|c|c|c|c|c|c|}
\hline $\begin{array}{l}\text { Serlal } \\
\text { Number }\end{array}$ & $\begin{array}{c}\text { Water } \\
\text { Inlet } \\
\text { Temperature } \\
\text { ( C) }\end{array}$ & $\begin{array}{l}\text { Llquid } \\
\text { Load1ng } \\
(\mathrm{kg} / \mathrm{m} 2 \mathrm{~s})\end{array}$ & $\begin{array}{l}\text { Evaporator } \\
\text { Pressure } \\
\text { (kPa) }\end{array}$ & $\begin{array}{l}\text { Spout } \\
\text { Helght } \\
\text { (m) }\end{array}$ & $\begin{array}{l}\text { super- } \\
\text { heat } \\
\text { (C) }\end{array}$ & $\begin{array}{c}\text { Water } \\
\text { Temperature } \\
\text { Drop } \\
\text { ( C) }\end{array}$ & $\begin{array}{c}\text { Thermal } \\
\text { Effect1veness } \\
(---)\end{array}$ & $\begin{array}{l}\text { Spout } \\
\text { Identifier }\end{array}$ \\
\hline 41 & 25.97 & 68.1 & 2.66 & 0.37 & 3.59 & 2.70 & 0.75 & $3-\mathrm{H}$ \\
\hline 42 & 25.80 & 51.2 & 2.70 & 0.40 & 3.16 & 2.70 & 0.86 & $3-\mathrm{H}$ \\
\hline 43 & 25.56 & 66.5 & 2.63 & 0.46 & 3.32 & 2.68 & 0.81 & $3-\mathrm{H}$ \\
\hline 44 & 25.56 & 70.3 & 2.62 & 0.47 & 3.38 & 2.71 & 0.80 & $3-\mathrm{H}$ \\
\hline 45 & 25.82 & 51.3 & 2.72 & 0.49 & 3.05 & 2.70 & 0.89 & $3-\mathrm{H}$ \\
\hline 46 & 25.96 & 69.0 & 2.69 & 0.52 & 3.39 & 2.70 & 0.80 & $3-\mathrm{H}$ \\
\hline 47 & 25.56 & 70.3 & 2.62 & 0.57 & 3.42 & 2.72 & 0.79 & $3-\mathrm{H}$ \\
\hline 48 & 25.57 & 67.1 & 2.63 & 0.58 & 3.36 & 2.71 & 0.81 & $3-\mathrm{H}$ \\
\hline 49 & 25.78 & 51.1 & 2.73 & 0.63 & 2.98 & 2.70 & 0.91 & $3-\mathrm{H}$ \\
\hline 50 & 25.80 & 69.8 & 2.60 & 0.09 & 3.76 & 2.71 & 0.72 & $8-\mathrm{H}$ \\
\hline 51 & 25.75 & 70.6 & 2.65 & 0.20 & 3.40 & 2.73 & 0.80 & $8-\mathrm{H}$ \\
\hline 52 & 25.85 & 70.0 & 2.69 & 0.29 & 3.23 & 2.71 & 0.84 & $8-\mathrm{H}$ \\
\hline 53 & 25.81 & 70.2 & 2.69 & 0.32 & 3.21 & 2.71 & 0.84 & $8-\mathrm{H}$ \\
\hline 54 & 25.79 & 68.8 & 2.70 & 0.40 & 3.12 & 2.71 & 0.87 & $8-\mathrm{H}$ \\
\hline 55 & 25.65 & 73.0 & 2.67 & 0.43 & 3.19 & 2.71 & 0.85 & $8-\mathrm{H}$ \\
\hline 56 & 25.84 & 70.5 & 2.71 & 0.46 & 3.10 & 2.70 & 0.87 & $8-\mathrm{H}$ \\
\hline 57 & 25.86 & 70.7 & 2.73 & 0.46 & 3.04 & 2.67 & 0.88 & $8-\mathrm{H}$ \\
\hline 58 & 25.74 & 71.5 & 2.71 & 0.48 & 3.00 & 2.70 & 0.90 & $8-\mathrm{H}$ \\
\hline 59 & 25.43 & 28.9 & 2.60 & 0.15 & 3.42 & 2.961 & 0.87 & $5-\mathrm{H}$ \\
\hline 60 & 25.51 & 27.9 & 2.64 & 0.20 & 3.24 & 2.947 & 0.91 & $5-\mathrm{H}$ \\
\hline 61 & 25.53 & 28.0 & 2.64 & 0.20 & 3.24 & 2.974 & 0.92 & $5-\mathrm{H}$ \\
\hline 62 & 25.42 & 28.9 & 2.59 & 0.29 & 3.44 & 2.953 & 0.86 & $5-\mathrm{H}$ \\
\hline 63 & 25.54 & 27.9 & 2.63 & 0.36 & 3.31 & 2.947 & 0.89 & $5-\mathrm{H}$ \\
\hline 64 & 25.51 & 28.0 & 2.63 & 0.37 & 3.28 & 2.978 & 0.91 & $5-\mathrm{H}$ \\
\hline 65 & 25.42 & 29.3 & 2.59 & 0.40 & 3.46 & 2.962 & 0.86 & $5-\mathrm{H}$ \\
\hline 66 & 25.45 & 28.0 & 2.63 & 0.53 & 3.24 & 2.947 & 0.91 & $5-\mathrm{H}$ \\
\hline 67 & 25.47 & 28.0 & 2.63 & 0.84 & 3.29 & 2.957 & 0.90 & $5-\mathrm{H}$ \\
\hline \multicolumn{9}{|c|}{ Influence of superheat ${ }^{C}$} \\
\hline 68 & 26.08 & 51.3 & 2.95 & 0.48 & 1.95 & 1.19 & 0.61 & $3-s$ \\
\hline 69 & 25.83 & 51.0 & 2.89 & 0.49 & 2.05 & 1.21 & 0.59 & $3-5$ \\
\hline 70 & 26.04 & 51.3 & 2.92 & 0.48 & 2.08 & 1.74 & 0.84 & $3-5$ \\
\hline 71 & 26.00 & 55.2 & 2.91 & 0.51 & 2.11 & 1.21 & 0.58 & $3-5$ \\
\hline 72 & 25.84 & 50.9 & 2.88 & 0.50 & 2.12 & 1.84 & 0.87 & $3-5$ \\
\hline 73 & 26.04 & 51.6 & 2.84 & 0.47 & 2.57 & 2.21 & 0.86 & $3-s$ \\
\hline 74 & 26.04 & 51.8 & 2.83 & 0.47 & 2.59 & 2.23 & 0.86 & $3-5$ \\
\hline 75 & 25.85 & 51.1 & 2.77 & 0.49 & 2.78 & 2.46 & 0.88 & $3-5$ \\
\hline 76 & 26.05 & 54.4 & 2.74 & 0.46 & 3.14 & 2.69 & 0.86 & $3-5$ \\
\hline 77 & 26.02 & 53.9 & 2.74 & 0.47 & 3.16 & 2.73 & 0.86 & $3-s$ \\
\hline 78 & 25.88 & 51.1 & 2.67 & 0.48 & 3.43 & 3.06 & 0.89 & $3-5$ \\
\hline 79 & 25.87 & 51.0 & 2.56 & 0.47 & 4.12 & 3.64 & 0.88 & $3-s$ \\
\hline 80 & 25.88 & 51.1 & 2.55 & 0.47 & 4.14 & 3.70 & 0.89 & $3-5$ \\
\hline 81 & 25.86 & 51.1 & 2.55 & 0.47 & 4.16 & 3.65 & 0.88 & $3-5$ \\
\hline 82 & 26.02 & 53.5 & 2.57 & 0.46 & 4.19 & 3.63 & 0.87 & $3-5$ \\
\hline 83 & 26.04 & 53.0 & 2.56 & 0.46 & 4.28 & 3.72 & 0.87 & $3-5$ \\
\hline
\end{tabular}


Table B-1. Experimental Data for Evaporation of Seawater Using Vertical Spouts* (Concluded)

\begin{tabular}{|c|c|c|c|c|c|c|c|c|}
\hline $\begin{array}{l}\text { Serlal } \\
\text { Number }\end{array}$ & $\begin{array}{c}\text { Water } \\
\text { Inlet } \\
\text { Temperature } \\
\text { ( (c) }\end{array}$ & $\begin{array}{l}\text { L1quid } \\
\text { Loading }^{a} \\
(\mathrm{~kg} / \mathrm{m} 2 \mathrm{~s})\end{array}$ & $\begin{array}{c}\text { Evaporator } \\
\text { Pressure } \\
\text { (kPa) }\end{array}$ & $\begin{array}{l}\text { Spout } \\
\text { Helght } \\
\text { (m) }\end{array}$ & $\begin{array}{c}\text { Super- } \\
\text { heat } \\
\text { (C) }\end{array}$ & $\begin{array}{c}\text { Water } \\
\text { Temperature } \\
\text { Drop } \\
\text { ( c) }\end{array}$ & $\begin{array}{c}\text { Thermal } \\
\text { Effectiveness } \\
(---)\end{array}$ & $\begin{array}{c}\text { Spout } \\
\text { Identifier }\end{array}$ \\
\hline 84 & 25.87 & 51.1 & 2.46 & 0.48 & 4.77 & 4.17 & 0.87 & $3-5$ \\
\hline 85 & 26.03 & 52.0 & 2.38 & 0.45 & 5.48 & 4.73 & 0.86 & $3-s$ \\
\hline 86 & 26.47 & 64.4 & 3.05 & 0.48 & 1.77 & 0.91 & 0.51 & $3-5$ \\
\hline 87 & 25.78 & 67.5 & 2.85 & 0.44 & 2.23 & 1.32 & 0.59 & $3-s$ \\
\hline 88 & 25.76 & 67.5 & 2.85 & 0.45 & 2.24 & 1.76 & 0.78 & $3-s$ \\
\hline 89 & 25.52 & 70.3 & 2.79 & 0.48 & 2.32 & 1.24 & 0.53 & $3-s$ \\
\hline 90 & 25.55 & 70.2 & 2.79 & 0.48 & 2.34 & 1.74 & 0.74 & $3-5$ \\
\hline 91 & 25.73 & 67.8 & 2.75 & 0.45 & 2.76 & 2.23 & 0.81 & $3-5$ \\
\hline 92 & 25.56 & 68.3 & 2.72 & 0.46 & 2.80 & 2.22 & 0.79 & $3-s$ \\
\hline 93 & 25.70 & 68.1 & 2.65 & 0.21 & 3.39 & 2.25 & 0.66 & $3-s$ \\
\hline 94 & 25.53 & 68.4 & 2.60 & 0.32 & 3.49 & 2.69 & 0.77 & $3-5$ \\
\hline 95 & 25.70 & 67.0 & 2.56 & 0.46 & 3.90 & 3.20 & 0.82 & $3-5$ \\
\hline 96 & 25.56 & 70.3 & 2.53 & 0.47 & 3.95 & 3.16 & 0.80 & $3-s$ \\
\hline 97 & 25.71 & 66.5 & 2.50 & 0.46 & 4.31 & 3.51 & 0.81 & $3-s$ \\
\hline 98 & 25.75 & 66.3 & 2.45 & 0.46 & 4.72 & 3.89 & 0.82 & $3-5$ \\
\hline 99 & 25.75 & 65.6 & 2.38 & 0.47 & 5.14 & 4.21 & 0.82 & $3-s$ \\
\hline 100 & 25.55 & 74.0 & 2.83 & 0.50 & 2.11 & 1.36 & 0.64 & $8-s$ \\
\hline 101 & 25.58 & 73.9 & 2.82 & 0.49 & 2.22 & 0.74 & 0.33 & $8-5$ \\
\hline 102 & 25.55 & 73.2 & 2.79 & 0.45 & 2.36 & 1.70 & 0.72 & $8-5$ \\
\hline 103 & 25.58 & 74.0 & 2.75 & 0.49 & 2.62 & 1.01 & 0.38 & $8-5$ \\
\hline 104 & 25.53 & 72.6 & 2.72 & 0.44 & 2.73 & 2.05 & 0.75 & $8-5$ \\
\hline 105 & 25.55 & 73.9 & 2.60 & 0.47 & 3.50 & 2.74 & 0.78 & $8-5$ \\
\hline 106 & 25.52 & 74.0 & 2.53 & 0.47 & 3.91 & 3.08 & 0.79 & 8-s \\
\hline 107 & 25.52 & 73.9 & 2.37 & 0.46 & 5.02 & 3.94 & 0.78 & $8-5$ \\
\hline 108 & 25.48 & 29.0 & 2.99 & 0.47 & 1.12 & 0.757 & 0.68 & $5-s$ \\
\hline 109 & 25.48 & 29.2 & 2.97 & 0.47 & 1.28 & 0.288 & 0.23 & $5-s$ \\
\hline 110 & 25.54 & 29.3 & 2.88 & 0.47 & $1: 81$ & 1.308 & 0.72 & $5-s$ \\
\hline 111 & 25.49 & 28.9 & 2.84 & 0.47 & 2.00 & 1.563 & 0.78 & $5-s$ \\
\hline 112 & 25.49 & 29.0 & 2.76 & 0.47 & 2.46 & 2.034 & 0.83 & $5-s$ \\
\hline 113 & 25.44 & 29.0 & 2.60 & 0.47 & 3.43 & 2.986 & 0.87 & $5-s$ \\
\hline 114 & 25.48 & 29.0 & 2.45 & 0.47 & 4.43 & 4.065 & 0.92 & $5-5$ \\
\hline 115 & 25.51 & 29.1 & 2.29 & 0.47 & 5.52 & 5.037 & 0.91 & $5-s$ \\
\hline
\end{tabular}

*The data are sorted by the major Influencing factor. Please note that certaln cross-couplings exist because of difficulty in maintalning all other parameters constant while varying one.

a. Llquid loading $1 \mathrm{~s}$ based on the cross-sectlonal area of the evaporator vessel of $0.894 \mathrm{~m} 2$.

b. Spout 1dentiflers: 3 - three spouts: 5, 8, 10 - spout nominal diameters of $5^{n}, 8^{n}$ and 10\%, respectively; I - 11quid loading: H - spout helght; $S$ - superheat.

c. Varlation of thermal effectiveness with superheat exhlbits hysteresis, with effectiveness lagging behind the changes in superheat. 
TP-3561

Table B-2. Experimental Data for Pressure Loss in the Mist Eliminator

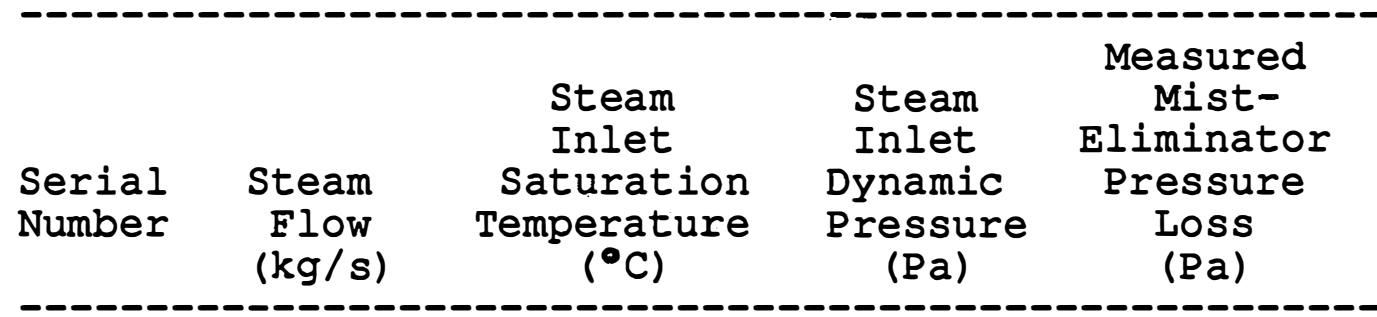

$\begin{array}{rl}1 & 0.04 \\ 2 & 0.06 \\ 3 & 0.07 \\ 4 & 0.09 \\ 5 & 0.09 \\ 6 & 0.10 \\ 7 & 0.10 \\ 8 & 0.11 \\ 9 & 0.11 \\ 10 & 0.11 \\ 11 & 0.12 \\ 12 & 0.13 \\ 13 & 0.13 \\ 14 & 0.13 \\ 15 & 0.13 \\ 16 & 0.13 \\ 17 & 0.13 \\ 18 & 0.13 \\ 19 & 0.13 \\ 20 & 0.13 \\ 21 & 0.13 \\ 22 & 0.13 \\ 23 & 0.13 \\ 24 & 0.13 \\ 25 & 0.14 \\ 26 & 0.14 \\ 27 & 0.15 \\ 28 & 0.15 \\ 29 & 0.15 \\ 30 & 0.17 \\ 31 & 0.17 \\ 32 & 0.17 \\ 33 & 0.17 \\ 34 & 0.18 \\ 35 & 0.18 \\ 36 & 0.19 \\ 37 & 0.19 \\ 38 & 0.19 \\ 39 & 0.20 \\ 40 & 0.20 \\ 41 & 0.20 \\ 42 & 0.20 \\ 43 & 0.20 \\ 44 & 0.20 \\ & \\ 13 & 0\end{array}$

24.05

23.42

23.18

23.82

23.47

22.73

23.59

22.77

21.84

22.71

22.15

22.35

21.99

21.97

21.90

21.88

21.93

22.66

21.71

21.92

21.68

23.66

21.66

21.89

21.71

23.41

22.55

22.91

22.57

23.16

21.97

23.14

23.13

23.21

20.75

22.39

22.76

21.98

21.80

22.02

22.50

22.88

22.10

22.50
0.0

0.1

0.2

0.3

0.3

0.3

0.3

0.3

0.4

0.4

0.4

0.5

0.5

0.5

0.5

0.5

0.5

0.5

0.6

0.6

0.6

0.5

0.6

0.6 .

0.6

0.6

0.7

0.7

0.7

0.8

0.9

0.9

0.9

1.0

1.1

1.1

1.1

1.2

1.3

1.3

1.3

1.3

1.3

1.3
0

0

1

2 
Table B-2. Experimental Data for Pressure Loss in the Mist Eliminator (Continued)

\begin{tabular}{|c|c|c|c|c|}
\hline $\begin{array}{l}\text { Serial } \\
\text { Number }\end{array}$ & $\begin{array}{c}\text { Steam } \\
\text { Flow } \\
(\mathrm{kg} / \mathrm{s})\end{array}$ & $\begin{array}{c}\text { Steam } \\
\text { Inlet } \\
\text { Saturation } \\
\text { Temperature } \\
\left({ }^{\circ} \mathrm{C}\right)\end{array}$ & $\begin{array}{l}\text { Steam } \\
\text { Inlet } \\
\text { Dynamic } \\
\text { Pressure } \\
\quad \text { (Pa) }\end{array}$ & $\begin{array}{c}\text { Measured } \\
\text { Mist- } \\
\text { Eliminator } \\
\text { Pressure } \\
\text { Loss } \\
\text { (Pa) }\end{array}$ \\
\hline $\begin{array}{l}45 \\
46 \\
47 \\
48 \\
49 \\
50 \\
51 \\
52 \\
53 \\
54 \\
55 \\
56 \\
57 \\
58 \\
59 \\
60 \\
61 \\
62 \\
63 \\
64 \\
65 \\
66 \\
67 \\
68 \\
69 \\
70 \\
71 \\
72 \\
73 \\
74 \\
75 \\
76 \\
77 \\
78 \\
79 \\
80 \\
81 \\
82 \\
83 \\
84 \\
85 \\
86 \\
87 \\
88\end{array}$ & $\begin{array}{l}0.20 \\
0.20 \\
0.21 \\
0.21 \\
0.21 \\
0.22 \\
0.22 \\
0.22 \\
0.22 \\
0.23 \\
0.24 \\
0.24 \\
0.27 \\
0.27 \\
0.27 \\
0.27 \\
0.27 \\
0.27 \\
0.28 \\
0.28 \\
0.28 \\
0.28 \\
0.28 \\
0.28 \\
0.28 \\
0.28 \\
0.28 \\
0.28 \\
0.29 \\
0.29 \\
0.29 \\
0.29 \\
0.29 \\
0.29 \\
0.29 \\
0.29 \\
0.29 \\
0.29 \\
0.29 \\
0.30 \\
0.31 \\
0.32 \\
0.32 \\
0.32\end{array}$ & $\begin{array}{l}22.04 \\
22.34 \\
22.46 \\
22.60 \\
22.55 \\
22.34 \\
22.66 \\
19.69 \\
22.49 \\
22.46 \\
22.14 \\
21.90 \\
21.94 \\
22.27 \\
21.78 \\
22.07 \\
22.32 \\
21.90 \\
21.74 \\
21.44 \\
21.40 \\
22.36 \\
21.66 \\
21.53 \\
22.31 \\
21.43 \\
22.18 \\
22.30 \\
21.49 \\
21.88 \\
21.84 \\
21.46 \\
22.04 \\
21.75 \\
21.68 \\
22.52 \\
22.43 \\
22.15 \\
22.19 \\
22.43 \\
21.31 \\
21.66 \\
21.49 \\
20.79\end{array}$ & $\begin{array}{l}1.3 \\
1.3 \\
1.3 \\
1.4 \\
1.4 \\
1.5 \\
1.5 \\
1.8 \\
1.6 \\
1.7 \\
1.8 \\
1.8 \\
2.3 \\
2.4 \\
2.4 \\
2.4 \\
2.4 \\
2.4 \\
2.5 \\
2.6 \\
2.6 \\
2.5 \\
2.6 \\
2.6 \\
2.5 \\
2.7 \\
2.6 \\
2.6 \\
2.7 \\
2.7 \\
2.7 \\
2.8 \\
2.7 \\
2.7 \\
2.7 \\
2.6 \\
2.7 \\
2.7 \\
2.8 \\
2.8 \\
3.2 \\
3.4 \\
3.5 \\
3.6\end{array}$ & $\begin{array}{r}9 \\
5 \\
6 \\
6 \\
7 \\
9 \\
8 \\
8 \\
6 \\
6 \\
8 \\
8 \\
11 \\
12 \\
11 \\
11 \\
9 \\
11 \\
11 \\
11 \\
11 \\
13 \\
11 \\
13 \\
12 \\
12 \\
12 \\
13 \\
25 \\
13 \\
13 \\
13 \\
14 \\
14 \\
13 \\
13 \\
13 \\
8 \\
13 \\
12 \\
20 \\
17 \\
14 \\
15\end{array}$ \\
\hline & & 240 & & \\
\hline
\end{tabular}


Table B-2. Experimental Data for Pressure Loss in the Mist Eliminator (Concluded)

\begin{tabular}{|c|c|c|c|c|c|}
\hline $\begin{array}{l}\text { Serial } \\
\text { Number }\end{array}$ & $\begin{array}{c}\text { Steam } \\
\text { Flow } \\
(\mathrm{kg} / \mathrm{s})\end{array}$ & $\begin{array}{c}\text { Steam } \\
\text { Inlet } \\
\text { Saturation } \\
\text { Temperature } \\
\left({ }^{\circ} \mathrm{C}\right)\end{array}$ & $\begin{array}{l}\text { Steam } \\
\text { Inlet } \\
\text { Dynamic } \\
\text { Pressure } \\
\quad \text { (Pa) }\end{array}$ & $\begin{array}{c}\text { Measure } \\
\text { Mist- } \\
\text { Eliminat } \\
\text { Pressure } \\
\text { Loss } \\
\text { (Pa) }\end{array}$ & or \\
\hline $\begin{array}{l}89 \\
90 \\
91 \\
92 \\
93 \\
94 \\
95 \\
96\end{array}$ & $\begin{array}{l}0.33 \\
0.35 \\
0.35 \\
0.36 \\
0.36 \\
0.37 \\
0.40 \\
0.44\end{array}$ & $\begin{array}{l}21 \cdot 30 \\
21 \cdot 10 \\
21 \cdot 87 \\
20.25 \\
22.05 \\
20.73 \\
20.31 \\
20.20\end{array}$ & $\begin{array}{l}3.7 \\
4.1 \\
4.1 \\
4.5 \\
4.3 \\
4.7 \\
5.7 \\
7.0\end{array}$ & & $\begin{array}{l}20 \\
18 \\
30 \\
25 \\
21 \\
27 \\
44 \\
58\end{array}$ \\
\hline
\end{tabular}

Note: Mist eliminator planform area was $0.894 \mathrm{~m} 2$. 


\section{B.2 EXPERIMENTAL DATA ON SURFACE CONDENSER}

Table B-3 summarizes the measured and calculated parameters for the vent (second-stage) condenser. Each test is presented on one line and identified with the file name and test number. The headings of the remaining data columns are shown below in the order in which they appear in the table.

\section{NOMENCLATURE (Vent Condenser, Table B-3)}

\begin{tabular}{lll} 
Abbrev. & Description & Units \\
\hline Mr & Refrigerant mass flow rate & $\mathrm{kg} / \mathrm{s}$ \\
Tri1 & Refrigerant temperature before expansion & ${ }^{\circ} \mathrm{C}$ \\
Tri & Inlet refrigerant temperature & ${ }^{\circ} \mathrm{C}$ \\
Tro & Outlet refrigerant temperature & ${ }^{\circ} \mathrm{C}$ \\
Pri & Inlet refrigerant pressure & $\mathrm{kPa}$ \\
Pro & Outlet refrigerant pressure & $\mathrm{kPa}$ \\
Psi & Inlet steam pressure & $\mathrm{kPa}$ \\
Pso & Outlet steam pressure & $\mathrm{kPa}$ \\
Pexh & Inlet steam pressure to vacuum pump & $\mathrm{kPa}$ \\
Tsi & Inlet steam temperature & ${ }^{\circ} \mathrm{C}$ \\
Tso & Outlet steam temperature & ${ }^{\circ} \mathrm{C}$ \\
Twbi & Inlet wet-bulb temperature & ${ }^{\circ} \mathrm{C}$ \\
& (located at main condenser outlet) & \\
Tdewo & Steam dewpoint at outlet & ${ }^{\circ} \mathrm{C}$ \\
Tsri & Inlet saturation temperature for refrigerant & ${ }^{\circ} \mathrm{C}$ \\
Tsro & Outlet saturation temperature for refrigerant & ${ }^{\circ} \mathrm{C}$ \\
Tsuper & Refrigerant vapor super heat at outlet & ${ }^{\circ} \mathrm{C}$ \\
Qr & Rate of heat transfer for vent condenser & $\mathrm{kW}$ \\
& (based on refrigerant heat balance) & $\mathrm{kg} / \mathrm{s}$ \\
Msi & Inlet steam mass flow rate & $\mathrm{kg} / \mathrm{s}$ \\
Mg & Noncondensable gas mass flow rate & $\% \mathrm{by}$ wt \\
Ygi & Gas concentration at inlet & $\%$ by wt \\
Ygo & Gas concentration at outlet & ${ }^{\circ} \mathrm{C}$ \\
Tssi & Inlet saturation temperature for steam/gas & ${ }^{\circ} \mathrm{C}$ \\
Tsso & Outlet saturation temperature for steam/gas & \\
Eff & Thermal effectiveness for vent condenser &
\end{tabular}


TP-3561

Table B-3. Data Summary for Vent Condenser Tests

Measured Parameters

\begin{tabular}{|c|c|c|c|c|c|c|c|c|c|c|c|c|c|c|}
\hline Data F1le & $\begin{array}{c}\text { Test } \\
\text { No }\end{array}$ & $\begin{array}{c}\mathrm{Mr} \\
\mathrm{kg} / \mathrm{s}\end{array}$ & $\begin{array}{c}\operatorname{Tr} 11 \\
\text { C }\end{array}$ & $\begin{array}{l}\text { Tr1 } \\
\text { C }\end{array}$ & $\begin{array}{c}\text { Tro } \\
\text { C }\end{array}$ & $\begin{array}{l}\text { Pr1 } \\
\text { kPa }\end{array}$ & $\begin{array}{l}\text { Pro } \\
\text { kPa }\end{array}$ & $\begin{array}{l}\text { Ps } 1 \\
\text { kPa }\end{array}$ & $\begin{array}{l}\text { Pso } \\
\text { kPa }\end{array}$ & $\begin{array}{r}\text { Pexh } \\
\text { Kpa }\end{array}$ & $\begin{array}{c}\text { Ts1 } \\
\text { C }\end{array}$ & $\begin{array}{c}\text { Tso } \\
\text { C }\end{array}$ & $\begin{array}{c}\text { Twb1 } \\
\text { C }\end{array}$ & $\begin{array}{c}\text { Tdewo } \\
\text { C }\end{array}$ \\
\hline 880708.007 & $\operatorname{sc} 4.1$ & 0.34 & 18.880 & .248 & 11.793 & 370.4 & 364.4 & 1.45 & 1.48 & 1.37 & 17.438 & 11.198 & 12.832 & 9.675 \\
\hline 880708.008 & sc4. 2 & 0.43 & 20.479 & 5.332 & 12.263 & 370.3 & 364.8 & 1.50 & 1.53 & 1.40 & 17.665 & 11.219 & 13.369 & 9.499 \\
\hline 880708.009 & $\operatorname{sc} 4.3$ & 0.49 & 21.567 & 5.090 & 12.475 & 367.6 & 361.7 & 1.53 & 1.56 & 1.43 & 17.750 & 11.229 & 13.659 & 9.562 \\
\hline 880708.010 & sc4.3R & 0.88 & 27.689 & 5.238 & 14.480 & 368.7 & 360.9 & 1.81 & 1.81 & 1.67 & 18.697 & 13.189 & 16.305 & 12.701 \\
\hline 880711.002 & SC4. 4 & 0.50 & 21.810 & 7.556 & 14.114 & 396.4 & 391.2 & 1.67 & 1.70 & 1.55 & 20.336 & 12.753 & 14.871 & 11.870 \\
\hline 880711.003 & SC4.4R & 0.34 & 17.162 & 7.426 & 6.895 & 398.1 & 392.8 & 1.83 & 1.89 & NA & 21.090 & 9.569 & 15.787 & 11.692 \\
\hline 880711.004 & SC4.4R & 0.50 & 22.673 & 4.976 & 13.595 & 365.2 & 359.9 & 1.65 & 1.67 & NA & 19.544 & 12.068 & 14.681 & 11.505 \\
\hline 880711.005 & SC4.4R & 0.61 & 23.109 & 5.050 & 13.396 & 366.4 & 360.6 & 1.70 & 1.74 & NA & 19.696 & .5 .916 & 15.085 & 10.279 \\
\hline 880711.006 & SC4 . 4R & 0.68 & 23.427 & 2.422 & 13.472 & 336.4 & 330.3 & 1.67 & 1.70 & $\mathbf{N A}$ & 19.363 & 4.402 & 14.910 & 10.401 \\
\hline 880711.008 & SC4 . 4R & 1.11 & 27.890 & 2.134 & 9.027 & 333.5 & 323.8 & 1.50 & 1.47 & 1.35 & 17.363 & 9.837 & 13.908 & 10.165 \\
\hline 880712.001 & SC4.4R & 1.25 & 29.828 & 3.460 & 5.641 & $347: 2$ & 336.7 & 1.49 & 1.45 & 1.32 & 17.229 & 9.695 & 14.264 & 9.668 \\
\hline 380713.001 & sc5.1 & 0.66 & 23.670 & 5.548 & 12.883 & 372.0 & 365.9 & 1.58 & 1.59 & 1.46 & 18.638 & 11.002 & 14.238 & 10.498 \\
\hline $880713 ., 003$ & $\operatorname{sc5} .2$ & 0.59 & 21.821 & 5.324 & 12.364 & 369.9 & 363.7 & 1.48 & 1.50 & 1.37 & 19.012 & 9.873 & 13.094 & 8.757 \\
\hline 880713.004 & $\operatorname{sc5} .3$ & 0.57 & 21.616 & 1.591 & 11.832 & 327.7 & 321.5 & $1.46^{\circ}$ & 1.47 & 1.35 & 18.203 & 9.467 & 12.981 & 8.843 \\
\hline 880713.005 & $\operatorname{sc5} .4$ & 0.46 & 20.988 & 7.740 & 11.913 & 398.8 & 393.5 & 1.48 & 1.51 & 1.39 & 18.102 & 10.076 & 13.059 & 9.701 \\
\hline 880713.006 & SC5.4R & 0.30 & 20.633 & 9.299 & 13.453 & 418.6 & 414.1 & 1.67 & 1.72 & 1.58 & 19.230 & 11.889 & 14.766 & 12.071 \\
\hline 880713.007 & $\operatorname{sc} 5.6$ & 0.88 & 26.470 & 8.048 & 9.367 & 402.1 & 395.7 & 1.74 & 1.75 & 1.61 & 19.495 & 12.699 & 15.678 & 12.381 \\
\hline 880713.008 & $\operatorname{sc5} .7$ & 1.24 & 30.891 & 3.891 & 4.194 & 352.0 & 341.7 & 1.62 & 1.59 & 1.47 & 18.394 & 10.697 & 15.166 & 10.670 \\
\hline 880715.005 & sc6.1 & 0.45 & 20.686 & .000 & 7.887 & 394.0 & 388.0 & 1.49 & 1.52 & 1.40 & 18.494 & 10.129 & 13.170 & 8.608 \\
\hline 880714.002 & sc6. 2 & 0.44 & 21.259 & 4.672 & 12.228 & 361.7 & 3556.7 & 1.45 & 1.47 & 1.35 & 17.996 & 10.020 & 12.843 & 9.101 \\
\hline 880714.007 & $\operatorname{sc6} .3$ & 0.34 & 19.729 & 6.793 & 12.224 & 386.9 & 382.0 & 1.46 & 1.50 & 1.38 & 18.751 & 10.777 & 12.980 & 9.964 \\
\hline 880714.009 & SC6.3R & 0.40 & 20.228 & 6.926 & 11.874 & 388.8 & 383.9 & 1.45 & 1.48 & 1.36 & 18.479 & 10.599 & 12.887 & 9.674 \\
\hline 880714.003 & sc6. 5 & 0.66 & 24.654 & 4.397 & 13.804 & 357.8 & 352.3 & 1.70 & 1.70 & 1.57 & 18.799 & 12.714 & 15.290 & 12.258 \\
\hline 880715.002 & SC6.5R & 0.90 & 26.315 & 8.013 & 11.682 & 402.1 & 395.0 & 1.68 & 1.70 & 1.56 & 21.199 & 13.541 & 15.386 & 11.882 \\
\hline
\end{tabular}

$c={ }^{\circ} \mathrm{C}$ 
Table B-3. Data Summary for Vent Condenser Tests (Concluded)

\begin{tabular}{|c|c|c|c|c|c|c|c|c|c|c|c|}
\hline $\begin{array}{l}\text { Test } \\
\text { No }\end{array}$ & $\begin{array}{l}\text { Tsr1 } \\
\text { C }\end{array}$ & $\begin{array}{l}\text { Tsro } \\
\text { C }\end{array}$ & $\begin{array}{c}\text { Tsuper } \\
\text { C }\end{array}$ & $\begin{array}{l}\text { Qr } \\
\text { kW }\end{array}$ & $\begin{array}{l}\mathrm{Ms1} \\
\mathrm{kg} / \mathrm{s}\end{array}$ & $\begin{array}{c}\mathrm{Mg} \\
\mathrm{kg} / \mathrm{s}\end{array}$ & Yg1 & Ygo & $\begin{array}{l}\text { Tss1 } \\
\text { C }\end{array}$ & $\begin{array}{l}\text { Tsso } \\
\text { C }\end{array}$ & Eff. \\
\hline sC4.1 & 5.701 & 5.176 & 6.617 & 48.1 & 0.0196 & 0.00117 & 0.044 & 0.247 & 12.024 & 9.645 & 0.443 \\
\hline $\operatorname{sc} 4.2$ & 5.689 & 5.218 & 7.045 & 59.5 & 0.0242 & 0.00143 & 0.047 & 0.299 & 12.564 & 9.460 & 0.504 \\
\hline sC4. 3 & 5.455 & 4.945 & 7.530 & 67.2 & 0.0273 & 0.00152 & 0.045 & 0.315 & 12.892 & 9.517 & 0.499 \\
\hline SC4.3R & 5.553 & 4.879 & 9.601 & 117.6 & 0.0478 & 0.00142 & 0.027 & 0.271 & 15.626 & 12.661 & 0.335 \\
\hline SC4. $4 R$ & 7.888 & 7.456 & 6.658 & 69.7 & 0.0283 & 0.00126 & 0.036 & 0.246 & 14.331 & 11.842 & 0.430 \\
\hline SC4. $4 R$ & 8.026 & 7.596 & -0.701 & 47.3 & 0.0192 & 0.00060 & 0.026 & 0.350 & 15.812 & 11.610 & 0.528 \\
\hline SC4.4R & 5.251 & 4.791 & 8.804 & 68.6 & 0.0279 & 0.00105 & 0.032 & 0.258 & 14.167 & 11.471 & 0.337 \\
\hline SC4.4R & 5.349 & 4.850 & 8.546 & 83.4 & 0.0339 & 0.00057 & 0.016 & 0.382 & 14.800 & 9.976 & 0.494 \\
\hline SC4. $4 R$ & 2.655 & 2.107 & 11.365 & 92.8 & 0.0377 & 0.00051 & 0.012 & 0.346 & 14.549 & 10.309 & 0.368 \\
\hline SC4.4R & 2.386 & 1.467 & 7.560 & 144.2 & 0.0586 & 0.00096 & 0.017 & 0.252 & 12.862 & 10.134 & 0.325 \\
\hline sc4. 4 & 3.460 & 2.782 & 2.859 & 156.9 & 0.0638 & 0.00103 & 0.017 & 0.284 & 12.805 & 9.637 & 0.425 \\
\hline sc5.1 & 5.835 & 5.315 & 7.568 & 89.7 & 0.0365 & 0.00137 & 0.033 & 0.285 & 13.517 & 10.461 & 0.445 \\
\hline sc5. 2 & 5.659 & 5.116 & 7.248 & 81.6 & 0.0332 & 0.00151 & 0.038 & 0.331 & 12.425 & 8.757 & 0.583 \\
\hline $\operatorname{sc} 5.3$ & 1.840 & 1.261 & 10.571 & 75.5 & 0.0307 & 0.00138 & 0.038 & 0.315 & 12.277 & 8.843 & 0.371 \\
\hline $\operatorname{sc} 5.4$ & 8.082 & 7.850 & 4.063 & 62.8 & 0.0255 & 0.00135 & 0.040 & 0.275 & 12.472 & 9.661 & 0.675 \\
\hline $\operatorname{sc} 5.41$ & 9.667 & 9.496 & 3.957 & 41.6 & 0.0169 & 0.00131 & 0.053 & 0.236 & 14.207 & 12.036 & 0.529 \\
\hline sc5.6 & 8.353 & 7.851 & 1.516 & 114.5 & 0.0465 & 0.00126 & 0.024 & 0.252 & 15.050 & 12.345 & 0.450 \\
\hline $\operatorname{sc5} .7$ & 4.078 & 3.160 & 1.034 & 153.7 & 0.0625 & 0.00128 & 0.020 & 0.298 & 14.019 & 10.632 & 0.405 \\
\hline 6.1 & 7.687 & 7.194 & 0.693. & 61.4 & 0.0250 & 0.00158 & 0.054 & 0.350 & 12.378 & 8.562 & 0.832 \\
\hline $\mathrm{sc} 6.2$ & 4.942 & 4.501 & 7.727 & 60.3 & 0.0245 & 0.00126 & 0.044 & 0.291 & 12.070 & 9.067 & 0.474 \\
\hline sc6. 3 & 7.100 & 6.687. & 5.537 & 47.9 & 0.0195 & 0.00143 & 0.043 & 0.240 & 12.226 & 9.934 & 0.513 \\
\hline SC6.3R & 7.255 & 6.847 & 5.027 & 54.8 & 0.0223 & 0.00106 & 0.040 & 0.253 & 12.138 & 9.644 & 0.570 \\
\hline sc6.5 & 4.397 & 4.114 & 9.690 & 90.1 & 0.0366 & 0.00115 & 0.028 & 0.235 & 14.658 & 12.229 & 0.278 \\
\hline C6.5R & 8.349 & 7.943 & 3.739 & 118.5 & 0.0482 & 0.00122 & 0.023 & 0.253 & 14.570 & 11.847 & 0.498 \\
\hline
\end{tabular}

$c={ }^{\circ} \mathrm{C}$ 
Table B-4 summarizes the measured and calculated parameters for the main (first-stage) condenser. Each test is again presented on one line and identified with the file name and test number. The headings of the remaining data columns are shown below in the order in which they appear in the table.

\section{NOMENCLATURE (Main Condenser, Table B-4)}

\begin{tabular}{|c|c|c|}
\hline Abbrev. & Description & $\underline{\text { Units }}$ \\
\hline $\begin{array}{l}\text { Qcw } \\
\text { Twi }\end{array}$ & $\begin{array}{l}\text { Cold water flow rate } \\
\text { Inlet temperature for cold water } \\
\quad \text { (average of two sensors) }\end{array}$ & $\begin{array}{l}\mathrm{kg} / \mathrm{s} \\
{ }^{\circ} \mathrm{C}\end{array}$ \\
\hline Two & $\begin{array}{l}\text { Outlet temperature for cold water } \\
\text { (average of two sensors) }\end{array}$ & ${ }^{\circ} \mathrm{C}$ \\
\hline Delta-T & Change in water temperature & ${ }^{\circ} \mathrm{C}$ \\
\hline Psi & Inlet steam pressure & $\mathbf{k P a}$ \\
\hline $\begin{array}{l}\text { Delta-Ps } \\
\text { Tsi }\end{array}$ & $\begin{array}{l}\text { Steam-side pressure drop } \\
\text { Inlet steam temperature }\end{array}$ & $\begin{array}{l}\mathrm{kPa} \\
{ }^{\circ} \mathrm{C}\end{array}$ \\
\hline Tso & Outlet steam temperature & ${ }^{\circ} \mathrm{C}$ \\
\hline Pexh & Steam pressure at vacuum pump inlet & $\mathrm{kPa}$ \\
\hline $\begin{array}{l}\text { Tdew } \\
\text { Msi } \\
\text { Mg }\end{array}$ & $\begin{array}{l}\text { Dewpoint of steam/gas at outlet of vent condenser } \\
\text { Inlet steam mass flow rate } \\
\text { Noncondensable gas flow rate }\end{array}$ & $\begin{array}{l}{ }^{\circ} \mathrm{C} \\
\mathrm{kg} / \mathrm{s} \\
\mathrm{kg} / \mathrm{s}\end{array}$ \\
\hline Ygi & Gas concentration at inlet & $\%$ by wt \\
\hline Ygo & Gas concentration at outlet & \% by wt \\
\hline Tss i & Inlet steam saturation temperature & ${ }^{\circ} \mathrm{C}$ \\
\hline Ts'so & Outlet steam saturation temperature & ${ }^{\circ} \mathrm{C}$ \\
\hline Qe & Rate of heat transfer for evaporator & $\mathrm{kW}$ \\
\hline Qc & $\begin{array}{l}\text { Rate of heat transfer for main condenser } \\
\text { (based on water-side heat balance) }\end{array}$ & $\mathrm{kW}$ \\
\hline Qs & $\begin{array}{l}\text { Rate of heat transfer for main condenser } \\
\text { (based on steam-side heat balance) }\end{array}$ & $\mathrm{kW}$ \\
\hline Qr & $\begin{array}{l}\text { Rate of heat transfer for vent condenser } \\
\text { (based on refrigerant-side heat balance) }\end{array}$ & $\mathrm{kW}$ \\
\hline $\begin{array}{l}\text { Uo } \\
\text { hw } \\
\text { hs }\end{array}$ & $\begin{array}{l}\text { Overall heat transfer coefficiency } \\
\text { Water-side heat transfer coefficient } \\
\text { Steam-side heat transfer coefficient }\end{array}$ & $\begin{array}{l}\mathrm{kW} / \mathrm{m}^{2} \mathrm{~K} \\
\mathrm{~kW} / \mathrm{m}^{2} \mathrm{~K} \\
\mathrm{~kW} / \mathrm{m}^{2} \mathrm{~K}\end{array}$ \\
\hline- & $\mathrm{m} 3, \mathrm{~m}^{\wedge} 3=\mathrm{m}^{3}$ & \\
\hline
\end{tabular}


TP-3561

Table B-4. Data Summary for Surface Condenser Tests, Main Condenser

Measured Parameters

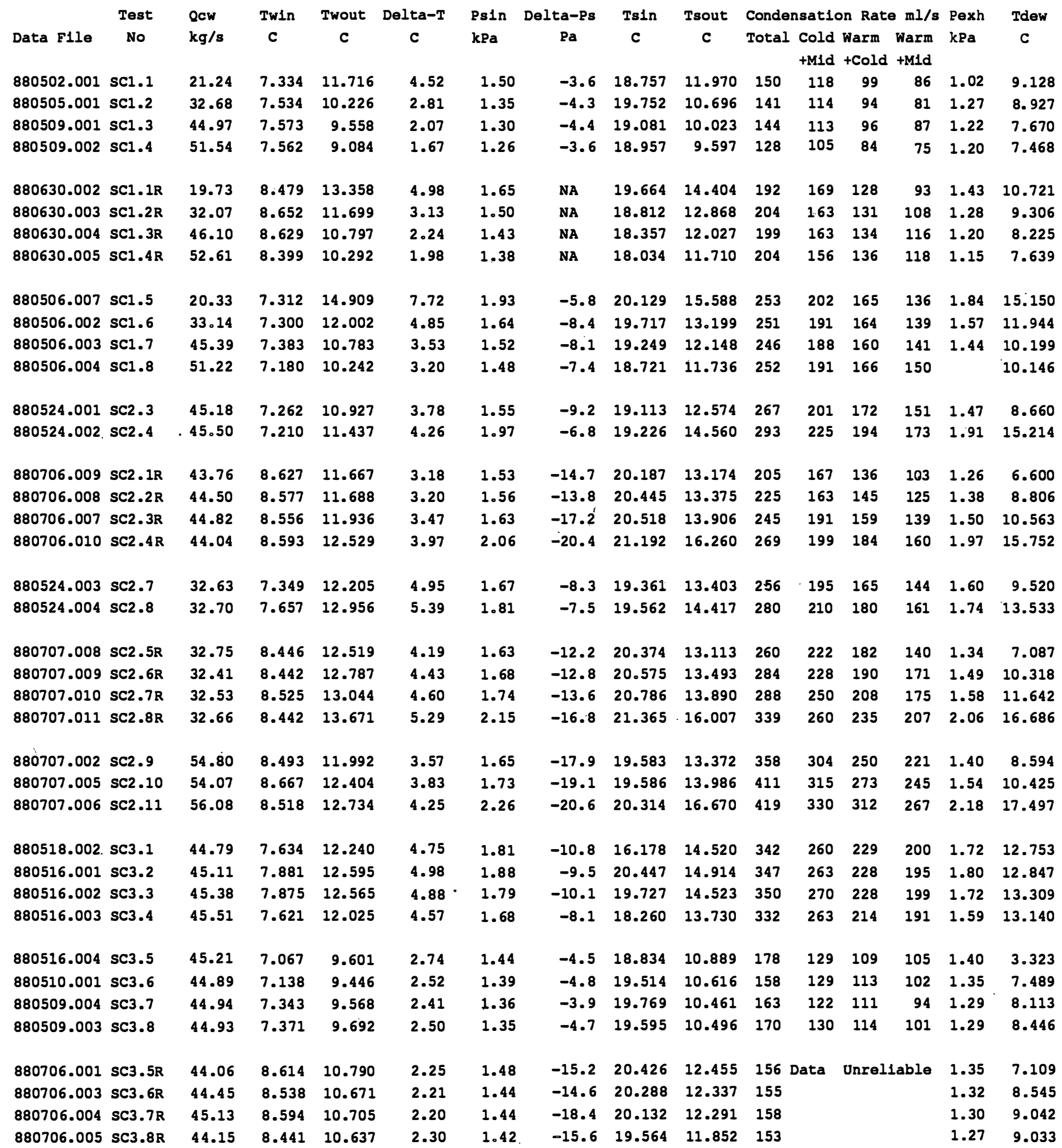


$\mathrm{TP}-3561$

\title{
Table B-4. Data Summary for Surface Condenser Tests, Main Condenser (Concluded)
}

\author{
Calculated Parameters
}

\begin{tabular}{|c|c|c|c|c|c|c|c|c|c|c|c|c|c|c|c|c|c|c|}
\hline \multirow{3}{*}{$\begin{array}{c}\text { Test } \\
\text { No }\end{array}$} & \multirow{2}{*}{\multicolumn{2}{|c|}{ Condensation }} & & & & & & & \multirow[b]{2}{*}{ Tssin } & \multirow[b]{2}{*}{$\begin{array}{c}\text { Tssou } \\
\text { C }\end{array}$} & \multicolumn{8}{|c|}{ Eraction } \\
\hline & & & $\begin{array}{l}\text { Rate } \\
\text { M1d }\end{array}$ & $\begin{array}{l}\mathrm{ml} / \mathrm{s} \\
\text { Warm }\end{array}$ & $\begin{array}{r}\mathrm{Ms1} \\
\mathrm{kg} / \mathrm{s}\end{array}$ & $\begin{array}{c}\mathrm{Mg} \\
\mathrm{kg} / \mathrm{s} .\end{array}$ & $\begin{array}{c}\text { Yg1 } \\
8\end{array}$ & $\begin{array}{c}\text { Ygo } \\
\text { \& }\end{array}$ & & & $\begin{array}{l}\text { Qe } \\
k W\end{array}$ & $\begin{array}{l}\text { Qc } \\
k W\end{array}$ & $\begin{array}{l}\text { Qs } \\
\mathrm{kW}\end{array}$ & $\begin{array}{l}\text { Qr } \\
\text { Kw }\end{array}$ & $\begin{array}{l}\text { Steam } \\
\text { Con- }\end{array}$ & $\begin{array}{c}\text { Uo } \\
k w / m 2 K\end{array}$ & hw & hs \\
\hline & & & & & & & by Wt. & by wt. & & & & & & & densed & & & \\
\hline sc1.1 & 155 & 78 & 48 & 29 & 0.183 & 0.00106 & 0.576 & 3.167 & 12.982 & $\star \star \star \star \star$ & 399 & 372 & 367 & 75 & 0.826 & 1.58 & 2.80 & 5.04 \\
\hline sc1. 2 & 144 & 67 & 46 & 31 & 0.161 & 0.00090 & 0.555 & 4.427 & 11.347 & $\star \star \star \star \star$ & 378 & 352 & 340 & 41 & 0.888 & 2.05 & 3.73 & 7.05 \\
\hline sc1. 3 & 147 & 64 & 48 & 35 & 0.167 & 0.00110 & 0.656 & 4.804 & 10.782 & $\star \star \star \star \star \star$ & 396 & 357 & 357 & 47 & 0.869 & 2.25 & 4.62 & 6.68 \\
\hline $\operatorname{scl} .4$ & 136 & 58 & 44 & 34 & 0.142 & 0.00102 & 0.711 & 6.332 & 10.331 & $\star \star \star \star \star$ & 342 & 313 & 316 & 30 & 0.896 & 2.23 & 5.06 & 5.83 \\
\hline SC1.1R & 159 & 84 & 48 & 27 & 0.216 & 0.00114 & 0.526 & 1.883 & 14.488 & $\star \star \star \star \star \star$ & 528 & 385 & 376 & 139 & 0.724 & 1.65 & 2.71 & 6.28 \\
\hline SC1.2R & 166 & 79 & 53 & 34 & 0.214 & 0.00096 & 0.446 & 1.667 & 13.021 & $\star \star \star \star \star$ & 507 & 391 & 399 & 133 & 0.742 & 1.93 & 3.74 & 5.87 \\
\hline SC1.3R & 175 & 78 & 57 & 41 & 0.219 & 0.00095 & 0.432 & 1.656 & 12.216 & $\star \star \star \star \star$ & 525 & 399 & 378 & 132 & 0.740 & 2.17 & 4.76 & 5.85 \\
\hline SC1.4R & 173 & 75 & 56 & 42 & 0.216 & 0.00092 & 0.425 & 1.674 & 11.764 & $\star \star \star \star \star$ & 529 & 398 & 378 & 127 & 0.749 & 2.22 & 5.19 & 5.58 \\
\hline sc1. 5 & 256 & 115 & 80 & 47 & 0.261 & 0.00096 & 0.367 & 9.943 & 16.915 & $\star \star \star \star \star \star$ & 642 & 618 & 620 & 10 & 0.962 & $1.65^{\circ}$ & 2.77 & 6.00 \\
\hline sc1. 6 & 248 & 113 & 80 & 55 & 0.271 & 0.00111 & 0.408 & 5.666 & 14.351 & $\star \star \star \star \star \star$ & 644 & 623 & 617 & 34 & 0.934 & 1.84 & 3.80 & 4.97 \\
\hline sc1.7 & 257 & 111 & 84 & 62 & 0.266 & 0.00122 & 0.456 & 6.939 & 13.165 & $\star \star \star \star \star$ & 638 & 615 & 608 & 32 & 0.939 & 2.06 & 4.68 & 5.22 \\
\hline sc1. 8 & 266 & 112 & 87 & 67 & 0.261 & 0.00106 & 0.405 & 10.968 & 12.746 & 11.7 & 642 & 627 & 624 & 31 & $0.976^{\circ}$ & 2.22 & 5.06 & 5.74 \\
\hline sc2. 3 & 279 & 119 & 91 & 68 & 0.301 & 0.00182 & 0.602 & 5.366 & 13.489 & $\star \star \star \star \star$ & 705 & 662 & 659 & 72 & 0.894 & 2.02 & 4.66 & 4.94 \\
\hline $\mathrm{sc} 2.4$ & 291 & 129 & 94 & 68 & 0.320 & 0.00110 & 0.343 & 15.595 & 17.197 & $\star \star \star \star \star$ & 717 & 769 & 719 & 3 & 0.976 & 1.34 & 4.70 & 2.19 \\
\hline SC2.1R & 215 & 95 & 70 & 50 & 0.293 & 0.00176 & 0.597 & 2.223 & 13.306 & $\star \star \star \star \star \star$ & 683 & 532 & 538 & 185 & 0.738 & 2.23 & 4.62 & 6.53 \\
\hline$S C 2.2 R$ & 203 & 91 & 66 & 47 & 0.271 & 0.00148 & 0.544 & 3.102 & 13.590 & $\star \star \star \star \star \star$ & 690 & 553 & 565 & 107 & 0.829 & 2.12 & 4.67 & 5.60 \\
\hline SC2.3R & 262 & 114 & 85 & 63 & 0.270 & 0.00135 & 0.498 & 5.097 & 14.286 & $\star \star \star \star \star \star$ & 699 & 606 & 605 & 54 & 0.912 & 2.00 & 4.70 & 4.78 \\
\hline$s c 2.4 R$ & 279 & 125 & 90 & 64 & 0.288 & 0.00109 & 0.377 & 16.621 & 17.925 & $\star \star \star \star \star$ & 687 & 693 & 659 & 2 & 0.978 & 1.30 & 4.66 & 2.10 \\
\hline $\operatorname{sc2} .7$ & 266 & 120 & 86 & 60 & 0.286 & 0.00204 & 0.708 & 6.548 & 14.621 & $\star \star \star \star \star$ & 695 & 634 & 630 & 64 & 0.901 & 1.82 & 3.76 & 4.88 \\
\hline sc2. 8 & 276 & 128 & 89 & 60 & 0.287 & 0.00116 & 0.402 & 13.923 & 15.886 & $\star \star \star \star \star$ & 707 & 693 & 688 & 8 & 0.981 & 1.82 & 3.76 & 4.85 \\
\hline$S C 2.5 R$ & 220 & 102 & 71 & 47 & 0.277 & 0.00197 & 0.705 & 3.142 & 14.244 & $\star \star \star \star \star \star$ & 727 & 533 & 505 & 144 & 0.782 & 1.65 & 3.79 & 5.83 \\
\hline$S C 2.6 R$ & 236 & 109 & 76 & 51 & 0.268 & 0.00150 & 0.556 & 4.040 & 14.753 & $\star \star \star \star \star$ & 723 & 563 & 566 & 107 & 0.854 & 1.87 & 3.78 & 5.24 \\
\hline$s c 2.7 R$ & 249 & 114 & 80 & 55 & 0.271 & 0.00138 & 0.507 & 4.152 & 15.266 & $\star \star \star \star \star$ & 723 & 588 & 538 & 70 & 0.882 & 1.79 & 3.80 & 4.60 \\
\hline SC2.8R & 269 & 128 & 85 & 56 & 0.284 & 0.00104 & 0.365 & 15.236 & 18.641 & $\star \star \star \star \star \star$ & 734 & 683 & 674 & 2 & 0.977 & 1.25 & 3.82 & 2.16 \\
\hline sc2. 9 & 315 & 133 & 103 & 78 & 0.376 & 0.00184 & 0.487 & 2.732 & 14.423 & $\star \star \star \star \star \star 1$ & 1000 & 767 & 714 & 155 & 0.829 & 2.38 & 5.38 & 6.44 \\
\hline sc2. 10 & 339. & 143 & 111 & 85 & 0.379 & 0.00173 & 0.454 & 3.248 & 15.213 & $\star \star \star \star \star \star 1$ & 1003 & 808 & 837 & 119 & 0.866 & 2.24 & 5.35 & 5.52 \\
\hline sc2.11 & 404 & 173 & 132 & 100 & 0.392 & 0.00181 & 0.460 & 23.023 & 19.452 & $\star \star \star \star \star$ & 995 & 945 & 855 & 2 & 0.980 & 1.52 & 5.49 & 2.53 \\
\hline sc3.1 & 363 & 154 & 119 & 90 & 0.361 & 0.00202 & 0.556 & 7.093 & 15.888 & $\star \star \star \star \star \star$ & 856 & 825 & 845 & 55 & 0.929 & 1.85 & 4.68 & 4.02 \\
\hline sc3. 2 & 350 & 155 & 114 & 81 & 0.369 & 0.00174 & 0.469 & 6.846 & 16.455 & $\star \star \star \star \star$ & 862 & 850 & 852 & 49 & 0.936 & 1.81 & 4.72 & 3.89 \\
\hline sc3.3 & 349 & 154 & 113 & 82 & 0.360 & 0.00117 & 0.324 & 7.958 & 15.726 & $\star \star \star \star \star$ & 872 & 851 & 860 & 23 & 0.960 & 2.11 & 4.73 & 5.44 \\
\hline sc3. 4 & 329 & 144 & 107 & 78 & 0.340 & 0.00073 & 0.214 & 5.462 & 14.713 & $\star \star \star \star \star \star$ & 807 & 801 & 816 & 21 & 0.957 & 2.22 & 4.72 & 6.28 \\
\hline $\operatorname{sc} 3.5$ & 182 & 78 & 59 & 45 & 0.215 & 0.00298 & 1.366 & 9.127 & 12.284 & $\star \star \star \star \star \star$ & 465 & 458 & 439 & 68 & 0.866 & 1.58 & 4.63 & 2.98 \\
\hline $\operatorname{sc} 3.6$ & 170 & 75 & 55 & 40 & 0.183 & 0.00163 & 0.884 & 9.951 & 11.787 & $\star \star \star \star \star \star$ & 427 & 414 & 413 & 29 & 0.919 & 1.67 & 4.60 & 3.31 \\
\hline $\operatorname{sc} 3.7$ & 167 & 73 & 54 & 40 & 0.183 & 0.00122 & 0.661 & 5.293 & 11.423 & $\star \star \star \star \star$ & 418 & 400 & 403 & 47 & 0.888 & 1.82 & 4.61 & 3.95 \\
\hline $\operatorname{sc} 3.8$ & 170 & 74 & 55 & 41 & 0.191 & 0.00108 & 0.562 & 4.534 & 11.340 & $\star \star \star \star \star \star$ & 428 & 417 & 420 & 49 & 0.887 & 2.01 & 4.62 & 4.97 \\
\hline SC3.5R & & & & & 0.180 & 0.00186 & 1.022 & 6.943 & 12.741 & $\star \star \star \star \star \star$ & 481 & 383 & 384 & 55 & 0.865 & 1.70 & 4.61 & 3.43 \\
\hline SC3.6R & & & & & 0.176 & 0.00125 & 0.706 & 5.346 & 12.387 & $\star \star \star \star \star \star$ & 454 & 379 & 382 & 47 & 0.875 & 1.82 & 4.64 & 3.94 \\
\hline $\operatorname{sc3} .7 \mathrm{R}$ & & & & & 0.179 & 0.00102 & 0.568 & 4.120 & 12.333 & $\star \star \star \star \star \star$ & 460 & 289 & 389 & 51 & 0.865 & 1.86 & 4.69 & 4.09 \\
\hline SC3.8R & & & & & 0.185 & 0.00088 & 0.474 & 3.018 & 12.096 & $\star \star \star \star \star$ & 449 & & 389 & 63 & 0.852 & 1.99 & 4.61 & 4.84 \\
\hline
\end{tabular}




\section{B.3 EXPERIMENTAL DATA ON DIRECT-CONTACT CONDENSER}

Table B-5 summarizes the experimental data gathered at the HMTSTA in the two direct-contact condenser (DCC) configurations tested. The data are divided by geometry of the two DCC stages and are shown chronologically within each set. Coaxial configuration tests, more typical of NPPE conditions, are shown first.

The second part of this table (last four pages) contains data collected early in the DCC test series. In some cases, variations in data were observed outside the predicted error margins for those measurements. Therefore, these data should only be used for general reference. Many of the tests conducted during this period were repeated and are shown in the front part of the table.

The data selected for this table provide sufficient information to calculate the performance parameters. The table does not contain all the data collected for redundant measurements and calculations. All differential temperature and pressure readings have been corrected for zero offset, which was measured daily and is stored in the first data file collected for each test sequence. The table consists of measured parameters such as temperature, pressure, and flow rates, as well as calculated operating and performance parameters. Elever temperatures are presented for the evaporator and for the two DCC condenser stages. Note that some system temperatures are obtained by adding (or subtracting) a differential temperature measurement to (or from) an absolute measurement.

Five pressures are shown. Because the pressure drop in the DCC stages is very small, the data are presented in $\mathrm{Pa}$, and the absolute pressure is shown in $\mathrm{kPa}$. Three water flow rates for the evaporator and the two DCC stages are shown. The flow rate for the first condenser stage is corrected from that shown in the raw data file, based on factory and field calibration during the experiments. The leakage into the system is calculated as described in Section 2.3.8 in Chapter 2. The single values shown apply for the entire set of data below each entry.

The remainder of the table contains noncondensable gas mass concentration in and out of the DCC stages, the Jakob number and percent steam condensed for each stage, and the steam and liquid loadings for each.

The last five columns describe overall DCC performance. "Error Heat" shows the percent discrepancy in the heat balance between evaporator and DCC. "Error NC" shows the percent discrepancy between the amount of noncondensable gas-exhausted from the system as compared to an assumed $90 \%$ release from the warm seawater plus $100 \%$ release from the cold seawater plus the leak. Vent ratio, overall thermal effectiveness, and overall percent steam condensed are calculated as described in Chapter 7.

Tables B-6 and B-7 show a few data points for each DCC stage indicating the influence of major parameters. The full data set for each point can be found in Table B-5 under the same data file name. For the cocurrent stage, Table B-6 shows that Jakob number and steam loading have the greatest influence. Note that the data shown for steam loading effects are taken from the side-by-side tests, where the stage effectiveness is consistently less than that for the coaxial configuration. This has been attributed to seawater contamination of 
the water reservoirs for the wicks covering the steam sensors. For the countercurrent stage, Table B-7 shows that the Jakob number and the freefall height have the greatest influence.

It is very difficult to reset the HMTSTA system to achieve precisely the same conditions. This is especially true for the two DCC stages because of crosscoupling effects. Therefore, there are small variations in each parameter within each set.

Several entries in these tables show repeatability for various test cases on different days.

\section{NOMENCLATURE (Table B-5)}

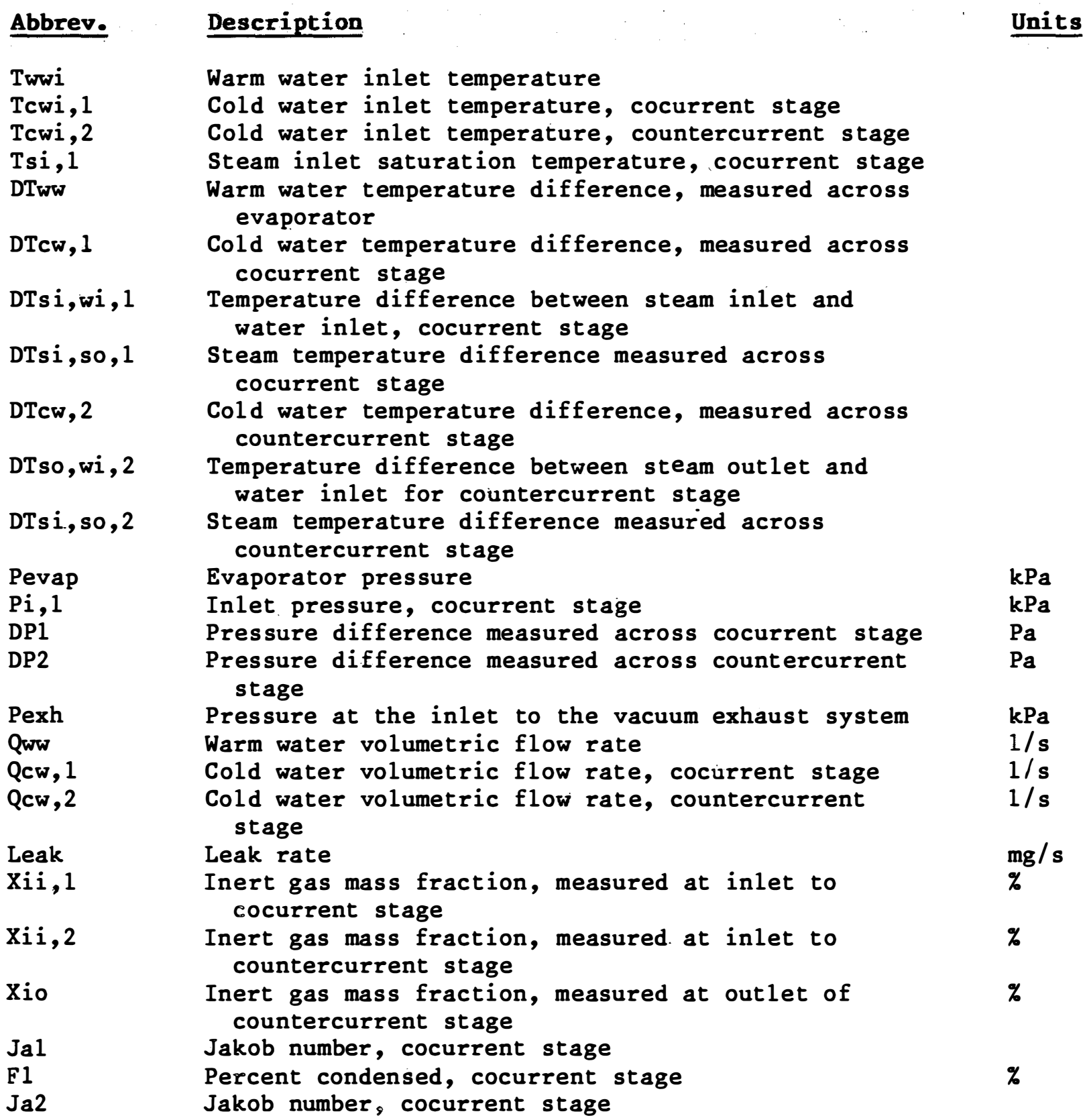


Abbrev.

F2

G1

G2

L1

L2

Errorheat

ErrorNC

Vent Ratio

Efftot

Ftot
Description

Percent condensed, cocurrent stage

Steam loading, cocurrent stage

Steam loading, countercurrent stage

Liquid loading, cocurrent stage

Liquid loading, countercurrent stage

Error in heat balance between DCC and evaporator

Error in noncondensable gas mass flow rate between vacuum exhaust system calculations and release rate predictions [negative numbers imply gas release is less than the assumed $90 \%$ from warm water, and $100 \%$ from cold water (plus air leak)] Ratio of ideal to actual exhaust gas volumetric flow rate

Overall DCC thermal effectiveness

Overall percent condensed in the DCC
Units

$\%$

$\mathrm{kg} / \mathrm{m}^{2} \mathrm{~s}$

$\mathrm{kg} / \mathrm{m}^{2} \mathrm{~s}$

$\mathrm{kg} / \mathrm{m}^{2} \mathrm{~s}$

$\mathrm{kg} / \mathrm{m}^{2} \mathrm{~s}$

$\%$

$\%$
$\mathrm{C}={ }^{\circ} \mathrm{C}$
$\mathrm{m} 2, \mathrm{~m}^{\wedge} 2=\mathrm{m}^{2}$
$\mathrm{m} 3, \mathrm{~m}^{\wedge} 3^{\circ}=\mathrm{m}^{3}$ 


\section{Table B-5. Data Summary for Direct-Contact Condenser Tests}

\begin{tabular}{|c|c|c|c|c|c|c|c|c|c|c|c|c|c|c|c|c|}
\hline Identifler & Tww1 & Tcw1, 1 & Tew1, 2 & Ts1, 1 & DTwW & DTCW & DTs1w1 & DTs1so & DTCW & DTsowi 1 & Ts1so & Pevap & $P 1,1$ & DP1 & DP2 & Pexh \\
\hline & (C) & & & & & 1 & 1 & 1 & 2 & 2 & 2 & (kPa) & & (Pa) & & \\
\hline axlal & es (\#) & Area, 1= & 1.021 & $\mathrm{H}, 1=$ & 1.02 & Hpk, 1- & 0.61 & & rea, 2= & $=0.343$ & H, 2= & 1.04 & Hpk, 2= & 0.61 & & \\
\hline 890306.004 & 24.6 & 6.3 & 6.06 & 12.3 & 3.42 & 4.85 & 6.01 & 0.44 & 4.63 & 0.67 & 4.8 & 2.345 & 1.47 & 4.4 & 29.4 & 1.39 \\
\hline 890306.005 & 24.7 & 6.2 & 5.97 & 12.7 & 4.13 & 6.3 & 6.47 & 0.16 & 5.36 & 1.19 & 5.1 & 2.251 & 1.497 & 2.8 & 27.7 & 1.393 \\
\hline 890306.006 & 24.7 & 6.3 & 6.02 & 12.9 & 4.12 & 6.36 & 6.54 & 0.14 & 5.11 & 0.52 & 5.81 & 2.251 & 1.506 & 1.7 & 27.8 & 1.243 \\
\hline 890306.007 & 24.7 & 6.4 & 6.07 & 12.9 & 4.07 & 6.36 & 6.53 & 0.12 & 5.11 & 0.57 & 5.81 & 2.25 & 1.511 & 3.3 & 47.1 & 1.249 \\
\hline 890306.008 & 24.5 & 6.1 & 5.82 & 13.2 & 3.98 & 6.8 & 7.07 & 0.16 & 2.98 & 0.03 & 6.92 & 2.235 & 1.535 & -1.6 & 32.9 & 1.069 \\
\hline 890306.009 & 24.5 & 6.3 & 5.98 & 12.9 & 4.04 & 6.43 & 6.63 & 0.12 & 4.51 & 0.12 & 6.34 & 2.232 & 1.506 & 0.7 & 33.4 & 1.151 \\
\hline 890306.01 & 24.5 & 6.3 & 5.98 & 13.2 & 3.38 & 6.65 & 6.87 & 0.16 & 4.8 & 0.23 & 6.43 & 2.316 & 1.533 & 2.1 & 31.4 & 1.274 \\
\hline
\end{tabular}

Area, $2=0.343$

$\begin{array}{rr}\text { Coaxlal stages ( }) \text { ) } \\ 890307.003 & 24.8 \\ 890307.004 & 24.8 \\ 890307.006 & 25.0 \\ 890310.002 & 24.9 \\ 890310.003 & 24.9 \\ 890310.004 & 24.9 \\ 890310.005 & 24.9 \\ 890310.006 & 24.9 \\ 890310.007 & 25.0 \\ 890310.008 & 25.0 \\ 890310.009 & 25.0 \\ 890310.01 & 25.0 \\ 890310.011 & 25.0 \\ 890310.012 & 25.0 \\ 890310.013 & 25.0 \\ 890313.002 & 24.9 \\ 890313.003 & 25.0 \\ 890313.005 & 25.1 \\ 890315.004 & 25.0 \\ 890315.005 & 25.0 \\ 890315.006 & 24.9 \\ 890315.007 & 25.0\end{array}$

$\begin{array}{rr}6.18 & 0.25 \\ 5.54 & -0.01 \\ 5.72 & 0.01 \\ 5.76 & 0.12 \\ 5.47 & -0.01 \\ 3.96 & -0.01 \\ 4.99 & -0.01 \\ 7.84 & 1.59 \\ 7.7 & 0.33 \\ 6.42 & 0.01 \\ 3.77 & 0.05 \\ 6.19 & 0.66 \\ 6.07 & 0.12 \\ 5.36 & 0 \\ 2.99 & 0.02 \\ 5.83 & 1.29 \\ 5.86 & 1.36 \\ 5.72 & 0.03 \\ 7.02 & 1.18 \\ 6.8 & 0.44 \\ 4.02 & 0.34 \\ 2.39 & 0.38\end{array}$

Area, 2 $=0.343$

H,2= $1.35 \mathrm{Hpk}, 2=0.91$

$$
\begin{array}{rrrrrr}
5.94 & 2.445 & 1.528 & 18 & 35 & 2.756 \\
6.68 & 2.451 & 1.55 & 17.3 & 9.6 & 2.787 \\
6.13 & 2.48 & 1.523 & 19 & 26.6 & 2.782 \\
5.96 & 2.495 & 1.522 & 16.5 & 66.5 & 1.362 \\
6.4 & 2.453 & 1.533 & 15.4 & 48.4 & 1.262 \\
6.99 & 2.464 & 1.586 & 11.7 & 21.3 & 1.144 \\
6.68 & 2.441 & 1.564 & 14.4 & 30.9 & 1.208 \\
6.21 & 2.504 & 1.722 & 5.2 & 44.2 & 1.143 \\
7.75 & 2.44 & 1.737 & 4.4 & 26.7 & 0.99 \\
8.48 & 2.445 & 1.758 & 2.4 & 6.1 & 0.92 \\
9.28 & 2.456 & 1.844 & -2.4 & -4.6 & 0.855 \\
5.58 & 2.577 & 1.552 & 8.6 & 59.2 & 1.397 \\
6.33 & 2.613 & 1.552 & 8.4 & 42.8 & 1.26 \\
6.78 & 2.614 & 1.562 & 6.1 & 24.8 & 1.16 \\
7.39 & 2.62 & 1.625 & 2.8 & 8.8 & 1.068 \\
4.51 & 2.457 & 1.528 & 5.1 & 58.8 & 1.372 \\
4.51 & 2.467 & 1.529 & 6.5 & 50.4 & 1.372 \\
6.18 & 2.504 & 1.528 & 0.6 & 10.5 & 1.05 \\
5.82 & 2.392 & 1.645 & 15.4 & 45.6 & 1.472 \\
6.95 & 2.388 & 1.643 & 15.7 & 24.9 & 1.259 \\
7.79 & 2.384 & 1.704 & 11.9 & 2 & 1.133 \\
8.22 & 2.4 & 1.75 & 9.1 & -0.1 & 1.089
\end{array}
$$

Coaxlal Stages (๑) Area, $1=1.021 \mathrm{H}, 1=1.02 \mathrm{Hpk}, 1=0.61$

$\begin{array}{ll}890317.003 & 25.2 \\ 890317.004 & 25.2 \\ 890317.005 & 25.1 \\ 890317.006 & 25.1 \\ 890317.007 & 25.1 \\ 890317.008 & 25.1\end{array}$

\begin{abstract}
$\begin{array}{lllllll}6.4 & 6.43 & 13.4 & 3.41 & 6.56 & 6.94 & 0.56\end{array}$
$\begin{array}{lllllll}6.3 & 6.39 & 13.7 & 3.37 & 6.86 & 7.22 & 0.6\end{array}$

$\begin{array}{lllllll}6.3 & 6.32 & 13.4 & 3.36 & 6.42 & 6.79 & 0.66\end{array}$

$\begin{array}{lllllll}6.2 & 6.28 & 13.5 & 3.35 & 6.47 & 6.87 & 0.69\end{array}$

$\begin{array}{llllllll}6.1 & 6.18 & 13.8 & 3.38 & 6.8 & 7.19 & 0.69\end{array}$

$\begin{array}{lllllll}6.2 & 6.26 & 14.9 & 3.37 & 7.76 & 8.21 & 0.71\end{array}$
\end{abstract}

$5.36-0.01$

$4.61-0.01$

$6.23 \quad 0.42$

5.990 .06

5.190

$1.93 \quad 0.07$
H, 2= $1.35 \mathrm{Hpk}, 2=0.91$

$\begin{array}{lllllll}6.5 & 2.42 & 1.53 & 20.6 & 46.8 & 1.385\end{array}$ $\begin{array}{llllll}6.85 & 2.416 & 1.554 & 18.5 & 21.8 & 1.272\end{array}$ $\begin{array}{lllllll}5.91 & 2.404 & 1.52 & 19.7 & 28.4 & 1.389\end{array}$ $\begin{array}{llllll}6.45 & 2.404 & 1.526 & 19.1 & 15.7 & 1.268\end{array}$ $\begin{array}{llllll}6.91 & 2.394 & 1.546 & 17.7 & -0.8 & 1.181\end{array}$ $\begin{array}{llllll}7.83 & 2.389 & 1.661 & 11.6 & -14.9 & 1.05\end{array}$
Coaxlal Stages (X) Area, $1=1.021 \mathrm{H,1}=1.02 \mathrm{Hpk}, 1=0.61$

$890413.002 \quad 25.8$ $890413.003 \quad 25.9$ $890413.004 \quad 25.9$ $890413.005 \quad 25.9$ $890413.006 \quad 25.9$ $\begin{array}{llllllll}5.9 & 5.37 & 13.8 & 3.63 & 7.76 & 7.9 & -0.02\end{array}$

$\begin{array}{lllllll}6.0 & 5.47 & 13.3 & 3.37 & 7.18 & 7.28 & 0.02\end{array}$

$\begin{array}{lllllll}6.0 & 5.39 & 13.9 & 3.34 & 7.78 & 7.96 & 0.05\end{array}$

$\begin{array}{lllllll}6.0 & 5.39 & 13.4 & 3.37 & 7.3 & 7.43 & 0.01\end{array}$

$\begin{array}{llllll}6.0 & 5.42 & 13.2 & 3.39 & 7.08 & 7.19\end{array}$
Area, $2=0.343$

$\begin{array}{lll}7.5 & 0.53\end{array}$ $6.65-0.01$ $4.1-0.01$

$6.09-0.01$ 6.710 .16
H,2 $=1.35 \mathrm{Hpk}, 2=0.91$

$\begin{array}{llllll}7.29 & 2.415 & 1.651 & 0 & 1.7 & 1.355\end{array}$

$\begin{array}{llllll}7.26 & 2.479 & 1.6 & 15.6 & 70.4 & 1.221\end{array}$

$\begin{array}{llllll}7.98 & 2.49 & 1.662 & 10.8 & 13.7 & 1.058\end{array}$

$\begin{array}{llllll}7.49 & 2.484 & 1.6 & 16.4 & 35.7 & 1.145\end{array}$ $\begin{array}{llllll}6.97 & 2.483 & 1.573 & 18.3 & 72.2 & 1.306\end{array}$ 
$\mathrm{TP}-3.561$

\title{
Table B-5. Data Summary for Direct-Contact Condenser Tests (Continued)
}

\author{
QwW Qcw, 1 Qcw, 2 Leak X11,1 X11,2 X10 Ja1 F1 Ja2 F2 G1 G2 L1 L 2 ErrorError Vent Total Total \\ $\begin{array}{llllll}(1 / \mathrm{s}) \operatorname{corr} & (\mathrm{mg} / \mathrm{s}) & (\mathrm{z}) & (\mathrm{z}) & (\mathrm{kg} / \mathrm{m} 2 \mathrm{~s}) & \text { Heat NC Rat1o Eff } \mathrm{F}\end{array}$
}

B turbulators in nozzles

\begin{tabular}{|c|c|c|c|c|c|c|c|c|c|c|c|c|c|c|c|c|c|c|c|}
\hline 55.07 & 39.75 & 2.59 & 145 & 0.32 & 7.7 & 39 & 1.22 & 93.5 & 1.11 & 87.4 & 0.33 & 0.06 & 39.98 & 7.75 & 9 & -13 & 0.82 & 0.76 & 99.2 \\
\hline 56.79 & 33.19 & 7.56 & & 0.27 & 2.3 & 37 & 0.90 & 83.4 & 1.20 & 95.8 & 0.40 & 0.20 & 33.37 & 22.63 & 7 & -17 & 0.77 & 0.90 & 99.3 \\
\hline 56.53 & 33.22 & 7.56 & & 0.27 & 2.4 & 42 & 0.91 & 84.2 & 1.27 & 96.3 & 0.40 & 0.19 & 33.40 & 22.63 & 7 & -17 & 0.85 & 0.89 & 99.4 \\
\hline 57.23 & 33.20 & 7.56 & & 0.27 & 2.4 & 41 & 0.91 & 84.2 & 1.28 & 96.3 & 0.40 & 0.19 & 33.38 & 22.63 & 7 & -17 & 0.81 & 0.89 & 99.4 \\
\hline 57.26 & 33.22 & 7.54 & & 0.27 & 4.1 & 48 & 0.99 & 90.8 & 2.39 & 95.0 & 0.40 & 0.11 & 33.40 & 22.57 & 9 & -17 & 0.92 & 0.82 & 99.5 \\
\hline 57.26 & 33.28 & 7.53 & & 0.27 & 2.7 & 44 & 0.93 & 86.1 & 1.47 & 96.3 & 0.40 & 0.17 & 33.47 & 22.54 & 7 & -17 & 0.89 & 0.87 & 99.5 \\
\hline 71.31 & 33.29 & 7.59 & & 0.32 & 2.9 & 45 & 0.92 & 85.6 & 1.42 & 96.1 & 0.42 & 0.18 & 33.48 & 22.72 & 7 & -16 & 0.88 & 0.87 & 99.4 \\
\hline
\end{tabular}

B turbulators in nozzles

\begin{tabular}{|c|c|c|c|c|c|c|c|c|c|c|c|c|c|c|c|c|c|c|c|}
\hline 39 & 87 & 07 & 45 & 33 & .8 & 41 & .84 & 9.8 & .01 & 4.4 & .41 & 0.25 & 32.04 & 24.16 & $?$ & 45 & .83 & .94 & 8.9 \\
\hline 3.24 & 1.80 & .04 & & .33 & 9 & 47 & .86 & 2.1 & .21 & 94.2 & 0.42 & 0.22 & 31.98 & 24.07 & & 69 & .94 & 0.92 & 18.9 \\
\hline 2.26 & 31.86 & 9.6 & & 33 & .5 & 42 & 81 & 7.9 & .09 & 4.9 & 41 & .27 & 32.03 & 28.74 & & 47 & .88 & .93 & 8.9 \\
\hline 3.86 & 31.98 & .66 & & 33 & .7 & 40 & 82 & 7.7 & .08 & .1 & 4.1 & .27 & .16 & 28.91 & & -24 & .80 & .93 & 9.4 \\
\hline .83 & 32.00 & 65 & & 33 & 0 & 13 & 83 & 3 & 20 & & & 26 & .18 & 28.88 & & -23 & 87 & .92 & 9.4 \\
\hline 3.87 & 32.04 & .64 & & .33 & 2.5 & 47 & .89 & 4.9 & .80 & 96.8 & 0.42 & 0.19 & 32.22 & 28.85 & 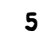 & -22 & .94 & 0.85 & 99.5 \\
\hline 3.92 & 2.00 & .64 & & 33 & .0 & 45 & .84 & 1.1 & .37 & 7.3 & .42 & 0.24 & 32.18 & 28.85 & & -22 & 91 & 91 & 9.5 \\
\hline 3.93 & 3.92 & .24 & & .33 & 1.4 & 39 & .79 & 7.1 & .01 & 7.6 & .41 & 0.28 & 24.05 & 21.67 & ? & -33 & .69 & 0.97 & 9.5 \\
\hline 4.03 & 3.90 & 7.25 & & 33 & .6 & 49 & .79 & 77.7 & .07 & 98.2 & 41 & 0.27 & 24.03 & 21.70 & 2 & -24 & .88 & 0.97 & 9.6 \\
\hline 3.87 & 23.82 & 7.24 & & $34^{\circ}$ & 1.9 & 53 & .82 & 1.1 & .35 & 98.1 & 0.40 & 0.23 & 23.94 & 21.67 & 1 & -23 & 0.96 & 0.92 & 99.6 \\
\hline 3.75 & 3.83 & $7: 23$ & & 34 & 3.3 & 56 & 91 & 88.8 & 2.51 & 97.2 & 0.40 & 0.13 & 23.95 & 21.64 & -3 & -23 & 97 & .84 & 9.7 \\
\hline 3.78 & 1.94 & .09 & & & 1.8 & 37 & 84 & 80.1 & 1.03 & & & 0.25 & 32.12 & 24.21 & 3 & -28 & & .95 & 9.3 \\
\hline 3.97 & 1.97 & 8.1 & & 33 & 1.9 & 43 & .85 & 80.5 & 1.09 & 97.1 & 0.42 & 0.24 & 32.15 & 24.24 & 3 & -24 & 0.85 & .94 & 99.4 \\
\hline 3.86 & 31.92 & .08 & & & 2.2 & 46 & & 82.8 & 1.29 & & & .21 & 32.09 & & 3 & -23 & & 91 & 9.5 \\
\hline 3.94 & .92 & .07 & & & 4.0 & 50 & 0.95 & 90.4 & 2.50 & 95.5 & 0.42 & 0.12 & 32.09 & 24.15 & 5 & -23 & .96 & .83 & 99.6 \\
\hline 54.9 & 3.98 & 7.44 & & 34 & 1.7 & 32 & 0.81 & 76.4 & 1.02 & 95.9 & 0.31 & 0.21 & 24.12 & 22.27 & 1 & -25 & 0.66 & 0.94 & 99.0 \\
\hline 4.85 & 23.99 & & & .35 & 1.8 & 31 & 0.82 & 78.2 & 1.02 & 95.5 & 0.30 & 0.20 & 24.13 & 20.05 & -1 & -25 & 0.67 & 0.94 & 9.0 \\
\hline 5.04 & 23.98 & 6.39 & & .35 & 2.1 & 42 & 0.85 & 79.7 & 1.12 & 96.7 & 0.30 & 0.18 & 24.12 & 19.13 & -1 & -21 & 0.92 & 0.93 & 9.3 \\
\hline 84.6 & 1.75 & 7.99 & & .34 & 1.8 & 39 & 0.91 & 79.7 & 1.02 & 96.8 & 0.46 & 0.28 & 31.93 & 23.91 & 1 & -26 & .72 & .87 & 9.4 \\
\hline 4.79 & 1.73 & 7.99 & & 0.34 & 2.0 & 47 & 0.92 & 80.6 & 1.12 & 97.5 & 0.46 & 0.26 & 31.90 & 23.91 & 1 & -21 & 0.87 & 0.86 & 9. \\
\hline 4.75 & 1.74 & 7.98 & & 0.35 & 3.5 & 52 & 1.03 & 88.3 & 2.08 & 96.5 & 0.45 & 0.16 & 31.92 & 23.89 & 1 & -19 & 0.93 & 0.77 & 9. \\
\hline 4.74 & 1.77 & 7.98 & 145 & 0.35 & 5.8 & 54 & 1.09 & 92.9 & 3.70 & 94.5 & 0.44 & 0.09 & 31.95 & 23.89 & -0 & -19 & 0.94 & 0.73 & 99. \\
\hline
\end{tabular}

C turbulators in nozzles

\begin{tabular}{|c|c|c|c|c|c|c|c|c|c|c|c|c|c|c|c|c|c|c|c|}
\hline .19 & 31.91 & 11.65 & 200 & 0.31 & 1.7 & 44 & 0.85 & 76.7 & 1.25 & 97.5 & 0.44 & 0.31 & 32.08 & 34.87 & 9 & -15 & 0.87 & 0.86 & 99.4 \\
\hline 73.21 & 31.94 & 11.65 & & 0.31 & 2.0 & 47 & 0.88 & 80.1 & 1.53 & 97.4 & 0.44 & 0.26 & 32.12 & 34.87 & 10 & -16 & 0.92 & 0.83 & 99.5 \\
\hline 73.25 & 31.58 & 8.12 & & 0.33 & 2.0 & 40 & 0.88 & 79.6 & 1.04 & 96.8 & 0.41 & 0.25 & 31.76 & 24.31 & 4 & -20 & 0.82 & 0.90 & 99.3 \\
\hline 73.49 & 31.45 & 8.05 & & 0.33 & 2.1 & 44 & 0.89 & 80.5 & 1.11 & 97.1 & 0.41 & 0.24 & 31.63 & 24.10 & 3 & -18 & 0.89 & 0.89 & 99.4 \\
\hline 73.3 & 31.44 & 8.02 & & 0.33 & 2.5 & 47 & 0.92 & 83.4 & 1.36 & 97.0 & 0.41 & 0.20 & 31.61 & 24.01 & 4 & -18 & 0.95 & 0.86 & 99.5 \\
\hline 73.44 & 31.45 & 7.98 & & 0.32 & 6.5 & 53 & 1.03 & 93.9 & 4.11 & 93.5 & 0.42 & 0.08 & 31.62 & 23.89 & 5 & -18 & 0.98 & 0.77 & 99.6 \\
\hline
\end{tabular}

Low-loss distributor

$76.48 \quad 25.5910 .85$

73.84. 25.59 10.84

$\begin{array}{llll}73.74 & 25.58 & 10.83\end{array}$

$74 \quad 25.54 \quad 10.84$

74.0725 .5410 .85

$150 \begin{array}{ll}0.32 & 1.4 \\ 0.34 & 1.5 \\ 0.35 & 2.4 \\ 0.34 & 1.6 \\ 0.34 & 1.5\end{array}$

$\begin{array}{rrrrr}2 & -9 & 0.90 & 0.93 & 99.5 \\ 4 & -14 & 0.82 & 0.92 & 99.5 \\ -0 & -15 & 0.92 & 0.81 & 99.6 \\ 2 & -15 & 0.88 & 0.89 & 99.5 \\ 2 & -13 & 0.78 & 0.93 & 99.4\end{array}$


Table B-5. Data Summary for Direct-Contact Condenser Tests (Continued)

\begin{tabular}{|c|c|c|c|c|c|c|c|c|c|c|c|c|c|c|c|c|}
\hline Identifler & & $w 1,1$ & $=w 1,2$ & 131,1 & DTwW & v & . & 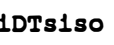 & D & & & & P1, 1 & DP1 & DP2 & Pe? \\
\hline & (c) & & & & & 1 & 1 & 1 & 2 & 2 & 2 & $(\mathrm{kPa})$ & & (Pa) & & \\
\hline 90413.007 & 26.0 & 6.1 & 5.49 & 12.4 & 3.37 & 6.23 & 6.36 & 0.04 & 5.66 & - & 6.32 & 2.508 & 1.494 & 13.2 & 47 & 1.255 \\
\hline 890413.008 & 26.0 & 5.9 & 5.36 & 12.6 & 3.38 & 6.26 & 6.51 & 0.25 & 4.82 & 0 & 6.61 & 2.493 & 1.518 & -3.5 & -7.3 & 1.291 \\
\hline 890413.009 & 26.0 & 5.9 & 5.36 & 12.5 & 3.40 & 6.25 & 6.42 & 0.17 & 5.22 & 0 & 6.5 & 2.489 & 1.501 & -3.5 & -0.6 & 1.334 \\
\hline 890413.01 & 26.0 & 5.9 & 5.33 & 12.5 & 3.42 & 6.4 & 6.53 & 0.27 & 4.23 & 0 & 6.32 & 2.488 & 1.493 & -3.8 & 3.7 & 1.313 \\
\hline 890413.011 & 26.0 & 6.0 & 5.40 & 12.3 & 3.43 & 6.28 & 6.37 & 0.23 & 4.88 & 0 & 6.14 & 2.489 & 1.483 & 13.1 & 33.6 & 1.344 \\
\hline 890413.012 & 26.0 & 6.1 & 5.48 & 12.8 & 3.41 & 6.7 & 6.83 & 0.35 & 3.06 & 0 & 6.47 & 2.497 & 1.527 & 6.7 & 17 & 1.238 \\
\hline 890414.002 & 25.9 & 6.0 & 5.36 & 12.8 & 3.39 & 6.75 & 6.76 & 0.01 & 5.44 & 0 & 6.66 & 2.468 & 1.526 & 21.2 & 16.9 & 1.372 \\
\hline 890414.004 & 25.9 & 6.2 & 5.54 & 13.0 & 3.36 & 6.78 & 6.79 & 0 & 5.13 & 0 & 6.75 & 2.471 & 1.545 & 21.4 & 10.3 & 1.343 \\
\hline 890414.005 & 26.0 & 6.1 & 5.47 & 12.7 & 3.46 & 6.61 & 6.62 & 0.01 & 5.01 & 0 & 6.69 & 2.479 & 1.518 & 20.3 & 42.1 & 1.34 \\
\hline 890417.002 & 26.0 & 6.2 & 6.26 & 12.7 & 3.38 & 6.55 & 6.58 & 0.01 & 4.7 & 0 & 6.67 & 2.499 & 1.53 & 18.2 & 70.1 & 1.35 \\
\hline 890417.003 & 26.0 & 6.1 & 6.22 & 13.0 & 3.38 & 6.86 & 6.9 & -0.01 & 3.89 & 0 & 7.07 & 2.498 & 1.555 & 14.9 & 45.7 & 1.248 \\
\hline 890417.004 & 26.1 & 6.2 & 6.31 & 14.2 & 3.39 & 7.82 & 8.01 & 0.04 & 1.66 & 0 & 8.16 & 2.508 & 1.682 & 3.7 & 10.4 & 1.131 \\
\hline 890418.002 & 26.1 & 6.0 & 5.47 & 12.5 & 3.44 & 6.44 & 6.49 & 0.13 & 5.03 & 0 & 6.48 & 2.506 & 1.521 & 22.8 & 44.5 & 1.345 \\
\hline 890418.003 & 26.1 & 6.1 & 5.58 & 12.9 & 3.43 & 6.76 & 6.79 & 0.07 & 4.1 & 0 & 6.82 & 2.515 & 1.565 & 17.9 & 24.1 & 1.258 \\
\hline 8.004 & 26.1 & .1 & 5.55 & 13.5 & 3.39 & 7.31 & 7.39 & 0.04 & 2.5 & 0 & 7.42 & 2.518 & 1.611 & 9.3 & 9.3 & 1.155 \\
\hline 890418.005 & 26.2 & 6.3 & 5.78. & 12.5 & 3.41 & 6.26 & 6.27 & 0.1 & 5.21 & .01 & 6.13 & 2.52 & 1.524 & 20.5 & 19.5 & 1.358 \\
\hline 890418.006 & 26.2 & 6.3 & 5.82 & 12.9 & 3.39 & 6.56 & 6.58 & 0.07 & 4.02 & 0 & 6.54 & 2.529 & 1.564 & 14.4 & 5.3 & 1.265 \\
\hline 890418.007 & 26.2 & 6.3 & 5.77 & 13.7 & 3.38 & 7.33 & 7.43 & 0.01 & 1.67 & 0 & 7.52 & 2.524 & 1.648 & 3.9 & -6.4 & 1.129 \\
\hline 890425.003 & 26.2 & 5.9 & 5.57 & 12.3 & 3.46 & 6.48 & 6.51 & 0.04 & 4.79 & 0 & 6.44 & 2.52 & 1.513 & 15.4 & 51.4 & 1.357 \\
\hline .004 & 26.2 & 5.9 & 5.53 & 12.7 & 3.43 & 6.8 & 6.82 & 02 & 4.04 & 0 & 6.8 & 2.529 & 1.55 & 10.2 & 35.6 & 1.274 \\
\hline 890425.005 & 26.2 & 5.9 & 5.95 & 13.5 & 3.37 & 7.58 & 7.7 & 0 & 2.09 & 0 & 7.66 & 2.541 & 1.642 & 0.4 & 18.6 & 1.139 \\
\hline 890425.006 & 26.3 & .9 & 6.03 & 12.3 & 3.40 & 6.37 & 6.39 & 0.05 & 5.21 & 0 & 6.26 & 2.548 & 1.515 & 14.7 & 40.4 & 1.343 \\
\hline 890425.007 & 26.3 & 6.0 & 6.09 & 12.7 & 3.37 & 6.7 & 6.73 & 0.03 & 3.94 & 0 & 6.66 & 2.553 & 1.572 & 10 & 22.1 & 1.242 \\
\hline 890425.008 & 26.3 & 6.0 & 6.12 & 13.5 & 3.42 & 7.43 & 7.52 & 0.01 & 2.3 & 0 & 7.46 & 2.541 & 1.656 & 3.3 & 9.9 & 1.121 \\
\hline 890425.009 & 26.3 & .3 & 6.37 & 12.8 & 3.40 & 6.54 & 6.57 & 0.03 & 5.86 & 0.6 & 5.93 & 2.55 & 1.584 & 13 & 30.2 & 1.388 \\
\hline 890425.01 & 26.3 & 6.2 & 6.30 & 12.9 & 3.40 & 6.67 & 6.71 & 0.03 & 5.42 & 0.06 & 6.46 & 2.552 & 1.597 & 11 & 20.6 & 1.252 \\
\hline 890425.011 & 26.3 & 6.2 & 6.31 & 13.2 & 3.38 & 7.03 & 7.09 & 0.02 & 3.71 & 0.01 & 6.97 & 2.557 & 1.626 & 7 & 8.2 & 1.156 \\
\hline 890426.003 & 26.1 & 6.1 & 5.99 & 12.8 & 3.38 & 6.67 & 6.74 & 0.01 & 6.03 & 0.04 & 6.56 & 2.506 & 1.814 & 5.8 & 107 & 1.347 \\
\hline 890426.004 & 26.1 & 6.1 & 5.75 & 12.9 & 3.37 & 6.8 & 6.87 & 0 & 5.86 & 0 & 6.84 & 2.508 & 1.887 & 24.6 & 88.9 & 1.241 \\
\hline 890426.006 & 26.1 & 6.2 & 5.54 & 13.8 & 3.43 & 7.45 & 7.55 & -0.01 & 4.63 & 0 & 7.57 & 2.492 & 1.967 & 18.6 & 54.2 & 1.064 \\
\hline 890426.007 & 26.1 & 6.3 & 6.39 & 13.7 & 3.45 & 7.36 & 7.47 & -0.01 & 6.96 & 1.27 & 6.38 & 2.498 & 2.025 & 23.4 & 139.6 & 1.39 \\
\hline 890426.008 & 26.2 & 6.3 & 4.74 & 13.8 & 3.44 & 7.41 & 7.5 & 0 & 6.96 & 0.41 & 7.09 & 2.507 & 2.006 & 22.8 & 118.8 & 1.205 \\
\hline 890426.009 & 26.2 & 6.3 & - & 14.0 & 3.43 & 7.56 & 7.66 & -0.01 & 6.77 & 0 & 7.66 & 2.508 & 2.01 & 21.4 & 84.8 & 1.053 \\
\hline 890426.01 & 26.1 & 6.2 & 6.12 & 14.8 & 3.37 & 8.44 & 8.62 & -0.02 & 4.16 & 0 & 8.72 & 2.519 & 2.1 & 13.7 & 40.1 & 0.921 \\
\hline 890426.011 & 26.1 & 6.3 & 6.19 & 14.3 & 3.39 & 7.93 & 8.06 & -0.02 & 5.64 & 0 & 8.12 & 2.5 & 1.957 & 17.8 & 53.4 & 0.966 \\
\hline 890427.002 & 26.1 & 6.2 & 6.39 & 12.5 & 3.43 & 6.25 & 6.27 & 0.09 & 5.75 & 0.4 & 5.83 & 2.489 & 1.519 & 24.8 & 18.7 & 1.373 \\
\hline 890427.003 & 26.1 & 6.3 & 6.39 & 12.6 & 3.42 & 6.3 & 6.34 & 0.06 & 5.28 & 0.01 & 6.26 & 2.488 & 1.524 & 23.7 & 12.5 & 1.257 \\
\hline 890427.004 & 26.1 & 6.3 & 6.41 & 13.1 & 3.40 & 6.75 & 6.82 & 0.01 & 2.65 & 0 & 6.95 & 2.489 & 1.564 & 17.7 & 1.7 & 1.159 \\
\hline 890427.005 & 26.1 & 6.1 & 6.17 & 12.3 & 3.44 & 6.24 & 6.26 & 0.09 & 3.23 & 0 & 6.26 & 2.49 & 1.479 & 27.6 & 24.6 & 1.337 \\
\hline 890427.006 & 26.1 & 6.1 & 6.25 & 12.3 & 3.47 & 6.13 & 6.15 & 0.07 & 3.99 & 0 & 6.03 & 2.49 & 1.472 & 28.7 & 18.2 & 1.337 \\
\hline 890427.007 & 26.1 & 6.2 & 6.34 & 12.8 & 3.43 & 6.49 & 6.52 & 0.01 & 2.33 & 0 & 6.52 & 2.496 & 1.518 & 21.9 & 5.9 & 1.239 \\
\hline
\end{tabular}

S1de-by-S1de (o) Area, 1- $0.426 \mathrm{H,1-} 1.63 \mathrm{Hpk,1=0.91}$ Note: DTs1so, 1 obtalned from (Ts1-Tso)
Area, 2-0.146 H, $\angle=1.22 \mathrm{Hpk}, 2=0.91$
$890125.002 \quad 24.9$ $890125.004 \quad 24.9$ $890126.002 \quad 24.8$ $890126.003 \quad 24.8$ $890126.004 \quad 24.8$ 890126.00524 .9 . $890126.006 \quad 24.9$

$\begin{array}{rrrrrr}6.3 & 6.26 & 16.9 & 3.30 & 10.52 & 10.74 \\ 6.3 & 6.25 & 17.5 & 3.24 & 11.36 & 11.24 \\ 6.5 & 6.42 & 13.6 & 3.31 & 6.54 & 7.13 \\ 6.3 & 6.29 & 13.6 & 3.38 & 6.64 & 7.31 \\ 6.3 & 6.28 & 13.5 & 3.42 & 6.62 & 7.2 \\ 6.4 & 6.38 & 13.8 & 3.40 & 6.71 & 7.44 \\ 6.2 & 6.15 & 16.0 & 3.37 & 9.34 & 9.9\end{array}$

0.1 $\begin{array}{lll}0.6 & 5.15 & 0.67\end{array}$ $\begin{array}{lll}0.6 & 5.44 & 0.75\end{array}$ $0.7 \quad 5.76 \quad 1.34$ $0.5 \quad 4.74 \quad 0.59$ $\begin{array}{llll}0.6 & 8.55 & 2.11\end{array}$ 7.051 .68

$\begin{array}{lrr}0.1 & 9.41 & 1.68 \\ 0.0 & 7.05 & 1.5 \\ 0.6 & 5.15 & 0.67 \\ 0.6 & 5.44 & 0.75 \\ 0.7 & 5.76 & 1.34 \\ 0.5 & 4.74 & 0.59 \\ 0.6 & 8.55 & 2.11\end{array}$

$8.872 .511 \quad 1.946$ $10.2 \div 2.516 \quad 2.01$ $5.892 .473 \quad 1.542$ $\begin{array}{lll}6.02 & 2.458 \quad 1.55\end{array}$ $\begin{array}{lll}5.18 & 2.46 \quad 1.539\end{array}$ 6.352 .4691 .577 $7.22 \quad 2.4321 .815$
$39.6 \quad 62.6 \quad 0.64$ $\begin{array}{llll}42.7 & 11.8 & 0.479\end{array}$ $\begin{array}{llll}40.5 & 17.8 & 0.782\end{array}$ $\begin{array}{llll}39.5 & 17.3 & 0.784\end{array}$ $\begin{array}{llll}39.8 & 30.4 & 0.961\end{array}$ $\begin{array}{lll}27.8 & 0.7 & 0.72\end{array}$ $\begin{array}{lll}47.7 \quad 46 & 0.968\end{array}$ 
TP-3561

Table B-5. Data Summary for Direct-Contact Condenser Tests (Continued)

\begin{tabular}{|c|c|c|c|c|c|c|c|c|c|c|c|c|c|c|c|c|c|c|c|}
\hline$w w$ & 1 & 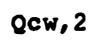 & & & & 10 & Jal & FI & Ja2 & F2 & 1 & G2 & LI & I 2 & Err & ror & lent & otal & otal \\
\hline (s) & nor & & $(\mathrm{mg} / \mathrm{s})$ & (z) & & & & (z) & & & & & & & Heat & NC & $D-1$ & Eff & $\boldsymbol{E}$ \\
\hline 75 & 25.53 & 10.84 & & 0.34 & 1.5 & 43 & .77 & 1.7 & 1.15 & 7.7 & 0.36 & 0.30 & 25.67 & 32.45 & 5 & -15 & .83 & 0.91 & 9.3 \\
\hline 65 & 32.27 & 10.22 & & 0.34 & 2.2 & 47 & 0.87 & 30.0 & .40 & 7.2 & 0.41 & 0.24 & 32.45 & 30.59 & 2 & -15 & .97 & 0.86 & 9.4 \\
\hline 51 & 32.24 & 10.22 & & 0.34 & 2.1 & 46 & .85 & 3.7 & .28 & 7.3 & .41 & .26 & 32.42 & 30.59 & 3 & -15 & .96 & 0.89 & 9.4 \\
\hline 37 & 36.55 & 8.14 & & 0.32 & 3.2 & 46 & 0.93 & 36.8 & 1.51 & 95.9 & .43 & 0.17 & 36.76 & 24.37 & 7 & -16 & 94 & 0.88 & 99.5 \\
\hline 34 & 36.56 & 8.15 & & 0.32 & 2.8 & 46 & .90 & 4.8 & .28 & 6.3 & .44 & .20 & 36.77 & 24.40 & 7 & -16 & .87 & 0.90 & 9.4 \\
\hline 25 & 36.53 & 8.14 & & 0.32 & 4.5 & 49 & 0.97 & 90.4 & 2.13 & 4.9 & .44 & .12 & 36.74 & 24.37 & 8 & -15 & .92 & 0.84 & 9.5 \\
\hline 22 & 36.28 & 8.27 & & 0.32 & 2.7 & 47 & 0.89 & 84.1 & 1.25 & 96.7 & .47 & 0.22 & 36.48 & 24.76 & 7 & -16 & .88 & 0.91 & 9.5 \\
\hline 9 & 36.24 & 8.27 & & 0.33 & .8 & 47 & 0.89 & 84.9 & 1.35 & 96.6 & 0.47 & 0.21 & 36.44 & 24.75 & 7 & -17 & .89 & 0.91 & 9.5 \\
\hline 65 & 31.99 & 11.67 & & 0.32 & 1.9 & 45 & 0.82 & 78.1 & 1.38 & 97.4 & 0.44 & 0.28 & 32.17 & 34.93 & 7 & -16 & .84 & 0.89 & 99.4 \\
\hline 52 & 32.36 & 11.67 & & 0.32 & .0 & 45 & 0.84 & 79.1 & 1.46 & 97.3 & 43 & 0.27 & 32.54 & 34.93 & 7 & -14 & .82 & 0.87 & 9.4 \\
\hline 45 & 32.36 & 11.67 & & 0.32 & .4 & 48 & .87 & 82.7 & .87 & 7.1 & .43 & 0.22 & 32.54 & 34.93 & 7 & -15 & .87 & 0.84 & 9.5 \\
\hline 81 & 32.36 & 11.67 & & 0.31 & 5.8 & 54 & 0.99 & 92.7 & 5.01 & 94.4 & 0.44 & 0.10 & 32.54 & 34.93 & 8 & -12 & .95 & 0.74 & 99.6 \\
\hline & 34.77 & 9.84 & & 0.31 & 2.3 & 46 & 0.86 & 81.5 & 1.32 & 97.0 & 0.44 & 0.24 & 34.97 & 29.46 & 8 & -14 & .85 & 0.90 & 99.4 \\
\hline 37 & 34.77 & 9.84 & & 0.31 & 2.8 & 48 & 0.89 & 85.0 & 1.70 & 96.7 & 0.45 & 0.20 & 34.97 & 29.46 & 9 & -14 & .89 & 0.87 & 9.5 \\
\hline 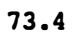 & 34.73 & 9.82 & & 0.30 & 4 & 52 & 0.96 & 90.9 & 3.00 & 95.4 & 0.45 & 0.12 & 34.93 & 29.40 & 11 & -15 & 0.93 & 0.81 & 99.6 \\
\hline 32 & 36.59 & 8.04 & & 0.31 & 2.0 & 45 & .89 & 84.1 & 1.20 & 96.4 & .44 & 0.21 & 36.80 & 24.07 & 8 & -16 & .88 & 0.92 & 9.4 \\
\hline 32 & 36.51 & 8.02 & & 0.31 & 3.4 & 47 & 0.92 & 87.8 & 1.65 & 95.9 & 0.44 & 0.16 & 36.71 & 24.01 & 9 & -16 & 0.92 & 0.88 & 9.5 \\
\hline 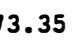 & 36.49 & 8.03 & & 0.30 & - & 52 & .00 & 95.0 & 4.43 & 92.0 & 0.45 & 0.07 & 36.69 & 24.04 & 12 & -16 & .96 & 0.81 & 9.6 \\
\hline 62 & 34.98 & 10.88 & 50 & 0.28 & 2.1 & 46 & 0.85 & 80.9 & 1.37 & 97.2 & 0.45 & 0.26 & 35.18 & 32.57 & 10 & -7 & 0.84 & 0.89 & 99.5 \\
\hline 0 & 35.07 & 10.91 & & 0.28 & .5 & 48 & 0.88 & 84.0 & 1.70 & 97.0 & & 0.22 & 35.27 & 32.66 & 12 & -8 & 0.88 & 0.86 & 99.5 \\
\hline 27 & 35.28 & 10.98 & & 0.27 & 4.0 & 53 & 0.97 & 91.8 & 3.64 & 95.3 & 0.47 & 0.12 & 35.48 & 32.87 & 15 & -9 & .93 & 0.79 & 99.6 \\
\hline 34 & 35.04 & 8.97 & & 0.29 & 2.3 & 45 & 0.86 & 82.2 & 1.22 & 96.9 & 0.44 & 0.23 & 35.24 & 26.85 & 8 & -9 & 0.86 & 0.92 & 99.4 \\
\hline & 35.2 & 9.02 & & 0.29 & 0 & 48 & 0.91 & 86.5 & 1.70 & 96.4 & & 0.18 & 35.40 & 27.00 & 9 & -10 & 0.91 & 0.87 & 99.5 \\
\hline 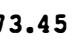 & 35.19 & 9.02 & & 0.28 & 5.0 & 52 & 97 & 92.3 & 3.20 & 94.8 & 0.46 & 0.11 & 35.39 & 27.00 & 11 & -11 & 0.94 & 0.82 & 99.6 \\
\hline 36 & 35.02 & 7.01 & & 0.29 & 2.7 & 43 & 0.88 & 84.3 & 1.12 & 96.2 & 0.44 & 0.21 & 35.22 & 20.98 & 8 & -8 & 0.83 & 0.94 & 99.4 \\
\hline & 35.03 & 7.01 & & 0.29 & & 46 & . 90 & 85.6 & 1.21 & 96.5 & 0.44 & 0.19 & 35.23 & 20.98 & 8 & -10 & .89 & 0.92 & 99.5 \\
\hline 39 & 35.02 & 7.01 & & 0.29 & 4.0 & 49 & 0.95 & 90.1 & 1.87 & 95.5 & & 0.13 & 35.22 & 20.98 & 9 & -11 & 0.92 & 0.88 & 99.6 \\
\hline & 29.8 & 11 & & 0.30 & 1.6 & 44 & 0.79 & 74.5 & 1.13 & 97.7 & 0.43 & 0.32 & 29.97 & 32.93 & 7 & -8 & 0.81 & 0.91 & 99.4 \\
\hline 2 & 29.81 & 11 & & 0.30 & 1.6 & 46 & 0.80 & 75.4 & 1.20 & 97.9 & 0.43 & 0.31 & 29.98 & 32.93 & 8 & -11 & .85 & 0.90 & 99.5 \\
\hline & 29.56 & 10.89 & & 0.29 & 2.0 & 51 & 0.86 & 81.1 & 1.68 & 97.9 & 0.44 & 0.25 & 29.73 & 32.60 & 8 & -14 & .89 & 0.84 & 99.6 \\
\hline & 25.22 & 10.97 & & 0.30 & 1.3 & 41 & 0.75 & 70.3 & 1.12 & 97.9 & 0.42 & 0.37 & 25.36 & 32.83 & 4 & -10 & 0.76 & 0.92 & 99.4 \\
\hline 1 & 25.19 & 10.95 & & 0.30 & 1.3 & 46 & 0.75 & 70.6 & 1.11 & 98.3 & 0.42 & 0.37 & 25.33 & 32.78 & 5 & -10 & 0.79 & 0.92 & 99.5 \\
\hline & 25.15 & 10.92 & & 0.30 & 1.3 & 50 & 0.76 & 71.6 & 1.17 & 98.5 & 0.43 & 0.36 & 25.29 & 32.69 & 6 & -14 & 0.81 & 0.91 & 99.6 \\
\hline & 25.13 & 10.9 & & 0.31 & 2.1 & 56 & 0.88 & 82.2 & 2.15 & 98.1 & 0.41 & 0.22 & 25.27 & 32.63 & 5 & -15 & 0.93 & 0.79 & 99.7 \\
\hline & 25.29 & 10.99 & & 0.30 & 1.5 & 53 & 0.81 & 76.1 & 1.48 & 98.5 & 0.42 & 0.30 & 25.43 & 32.89 & 6 & -16 & 0.90 & 0.86 & 99.6 \\
\hline & 40.07 & 5.02 & & 0.28 & 3.9 & 44 & 0.94 & 89.2 & 1.08 & 94.8 & 0.45 & 0.15 & 40.29 & 15.03 & 11 & -9 & 0.85 & 0.94 & 99.4 \\
\hline . & 40.09 & 5.02 & & 0.28 & 4.0 & 46 & 0.95 & 90.0 & 1.19 & 95.0 & 0.45 & 0.13 & 40.31 & 15.03 & 11 & -13 & 0.89 & 0.93 & 99.5 \\
\hline & 40.01 & 5.01 & & 0.28 & 7.7 & 50 & 1.00 & 94.9 & 2.53 & 91.5 & 0.46 & 0.07 & 40.23 & 15.00 & 13 & -13 & 0.94 & 0.88 & 99.6 \\
\hline & 40.01 & 10.01 & & 0.28 & 3.3 & 45 & 0.93 & 88.1 & 1.95 & 95.5 & 0.46 & 0.16 & 40.24 & 29.97 & 11 & -13 & 0.87 & 0.86 & 99.5 \\
\hline & 39.99 & 7.96 & & 0.29 & 3.3 & 44 & 0.93 & 88.1 & 1.52 & 95.4 & 0.45 & 0.16 & 40.22 & 23.83 & 9 & -14 & 0.86 & 0.89 & 99.4 \\
\hline & & & & 0.28 & 5.6 & $47 \quad-$ & 98 & 92.9 & 2.75 & 93.1 & 0.45 & 0.09 & 40.25 & 3.74 & 10 & -14 & .91 & 0.85 & 99.5 \\
\hline
\end{tabular}

Motorized nozzle

$\begin{array}{lll}31.47 & 7.02 & 3.39\end{array}$ $\begin{array}{lll}31.37 & 7.01 & 3.39\end{array}$ $\begin{array}{llll}30.84 & 13.37 \quad 3.41\end{array}$ $30.76 \quad 13.35 \quad 3.43$ $30.75 \quad 13.40 \quad 3.46$ $30.63 \quad 13.38 \quad 3.46$ $44.92 \quad 13.30 \cdot 3.4$ $\begin{array}{lllllllllll}0.33 & 1.9 & 53 & 0.73 & 69.5 & 1.13 & 98.1 & 0.41 & 0.37 & 16.91 & 23.83 \\ 0.34 & 2.2 & 60 & 0.78 & 76.7 & 1.69 & 98.4 & 0.40 & 0.27 & 16.89 & 23.83 \\ 0.33 & 3.2 & 41 & 0.95 & 82.5 & 1.27 & 95.2 & 0.41 & 0.21 & 32.22 & 23.98 \\ 0.32 & 3.0 & 42 & 0.95 & 81.8 & 1.25 & 95.5 & 0.42 & 0.22 & 32.17 & 24.12 \\ 0.32 & 2.9 & 35 & 0.92 & 80.7 & 1.12 & 94.4 & 0.42 & 0.24 & 32.29 & 24.33 \\ 0.32 & 3.4 & 45 & 0.98 & 83.9 & 1.47 & 95.5 & 0.41 & 0.19 & 32.25 & 24.33 \\ 0.32 & 2.8 & 45 & 0.88 & 80.4 & 1.09 & 96.5 & 0.60 & 0.34 & 32.05 & 23.90\end{array}$ $\begin{array}{lllll}3 & 33 & 0.77 & 0.92 & 99.4\end{array}$ $\begin{array}{lllll}3 & 15 & 0.90 & 0.86 & 99.6\end{array}$ $\begin{array}{lllll}3 & 9 & 0.83 & 0.83 & 99.2\end{array}$ $\begin{array}{lllll}3 & 11 & 0.84 & 0.83 & 99.2\end{array}$ $\begin{array}{lllll}3 & 14 & 0.72 & 0.85 & 98.9\end{array}$ $\begin{array}{llllll}2 & 10 & 0.91 & 0.81 & 99.3\end{array}$ $\begin{array}{llllll}2 & 22 & 0.73 & 0.89 & 99.3\end{array}$ 


\section{Table B-5. Data Summary for Direct-Contact Condenser Tests (Continued)}

\begin{tabular}{|c|c|c|c|c|c|c|c|c|c|c|c|c|c|c|c|c|}
\hline \multirow[t]{2}{*}{ Identifler } & \multirow{2}{*}{$\begin{array}{l}\text { Tww1 } \\
\text { (c) }\end{array}$} & \multirow[t]{2}{*}{ Tcw1, 1} & \multirow[t]{2}{*}{$c w 1,2$} & \multirow[t]{2}{*}{ Ts1, 1} & \multirow[t]{2}{*}{ DTww } & \multirow{2}{*}{$\begin{array}{r}\text { DTCW } \\
1\end{array}$} & \multicolumn{2}{|c|}{ DTs1w1DTs1so } & \multirow{2}{*}{$\begin{array}{r}\text { DTCw } \\
2\end{array}$} & \multicolumn{2}{|c|}{ DTsow1DTsiso } & \multirow{2}{*}{$\begin{array}{l}\text { Pevap } \\
\text { (kPa) }\end{array}$} & \multirow{2}{*}{$P 1,1$} & \multirow{2}{*}{$\begin{array}{l}\text { DP1 } \\
\text { (Pa) }\end{array}$} & \multirow[t]{2}{*}{ DP2 } & \multirow[t]{2}{*}{ Pexh } \\
\hline & & & & & & & 1 & 1 & & 2 & 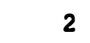 & & & & & \\
\hline & & & & & 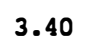 & & & & & & 84 & & 1.826 & & .1 & \\
\hline 0126.009 & 5.0 & & & 4.6 & .43 & .9 & & & & & .25 & 2.461 & 1.658 & 6.2 & 0.2 & 168 \\
\hline 890126.01 & 5.0 & .1 & .11 & 4.9 & .41 & .14 & .67 & & .81 & 0.9 & .71 & 2.466 & 1.689 & 8.6 & 63.4 & 0.977 \\
\hline 26.011 & . & & & . & . & .95 & & & & & 03 & & .75 & & 23.2 & 0.837 \\
\hline 26.012 & 5.0 & 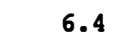 & 39 & 5.1 & .36 & .69 & .44 & .5 & .34 & 0.6 & .58 & 2.472 & 1.712 & 3.1 & 44.6 & 0.901 \\
\hline 0127.003 & 4.8 & .1 & 09 & 6.3 & .31 & 9.4 & .1 & & .19 & & 8.4 & 407 & 1.821 & 9.5 & 192.5 & 0.959 \\
\hline 27.004 & 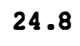 & & & & .37 & .64 & & & & & & & 1.862 & 6.7 & 45.7 & 0.875 \\
\hline 27.006 & 4.9 & .1 & & 6.7 & .31 & 9.68 & 10.42 & .0 & .61 & .68 & .75 & 415 & 1.873 & 7.4 & 99.7 & 0.784 \\
\hline 27.007 & 4.9 & & & 7.1 & .35 & 10.04 & 32 & 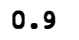 & .07 & & 9.6 & & 1.921 & 5.9 & 7.2 & 0.689 \\
\hline .009 & 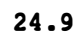 & & & & .41 & .14 & & & & & & & & 4.8 & & 0.708 \\
\hline 30.002 & 4.9 & .0 & & 1.3 & .38 & 7.61 & 8.05 & 4 & 97 & 78 & 89 & 2.467 & 1.597 & 5.2 & 38 & 0.691 \\
\hline 30.003 & 4.9 & & & 6 & .41 & 7.9 & & & & & 59 & & & 5.4 & 7.6 & 0.596 \\
\hline .004 & 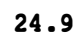 & & & & .42 & & & & & & & & & & & \\
\hline .005 & 4.9 & & & .4 & 38 & .69 & & .6 & 51 & 22 & 42 & 77 & 1.613 & 37 & 15.4 & 0.643 \\
\hline 006 & . & & & & 38 & & & & & & & & 1.625 & & & \\
\hline .007 & 4.9 & 0 & 6 & 3.9 & .46 & 7.46 & 95 & .5 & 5.44 & .57 & 5.9 & 2.466 & 1.575 & 8.4 & 55.5 & 0.841 \\
\hline 890130.01 & 40 & & & & .40 & 6.43 & & & & & & & & & 2.5 & 318 \\
\hline .011 & 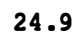 & & & & . 34 & 6.33 & & & & & .03 & & 1.52 & 36 & .2 & 63 \\
\hline .012 & 4.9 & 6.2 & 14 & .9 & .44. & 6.31 & .76 & 7 & .78 & .53 & .58 & 2.47 & 1.485 & 5.1 & 7.1 & 0.893 \\
\hline & 10 & & & & & .26 & & & & & & & & & .9 & 0.993 \\
\hline . 014 & 4.9 & & & & .38 & 6.07 & & & & & .01 & & 1.476 & 0.1 & 63.1 & 1.073 \\
\hline .015 & 4.9 & 3 & 9 & .9 & .38 & 6.12 & 53 & 8 & 32 & 0.5 & .31 & & 1.48 & 8.8 & 50.2 & 0.99 \\
\hline & 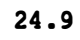 & & & & .37 & .27 & & & & & & & 1.49 & & .5 & 0.876 \\
\hline & & & & & & & & & & & .03 & & & & & \\
\hline & 4.9 & 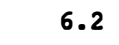 & & & .34 & .37 & 3 & 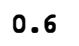 & & 6 & 6.2 & 86 & 1.513 & 5.1 & 6.5 & 0.772 \\
\hline 9 & 4.9 & & & & 38 & & & & & & 4.3 & & & 8.4 & 17.2 & 1.081 \\
\hline .02 & 4.9 & 0 & 23 & .2 & .38 & .37 & 94 & 6 & 95 & 1.44 & .95 & & 1.506 & 7.7 & 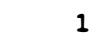 & 0.77 \\
\hline 021 & 4.9 & & & & 3.37 & 6.38 & & & & & .87 & & 1.528 & 6.8 & -9.9 & 0.671 \\
\hline .022 & 4.9 & & & & .36 & & & & & 1 & .03 & & 1.541 & 6.4 & -13.4 & 0.655 \\
\hline & 4.9 & & & .8 & .35 & 54 & & $=$ & 66 & 1 & .63 & 2.492 & 1.563 & 19.3 & -31.2 & 0.583 \\
\hline & 4.9 & & & & & & & & & & .72 & & 1.546 & .2 & 3.3 & 0.575 \\
\hline .002 & 4.9 & 6 & & 5 & .69 & .52 & & 0 & 18 & 0.89 & .75 & 2.444 & 1.643 & 42 & 30.8 & 0.694 \\
\hline 31.003 & 4.5 & & & .4 & .70 & 46 & & & 31 & 1.75 & .83 & 43 & 1.639 & .7 & 46.4 & 0.788 \\
\hline & & & & & & & & & & & & & 1.689 & & -2.7 & 0.592 \\
\hline & 24.9 & & .47 & 14.5 & 3.68 & 7.56 & & 0.4 & 5.64 & 0.39 & 7.21 & 2.448 & 1.645 & 37.1 & 11.1 & 0.654 \\
\hline .006 & 5 & 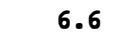 & 63 & 6.4 & 3.32 & 04 & & & .64 & 1.96 & 7.26 & 2.465 & 1.846 & 7.4 & 31.1 & 0.788 \\
\hline & . & 0. & & .6 .4 & 3.31 & 9.13 & & & & 0.8 & 8.94 & 2.467 & 1.858 & 40.8 & -4.3 & 0.608 \\
\hline 90131.008 & 5.1 & 6.5 & .50 & 6.8 & .27 & 9.24 & 0.29 & 0.0 & 5.49 & .46 & 8.88 & 2.477 & 1.397 & 9.7 & 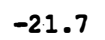 & 0.545 \\
\hline
\end{tabular}

$890225.007 \quad 24.9$ $890225.008 \quad 25.0$ $890225.009 \quad 25.0$ $890225.011 \quad 25.0$ $890225.012 \quad 25.0$ 890225.01325 .0 890225.01425 .0 $890225.015 \quad 25.0$ $890225.016 \quad 25.0$ $890227.002 \quad 24.9$ $\begin{array}{llllllll}6.1 & 6.08 & 12.6 & 3.37 & 5.57 & 6.69 & 0.74\end{array}$

$\begin{array}{lllllll}6.1 & 6.05 & 12.3 & 3.41 & 5.6 & 6.31 & 0.56\end{array}$

$\begin{array}{lllllll}6.0 & 6.01 & 12.6 & 3.40 & 5.55 & 6.63^{\circ} & 0.76\end{array}$

$\begin{array}{lllllll}6.2 & 6.26 & 12.2 & 3.57 & 5.78 & 6.03 & 0.31\end{array}$

$\begin{array}{lllllll}6.2 & 6.23 & 12.2 & 3.57 & 5.8 & 6.1 & 0.31\end{array}$

$\begin{array}{lllllll}6.2 & 6.20 & 12.3 & 3.55 & 5.88 & 6.2 & 0.32\end{array}$

$\begin{array}{lllllll}6.2 & 6.20 & 12.5 & 3.54 & 6 & 6.39 & 0.36\end{array}$

$\begin{array}{lllllll}6.2 & 6.26 & 13.3 & 3.44 & 6.33 & 7.14 & 0.56\end{array}$

$\begin{array}{llllllll}6.4 & 6.39 & 13.2 & 3.52 & 6.26 & 6.88 & 0.44\end{array}$

$\begin{array}{lllllll}6.5 & 6.52 & 13.0 & 3.35 & 5.89 & 6.55 & 0.35\end{array}$
Area, 2 $=0.146$

$3.84 \quad 1.23$

4.121 .45

$3.8 \quad 1.59$

$4.94 \quad 2.52$

$4.88 \quad 2.29$

$4.73 \quad 1.58$

$4.27 \quad 0.65$

$\begin{array}{lll}2.71 & 0.13\end{array}$

$2.97 \quad 0.09$

$5.43 \quad 2.28$
$H, 2=0.92$ figk, $2=0.61$

$\begin{array}{llllll}4.61 & 2.512 & 1.496 & 46.6 & 31.6 & 1.204\end{array}$ $\begin{array}{llllll}4.32 & 2.515 & 1.471 & 48.7 & 39.8 & 1.256\end{array}$ $\begin{array}{llllll}4.32 & 2.525 & 1.505 & 44 & 37.2 & 1.354\end{array}$ $\begin{array}{llllll}3.13 & 2.525 & 1.46 & 28.8 & 27.6 & 1.274\end{array}$ $\begin{array}{llllll}3.4 & 2.529 & 1.462 & 27.9 & 24.7 & 1.173\end{array}$ $\begin{array}{llllll}4.24 & 2.536 & 1.468 & 26.8 & 17.5 & 0.959\end{array}$ $\begin{array}{lllllll}5.37 & 2.528 & 1.483 & 24.4 & 8.1 & 0.787\end{array}$ $\begin{array}{llllll}6.46 & 2.54 & 1.565 & 16.5 & -0.7 & 0.678\end{array}$ $\begin{array}{llllll}6.38 & 2.524 & 1.549 & 3.9 & 20.2 & 0.643\end{array}$ $\begin{array}{llllll}3.85 & 2.491 & 1.521 & 30.1 & -7.9 & 1.049\end{array}$ 


\section{Table B-5. Data Summary for Direct-Contact Condenser Tests (Continued)}

\begin{tabular}{|c|c|c|c|c|c|c|c|c|c|c|c|c|c|c|c|c|c|c|c|}
\hline & & & & & & & & & & & & & 1 & 2 & & & ent & tal: & bta. \\
\hline (s) & corr & & $(\mathrm{mg} / \mathrm{s})$ & (z) & & & & 8 & & & & & 2s) & & Heat & NC & Rat10 & Eff & $\boldsymbol{E}$ \\
\hline & 13.30 & 3.39 & & 0.32 & 10 & 49 & 89 & 0.5 & $: 11$ & 6.7 & $\therefore 9$ & .34 & 32.05 & 20.00 & 1 & 30 & 0.79 & 0.89 & 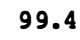 \\
\hline .64 & 15.58 & 6.62 & & 0.31 & .1 & 36 & .86 & 7.5 & 1.42 & 5.9 & . ن & .40 & 37.55 & 46.55 & 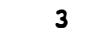 & 5 & 0.64 & 0.80 & 9.1 \\
\hline .67 & 15.39 & 6.65 & & 0.31 & 2.2 & 42 & .88 & 9.1 & 1.60 & 6.6 & .61 & .37 & 37.09 & 46.76 & 4 & 4 & .75 & .79 & 9.3 \\
\hline .46 & 15.69 & 6.76 & & 0.34 & .5 & 46 & .01 & 6.4 & .89 & 5.4 & .56 & .22 & 37.81 & 47.54 & -3 & -2 & .81 & .69 & 9.4 \\
\hline .51 & 15.33 & 6.75 & & 0.33 & 2.2 & 42 & 0.91 & 9.5 & 1.68 & 6.6 & .57 & .34 & 36.94 & 47.46 & -1 & -5 & 0.75 & 0.76 & 9.3 \\
\hline 45.7 & 11.69 & 5.95 & & 0.33 & .9 & 47 & .80 & 1.5 & 1.28 & 7.6 & .59 & .49 & 28.17 & 41.83 & 4 & 22 & .67 & .83 & 9.3 \\
\hline 5.72 & 11.64 & 6.01 & & 0.32 & .8 & 50 & 0.80 & 1.8 & .32 & 8.0 & .60 & .50 & 28.05 & 42.26 & 3 & 19 & .72 & 0.82 & 9.4 \\
\hline .71 & 11.63 & 6 & & 0.33 & .9 & 52 & 0.82 & 3.6 & 1.45 & 8.1 & 59 & .46 & 28.02 & 42.19 & 3 & 12 & 0.78 & 0.80 & 9.5 \\
\hline .78 & 11.62 & 6 & & 0.33 & .0 & 57 & .85 & 5.9 & .67 & .3 & 59 & 42 & .00 & 19 & 2 & 8 & .86 & .78 & 9.6 \\
\hline .79 & 11.64 & 6.01 & & 0.32 & .9 & 56 & .83 & 5.2 & 1.57 & 3.4 & .61 & .44 & 28.05 & 42.26 & 3 & 9 & .86 & 0.79 & 9.6 \\
\hline .26 & 9.96 & 4.5 & 4 & 0.33 & L. 9 & 44 & 0.81 & 73.3 & 1.31 & 7.3 & .40 & .31 & 24.00 & 31.64 & - & 9 & .79 & 0.84 & 9.3 \\
\hline .58 & 9.94 & 4.49 & & 0.34 & 7 & 49 & 0. & 80.5 & 1.98 & .9 & 38 & 21 & 96 & 57 & 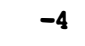 & 6 & .88 & .76 & 9.4 \\
\hline .97 & 9.96 & 4.49 & & 0.33 & 2.0 & 45 & 0.81 & 72.9 & 1.27 & 7.3 & .40 & .31 & 24.00 & 31.57 & 0 & 12 & 0.82 & 0.84 & 9.3 \\
\hline 0.27 & 9.95 & 4.47 & & 0.33 & .1 & 47 & 0.83 & .8 & . 39 & $.4^{\circ}$ & 39 & 29 & 98 & 31.43 & -0 & 10 & .88 & .83 & 99.3 \\
\hline .12 & 9.98 & .47 & & 0.34 & .3 & 48 & .86 & 7.5 & .61 & .2 & .39 & .25 & .05 & 31.43 & -2 & 8 & .89 & 0.80 & 99.4 \\
\hline 9.76 & 9.98 & 4.47 & & 0.32 & .8 & 37 & 0.79 & 71.4 & 1.17 & 96.6 & .40 & .34 & 24.05 & 31.43 & 1 & 12 & 0.71 & 0.86 & 9.0 \\
\hline .96 & 13.36 & 4.85 & & 0.32 & .8 & 40 & 0.89 & 9.6 & .46 & 5.7 & .42 & .25 & 20 & 11 & 2 & 6 & .87 & .82 & 9.1 \\
\hline 0.88 & 13.35 & 4.86 & & 0.34 & 3.1 & 42 & 0.95 & 82,4 & .84 & 5.2 & 39 & .20 & 32.18 & 34.18 & -1 & 5 & .90 & 0.76 & 99.2 \\
\hline .84 & 13.36 & 4.84 & & 0.32 & .4 & 37 & $: 88$ & 77.7 & 9 & 5.5 & 42 & 27 & 20 & & 1 & 7 & .81 & 0.83 & 9.0 \\
\hline 0.81 & 13.35 & 4.84 & & 0.32 & 2 & 33 & .87 & 6.9 & .23 & 1.9 & 42 & 28 & .18 & 04 & 1 & 4 & .73 & .84 & 8.8 \\
\hline 0.73 & 13.26 & 5.7 & & 32 & .0 & 30. & .85 & 15.1 & .30 & 4.7 & .41 & .30 & 31.96 & 40.09 & 2 & 2 & .70 & 0.81 & 98.7 \\
\hline .74 & 13.26 & 5.7 & & 32 & 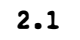 & 33 & .85 & .8 & & & & 29 & 96 & & & 4 & & 81 & 8.8 \\
\hline .74 & 13.26 & 5.69 & & 0.32 & t. & 38 & 0.88 & 78.1 & 55 & 5.5 & .41 & .26 & 31.96 & 40.02 & 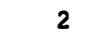 & 6 & .83 & .79 & 9.0 \\
\hline 0.74 & 13.26 & 5.69 & & 0.33 &. .9 & 40 & .92 & 1.3 & 94 & 5.1 & .40 & .22 & 31.96 & 40.02 & -1 & 5 & .87 & 0.75 & 9.1 \\
\hline 0.71 & 13.27 & 5.69 & & 0.35 & 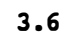 & 42 & 0.98 & 84.6 & .51 & & 38 & 17 & 99 & & -3 & 4 & .90 & .71 & 9.1 \\
\hline 0.68 & 13.22 & 3.41 & & 0.33 & 2.6 & 29 & 0.91 & 79.9 & .05 & 3.1 & .41 & .24 & 31.86 & 23.98 & 1 & 3 & .65 & 0.86 & 8.6 \\
\hline 0.59 & 13.21 & 3.41 & & 0.33 & 2.1 & 34 & 0.91 & 79.8 & .08 & .5 & 41 & .24 & 31.84 & 98 & 1 & -14 & .74 & 0.86 & 9.1 \\
\hline 30.62 & 13.21 & 3.41 & & 0.33 & . & 40 & 0.92 & 80.4 & .13 & 6.3 & .40 & .23 & 31.84 & 23.98 & 1 & -10 & .87 & .85 & 9.3 \\
\hline 0.59 & 13.21 & 3.4 & & 0.33 & 2.4 & 42 & 0.93 & 80.7 & .15 & 6.4 & .40 & .23 & 31.84 & 23.91 & 1 & -9 & .89 & 0.85 & 9.3 \\
\hline 0.56 & 13.22 & 3.4 & & 0.35 & • & 40 & .03 & & .91 & & 38. & .15 & 31.86 & 23.91 & -3 & -9 & . 96 & 0.77 & 9.4 \\
\hline 0.59 & 13.22 & 3.38 & & 0.34 & 3.7 & 47 & 1.04 & 87.2 & .95 & 5.4 & .38 & .14 & 31.86 & 23.77 & -3 & -9 & .95 & 0.76 & 9.4 \\
\hline 8.15 & 10.11 & 4.58 & & 0.30 & 1.8 & 44 & 0.80 & 72.3 & 1.26 & 97.4 & .41 & .33 & 24.36 & 32.20 & 2 & 13 & 0.82 & 0.86 & 99.3 \\
\hline 8.18 & 10.07 & 4.61 & & 0.30 & 1.1 & 38 & 0.79 & 71.4 & 1.21 & 96.9 & 0.41 & 0.34 & 24.27 & 32.41 & 1 & 11 & 0.72 & 0.86 & 99.1 \\
\hline 28.23 & 10.09 & 4.57 & & 0.31 & 2.4 & 50 & 0.87 & 78.8 & 1.78 & 97.3 & 0.39 & 0.24 & 24.32 & 32.13 & -0 & 11 & 0.93 & 0.79 & 99.4 \\
\hline 28.29 & 10.31 & 4.65 & & 0.30 & 2.0 & 47 & 0.82 & 74.3 & 1.37 & 97.5 & .40 & .30 & 24.85 & 32.70 & 1 & 13 & 0.88 & 0.83 & 99.3 \\
\hline 45.8 & 13.37 & 3.42 & & 0.33 & 2.2 & 46 & 0.89 & 79.9 & 1.07 & & 0.59 & 0.34 & 32.21 & 24.04 & 0 & -2 & 0.74 & 0.89 & 99.4 \\
\hline 15.89 & 13.37 & 3.42 & & 0.33 & 2.3 & 55 & 0.92 & 81.4 & 1.24 & 98.0 & 0.58 & 0.32 & 32.21 & 24.04 & -0 & -8 & 0.92 & 0.87 & 99.6 \\
\hline 45.8 & 13.37 & 3.41 & & 0.35 & 3.0 & 57 & 1.00 & 86.6 & 1.90 & 97.6 & 0.55 & 0.22 & 32.22 & 23.97 & -4 & -15 & 0.94 & 0.80 & 99.7 \\
\hline
\end{tabular}

Motorized nozzle

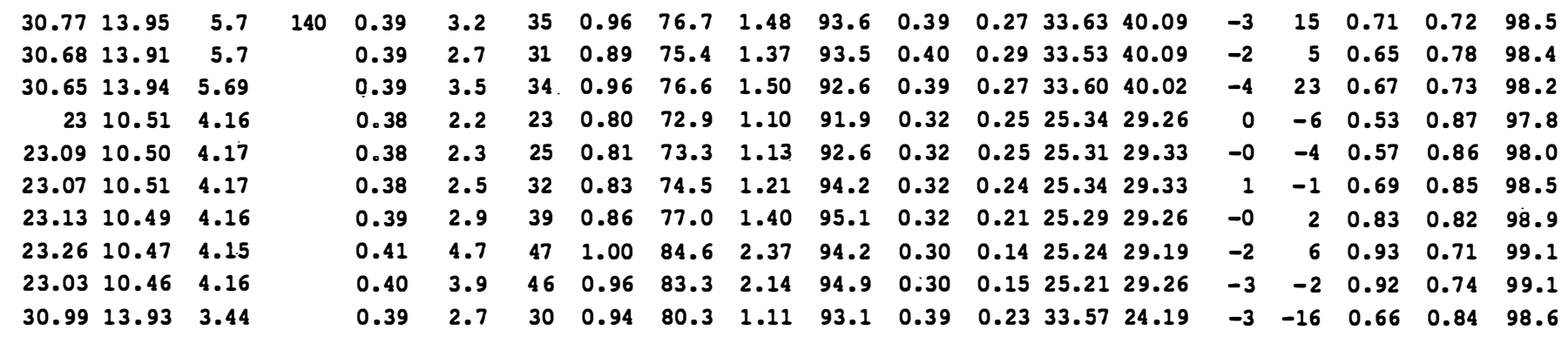




\section{Table B-5. Data Summary for Direct-Contact Condenser Tests (Continued)}

\begin{tabular}{|c|c|c|c|c|c|c|c|c|c|c|c|c|c|c|c|c|}
\hline \multirow[t]{2}{*}{ Identifier } & \multicolumn{2}{|c|}{ Tww1 Tcw1,1 } & \multirow[t]{2}{*}{ Tcw1, 2} & \multirow[t]{2}{*}{ Ts1, 1} & \multirow[t]{2}{*}{ DTwW } & \multirow{2}{*}{$\begin{array}{r}\text { DTCW } \\
1\end{array}$} & \multicolumn{2}{|c|}{ DTs1w1DTs1so } & \multicolumn{3}{|c|}{ DTcw DTsow1DTs1so } & \multirow{2}{*}{$\begin{array}{l}\text { Pevap } \\
\text { (kPa) }\end{array}$} & \multirow[t]{2}{*}{$P 1,1$} & \multirow{2}{*}{$\begin{array}{l}\text { DP1 } \\
(\mathrm{Pa})\end{array}$} & \multirow[t]{2}{*}{ DP2 } & \multirow[t]{2}{*}{ Pexh } \\
\hline & (c) & & & & & & 1 & 1 & 2 & 2 & 2 & & & & & \\
\hline 890227.003 & 24.9 & 6.5 & 6.56 & 12.9 & 3.36 & 5.84 & 6.41 & 0.34 & 5.16 & 2.01 & 4.01 & 2.488 & 1.512 & 31.4 & 2.6 & 1.053 \\
\hline 890227.004 & 24.9 & 6.5 & 6.49 & 12.7 & 3.38 & 5.77 & 6.28 & 0.35 & 4.84 & 1.67 & 4.28 & 2.483 & 1.493 & 33.5 & 3 & 1.033 \\
\hline 890227.005 & 24.9 & 6.3 & 6.34 & 12.5 & 3.41 & 5.7 & 6.2 & 0.37 & 4.42 & 1.34 & 4.51 & 2.476 & 1.47 & 35.4 & 6.8 & 1.012 \\
\hline 890227.006 & 24.9 & 6.3 & 6.33 & 12.3 & 3.31 & 5.68 & 6.07 & 0.37 & 4.19 & 1.34 & 4.33 & 2.493 & 1.446 & 30.7 & 3.7 & 1.017 \\
\hline 890227.007 & 24.9 & 6.3 & 6.37 & 12.4 & 3.16 & 5.75 & 6.13 & 0.35 & 4.18 & 1.04 & 4.69 & 2.516 & 1.456 & 30.8 & 0.2 & 0.929 \\
\hline 890227.008 & 24.9 & 6.4 & 6.40 & 12.9 & 3.45 & 6.26 & 6.62 & 0.32 & 4.67 & 1.05 & 5.22 & 2.463 & 1.506 & 33.2 & 2.7 & 0.847 \\
\hline 890227.009 & 24.9 & 6.3 & 6.39 & 13.1 & 3.43 & 6.38 & 6.82 & 0.3 & 4.06 & 0.58 & 5.87 & 2.467 & 1.523 & 29.1 & -8.2 & 0.763 \\
\hline 890227.01 & 24.9 & 6.3 & 6.40 & 13.4 & 3.41 . & 6.52 & 7.11 & 0.3 & 3.41 & 0.24 & 6.49 & 2.472 & 1.553 & 23.6 & -19.6 & 0.689 \\
\hline 890227.011 & 24.9 & 6.4 & 6.52 & 13.1 & 3.44 & 6.08 & 6.71 & 0.32 & 4.82 & 0.78 & 5.58 & 2.469 & 1.528 & 26.8 & -13.9 & 0.779 \\
\hline
\end{tabular}

Fresh Water Tests

$\begin{array}{rrrrrrrrrr}\text { S1de-by-S1de } & \text { (FW) } & \text { Area, } 1= & 0.426 & \text { H, } 1= & 1.63 & \text { Hpk, } 1=0.91 & \\ 890202.002 & 24.9 & 7.7 & 7.78 & 13.7 & 3.27 & 5.56 & 5.8 & 0.36 \\ 890202.003 & 24.9 & 7.7 & 7.76 & 13.7 & 3.28 & 5.61 & 5.84 & 0.37 \\ 890202.004 & 24.9 & 7.7 & 7.75 & 13.7 & 3.28 & 5.66 & 5.89 & 0.36 \\ 890202.005 & 24.9 & 7.6 & 7.75 & 13.8 & 3.27 & 5.74 & 5.98 & 0.32 \\ 890202.006 & 24.9 & 7.6 & 7.75 & 13.9 & 3.26 & 5.86 & 6.12 & 0.29 \\ 890202.007 & 25.0 & 7.7 & 7.75 & 14.4 & 3.23 & 6.22 & 6.53 & 0.28 \\ 890202.008 & 25.2 & 9.0 & 9.07 & 16.5 & 3.35 & 7.07 & 7.4 & 0.48 \\ 890202.009 & 25.2 & 9.0 & 9.06 & 16.6 & 3.35 & 7.16 & 7.48 & 0.45 \\ 890202.01 & 25.2 & 9.0 & 9.05 & 16.7 & 3.34 & 7.26 & 7.57 & 0.42 \\ 890202.011 & 25.2 & 8.9 & 9.04 & 16.9 & 3.28 & 7.47 & 7.81 & 0.34 \\ 890202.012 & 25.2 & 8.9 & 9.00 & 18.3 & 3.32 & 5.25 & 9.2 & 0.56 \\ 890202.013 & 25.2 & 9.0 & 9.09 & 18.8 & 3.31 & 5.27 & 9.52 & 0.44\end{array}$

Area, 2-0.146 H,2= 1.22 Hpk, 2= 0.91

S1de-by-S1de (FW) Area, $1=0.426 \quad \mathrm{H}, 1=1.63 \mathrm{Hpk,1}=0.61$

$\begin{array}{lllllllll}890209.002 & 25.0 & 7.6 & 7.70 & 13.4 & 3.34 & 5.42 & 5.65 & 0.35 \\ 890209.003 & 24.9 & 7.6 & 7.69 & 13.4 & 3.34 & 5.42 & 5.66 & 0.35 \\ 890209.006 & 24.9 & 7.6 & 7.70 & 13.4 & 3.36 & 5.43 & 5.67 & 0.34 \\ 890209.007 & 24.9 & 7.7 & 7.82 & 13.6 & 3.35 & 5.45 & 5.68 & 0.34 \\ 890209.008 & 24.9 & 7.8 & 7.88 & 13.6 & 3.35 & 5.48 & 5.71 & 0.32 \\ 890209.009 & 24.9 & 7.6 & 7.76 & 13.7 & 3.35 & 5.68 & 5.93 & 0.31 \\ 890210.001 & 24.9 & 9.0 & 8.91 & 16.3 & 3.38 & 6.93 & 7.16 & 0.5 \\ 890210.002 & 24.9 & 9.0 & 8.92 & 16.4 & 3.39 & 7 & 7.23 & 0.47 \\ 890210.003 & 24.9 & 9.0 & 8.97 & 16.5 & 3.42 & 7.13 & 7.39 & 0.45 \\ 890210.004 & 24.9 & 8.9 & 8.91 & 16.8 & 3.36 & 7.28 & 7.55 & 0.39 \\ 890210.006 & 24.9 & 8.8 & 8.76 & 16.9 & 3.32 & 7.48 & 7.87 & 0.37 \\ 890210.007 & 24.9 & 8.6 & 8.66 & 17.5 & 3.16 & 5.43 & 8.6 & 0.43 \\ 890210.008 & 24.9 & 8.6 & 8.68 & 17.7 & 3.06 & 5.36 & 8.85 & 0.36 \\ 890210.009 & 24.9 & 8.6 & 8.70 & 18.0 & 3.07 & 5.19 & 8.84 & 0.32\end{array}$

S1de-by-Side (FW) Area,1= 0.426 H,1- $1.63 \mathrm{Hpk,1=0.61}$

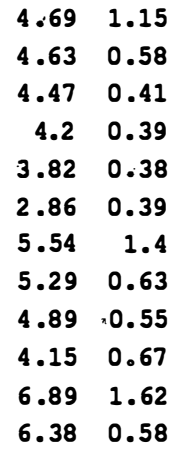

Area, 2=0.146

$$
\begin{array}{rr}
4.66 & 1.72 \\
4.6 & 1.5 \\
4.52 & 1.19 \\
4.38 & 0.86 \\
4.14 & 0.54 \\
3.53 & 0.5 \\
5.62 & 1.77 \\
5.36 & 1.61 \\
4.94 & 0.92 \\
\hline 4.27 & 0.79 \\
3.64 & 0.79 \\
6.56 & 2.03 \\
6.05 & 1.8 \\
5.33 & 1.05
\end{array}
$$

Area, $2=0.146$ $\begin{array}{llllll}4.37 & 2.496 & 1.595 & 68.1 & 42.4 & 0.862\end{array}$ $\begin{array}{lllllll}4.95 & 2.5 & 1.6 & 69.6 & 26.7 & 0.763\end{array}$ $\begin{array}{llllll}5.18 & 2.503 & 1.605 & 66.7 & 14 & 0.712\end{array}$ $\begin{array}{llllll}5.32 & 2.509 & 1.612 & 61.2 & 0.7 & 0.664\end{array}$ $\begin{array}{llllll}5.47 & 2.519 & 1.626 & 50.9 & -11.8 & 0.621\end{array}$ $\begin{array}{lllllll}5.86 & 2.531 & 1.667 & 44.8 & -23.9 & 0.541\end{array}$ $\begin{array}{llllll}5.44 & 2.501 & 1.907 & 72.1 & 70.7 & 0.9\end{array}$ $\begin{array}{llllll}6.19 & 2.505 & 1.918 & 69.1 & 31.7 & 0.8\end{array}$ $\begin{array}{llllll}6.37 & 2.507 & 1.926 & 65.8 & 8.2 & 0.718\end{array}$ $\begin{array}{llllll}6.51 & 2.51 .7 & 1.953 & 55.8 & -17.7 & 0.632\end{array}$ $\begin{array}{llllll}7.04 & 2.508 & 2.124 & 101 & 104 & 0.864\end{array}$

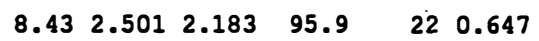

H,2= $0.92 \mathrm{Hpk,2}=0.61$

$\begin{array}{rrrrrr}3.7 & 2.516 & 1.566 & 24 & 22.2 & 0.997 \\ 3.95 & 2.512 & 1.564 & 22.8 & 15.9 & 0.93 \\ 4.25 & 2.531 & 1.571 & 17.7 & 2.5 & 0.836 \\ 4.58 & 2.525 & 1.584 & 15.7 & -6.2 & 0.775 \\ 4.9 & 2.52 & 1.592 & 13 & -17 & 0.716 \\ 5.13 & 2.518 & 1.6 & 8.5 & -28.1 & 0.625 \\ 5.02 & 2.438 & 1.864 & 42 & 75.7 & 0.999 \\ 5.29 & 2.441 & 1.874 & 38.2 & 37 & 0.834 \\ 6.21 & 2.445 & 1.89 & 33.5 & 10.7 & 0.724 \\ 6.68 & 2.454 & 1.915 & 24.3 & -17.5 & 0.635 \\ 6.94 & 2.459 & 1.93 & 18.1 & -27.2 & 0.584 \\ 6.21 & 2.477 & 1.998 & 42.2 & 90.1 & 0.896 \\ 6.68 & 2.481 & 2.025 & 38.2 & 34.3 & 0.731 \\ 7.81 & 2.491 & 2.059 & 33.7 & 6.9 & 0.6\end{array}$

$\mathrm{H}, 2=0.92 \mathrm{Hpk}, 2=0.61$

$\begin{array}{rrrrrr}3.67 & 2.497 & 1.63 & 24 & 19.5 & 0.938 \\ 4.14 & 2.504 & 1.645 & 23 & 5.8 & 0.834 \\ 4.48 & 2.507 & 1.664 & 21.4 & -0.5 & 0.789 \\ 3.98 & 2.505 & 1.575 & 38.5 & 34.6 & 0.899 \\ 4.39 & 2.507 & 1.578 & 37.3 & 26.1 & 0.832 \\ 5 & 2.509 & 1.588 & 34.7 & 14.9 & 0.732 \\ 5.3 & 2.514 & 1.6 & 32.2 & 7.7 & 0.695 \\ 6.04 & 2.529 & 1.697 & 20.9 & -0.3 & 0.588\end{array}$


$\mathrm{TP}-3561$

Table B-5. Data Summary for Direct-Contact Condenser Tests (Continued)

\begin{tabular}{|c|c|c|c|c|c|c|c|c|c|c|c|c|c|c|c|c|c|c|c|}
\hline QWW & Qcw, 1 & ה, 2 & & & 11,2 & $x 10$ & Jal & F1 & $\mathrm{Ja2}$ & F2 & G1 & G2 & L1 & L2 & Error & Error & Vent & Total & Total \\
\hline$(1 / s)$ & corr & & $(\mathrm{mg} / \mathrm{s})$ & (z) & & & & (z) & & & & & $g / m 2 s)$ & & Heat & NC & Rat10 & Eff & $\boldsymbol{E}$ \\
\hline .93 & 13.91 & 3.86 & & 0.39 & 2.6 & 31 & 0.92 & 9.2 & 1.15 & 93.5 & .39 & .24 & 33.52 & 27.14 & -2 & -13 & 0.69 & 0.84 & 98.6 \\
\hline 30.95 & 13.91 & 4.41 & & 0.39 & 2.5 & 32 & 0.90 & 77.9 & 1.22 & 94.1 & 0.40 & 0.26 & 33.52 & 31.01 & -3 & -12 & 0.7 .2 & 0.84 & 98.7 \\
\hline 30.7 & 13.97 & 4.96 & & 0.39 & 2.4 & 32 & 0.89 & 77.4 & 1.32 & 94.3 & 0.40 & 0.26 & 33.68 & 34.88 & -3 & -15 & 0.73 & 0.82 & 98.7 \\
\hline 29.12 & 12.81 & 4.9 & & 0.40 & 2.4 & 30 & 0.87 & 76.9 & 1.35 & 93.9 & 0.36 & 0.25 & 30.88 & 34.46 & -3 & -16 & 0.71 & 0.82 & 98.6 \\
\hline 30.75 & 12.78 & 4.9 & & 0.42 & 2.4 & 33 & 0.87 & 77.2 & 1.37 & 94.5 & 0.37 & 0.24 & 30.80 & 34.46 & -3 & -17 & 0.76 & 0.82 & 98.7 \\
\hline 30.8 & 12.82 & 4.92 & & 0.38 & 2.2 & 37 & 0.86 & 77.0 & 1.35 & 95.7 & 0.40 & 0.27 & 30.90 & 34.60 & -3 & -15 & 0.79 & 0.83 & 99.0 \\
\hline 30.85 & 12.85 & 4.91 & & 0.39 & 2.6 & 40 & 0.90 & 79.8 & 1.60 & 95.8 & 0.40 & 0.23 & 30.98 & 34.53 & -3 & -16 & 0.86 & 0.80 & 99.1 \\
\hline 30.92 & 12.84 & 4.92 & & 0.40 & 3.0 & 44 & 0.95 & 82.7 & 1.99 & 95.7 & 0.39 & 0.20 & 30.95 & 34.60 & -5 & -17 & 0.92 & 0.75 & 99.3 \\
\hline 0.71 & 13.70 & 3.97 & & 0.39 & 2.7 & 40 & 0.94 & 80.6 & 1.33 & 95.5 & 0.40 & 0.23 & 33.02 & 27.92 & -3 & -15 & 0.86 & 0.82 & 99.1 \\
\hline
\end{tabular}

Motorized nozzle (water distribution tests)

\begin{tabular}{|c|c|c|c|c|c|c|c|c|c|c|c|c|c|c|c|c|c|c|c|}
\hline 0.64 & 13.20 & 5.72 & 20 & 0.38 & 1.8 & 31 & 0.76 & 72.6 & 1.15 & 96.1 & 0.40 & 0.32 & 30.99 & 39.18 & 2 & 7 & 0.69 & 0.90 & 98.9 \\
\hline 30.63 & 13.19 & 5.71 & & 0.38 & 1.8 & 35 & 0.77 & 73.1 & 1.17 & 96.7 & 0.40 & 0.31 & 30.97 & 39.11 & 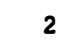 & 8 & 0.78 & 0.90 & 99.1 \\
\hline 30.64 & 13.17 & 5.75 & & 0.38 & 1.9 & 37 & 0.78 & 73.9 & 1.23 & 96.9 & 0.40 & 0.30 & 30.92 & 39.39 & 2 & 6 & 0.82 & 0.89 & 99.2 \\
\hline 30.65 & 13.20 & 5.72 & & 0.38 & 1.9 & 39 & 0.79 & 75.5 & 1.34 & 97.0 & 0.40 & 0.28 & 30.99 & 39.18 & 2 & 3 & 0.86 & 0.87 & $99: 3$ \\
\hline 30.65 & 13.20 & 5.72 & & 0.38 & 2.1 & 41 & 0.82 & 77.6 & 1.51 & 97.0 & 0.39 & 0.26 & 30.99 & 39.18 & 1 & 1 & 0.90 & 0.85 & 99.3 \\
\hline 30.61 & 13.20 & 5.71 & & 0.39 & 2.6 & 44 & 0.88 & 83.2 & 2.16 & 96.6 & 0.39 & 0.19 & 30.99 & 39.11 & 2 & -5 & 0.93 & 0.79 & 99.4 \\
\hline 45.76 & 15.76 & 6.98 & & 0.35 & 1.5 & 36 & 0.78 & 73.8 & 1.22 & 97.3 & 0.60 & 0.46 & 36.99 & 47.80 & -0 & -1 & 0.68 & 0.88 & 99.3 \\
\hline 45.78 & 15.76 & 6.98 & & 0.36 & 1.7 & 42 & 0.79 & 75.0 & 1.28 & 97.7 & 0.60 & 0.43 & 36.99 & 47.80 & -0 & 3 & 0.80 & 0.87 & 99.4 \\
\hline 45.78 & 15.78 & 6.98 & & 0.36 & 1.7 & 44 & 0.81 & 76.8 & 1.40 & 97.8 & 0.59 & 0.40 & 37.04 & 47.80 & -1 & -4 & 0.84 & 0.86 & 99.5 \\
\hline 46.09 & 15.79 & 6.98 & & 0.37 & 1.9 & 46 & 0.84 & 80.1 & 1.72 & 97.8 & 0.58 & 0.34 & 37.06 & 47.80 & -1 & -12 & 0.87 & 0.82 & 99.6 \\
\hline 46.05 & 15.76 & 7 & & 0.41 & 1.5 & 44 & 1.11 & 62.7 & 1.25 . & 98.1 & 0.52 & 0.57 & 36.99 & 47.94 & -14 & 18 & 0.68 & 0.62 & 99.3 \\
\hline 45.95 & 15.78 & 6.99 & & 0.42 & 1.5 & 53 & 1.18 & 64.8 & 1.41 & 98.7 & 0.51 & 0.52 & 37.04 & $47 . .87$ & -17 & 8 & 0.85 & 0.58 & 99.5 \\
\hline
\end{tabular}

Motorized nozzle (high)

\begin{tabular}{|c|c|c|c|c|c|c|c|c|c|c|c|c|c|c|c|c|c|c|c|}
\hline .24 & 26 & 5.7 & 0 & .38 & 1.7 & 27 & 0.76 & 72.2 & 1.13 & 5.2 & 0.39 & 0.32 & 31.13 & 39.05 & -0 & 6 & 0.70 & 0.91 & 98.7 \\
\hline 30.09 & 13.27 & 5.7 & & 0.38 & 1.8 & 29 & 0.76 & 72.6 & 1.15 & 5.6 & 0.39 & 0.31 & 31.15 & 39.05 & -0 & 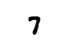 & 0.75 & 0.90 & 98.8 \\
\hline 9.99 & 13.27 & 5.7 & & 0.38 & 1.8 & 32 & 0.77 & 73.1 & 1.18 & 96.1 & 0.39 & 0.31 & 31.15 & 39.05 & -1 & 7 & 0.83 & 0.90 & 98.9 \\
\hline 9.91 & 13.26 & 5.7 & & .38 & 1.9 & 34 & .78 & 3.8 & .22 & .4 & 0.39 & 0.30 & 31.13 & 39.05 & - & 8 & .89 & .89 & 99.0 \\
\hline 9.78 & 13.27 & 5.7 & & .39 & 2.0 & 37 & 0.79 & 75.0 & .29 & 96.6 & 0.38 & 0.28 & 31.15 & 39.05 & -1 & 8 & .95 & .88 & 99.1 \\
\hline 9.78 & 13.27 & 5.7 & & 0.39 & 2.2 & 39 & 0.83 & 78.6 & 1.58 & 96.6 & 0.38 & 0.24 & 31.15 & 39.05 & -2 & -1 & 0.98 & 0.84 & 99.3 \\
\hline 5.27 & 15.80 & .05 & & 0.32 & & 32 & 0.76 & 73.2 & 1.20 & 96.9 & 0.59 & 0.47 & 37.08 & 48.28 & 0 & 22 & 0.64 & .90 & 99.2 \\
\hline 5.25 & 15.82 & 7.05 & & 0.32 & 1.5 & 36 & 0.77 & .74 .4 & 1.29 & 97.4 & 0.59 & 0.44 & 37.13 & 48.28 & -0 & 14 & 0.73 & 0.89 & 99.3 \\
\hline 5.24 & 15.80 & 7.04 & & .32 & 1.6 & 42 & 0.80 & 76.4 & 1.45 & 97.7 & 0.59 & 0.40 & 37.08 & 48.21 & - & 16 & 0.85 & 0.86 & 99.5 \\
\hline 5.25 & 15.85 & 7.05 & & 0.32 & 1.8 & 46 & 0.83 & 79.4 & 1.77 & 97.8 & 0.58 & 0.35 & 37.20 & 48.28 & -2 & 12 & 0.91 & 0.83 & 99.6 \\
\hline 5.35 & 5.87 & 7 & & 0.33 & 2.1 & 48 & 0.87 & 82.4 & 2.15 & 97.7 & 0.57 & 0.29 & .37 .25 & 47.94 & -2 & 7 & 0.94 & 0.79 & 99.6 \\
\hline .51 & .89 & 7.01 & & 0.36 & 1.3 & 37 & 1.04 & 65.0 & 1.25 & & 0.53 & 0.54 & 37.30 & 48.01 & - & 28 & 0.65 & .66 & 99.2 \\
\hline 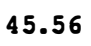 & .82 & 7.02 & & 0.37 & 1.4 & 43 & 1.11 & 66.5 & 1.41 & 98.2 & 0.51 & 0.49 & 37.14 & 48.08 & -7 & 21 & 0.75 & 0.62 & 99.4 \\
\hline & 99 & 6.99 & & 0.39 & 1.5 & 49 & 1.19 & 59.0 & 1.68 & 98.4 & 0.48 & 0.43 & 37.54 & 7.88 & 13 & 15 & 0.86 & 0.58 & 9. \\
\hline
\end{tabular}

Motorlzed nozzle (low)

$\begin{array}{rrrrrrrrrrrrrrrrrrrr}31.15 & 13.01 & 5.81 & 70 & 0.36 & 1.8 & 28 & 0.79 & 72.6 & 1.19 & 95.5 & 0.39 & 0.31 & 30.54 & 39.80 & -2 & 21 & 0.67 & 0.86 & 98.8 \\ 31.06 & 13.13 & 5.69 & & 0.36 & 1.9 & 32 & 0.82 & 73.8 & 1.24 & 96.0 & 0.39 & 0.30 & 30.82 & 38.98 & -2 & 23 & 0.76 & 0.85 & 98.9 \\ 30.94 & 13.12 & 5.7 & & 0.36 & 2.0 & 35 & 0.84 & 74.3 & 1.31 & 96.2 & 0.38 & 0.29 & 30.80 & 39.04 & -3 & 27 & 0.81 & 0.82 & 99.0 \\ 30.59 & 13.81 & 5.72 & 125 & 0.39 & 2.0 & 31 & 0.84 & 74.3 & 1.24 & 95.5 & 0.39 & 0.29 & 32.43 & 39.18 & -2 & 9 & 0.68 & 0.83 & 98.8 \\ 30.62 & 13.75 & 5.74 & & 0.40 & 2.0 & 32 & 0.85 & 75.1 & 1.31 & 95.8 & 0.39 & 0.28 & 32.29 & 39.32 & -2 & 4 & 0.71 & 0.82 & 98.9 \\ 30.62 & 13.73 & 5.76 & & 0.40 & 2.3 & 38 & 0.87 & 76.9 & 1.47 & 96.3 & 0.38 & 0.26 & 32.24 & 39.46 & -3 & 9 & 0.83 & 0.80 & 99.1 \\ 30.63 & 13.73 & 5.75 & & 0.41 & 2.4 & 39 & 0.90 & 78.2 & 1.61 & 96.3 & 0.38 & 0.24 & 32.24 & 39.39 & -4 & 7 & 0.86 & 0.78 & 99.2 \\ 30.68 & 13.74 & 5.74 & & 0.44 & 4.6 & 45 & 1.12 & 87.8 & 3.49 & 94.3 & 0.35 & 0.12 & 32.26 & 39.32 & -10 & 4 & 0.90 & 0.62 & 99.3\end{array}$


TP-3561

Table B-5. Data Summary for Direct-Contact Condenser Tests (Continued)

NOTE: DATA USED FOR GENERAL REFERENCE - DISCREPANCIES IN SOME READINGS WERE FOUND, WELL OUTSIDE OF PREDICTED

Note: Some data were obtalned from $T$ differences when DT sensors were over range, or were calculated from other

Identifler Tww1 Tcw1, 1 Tcw1,2 Ts1,1 DTwW DTCW DTs1w1DTs1so DTcw DTsow1DTs1so Pevap P1,1 DP1 DP2 Pexh

(c)

2 (kPa) (Pa)

\begin{tabular}{|c|c|c|c|c|c|c|c|c|c|c|c|c|c|c|c|c|}
\hline 1 de-by-side & & $1=$ & 26 & $.1=$ & .63 & Hpk, 1 & 0.91 & & rea, $2=$ & 16 & H, 2= & 1.22 & $\mathrm{Hpk}, 2=$ & $=0.91$ & & B \\
\hline 881201.003 & 26.6 & 6.4 & 6.24 & 13.2 & 4.3 & 6.0 & 6.9 & 0.2 & 6.0 & 0.8 & 5.6 & 2.625 & 1.536 & 30.6 & 66 & 0.709 \\
\hline 881201.004 & 26.7 & 6.3 & 6.18 & 13.3 & 4.4 & 6.0 & 7.0 & 0.1 & 5.8 & 0.1 & 6.5 & 2.604 & 1.538 & 26.2 & 51.2 & 0.573 \\
\hline 881201.005 & 26.7 & 6.3 & 6.16 & 3.6 & 4.4 & 6.2 & 7.3 & 0.1 & 4.7 & 0.1 & 6.9 & 2.611 & 1.571 & 20.7 & 32.9 & 0.525 \\
\hline 881201.006 & 26.7 & 6.3 & 6.17 & 14.9 & 4.3 & 6.2 & 8.6 & -0.0 & 2.1 & 0.1 & 8.2 & 2.636 & 1.708 & 8.4 & 19.2 & 0.465 \\
\hline 881201.007 & 26.7 & 6.3 & 6.21 & 15.8 & 4.2 & 6.2 & 9.4 & 0.0 & 0.9 & 0.2 & 8.9 & 2.663 & 1.8 & 2.6 & 17.4 & 0.491 \\
\hline 881201.008 & 26.7 & 6.4 & 6.28 & 13.2 & 4.5 & 6.1 & 6.8 & 0.1 & 6.0 & 0.0 & 6.4 & 2.621 & 1.538 & 27.5 & 56.7 & 0.579 \\
\hline 881201.009 & 26.7 & 6.4 & 6.33 & 4.1 & 4.4 & 6.5 & 7.7 & -0.0 & 3.6 & 0.1 & 7.2 & 2.635 & 1.625 & 14.1 & 24.8 & 0.52 \\
\hline 881201.01 & 26.8 & 6.5 & 6.35 & 13.2 & 4.5 & 6.1 & 6.8 & 0.1 & 6.1 & 0.5 & 5.8 & 2.63 & 1.542 & 32.2 & 73.4 & 0.661 \\
\hline 881201.011 & 26.8 & 6.3 & 6.21 & 13.2 & 4.5 & 6.0 & 6.9 & 0.1 & 6.4 & 0.8 & 5.6 & 2.639 & 1.543 & 29.8 & 60 & 0.667 \\
\hline 881201.012 & 26.7 & 6.3 & 6.23 & 3.4 & 4.5 & 6.1 & 7.0 & 0.1 & 6.6 & 0.9 & 5.5 & 2.643 & 1.556 & 29.3 & 48.5 & 0.659 \\
\hline 881207.002 & 26.4 & 6.3 & 6.20 & 13.2 & 3.4 & 5.8 & 7.0 & 0.3 & 6.4 & 0.9 & 5.4 & 2.745 & 1.52 & 33.9 & 52.7 & 0.767 \\
\hline 881207.003 & 26.4 & 6.2 & 6.13 & 13.5 & 3.4 & 5.9 & 7.3 & 0.2 & 5.5 & 0.2 . & 6.9 & 2.752 & 1.55 & 26.2 & 31.4 & 0.564 \\
\hline 881207.004 & 26.4 & 6.3 & 6.19 & 13.4 & 3.4 & 5.8 & 7.1 & 0.2 & 6.0 & 0.4 & 6.3 & 2.755 & 1.544 & 27.9 & 44.7 & 0.605 \\
\hline 881207.005 & 26.5 & 6.3 & 6.26 & 14.6 & 3.4 & 5.9 & 8.2 & 0.0 & 2.5 & 0.1 & 7.8 & 2.767 & 1.664 & 11.9 & 23.8 & 0.508 \\
\hline 881207.006 & 26.5 & 6.2 & 6.16 & 15.2 & 3.4 & 7.5 & 9.0 & 0.2 & 8.4 & 1.6 & 6.7 & 2.75 & 1.732 & 30.5 & 48.5 & 0.697 \\
\hline 881207.007 & 26.5 & 6.2 & 6.12 & 15.2 & 3.4 & 7.5 & 9.0 & 0.2 & 8.4 & 0.7 & 7.5 & 2.753 & 1.735 & 28.4 & 44.7 & 0.576 \\
\hline 881207.008 & 26.5 & 6.1 & 6.09 & 15.6 & 3.4 & 7.7 & 9.5 & 0.0 & 6.4 & 0.3 & 8.9 & 2.763 & 1.79 & 13.5 & 25 & 0.515 \\
\hline 881207.009 & 26.6 & 6.1 & 6.08 & 15.6 & 3.4 & 7.7 & 9.5 & -0.0 & 6.5 & 0.3 & 9.0 & 2.765 & 1.791 & 14.2 & 25 & 0.514 \\
\hline 881207.01 & 26.6 & 6.1 & 6.08 & 16.6 & 3.3 & 7.7 & 10.4 & 0.0 & 3.4 & 0.4 & 9.9 & 2.79 & 1.897 & -1.7 & 20 & 0.489 \\
\hline 881207.011 & 26.6 & 6.2 & 6.20 & 16.9 & 3.6 & 9.2 & 10.7 & 0.2 & 10.0 & 2.2 & 7.5 & 2.713 & 1.927 & .27 .6 & 49.6. & 0.694 \\
\hline 881207.012 & 26.6 & 6.2 & 6.13 & 16.9 & 3.7 & 9.2 & 10.7 & 0.3 & 9.9 & 0.8 & 9.2 & 2.699 & 1.923 & 33.9 & 41.4 & 0.538 \\
\hline 881207.013 & 26.6 & 6.2 & 6.14 & 17.1 & 3.6 & 9.3 & 10.9 & 0.3 & 8.8 & 0.5 & 9.9 & 2.705 & 1.947 & 27.9 & 25.3 & 0.506 \\
\hline 881207.014 & 26.6 & 6.3 & 6.24 & 18.0 & 3.5 & 9.3 & 11.7 & 0.2 & 5.0 & 0.6 & 10.7 & 2.727 & 2.052 & 13.9 & 16.7 & 0.482 \\
\hline 881208.002 & 26.7 & 6.5 & 6.45 & 14.6 & 3.5 & 6.0 & 8.1 & 0.4 & 7.6 & 2.0 & 5.7 & 2.785 & 1.678 & 60.1 & 35.7 & 0.791 \\
\hline 881208.003 & 26.7. & 6.5 & 6.47 & 14.8 & 3.5 & 6.0 & 8.3 & 0.5 & 7.6 & 1.3 & 7.1 & 2.782 & 1.694 & 61.9 & 24.6 & 0.6 \\
\hline 881208.004 & 26.7 & 6.6 & 6.52 & 15.0 & 3.5 & 6.2 & 8.4 & 0.5 & 6.4 & 1.1 & 7.3 & 2.786 & 1.704 & 61.5 & 15.2 & 0.539 \\
\hline 881208.005 & 26.7 & 6.6 & 6.53 & 14.8 & 3.5 & 6.6 & 8.2 & 0.6 & 0.2 & 0.8 & 7.1 & 2.779 & 1.675 & 64.4 & 13.8 & 0.53 \\
\hline 881208.006 & 26.7 & 6.5 & 6.51 & 14.2 & 3.6 & 6.5 & 7.7 & 0.7 & 7.0 & 1.2 & 6.4 & 2.769 & 1.621 & 74.8 & 25.5 & 0.613 \\
\hline 881208.007 & 26.7 & 6.5 & 6.47 & 14.2 & 3.6 & 6.5 & 7.6 & 0.7 & 7.1 & 1.5 & 5.8 & 2.766 & 1.618 & 75.1 & 31 & 0.71 \\
\hline 881208.008 & 26.7 & 6.5 & 6.42 & 11.3 & 3.1 & 3.2 & 4.9 & 0.5 & 1.4 & 0.0 & 3.9 & 2.859 & 1.349 & 54.7 & 18.4 & 0.583 \\
\hline 881208.009 & 26.7 & 6.4 & 6.39 & 12.1 & 3.1 & 3.1 & 5.6 & 0.5 & 0.8 & 0.0 & 4.3 & 2.863 & 1.413 & 49 & 16.2 & 0.518 \\
\hline 881208.01 & 26.7 & 6.4 & 6.40 & 10.6 & 3.1 & 3.1 & 4.2 & 0.6 & 2.7 & -0.0 & 3.6 & 2.859 & 1.287 & 56.6 & 22.8 & 0.669 \\
\hline 881208.011 & 26.7 & 6.5 & 6.44 & 10.5 & 3.1 & 3.0 & 4.0 & 0.7 & 3.2 & -0.0 & 3.4 & 2.858 & 1.27 & 60.2 & 26.8 & 0.732 \\
\hline 881208.012 & 26.7 & 6.5 & 6.48 & 10.4 & 3.1 & 3.0 & 3.9 & 0.7 & 3.2 & 0.5 & 2.8 & 2.854 & 1.264 & 62.1 & 32.1 & 0.964 \\
\hline 881209.003 & 26.5 & 6.3 & 6.19 & 13.3 & 3.1 & 5.0 & 7.0 & 0.0 & 6.4 & 0.6 & 6.1 & 2.833 & 1.543 & -12.4 & 32 & 0.665 \\
\hline 881209.004 & 26.5 & 6.4 & 6.34 & 12.3 & 2.9 & 5.6 & 6.0 & 0.0 & 5.7 & 1.1 & 4.2 & 2.884 & 1.464 & -39.6 & 30.4 & 0.864 \\
\hline 881209.005 & 26.6 & 6.4 & 6.39 & 12.9 & 3.3 & 5.8 & 6.5 & 0.0 & 6.0 & 1.4 & 4.1 & 2.817 & 1.503 & -34.8 & 30.3 & 0.882 \\
\hline 881209.006 & 26.6 & $6: 3$ & 6.32 & 13.0 & 3.3 & 5.8 & 6.7 & 0.0 & 6.0 & 1.0 & 4.9 & 2.827 & 1.493 & -19 & 26.7 & 0.662 \\
\hline 881209.007 & 26.7 & 6.2 & 6.26 & 13.1 & 3.3 & 5.9 & 6.8 & 0.0 & 6.1 & 0.6 & 5.4 & 2.834 & 1.489 & -13.2 & 24.1 & 0.504 \\
\hline 881209.008 & 26.7 & 6.3 & 6.31 & 13.1 & 3.3 & 5.9 & 6.9 & 0.0 & 6.0 & 0.4 & 5.8 & 2.84 & 1.498 & -12 & 22.9 & 0.427 \\
\hline 881209.009 & 26.7 & 6.3 & 6.36 & 13.9 & 3.3 & 6.0 & 7.5 & 0.1 & 3.0 & 0.1 & 6.3 & 2.841 & 1.563 & -15.3 & 18.4 & 0.366 \\
\hline 881209.01 & 26.8 & 6.2 & 6.15 & 15.4 & 3.8 & 7.2 & 9.2 & 0.1 & 6.9 & 0.6 & 8.2 & 2.749 & 1.78 & 39.6 & 90.4 & 0.908 \\
\hline 881209.011 & 26.8 & 6.1 & 6.04 & 16.4 & 3.7 & 7.3 & 10.3 & 0.0 & 4.8 & 0.7 & 9.6 & 2.761 & 1.886 & 9.5 & 37.1 & 0.899 \\
\hline 881209.012 & 26.8 & 6.1 & 6.04 & 16.1 & 3.7 & 7.2 & 10.0 & 0.0 & 5.4 & 0.6 & 9.2 & 2.754 & 1.879 & 22.4 & 46.2 & 1.034 \\
\hline 881209.013 & 26.8 & 6.2 & 6.10 & 15.4 & 3.8 & 7.2 & 9.2 & 0.2 & 6.8 & 0.6 & 8.1 & 2.734 & 1.773 & 51.6 & 84.1 & 0.889 \\
\hline
\end{tabular}


TP-3561

Table B-5. Data Summary for Direct-Contact Condenser Tests (Continued)

ERROR MARGINS

aultiple sensor readings

Qww Qcw,1 Qcw, 2 Leak $x 11,1$ x11,2 $x 10$ Jal F1 Ja2 F2 G1 G2 L1 L2 ErrorError Vent Total Total $(1 / \mathrm{s}) \operatorname{corr}(\mathrm{mg} / \mathrm{s})(\mathrm{z}) \quad(z) \quad(\mathrm{kg} / \mathrm{m} 2 \mathrm{~s}) \quad$ Heat NC Rat10 Eff $F$

ulators in nozzles

\begin{tabular}{|c|c|c|c|c|c|c|c|c|c|c|c|c|c|c|c|c|c|c|c|}
\hline & 39 & 88 & 60 & 0.21 & 9 & 38 & 87 & 2.6 & 07 & .3 & .43 & 34 & 32.27 & 34.32 & 1 & 9 & 0.73 & 0.83 & 9.3 \\
\hline 2.76 & 13.30 & 4.76 & & 0.21 & 0.9 & 45 & .90 & 74.1 & .13 & 7.9 & .42 & 0.32 & 32.06 & 33.47 & 6 & 7 & 0.86 & 0.82 & 99.4 \\
\hline 2.69 & 13.29 & 4.72 & & 0.22 & 1 & 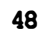 & .97 & 8.4 & .47 & 7.7 & .41 & .26 & 32.04 & 33.19 & 5 & 6 & .91 & .76 & 9.5 \\
\hline 2.66 & 13.28 & 4.7 & & 0.24 & 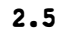 & 34 & .28 & 38.9 & 59 & 6.0. & 36 & .12 & 32.01 & 33.05 & -5 & 8 & .95 & .57 & 9.6 \\
\hline 2.66 & 13.30 & 4.69 & & 0.26 & .7 & 6 & .50 & 14.9 & .44 & .5 & 34 & .05 & 32.07 & 32.98 & -11 & 18 & . 95 & .49 & 9.5 \\
\hline 2.63 & 13.25 & .72 & & 0.21 & .9 & 4 & .87 & 3.8 & .08 & 7.9 & .43 & .33 & 31.93 & 33.19 & 7 & 7 & .85 & .85 & 9.4 \\
\hline 22.6 & 13.28 & 4.7 & & 0.22 & 1.4 & 50 & 1.01 & 83.1 & .00 & 7.2 & .41 & .20 & 32.01 & 33.05 & 4 & 10 & 0.93 & .72 & 9.5 \\
\hline 2.64 & 13.28 & 4.72 & & 0.21 & .9 & 11 & 0.86 & 73.1 & .05 & 7.5 & .43 & .34 & 32.01 & 33.19 & 7 & 3 & 0.75 & .86 & 9.3 \\
\hline .66 & 13.89 & 4.05 & & 0.20 & .9 & 0 & .91. & 15.8 & .04 & 7.2 & .43 & .30 & 33.47 & 28.48 & & 1 & .72 & .85 & 9.3 \\
\hline 2.63 & 14.17 & 3.6 & & 0.20 & 0.9 & 39 & 0.94 & 77.9 & .05 & 7.0 & .43 & 0.28 & 34.16 & 25.32 & 8 & 9 & 0.70 & .84 & 9.3 \\
\hline 9.08 & 13.74 & 3.41 & 7 & 0.28 & .4 & 7 & .98 & 77.7 & .06 & 6.0 & .40 & .26 & 33.11 & 23.98 & 2 & 4 & .67 & .81 & 9.1 \\
\hline 9.08 & 13.73 & 3.48 & & 0.29 & .6 & 48 & .04 & 80.4 & .26 & 7.1 & . 39 & .22 & 33.09 & 24.47 & 1 & 2 & .89 & .76 & 9.4 \\
\hline 8.99 & 13.72 & 3.55 & & 0.29 & .5 & 44 & 1.00 & 78.4 & .14 & 7.1 & .39 & 0.25 & 33.06 & 24.97 & 2 & -1 & .81 & .79 & 99.4 \\
\hline 3.85 & 13.71 & .59 & & 0.32 & 8 & 3 & .29 & 89.7 & .94 & 5.1 & .35 & .11 & 33.04 & 25.25 & -7 & 3 & . 94 & .61 & 9.5 \\
\hline 8.47 & 13.88 & 3.51 & & 0.28 & .4 & 43 & .96 & 77.6 & .07 & $7: 5$ & .52 & .34 & 33.44 & 24.68 & 3 & -7 & .68 & .83 & 99.4 \\
\hline 8.43 & 13.91 & 3.52 & & 0.28 & .4 & 50 & 0.96 & 77.7 & .01 & 8.2 & 0.52 & 0.34 & 3.3 .52 & 24.75 & 3 & -9 & 0.82 & .83 & 9.6 \\
\hline 3.47 & 13.91 & .52 & & 0.30 & & 7 & .05 & 82.4 & 20 & .1 & 50 & 26 & .52 & .75 & -0 & -6 & .94 & .76 & 9.7 \\
\hline 8.48 & 13.88 & 3.51 & & 0.30 & 1.8 & 57 & 1.05 & 82.1 & 1.18 & 8.1 & .51 & 0.26 & 33.44 & 24.68 & 0 & -6 & .94 & .76 & 99.7 \\
\hline 3.55 & 13.89 & 3.53 & & 0.32 & .4 & 0 & 1.25 & 89.6 & .23 & 6.9 & .47 & .14 & 33.47 & 24.82 & -6 & -5 & . 96 & .64 & 9.7 \\
\hline 3.64 & 14.03 & 3.47 & & 0.26 & 1.4 & 47 & 0.94 & 78.4 & .06 & 8.0 & .64 & .40 & 33.79 & 24.40 & 3 & -7 & .68 & .85 & 9.6 \\
\hline 3.24 & 13.89 & 3.44 & & 0.26 & 4 & 57 & 0.94 & 78.8 & .84 & 8.7 & 0.63 & .39 & 33.46 & 24.18 & 3. & -9 & .86 & .85 & 99.7 \\
\hline 3.29 & 13.91 & 3.42 & & 0.27 & . & 60 & 0.98 & 80.9 & .89 & 8.7 & .62 & 35 & 33.51 & 24.04 & 1 & -9 & 92 & .82 & 9.7 \\
\hline 3.19 & 13.91 & 3.39 & & 0.29 & 8 & 63 & 1.14 & 88.2 & .57 & 7.9 & .57 & 0.20 & 33.51 & 23.83 & -4 & -8 & .95 & .70 & 9.8 \\
\hline 30 & 13.54 & 3.49 & & 0.28 & .8 & 40 & 1.05 & 74.7 & 1.02 . & 6.7 & 0.42 & 0.31 & 32.62 & 24.54 & 2 & 15 & .64 & .75 & 9.2 \\
\hline .91 & 13.55 & .48 & & 0.28 & & 50 & 1.08 & 75.0 & .00 & 97.8 & .42 & .31 & 32.65 & 24.47 & 1 & 11 & .83 & .73 & 9.5 \\
\hline 0.13 & 13.55 & 47 & & 0.28 & 1. & 51 & 1.11 & 78.7 & 20 & 7.8 & .41 & 0.26 & 32.65 & 24.40 & 1 & 2 & .85 & .71 & 9.5 \\
\hline 0.09 & 13.58 & 3.44 & & 0.28 & & 50 & 1.06 & 83.0 & 1.41 & & .42 & .21 & 32.73 & 24.19 & 2 & -1 & .86 & .75 & 9.5 \\
\hline 0.03 & 13.58 & 3.43 & & 0.26 & 1.3 & 46 & 0.96 & 78.2 & و.99 & 7.5 & .44 & 0.28 & 32.73 & 24.12 & 5. & 4 & .78 & .83 & 9.4 \\
\hline 9.91 & 13.49 & 3.47 & & 0.26 & 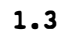 & 1 & 0.95 & 77.5 & 01 & & 44 & 0.29 & .52 & 40 & & 7 & .68 & .83 & 9.3 \\
\hline 5.68 & 13.58 & .43 & & 0.32 & 3.1 & 6 & 1.44 & 88.5 & .44 & 8.0 & .19 & 0.06 & 32.74 & 24.13 & -6 & 8 & .82 & .55 & 8.6 \\
\hline 5.64 & 13.58 & 3.39 & & 0.34 & 3 & 41 & 1.77 & 92.8 & .49 & 3.1 & .18 & 0.04 & 32.74 & 23.85 & -7 & 8 & .86 & .45 & 8.8 \\
\hline 5.65 & 13.56 & 3.32 & & 0.30 & & 32 & 1.17 & 81.4 & 1.26 & & .20 & .11 & .68 & .35 & 5 & 7 & .77 & .67 & 8.4 \\
\hline 5.62 & 13.57 & 3.26 & & 0.30 & 1.5 & 29 & 1.11 & 78.6 & 1.03 & 1.7 & 0.20 & 0.13 & 32.71 & 22.93 & 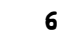 & 8 & .72 & .71 & 8.2 \\
\hline 5.63 & 13.55 & 3.23 & & 0.30 & .5 & 23 & 1.08 & 77.5 & 0.99 & 8.6 & .20 & 0.13 & 32.66 & & 5 & 10 & .54 & .73 & 7.4 \\
\hline 9.74 & 13.95 & 3.03 & 175 & 0.33 & & 44 & 1.14 & 77.6 & 1.00 & 96.5 & .35 & 0.23 & 33.63 & 21.31 & -2 & 9 & 0.92 & .71 & 9.2 \\
\hline 6.75 & 6.95 & 2.07 & & 0.32 & 1.4 & 30 & 0.84 & 75.0 & 1.00 & 91.5 & .20 & 0.15 & 16.74 & 14.56 & 5 & 42 & 0.74 & .90 & 7.8 \\
\hline 5.35 & 7.47 & 1.87 & & 0.28 & & 31 & 0.92 & 77.8 & .99 & .8 & .21 & .14 & 17.99 & 5 & 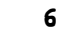 & 7 & .70 & .85 & 7.9 \\
\hline 5.29 & 7.47 & 1.89 & & 0.27 & & 38 & 0.94 & 78.2 & 0.91 & 93.8 & .22 & 0.14 & 17.99 & 13.29 & 8 & 3 & 0.82 & .83 & 8.6 \\
\hline 5.32 & 7.49 & 1.86 & & 0.27 & 1.4 & 42 & 0.96 & 78.8 & 0.97 & 95.5 & 0.22 & 0.13 & 18.05 & 13.08 & 7 & 31 & 0.89 & .82 & 9.0 \\
\hline 5.31 & 7.49 & 1.85 & & 0.28 & & 44 & 0.97 & 79.2 & 0.98 & 96.3 & 0.22 & 0.13 & 18.05 & 01 & 8 & 22 & 0.94 & .82 & 9.2 \\
\hline 5.32 & 7.49 & 1.83 & & 0.30 & 2.9 & 48 & 1.15 & 88.5 & 2.03 & 94.1 & 0.20 & 0.07 & 18.05 & 12.87 & 0 & 17 & 0.97 & 0.70 & 99.3 \\
\hline 0.53 & 15.61 & 5.95 & & 0.26 & 1.1 & 49 & 0.96 & 72.8 & 1.18 & 97.8 & 0.60 & 0.48 & 37.61 & 41.84 & 1 & 24 & 0.78 & 0.75 & 99.4 \\
\hline 0.48 & 15.65 & 5.89 & & 0.28 & & 57 & 1.15 & 79.8 & & 97.3 & 0.56 & 0.33 & 37.72 & 41.42 & -3 & 37 & 0.91 & 0.63 & 9.4 \\
\hline 39.91 & 15.66 & 5.89 & & 0.27 & 1.3 & 56 & 1.11 & 77.5 & 1.48 & 97.1 & 0.57 & 0.37 & 37.74 & 41.42 & -2 & 45 & 0.88 & 0.65 & 99.3 \\
\hline 9.91 & 15.61 & 6 & & 0.26 & 1.1 & 49 & 0.96 & 73.0 & 1.20 & $97: 8$ & 0.60 & 0.47 & 37.61 & 42.19 & 1 & 23 & 0.78 & 0.75 & 99.4 \\
\hline
\end{tabular}




\section{Table B-5. Data Summary for Direct-Contact Condenser Tests (Continued)}

NOTE: DATA USED FOR GENERAI REFERENCE - DISCREPANCIES IN SOME READINGS WERE FOUND, WELL OUTSIDE OF PREDICTED

Note: Some data were obtained from $T$ differences when DT sensors were over range, or were calculated from other

Ident1fler Tww1 TCw1, 1 Tcw1, 2 Ts1,1 DTwW (C)

$881209.014 \quad 26.8$

$881209.015 \quad 26.8$

$881209.016 \quad 26.8$

$881209.017 \quad 26.8$

$881209.018 \quad 26.8$

$881209.019 \quad 26.7$

$881212.002 \quad 26.5$

$881212.003 \quad 26.5$

$881212.004 \quad 26.5$

$881212.005 \quad 26.6$

$881212.006 \quad 26.6$

$881212.007 \quad 26.6$

$881212.008 \quad 26.6$

$881212.009 \quad 26.6$

$881212.01 \quad 26.6$

881212.01126 .7 .

$881212.012 \quad 26.7$

$881212.013 \quad 26.7$

$881212.014 \quad 26.7$

$881212.015 \quad 26.7$

$881212.016 \quad 26.7$

$881212.017 \quad 26.7$

$881212.018 \quad 26.7$

$\begin{array}{ll}881212.019 & 26.7\end{array}$

$881213.002 \quad 26.4$

$881213.003 \quad 26.4$

$881213.004 \quad 26.4$

$881213.005 \quad 26.4$

$881213.006 \quad 26.4$

$881213.007 \quad 26.4$

$881213.008 \quad 26.4$

$881213.009 \quad 26.4$

$881213.01 \quad 26.4$

$881213.011 \quad 26.5$

$881213.012 \quad 26.5$

$881213.013 \quad 26.5$

$881213.014 \quad 26.5$

$881213.015 \quad 26.5$

$881213.016 \quad 26.5$

$881213.017 \quad 26.5$

$881213.018 \quad 26.5$

$881213.019 \quad 26.5$

$881214.002 \quad 26.4$

$881214.003 \quad 26.5$

$881214.004 \quad 26.5$

$881214.005 \quad 26.5$

$881214.006 \quad 26.5$

\begin{tabular}{|c|c|c|c|c|c|c|c|c|}
\hline 6.2 & 6.16 & 15.4 & 3.9 & 7.2 & 9.2 & 0.3 & 7.1 & 0.7 \\
\hline 6.3 & 6.17 & 15.7 & 3.8 & 7.3 & 9.4 & 0.2 & 6.5 & 0.6 \\
\hline 6.3 & 6.19 & 16.0 & 3.8 & 9.0 & 9.7 & 0.7 & 7.9 & 1.5 \\
\hline 6.2 & 6.15 & 16.0 & 3.8 & 9.0 & 9.8 & 0.7 & 7.7 & 0.8 \\
\hline 6.2 & 6.16 & 16.2 & 3.7 & 9.2 & 10.0 & 0.5 & 6.9 & 0.6 \\
\hline 6.3 & 6.17 & 17.1 & 3.6 & 9.6 & 10.8 & 0.3 & 3.8 & 1.2 \\
\hline 6.4 & 6.24 & 12.9 & 3.7 & 5.6 & 6.6 & 0.2 & 5.2 & 0.6 \\
\hline 6.4 & 6.31 & 12.7 & 3.4 & 5.4 & 6.3 & 0.2 & 5.0 & 0.5 \\
\hline 6.4 & 6.32 & 13.0 & 3.4 & 5.6 & 6.6 & 0.2 & 4.5 & 0.3 \\
\hline 6.4 & 6.30 & 13.7 & 3.4 & 5.8 & 7.3 & 0.1 & 2.5 & 0.7 \\
\hline 6.4 & 6.28 & 14.2 & 3.4 & 5.9 & 7.8 & 0.2 & 1.6 & 0.5 \\
\hline 6.4 & 6.27 & 12.9 & 3.5 & 4.9 & 6.5 & 0.4 & 5.7 & 1.1 \\
\hline 6.4 & 6.31 & 13.0 & 3.5 & 4.9 & 6.6 & 0.4 & 5.7 & 0.5 \\
\hline 6.5 & 6.40 & 13.6 & 3.4 & 5.0 & 7.1 & 0.2 & 4.3 & 0.6 \\
\hline 6.5 & 6.39 & 13.1 & 3.5 & 4.9 & 6.6 & 0.3 & 5.7 & 0.9 \\
\hline 6.4 & 6.32 & 14.5 & 3.4 & 7.7 & 8.1 & 0.0 & 7.7 & 2.5 \\
\hline 6.4 & 6.29 & 15.3 & 3.3 & 7.6 & 8.9 & 0.0 & 6.3 & 1.4 \\
\hline 6.4 & 6.26 & 14.6 & 3.4 & 7.6 & 8.2 & 0.1 & 7.6 & 1.3 \\
\hline 6.3 & 6.25 & 14.6 & 3.4 & 7.7 & 8.3 & 0.1 & 7.0 & 1.1 \\
\hline 6.3 & 6.26 & 15.2 & 3.4 & 8.0 & 8.8 & 0.1 & 4.7 & 0.8 \\
\hline 6.4 & 6.30 & 15.2 & 3.4 & 7.8 & 8.9 & 0.2 & 6.6 & 0.9 \\
\hline 6.4 & 6.31 & 14.9 & 3.4 & 7.7 & 8.6 & 0.3 & 8.1 & 1.6 \\
\hline 6.4 & 6.32 & 15.0 & 3.4 & 7.7 & 8.6 & 0.3 & 8.0 & 1.2 \\
\hline 6.4 & 6.33 & 14.9 & 3.4 & 7.7 & 8.5 & 0.5 & 8.1 & 2.1 \\
\hline 6.5 & 6.43 & 13.9 & 3.3 & 6.9 & 7.4 & 0.5 & 6.5 & 0.8 \\
\hline 6.5 & 6.41 & 14.0 & 3.3 & 7.0 & 7.5 & 0.4 & 6.4 & 0.1 \\
\hline 6.5 & 6.37 & 14.3 & 3.3 & 7.2 & 7.8 & 0.2 & 5.3 & 0.1 \\
\hline 6.5 & 6.37 & 14.5 & 3.3 & 7.3 & 8.0 & 0.2 & 4.4 & 0.2 \\
\hline 6.5 & 6.41 & 15.2 & 3.3 & 7.6 & 8.7 & 0.0 & 2.5 & 0.4 \\
\hline 6.5 & 6.40 & 16.9 & 3.4 & 10.0 & 10.4 & 0.2 & 9.9 & 3.7 \\
\hline 6.5 & 6.39 & 17.1 & 3.4 & 10.0 & 10.6 & 0.3 & 10.0 & 1.6 \\
\hline 6.5 & 6.45 & 17.3 & 3.4 & 10.0 & 10.7 & 0.4 & 9.8 & 0.6 \\
\hline 6.7 & 6.60 & 17.8 & 3.3 & 10.2 & 11.1 & 0.4 & 8.5 & 0.5 \\
\hline 6.7 & 6.65 & 19.0 & 3.2 & 10.6 & 12.3 & 0.3 & 3.9 & 0.4 \\
\hline 6.4 & 6.29 & 15.2 & 3.5 & 5.5 & 8.8 & 0.0 & 8.4 & 1.8 \\
\hline 6.3 & 6.27 & 14.4 & 3.4 & 6.3 & 8.0 & 0.0 & 7.6 & 0.9 \\
\hline 6.4 & 6.34 & 14.5 & 3.4 & 6.3 & 8.1 & 0.0 & 7.5 & 0.4 \\
\hline 6.4 & 6.36 & 15.0 & 3.4 & 6.3 & 8.6 & 0.0 & 5.6 & 0.4 \\
\hline 6.4 & 6.34 & 14.4 & 3.4 & 6.3 & 8.0 & -0.0 & 7.6 & 1.1 \\
\hline 6.3 & 6.20 & 14.1 & 3.4 & 6.3 & 7.9 & 0.0 & 7.3 & 0.9 \\
\hline 6.2 & 6.13 & 13.8 & 3.4 & 6.5 & 7.6 & 0.0 & 7.0 & 0.7 \\
\hline 6.2 & 6.17 & 14.6 & 3.3 & 6.5 & 8.4 & 0.0 & 3.9 & 0.5 \\
\hline 6.6 & 6.56 & 14.1 & 3.3 & 6.2 & 7.5 & 0.2 & 7.0 & 0.8 \\
\hline 6.6 & 6.57 & 14.2 & 3.3 & 6.3 & 7.6 & 0.1 & 7.1 & 1.4 \\
\hline 6.5 & 6.43 & 14.5 & 3.3 & 6.4 & 8.0 & 0.1 & $5.7^{\circ}$ & 0.4 \\
\hline 6.3 & 6.30 & 15.8 & 3.2 & 6.2 & 9.5 & 0.1 & 1.9 & 0.4 \\
\hline 6.5 & 6.48 & 14.0 & 3.3 & 6.4 & 7.5 & 0.0 & 7.0 & 0.9 \\
\hline
\end{tabular}

DTCW DTs1W1DTs1so

DTcW DTsow1DTs1so Pevap P1, 1 2 (kPa)

DP1

$7.9 \quad 2.75 \quad 1.774$

$\begin{array}{llllll}8.3 & 2.757 & 1.804 & 43.4 & 64 & 0.813\end{array}$

$\begin{array}{lllllll}7.4 & 2.733 & 1.815 & 76.7 & 175.4 & 1.058\end{array}$

$\begin{array}{llllll}8.0 & 2.722 & 1.814 & 77.5 & 121 & 0.901\end{array}$

$\begin{array}{lllllll}8.4 & 2.714 & 1.839 & 57.6 & 60.1 & 0.74\end{array}$

$\begin{array}{lllllll}10.0 & 2.732 & 1.939 & 26.7 & 26.7 & 0.592\end{array}$

$\begin{array}{lllllll}5.6 & 2.708 & 1.517 & 48.5 & 83.4 & 0.912\end{array}$

$\begin{array}{llllll}5.3 & 2.755 & 1.503 & 50.1 & 80.1 & 0.908\end{array}$

$\begin{array}{lllllll}5.9 & 2.761 & 1.526 & 48.9 & 52.3 & 0.764\end{array}$

$\begin{array}{llllll}6.5 & 2.768 & 1.589 & 38.5 & 31.3 & 0.619\end{array}$

$\begin{array}{llllll}7.1 & 2.776 & 1.636 & 38 & 27.4 & 0.559\end{array}$

$\begin{array}{llllll}5.1 & 2.764 & 1.509 & 64.4 & 72.1 & 0.994\end{array}$

$\begin{array}{lllllll}5.7 & 2.767 & 1.52 & 61.4 & 54.3 & 0.766\end{array}$

$\begin{array}{lllllll}6.1 & 2.777 & 1.585 & 46.5 & 31.7 & 0.72\end{array}$

$\begin{array}{lllllll}5.4 & 2.789 & 1.526 & 48.1 & 65.5 & 0.87\end{array}$

$\begin{array}{llllllll}5.2 & 2.814 & 1.686 & 17.4 & 55.8 & 0.787\end{array}$

$\begin{array}{llllll}6.6 .2 .832 & 1.756 & 13.7 & 43.3 & 0.885\end{array}$

$\begin{array}{llllll}6.9 & 2.825 & 1.678 & 30.5 & 44.2 & 0.57\end{array}$

$\begin{array}{lllllll}7.2 & 2.823 & 1.69 & 32.2 & 30.1 & 0.508\end{array}$

$\begin{array}{llllll}8.2 & 2.834 & 1.738 & 27.6 & 22.1 & 0.441\end{array}$

$\begin{array}{lllllll}8.1 & 2.825 & 1.745 & 34.9 & 21.6 & 0.439\end{array}$

$\begin{array}{lllllll}6.7 & 2.817 & 1.708 & 44.1 & 30.3 & 0.549\end{array}$

$\begin{array}{lllllll}7.3 & 2.817 & 1.712 & 37.8 & 24.6 & 0.463\end{array}$

$\begin{array}{llllll}5.7 & 2.805 & 1.692 & 50 & 32.9 & 0.712\end{array}$

$\begin{array}{lllllll}6.1 & 2.739 & 1.579 & 39.8 & 58.9 & 0.784\end{array}$

$\begin{array}{llllll}6.9 & 2.744 & 1.593 & 29.9 & 36.7 & 0.642\end{array}$

$\begin{array}{llllll}7.3 & 2.748 & 1.616 & 15.8 & 12.7 & 0.543\end{array}$

$\begin{array}{llllll}7.4 & 2.752 & 1.642 & 8.8 & 7.1 & 0.505\end{array}$

$\begin{array}{llllll}8.3 & 2.768 & 1.719 & -4.3 & -0.6 & 0.443\end{array}$

$\begin{array}{llllll}6.3 & 2.747 & 1.904 & 3.5 & 43.8 & 0.676\end{array}$

$\begin{array}{llllll}8.1 & 2.749 & 1.915 & 1.2 & 34.8 & 0.541\end{array}$

$\begin{array}{llllll}9.4 & 2.752 & 1.923 & -0.4 & 20.3 & 0.459\end{array}$

$\begin{array}{llllll}10.3 & 2.773 & 1.982 & -11.9 & 2.5 & 0.394\end{array}$

$\begin{array}{llllll}11.4 & 2.801 & 2.124 & -31.9 & -7.7 & 0.332\end{array}$

$\begin{array}{llllll}6.5 & 2.769 & 1.743 & -24 & 16.4 & 0.68\end{array}$

$\begin{array}{lllllll}6.6 & 2.776 & 1.657 & -20.6 & 16.1 & 0.645\end{array}$

$\begin{array}{lllllllll}7.3 & 2.78 & 1.669 & -18.1 & 12.9 & 0.553\end{array}$

$\begin{array}{llllll}8.4 & 2.781 & 1.71 & -20.1 & 4 & 0.486\end{array}$

$\begin{array}{lllllll}6.4 & 2.767 & 1.644 & -3.1 & 15.5 & 0.664\end{array}$

$\begin{array}{llllll}6.5 & 2.773 & 1.617 & -1.8 & 15.1 & 0.649\end{array}$

$\begin{array}{llllll}6.4 & 2.762 & 1.579 & 2.4 & 14.6 & 0.636\end{array}$

$\begin{array}{llllll}7.3 & 2.771 & 1.662 & -6.5 & 2.3 & 0.478\end{array}$

$\begin{array}{llllll}6.0 & 2.749 & 1.605 & 17.2 & 6.3 & 0.667\end{array}$

$\begin{array}{llllll}5.4 & 2.757 & 1.616 & 8.5 & 9.3 & 0.809\end{array}$

$\begin{array}{llllll}7.2 & 2.761 & 1.644 & 7.4 & -2.3 & 0.456\end{array}$

$\begin{array}{lllllll}8.9 & 2.781 & 1.787 & 0.8 & -6.5 & 0.388\end{array}$

$\begin{array}{llllll}5.7 & 2.773 & 1.613 & 3.4 & 9.9 & 0.692\end{array}$ 
TP-3561

Table B-5. Data Summary for Direct-Contact Condenser Tests (Continued)

ERROR MARGINS

multiple sensor readings

\begin{tabular}{|c|c|c|c|c|c|c|c|c|c|c|c|c|c|c|c|c|c|c|c|}
\hline$w w$ &, 1 & & Tont & & & Lo & al & - & 2 & 2 & G1 & & L1 & 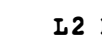 & & ror & . & tal & otc \\
\hline 8 & corr & & - & (z) & & & & (2) & & & & & 2s) & & Heat & NC & at1o & Eff & $\boldsymbol{E}$ \\
\hline 92 & 15.56 & 6 & & 0.25 & 1.0 & 47 & .95 & 2.2 & .16 & 7.6 & .61 & 0.49 & 37.51 & 42.19 & 1 & 27 & .72 & 0.76 & \\
\hline 39.9 & 15.57 & .01 & & 0.26 & .1 & 51 & 98 & 4.1 & .26 & 8.0 & .60 & .45 & 37.53 & 42.26 & 1 & 19 & .82 & .73 & 99.5 \\
\hline 9.91 & 12.03 & 6 & & 0.25 & .9 & 41 & .77 & 9.1 & .12 & 7.5 & .61 & 0.55 & 28.99 & 42.19 & 3 & 26 & .59 & 0.86 & 99.2 \\
\hline 39.8 & 12.00 & 98 & & 0.25 & .9 & 48 & .78 & 9.7 & .08 & 8.0 & .61 & .54 & 28.91 & 42.04 & 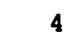 & 26 & .71 & .85 & 99.4 \\
\hline 9.56 & 11.98 & 6 & & 0.26 & .0 & 52 & .81 & 2.4 & 1.22 & 8.3 & .59 & .48 & 28.86 & 42.19 & 2 & 18 & .80 & .82 & 99.5 \\
\hline 9.55 & 11.96 & 6.02 & & 0.28 & 9 & 59 & .96 & 3.1 & 2.08 & 7.9 & .54 & 0.27 & 28.81 & 42.33 & -4 & 11 & 92 & .69 & 99.6 \\
\hline .77 & 14.79 & 88 & & .26 & .1 & 35 & .89 & 2.4 & .16 & 6.5 & .45 & .36 & 35.65 & 41.35 & - & 9 & 71 & .80 & 99.0. \\
\hline 0.21 & 14.64 & 5.9 & & 0.27 & .1 & 34 & .89 & 2.2 & 1.15 & 96.3 & .43 & 0.35 & 35.29 & 41.49 & 5 & 6 & .71 & 0.80 & 99.0 \\
\hline .08 & 14.55 & 5.87 & & 0.28 & 1.2 & 40 & .93 & 4.9 & 1.34 & 96.8 & .42 & 0.31 & 35.06 & 41.28 & 4 & 6 & .81 & .76 & 99.2 \\
\hline .03 & 14.57 & 5.87 & & 0.30 & .2 & 46 & .10 & 4.7 & 2.63 & 5.9 & .39 & 0.17 & 35.11 & 41.28 & -2 & -2 & 87 & .65 & 99.4 \\
\hline .08 & 14.55 & 5.9 & & 0.31 & 3.3 & 49 & .22 & 9.4 & 4.32 & 94.7 & .37 & 0.12 & 35.06 & 41.49 & -6 & -5 & .88 & 0.58 & 99.4 \\
\hline .07 & 16.15 & .52 & & .28 & .2 & 34 & .03 & 4.5 & 1.04 & 95.4 & .41 & 0.31 & 38.92 & 31.79 & 1 & 13 & .63 & .75 & 98.8 \\
\hline .02 & 16.17 & 47 & & 0 & 1.3 & 40 & .06 & .3 & .06 & .7 & .41 & .30 & 38.97 & 31.44 & 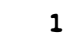 & 5 & .76 & 0.74 & 99.2 \\
\hline .04 & 16.34 & .44 & & 0.30 & .7 & 46 & .19 & 0.5 & 1.48 & 96.2 & .39 & .22 & 39.38 & 31.23 & -3 & 13 & .84 & 0.65 & 99.3 \\
\hline .02 & 16.36 & 4.43 & & 0.28 & .3 & 39 & .05 & 5.5 & 1.04 & 96.2 & .42 & 0.30 & 39.43 & 31.15 & 2 & 16 & .73 & 0.74 & 99.1 \\
\hline .09 & 0.85 & . 39 & & .27 & .2 & 39 & .83 & 5.5 & 1.01 & 96.6 & .43 & 0.31 & 26.15 & 23.84 & 7 & 16 & .64 & .91 & 9.2 \\
\hline .37 & 10.93 & 3.4 & & 0.29 & .5 & 49 & 0.95 & 8.7 & 1.25 & 95.9 & .41 & 0.25 & 26.33 & 23.91 & 4 & 43 & .80 & 0.79 & 99.1 \\
\hline .27 & 11.01 & 3.35 & & 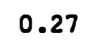 & .3 & 49 & .85 & 6.3 & 99. & .9 & .43 & 0.30 & 26.53 & 23.55 & 7 & 9 & 84 & 0.90 & 9.5 \\
\hline .88 & 11.00 & 3.33 & & 0.27 & .4 & 52 & .87 & 8.0 & 1.09 & 98.0 & .42 & 0.27 & 26.51 & 23.41 & 6 & 3 & .88 & 0.87 & 9.9 .6 \\
\hline .99 & 10.99 & 3.33 & & 29 & 1 & 54 & $.9 \%$ & 4.5 & 1.66 & 97.6 & .40 & 0.18 & 26.48 & 23.42 & 9 & -7 & 90 & 0.79 & 99.6 \\
\hline .82 & 11.32 & . 49 & & 0.28 & $\cdot 0$ & 54 & .99 & 4.0 & 1.20 & 97.7 & .41 & 0.19 & 27.28 & 17.51 & & -6 & 89 & 0.83 & 99.6 \\
\hline .06 & 11.33 & 2.49 & & 0.28 & 1.6 & 48 & .93 & 0.8 & 0.98 & 97.4 & .42 & 0.23 & 27.30 & 17.51 & 5 & 4 & .78 & 0.87 & 99.5 \\
\hline .06 & 11.32 & 2.48 & & 0 & 6 & 52 & 94 & 1.2 & 0.98 & 97.9 & .42 & 0.23 & 27.28 & 17.44 & 6 & -6 & .86 & .87 & 99.6 \\
\hline 9.94 & 11.32 & 2.46 & & 0.28 & 1.6 & 40 & .93 & 0.8 & 1.01 & 96.1 & .42 & 0.23 & 27.28 & 17.30 & 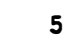 & 10 & & .88 & 9.2 \\
\hline 0.48 & 11.24 & 4.67 & & 0.28 & 1.1 & 39 & .79 & 71.2 & 1.06 & 97.1 & 0.42 & 0.36 & 27.10 & 32.84 & 6 & 11 & .74 & 0.89 & 99.2 \\
\hline 0.43 & 11.21 & 4.71 & & 0.28 & - & 44 & .80 & 1.8 & $1.11^{\circ}$ & 97.8 & .42 & 0.35 & 27.02 & 33.12 & 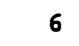 & 6 & .87 & 0.87 & 99.4 \\
\hline 0.43 & 11.22 & 4.68 & & 0.29 & 1.3 & 48 & .86 & 6.0 & 1.38 & 97.9 & .41 & 0.29 & 27.05 & 32.91 & 4 & -2 & .95 & 0.82 & 99.5 \\
\hline .37 & 11.21 & 4.68 & & 0.2 & $c$ & 50 & 90 & 9.5 & 1.70 & 97.7 & .40 & 0.24 & 27.02 & 32.91 & 2 & -6 & .96 & 0.78 & 99.5 \\
\hline .55 & 11.20 & & & 0.31 & & 53 & .03 & 7.5 & 2.99 & 96.8 & .38 & 0.14 & 27.00 & 32.63 & -2 & -13 & 98 & 0.68 & 99.6 \\
\hline .51 & 7.77 & .37 & & 0.2 & 1.0 & 42 & 15 & .5 & .00 & .8 & & 0.39 & 18.73 & & 7 & 15 & 66 & 0.93 & 99.3 \\
\hline .49 & 7.81 & 32 & & 0.2 &. & -8 & 76 & .9 & 0.96 & 98.5 & .43 & 0.38 & 18.81 & 34 & 7 & 13 & 80 & 0.91 & 9.5 \\
\hline .43 & 7.80 & 33 & & 0 & 1.0 & 56 & 17 & .1 & 0.85 & 98.8 & .43 & 0.38 & 18.78 & 23.41 & 8 & 9 & .92 & .90 & 9.7 \\
\hline .44 & .76 & 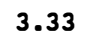 & & & & 6 & 83 & .4 & 93 & 98.9 & 42 & 0.32 & .70 & 41 & 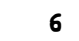 & 1 & 98 & .84 & 9.7 \\
\hline 0.06 & 7.76 & 31 & & 0.3 & 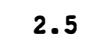 & 64 & .02 & 6.1 & 2.02 & 98.2 & .37 & 0.15 & 18.71 & 23.27 & -2 & -9 & 01 & 0.68 & 9.8 \\
\hline 0.04 & 13.86 & & & & & 46 & .29 & 78.2 & 1.02 & 96.7 & 8 & 0.24 & 33.39 & 17.23 & -6 & 15 & 81 & 0.65 & 99.3 \\
\hline .83 & 13.90 & 2.42 & & & 0 & 47 & 1.08 & .3 & 1.01 & 96.5 & .42 & 0.21 & 33.49 & 02 & 2 & 12 & .89 & 0.78 & 99.4 \\
\hline 95 & .88 & & & 0.2 & & 51 & .09 & 2.4 & 1.00 & 97.2 & .42 & 0.21 & 33.44 & 17.02 & 2 & 5 & .97 & 0.78 & 99.5 \\
\hline .84 & 13.89 & 2.38 & & 0.30 & 2,5 & 53 & 1.21 & 86.5 & 1.37 & 96.8 & .40 & 0.16 & 33.47 & 16.74 & -2 & -3 & 99. & 0.70 & 99.6 \\
\hline .72 & .91 & .28 & & 0.2 & .9 & 45 & .10 & 3.1 & 1.00 & 96.1 & .41 & 0.20 & 33.52 & 16.03 & 1 & 10 & .85 & 0.78 & 99.3 \\
\hline .74 & .79 & 2.42 & & 0.29 & 1.9 & 45 & 1.08 & 82.4 & 1.01 & 96.3 & 0.41 & 0.21 & 33.24 & 17.02 & 1 & 9 & .87 & 0.78 & 9.4 \\
\hline 0.62 & 3.78 & 2.4 & & 0.29 & 1.9 & 45 & 1.02 & 83.7 & 1.01 & 96.2 & 0.42 & 0.20 & 33.21 & 16.88 & 3 & 7 & .89 & 0.83 & 99.4 \\
\hline 0.62 & 13.74 & 2.37 & & & & 52 & 1.20 & 0.4 & 1.92 & 95.4 & 0.39 & 0.11 & 33.11 & 16.67 & -3 & -8 & 0.97 & 0.71 & 99.6 \\
\hline 0.39 & $14: 10$ & 2.55 & & 0.28 & 1.8 & 42 & 1.04 & 82.5 & 1.02 & 96.1 & 0.41 & 0.21 & 33.98 & 17.93 & 5 & 2 & 0.82 & 0.81 & 99.3 \\
\hline 30.49 & 13.95 & 2.54 & & 0.28 & .8 & 38 & 1.03 & 2.3 & 1.02 & 95.0 & 0.42 & 0.21 & 33.62 & 17.86 & 5 & 11 & 0.74 & 0.82 & 99.1 \\
\hline 0.45 & .95 & 2.51 & & 0.29 & 2.00 & 50 & 1.12 & 85.8 & $1.29^{\circ}$ & & 0.40 & 0.17 & 33.62 & 17.65 & 3 & -19 & .96 & 0.75 & 99.6 \\
\hline 30.47 & 13.94 & 2.46 & & 0.33 & 6.6 & 56 & 1.49 & 94.4 & 3.81 & 93.6 & 0.36 & 0.06 & 33.60 & 17.30 & -7 & -23 & .98 & 0.57 & 99.6 \\
\hline 30.45 & 13.91 & 2.42 & & 0.28 & 1.9 & 42 & 1.02 & 83.5 & 1.01 & 95.7 & 0.41 & 0.20 & 33.52 & 17.02 & 4 & 7 & 0.82 & 0.83 & 99.3 \\
\hline
\end{tabular}


$\mathrm{TP}-3561$

\section{Table B-5. Data Summary for Direct-Contact Condenser Tests (Continued)}

\begin{tabular}{|c|c|c|c|c|c|c|c|c|c|c|c|c|c|c|c|c|c|}
\hline te: & ome & data & were ob & alned fy & rom To & d & ces & when DT & T sen & rs wer & e over & e, & , or We & Nere & $\perp \mathbf{a}$ & d from & \\
\hline \multirow{2}{*}{\multicolumn{2}{|c|}{ Identifler }} & Tww1 & TCw1, 1 & TcW 1, 2 & Ts1, 1 & DTwW & DTCW & DTs1w1D & $31 s 0$ & Tew & DTsow1D: & 1 so & Pevap & $P 1,1$ & DP1 & DP2 & \\
\hline & & (C) & & & & & 1 & 1 & 1 & 2 & 2 & 2 & $(\mathrm{kPa})$ & & (Pa) & & \\
\hline 88121 & 4.007 & 26.5 & 6.5 & 6.52 & 14.4 & 3.3 & 6.2 & 7.8 & 0.0 & 7.3 & 1.2 & 5.8 & 2.781 & 1.65 & -0.9 & 10.8 & 0.7 \\
\hline 88121 & 4.008 & 26.5 & 6.5 & 6.46 & 14.6 & 3.3 & 5.7 & 8.1 & -0.0 & 7.7 & 1.5 & 5.9 & 2.778 & 31.674 & 5.4 & 10.4 & 0.722 \\
\hline 88121 & 4.009 & 26.5 & 6.3 & 6.15 & 13.5 & 3.4 & 5.6 & 7.2 & 0.3 & 3.7 & 0.0 & 6.8 & 2.746 & 61.545 & 33.7 & 28.5 & 0.647 \\
\hline 8812 & 14.01 & 26.5 & 6.2 & 6.10 & 13.3 & 3.4 & 6.0 & 7.1 & 0.2 & 3.1 & 0.1 & 6.6 & 2.748 & 31.535 & 28.3 & 26.3 & 0.643 \\
\hline 88121 & 4.011 & 26.5 & 6.3 & 6.21 & 13.2 & 3.6 & 6.1 & 6.9 & 0.1 & 2.8 & 0.1 & 6.2 & 2.709 & 1.529 & 21 & 25.8 & 0.64 \\
\hline 88121 & 5.003 & 26.5 & 6.4 & $6.33^{\circ}$ & 13.3 & 6.7 & 6.3 & 6.9 & 0.3 & 6.3 & 1.4 & 4.8 & 2.235 & 51.545 & 51.1 & 53.6 & 0.734 \\
\hline 88121 & 5.004 & 26.5 & 6.4 & 6.35 & 13.3 & 6.8 & 6.3 & 6.9 & 0.4 & 6.3 & 0.4 & 5.9 & 2.234 & 1.548 & 53.2 & 48.3 & 0.593 \\
\hline 88121 & 5.005 & 26.6 & 6.7 & 6.59 & 13.6 & 6.7 & 6.3 & 6.9 & 0.4 & 6.3 & 0.2 & 6.3 & 2.248 & 31.572 & 53.1 & 43.9 & 0.522 \\
\hline 88121 & 5.006 & 26.6 & 6.7 & 6.61 & 13.9 & 6.7 & 6.4 & 7.2 & 0.3 & 4.9 & 0.3 & 6.7 & 2.255 & 51.606 & 42.3 & 22.6 & 0.438 \\
\hline 88121 & 5.008 & 26.6 & 6.7 & 6.59 & 13.6 & 6.7 & 6.3 & 7.0 & 0.3 & 6.3 & 0.2 & 6.3 & 2.261 & 11.579 & 48.8 & 44.4 & 0.539 \\
\hline 88121 & 5.009 & 26.6 & 6.7 & 6.60 & 13.6 & 6.7 & 6.4 & 6.9 & 0.3 & 6.3 & 0.3 & 6.2 & 2.268 & 31.579 & 48.7 & 46.9 & 0.537 \\
\hline 8812 & 15.01 & 26.6 & 6.7 & 6.66 & 13.9 & 6.7 & 6.5 & 7.2 & 0.2 & 5.2 & 0.2 & 6.6 & 2.275 & $5 \quad 1.61$ & 41 & 23.7 & 0.428 \\
\hline 88121 & 5.011 & 26.7 & 6.9 & 6.83 & 14.5 & 2.4 & 6.2 & 7.6 & 0.1 & 7.0 & 1.0 & 5.7 & 2.958 & 31.669 & 35.4 & 29.5 & 0.896 \\
\hline 88121 & 5.012 & 26.7 & 6.8 & 6.80 & 14.5 & 2.4 & 6.3 & 7.6 & 0.0 & 7.0 & 0.5 & 6.4 & 2.96 & 61.674 & 32.6 & 27.4 & 0.77 \\
\hline 88121 & 5.013 & 26.7 & 6.8 & 6.73 & 14.5 & 2.4 & 6.3 & 7.7 & 0.0 & 7.0 & 0.2 & 6.9 & 2.961 & 11.675 & 30.8 & 24.1 & 0.66 \\
\hline 88121 & 5.014 & 26.2 & 6.6 & 6.55 & 14.3 & 2.2 & 6.2 & 7.7 & 0.1 & 4.6. & 0.1 & 6.9 & 2.946 & 61.661 & 38.7 & 22.2 & 0.791 \\
\hline 88121 & 5.015 & 26.3 & 6.5 & 6.45 & 13.8 & 2.2 & 6.2 & 7.3 & 0.3 & 6.3 & 0.1 & 6.5 & 2.938 & 3 1.595 & 51.3 & 39.8 & 0.869 \\
\hline 88121 & 5.016 & 26.4 & 6.5 & 6.44 & 13.7 & 2.2 & 6.2 & 7.2 & 0.3 & 6.4 & 0.5 & 5.9 & 2.934 & 41.589 & 54.8 & 50.1 & 1.03 \\
\hline
\end{tabular}

Deaerated cold seawater tests

\begin{tabular}{|c|c|c|c|c|c|c|c|c|c|c|c|c|c|c|c|c|}
\hline 81222.002 & 6.2 & 6.5 & 6.44 & 3.5 & 3.3 & 6.3 & 7.0 & 0.1 & 5.4 & 0.6 & 6.0 & 2.731 & 1.564 & 25.6 & 34.7 & 0.664 \\
\hline 881222.003 & 6.2 & 6.7 & 6.59 & 3.5 & 3.4 & 6.2 & 6.8 & 0.3 & 5.9 & 1.3 & 5.0 & 2.72 & 1.562 & 45.9 & 59.8 & 0.835 \\
\hline 81222.004 & 6.2 & 6.7 & 6.63 & 14.1 & .3 & 5.5 & 7.4 & 0.2 & .9 & 1.0 & .3 & 2.722 & 1.625 & 38.1 & 16.8 & 0.57 \\
\hline 381222.005 & 6.2 & 6.6 & 6.56 & 4.9 & .3 & .5 & 8.3 & 0.2 & .7 & 1.0 & .8 & 2.729 & 1.705 & 37.9 & 9.6 & 0.49 \\
\hline 881222.006 & 26.2 & 6.6 & 6.54 & 13.6 & .4 & .2 & 7.0 & 0.3 & .7 & 0.8 & .0 & 2.715 & 1.576 & 3.7 & 45 & 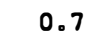 \\
\hline 381222.007 & 26.2 & 6.6 & 6.52 & 13.7 & .4 & 6.1 & 7.1 & 0.1 & .9 & 0.8 & 6.0 & 2.735 & 1.595 & 41 & 42.9 & 0.68 \\
\hline 881222.008 & 26.2 & 9.0 & 8.96 & 15.7 & .3 & 5.5 & 6.7 & 0.1 & 5.0 & .6 & 5.8 & 2.741 & 1.811 & 40.4 & 39.2 & 0.51 \\
\hline 81222.009 & 26.3 & 9.3 & 9.24 & 16.0 & .3 & 5.6 & 6.7 & 0.2 & 6.1 & 0.8 & 5.7 & 2.741 & 1.837 & 40.4 & 41.1 & 0.52 \\
\hline 881222.01 & 26.3 & 9.4 & 9.36 & 16.1 & .4 & 5.7 & 6.7 & 0.3 & .2 & 0.9 & 5.5 & 2.732 & 1.85 & 47.8 & 42.7 & 0.52 \\
\hline 881222.011 & 26.3 & .9 .7 & 9.65 & 16.4 & .4 & 5.7 & & & .2 & 1.7 & 1.7 & 2.739 & 1.875 & 52.9 & 48.2 & 0.61 \\
\hline 81222.012 & 26.3 & 9.9 & 9.78 & 16.5 & 3.3 & 5.6 & 6.7 & 0.3 & 6.0 & 0.6 & 6.0 & 2.745 & 1.896 & 50.8 & 27.7 & 0.48 \\
\hline 381222.013 & 26.3 & 9.8 & 9.72 & 16.7 & 3.3 & 5.6 & 6.9 & 0.3 & 5.1 & 0.6 & 6.2 & 2.747 & 1.911 & 47.9 & 12.7 & 0.41 \\
\hline 381222.014 & 26.3 & 9.7 & 9.63 & 17.0 & 3.3 & 5.6 & 7.3 & 0.3 & 3.4 & 0.7 & 6.5 & 2.751 & 1.951 & 41.8 & 4.3 & 0.36 \\
\hline 881227.002 & 26.1 & 6.3 & 6.23 & 16.4 & 3.4 & 7.5 & 10.1 & 0.0 & 4.9 & 0.5 & 9.4 & 2.617 & 1.889 & 21.5 & 48.2 & 0.74 \\
\hline 881227.003 & 26.1 & 6.4 & 6.27 & 16.1 & 3.4 & 7.4 & 9.7 & 0.0 & 5.5 & 0.6 & 9.1 & 2.614 & 1.85 & 29.5 & 65.3 & 0.81 \\
\hline 881227.004 & 26.2 & 6.4 & 6.26 & 15.5 & 3.4 & 7.2 & 9.1 & 0.3 & 6.1 & 0.4 & 8.4 & 2.638 & 1.791 & 61.1 & 102.6 & 0.95 \\
\hline 881227.005 & 26.2 & 6.3 & 6.19 & 15.1 & 3.4 & 6.9 & 8.8 & 0.4 & 6.3 & 0.8 & 7.5 & 2.647 & 1.742 & 76.1 & 143.5 & 1.10 \\
\hline 881227.006 & 26.1 & .0 & 85 & 19.8 & 3.3 & 6.5 & & 0.8 & 4.9 & 1.7 & 5.1 & 2.642 & 2.305 & 104.9 & 94.8 & 0.7 \\
\hline 881227.007 & 26.1 & 11.9 & 11.80 & 20.0 & 3.3 & 6.5 & 8.1 & 0.8 & 4.8 & 0.8 & 6.6 & 2.638 & 2.33 & 98.7 & 68.2 & 0.60 \\
\hline 881227.008 & 26.1 & 11.9 & 11.78 & 20.7 & 3.4 & 6.9 & 8.8 & 0.7 & 4.0 & 1.0 & 7.2 & 2.627 & 2.424 & 83.2 & 39 & 0.5 \\
\hline 881227.009 & 26.1 & 12.0 & 11.86 & 21.0 & 3.3 & 7.0 & 9.0 & 0.7 & 3.3 & 1.0 & 7.4 & 2.614 & 2.464 & 84 & 32 & 0.51 \\
\hline 881228.002 & 26.0 & 6.4 & 6.32 & 12.3 & 3.3 & 5.7 & 5.9 & 0.2 & 5.6 & 1.2 & 4.7 & 2.757 & 1.456 & 40.7 & 24 & 0.58 \\
\hline 881228.003 & 26.0 & 6.5 & 6.38 & 12.7 & 3.3 & 5.8 & 6.2 & 0.5 & 5.4 & 0.7 & 5.5 & 2.746 & 1.464 & 47.4 & 15.1 & 0.4 \\
\hline 881228.004 & 26.0 & 6.4 & 6.33 & 13.7 & 3.3 & 6.1 & 7.2 & 1.1 & 4.3 & 0.7 & 5.8 & 2.728 & 1.5 & 45.2 & -2 & 0.3 \\
\hline 881228.005 & 26.1 & 6.7 & 6.58 & 12.3 & 3.3 & 5.7 & 5.7. & -0.0 & 5.5 & 0.7 & 5.0 & 2.725 & 1.481 & 47.3 & 16.3 & 0.45 \\
\hline 881228.006 & 26.1 & 6.6 & 6.52 & 12.6 & 3.3 & 6.0 & 6.0 & -0.0 & 4.5 & 0.5 & 5.7 & 2.731 & 1.51 & 47.3 & -1.4 & 0.3 \\
\hline 881228.007 & 26.0 & 6.4 & 6.30 & 13.3 & 3.3 & 6.6 & 7.0 & 0.0 & 2.5 & 0.4 & 6.5 & 2.736 & 1.575 & 44.5 & -9.4 & 0.3 \\
\hline
\end{tabular}


TP-3561

Table B-5. Data Summary for Direct-Contact Condenser Tests (Continued)

ERROR MARGINS

multiple sensor readings

QWW QcW,1 QcW, 2 Leak $x 11,1$ x11,2 X10 Jal F1 Ja2 F2 $\quad$ G1 G2 L1 L2 ErrorError Vent Total Total

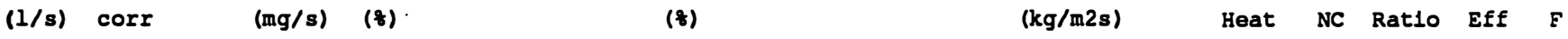

$\begin{array}{rrr}30.48 & 13.95 & 2.39 \\ 30.55 & 13.94 & 2.38 \\ 29.75 & 13.93 & 5.98 \\ 29.79 & 13.94 & 5.98 \\ 27.91 & 13.92 & 5.99 \\ 15.46 & 13.73 & 3.64 \\ 15.43 & 13.72 & 3.63 \\ 15.42 & 13.72 & 3.65 \\ 15.44 & 13.74 & 3.63 \\ 15.41 & 13.73 & 3.63 \\ 15.4 & 13.72 & 3.63 \\ 15.42 & 13.72 & 3.63 \\ 43.15 & 13.82 & 2.5 \\ 43.21 & 13.81 & 2.49 \\ 43.14 & 13.80 & 2.48 \\ 46.91 & 13.78 & 3.5 \\ 46.61 & 13.72 & 3.49 \\ 46.52 & 13.70 & 3.31\end{array}$

$30.57 \quad 13.10 \quad 3.45$ $30.45 \quad 13.08 \quad 3.37$

$30.5 \quad 13.06 \quad 3.34$

$30.58 \cdot 13.06 \quad 3.39$

$\begin{array}{lll}30.6 & 13.07 \quad 3.4\end{array}$

$30.59 \quad 13.18 \quad 3.46$

$30.57 \quad 13.36 \quad 3.49$

$30.79 \quad 13.54 \quad 3.5$

$30.67 \quad 13.43 \quad 3.57$

$30.7 \quad 13.35 \quad 3.64$

$30.65 \quad 13.35 \quad 3.62$

$30.5 \quad 13.37 \quad 3.64$

$30.55 \quad 13.39 \quad 3.68$

$46.13 \quad 15.20 \quad 5.89$

$\begin{array}{llll}46.16 & 15.21 \quad 5.9\end{array}$

$45.68 \quad 15.16 \quad 5.96$

$\begin{array}{lll}45.74 & 15.30 \quad 5.9\end{array}$

$\begin{array}{lll}45.34 & 15.23 \quad 6.19\end{array}$

$45.315 .18 \quad 6$

$\begin{array}{llll}45.27 & 15.20 \quad 6.07\end{array}$

$\begin{array}{llll}45.18 & 15.28 & 6.08\end{array}$

$\begin{array}{lll}15.27 & 6.19 & 2.01\end{array}$

$\begin{array}{lll}15.27 & 6.19 & 2\end{array}$

$\begin{array}{lll}15.26 & 6.21 & 1.99\end{array}$

$\begin{array}{lll}15.27 & 6.31 & 1.95\end{array}$

$\begin{array}{lll}15.25 & 6.32 & 1.99\end{array}$

$\begin{array}{lll}15.2 & 6.30 & 2.03\end{array}$

$\begin{array}{ll}0.29 & 1.8 \\ 0.31 & 1.8 \\ 0.29 & 1.5 \\ 0.29 & 1.7 \\ 0.27 & 1.8 \\ 0.14 & 0.7 \\ 0.14 & 0.7 \\ 0.14 & 0.7 \\ 0.14 & 1.0 \\ 0.14 & 0.7 \\ 0.14 & 0.7 \\ 0.14 & 0.9 \\ 0.41 & 2.6 \\ 0.41 & 2.6 \\ 0.41 & 2.7 \\ 0.45 & 3.1 \\ 0.43 & 2.3 \\ 0.43 & 2.3\end{array}$

$\begin{array}{llllllllll}41 & 1.09 & 82.5 & 1.02 & 95.7 & 0.41 & 0.21 & 33.62 & 16.81\end{array}$

$\begin{array}{llllllllll}41 & 1.19 & 80.6 & 1.02 & 95.8 & 0.39 & 0.22 & 33.60 & 16.74\end{array}$

$\begin{array}{lllllllll}45 & 1.04 & 77.6 & 1.85 & 97.0 & 0.39 & 0.26 & 33.58 & 42.06\end{array}$

$\begin{array}{lllllllll}45 & 1.01 & 81.2 & 2.11 & 96.5 & 0.40 & 0.22 & 33.60 & 42.06\end{array}$

$\begin{array}{lllllllll}44 & 0.99 & 82.9 & 2.24 & 96.1 & 0.39 & 0.20 & 33.55 & 42.13\end{array}$

$\begin{array}{llllllllll}33 & 0.90 & 78.4 & 1.02 & 96.2 & 0.43 & -0.27 & 33.08 & 25.60\end{array}$

$\begin{array}{llllllllll}40 & 0.90 & 78.7 & 1.04 & 97.2 & 0.43 & 0.27 & 33.06 & 25.53\end{array}$

$\begin{array}{lllllllll}43 & 0.90 & 78.7 & 1.04 & 97.7 & 0.43 & 0.27 & 33.06 & 25.67\end{array}$

$\begin{array}{lllllllll}47 & 0.98 & 83.0 & 1.40 & 97.6 & 0.41 & 0.20 & 33.11 & 25.53\end{array}$

$\begin{array}{lllllllll}44 & 0.90 & 78.8 & 1.04 & 97.6 & 0.43 & 0.27 & 33.08 & 25.53\end{array}$

$\begin{array}{lllllllll}43 & 0.90 & 78.8 & 1.04 & 97.6 & 0.43 & 0.27 & 33.06 & 25.53\end{array}$

$\begin{array}{lllllllll}47 & 0.95 & 82.1 & 1.30 & 97.9 & 0.42 & 0.22 & 33.06 & 25.53\end{array}$

$\begin{array}{llllllllll}41 & 1.04 & 82.4 & 1.02 & 94.5 & 0.41 & 0.21 & 33.31 & 17.58\end{array}$

$46 \quad 1.05$

$82.6 \quad 1.02$

$\begin{array}{lllll}95.6 & 0.41 & 0.21 & 33.29 & 17.51\end{array}$

501.06

$82.9 \quad 1.01$

$50 \quad 1.08$

$46 \quad 0.97$

83.51 .49

$\begin{array}{llllll}96.4 & 0.41 & 0.20 & 33.26 & 17.44\end{array}$

$\begin{array}{lllllll}95.4 & 0.40 & 0.19 & 33.21 & 24.61\end{array}$

420.96

$79.0 \quad 1.03$

$94.0 \quad 0.42 \quad 0.26 \quad 33.06 \quad 24.54$

$\begin{array}{rrrrr}3 & 8 & 0.79 & 0.78 & 99.2 \\ -2 & 8 & 0.75 & 0.71 & 99.2 \\ -1 & 3 & 0.89 & 0.67 & 99.3 \\ 2 & 3 & 0.90 & 0.69 & 99.3 \\ 0 & 4 & 0.91 & 0.70 & 99.3 \\ 5 & 20 & 0.63 & 0.87 & 99.2 \\ 5 & 19 & 0.76 & 0.87 & 99.4 \\ 6 & 14 & 0.81 & 0.87 & 99.5 \\ 3 & 6 & 0.88 & 0.81 & 99.6 \\ 5 & 20 & 0.82 & 0.87 & 99.5 \\ 6 & 18 & 0.79 & 0.88 & 99.5 \\ 5 & 6 & 0.88 & 0.83 & 99.6 \\ 2 & 9 & 0.72 & 0.81 & 99.0 \\ 2 & 5 & 0.82 & 0.80 & 99.2 \\ 2 & -2 & 0.89 & 0.80 & 99.4 \\ -0 & 11 & 0.89 & 0.73 & 99.2 \\ 3 & 11 & 0.83 & 0.82 & 99.1 \\ 2 & 18 & 0.74 & 0.83 & 98.9\end{array}$

20

$\begin{array}{ll}0.30 & 1.8 \\ 0.30 & 1.6 \\ 0.31 & 2.5 \\ 0.33 & 5.3 \\ 0.30 & 1.7 \\ 0.30 & 1.6 \\ 0.32 & 1.6 \\ 0.31 & 1.6 \\ 0.31 & 1.5 \\ 0.31 & 1.5 \\ 0.31 & 1.5 \\ 0.32 & 1.8 \\ 0.35 & 2.6 \\ 0.32 & 1.7 \\ 0.32 & 1.5 \\ 0.31 & 1.4 \\ 0.32 & 1.3 \\ 0.35 & 1.6 \\ 0.35 & 1.7 \\ 0.34 & 2.0 \\ 0.35 & 2.4 \\ 0.32 & 1.4 \\ 0.32 & 1.5 \\ 0.33 & 1.9 \\ 0.32 & 1.5 \\ 0.32 & 1.8 \\ 0.32 & 3.2 \\ & \end{array}$

340.91

$46 \quad 1.02 \quad 86$

$51 \quad 1.22$$$
41
$$

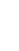

35

$\begin{array}{llllllllll}35 & 0.93 & 76.5 & 0.98 & 96.9 & 0.39 & 0.26 & 32.15 & 25.58\end{array}$

$\begin{array}{lllllllll}43 & 0.96 & 77.3 & 1.05 & 97.7 & 0.38 & 0.25 & 32.15 & 25.44\end{array}$

$\begin{array}{lllllllll}45 & 1.02 & 79.9 & 1.26 & 97.8 & 0.37 & 0.22 & 32.20 & 25.58\end{array}$

$\begin{array}{llllllllll}47 & 1.16 & 85.4 & 1.97 & 97.3 & 0.34 & 0.15 & 32.25 & 25.87\end{array}$

$\begin{array}{llllllllll}56 & 1.10 & 79.7 & 1.64 & 97.7 & 0.56 & 0.33 & 36.64 & 41.42\end{array}$

$\begin{array}{llllllllll}54 & 1.05 & 77.1 & 1.43 & 97.7 & 0.57 & 0.38 & 36.66 & 41.49\end{array}$

$\begin{array}{lllllllll}51 & 0.98 & 74.6 & 1.29 & 97.4 & 0.57 & 0.42 & 36.54 & 41.91\end{array}$

$\begin{array}{llllllllll}45 & 0.96 & 73.3 & 1.20 & 96.9 & 0.56 & 0.44 & 36.87 & 41.49\end{array}$

$\begin{array}{llllllllll}34 & 0.96 & 76.0 & 1.49 & 97.3 & 0.51 & 0.36 & 36.68 & 43.48\end{array}$

$\begin{array}{llllllllll}43 & 0.99 & 77.2 & 1.61 & 97.8 & 0.50 & 0.33 & 36.55 & 42.15 & -18\end{array}$

$\begin{array}{lllllllllll}47 & 1.06 & 81.0 & 2.11 & 97.9 & 0.51 & 0.28 & 36.60 & 42.64 & -17\end{array}$

$\begin{array}{lllllllllll}47 & 1.11 & 83.8 & 2.61 & 97.6 & 0.50 & 0.24 & 36.78 & 42.71 & -18\end{array}$

$\begin{array}{llllllllll}32 & 0.82 & 74.9 & 1.02 & 94.1 & 0.18 & 0.13 & 14.93 & 14.14\end{array}$

$\begin{array}{llllllllll}39 & 0.86 & 75.9 & 1.05 & 95.4 & 0.18 & 0.13 & 14.93 & 14.06\end{array}$

$\begin{array}{lllllllll}44 & 1.00 & 81.0 & 1.41 & 95.5 & 0.18 & 0.10 & 14.98 & 13.99\end{array}$

$\begin{array}{llllllllll}38 & 0.80 & 76.1 & 1.01 & 95.1 & 0.18 & 0.13 & 15.21 & 13.71\end{array}$

$\begin{array}{llllllllll}44 & 0.85 & 80.3 & 1.32 & 95.7 & 0.18 & 0.10 & 15.23 & 13.99\end{array}$

48

$\begin{array}{rrrrr}-1 & 3 & 0.85 & 0.84 & 99.3 \\ -1 & 4 & 0.67 & 0.87 & 99.0 \\ -4 & -3 & 0.87 & 0.77 & 99.4 \\ -9 & -8 & 0.90 & 0.65 & 99.5 \\ -2 & 8 & 0.81 & 0.84 & 99.2 \\ -2 & 12 & 0.82 & 0.81 & 99.3 \\ -7 & -29 & 0.83 & 0.81 & 99.4 \\ -6 & -32 & 0.81 & 0.82 & 99.4 \\ -5 & -35 & 0.78 & 0.83 & 99.4 \\ -5 & -33 & 0.67 & 0.83 & 99.3 \\ -6 & -38 & 0.85 & 0.82 & 99.5 \\ -8 & -51 & 0.89 & 0.77 & 99.6 \\ -14 & -66 & 0.91 & 0.67 & 99.6 \\ -9 & 13 & 0.89 & 0.65 & 99.5 \\ -8 & 18 & 0.86 & 0.69 & 99.5 \\ -7 & 26 & 0.78 & 0.73 & 99.3 \\ -7 & 27 & 0.67 & 0.74 & 99.2 \\ -18 & -66 & 0.54 & 0.74 & 99.3 \\ -18 & -50 & 0.72 & 0.72 & 99.5 \\ -17 & -56 & 0.77 & 0.67 & 99.6 \\ -18 & -59 & 0.77 & 0.64 & 99.6 \\ -9 & 23 & 0.71 & 0.91 & 98.5 \\ -9 & 21 & 0.83 & 0.87 & 98.9 \\ -9 & 16 & 0.88 & 0.75 & 99.1 \\ -9 & 24 & 0.79 & 0.94 & 98.8 \\ -8 & 16 & 0.88 & 0.89 & 99.2 \\ -6 & 10 & 0.90 & 0.77 & 99.3\end{array}$




\section{Table B-5. Data Summary for Direct-Contact Condenser Tests (Concluded)}

\begin{tabular}{|c|c|c|c|c|c|c|c|c|c|c|c|c|c|c|c|c|}
\hline Note: Some & data & were obt & alned $f_{x}$ & $\operatorname{com} T$ & differ & ences & when DT & senso & ors wer & e over & c range, & or we & ere cal & culated & ad fron & m othe \\
\hline \multirow[t]{2}{*}{ Identifler } & TwW1 & Tcw1, 1 & TcW1, 2 & $T s 1,1$ & DTwW & DTcw & DTs1w1D & Ts1so & DTew I & DTsow1D & LDTs1so & Pevap & $\mathrm{P} 1,1$ & DP1 & DP2 & Pexh \\
\hline & (C) & & & & & 1 & 1 & 1 & 2 & 2 & 2 & (kPa) & & $(\mathrm{Pa})$ & & \\
\hline \multicolumn{17}{|l|}{ Fresh water } \\
\hline 890106.002 & 25.3 & 9.6 & 9.47 & 16.1 & 3.3 & 6.1 & 6.5 & 0.5 & 6.1 & 1.5 & 4.3 & 2.563 & 1.877 & 49.2 & 21.4 & 0.517 \\
\hline 890106.003 & 25.3 & 9.5 & 9.42 & 16.1 & 3.3 & 6.1 & 6.6 & 0.6 & 6.1 & 0.6 & 5.4 & 2.567 & 1.875 & 50 & 13 & 0.456 \\
\hline 890106.004 & 25.3 & 9.6 & 9.51 & 16.2 & 3.3 & 6.3 & 6.7 & 0.6 & 5.9 & 0.3 & 5.9 & 2.582 & 1.895 & 49.4 & -1.8 & 0.419 \\
\hline 890106.005 & 25.3 & 9.5 & 9.42 & 16.7 & 3.2 & 6.3 & 7.3 & 0.6 & 4.1 & 0.4 & 6.3 & 2.589 & 1.944 & 48.1 & -18.5 & 0.351 \\
\hline 890106.006 & 25.3 & 9.5 & 9.38 & 16.9 & 3.2 & 6.4 & 7.4 & 0.7 & 3.5 & 0.5 & 6.4 & 2.603 & 1.97 & 39.4 & -19.8 & 0.346 \\
\hline 890106.007 & 25.3 & 9.7 & 9.64 & 16.3 & 3.3 & 6.1 & 6.6 & 0.6 & 6.1 & 0.7 & 5.3 & 2.587 & 1.905 & 12.6 & -17.9 & 0.471 \\
\hline 890106.008 & 25.3 & 9.8 & 9.68 & 16.3 & 3.3 & 6.1 & 6.6 & 0.6 & 6.1 & 0.7 & 5.3 & 2.6 & 1.908 & 18 & 17.8 & 0.472 \\
\hline
\end{tabular}


Table B-5. Data Summary for Direct-Contact Condenser Tests (Concluded)

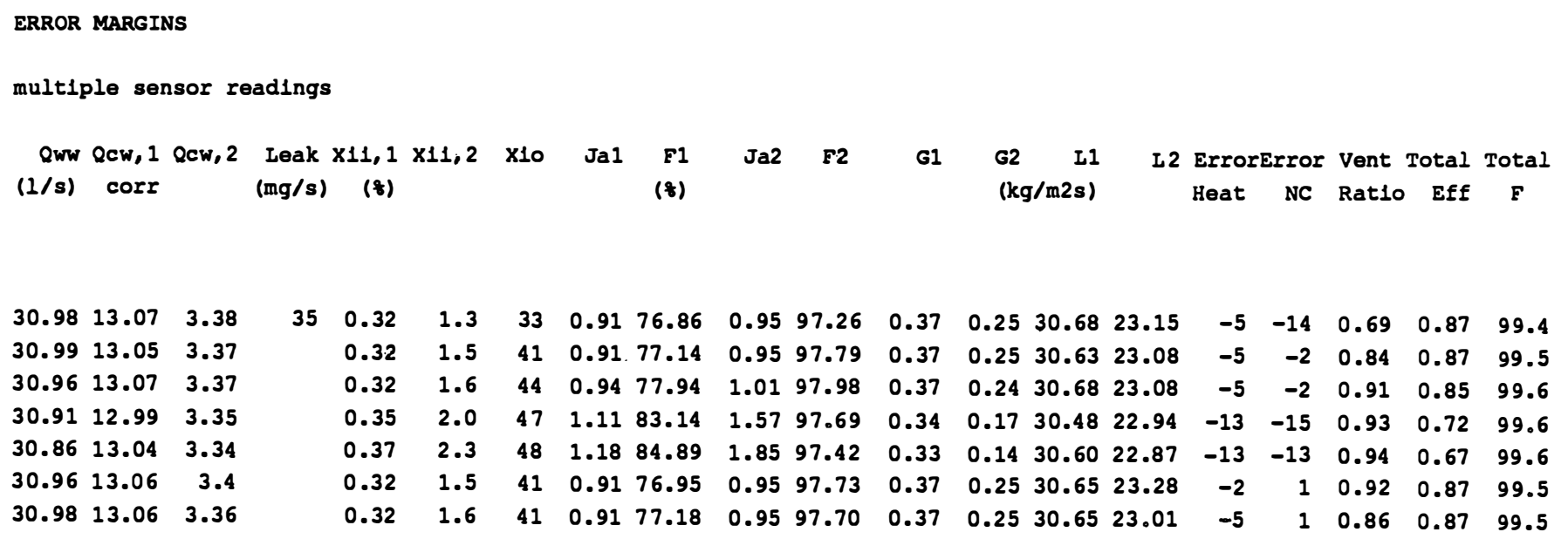


Table B-6. Effect of Principal Parameters on Cocurrent Stage

$\begin{array}{cccccccccccc}\text { Dataf1le } & \text { TCw1,1 } & \text { Ts1,1 } & \text { DTCW } & \text { P1,1 } & \text { DP1 } & \text { X11,1 } & \text { G1 } & \text { I1 } & \text { Jal } & \text { F1 } & \text { Eff1 } \\ & \text { (C) } & & 1 & \text { (kPa) } & \text { (Pa) } & \text { (z) } & \text { (kg/m2s) } & & \text { (z) } & \end{array}$

Effect of. Jakob Number (coaxlal data)

$\begin{array}{rrrrrrrrrrrr}890413.006 & 6.0 & 13.2 & 7.08 & 1.573 & 18.3 & 0.34 & 0.41 & 25.68 & 0.75 & 70.9 & 0.94 \\ 890413.005 & 6.0 & 13.4 & 7.3 & 1.6 & 16.4 & 0.34 & 0.41 & 25.68 & 0.78 & 73.6 & 0.94 \\ 890307.006 & 6.2 & 12.5 & 6.25 & 1.523 & 19 & 0.33 & 0.41 & 32.03 & 0.81 & 77.9 & 0.96 \\ 890310.002 & 6.6 & 12.8 & 6.2 & 1.522 & 16.5 & 0.33 & 0.41 & 32.16 & 0.82 & 77.7 & 0.94 \\ 890307.003 & 6.1 & 12.6 & 6.42 & 1.528 & 18 & 0.33 & 0.41 & 32.04 & 0.84 & 79.8 & 0.95 \\ 890413.009 & 5.9 & 12.5 & 6.25 & 1.501 & -3.5 & 0.34 & 0.41 & 32.42 & 0.85 & 78.7 & 0.93 \\ 890413.008 & 5.9 & 12.6 & 6.26 & 1.518 & -3.5 & 0.34 & 0.41 & 32.45 & 0.87 & 80.0 & 0.92 \\ 890426.01 & 6.2 & 14.8 & 8.44 & 2.1 & 13.7 & 0.31 & 0.41 & 25.27 & 0.88 & 82.2 & 0.94 \\ 890317.006 & 6.2 & 13.5 & 6.47 & 1.526 & 19.1 & 0.33 & 0.41 & 31.63 & 0.89 & 80.5 & 0.90 \\ 890306.005 & 6.2 & 12.7 & 6.3 & 1.497 & 2.8 & 0.27 & 0.40 & 33.37 & 0.90 & 83.4 & 0.93 \\ 890306.006 & 6.3 & 12.9 & 6.36 & 1.506 & 1.7 & 0.27 & 0.40 & 33.40 & 0.91 & 84.2 & 0.93 \\ 890317.007 & 6.1 & 13.8 & 6.8 & 1.546 & 17.7 & 0.33 & 0.41 & 31.61 & 0.92 & 83.4 & 0.91 \\ 890306.009 & 6.3 & 12.9 & 6.43 & 1.506 & 0.7 & 0.27 & 0.40 & 33.47 & 0.93 & 86.1 & 0.93 \\ 890306.008 & 6.1 & 13.2 & 6.8 & 1.535 & -1.6 & 0.27 & 0.40 & 33.40 & 0.99 & 90.8 & 0.92\end{array}$

Effect of Steam Loading (s1de-by-side data)

$\begin{array}{rrrrrrrrrrrr}881209.007 & 6.2 & 13.1 & 5.9 & 1.489 & -13.2 & 0.27 & 0.22 & 18.05 & 0.96 & 78.8 & 0.82 \\ 881212.012 & 6.4 & 15.3 & 7.6 & 1.756 & 13.7 & 0.29 & 0.41 & 26.33 & 0.95 & 78.7 & 0.82 \\ 881215.016 & 6.5 & 13.7 & 6.2 & 1.589 & 54.8 & 0.43 & 0.42 & 33.01 & 0.96 & 79.0 & 0.82 \\ 881201.012 & 6.3 & 13.4 & 6.1 & 1.556 & 29.3 & 0.20 & 0.43 & 34.16 & 0.94 & 77.9 & 0.83 \\ 881208.006 & 6.5 & 14.2 & 6.5 & 1.621 & 74.8 & 0.26 & 0.44 & 32.73 & 0.96 & 78.2 & 0.82 \\ 881207.006 & 6.2 & 15.2 & 7.5 & 1.732 & 30.5 & 0.28 & 0.52 & 33.44 & 0.96 & 77.6 & 0.81 \\ 881209.013 & 6.2 & 15.4 & 7.2 & 1.773 & 51.6 & 0.26 & 0.60 & 37.61 & 0.96 & 73.0 & 0.76 \\ 881209.01 & 6.2 & 15.4 & 7.2 & 1.78 & 39.6 & 0.26 & 0.60 & 37.61 & 0.96 & 72.8 & 0.76 \\ 881209.014 & 6.2 & 15.4 & 7.2 & 1.774 & 56.8 & 0.25 & 0.61 & 37.51 & 0.95 & 72.2 & 0.76\end{array}$

Effect of Inlet Steam Saturation Temperature

$\begin{array}{rrrrrrrrrrrr}890413.011 & 6.0 & 12.3 & 6.28 & 1.483 & 13.1 & 0.32 & 0.44 & 36.77 & 0.90 & 84.8 & 0.94 \\ 890414.002 & 6.0 & 12.8 & 6.75 & 1.526 & 21.2 & 0.32 & 0.47 & 36.48 & 0.89 & 84.1 & 0.95 \\ 890425.009 & 6.3 & 12.8 & 6.54 & 1.584 & 13 & 0.29 & 0.44 & 35.22 & 0.88 & 84.3 & 0.95 \\ 890418.003 & 6.1 & 12.9 & 6.76 & 1.565 & 17.9 & 0.31 & 0.45 & 34.97 & 0.89 & 85.0 & 0.95 \\ 890414.004 & 6.2 & 13.0 & 6.78 & 1.545 & 21.4 & 0.33 & 0.47 & 36.44 & 0.89 & 84.9 & 0.95 \\ 890310.004 & 6.6 & 13.5 & 6.83 & 1.586 & 11.7 & 0.33 & 0.42 & 32.22 & 0.89 & 84.9 & 0.95 \\ 890317.004 & 6.3 & 13.7 & 6.86 & 1.554 & 18.5 & 0.31 & 0.44 & 32.12 & 0.88 & 80.1 & 0.91 \\ 890315.004 & 6.5 & 14.3 & 7.31 & 1.645 & 15.4 & 0.34 & 0.46 & 31.93 & 0.91 & 79.7 & 0.88 \\ 890426.01 & 6.2 & 14.8 & 8.44 & 2.1 & 13.7 & 0.31 & 0.41 & 25.27 & 0.88 & 82.2 & 0.94 \\ 890310.009 & 6.6 & 15.7 & 9.24 & 1.844 & -2.4 & 0.34 & 0.40 & 23.95 & 0.91 & 88.8 & 0.98\end{array}$

Effect of Inlet Noncondensable Gas Concentration

$\begin{array}{rrrrrrrrrrrr}881215.01 & 6.7 & 13.9 & 6.5 & 1.61 & 41 & 0.14 & 0.42 & 33.06 & 0.95 & 82.1 & 0.86 \\ 881201.005 & 6.3 & 13.6 & 6.2 & 1.571 & 20.7 & 0.22 & 0.41 & 32.04 & 0.97 & 78.4 & 0.81 \\ 881212.012 & 6.4 & 15.3 & 7.6 & 1.756 & 13.7 & 0.29 & 0.41 & 26.33 & 0.95 & 78.7 & 0.82 \\ 881215.016 & 6.5 & 13.7 & 6.2 & 1.589 & 54.8 & 0.43 & 0.42 & 33.01 & 0.96 & 79.0 & 0.82\end{array}$


Table B-7. Effect of Principal Parameters on Countercurrent Stage

Dataf1le TCW1,2: Ts1,2 DTCW P1n,2 DP2 X11,2 X10 He1ght G2 L2 Ja2 $^{\text {F2 }}$ Eff2
(c)
$2 \quad(\mathrm{kPa}) \quad(\mathrm{Pa})$
(ซ)
(m) $\quad(\mathrm{kg} / \mathrm{m} 2 \mathrm{~s})$
(子)

Effect of Jakob Number

\begin{tabular}{|c|c|c|c|c|c|c|c|c|c|c|c|c|c|}
\hline 90307.003 & 6.0 & 12.33 & 6.18 & 1.510 & 35 & 3.8 & 41 & 1.35 & 0.25 & 24.16 & 1.01 & 94.4 & 0.93 \\
\hline 890310.01 & 6.4 & 12.93 & 6.19 & 1.543 & 59.2 & 1.8 & 37 & 1.35 & 0.25 & 24.21 & 1.03 & 96.6 & 0.94 \\
\hline 890317.005 & 6.3 & 12.77 & 6.23 & 1.500 & 28.4 & 2.0 & 40 & 1.35 & 0.25 & 24.31 & 1.04 & 96.8 & 0.93 \\
\hline 890310.011 & 6.4 & 12.98 & 6.07 & 1.544 & 42.8 & 1.9 & 43 & 1.35 & 0.24 & 24.24 & 1.09 & 97.1 & 0.89 \\
\hline 890317.006 & 6.3 & 12.83 & 5.99 & 1.507 & 15.7 & 2.1 & 44 & 1.35 & 0.24 & 24.10 & 1.11 & 97.1 & 0.87 \\
\hline 890315.005 & 6.4 & 13.95 & 6.8 & 1.627 & 24.9 & 2.0 & 47 & 1.35 & 0.26 & 23.91 & 1.12 & 97.5 & 0.87 \\
\hline 890310.003 & 6.5 & 12.85 & 5.47 & 1.518 & 48.4 & 1.8 & 43 & 1.35 & 0.26 & 28.88 & 1.20 & 97.3 & 0.81 \\
\hline 890413.009 & 5.4 & 12.32 & 5.22 & 1.505 & -0.6 & 2.1 & 46 & 1.35 & 0.26 & 30.59 & 1.28 & 97.3 & 0.76 \\
\hline 890418.002 & 5.5 & 12.32 & 5.03 & 1.498 & 44.5 & 2.3 & 46 & 1.35 & 0.24 & 29.46 & 1.32 & 97.0 & 0.74 \\
\hline 890425.003 & 5.6 & 12.29 & 4.79 & 1.498 & 51.4 & 2.1 & 46 & 1.35 & 0.26 & 32.57 & 1.37 & 97.2 & 0.71 \\
\hline 890310.005 & 6.5 & 13.1 & 4.99 & 1.550 & 30.9 & 2.0 & 45 & 1.35 & 0.24 & 28.85 & 1.37 & 97.3 & 0.71 \\
\hline 890413.008 & 5.4 & 12.36 & 4.82 & 1.522 & -7.3 & 2.2 & 47 & 1.35 & 0.24 & 30.59 & 1.40 & 97.2 & 0.69 \\
\hline 890317.004 & 6.4 & 13.12 & .4 .61 & 1.536 & 21.8 & 2.0 & 47 & 1.35 & 0.26 & 34.87 & 1.53 & 97.4 & 0.64 \\
\hline 390426.006 & 5.5 & 13.79 & 4.63 & 1.948 & 54.2 & 2.0 & 51 & 1.35 & 0.25 & 32.60 & 1.68 & 97.9 & 0.58 \\
\hline
\end{tabular}

Effect of Steam Loading

\begin{tabular}{|c|c|c|c|c|c|c|c|c|c|c|c|c|c|}
\hline 890425.01 & 6.3 & 12.82 & 5.42 & 1.586 & 20.6 & 2.8 & 46 & 1.35 & 0.19 & 20.98 & 1.21 & 96.5 & 0.80 \\
\hline 890418.005 & 5.8 & 12.42 & 5.21 & 1.504 & 19.5 . & 2.6 & 45 & 1.35 & 0.21 & 24.07 & 1.20 & 96.4 & 0.80 \\
\hline 90310.00 & 6.5 & 12.85 & .47 & 1.518 & 48.4 & 1.8 & 43 & 1.35 & 0.26 & 28.88 & 1.20 & 97.3 & 0.81 \\
\hline 890426.004 & 5.8 & 12.92 & 5.86 & 1.862 & 88.9 & 1.6 & 46 & 1.35 & 0.31 & 32.93 & 1.20 & 97.9 & 0.81 \\
\hline
\end{tabular}

Effect of Noncondensable Gas Concentration

\begin{tabular}{|c|c|c|c|c|c|c|c|c|c|c|c|c|c|}
\hline 890426.008 & 4.7 & 13.8 & 6.96 & 1.983 & 118.8 & 1.3 & 46 & 1.35 & 0.37 & 32.78 & 1.11 & 98.3 & 0.89 \\
\hline 890413.003 & 5.5 & 13.27 & 6.65 & 1.584 & 70.4 & 1.5 & 48 & 1.35 & 0.35 & 32.45 & 1.12 & 98.2 & 0.88 \\
\hline 890310.011 & 6.4 & 12.98 & 6.07 & 1.544 & 42.8 & 1.9 & 43 & 1.35 & 0.24 & 24.24 & 1.09 & 97.1 & 0.89 \\
\hline 890315.005 & 6.4 & 13.95 & 6.8 & 1.627 & 24.9 & 2.0 & 47 & 1.35 & 0.26 & $23: 91$ & 1.12. & 97.5 & 0.87 \\
\hline 890317.006 & 6.3 & 12.83 & 5.99 & 1.507 & 15.7 & 2.1 & 44 & 1.35 & 0.24 & 24.10 & 1.11 & 97.1 & 0.87 \\
\hline 890313.005 & 5.8 & 12.95 & 5.72 & 1.527 & 10.5 & 2.1 & 42 & 1.35 & 0.18 & 19.13 & 1.12 & 96.7 & 0.87 \\
\hline 890425.009 & 6.4 & 12.74 & 5.86 & 1.571 & 30.2 & 2.7 & 43 & 1.35 & 0.21 & 20.98 & 1.12 & 96.2 & 0.86 \\
\hline 390307.006 & 6.1 & 12.43 & 5.72 & 1.504 & 26.6 & 3.5 & 42 & 1.35 & 0.27 & 28.74 & 1.09 & 94.9 & 0.87 \\
\hline
\end{tabular}

Effect of Freefall Helght

\begin{tabular}{|c|c|c|c|c|c|c|c|c|c|c|c|c|c|}
\hline 890227.002 & 6.5 & 12.62 & 5.43 & 1.491 & -7.9 & 2.7 & 30 & 0.92 & 0.23 & 24.19 & 1.11 & 93.1 & 0.84 \\
\hline 890225.011 & 6.3 & 11.9 & 4.94 & 1.431 & 27.6 & 2.2 & 23 & 0.92 & 0.25 & 29.26 & 1.10 & 91.9 & 0.84 \\
\hline 890126.004 & 6.3 & 12.8 & 5.76 & 1.499 & 30.4 & 2.9 & 35 & 1.22 & 0.24 & 24.33 & 1.12 & 94.4 & 0.84 \\
\hline 890130.021 & 6.4 & 12.85 & 5.77 & 1.501 & -9.9 & 2.3 & 40 & 1.22 & ט.23 & 23.98 & 1.13 & 96.3 & 0.86 \\
\hline 890317.006 & 6.3 & 12.83 & 5.99 & 1.507 & 15.7 & 2.1 & 44 & 1.35 & 0.24 & 24.10 & 1.11 & 97.1 & 0.87 \\
\hline 890310.011 & 6.4 & 12.98 & 6.07 & 1.544 & 42.8 & 1.9 & 43 & 1.35 & 0.24 & 24.24 & 1.09 & 97.1 & 0.89 \\
\hline
\end{tabular}


APPENDIX C

PHYSICAL PROPERTIES 


\section{NOMENUCLATURE}

\begin{tabular}{llc} 
Abbrev. & Description & Units \\
\hline $\mathrm{P}$ & pressure & $\mathrm{kPa}$ \\
$\sigma_{\mathrm{T}}$ & dimensionless density at temperature $\mathrm{T}$ & -- \\
$\mathrm{t}$ & temperature & ${ }^{\circ} \mathrm{F}$ \\
$\mathrm{T}$ & temperature & ${ }^{\circ} \mathrm{C}$ \\
$\mathrm{T}_{\mathrm{R}}$ & temperature & $\mathrm{R}$
\end{tabular}

\section{Subscripts}

$\begin{array}{ll}\text { eq } & \text { equilibrium } \\ \text { exh } & \text { exhaust } \\ \text { f } & \text { liquid } \\ \text { g } & \text { gas } \\ \text { FW } & \text { fresh water } \\ \text { I } & \text { liquid } \\ \text { s } & \text { saturated vapor } \\ \text { sat } & \text { saturation } \\ \text { SW } & \text { seawater } \\ \text { v } & \text { vapor }\end{array}$


This appendix describes the physical property functions used in the data analysis. The properties shown in Section C.1 were used in the evaporator, mist eliminator, predeaerator, direct-contact condenser, and $\mathrm{CO}_{2}$ release sections. These are based on property functions documented in Bharathan, Parsons and Althof (1988) for fresh water and modified for seawater as shown below. Slightly different physical property functions were used for the surface condenser data, as shown in section C.2. These functions are presented in the original British units used by the principal investigator to calculate the performance parameters shown in the data table. These calculated values were then converted to metric units. The original property functions must be used to reproduce the original calculations. Functions in Section C.1 can be used as metric equivalents for the functions shown in Section C.2 because the calculated values for the same property are within about $1 \%$ of those shown in Section C.1.

\section{C.1 PHYSICAL PROPERTIES-DIRECT-CONTACT CONDENSER AND FLASH EVAPORATOR}

Physical properties are fitted to curves as functions of temperature $T$ in degrees Celsius from data in Kellogg (1975) as follows:

Density:

$$
\begin{aligned}
& \rho_{\mathrm{SW}}=1000+\sigma_{\mathrm{T}} \\
& \sigma_{\mathrm{T}}=27.7154-0.04992 \mathrm{~T}-0.006773 \mathrm{~T}^{2}+4.766 \times 10^{-5} \mathrm{~T}^{3} \\
& \rho_{\mathrm{FW}}=1000.0-\left(-0.6922-0.001757 \mathrm{Tg} / \mathrm{m}^{3}\right) \\
& \text { for } \left.\mathrm{T}>11.85^{\circ} \mathrm{C} ; \text { otherwise } \rho=1000.005571 \mathrm{~T}^{2}\right) \quad\left(\mathrm{kg} / \mathrm{m}^{3}\right)
\end{aligned}
$$

Specific Heat:

$$
\begin{array}{ll}
C_{\mathrm{P}, \mathrm{SW}}=3.9867+4.773 \times 10^{-4} \mathrm{~T} & \left(\mathrm{~kJ} / \mathrm{kg}^{\circ} \mathrm{C}\right) \\
C_{\mathrm{P}, \mathrm{FW}}=\left(4217044-3504.25 \mathrm{~T}+113.17 \mathrm{~T}^{2}-1.309 \mathrm{~T}^{3}\right) / 10^{6} & \left(\mathrm{~kJ} / \mathrm{kg}^{\circ} \mathrm{C}\right)
\end{array}
$$

Viscosity:

$$
\begin{array}{ll}
\mu_{\mathrm{SW}}=1.079 \mu_{\mathrm{FW}} & (\mathrm{kg} / \mathrm{ms}) \\
\mu_{\mathrm{FW}}=\left(2.414 \times 10^{-5}\right) 10^{\mathrm{a}} & (\mathrm{kg} / \mathrm{ms})
\end{array}
$$

- where $a=\left[\frac{0.38281}{(T+273.15) / 647.3-0.2163}\right]$

\section{Thermal Conductivity:}

$$
\begin{array}{ll}
k_{\mathrm{SW}}=0.5441+2.15 \times 10^{-3} \mathrm{~T} & \left(\mathrm{~W} / \mathrm{m}^{\circ} \mathrm{C}\right) \\
\mathrm{k}_{\mathrm{FW}}=0.569+0.001575 \mathrm{~T} & \left(\mathrm{~W} / \mathrm{m}^{\circ} \mathrm{C}\right)
\end{array}
$$


Saturation Pressure:

$$
\begin{aligned}
& P_{\text {sat }, S W}=0.9816 * P_{\text {sat }, F W} \\
& P_{\text {sat }, F W}=161.7574 * \exp \left[18.4779-\left(\frac{4026.9759}{T_{\text {sat }}+234.7384}\right)\right]+3.74
\end{aligned}
$$

Enthalpy of Seawater:

$$
\begin{array}{ll}
\mathrm{h}_{\mathrm{f}, \mathrm{SW}}=\mathrm{C}_{\mathrm{P}, \mathrm{SW}} * \mathrm{~T}_{\text {sat }} & (\mathrm{kJ} / \mathrm{kg}) \\
\mathrm{h}_{\mathrm{f}, \mathrm{FW}}=\mathrm{C}_{\mathrm{P}, \mathrm{FW}} * \mathrm{~T}_{\text {sat }} & (\mathrm{kJ} / \mathrm{kg})
\end{array}
$$

Enthalpy of Steam:

$$
h_{f g}=2501.6+1.86 \cdot T_{\text {sat }}-C_{p, S W} T_{\text {sat }}
$$

Exhaust Flow Rate:

$$
\begin{aligned}
& \dot{\mathrm{V}}=0.313+0.1 \mathrm{P}_{\text {exh }}-0.032 \mathrm{P}_{\text {exh }}^{2} \\
& \text { for } \mathrm{P}_{\text {exh }}<1.5 \mathrm{kPa}
\end{aligned}
$$

while $\quad \dot{\mathrm{V}}=0.39$

$$
\text { for } P_{\text {exh }} \geq 1.5 \mathrm{kPa}
$$

Steam Saturation Temperature (Condenser and Evaporator):

$$
\mathrm{T}_{\text {sat }}=\mathrm{T}_{\text {eq, } \mathrm{FW}}+0.28 \text { and } \mathrm{T}_{\text {sat }}=\mathrm{T}_{\text {eq, } \mathrm{FW}}+0.31
$$

\section{C.2 PHYSICAL PROPERTIES-SURFACE CONDENSER}

For temperature $t$ in ${ }^{\circ} \mathrm{F}$

Seawater Properties:

$$
\begin{array}{llrr}
\text { Density } & \rho=64.2971-0.00662 \mathrm{t} & \left(1 \mathrm{~b} / \mathrm{ft}^{3}\right) \\
\text { Viscosity } & \mu=0.0019863 \exp (3791.39 /(459.699+\mathrm{t})) & (1 \mathrm{~b} / \mathrm{hr} \mathrm{ft}) \\
\text { Conductivity } k=0.3104+0.00052 t & \left(B t u / \mathrm{hr} \mathrm{ft}^{\circ} \mathrm{F}\right)
\end{array}
$$

\section{Fresh-Water Properties:}

$$
\begin{array}{llrr}
\text { Density } & \rho=62.4-6.61818 t & \left(1 \mathrm{~b} / \mathrm{ft}^{3}\right) \\
\text { Viscosity } & \mu=0.0009146 \exp (4157.27 /(459.69+\mathrm{t})) & (1 \mathrm{~b} / \mathrm{hr} \mathrm{ft}) \\
\text { Conductivity } & k=0.2951+0.000745 t & \left(\mathrm{Btu} / \mathrm{hr} \mathrm{ft}{ }^{\circ} \mathrm{F}\right)
\end{array}
$$


$\mathrm{TP}-3561$

Vapor Pressure of Fresh Water:

$$
\mathrm{P} \quad=10^{\mathrm{K}} \quad \text { ( } \mathrm{mm} \text { of mercury) }
$$

where $\quad K=7.89182-2967.771 /(378.4+t) \hat{e}$

Enthalpy of Steam and Water:

Steam

$$
h_{v}=1061.36+0.43 t_{s}+0.444 \hat{e}
$$

$(\mathrm{Btu} / 1 \mathrm{~b})$

t $\quad$ steam temperature

$t_{s} \quad=$ saturation temperature

Water

$$
h_{1}=-31.97+1.0008 t \hat{e}
$$

$(\mathrm{Btu} / 1 \mathrm{~b})$

Gas Mixture Density:

$$
\begin{aligned}
\rho= & \mathrm{P} /(0.731(459.69+\mathrm{t})) \quad\left(\mathrm{MW} 1 \mathrm{~b} / \mathrm{ft}^{3}\right) \\
& P \text { in atmosphere }
\end{aligned}
$$

Refrigerant Properties:

$$
\begin{aligned}
& \text { Density } \quad \rho=77.025+0.11751 \mathrm{t}-0.000176 \mathrm{t}^{2} \quad\left(1 \mathrm{~b} / \mathrm{ft}^{3}\right) \\
& \text { Vapor Pressure: } \\
& \mathrm{P}=\exp \left(12.708-4379.06 / \mathrm{T}_{\mathrm{R}}+3.149610^{-8} \log \left(\mathrm{T}_{\mathrm{R}}\right)\right) \quad(\mathrm{psia}) \\
& h_{v, s}=77.02+0.1175 t_{s}-0.0001766 t_{s}^{2} \\
& \text { Vapor. . } h_{v}=h_{v, s}+0.1072-0.000171 t\left(t-t_{s}\right) \\
& \text { Saturation temperature } t_{s} \text { in }{ }^{\circ} \mathrm{F} \\
& \text { Liquid } h_{1}=8.5389+0.21331 t+0.0001208 t^{2}
\end{aligned}
$$

\section{C.3 REFERENCES}

M. W. Kellogg Company, Oct. 1975, Saline Water Conversion Engineering Data Book, NTIS No. PB 250 907, Washington, DC: Office of Water Research and Technology.

Bharathan, D., Parsons, B. K., and Althof, J. A., Oct. 1988, Direct-Contact Condensers for Open-Cycle OTEC Applications, SERI/TR-252-3108, Golden, CO: Solar Energy Research Institute. 


\begin{abstract}
APPENDIX D
OXYGEN DESORPTION FROM WARM SEAWATER: SUPPORTING INFORMATION
\end{abstract}

A. A. Pesaran

Solar Energy Research Institute 


\section{NOMENCLATURE}

Abbrev.

Description

Units

${ }_{\text {cal }}$

overall sensor calibration error

$\mathrm{mg} / \mathrm{L}$

Bink

bias error for Winkler method measurement

$\mathrm{mg} / \mathrm{L}$

Ceq

equilibrium dissolved oxygen concentration

$\mathrm{mg} / \mathrm{L}$

Cerror,i

error in D.0. concentration for either "in" or "spout"

$\mathrm{mg} / \mathrm{L}$ positions

$\mathrm{C}_{\mathbf{i}}$

$c_{\text {in }}$

concentration of dissolved gas $i$ in water

$\mathrm{mg} / \mathrm{L}$

inlet dissolved oxygen concentration

$\mathrm{mg} / \mathrm{L}$

dissolved oxygen concentration

$\mathrm{mg} / \mathrm{L}$

outlet dissolved oxygen concentration from evaporator

$\mathrm{mg} / \mathrm{L}$

combined root-sum-square random error in $C$

$\mathrm{mg} / \mathrm{L}$

$C_{\text {random }}$

$C_{\text {spout }}$

$\left[\mathrm{Cl}^{-}\right]$

inlet dissolved oxygen concentration at the spout entrance

$\mathrm{mg} / \mathrm{L}$

Fias

Feq

$F_{\text {pd }}$

concentration of chlorine ion in water

$\mathrm{g} / \mathrm{kg}$ or ppt

propagated bias errors in $F_{p d}$

fraction of oxygen desorbed at equilibrium (Eq. D-6)

fraction of oxygen desorbed in the predeaeration chamber

Frandom

propagated random errors in $F_{p d}$

$\mathrm{H}_{\mathbf{i}}$

Henry's Law proportionality constant for gas i

(Eq. D-1)

Pair

partial pressure of air

$\mathrm{Pa} /(\mathrm{mg} / \mathrm{L})$

Patm

$P_{i}$

oxygen pressure at one atmosphere

$\mathrm{Pa}$

partial pressure of gas $i$

$\mathrm{Pa}$

partial pressure of oxygen

$\mathrm{Pa}$

$\mathrm{P}_{0}$

$P_{\text {sat }}$

saturation pressure of water

$\mathrm{Pa}$

$\mathrm{P}_{\mathrm{T}}$

total pressure of air

$\mathrm{Pa}$

difference between Winkler and sensor readings

$\mathrm{Pa}$

$\mathbf{R}_{\text {cal, }, i}$

(Column J, Table D-2)

$\mathrm{mg} / \mathrm{L}$

$\mathrm{R}_{\text {read }}$

random sensor reading error

$\mathrm{mg} / \mathrm{L}$

random error for sensor-to-sensor variations

$\mathrm{mg} / \mathrm{L}$

$\mathbf{R}_{\text {s }}$

random error for Winkler method measurement

$\mathrm{mg} / \mathrm{L}$

solubility of dissolved gas $i$ in water

$\mathrm{mg} / \mathrm{L}$

two-tailed student $t$ value

temperature

${ }^{\circ} \mathrm{C}$

overall uncertainty in $\mathrm{F}_{\text {pd }}$

uncertainty for Winkler method measurement

$\mathrm{mg} / \mathrm{L}$ 
The data collected for the predeaeration tests and the error analyses for before and after the experiment have been separated from the other data because the data analysis methodology is different from that used in the other sections and the raw data cannot be presented in the same format.

Section D.1 describes the thermodynamic aspects of dissolved oxygen; it describes the solubility of the main noncondensable gases and their equilibrium levels.

Section D.2. describes in detail the uncertainty analysis for the dissolved oxygen measurements; it describes calibration and sensor errors and the propagation of these errors into the measurements. The detailed postexperiment analysis was conducted to verify that the data collected did indeed fall in the appropriate error margins of the measurement techniques.

Section D.3 makes recommendations to improve the measurement accuracy for future oxygen measurements.

Section D.4 presents the data tables for the predeaeration tests. These are not raw data as presented for other components tested; i.e., data files cannot be retrieved directly to show the values presented in Section D.4. Rather, the raw data were handled as described in Section 5.4.2.3 of Chapter 5 .

\section{D.1 THERMODYNAMIC ASPECTS OF DISSOLVED OXYGEN}

The solubility of oxygen and nitrogen in water depends primarily upon pressure, temperature, and concentration of dissolved salts (Hitchman 1978). At constant temperature, the solubility of a gas follows the generalized form of Henry's Law. For dilute solutions and low pressures Henry's Law becomes

$$
\mathrm{P}_{\mathrm{i}}=\mathrm{H}_{\mathrm{i}} \mathrm{S}_{\mathrm{i}} \text {, }
$$

where $P_{i}$ is the partial pressure of gas $i, s_{i}$ is concentration of dissolved gas in $\mathrm{mg} / \mathrm{L}$, and $\mathrm{H}_{i}$ is the proportionality constant for gas $i$.

The solubility of dissolved gases, such as oxygen and nitrogen, decreases with increasing temperature (Hitchman 1978). The solubility of oxygen and nitrogen decreases with the increase of salt concentration. (Solubility decreases in many nonelectrolytes when an electrolyte is added to the solution, a phenomenon called the salting-out effect.) Several curve fits to the existing data of oxygen and nitrogen solubilities in water are well documented (Zapka 1988; Hitchman 1978). For the solubility of oxygen in saline water exposed to dry oxygen at a pressure of one atmosphere, Hitchman (1978) recommends the following correlation:

$$
\begin{aligned}
S_{0}= & 1.4277\left\{\left(a+b T+c T^{2}+d T^{3}+e T^{4}\right)\right. \\
& \left.-\left[C 1^{-}\right]\left(p+q T+r T^{2}+s T^{3}+t T^{4}\right)\right\},
\end{aligned}
$$

where $\mathrm{S}_{0}$ is the dissolved oxygen concentration in $\mathrm{mg} / \mathrm{L}$ and $\mathrm{T}$ is water temperature in degrees Celsius. The coefficients a-e and $p-t$ are given: in Table D-1. $\left[\mathrm{Cl}^{-}\right]$is the concentration of chloride ion in parts per thousand $(\mathrm{g} / 1000 \mathrm{~g})$ and is related to salinity of seawater through the relation 


$$
\text { salinity }=1.805\left[\mathrm{Cl}^{-}\right]+0.03
$$

The typical value of the salinity for warm surface seawater at the site of the experiment performed for this study is about 34.8 parts per thousand (Krock 1981).

Table D-1. Values of the Coefficients in Eq. D-2

\begin{tabular}{rrrr}
\hline a & $4.900 \mathrm{E} 1$ & $\mathrm{P}$ & $5.516 \mathrm{E}-1$ \\
$\mathrm{~b}$ & -1.335 & $\mathrm{q}$ & $-1.759 \mathrm{E}-2$ \\
$\mathrm{c}$ & $2.759 \mathrm{E}-2$ & $\mathrm{r}$ & $2.253 \mathrm{E}-4$ \\
$\mathrm{~d}$ & $-3.235 \mathrm{E}-4$ & $\mathrm{~s}$ & $-2.654 \mathrm{E}-7$ \\
$\mathrm{e}$ & $1.614 \mathrm{E}-6$ & $\mathrm{t}$ & $5.362 \mathrm{E}-8$ \\
\hline
\end{tabular}

For a sealed chamber containing water and air in equilibrium, Henry's Law (Eq. D-1) can be used to obtain the solubility of oxygen at partial pressures other than atmospheric pressure but at the same temperature,

$$
s_{0}^{\prime}=s_{0} \frac{P_{0}}{P_{\text {atm }}},
$$

where $S_{0}$ is the solubility of oxygen at pressure of $P_{\text {atm }}$, and $S_{0}^{\prime}$ is solubility of oxygen at pressure of $\mathrm{P}_{0}$. From this relation a useful relation can be derived (Hitchman 1978):

$$
s_{0}=s_{0}^{\prime} \frac{P_{T}-P_{\text {sat }}}{P_{\text {air }}-P_{\text {sat }}}
$$

where $S_{0}$ is, the solubility of oxygen in water at an atmospheric pressure of $P_{\text {air' }}$ and $S_{O}$ is solubility of oxygen in water at total pressure of $P_{T}$. The term $P_{\text {sat }}$ is the saturation vapor pressure of water at the solution temperature. She expression $\mathrm{P}_{\mathrm{T}}-\mathrm{P}_{\text {sat }}$ is the partial pressure of dry air above the solution.

Figure D-1 shows the dissolved oxygen (D.O.) concentration of seawater in equilibrium with atmospheric air containing $20.95 \%$ oxygen as a function of temperature. Figure $\mathrm{D}-2$ shows equilibrium $\mathrm{D} .0$. contents of $7^{\circ} \mathrm{C}$ and $26.5^{\circ} \mathrm{C}$ seawater at various air pressures. Figure D-3 shows the fraction of oxygen desorbed at equilibrium when exposed to different air pressures. This figure is obtained assuming the concentration of dissolved oxygen $C_{\text {in }}$ at the inlet of the test chamber is $6.6 \mathrm{mg} / \mathrm{L}$. At equilibrium, the concentration of $\mathrm{D} .0$. equals the solubility in seawater. The fraction of oxygen desorbed at equilibrium is defined as

$$
\mathrm{F}_{\text {eq }}=\left(\mathrm{c}_{\mathrm{in}}-\mathrm{c}_{\mathrm{eq}}\right) / \mathrm{c}_{\mathrm{in}} \cdot
$$

Note that in Figure $\mathrm{D}-3$, the equilibrium level depends on the fraction of oxygen in the air in equilibrium with seawater. It can be shown that the equilibrium level is not very sensitive to the level of inlet D.0. concentration. 

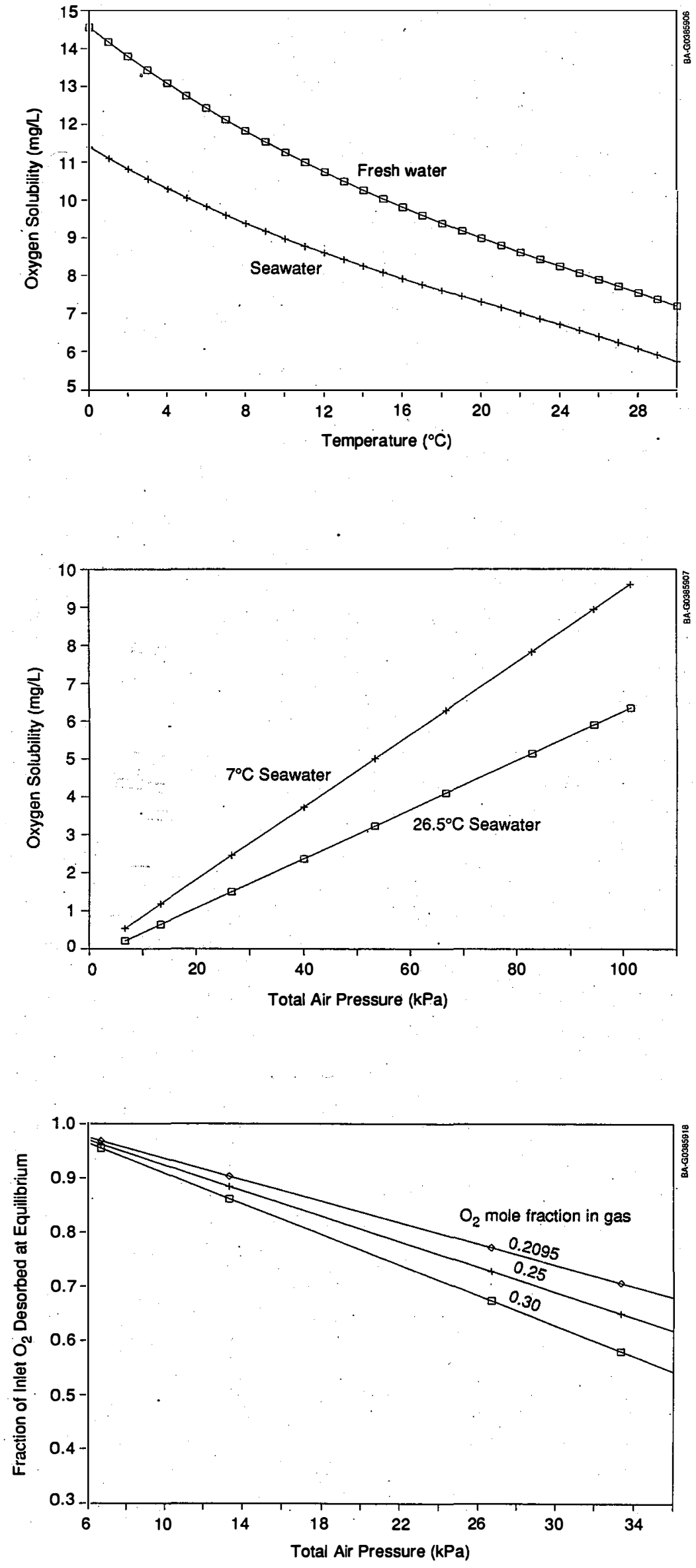

Figure D-1. Temperature dependence of solubility of oxygen in water at equilibrium with atmospheric air
Figure D-2. Pressure dependence of solubility of oxygen in seawater in equilibrium with air containing 20.957 oxygen
Figure D-3. Fraction of orygen desorbed at equilibrium from seawater as a function of total pressure (temperature: $26.5^{\circ} \mathrm{C}$, inlet dissolved oxygen content: $6.6 \mathrm{mg} / \mathrm{L}$ ) 


\section{D.1.1 References}

Hitchman, M. I., 1978, Measurement of Dissolved Oxygen, New York: John Wiley and Sons.

Krock, H. J., 1981, Gas Analyses of Water Samples for OTEC Program, J.K.K. Look Laboratory Technical Report No. 51, University of Hawaii at Manoa.

Zapka, M. J., 1988, Gas Exchange in Seawater with Special Emphasis on OpenCycle Ocean Thermal Energy Conversion, Ph.D. Dissertation, Manoa: University of Hawaii.

\section{D.2 UNCERTAINTY ANALYSIS IN DISSOLVED OXYGEN MEASUREMENTS}

\section{D.2.1 Approach}

A postexperiment error analysis is documented here to estimate the uncertainty in the measurements. To estimate the total uncertainty in the calculated fraction of oxygen desorbed in the predeaerator, the calibration errors, random errors, and bias errors in the dissolved oxygen (D.O.) measurement are estimated. Then, the errors are appropriately propagated into the estimation of fraction of oxygen desorbed. Note that bias errors are systematic errors (e.g., a zero offset of a sensor) and random errors have a random distribution (e.g., note scatter among several readings from one sensor for the same measurement). Calibration error is the difference between values obtained with the sensors and values measured with a standard, in this case the Winkler method for D.0. measurements.

To estimate various error elements, the sensor measurements were checked using the Winkler method. The seawater was passed through the three sensors to measure its dissolved oxygen content. Simultaneous measurement of the D. 0 . concentrations of two or three different samples of this water were made using the Winkler method. This approach was repeated at various times to obtain a sense of the performance of the sensors with time. Table D-2 shows the results of these measurements. Various errors are estimated in the following sections.

\section{D.2.2 Error Elements}

\section{D.2.2.1 Uncertainty in Winkler Measurements}

1. The Winkler method has a precision of better than $\pm 0.1 \mathrm{mg} / \mathrm{L}$ when performed carefully (Hitchman 1978). This is a systematic or bias error for the Winkler method $\mathrm{B}_{\text {Wink }}$ •

2. ê Using the Winkler method, variations exist in D.0. concentrations in water samples taken from the same water. This produces a random error from water sampling. The mean of the D.0. measurements of different samples of the same water (column $\mathrm{J}$ of Table $\mathrm{D}-2$ ) is used. The maximum value of the standard deviation of each mean (column $\mathrm{K}$ ) is chosen as the random erroi $\mathrm{R}_{\text {Wink }}$ in water sampling for the Winkler measurements. This error is $0.11 \mathrm{mg} / \mathrm{L}$.

3. To combine the above two errors, the root-sum-square model (ANSI/ASME 1986), which has a confidence level of $95 \%$, is used. 
Table D-2. Comparison of Dissolved Oxygen Concentrations Measured with the Polarographic Instruments and by the Winkler Titration Method

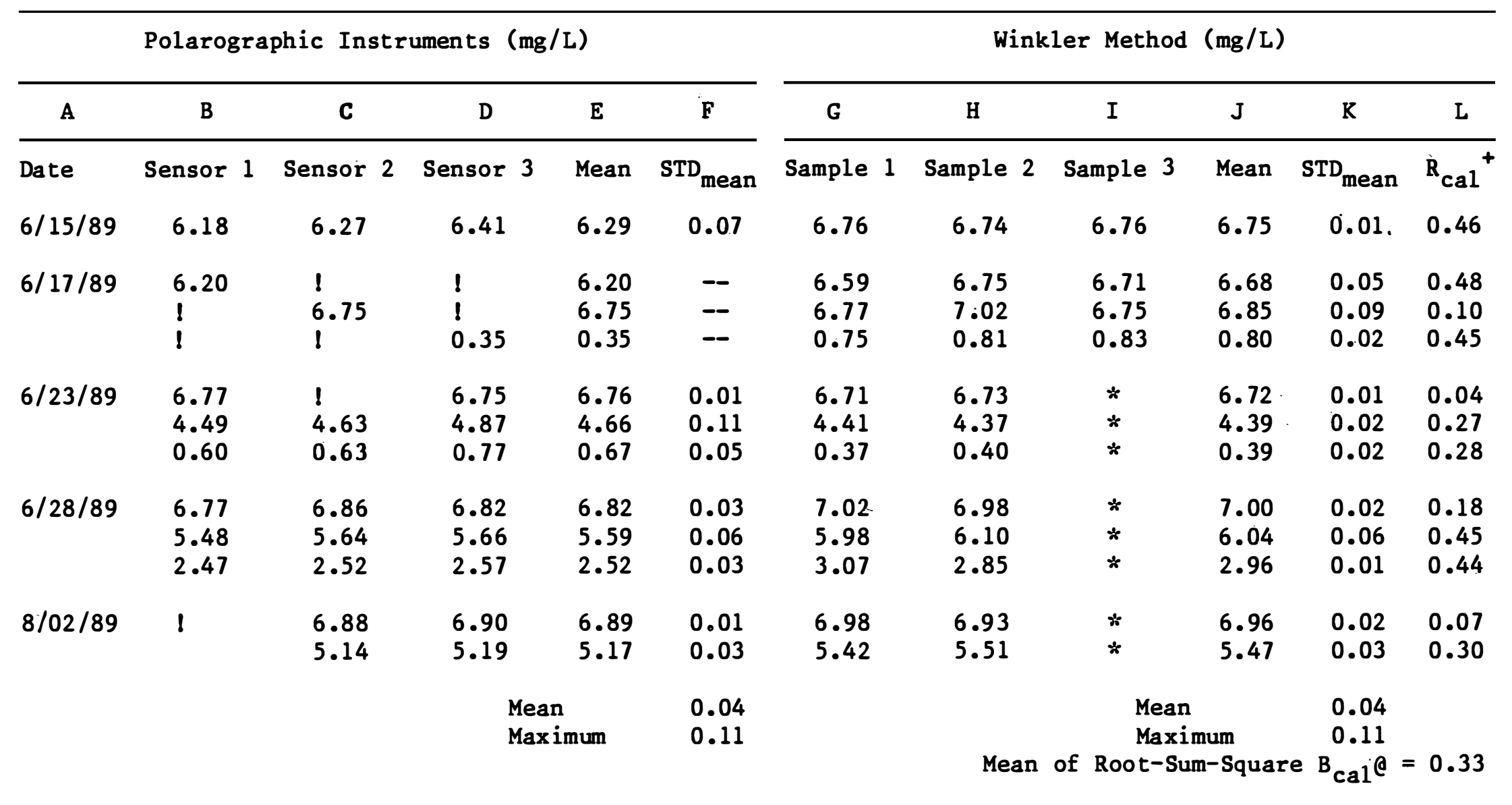

'This sensor was not used at the time.

*Only two water samples were taken for Winkler titration.

${ }_{R_{c a l}}=$ Absolute value of (Instruments mean - Winkler mean) or absolute value of (Column E - Column J).

$\mathrm{C}_{\mathrm{B}} \mathrm{cal}=\sum_{\mathrm{i}=1}^{12} \mathrm{R}_{\mathrm{cal}, \mathrm{i}}$ 


$$
\mathrm{U}_{\text {Wink }}=\left[\left(\mathrm{B}_{\text {Wink }}\right)^{2}+\left(t * \mathrm{R}_{\text {Wink }}\right)^{2}\right]^{1 / 2},
$$

where $t$ is the 95th percentile point for the two-tailed Student $t$ distribution (ANSI/ASME 1986). There are a total of 26 Winkler measurements in Table D-2, and the value of $t$ for this many measurements is about 2 (ANSI/ASME 1986). Using $0.1 \mathrm{mg} / \mathrm{L}$ for $B_{\text {Wink }}$ and $0.11 \mathrm{mg} / \mathrm{L}$ for $R_{\text {Wink }}$, the value of calibration uncertainty is

$$
\mathrm{U}_{\text {Wink }}= \pm 0.24 \mathrm{mg} / \mathrm{L}
$$

This uncertainty is a systematic error for D.O. sensors and is treated as a bias (fixed) error.

\section{D.2.2.2 Sensor-to-Sensor Error}

There is a variation in readings of three D.O. sensors in measuring the same water sample. These values were averaged (column $E$ ) to arrive at a mean value for comparison with the Winkler results of the same water sample. The maximum standard deviation of the mean values (column $F$ ) is taken to be the sensor-tosensor error. This error is considered a random error because it does not change in a systematic fashion. The magnitude of this error $R_{s}$ is $0: 11 \mathrm{mg} / \mathrm{L}$.

\section{D.2.2.3 Sensor Calibration Error}

The difference between the average reading from the sensors (column $E$ of Table D-2) and the average of Winkler results (column J) for the same water is the sensor calibration error $R_{c a l}, i^{*}$ These errors for various water samples are combined in the following manner:

$$
B_{c a l}=\frac{\sum_{i=1}^{N}\left(R_{c a l, i}\right)^{2}}{N},
$$

where $\mathbf{N}$ is the number of average differences, 12 , and $B_{c a l}$ is the overall sensor calibration error. Because the calibration errors. $R$ cal, fluctuated with time over the course of two months of testing (Table D-2), B cal is considered a random error. After calculation, $B_{c a l}$ was estimated to be $0.33 \mathrm{mg} / \mathrm{L}$.

\section{D.2.2.4 Sensor Reading Error}

To obtain a measurement from one D.0. sensor over a 30-second interval, instantaneous values of about 470 readings are averaged. The standard deviation of these readings is the sensor reading error for the measurement, $R_{\text {fead }}$. This is a random error. During experiments, the average readings and their standard deviations are recorded. Most of the readings have standard deviations of less than $0.05 \mathrm{mg} / \mathrm{L}$. This value was selected as $\mathrm{R}_{\text {read }}$; any reading having standard deviation of more than $0.05 \mathrm{mg} / \mathrm{L}$ was rejected. 


\section{D.2.3 Error Propagation}

The errors identified in D.0. measurements are propagated to estimate the fraction of oxygen desorbed by using Taylor series expansion (ANSI/ASME 1986). Bias and random errors are propagated separately. According to ANSI/ASME (1986) standards, if $Q=f\left(x_{1}, x_{2} \cdot\right.$ - . $\left.x_{n}\right)$, then the propagated error in $Q$ caused by errors in $x_{i}$ is

$$
Q_{R}=\sum_{i=1}^{N}\left(\frac{\partial Q}{\partial x_{i}} R_{i}\right)^{2} 1 / 2,
$$

where $R_{i}$ is the error in $x_{i}$.

The fraction of oxygen desorbed in the predeaerator is defined as

$$
F_{\text {pd }}=\left(c_{\text {in }}-C_{\text {spout }}\right) / C_{\text {in }} \cdot
$$

Propagating the errors in D.O. measurements into the estimation of the fraction of oxygen desorbed in the predeaerator according to the above approach will result in

$$
F_{\text {error }, i}=c_{\text {error }, i} *\left[\left(c_{i n}^{2}+c_{s p o u t}^{2}\right)^{1 / 2} / c_{i n}^{2}\right],
$$

where $C_{\text {error, }} i$ is the error in D.O. concentration that is the same for both $C_{\text {in }}$ and $C_{\text {spout }}$. In this approach, random and bias errors are to be propagated separately. There are four separate errors identified in Section D.2.2 that need to be propagated. The term $U_{\text {Wink }}$ is considered to be a bias error, and the others are random errors. The random errors are combined by the root-sumsquare method:

$$
\mathrm{C}_{\text {random }}=\left(\mathrm{R}_{\mathrm{S}}^{2}+\mathrm{B}_{\mathrm{cal}}^{2}+\mathrm{R}_{\mathrm{read}}^{2}\right)^{1 / 2}
$$

Then the propagated errors are

$$
\begin{aligned}
F_{\text {bias }} & =U_{\text {Wink }} *\left[\left(c_{\text {in }}^{2}+c_{\text {spout }}^{2}\right)^{1 / 2} / c_{\text {in }}^{2}\right], \\
F_{\text {random }} & =C_{\text {random }} *\left[\left(c_{\text {in }}^{2}+c_{\text {spout }}^{2}\right)^{1 / 2} / c_{\text {in }}^{2}\right] .
\end{aligned}
$$

To estimate the overall uncertainty $U_{F_{p d}}$ the errors in the fraction of oxygen desorbed are combined using the root-sum-square model (ANSI/ASME 1986):

$$
\mathrm{U}_{\mathrm{Fd}}=\left[\mathrm{F}_{\text {bias }}{ }^{2}+\left(2 * \mathrm{~F}_{\text {random }}\right)^{2}\right]^{1 / 2} \text {. }
$$

Table D-3 shows the results of the uncertainty analysis for about 100 randomly selected data points. The average uncertainty obtained from these data sets is selected as an overall uncertainty for all the data obtained.

\section{D.2.4 Summary}

The errors identified in the D.0. measurements are as follows:

Uncertainty in standard Winkler values

Error in sensor relative to sensor measurements

Error in sensors relative to Winkler results

Random error in sensor reading

$$
\begin{aligned}
\mathrm{U}_{\text {Wink }} & = \pm 0.24 \mathrm{mg} / \mathrm{L} \\
\mathrm{R}_{\mathrm{S}} & = \pm 0.11 \mathrm{mg} / \mathrm{L} \\
B_{\text {cal }} & = \pm 0.33 \mathrm{mg} / \mathrm{L} \\
\mathrm{R}_{\text {read }} & = \pm 0.05 \mathrm{mg} / \mathrm{L} .
\end{aligned}
$$


Table D-3. Results of Uncertainty Analysis of Dissolved Oxygen Measurements

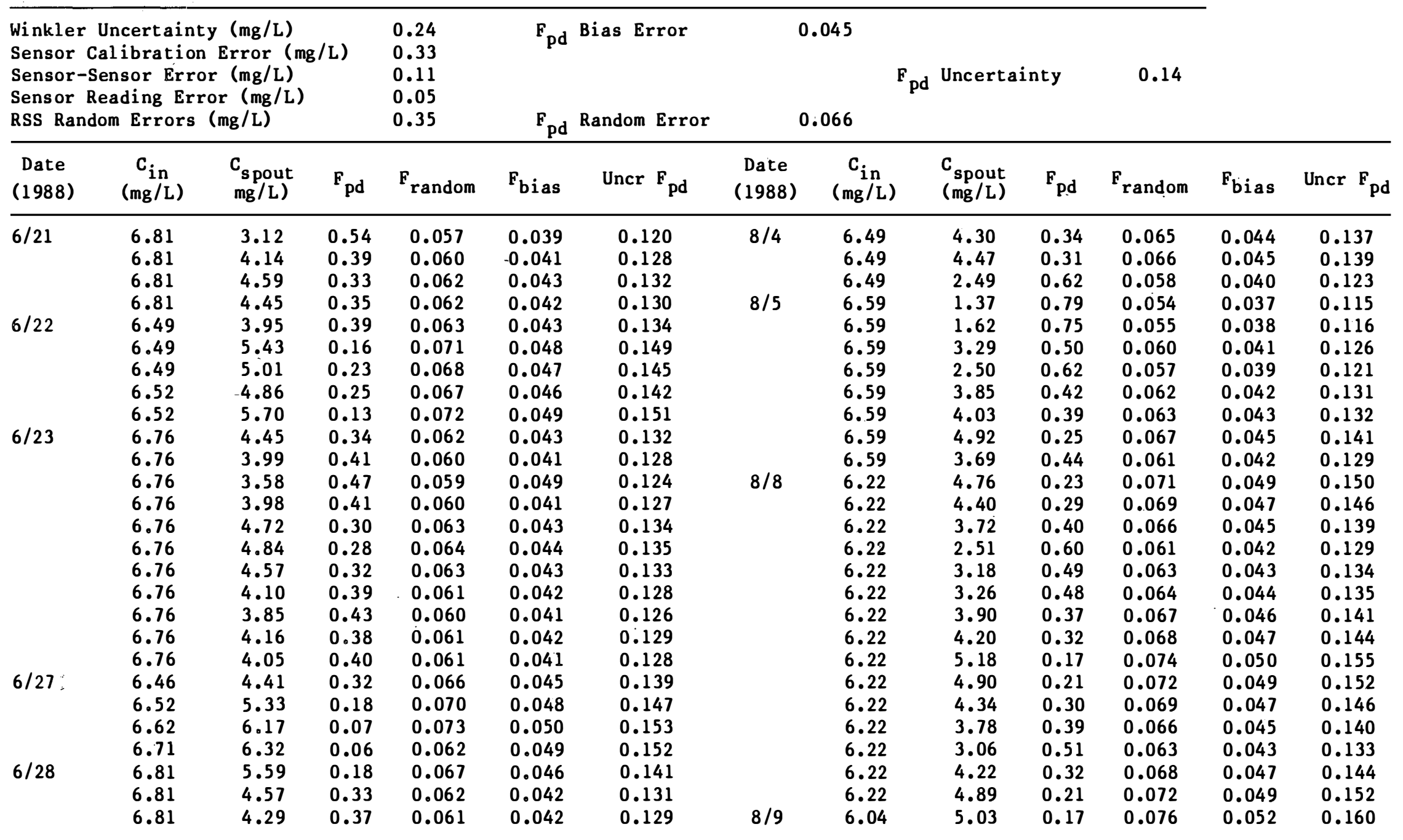


Table D-3. Results of Uncertainty Analysis of Dissolved Oxygen Measurements (Concluded)

\begin{tabular}{|c|c|c|c|c|c|c|c|c|c|c|c|c|c|}
\hline \multicolumn{4}{|c|}{$\begin{array}{l}\text { Winkler Uncertainty (mg/L) } \\
\text { Sensor Calibration Error (mg/L) } \\
\text { Sensor-Sensor Error (mg/L) } \\
\text { Sensor Reading Error (mg/L) } \\
\text { RSS Random Errors }(\mathrm{mg} / \mathrm{L})\end{array}$} & \multirow{2}{*}{$\begin{array}{l}0.24 \\
0.33 \\
0.11 \\
0.05 \\
0.35 \\
\\
\text { Frandom }\end{array}$} & \multicolumn{2}{|c|}{$\begin{array}{l}\text { F pd }_{\text {Bias Error }} \\
\text { F }_{\text {pd Random Error }}\end{array}$} & \multicolumn{2}{|c|}{$\begin{array}{l}0.045 \\
0.066\end{array}$} & \multicolumn{2}{|c|}{ Uncertainty } & 0.14 & \multirow{2}{*}{\multicolumn{2}{|c|}{ s Uncr $\mathbf{F}_{\mathbf{p c}}$}} \\
\hline $\begin{array}{l}\text { Date } \\
(1988)\end{array}$ & $\underset{(\mathrm{mg} / \mathrm{L})}{\mathrm{C}_{\mathrm{in}}}$ & $\begin{array}{c}C_{\text {s pout }} \\
\mathrm{mg} / \mathrm{L})\end{array}$ & $F_{p d}$ & & $F_{\text {bias }}$ & Uncr $F_{p d}$ & $\begin{array}{l}\text { Date } \\
\text { (1988) }\end{array}$ & $\underset{(\mathrm{mg} / \mathrm{L})}{\mathrm{C}_{\mathrm{in}}}$ & $\begin{array}{l}C_{\text {spout }} \\
(\mathrm{mg} / \mathrm{L})\end{array}$ & $F_{p d}$ & $\mathrm{~F}_{\text {random }}$ & & \\
\hline $6 / 29$ & $\begin{array}{l}6.81 \\
6.81 \\
6.81 \\
6.45 \\
6.45 \\
6.45 \\
6.45 \\
6.45 \\
6.45 \\
6.45 \\
6.45 \\
6.95 \\
6.95 \\
6.89 \\
6.89 \\
6.89 \\
6.39 \\
6.39 \\
6.39 \\
6.39 \\
6.49 \\
6.49 \\
6.49\end{array}$ & $\begin{array}{l}4.03 \\
4.27 \\
3.98 \\
5.81 \\
5.49 \\
5.33 \\
5.02 \\
5.61 \\
5.04 \\
5.72 \\
5.33 \\
5.07 \\
4.99 \\
5.27 \\
5.77 \\
5.17 \\
5.33 \\
5.59 \\
4.42 \\
5.76 \\
2.26 \\
3.10 \\
2.80\end{array}$ & $\begin{array}{l}0.41 \\
0.37 \\
0.42 \\
0.10 \\
0.15 \\
0.17 \\
0.22 \\
0.13 \\
0.22 \\
0.11 \\
0.17 \\
0.27 \\
0.28 \\
0.24 \\
0.16 \\
0.25 \\
0.17 \\
0.13 \\
0.31 \\
0.10 \\
0.65 \\
0.52 \\
0.57\end{array}$ & $\begin{array}{l}0.060 \\
0.061 \\
0.060 \\
0.073 \\
0.072 . \\
0.071 \\
0.069 \\
0.072 \\
0.069 \\
0.073 \\
0.071 \\
0.063 \\
0.062 \\
0.064 \\
0.067 \\
0.064 \\
0.072 \\
0.073 \\
0.067 \\
0.074 \\
0.057 \\
0.060 \\
0.059\end{array}$ & $\begin{array}{l}0.041 \\
0.042 \\
0.041 \\
0.050 \\
0.049 \\
0.048 \\
0.047 \\
0.049 \\
0.047 \\
0.050 \\
0.048 \\
0.043 \\
0.043 \\
0.044 \\
0.045 \\
0.044 \\
0.049 \\
0.050 \\
0.046 \\
0.051 \\
0.039 \\
.0 .041 \\
0.040\end{array}$ & $\begin{array}{l}0.127 \\
0.129 \\
0.126 \\
0.155 \\
0.151 \\
0.149 \\
0.146 \\
0.153 \\
0.146 \\
0.154 \\
0.149 \\
0.132 \\
0.132 \\
0.136 \\
0.141 \\
0.135 \\
0.151 \\
0.154 \\
0.141 \\
0.156 \\
0.121 \\
0.127 \\
0.125\end{array}$ & . & $\begin{array}{l}6.04 \\
6.04 \\
6.04 \\
6.04 \\
6.04 \\
6.04 \\
6.04 \\
6.04 \\
6.04 \\
6.04 \\
6.04 \\
6.04 \\
6.04 \\
6.04 \\
6.04 \\
6.04 \\
6.04 \\
6.04 \\
6.04 \\
6.04 \\
6.04 \\
\\
\text { Mean } \\
\text { Standard }\end{array}$ & $\begin{array}{l}4.73 \\
5.36 \\
5.51 \\
5.18 \\
4.61 \\
3.34 \\
2.63 \\
4.23 \\
5.22 \\
5.41 \\
5.12 \\
4.87 \\
3.03 \\
3.83 \\
2.84 \\
4.28 \\
3.55 \\
4.36 \\
3.94 \\
3.70 \\
4.77\end{array}$ & $\begin{array}{l}0.22 \\
0.11 \\
0.09 \\
0.14 \\
0.24 \\
0.45 \\
0.56 \\
0.30 \\
0.14 \\
0.10 \\
0.15 \\
0.19 \\
0.50 \\
0.37 \\
0.53 \\
0.29 \\
0.41 \\
0.28 \\
0.35 \\
0.39 \\
0.21\end{array}$ & $\begin{array}{l}0.074 \\
0.078 \\
0.079 \\
0.077 \\
0.073 \\
0.066 \\
0.063 \\
0.071 \\
0.077 \\
0.078 \\
0.076 \\
0.075 \\
0.065 \\
0.069 \\
0.064 \\
0.071 \\
0.067 \\
0.072 \\
0.069 \\
0.068 \\
0.074 \\
\\
0.066 \\
0.006\end{array}$ & $\begin{array}{l}0.050 \\
0.053 \\
0.054 \\
0.052 \\
0.050 \\
0.045 \\
0.043 \\
0.049 \\
0.053 \\
0.053 \\
0.052 \\
0.051 \\
0.044 \\
0.047 \\
0.044 \\
0.049 \\
0.046 \\
0.049 \\
0.047 \\
0.047 \\
0.051 \\
\\
0.045 \\
0.004\end{array}$ & $\begin{array}{r}0.156 \\
0.164 \\
0.166 \\
0.162 \\
0.155 \\
0.141 \\
0.134 \\
0.150 \\
0.163 \\
0.165 \\
0.161 \\
0.158 \\
0.138 \\
0.146 \\
0.136 \\
0.151 \\
0.143 \\
0.152 \\
0.147 \\
0.144 \\
0.157 \\
0.141 \\
0.012\end{array}$ \\
\hline
\end{tabular}


Combining the last three random errors by root-sum-squaring will result in an overall random error of

$$
\mathrm{C}_{\text {random }}= \pm 0.35 \mathrm{mg} / \mathrm{L} \text {. }
$$

Propagating these errors into 100 randomly selected data points (Table D-3) for estimating fraction of oxygen desorbed $F_{p d}$ results in

Overall average bias error

Overall average random error

$$
\begin{aligned}
F_{\text {bias }} & = \pm 0.045 \\
F_{\text {random }} & = \pm 0.066
\end{aligned}
$$

Combining these two errors using the root-sum-square model (ANSI/ASME 1986) and using a value of 2 for student $t$, the overall average uncertainty in fraction of oxygen desorbed will be

$$
\mathrm{U}_{\mathrm{pd}}= \pm 0.14
$$

This represents a large uncertainty in the absolute value of $F_{p d}$, which ranges from 0 to 1. For asserting relative changes between two $F_{p d}$ measurements, the bias error is the same for both measurements and cancels out. For example, if the effect of bubble injection for tests performed within two hours is considered, then the errar from the Winker analysis $U_{\text {Wink }}$ and the error from sensor calibration $B_{c a l}$ will not enter into the comparison. Only the sensor-tosensor error $R_{s}$ and random reading error $R_{\text {read }}$ contribute to uncertainty in relative comparisons. In this case, the overall uncertainty in $F_{p d}$ will be 0.05. Furthermore, if only one D.0. sensor is used for comparing the data, only the random error in sensor reading $\mathrm{R}_{\text {read }}$ needs to be considered. This will result in an uncertainty of 0.02 in $\mathrm{F}_{\mathrm{pd}}$.

To reduce the uncertainty $F_{p d}$, focus should be on reducing the errors that contribute the most, i.e., U Wink and $B_{c a l}$. To reduce $U_{\text {Wink }}$, the method of sampling water for Winkler analysis should be identical each time, and also more samples should be taken. To improve $B_{c a l}$, the accuracy of D.O. sensors and the method of exposing water samples to sensors should be improved. More accurate sensors or methods to measure dissolved oxygen sensors where their response does not depend on the sample water conditions, such as flow rate, should be used.

\section{D.2.5 References}

ANSI/ASME PTC 19.1-1985, 1986, Measurement Uncertainty, supplement to ASME Instrument and Apparatus Performance Test Codes, New York, NY: American Society of Mechanical Engineers.

Hitchman, M. I., 1978, Measurement of Dissolved Oxygen, New York: John Wiley and Sons.

\section{D.3 METHODS OF IMPROVING DISSOLVED OXYGEN MEASUREMTNT ACCURACY}

In Sections 5.4 and 5.5 of Chapter 5 the difficulties of and uncertainties in measurement accuracy were discussed. In this section of the appendix, ways to improve the dissolved oxygen measurements are discussed. One source of scatter 
in the data may be changes in the seawater quality and the size and number density of nucleation sites. However, the larger source of the scatter was the rather large errors in the $D .0$. measurements. These errors (estimated in Section D.2 of this appendix) were an uncertainty of $0.21 \mathrm{mg} / \mathrm{L}$ in the Winkler method as the calibration standard $(0.10 \mathrm{mg} / \mathrm{L}$, from accuracy of Winkler, and $0.11 \mathrm{mg} / \mathrm{L}$, from water sampling technique), an average error of $0.33 \mathrm{mg} / \mathrm{L}$ between the sensor readings and the calibration values, an average error of $0.11 \mathrm{mg} / \mathrm{L}$ among various sensors, and a sensor fluctuation of $0.05 \mathrm{mg} / \mathrm{L}$.

The largest of these errors is the average error between the sensor reading and the Winkler calibration values. This error stems from the inherent inaccuracy of the Clark-type polarographic D.O. sensors, which is about $0.1 \mathrm{mg} / \mathrm{L}$ (Yellow Springs Instruments 1987); the drift from calibration; and the variation in sample flow conditions, such as flow rate. The only remedy for improving the inherent inaccuracy is to change the sensors. Although small, the error caused by drift from Winkler calibration can be improved by calibrating more frequently, every day of testing. It is believed that the variation in flow conditions is the major contributor of error. The D.0. measurements are sensitive to water flow rate passed across the sensors. Flow velocities below $0.3 \mathrm{~m} / \mathrm{s}$ cause oxygen depletion at the electrodes of the sensors because the D.O. sensors consume oxygen by oxidation. A continual supply of oxygen should be available for the sensors. The impeller pumps that provide sufficient flow rate caused cavitation. The peristaltic pumps, which did not cavitate, could not produce sufficient flow rate. Incoming bubbles in the sampling water also added to the error. To reduce the error caused by sample flow conditions, the sampling set-up needs to be redesigned and monitored closely to ensure the repeatability of the sampling technique.

Another approach is to replace the existing sensors with sensors or measurement techniques that do not depend on the sample flow conditions. For example, gas chromatography and mass spectrometry techniques, or "balanced electrode reaction" sensors, do not consume oxygen, and therefore their operation does not depend on water flow rate. One other advantage of these sensors is that unlike the Clark-type sensors their electrolyte solution and membrane do not need frequent replacement. Currently, one drawback of the "balanced electrode reaction" sensors is that they cannot automatically compensate for the salinity of seawater. Note. also that gas chromatography and mass spectrometry techniques are not easily adaptable for online measurements.

The second largest source of error was the uncertainty in the Winkler method; $0.10 \mathrm{mg} / \mathrm{L}$ of this error is inherent in the Winkler titration method and cannot be reduced. The other $0.11 \mathrm{mg} / \mathrm{L}$ is because of sampling techniques and can be reduced by taking more samples (five rather than two or three) or adapting a procedure to ensure uniformity in sampling.

The $0.11 \mathrm{mg} / \mathrm{L}$ error caused by sensor-to-sensor variation may be eliminated by using only one sensor for all measurements. The error caused by the fluctuation of the sensor reading $(0.05 \mathrm{mg} / \mathrm{L})$ does not.contribute much to the overall uncertainty in the fraction of oxygen desorbed.

\section{D.3.1 References}

Yell ow Springs Instruments, 1987, Instruction Manual, YSI Model 58 Dissolved Oxygen Meter, Item No. 069387, Yellow Springs, OH: Yellow Springs Instruments Co., Inc. 
D.4 SUMARY OF MEASURED AND CALCULATED PARAMETERS FOR PREDEAERATION TEST

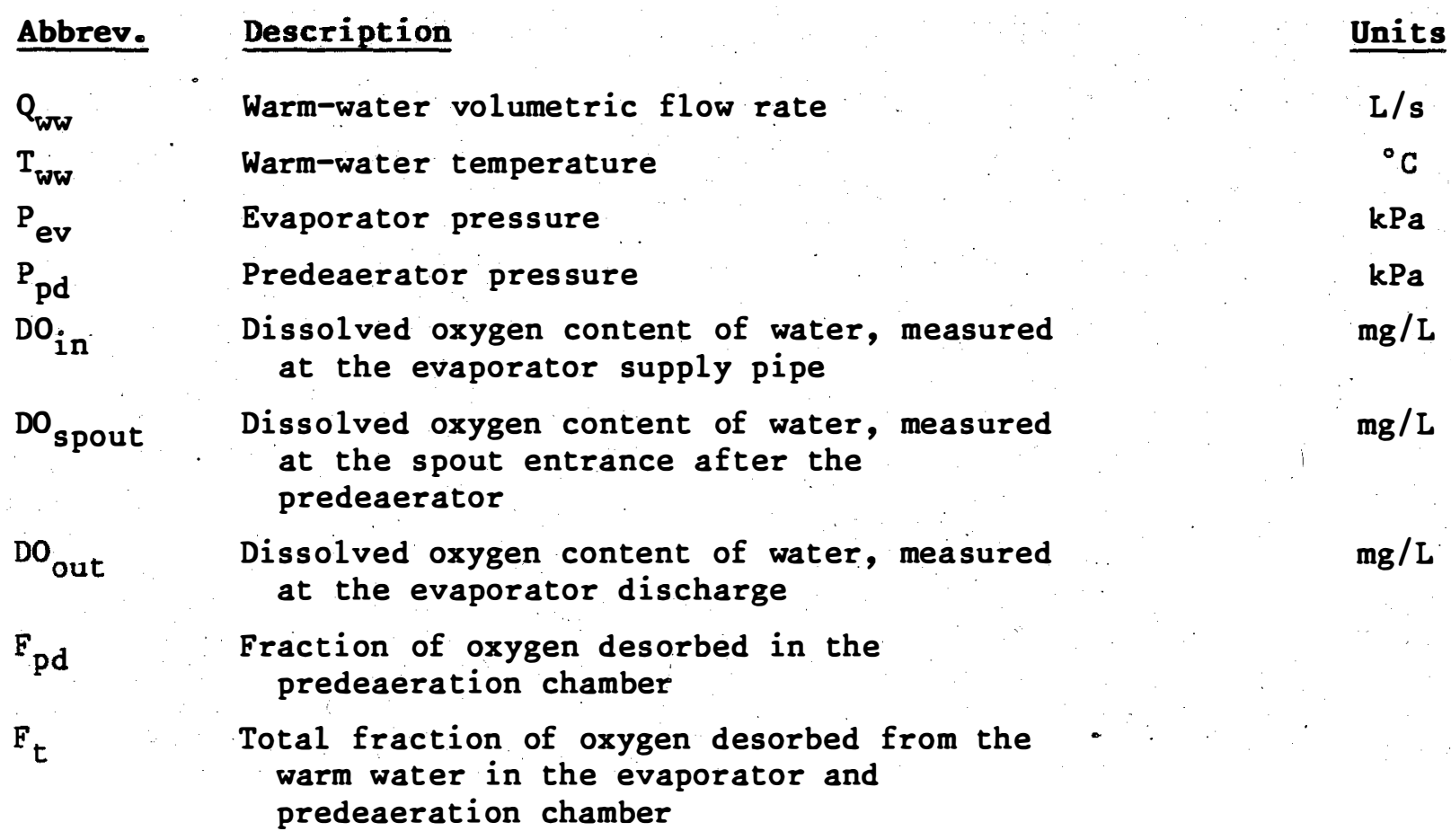


Table D-4. Data Table for Predeaeration Tests

\begin{tabular}{|c|c|c|c|c|c|c|c|c|c|c|}
\hline Run ID & Descrip & $Q_{\text {ww }}$ & $\mathrm{T}_{\mathrm{ww}}$ & $P_{\text {ev }}$ & $\mathrm{P}_{\mathrm{pd}}$ & $\mathrm{DO}_{\text {in }}$ & $\mathrm{DO}_{\text {spt }}$ & ${ }^{\mathrm{DO}}$ out & $F_{p d}$ & $F_{t}$ \\
\hline $\begin{array}{l}621.283 \\
621.004 \\
621.005 \\
621.006 \\
621.007 \\
621.008 \\
621.009\end{array}$ & $\begin{array}{l}\mathrm{NB}, \mathrm{NI} \\
\mathrm{NB}, \mathrm{NI} \\
\mathrm{NB}, \mathrm{NI} \\
\mathrm{NB}, \mathrm{NI} \\
\mathrm{NB}, \mathrm{NI} \\
\mathrm{NB}, \mathrm{NI} \\
\mathrm{NB}, \mathrm{NI}\end{array}$ & $\begin{array}{l}37.53 \\
37.66 \\
37.47 \\
37.34 \\
37.04 \\
75.30 \\
73.45\end{array}$ & $\begin{array}{l}26.0 \\
26.1 \\
26.1 \\
26.2 \\
26.2 \\
26.1 \\
26.0\end{array}$ & $\begin{array}{r}2.45 \\
5.19 \\
7.89 \\
11.06 \\
16.10 \\
2.78 \\
9.33\end{array}$ & $\begin{array}{l}16.64 \\
18.13 \\
21.14 \\
24.77 \\
29.47 \\
19.54 \\
24.70\end{array}$ & $\begin{array}{l}6.82 \\
6.82 \\
6.61 \\
6.68 \\
6.66 \\
6.70 \\
6.50\end{array}$ & $\begin{array}{l}3.12 \\
3.43 \\
3.76 \\
4.14 \\
4.59 \\
4.09 \\
4.45\end{array}$ & $\begin{array}{l}0.53 \\
1.38 \\
3.07 \\
2.17 \\
3.59 \\
0.50 \\
2.36\end{array}$ & $\begin{array}{l}0.53 \\
0.49 \\
0.44 \\
0.38 \\
0.31 \\
0.39 \\
0.33\end{array}$ & $\begin{array}{l}0.92 \\
0.79 \\
0.54 \\
0.68 \\
0.46 \\
0.92 \text { ê } \\
0.65\end{array}$ \\
\hline $\begin{array}{l}622.001 \\
622.002 \\
622.003 \\
622.004 \\
622.005 \\
622.006 \\
622.007 \\
622.008 \\
622.009 \\
622.010 \\
622.011 \\
622.012 \\
622.013 \\
622.014\end{array}$ & $\begin{array}{l}\mathrm{NB}, \mathrm{NI} \\
\mathrm{NB}, \mathrm{NI} \\
\mathrm{NB}, \mathrm{NI} \\
\mathrm{NB}, \mathrm{NI} \\
\mathrm{NB}, \mathrm{NI} \\
\mathrm{NB}, \mathrm{NI} \\
\mathrm{NB}, \mathrm{NI} \\
\mathrm{NB}, \mathrm{NI} \\
\mathrm{NB}, \mathrm{NI} \\
\mathrm{NB}, \mathrm{NI} \\
\mathrm{NB}, \mathrm{NI} \\
\mathrm{NB}, \mathrm{NI} \\
\mathrm{NB}, \mathrm{NI} \\
\mathrm{NB}, \mathrm{NI}\end{array}$ & $\begin{array}{l}26.10 \\
25.53 \\
25.09 \\
24.60 \\
23.99 \\
49.37 \\
50.07 \\
51.01 \\
51.77 \\
51.23 \\
75.72 \\
47.41 \\
49.49 \\
49.51\end{array}$ & $\begin{array}{l}25.9 \\
26.0 \\
26.0 \\
26.0 \\
26.0 \\
26.0 \\
26.1 \\
26.1 \\
26.1 \\
26.1 \\
26.2 \\
26.1 \\
26.1 \\
26.1\end{array}$ & $\begin{array}{r}2.33 \\
5.91 \\
10.94 \\
15.77 \\
21.98 \\
19.80 \\
15.22 \\
10.13 \\
2.26 \\
6.76 \\
13.61 \\
20.22 \\
19.88 \\
19.51\end{array}$ & $\begin{array}{l}15.50 \\
18.45 \\
23.42 \\
28.75 \\
34.62 \\
33.50 \\
30.09 \\
25.41 \\
18.75 \\
21.11 \\
30.39 \\
33.79 \\
34.38 \mathrm{e} \\
33.11\end{array}$ & $\begin{array}{l}6.62 \\
6.63 \\
6.60 \\
6.60 \\
6.60 \\
6.22 \\
6.39 \\
6.52 \\
6.20 \\
6.52 \\
6.52 \\
6.52 \\
6.52 \\
6.42\end{array}$ & $\begin{array}{l}3.95 \\
4.65 \\
5.04 \\
5.43 \\
5.77 \\
5.80 \\
5.59 \\
5.01 \\
5.07 \\
4.86 \\
5.35 \\
5.70 \\
5.49 \\
5.56\end{array}$ & $\begin{array}{l}0.50 \\
2.12 \\
2.26 \\
2.68 \\
3.46 \\
3.15 \\
2.32 \\
1.90 \\
0.44 \\
1.32 \\
2.27 \\
3.52 \\
3.77 \\
2.85\end{array}$ & $\begin{array}{l}0.39 \\
0.28 \\
0.22 \\
0.16 \\
0.11 \\
0.11 \\
0.14 \\
0.23 \\
0.22 \\
0.25 \\
0.18 \\
0.12 \\
0.15 \\
0.14\end{array}$ & $\begin{array}{l}0.92 \\
0.67 \\
0.65 \\
0.59 \\
0.47 \\
0.51 \\
0.64 \\
0.71 \\
0.93 \\
0.80 \\
0.65 \\
0.47 \\
0.43 \\
0.56\end{array}$ \\
\hline $\begin{array}{l}623.001 \\
623.002 \mathrm{~N} 1 \\
623.002 \mathrm{~B} 1 \\
623.002 \mathrm{~B} 2 \\
623.002 \mathrm{~B} 3 \\
623.002 \mathrm{~B} 4 \\
623.002 \mathrm{~N} 2 \\
623.002 \mathrm{~N} 1 \\
623.003 \mathrm{~B} 1 \\
623.003 \mathrm{~B} 2 \\
623.003 \mathrm{~B} 3 \\
623.003 \mathrm{~B} 4 \\
623.003 \mathrm{~N} 2 \\
623.004 \mathrm{~N} 1 \\
623.004 \mathrm{~B} 1 \\
623.004 \mathrm{~B} 2 \\
623.004 \mathrm{~N} 2 \\
623.005 \mathrm{~N} 1 \\
623.005 \mathrm{~B} 1 \\
623.005 \mathrm{~B} 2 \\
623.006 \\
623.007 \\
623.008 \\
623.009 \\
623.010 \\
623.011\end{array}$ & $\begin{array}{l}\text { NB,NI } \\
\text { NB,NI } \\
\text { NB,HI } \\
\text { NB, LI } \\
\text { NB,LI } \\
\text { NB, LI } \\
\text { NB,NI } \\
\text { NB,NI } \\
\text { NB,HI } \\
\text { NB,LI } \\
\text { NB, LI } \\
\text { NB, LI } \\
\text { NB,NI } \\
\text { NB,NI } \\
\text { NB,HI } \\
\text { NB, LI } \\
\text { NB,NI } \\
\text { NB,NI } \\
\text { NB,HI } \\
\text { NB, LI } \\
\text { NB,NI } \\
\text { NB,NI } \\
\text { NB,NI } \\
\text { NB,NI } \\
\text { NB,NI } \\
\text { NB,NI }\end{array}$ & $\begin{array}{l}26.42 \\
24.70 \\
24.70 \\
24.70 \\
24.70 \\
24.70 \\
24.70 \\
23.80 \\
23.80 \\
23.80 \\
23.80 \\
23.80 \\
23.80 \\
49.34 \\
49.34 \\
49.34 \\
49.34 \\
51.08 \\
51.08 \\
51.08 \\
50.67 \\
50.65 \\
50.40 \\
50.38 \\
50.77 \\
43.56\end{array}$ & $\begin{array}{l}26.0 \\
26.0 \\
26.0 \\
26.0 \\
26.0 \\
26.0 \\
26.0 \\
26.0 \\
26.0 \\
26.0 \\
26.0 \\
26.0 \\
26.0 \\
26.0 \\
26.0 \\
26.0 \\
26.0 \\
26.0 \\
26.0 \\
26.0 \\
26.0 \\
26.0 \\
26.0 \\
26.0 \\
26.0 \\
26.0\end{array}$ & $\begin{array}{r}2.31 \\
2.28 \\
2.28 \\
2.28 \\
2.28 \\
2.28 \\
2.28 \\
12.07 \\
12.07 \\
12.07 \\
12.07 \\
12.07 \\
12.07 \\
11.99 \\
11.99 \\
11.99 \\
11.99 \\
2.67 \\
2.67 \\
2.67 \\
2.66 \\
2.73 \\
2.60 \\
2.60 \\
2.66 \\
2.56\end{array}$ & $\begin{array}{l}15.02 \\
15.68 \\
15.68 \\
15.68 \\
15.68 \\
15.68 \\
15.68 \\
24.81 \\
24.81 \\
24.81 \\
24.81 \\
24.81 \\
24.81 \\
26.28 \\
26.28 \\
26.28 \\
26.28 \\
19.04 \\
19.04 \\
19.04 \\
16.65 \\
20.99 \\
16.73 \\
16.55 \\
16.57 \\
16.01\end{array}$ & $\begin{array}{l}6.76 \\
6.76 \\
6.76 \\
6.76 \\
6.76 \\
6.76 \\
6.76 \\
6.76 \\
6.76 \\
6.76 \\
6.76 \\
6.76 \\
6.76 \\
6.76 \\
6.76 \\
6.76 \\
6.76 \\
6.76 \\
6.76 \\
6.76 \\
6.76 \\
6.76 \\
6.76 \\
6.76 \\
6.76 \\
6.76\end{array}$ & $\begin{array}{l}4.56 \\
4.05 \\
3.65 \\
3.94 \\
3.93 \\
4.05 \\
4.07 \\
4.95 \\
4.58 \\
4.84 \\
4.89 \\
4.91 \\
4.95 \\
4.93 \\
4.67 \\
4.88 \\
4.94 \\
4.19 \\
3.94 \\
4.18 \\
4.04 \\
4.16 \\
4.10 \\
4.04 \\
4.05 \\
4.07\end{array}$ & $\begin{array}{l}0.74 \\
1.71 \\
1.57 \\
1.58 \\
1.71 \\
1.62 \\
1.66 \\
3.08 \\
2.52 \\
2.61 \\
2.58 \\
2.66 \\
2.99 \\
2.64 \\
2.74 \\
2.85 \\
3.07 \\
0.87 \\
1.13 \\
1.05 \\
0.91 \\
0.94 \\
0.73 \\
1.34 \\
2.21 \\
3.76\end{array}$ & $\begin{array}{l}0.33 \\
0.40 \\
0.46 \\
0.42 \\
0.42 \\
0.40 \\
0.40 \\
0.27 \\
0.32 \\
0.28 \\
0.28 \\
0.27 \\
0.27 \\
0.27 \\
0.31 \\
0.28 \\
0.27 \\
0.38 \\
0.42 \\
0.38 \\
0.40 \\
0.38 \\
0.39 \\
0.40 \\
0.40 \\
0.40\end{array}$ & $\begin{array}{l}0.89 \\
0.75 \\
0.77 \\
0.77 \\
0.75 \\
0.75 \\
0.76 \\
0.75 \\
0.54 \\
0.7 \\
0.63 \\
0.61 \\
0.62 \\
0.61 \\
0.56 \\
0.61 \\
0.61 \\
0.60 \\
0.58 \\
0.55 \\
0.87 \\
0.83 \\
0.84 \\
0.87 \\
0\end{array}$ \\
\hline
\end{tabular}


Table D-4. Data Tấle for Predeaeration Tests (Continued)

\begin{tabular}{|c|c|c|c|c|c|c|c|c|c|c|}
\hline Run ID & Descrip & $Q_{w w}$ & $T_{w w}$ & $P_{\text {ev }}$ & $P_{p d}$ & $\mathrm{DO}_{\mathrm{in}}$ & $\mathrm{DO}_{\text {spt }}$ & Do out & $F_{p d}$ & $\mathbf{F}_{t \hat{\mathrm{e}}}$ \\
\hline $\begin{array}{l}627.002 \\
627.003 \\
627.004 \\
627.005 \\
627.006 \\
627.007\end{array}$ & $\begin{array}{l}\mathrm{BI}, \mathrm{NI} \\
\mathrm{BI}, \mathrm{NI} \\
\mathrm{BI}, \mathrm{NI} \\
\mathrm{BI}, \mathrm{NI} \\
\mathrm{BI}, \mathrm{NI} \\
\mathrm{BI}, \mathrm{NI}\end{array}$ & $\begin{array}{l}24.93 \\
25.30 \\
24.71 \\
25.13 \\
49.27 \\
50.15\end{array}$ & $\begin{array}{l}26.1 \\
26.1 \\
26.1 \\
26.2 \\
26.2 \\
26.1\end{array}$ & $\begin{array}{r}7.97 \\
13.07 \\
17.74 \\
22.66 \\
22.81 \\
18.15\end{array}$ & $\begin{array}{l}20.33 \\
25.46 \\
30.09 \\
35.41 \\
35.26 \\
32.65\end{array}$ & $\begin{array}{l}6.52 \\
6.52 \\
6.56 \\
6.62 \\
6.71 \\
6.63\end{array}$ & $\begin{array}{l}5.01 \\
5.33 \\
5.78 \\
6.17 \\
6.32 \\
6.19\end{array}$ & $\begin{array}{l}3.50 \\
3.50 \\
4.62 \\
5.01 \\
5.72 \\
\ldots \times 4\end{array}$ & $\begin{array}{l}0.23 \\
0.18 \\
0.12 \\
0.07 \\
0.06 \\
0.07\end{array}$ & $\begin{array}{l}0.46 \\
0.46 \\
0.29 \\
0.24 \\
0.15 \\
* * * 4\end{array}$ \\
\hline $\begin{array}{l}628.001 \\
628.002 \\
628.003 \\
628.004 \\
628.005 \\
628.006 \\
628.007 \\
628.008 \mathrm{~N} 1 \\
628.008 \mathrm{BI} \\
628.008 \mathrm{~B} 2 \\
628.008 \mathrm{~N} 2 \\
628.009 \mathrm{~N} 1 \\
628.009 \mathrm{~B} 1 \\
628.009 \mathrm{~B} 2 \\
628.009 \mathrm{~N} 2\end{array}$ & $\begin{array}{l}\mathrm{BI}, \mathrm{NI} \\
\mathrm{BI}, \mathrm{NI} \\
\mathrm{BI}, \mathrm{NI} \\
\mathrm{BI}, \mathrm{NI} \\
\mathrm{BI}, \mathrm{NI} \\
\mathrm{BI}, \mathrm{NI} \\
\mathrm{BI}, \mathrm{NI} \\
\mathrm{BI}, \mathrm{NI} \\
\mathrm{BI}, \mathrm{HI} \\
\mathrm{BI}, \mathrm{LI} \\
\mathrm{BI}, \mathrm{NI} \\
\mathrm{BI}, \mathrm{NI} \\
\mathrm{BI}, \mathrm{HI} \\
\mathrm{BI}, \mathrm{LI} \\
\mathrm{BI}, \mathrm{NI}\end{array}$ & $\begin{array}{l}49.62 \\
51.08 \\
49.26 \\
75.07 \\
76.90 \\
70.87 \\
50.01 \\
49.87 \\
49.87 \\
49.87 \\
49.87 \\
24.64 \\
24.64 \\
24.64 \\
24.64\end{array}$ & $\begin{array}{l}25.9 \\
25.9 \\
26.0 \\
26.2 \\
26.2 \\
26.3 \\
26.3 \\
26.3 \\
26.3 \\
26.3 \\
26.3 \\
26.3 \\
26.3 \\
26.3 \\
26.3\end{array}$ & $\begin{array}{r}18.15 \\
12.42 \\
8.20 \\
15.08 \\
10.06 \\
2.33 \\
2.21 \\
2.16 \\
2.16 \\
2.16 \\
2.16 \\
1.81 \\
1.81 \\
1.81 \\
1.81\end{array}$ & $\begin{array}{l}32.14 \\
26.56 \\
22.17 \\
31.88 \\
27.22 \\
20.24 \\
17.21 \\
17.21 \\
17.21 \\
17.21 \\
17.21 \\
14.92 \\
14.92 \\
14.92 \\
14.92\end{array}$ & $\begin{array}{l}6.82 \\
6.68 \\
6.69 \\
6.81 \\
6.50 \\
6.50 \\
6.37 \\
6.46 \\
6.46 \\
6.46 \\
6.46 \\
6.56 \\
6.56 \\
6.56 \\
6.56\end{array}$ & $\begin{array}{l}5.54 \\
5.18 \\
4.73 \\
5.59 \\
5.22 \\
4.57 \\
4.29 \\
4.46 \\
4.19 \\
4.40 \\
4.45 \\
4.22 \\
3.85 \\
4.01 \\
4.16\end{array}$ & $\begin{array}{l}2.96 \\
3.03 \\
1.80 \\
2.52 \\
1.81 \\
0.76 \\
0.41 \\
0.45 \\
0.44 \\
0.43 \\
0.45 \\
0.44 \\
0.43 \\
0.42 \\
0.44\end{array}$ & $\begin{array}{l}0.19 \\
0.22 \\
0.29 \\
0.18 \\
0.20 \\
0.30 \\
0.33 \\
0.31 \\
0.35 \\
0.32 \\
0.31 \\
0.36 \\
0.41 \\
0.39 \\
0.37\end{array}$ & $\begin{array}{l}0.57 \\
0.55 \\
0.73 \\
0.63 \\
0.72 \\
0.88 \\
0.94 \\
0.93 \\
0.93 \\
0.93 \\
0.93 \\
0.93 \\
0.93 \\
0.94 \\
0.93\end{array}$ \\
\hline $\begin{array}{l}629.001 \mathrm{~N} 1 \\
629.001 \mathrm{~B} 1 \\
629.001 \mathrm{~B} 2 \\
629.001 \mathrm{~N} 2 \\
629.002 \mathrm{~N} 1 \\
629.002 \mathrm{~B} 1 \\
629.002 \mathrm{~B} 2 \\
629.002 \mathrm{~N} 2 \\
629.003 \\
629.004 \mathrm{~N} 1 \\
629.004 \mathrm{~B} 1 \\
629.004 \mathrm{~B} 2 \\
629.004 \mathrm{~N} 2 \\
629.005 \mathrm{~N} 1 \\
629.005 \mathrm{~B} 1 \\
629.005 \mathrm{~B} 2 \\
629.005 \mathrm{~N} 2\end{array}$ & $\begin{array}{l}\mathrm{BI}, \mathrm{NI} \\
\mathrm{BI}, \mathrm{HI} \\
\mathrm{BI}, \mathrm{LI} \\
\mathrm{BI}, \mathrm{NI} \\
\mathrm{BI}, \mathrm{NI} \\
\mathrm{BI}, \mathrm{HI} \\
\mathrm{BI}, \mathrm{LI} \\
\mathrm{BI}, \mathrm{NI} \\
\mathrm{BI}, \mathrm{NI} \\
\mathrm{BI}, \mathrm{NI} \\
\mathrm{BI}, \mathrm{HI} \\
\mathrm{BI}, \mathrm{LI} \\
\mathrm{BI}, \mathrm{NI} \\
\mathrm{BI}, \mathrm{NI} \\
\mathrm{BI}, \mathrm{HI} \\
\mathrm{BI}, \mathrm{LI} \\
\mathrm{BI}, \mathrm{NI}\end{array}$ & $\begin{array}{l}25.83 \\
25.83 \\
25.83 \\
25.83 \\
25.09 \\
25.09 \\
25.09 \\
25.09 \\
49.60 \\
49.66 \\
49.66 \\
49.66 \\
49.66 \\
49.82 \\
49.82 \\
49.82 \\
49.82\end{array}$ & $\begin{array}{l}26.0 \\
26.0 \\
26.0 \\
26.0 \\
26.0 \\
26.0 \\
26.0 \\
26.0 \\
26.0 \\
26.0 \\
26.0 \\
26.0 \\
26.0 \\
26.0 \\
26.0 \\
26.0 \\
26.0\end{array}$ & $\begin{array}{l}22.75 \\
22.75 \\
22.75 \\
22.75 \\
13.37 \\
13.37 \\
13.37 \\
13.37 \\
12.33 \\
12.30 \\
12.30 \\
12.30 \\
12.30 \\
17.84 \\
17.84 \\
17.84 \\
17.84\end{array}$ & $\begin{array}{l}35.13 \\
35.13 \\
35.13 \\
35.13 \\
25.73 \\
25.73 \\
25.73 \\
25.73 \\
26.23 \\
26.23 \\
26.23 \\
26.23 \\
26.23 \\
31.86 \\
31.86 \\
31.86 \\
31.86\end{array}$ & $\begin{array}{l}6.45 \\
6.45 \\
6.45 \\
6.45 \\
6.45 \\
6.45 \\
6.45 \\
6.45 \\
6.45 \\
6.45 \\
6.45 \\
6.45 \\
6.45 \\
6.45 \\
6.45 \\
6.45 \\
6.45\end{array}$ & $\begin{array}{l}5.85 \\
5.50 \\
5.70 \\
5.87 \\
5.30 \\
5.02 \\
5.19 \\
5.33 \\
5.61 \\
5.36 \\
5.04 \\
5.24 \\
5.29 \\
5.72 \\
5.33 \\
5.54 \\
5.66\end{array}$ & $\begin{array}{l}3.43 \\
3.29 \\
3.41 \\
3.52 \\
2.86 \\
2.89 \\
3.10 \\
3.20 \\
2.79 \\
2.38 \\
2.25 \\
2.34 \\
2.38 \\
3.12 \\
2.95 \\
3.08 \\
3.12\end{array}$ & $\begin{array}{l}0.09 \\
0.15 \\
0.12 \\
0.09 \\
0.18 \\
0.22 \\
0.20 \\
0.17 \\
0.13 \\
0.17 \\
0.22 \\
0.19 \\
0.18 \\
0.11 \\
0.17 \\
0.14 \\
0.12\end{array}$ & $\begin{array}{l}0.47 \\
0.49 \\
0.47 \\
0.45 \\
0.056 \\
0.55 \\
0.52 \\
0.50 \\
0.57 \\
0.63 \\
0.65 \\
0.64 \\
0.63 \\
0.52 \\
0.54 \\
0.52 \\
0.52\end{array}$ \\
\hline $\begin{array}{l}802.003 W D \\
802.004 W D \\
802.005 W D \\
802.006 W D \\
802.008 W D \\
802.009 W D \\
802.012 W D\end{array}$ & $\begin{array}{l}\mathrm{BI}, \mathrm{NI} \\
\mathrm{BI}, \mathrm{NI} \\
\mathrm{BI}, \mathrm{NI} \\
\mathrm{BI}, \mathrm{NI} \\
\mathrm{BI}, \mathrm{NI} \\
\mathrm{BI}, \mathrm{NI} \\
\mathrm{BI}, \mathrm{NI}\end{array}$ & $\begin{array}{l}24.85 \\
37.17 \\
50.13 \\
75.60 \\
75.66 \\
74.96 \\
76.25\end{array}$ & $\begin{array}{l}26.9 \\
26.9 \\
26.9 \\
26.9 \\
26.9 \\
26.9 \\
26.9\end{array}$ & $\begin{array}{r}12.58 \\
11.92 \\
10.98 \\
7.92 \\
13.14 \\
8.08 \\
2.29\end{array}$ & $\begin{array}{l}24.99 \\
25.00 \\
25.00 \\
24.99 \\
30.07 \\
25.01 \\
20.87\end{array}$ & $\begin{array}{l}6.76 \\
6.76 \\
6.76 \\
6.76 \\
6.76 \\
6.76 \\
6.76\end{array}$ & $\begin{array}{l}5.07 \\
4.99 \\
5.27 \\
5.20 \\
5.77 \\
5.39 \\
5.17\end{array}$ & 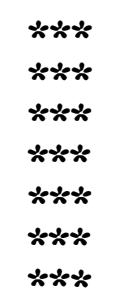 & $\begin{array}{l}0.25 \\
0.26 \\
0.22 \\
0.23 \\
0.15 \\
0.21 \\
0.24\end{array}$ & 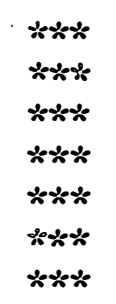 \\
\hline
\end{tabular}


Table D-4. Data Table for Predeaeration Tests (Continued)

\begin{tabular}{|c|c|c|c|c|c|c|c|c|c|c|}
\hline Run ID & Descrip & $Q_{w W}$ & $T_{w w}$ & $P_{\text {ev }}$ & $P_{p d}$ & $\mathrm{DO}_{\text {in }}$ & $\mathrm{DO}_{\text {spt }}$ & Do out & $F_{p d}$ & $F_{t} \hat{e}$ \\
\hline $\begin{array}{l}803.003 W D \\
803.004 W D \\
803.005 W D \\
803.006 W D \\
803.007 W D \\
803.015 W D \\
803.016 W D \\
803.017 W D \\
803.018 W D\end{array}$ & $\begin{array}{l}\mathrm{BI}, \mathrm{NI} \\
\mathrm{BI}, \mathrm{NI} \\
\mathrm{BI}, \mathrm{NI} \\
\mathrm{BI}, \mathrm{NI} \\
\mathrm{BI}, \mathrm{NI} \\
\mathrm{BI}, \mathrm{NI} \\
\mathrm{BI}, \mathrm{NI} \\
\mathrm{BI}, \mathrm{NI} \\
\mathrm{BI}, \mathrm{NI}\end{array}$ & $\begin{array}{l}25.51 \\
25.07 \\
25.14 \\
24.30 \\
24.99 \\
49.59 \\
49.85 \\
49.57 \\
50.15\end{array}$ & $\begin{array}{l}26.6 \\
26.7 \\
26.7 \\
26.7 \\
26.7 \\
27.2 \\
27.2 \\
27.2 \\
27.2\end{array}$ & $\begin{array}{r}1.73 \\
12.69 \\
7.56 \\
17.71 \\
22.10 \\
16.15 \\
20.25 \\
11.14 \\
6.16\end{array}$ & $\begin{array}{l}14.96 \\
25.07 \\
19.99 \\
30.06 \\
34.54 \\
30.11 \\
34.28 \\
25.05 \\
20.04\end{array}$ & $\begin{array}{l}6.33 \\
6.33 \\
6.33 \\
6.33 \\
6.33 \\
6.33 \\
6.33 \\
6.33 \\
6.33\end{array}$ & $\begin{array}{l}4.18 \\
5.00 \\
4.67 \\
5.33 \\
5.59 \\
5.47 \\
5.76 \\
4.99 \\
4.42\end{array}$ & 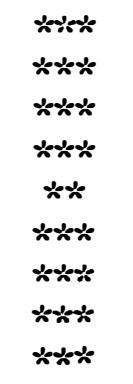 & $\begin{array}{l}0.34 \\
0.21 \\
0.26 \\
0.16 \\
0.12 \\
0.13 \\
0.09 \\
0.21 \\
0.30\end{array}$ & 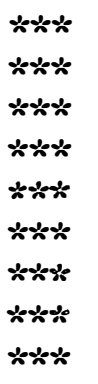 \\
\hline $\begin{array}{l}804.003 \mathrm{WD} \\
804.004 \mathrm{WD} \\
804.005 \mathrm{WD} \\
804.006 \mathrm{WD} \\
804.008 \mathrm{WD} \\
804.009 \mathrm{WD} \\
804.010 \mathrm{WD} \\
804.011 \mathrm{WD} \\
804.012 \mathrm{WD} \\
804.014 \mathrm{WD} \\
804.015 \mathrm{WD} \\
804.016 \mathrm{WD} \\
804.017 \mathrm{WD}\end{array}$ & $\begin{array}{l}\mathrm{BI}, \mathrm{NI} \\
\mathrm{BI}, \mathrm{NI} \\
\mathrm{BI}, \mathrm{NI} \\
\mathrm{BI}, \mathrm{NI} \\
\mathrm{BI}, \mathrm{NI} \\
\mathrm{BI}, \mathrm{NI} \\
\mathrm{BI}, \mathrm{NI} \\
\mathrm{BI}, \mathrm{NI} \\
\mathrm{BI}, \mathrm{NI} \\
\mathrm{BI}, \mathrm{NI} \\
\mathrm{BI}, \mathrm{NI} \\
\mathrm{BI}, \mathrm{NI} \\
\mathrm{BI}, \mathrm{NI}\end{array}$ & $\begin{array}{l}24.84 \\
24.93 \\
24.90 \\
24.83 \\
24.82 \\
24.76 \\
24.68 \\
24.51 \\
25.46 \\
49.84 \\
50.68 \\
50.92 \\
50.33\end{array}$ & $\begin{array}{l}27.1 \\
27.2 \\
27.2 \\
27.2 \\
27.3 \\
27.3 \\
27.3 \\
27.3 \\
27.3 \\
27.3 \\
27.2 \\
27.2 \\
27.2\end{array}$ & $\begin{array}{r}1.86 \\
2.44 \\
3.39 \\
4.22 \\
4.46 \\
5.6 .7 \\
7.10 \\
10.35 \\
15.30 \\
13.11 \\
8.15 \\
6.00 \\
4.35\end{array}$ & $\begin{array}{r}8.93 \\
9.08 \\
9.41 \\
9.73 \\
9.67 \\
10.43 \\
11.74 \\
14.92 \\
19.90 \\
19.81 \\
15.01 \\
13.26 \\
12.23\end{array}$ & $\begin{array}{l}6.46 \\
6.46 \\
6.46 \\
6.46 \\
6.46 \\
6.46 \\
6.46 \\
6.46 \\
6.46 \\
6.46 \\
6.46 \\
6.46 \\
6.46\end{array}$ & $\begin{array}{l}2.26 \\
2.30 \\
3.10 \\
3.26 \\
2.80 \\
3.07 \\
3.79 \\
4.30 \\
4.27 \\
4.47 \\
3.33 \\
2.95 \\
2.49\end{array}$ & 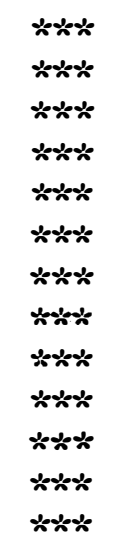 & $\begin{array}{l}0.65 \\
0.64 \\
0.52 \\
0.49 \\
0.57 \\
0.52 \\
0.41 \\
0.33 \\
0.34 \\
0.31 \\
0.48 \\
0.54 \\
0.61\end{array}$ & 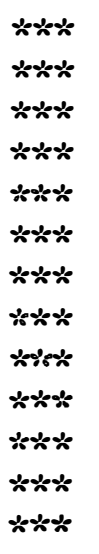 \\
\hline $\begin{array}{l}805.002 \mathrm{DW} \\
805.004 \mathrm{WD} \\
805.005 \mathrm{DW} \\
805.006 \mathrm{DW} \\
805.007 \mathrm{DW} \\
805.008 \mathrm{DW} \\
805.009 \mathrm{DW} \\
805.010 \mathrm{DW} \\
805.011 \mathrm{DW} \\
805.012 \mathrm{DW} \\
805.013 \mathrm{DW} \\
805.014 \mathrm{DW} \\
805.015 \mathrm{DW} \\
805.016 \mathrm{DW}\end{array}$ & $\begin{array}{l}\mathrm{BI}, \mathrm{NI} \\
\mathrm{BI}, \mathrm{NI} \\
\mathrm{BI}, \mathrm{NI} \\
\mathrm{BI}, \mathrm{NI} \\
\mathrm{BI}, \mathrm{NI} \\
\mathrm{BI}, \mathrm{NI} \\
\mathrm{BI}, \mathrm{NI} \\
\mathrm{BI}, \mathrm{NI} \\
\mathrm{BI}, \mathrm{NI} \\
\mathrm{BI}, \mathrm{NI} \\
\mathrm{BI}, \mathrm{NI} \\
\mathrm{BI}, \mathrm{NI} \\
\mathrm{BI}, \mathrm{NI} \\
\mathrm{BI}, \mathrm{NI}\end{array}$ & $\begin{array}{l}50.01 \\
49.96 \\
49.90 \\
49.77 \\
49.87 \\
49.74 \\
49.42 \\
49.10 \\
48.56 \\
48.04 \\
74.72 \\
74.87 \\
75.36 \\
75.41\end{array}$ & $\begin{array}{l}26.9 \\
27.0 \\
27.0 \\
27.0 \\
27.0 \\
27.0 \\
27.0 \\
27.0 \\
27.1 \\
27.0 \\
27.0 \\
27.1 \quad \hat{\mathrm{e}} \\
27.0 \\
27.0\end{array}$ & $\begin{array}{r}2.12 \\
2.63 \\
2.87 \\
4.07 \\
3.23 \\
2.13 \\
5.42 \\
7.22 \\
10.74 \\
13.36 \\
9.67 \\
4.82 \\
4.50 \\
2.28\end{array}$ & $\begin{array}{l}10.63 \\
11.01 \\
11.04 \\
11.40 \\
11.05 \\
10.64 \\
12.25 \\
13.85 \\
17.25 \\
19.82 \\
19.83 \\
16.96 \\
14.67 \\
13.79\end{array}$ & $\begin{array}{l}6.52 \\
6.52 \\
6.52 \\
6.52 \\
6.52 \\
6.52 \\
6.52 \\
6.52 \\
6.52 \\
6.52 \\
6.52 \\
6.52 \\
6.52 \\
6.52\end{array}$ & $\begin{array}{l}1.37 \\
1.37 \\
1.62 \\
3.29 \\
3.04 \\
2.50 \\
3.57 \\
3.85 \\
3.97 \\
4.03 \\
4.92 \\
4.53 \\
3.69 \\
3.39\end{array}$ & 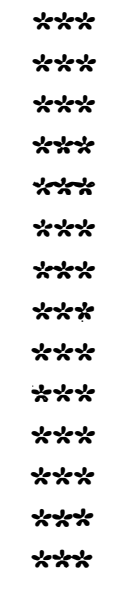 & $\begin{array}{l}0.79 \\
0.79 \\
0.75 \\
0.50 \\
0.54 \\
0.62 \\
0.46 \\
0.42 \\
0.40 \\
0.39 \\
0.25 \\
0.31 \\
0.44 \\
0.49\end{array}$ & 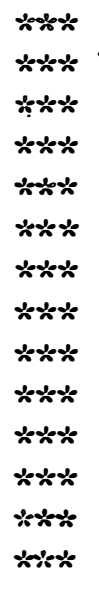 \\
\hline $\begin{array}{l}\text { 808.002ND } \\
808.003 \mathrm{ND} \\
808.004 \mathrm{ND} \\
808.005 \mathrm{ND} \\
808.006 \mathrm{ND} \\
808.007 \mathrm{DW} \\
808.008 \mathrm{DW} \\
808.009 \mathrm{WD} \\
808.010 \mathrm{WD} \\
808.011 \mathrm{WD}\end{array}$ & $\begin{array}{l}\mathrm{BI}, \mathrm{NI} \\
\mathrm{BI}, \mathrm{NI} \\
\mathrm{BI}, \mathrm{NI} \\
\mathrm{BI}, \mathrm{NI} \\
\mathrm{BI}, \mathrm{NI} \\
\mathrm{BI}, \mathrm{NI} \\
\mathrm{BI}, \mathrm{NI} \\
\mathrm{BI}, \mathrm{NI} \\
\mathrm{BI}, \mathrm{NI} \\
\mathrm{BI}, \mathrm{NI}\end{array}$ & $\begin{array}{l}25.19 \\
25.38 \\
25.52 \\
25.77 \\
25.90 \\
25.88 \\
25.79 \\
49.66 \\
49.93 \\
50.22\end{array}$ & $\begin{array}{l}26.7 \\
26.7 \\
26.7 \\
26.7 \\
26.7 \\
26.7 \\
26.7 \\
26.7 \\
26.7 \\
26.7 \text { ê }\end{array}$ & $\begin{array}{r}15.37 \\
12.22 \\
9.77 \\
4.77 \\
1.70 \\
1.70 \\
1.67 \\
3.21 \\
2.05 \\
2.05\end{array}$ & $\begin{array}{r}19.96 \\
17.24 \\
14.82 \\
10.03 \\
9.03 \\
8.85 \\
10.39 \\
14.05 \\
12.17 \\
10.97\end{array}$ & $\begin{array}{l}6.22 \\
6.22 \\
6.22 \\
6.22 \\
6.22 \\
6.22 \\
6.22 \\
6.22 \\
6.22 \\
6.22\end{array}$ & $\begin{array}{l}4.76 \\
4.54 \\
4.40 \\
3.72 \\
3.45 \\
2.51 \\
3.18 \\
3.45 \\
3.26 \\
2.69\end{array}$ & 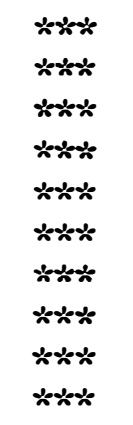 & $\begin{array}{l}0.24 \\
0.27 \\
0.29 \\
0.40 \\
0.45 \\
0.60 \\
0.49 \\
0.45 \\
0.48 \\
0.57\end{array}$ & 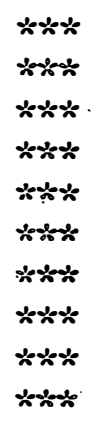 \\
\hline
\end{tabular}


Table D-4. Data Table for Predeaeration Tests (Continued)

\begin{tabular}{|c|c|c|c|c|c|c|c|c|c|c|}
\hline Run ID & Descrip & $Q_{w w}$ & $T_{\text {ww }}$ & $P_{\text {ev }}$ & $P_{\text {pd }} \hat{e}$ & $\mathrm{DO}_{\text {in }}$ & $\mathrm{DO}_{\text {spt }}$ & Do out & $\mathrm{F}_{\mathrm{pd}}$ & $\mathrm{F}_{\mathrm{t}}$ \\
\hline $\begin{array}{l}808.012 \mathrm{WD} \\
808.013 \mathrm{WD} \\
808.014 \mathrm{WD} \\
808.015 \mathrm{WD} \\
808.016 \mathrm{WD} \\
808.017 \mathrm{WD} \\
808.018 \mathrm{WD} \\
808.019 \mathrm{WD} \\
808.020 \mathrm{WD} \\
808.021 \mathrm{WD} \\
808.022 \mathrm{WD} \\
808.023 \mathrm{WD} \\
808.024 \mathrm{WD}\end{array}$ & $\begin{array}{l}\mathrm{BI}, \mathrm{NI} \\
\mathrm{BI}, \mathrm{NI} \\
\mathrm{BI}, \mathrm{NI} \\
\mathrm{BI}, \mathrm{NI} \\
\mathrm{BI}, \mathrm{NI} \\
\mathrm{BI}, \mathrm{NI} \\
\mathrm{BI}, \mathrm{NI} \\
\mathrm{BI}, \mathrm{NI} \\
\mathrm{BI}, \mathrm{NI} \\
\mathrm{BI}, \mathrm{NI} \\
\mathrm{BI}, \mathrm{NI} \\
\mathrm{BI}, \mathrm{NI} \\
\mathrm{BI}, \mathrm{NI}\end{array}$ & $\begin{array}{l}49.79 \\
49.72 \\
49.97 \\
49.19 \\
49.82 \\
50.16 \\
50.30 \\
50.68 \\
50.57 \\
49.31 \\
75.00 \\
75.10 \\
74.88\end{array}$ & $\begin{array}{l}26.7 \\
26.7 \\
26.7 \\
26.7 \\
26.7 \\
26.7 \\
26.7 \\
26.8 \\
26.8 \\
26.7 \\
26.7 \\
26.6 \\
26.7\end{array}$ & $\begin{array}{r}10.70 \\
13.23 \\
15.74 \\
18.43 \\
15.74 \\
13.26 \\
10.60 \\
8.37 \\
6.00 \\
2.03 \\
2.14 \\
2.28 \\
9.03\end{array}$ & $\begin{array}{l}17.35 \\
19.90 \\
22.43 \\
25.05 \\
22.44 \\
19.95 \\
17.33 \\
15.17 \\
12.90 \\
11.13 \\
13.65 \\
18.48 \\
19.28\end{array}$ & $\begin{array}{l}6.22 \\
6.22 \\
6.22 \\
6.22 \\
6.22 \\
6.22 \\
6.22 \\
6.22 \\
6.22 \\
6.22 \\
6.22 \\
6.22 \\
6.22\end{array}$ & $\begin{array}{l}3.90 \\
4.04 \\
4.20 \\
5.18 \\
4.90 \\
4.64 \\
4.34 \\
4.04 \\
3.78 \\
3.06 \\
4.10 \\
4.22 \\
4.89\end{array}$ & אي & $\begin{array}{l}0.37 \\
0.35 \\
0.33 \\
0.17 \\
0.21 \\
0.25 \\
0.30 \\
0.35 \\
0.39 \\
0.51 \\
0.34 \\
0.32 \\
0.21\end{array}$ & אה \\
\hline $\begin{array}{l}809.002 W D \\
809.003 W D \\
809.004 W D \\
809.005 W D \\
809.006 W D \\
809.007 W D \\
809.008 W D \\
809.009 W D \\
809.010 W D \\
809.011 W D \\
809.012 W D \\
809.013 W D \\
809.014 W D \\
809.015 W D \\
809.016 W D \\
809.017 W D \\
809.018 W D \\
809.019 W D \\
809.020 W D\end{array}$ & $\begin{array}{l}\mathrm{BI}, \mathrm{NI} \\
\mathrm{BI}, \mathrm{NI} \\
\mathrm{BI}, \mathrm{NI} \\
\mathrm{BI}, \mathrm{NI} \\
\mathrm{BI}, \mathrm{NI} \\
\mathrm{BI}, \mathrm{NI} \\
\mathrm{BI}, \mathrm{NI} \\
\mathrm{BI}, \mathrm{NI} \\
\mathrm{BI}, \mathrm{NI} \\
\mathrm{BI}, \mathrm{NI} \\
\mathrm{BI}, \mathrm{NI} \\
\mathrm{BI}, \mathrm{NI} \\
\mathrm{BI}, \mathrm{NI} \\
\mathrm{BI}, \mathrm{NI} \\
\mathrm{BI}, \mathrm{NI} \\
\mathrm{BI}, \mathrm{NI} \\
\mathrm{NB}, \mathrm{NI} \\
\mathrm{NB}, \mathrm{NI} \\
\mathrm{NB}, \mathrm{NI}\end{array}$ & $\begin{array}{l}75.51 \\
76.07 \\
75.32 \\
74.58 \\
73.25 \\
50.13 \\
50.78 \\
49.34 \\
50.36 \\
50.41 \\
25.39 \\
25.41 \\
25.03 \\
24.63 \\
24.11 \\
23.52 \mathrm{e} \\
24.14 \\
24.86 \\
25.36\end{array}$ & $\begin{array}{l}26.7 \\
26.7 \\
26.7 \\
26.7 \\
26.7 \\
26.8 \\
26.8 \\
26.8 \\
26.8 \\
26.7 \\
26.7 \\
26.6 \\
26.7 \\
26.8 \\
26.9 \\
26.9 \\
27.0 \\
27.0 \\
26.8\end{array}$ & $\begin{array}{r}10.30 \\
7.81 \\
2.14 \\
15.28 \\
18.87 \\
22.88 \\
18.25 \\
13.20 \\
7.84 \\
2.05 \\
1.70 \\
4.83 \\
10.16 \\
15.50 \\
20.45 \\
25.77 \\
25.86 \\
20.56 \\
15.47\end{array}$ & $\begin{array}{r}20.40 \\
18.92 \\
13.88 \\
25.04 \\
28.51 \\
29.56 \\
25.02 \\
19.81 \\
14.63 \\
10.75 \\
8.77 \\
9.81 \\
14.73 \\
20.04 \\
24.93 \\
30.23 \\
30.25 \\
24.97 \\
19.90\end{array}$ & $\begin{array}{l}6.04 \\
6.04 \\
6.04 \\
6.04 \\
6.04 \\
6.04 \\
6.04 \\
6.04 \\
6.04 \\
6.04 \\
6.04 \\
6.04 \\
6.04 \\
6.04 \\
6.04 \\
6.04 \\
6.04 \\
6.04 \\
6.04\end{array}$ & $\begin{array}{l}5.03 \\
4.73 \\
3.89 \\
5.36 \\
5.51 \\
5.58 \\
5.18 \\
4.61 \\
3.98 \\
3.34 \\
2.63 \\
3.45 \\
4.23 \\
4.82 \\
5.22 \\
5.41 \\
5.12 \\
4.95 \\
4.87\end{array}$ & 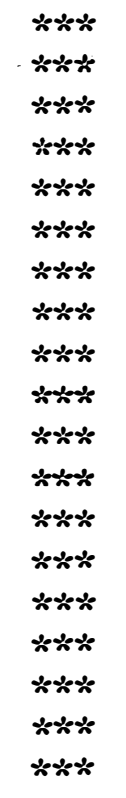 & $\begin{array}{l}0.17 \\
0.22 \\
0.36 \\
0.11 \\
0.09 \\
0.08 \\
0.14 \\
0.24 \\
0.34 \\
0.45 \\
0.57 \\
0.43 \\
0.30 \\
0.20 \\
0.14 \\
0.10 \\
0.15 \\
0.18 \\
0.19\end{array}$ & אוג \\
\hline $\begin{array}{l}810.001 \mathrm{WD} \\
810.002 \mathrm{WD} \\
810.003 \mathrm{WD} \\
810.004 \mathrm{WD} \\
810.005 \mathrm{WD} \\
810.006 \mathrm{WD} \\
810.007 \mathrm{WD} \\
810.008 \mathrm{WD} \\
810.009 \mathrm{WD} \\
810.010 \mathrm{WD} \\
810.011 \mathrm{WD} \\
810.012 \mathrm{WD} \\
810.013 \mathrm{WD} \\
810.014 \mathrm{WD} \\
810.015 \mathrm{WD}\end{array}$ & $\begin{array}{l}\mathrm{NB}, \mathrm{NI} \\
\mathrm{NB}, \mathrm{NI} \\
\mathrm{NB}, \mathrm{NI} \\
\mathrm{NB}, \mathrm{NI} \\
\mathrm{NB}, \mathrm{NI} \\
\mathrm{NB}, \mathrm{NI} \\
\mathrm{NB}, \mathrm{NI} \\
\mathrm{NB}, \mathrm{NI} \\
\mathrm{NB}, \mathrm{NI} \\
\mathrm{NB}, \mathrm{NI} \\
\mathrm{NB}, \mathrm{NI} \\
\mathrm{NB}, \mathrm{NI} \\
\mathrm{NB}, \mathrm{NI} \\
\mathrm{NB}, \mathrm{NI} \\
\mathrm{NB}, \mathrm{NI}\end{array}$ & $\begin{array}{l}27.33 \\
26.10 \\
25.45 \\
26.93 \\
27.34 \\
25.67 \\
24.78 \\
24.91 \\
50.60 \\
50.49 \\
49.81 \\
48.96 \\
50.74 \\
50.08 \\
50.50\end{array}$ & $\begin{array}{l}26.7 \\
26.7 \\
26.7 \\
26.7 \\
26.8 \\
26.9 \\
27.0 \\
27.0 \\
27.0 \\
27.0 \\
26.9 \\
26.9 \\
27.0 \\
27.0 \\
27.0\end{array}$ & $\begin{array}{r}9.12 \\
25.31 \\
29.85 \\
19.64 \\
14.63 \\
9.43 \\
5.79 \\
1.74 \\
2.10 \\
3.32 \\
8.00 \\
13.49 \\
18.28 \\
23.63 \\
30.23\end{array}$ & $\begin{array}{l}19.91 \\
30.36 \\
35.11 \\
24.95 \\
19.85 \\
14.73 \\
11.06 \\
7.68 \\
13.06 \\
11.57 \\
14.71 \\
19.89 \\
24.83 \\
30.22 \\
35.40\end{array}$ & $\begin{array}{l}6.04 \\
6.04 \\
6.04 \\
6.04 \\
6.04 \\
6.04 \\
6.04 \\
6.04 \\
6.04 \\
6.04 \\
6.04 \\
6.04 \\
6.04 \\
6.04 \\
6.04\end{array}$ & $\begin{array}{l}3.03 \\
3.73 \\
3.83 \\
3.26 \\
3.00 \\
2.74 \\
2.61 \\
2.53 \\
2.84 \\
2.87 \\
3.17 \\
3.50 \\
3.70 \\
3.97 \\
4.28\end{array}$ & 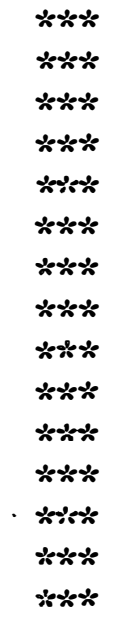 & $\begin{array}{l}0.51 \\
0.39 \\
0.38 \\
0.47 \\
0.51 \\
0.55 \\
0.57 \\
0.59 \\
0.54 \\
0.53 \\
0.48 \\
0.43 \\
0.40 \\
0.35 \\
0.30\end{array}$ & שي \\
\hline
\end{tabular}


$\mathrm{TP}-3561$

Table D-4. Data Table for Predeaeration Tests (Concluded)

\begin{tabular}{|c|c|c|c|c|c|c|c|c|c|c|}
\hline Run ID & Descrip & $Q_{w w}$ & $T_{w w}$ & $P_{\text {ev }}$ & $\mathrm{P}_{\mathrm{pd}}$ & $\mathrm{DO}_{\mathrm{in}}$ & $\mathrm{DO}_{\text {spt }}$ & $\mathrm{DO}_{\text {out }}$ & $F_{p d}$ & $F_{t}$ \\
\hline $\begin{array}{l}810.016 \mathrm{WD} \\
810.017 \mathrm{WD} \\
810.018 \mathrm{WD} \\
810.019 \mathrm{WD} \\
810.020 \mathrm{WD} \\
810.021 \mathrm{WD} \\
810.022 \mathrm{WD}\end{array}$ & $\begin{array}{l}\text { NB, NI } \\
. \mathrm{NB}, \mathrm{NI} \\
\mathrm{NB}, \mathrm{NI} \\
\mathrm{NB}, \mathrm{NI} \\
\mathrm{NB}, \mathrm{NI} \\
\mathrm{NB}, \mathrm{NI} \\
\mathrm{NB}, \mathrm{NI}\end{array}$ & $\begin{array}{l}50.85 \\
75.02 \\
74.76 \\
76.03 \\
75.72 \\
74.94 \\
37.26\end{array}$ & $\begin{array}{l}27.0 \\
27.0 \\
27.0 \\
27.0 \\
26.8 \\
27.0 \\
27.0\end{array}$ & $\begin{array}{r}27.39 \\
23.72 \\
15.77 \\
10.45 \\
6.03 \\
4.12 \\
5.76\end{array}$ & $\begin{array}{l}33.67 \\
32.56 \\
24.92 \\
19.90 \\
15.37 \\
13.19 \\
11.24\end{array}$ & $\begin{array}{l}6.04 \\
6.04 \\
6.04 \\
6.04 \\
6.04 \\
6.04 \\
6.04\end{array}$ & $\begin{array}{l}4.35 \\
4.23 \\
3.71 \\
3.55 \\
3.42 \\
3.28 \\
3.30\end{array}$ & 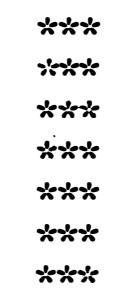 & $\begin{array}{l}0.29 \\
0.31 \\
0.40 \\
0.42 \\
0.44 \\
0.47 \\
0.46\end{array}$ & 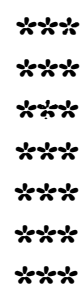 \\
\hline $\begin{array}{l}811.001 \mathrm{WD} \\
811.002 \mathrm{WD} \\
811.003 \mathrm{WD} \\
811.004 \mathrm{WD} \\
811.005 \mathrm{WD} \\
811.006 \mathrm{WD} \\
811.007 \mathrm{WD} \\
811.008 \mathrm{WD} \\
811.009 \mathrm{WD} \\
811.010 \mathrm{WD} \\
811.011 \mathrm{WD} \\
811.012 \mathrm{WD} \\
811.013 \mathrm{WD}\end{array}$ & $\begin{array}{l}\mathrm{NB}, \mathrm{NI} \\
\mathrm{NB}, \mathrm{NI} \\
\mathrm{NB}, \mathrm{NI} \\
\mathrm{NB}, \mathrm{NI} \\
\mathrm{NB}, \mathrm{NI} \\
\mathrm{NB}, \mathrm{NI} \\
\mathrm{NB}, \mathrm{NI} \\
\mathrm{NB}, \mathrm{NI} \\
\mathrm{NB}, \mathrm{NI} \\
\mathrm{NB}, \mathrm{NI} \\
\mathrm{NB}, \mathrm{NI} \\
\mathrm{NB}, \mathrm{NI} \\
\mathrm{NB}, \mathrm{NI}\end{array}$ & $\begin{array}{l}37.40 \\
37.93 \\
37.27 \\
37.57 \\
37.60 \\
37.70 \\
25.62 \\
24.91 \\
23.90 \\
23.61 \\
50.32 \\
49.36 \\
50.22\end{array}$ & $\begin{array}{l}27.0 \\
27.0 \\
27.0 \\
27.0 \\
27.1 \\
27.1 \\
27.1 \\
27.1 \\
27.0 \\
27.1 \\
27.3 \\
27.4 \\
27.4\end{array}$ & $\begin{array}{r}24.83 \\
19.67 \\
14.74 \\
9.44 \\
9.43 \\
2.73 \\
2.62 \\
15.44 \\
25.98 \\
32.38 \\
29.87 \\
10.43 \\
4.80\end{array}$ & $\begin{array}{r}30.05 \\
24.92 \\
19.96 \\
14.66 \\
14.66 \\
10.69 \\
8.54 \\
19.79 \\
30.29 \\
35.46 \\
35.10 \\
16.55 \\
11.07\end{array}$ & $\begin{array}{l}6.04 \\
6.04 \\
6.04 \\
6.04 \\
6.04 \\
6.04 \\
6.04 \\
6.04 \\
6.04 \\
6.04 \\
6.04 \\
6.04 \\
6.04\end{array}$ & $\begin{array}{l}4.36 \\
4.11 \\
3.94 \\
3.78 \\
3.70 \\
3.43 \\
3.41 \\
4.10 \\
4.53 \\
4.77 \\
4.67 \\
3.98 \\
3.68\end{array}$ & 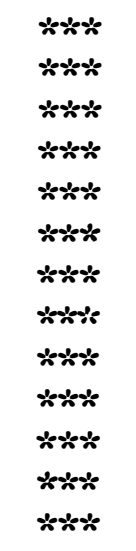 & $\begin{array}{l}0.29 \\
0.33 \\
0.36 \\
0.38 \\
0.40 \\
0.44 \\
0.44 \\
0.33 \\
0.26 \\
0.22 \\
0.24 \\
0.35 \\
0.40\end{array}$ & 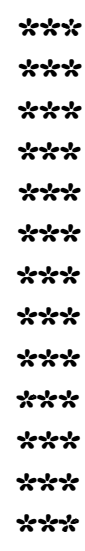 \\
\hline
\end{tabular}

\footnotetext{
Description Key: NB = No baffle installed

$B I=$ Baffle installed

NI $=$ No bubble injection

$\mathrm{LI}=$ Low bubble injection rate $\left(40 \mathrm{~cm}^{3} / \mathrm{min}\right.$ gas $)$

$\mathrm{HI}=\mathrm{High}$ bubble injection rate $\left(150 \mathrm{~cm}^{3} / \mathrm{min}\right.$ gas $)$

$* * *$ No data obtained
} 
APPENDIX E

OPERATION OF THE TEST APPARATUS

AND LESSONS LEARNED 
This appendix summarizes the general management arrangement and procedures used in normal operation of the test apparatus. During operation of such a large and complex facility, valuable lessons in operational aspects and test procedures were acquired. These are summarized here as recommendations to be considered in the design and operation of future OC-OTEC facilities.

\section{E.1 ORGANIZATION AND MANAGEMENT}

The HMTSTA was designed, constructed, and operated under funding by the U.S. Department of Energy's Ocean Energy Technology Program. DOE gave SERI the responsibility of directing design and construction of an apparatus suitable for the testing of evaporators, warm-water predeaerators, and surface condensers. using seawater as a working fluid. In an interlaboratory agreement, SERI enlisted the expertise of Argonne National Laboratory (ANL) to design the apparatus, to fabricate as much of it as was practical at ANL's Illinois facility, to ship it to the test site in Hawaii, and to assemble the apparatus and its instruments. Through other contracts, SERI directed the Natural Energy Laboratory of Hawaii (NELH) and local contractors to prepare the site and to assist ANL with erection and checkout of the apparatus.

Once the apparatus passed its acceptance tests (Bharathan and Hagen 1987) in October 1987, SERI assumed responsibility for operations during Phase I and Phase II testing. A SERI employee was relocated to Hawaii as field test engineer during this period. NELH. was funded to continue support of testing in the apparatus by providing a site, electrical power, water, and personnel including one full-time technician.

Concurrently with Phase I tests, SERI and ANL designed and fabricated parts required for the modification of the apparatus for the Phase II direct-contact condenser tests. ANL designed and fabricated the DCC vessel and support tower while SERI designed and fabricated the DCC internal components.

The Pacific International Center for High Technology Research (PICHTR) began supporting the test efforts at the HMTSTA in August 1988 by providing an engineer to assist with operations. PICHTR was given responsibility to operate the apparatus as part of its 1988 subcontract from SERI. However, through mutual agreement, PICHTR continued to support the SERI field test engineer until Phase II tests were completed in May, 1989. At that time operational control of the facility was passed to a new PICHTR field test engineer.

Each test conducted at the HMTSTA was preceded by a comprehensive test plan (Parsons et al. 1989) which described the objectives of the test, the parameters to be measured, sensors, procedures, and expected uncertainty. The principal investigator (PI) for the test prepared the test articles and procured any special test instrumentation. Typically the PI traveled to the test site to ensure that equipment and instrumentation were properly installed and that the test procedures provided reasonable results. After this startup period, the PI left the site and thereafter coordinated test activities with the field test engineer by telephone. The PI analyzed test data provided by the field test engineer and specified new test conditions and/or procedures as appropriate. 
The field test engineer operated the apparatus to obtain the desired test conditions, performed initial data analysis to ensure that sensors were operating properly and that data were self-consistent, and provided the PIs with test results including computer data files, laboratory record book, and strip chart logs. The field test engineer also coordinated activities among the various PIs and with NELH and other organizations, calibrated instruments, maintained HMTSTA equipment, and conducted tours and other public relations activities.

\section{E.2 STARTUP AND SHUTDOWN}

The following startup and shutdown procedures were used during Phase $I$ and Phase II tests during normal operations. Variations of these procedures were required for special conditions.

\section{E.2.1 Startup}

1. Check that test equipment is properly installed and that all openings into the vacuum vessels are closed.

2. Open isolation valves in the refrigeration system.

3. Begin flowing cold water to the refrigerant condenser. (Changing seawater flows always required coordination with NELH to ensure that their water supply system would be properly rebalanced.)

4. Start the refrigeration system and the liquid-ring vacuum pump.

5. Adjust warm and cold seawater flows to specified test conditions.

6. Turn on warm and (for DCC tests) cold seawater discharge pumps and set controls to maintain desired discharge pool levels.

7. When water temperatures have stabilized, obtain a data set to provide a "no-steam" temperature profile that can be used to show zero offsets for differential temperature and pressure sensors. (Without the booster vacuum pump in operation, the liquid-ring pump would not bring system pressure low enough to begin significant steam generation in the evaporator.)

8. Turn on the booster vacuum pump.

9. Readjust water flows and adjust steam valves to provide the desired test conditions.

10. When steady state is obtained at the desired test conditions and when consistency checks have been completed among various sensors and methods to calculate performance parameters, record a data set for this test.

11. Repeat steps 9 and 10 for new test conditions.

\section{E.2.2 Shutdown}

1. Turn off the refrigerant compressor.

2. Turn off the booster liquid-ring and vacuum pumps.

3. Stop cold and warm seawater flows and shut off seawater discharge $\operatorname{pump}(s)$. 
* 4. Record system vacuum level for at least 30 min to obtain a vacuum decayvs.-time curve for determining air leakage into the isolated system.

5. If tests were scheduled for the following working day, vacuum in the vessels was maintained overnight. Otherwise air was vented into the vacuum vessels.

\section{E.3 OPERATIONAL LIMITATIONS}

The limited-capacity margin afforded by the vacuum pump system resulted in delays during some experiments and 1 imitation of some test conditions. The system was specified for $0.28 \mathrm{~m} / \mathrm{s}(600 \mathrm{acfm})$ at $1.33 \mathrm{kPa}$ (10 torr), inlet pressure and a $50 \%$ steam - 50\% air inlet gas composition. The second-stage surface condenser was expected to reduce the steam content at the vacuum pump inlet to the specified condition because the refrigerant could be maintained at near-freezing temperatures. Thus, the combination of refrigerant-cooled condenser and vacuum pump was expected to permit testing of first-stage, surface-type and direct-contact-type condensers over a wide range of exhaust gas flow rates. In practice, two difficulties were encountered.

First, the second-stage surface condenser was not as successful as had been anticipated at reducing the steam temperature to near freezing (typical outlet temperatures were about $7^{\circ} \mathrm{C}$ ), resulting in difficulties during the surface condenser tests, as described in Section 2.4.2.

Second, the liquid-ring vacuum pump tended to have a lower capacity than the mechanical booster pump. When the liquid-ring pump was loaded with more noncondensable gases than were originally specified, the cold water in the ring could not condense as large a percentage of the inlet steam/gas mixture as normal. The pump's inlet pressure would then rise and increase the compression ratio of the booster pump. The higher compression ratio in the booster pump caused the gas temperature at its outlet to increase sufficiently to trip the "high-temperature" safety interlock. When the booster pump stopped, pressure in the vacuum system would increase rapidly and steady-state conditions would be lost. This problem was alleviated to some extent by decreasing the speed (and thus the capacity) of the booster compressor and by cooling the liquid-ring pump's sealant water with the refrigerant system.

\section{E.4 LESSONS LEARNED}

Design and operation of the HMTSTA was aided by the experience of various members of the DOE Ocean Energy Technology Program with other experimental devices and test programs. In addition, Argonne personnel brought experience from both the OTEC-1 experiment and their tests in Illinois; and SERI personnel contributed experience gained from designing and operating the OC-OTEC laboratory at SERI's Colorado facility. Nonetheless, a number of improvements were identified during the shakedown and test periods, and some were incorporated, that enhanced operations at the HMTSTA. The following sections describe changes made as well as those that should be considered for future tests at the STF. 


\section{E.4.1 Improvements in Facility Operation}

\section{E.4.1.1 Water Flow Control}

Water flow control was an important aspect of HMTSTA operations. The first major problem with the apparatus was its failure to achieve the specified water flow capacity. This problem was eliminated by incorporating the following design features:

- Pipes and valves of ample size. Water supply pressures tend to be significantly lower in OTEC systems than in most other piping systems, and pipe diameters and valve sizes that are conservative for normal piping systems may be too small for OTEC systems.

- High-point vents. Gas pockets resulting from deaeration of seawater and leakage of air into pipes containing water at subatmospheric pressure can cause significant pressure losses. All high points, especially those just ahead of pipes in which water flow is sharply downward (downcomers), require vents.

- Vent gas removal. Vents must be connected to a low pressure source-preferably to the vent line leading to the vent compressor--to prevent noncondensable gases from entering the OC-OTEC heat exchangers.

- Vent water separation. Vents must be configured to prevent water from entering the compressor. The easiest method of allowing gas to vent while preventing water from flowing out the vent line is to provide a largediameter tube (2 cm or larger for small vents) from the water pipe to a point well above the barometric height. At the high point, a larger volume should be provided to ensure that any water brought up by gas bubbles can settle out of the gas stream and drain back down the vent line.

- Visual checks. Acrylic or glass viewports at vents and clear vent lines permit visual observation that gas is venting properly. Viewports also provide a way to determine whether vented gas is deaerated from the water or leaking into the pipe. Downcomers should feature tees at their upper connections. The upper leg of the tee can then be fitted with a viewport.

Another required modification which was determined late in the design of the HMTSTA was that water supply controls should be based, not on the level in the supply sump, but on the measured flow rate. The supply sump level is automatically determined by the physical configuration of the barometric leg and head losses in the supply upcomer and heat exchanger. For all tests, one of the controlled parameters was water flow rate. It is more useful to control it directly rather than to attempt control through measurement of a sump level.

\section{E.4.1.2 Level Control}

A second area of concern regarding high water flows typical of OC-OTEC plants is maintenance of correct discharge pool levels in the evaporator and directcontact condenser. Failure of a level sensor or plugging of a discharge pump inlet can result in rapid overfilling of the system. In the HMTSTA the following design features minimized that problem: 
- Use of industrial-grade pressure sensors to indicate water levels in the evaporator and discharge..sumps for the evaporator and direct-contact condenser

- Use of "bubblers" to prevent, where possible, seawater from contacting level sensor diaphragms

- Provision of pressure switches connected to audible and visual alarms to indicate higher-than-normal levels in the discharge sumps. Although sump level was an indirect indication of water pool level in the heat exchanger, the pressure switches were located in the bubbler system and thus were not exposed to seawater.

- Provision of float switches inside the heat exchangers that also activated audible and visual alarms and opened a vacuum vent valve.

The above features were helpful in reducing the probability of overfilling, but other methods should also be considered for future experimental facilities such as the NPPE:

- Use instruments and equipment that can withstand flooding.

- Locate instruments and equipment that cannot withstand flooding above the highest water level that can be physically reached by combined pump head and barometric leg.

- Besides increasing system pressure by venting air, shut off seawater supply pumps and the vent compressor in case of high water levels.

\section{E.4.1.3 Air Leakage}

Air leaks into the vacuum system are of critical concern in OC-OTEC systems. If large enough, they can seriously affect operation of the vent compressor as well as the surface and direct-contact condenser.

Time lost searching for leaks can be minimized by incorporating the following features into the design and operation of the NPPE:

- Minimize piping outside the vacuum vessels.

- Provide means to observe bubbles in water pools as a way of finding leaks inside the main vacuum vessel.

- Provide means to isolate and vacuum check piping and components outside the main vacurm vessel.

\section{E.4.1.4 Control Room Features}

One of the least desirable features of the HMTSTA, which should be avoided in the future, is the size and layout of the control room. Interruptions and communication difficulties seriously reduced the operator's ability to conduct tests. The control room should have the following features to enhance productivity:

- Provide sufficient room for the operator, one assistant, and one researcher to observe and control operations without disturbing each other. 
- Provide easy access to all parts of the apparatus, including office, without requiring passage through the control room.

- Provide a means for visitors to view the control room without entering it or disturbing the operator.

- Provide auditory and visual communication between the operator and other workers in the facility. Hand-held radios are adequate if radio signals are not attenuated by walls or equipment and if a frequency can be allotted for operation use only. Visual communications may be provided by windows or, if necessary, by video cameras and monitors.

\section{E.4.2 Improvements in Instrumentation}

Instrumentation in the HMTSTA was adequate for the research objectives of the Phase I and Phase II tests. It can be improved for NPPE tests in the following ways:

- Use industrial-grade sensors wherever possible, rather than high-precision but fragile scientific sensors. Often the increased accuracy of the scientific sensor is lost when it is exposed to seawater and salt spray.

- Bubble-type level sensors provided considerably better reliability than sensors that required direct contact between seawater and sensing diaphragms. In an experiment the size of NPPE, the effect of noncondensable gases added from bubblers should be very small.

- Provide large-diameter, clear tubing connections between the vacuum vessel and external pressure sensors to minimize the probability of water accumulations that affect pressure readings.

- RTD temperature probes are characterized by high rates of calibration drift, and therefore frequent recalibration is required to maintain accuracies within those required for OC-OTEC experiments. High-stability thermistors should be investigated for use in the NPPE.

- Whenever possible, wiring connections in junction boxes are preferable to field splices. A combination penetration/junction box configuration could reduce the number of connections required between sensors and signal conditioners as well as facilitate changes in instrumentation.

- Signal conditioners should be located in the building housing the control room, where they can be protected from dirt, salt spray, and temperature changes.

- Large cross-connect panels are preferable to tightly bunched terminal drawers in the control room building. These panels should provide a means of easily changing connections from field sensors and control actuators to signal conditioners, analog-to-digital converters, and monitoring and control devices.

- Conversion of analog signals to digital signals should be accomplished using industrial-grade components that are protected from overvoltages and shorts. The emphasis should be on accuracy and reliability rather than conversion speed.

- Controls should be integrated with the data-acquisition computer using modern computer technology. 
- Data-acquisition and storage software should be easily modifiable to permit versatility in real-time data analysis, graphing, and modification of algorithms used to calculate key performance and operating parameters.

- On-site calibration equipment should be obtained to permit calibration checks of temperature and pressure sensors. A pressure standard is available on site for pressure calibrations, but it should be complemented with equipment that will obtain and hold multipoint calibration pressures without removing the sensor from its installed position. Similarly, if constant temperature baths were provided, absolute and differential temperature probes could be calibrated more reliably and accurately using high-precision temperature probes already on site.

\section{E.4.3 Improvements in Test Procedures}

A key improvement made during HMTSTA tests was the development of real-time data analysis capability based on a spreadsheet program. Other programs of similar capability are available and should be considered for use in the NPPE. The original FORTRAN-based data-acquisition program was useful for viewing and recording the raw sensor data, but it was unwieldy for checking "reasonableness" of data. Some of the features of the real-time analysis program should be

- Display of key operating and performance parameters using various combinations of sensors

- Graphic display of performance parameters for current and previous tests.

- Ability to scroll or page through more data than can be displayed on one screen

- Easy changing and display of zero offsets for sensors such as differential pressure and temperature sensors

- Selection of which sensors to use to calculate operating conditions and performance levels.

\section{E.5 REFERENCES}

Bharathan, D. B., and D. H. Hagen, Dec. 1987, Acceptance Test Report for the Heat- and Mass-Transfer Scoping Test Apparatus, Golden, Co: Solar Energy Research Institute.

Parsons, B. K., H. F. Link, D. Bharathan, A. A. Pesaran, F. Zangrando, and C. B. Panchal, April 1989, Test Plan for the Heat- and Mass-Transfer Scoping Test Apparatus: Phase I and Phase II Tests, Internal Program Report, SERI/PR-253-3385, Golden, CO: Solar Energy Research Institute. 


\begin{abstract}
APPENDIX F
IMPACT OF COMPONENT PERFORMANCE ON THE PERFORMANCE

OF THE NET POWER-PRODUCING EXPERIMENT
\end{abstract}


This appendix indicates how component performance verified in the HMTSTA tests can affect the performance of a complete OC-OTEC system--namely the net powerproducing experiment (NPPE). Within the range of parameters expected for the NPPE, the results of the sensitivity analysis show that care must be given to

- Evaporator thermal effectiveness

- Direct-contact condenser overall thermal effectiveness

- Gas-side pressure drop in the condenser.

Other parameters, such as water-side pressure loss, steam-to-seawater approach temperature, and fraction of dissolved gas released, have a somewhat smaller effect on net power. The sensitivity results in potential losses as well as potential gains in power if the operating conditions are different from those assumed for the NPPE nominal conditions. The assumptions made and the results of the sensitivity analysis are described below.

The NPPE will use the full capacity of the new seawater supply system at the Seacoast Test Facility (i.e., $620 \mathrm{~kg} / \mathrm{s}$ of warm seawater and $421 \mathrm{~kg} / \mathrm{s}$ of cold seawater). In addition to the spout evaporator and direct-contact condenser tested in the HMTSTA, the NPPE will feature a steam turbine, a high-efficiency vacuum compressor, and a high-efficiency seawater supply system. Projections have been made as part of a conceptual design of the NPPE of the performance and power requirements of each component of the system. The design continues to be developed and performance projections are continually modified; the graphs contained in this appendix reflect performance projections made on September 26, 1989. Those projections were that the NPPE would produce $83 \mathrm{~kW}_{e}$ net power after parasitic loads consume $134 \mathrm{~kW}_{e}$ of the $217 \mathrm{~kW}_{e}$ produced by the turbine/generator unit.

The analysis supporting the following graphs was performed using a Lotus 123을 spreadsheet program. Key inputs to these programs are that the seawater pumps will operate at an efficiency of $72 \%$ and that the vacuum compressor will operate at $60 \%$ efficiency over the range of conditions considered here. In both cases efficiency accounts for losses in electrical motors and variable frequency motor speed controllers. Other key inputs are discussed for each graph below.

Two of the most important component-performance parameters having to do with overall system performance are evaporator and direct-contact condenser thermal effectiveness. At low values of thermal effectiveness, the turbine is underpowered because less steam is generated at a lower enthalpy difference. The analysis accounts for degradation of turbine efficiency when operated under the off-design conditions which would occur if the heat exchangers did not perform as expected. Figure $\mathrm{F}-1$ shows that net power production could be as much as $11 \mathrm{~kW}$ lower if either the evaporator or direct-contact condenser performed with a thermal effectiveness of only 0.80 . Such poor performance is not anticipated for either heat exchanger. Although seriously degraded, the NPPE would still be able to produce $72 \mathrm{~kW}$ of net power.

Before the HMTSTA experiments, the range of uncertainty on water-side head loss through the heat exchangers was higher than at present. HMTSTA tests quantified the head losses when thermal effectiveness was high. Using the same heat-exchanger configurations for the NPPE greatly reduces the uncertainty in water-side head loss and narrows the impact on system performance to $\pm 5 \mathrm{~kW}_{e}$ (see Figure $\mathrm{F}-2$ ). 
Figure F-1. Effect of heat-exchanger thermal effectiveness on net power

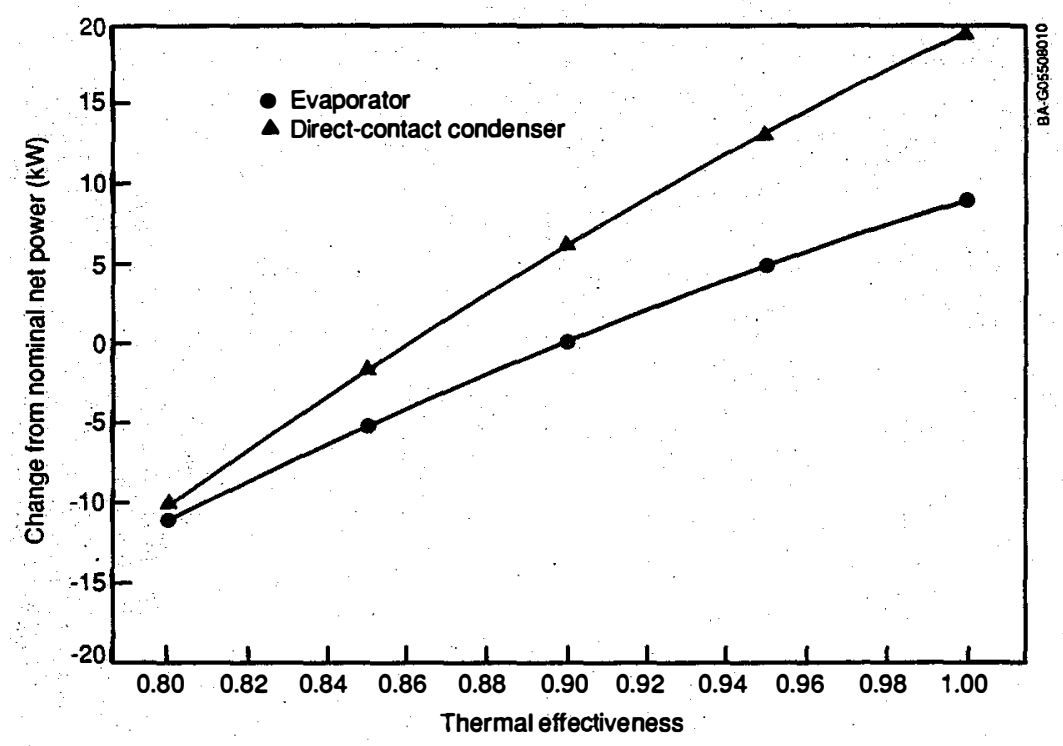

Figure F-2. Effect of heat-erchanger head loss on net power

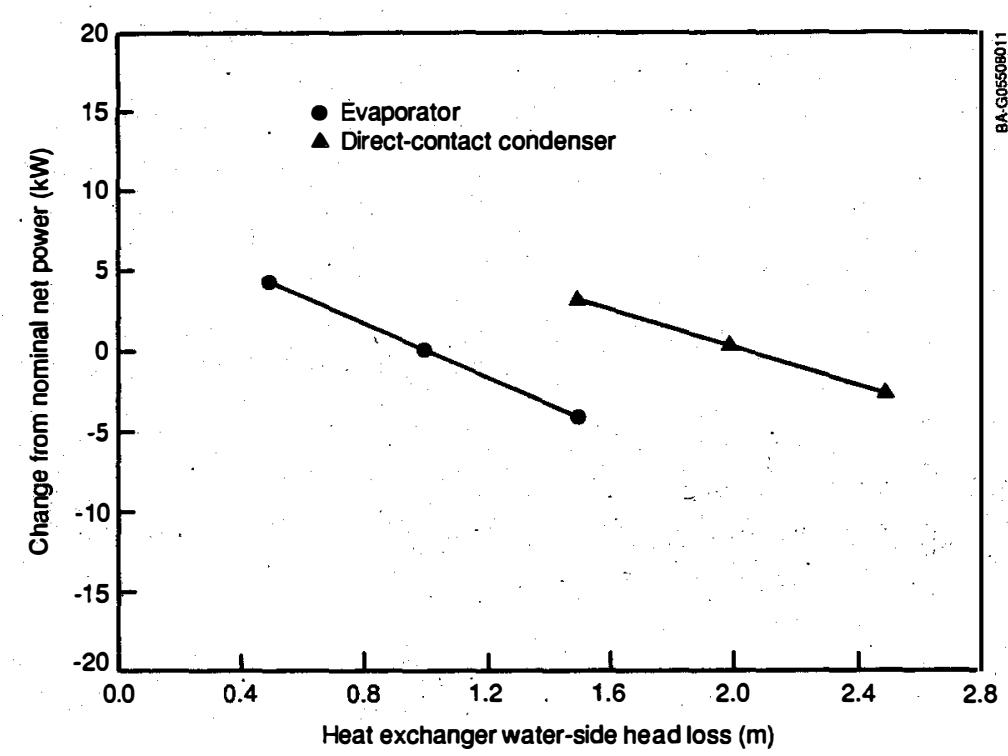

Figures F-3 and F-4 show the potential impact of changes in two other performance parameters for the direct-contact condenser. These parameters, gasside pressure loss and temperature approach between outlet steam and inlet cold seawater, have a direct effect on the fraction of steam condensed. As the value of either parameter is increased, more steam exits the condenser and vacuum-compressor power increases. Assumed in this analys is is that the vacuum compressor will have sufficient capacity to handle the higher steam flow rates and that its efficiency. will not change significantly under these off-design conditions.

Over a range of uncertainty shown in these figures, which is broader than expected (but could be attained by poor design), the gas-side pressure drop is significantly more important than temperature approach, because it can result 

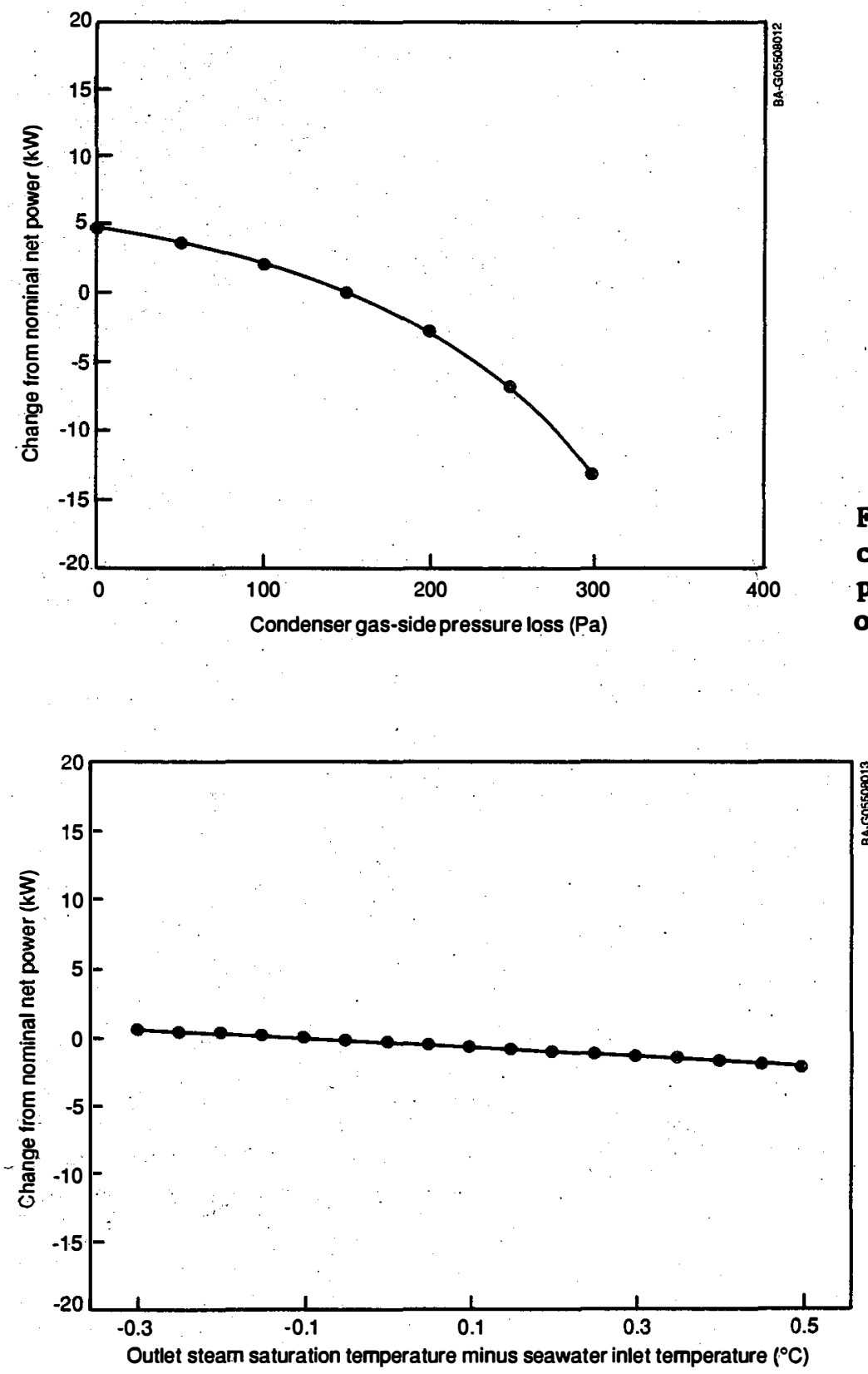

Figure F-3. Effect of condenser gas-side pressure loss on net power
Figure F-4. Effect of condenser temperature approach on net power

in a loss of almost $15 \mathrm{~kW}_{e}$. This finding suggests not only that the condenser $\hat{\mathrm{e}}$ should be designed to ensure that internal pressure losses are not higher than measured in the HMTSTA, but that care should be taken to prevent excessive pressure losses in the vent pipe between the condenser and the vacuum compressor.

The negative temperature approach at the outlet of the condenser occurs because the steam temperature is a wet-bulb measurement relative to the saturation temperature of fresh water. The saturation temperature with respect to seawater is $0.28^{\circ} \mathrm{C}$ below the temperature of the seawater. Thus, condensation can occur when the steam saturation temperature is lower than the seawater temperature (see Chapter 8 ). 
The final heat exchanger performance parameter considered here is the fraction of noncondensable gas released in the evaporator and direct-contact condenser. Less gas released in either exchanger results in lower inlet flows to the vacuum compressor and reduced power consumption by the compressor. Again, the analysis assumes that the compressor will maintain its $60 \%$ efficiency under off-design conditions. HMTSTA tests indicated that virtually all the dissolved gas contained in seawater is released in both the evaporator and direct-contact condenser. If the fraction of gas released in either heat exchanger is reduced, performance of the NPPE might be improved by as much as $10 \mathrm{~kW}_{e}$ (Figure $\mathrm{F}-5$ ).

Other components tested in the HMTSTA were warm and cold seawater predeaerators, a mist eliminator, and two surface condensers. Plans for the NPPE do not include predeaeration, as discussed in Chapter 5. Initial warm seawater predeaeration tests in the HMTSTA indicated low release rates and confirmed projections that the device would provide little improvement in NPPE performance. Later, still undocumented tests indicated higher release rates might be achievable but only under flow conditions significantly lower than those that will exist in the NPPE. Potential complications resulting from the configuration tested in later predeaeration tests include more complicated seawater piping arrangements (resulting in higher water-side head losses), integration of predeaeration gas flows into higher pressure stages of the vacuum compressor train, and maintenance of the fine-mesh screens that effected high release rates.

Figure F-5. Effect of heat-erchanger gas release on net power

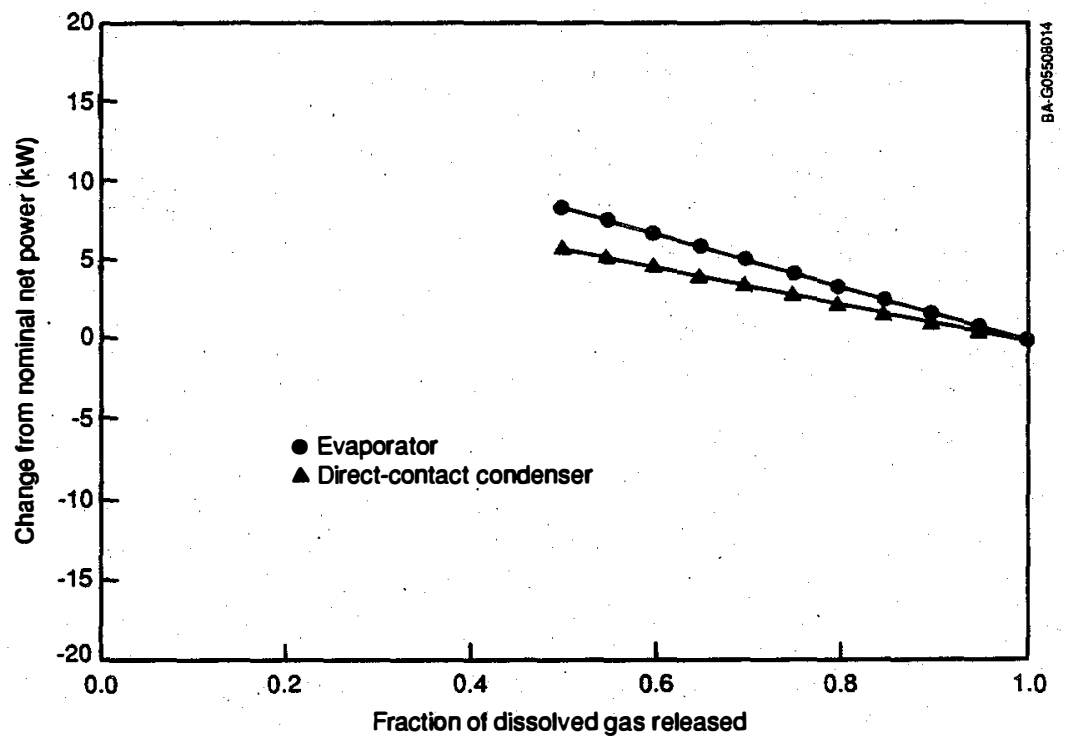




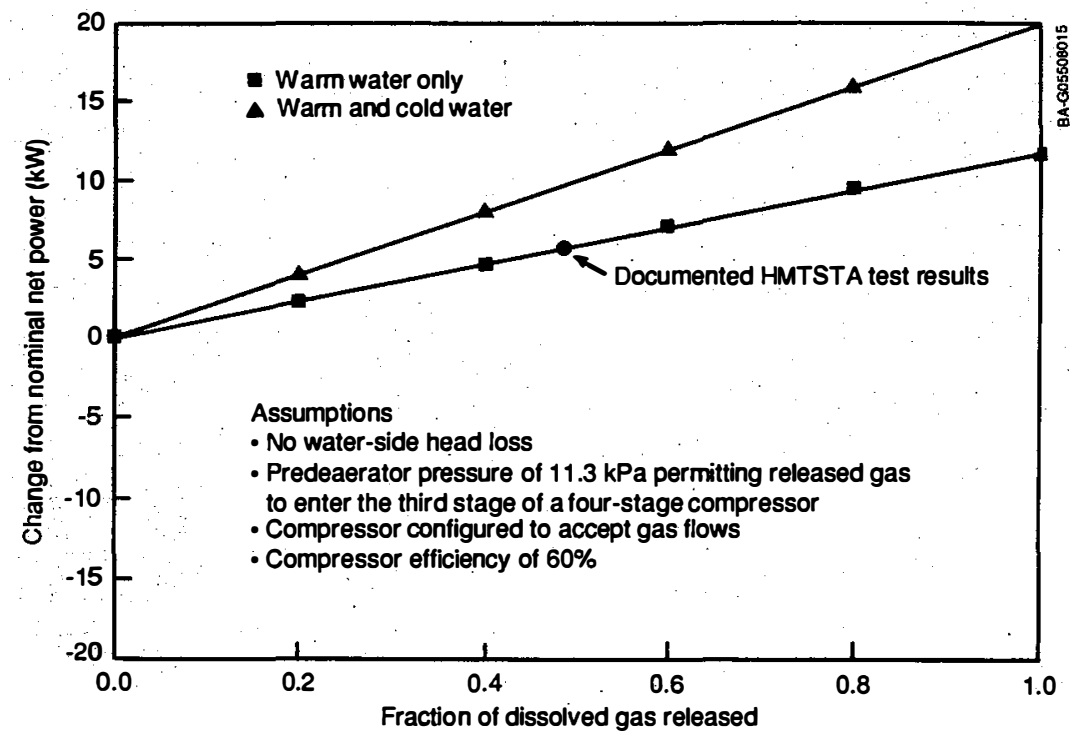

Figure F-6. Effect of predeaeration on net power

The analysis used to show the maximum potential impact of predeaeration performance on net power assumes no water-side pressure loss and no impact on vacuum compressor efficiency. The predeaerators would be operated at $11.3 \mathrm{kPa}$ to permit the released gas to be admitted to the third stage of a four-stage vacuum compressor train. With these assumptions, as Figure F-6 shows, warm seawater predeaeration could increase net power by as much as 10 If both warm and cold seawater were predeaerated, as much as $20 \mathrm{~kW} /$ be saved. After accounting for water-side pressure losses, however, projections based on predearation tests described in Chapter 5 indicate only a potential 5-kW savings.

The pressure-drop coefficient of the mist eliminator has a negligible effect on NPPE performance because steam velocity through that component will be very low $(6 \mathrm{~m} / \mathrm{s}$ vs. earlier projections of $30 \mathrm{~m} / \mathrm{s})$. Such low velocities would result in a low pressure loss even if the pressure-loss coefficient were much greater than shown in HMTSTA tests.

Surface condenser performance parameters have no effect on NPPE performance because power production will be obtained with the direct-contact condenser. A small surface condenser will be incorporated into the NPPE to produce desalinated water and to obtain performance data on a new configuration, but its consumption will not be included in net power measurements.

In summary, performance of the NPPE will be most strongly affected by evaporator thermal effectiveness, direct-contact condenser overall thermal effectiveness, and gas-side pressure drop in the condenser. 


\section{SELECTED DISTRIBUTION LIST}

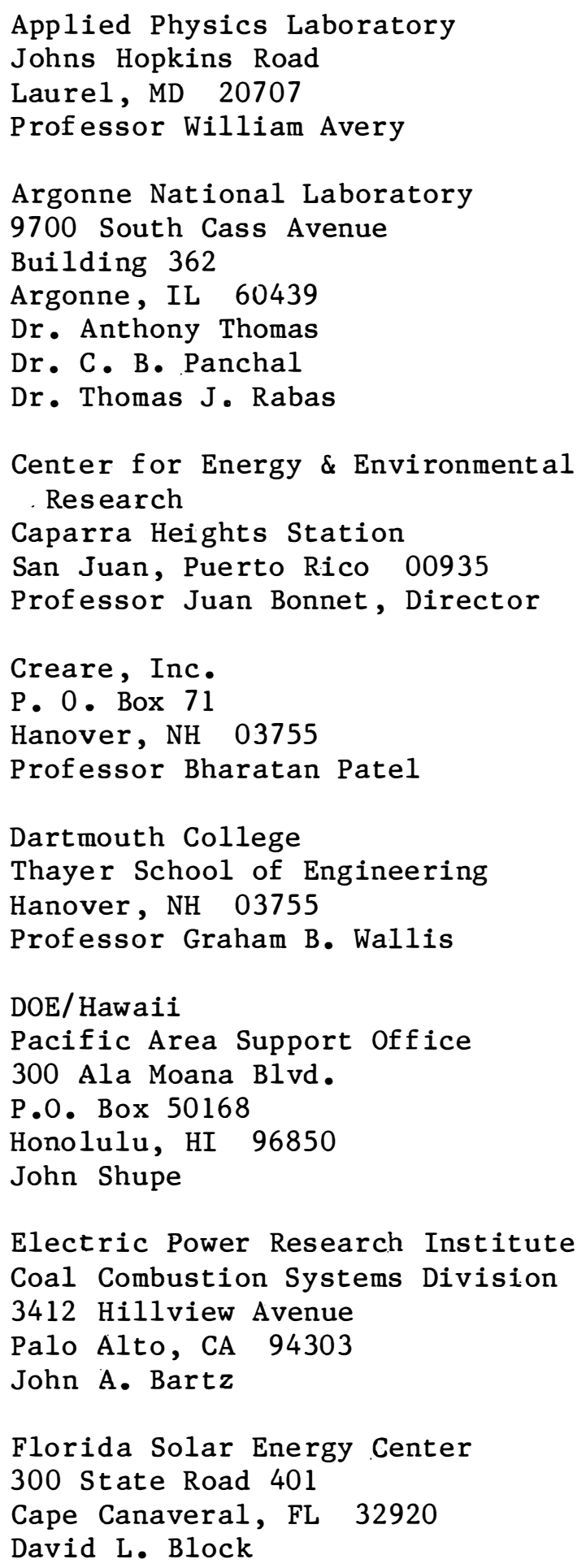

\author{
GEC-Marconi Research Center \\ West Hanningfield Road \\ Great Baddow \\ Chelmsford, Essex CM2 8HN \\ ENGLAND \\ F. A. Johnson \\ Hawaiian Electric Renewable \\ Systems, Inc. \\ 915 Fort Street Mall, Suite 701 \\ Honolulu, HI 96813 \\ Alf red P. Manning \\ Hawaii Natural Energy Institute \\ University of Hawaii - Manoa \\ 2540 Dole Street \\ Holmes 246 \\ Honolulu, HI 96822 \\ Patrick Takahashi \\ HTRI \\ 1000 S. Fremont Ave. \\ Alhambra, CA 91802 \\ Dr. Duncan Chisholm \\ Meridian Corporation \\ 4300 King Street \\ Alexandria, VA 22302 \\ D. Kerner (4)
}

The Munters Corporation

P. 0. Box 6428

Ft. Myers, FL 33911

E. A. Winkler

Natural Energy Laboratory of Hawaii P. 0. Box 1749

Kailua-Kona, HI 96740

Thomas H. Daniel

Naval Postgraduate School

Department of Mechanical Engineering

Monterey, CA 93940

Professor Paul J. Marto, Chairman

Oklahoma State University

College of Engineering

Stillwater, OK 74074

Professor Kenneth J. Bell 
Pacific International Center for High Technology Research

711 Kapiolani Blvd., Suite 200 Honolulu, HI 96814

Andrew Trenka (6)

Dr. Luis Vega

Richardson School of Law

Ocean Engineering

Law of Sea Institute

University of Hawaii

Honolulu, HI 96822

Professor John P. Craven

Science Applications Int 1. Corp.

21151 Western Avenue

Torrance, CA 90501-1724

Dr.A. T. Wassel, Program Manager

Scripps Institution of Oceanography

Marine Research Division

Ocean Engineering Research Group

Mail Code A-022, UCSD

La Jolla, CA 92093-0222

Prof . Richard J. Seymour, Head
U. S. Department of Energy

1000 Independence Ave., SW

Washington, DC 20585

Carmine C. Castellano

Dr. Lloyd F. Lewis

Ronald R. Loose

Roland R. Kessler

University of Hawaii

J.K.K. Look Laboratory

811 Olomehani Street

Honolulu, HI 96813

Professor Hans-Jurgen Krock

University of Pennsylvania

Mechanical Engineering Department

3451 Walnut Street

Philadelphia, PA 19104

Professor Noam Lior

University of Texas

Department of Chemical Engineering

Austin, TX 78712

Professor J. L. Bravo

Professor James Fair 


\begin{tabular}{|c|c|c|c|}
\hline $\begin{array}{l}\text { DOCUMENT } \\
\text { CONTROL PAGE }\end{array}$ & $\begin{array}{l}\text { 1. SERI Report No. } \\
\text { SERi/TP-253-3561. }\end{array}$ & $\begin{array}{c}\text { 2. NTIS Accession No. } \\
\text { DE89009514 }\end{array}$ & 3. Recipient's Accession No. \\
\hline \multirow{3}{*}{\multicolumn{3}{|c|}{$\begin{array}{l}\text { 4. Title and Subtitle } \\
\text { Results of Scoping Tests for Open-Cycle OTEC } \\
\text { Components Operating with Seawater }\end{array}$}} & 5. Publication Date. \\
\hline & & & September 1990 \\
\hline & & & 6. \\
\hline \multicolumn{3}{|c|}{$\begin{array}{l}\text { 7. Author(s) } \\
\text { F. Zangrando, D. Bharathan, H. J. Green, H. F. Link, C. B. Panchal, } \\
\text { B. K. Parsons, J. M. Parsons, A. A. Pesaran }\end{array}$} & 8. Performing Organization Rept. No. \\
\hline \multirow{4}{*}{\multicolumn{2}{|c|}{$\begin{array}{l}\text { 9. Performing Organization Name and Address } \\
\text { Solar Energy Research Institute } \\
\text { A Division of Midwest Research Institute } \\
1617 \text { Cole Boulevard } \\
\text { Golden, Colorado } 80401-3393\end{array}$}} & \multirow{4}{*}{$\cdot$} & 10. Projectrask/Work Unit No. \\
\hline & & & OE012031 \\
\hline & & & $\begin{array}{l}\text { 11. Contract (C) or Grant (G) No. } \\
\text { (C) DE-AC02-83CH10093 }\end{array}$ \\
\hline & & & (G) \\
\hline \multicolumn{3}{|c|}{ 12. Sponsoring Organization Name and Address } & 13. Type of Report \& Period Covered \\
\hline \multirow{2}{*}{\multicolumn{2}{|c|}{$\begin{array}{l}\text { Solar Energy Research Institute } \\
\text { A Division of Midwest Research Institute } \\
1617 \text { Cole Boulevard } \\
\text { Golden, Colorado } 80401-3393\end{array}$}} & \multirow{2}{*}{$=$} & Technical Report \\
\hline & & & 14. \\
\hline
\end{tabular}

15. Supplementary Notes

\section{Abstract}

The most recent research effort in the Ocean Energy Technology program of the U.S. Department of Energy has been to scale up the experimental apparatus for open-cycle ocean thermal energy conversion (OC-OTEC) research to a thermal capacity of more than $1 \mathrm{MW}$ using seawater as the process fluid. This apparatus, the Heat- and Mass-Transfer Scoping Test Apparatus (HMTSTA), was designed and built to determine the performance of key open-cycle OTEC components. operating in seawater. This research builds on extensive data bases and analytical capabilities developed over the last decade In open-cycle technology. Seawater tests in the HMTSTA have confirmed the excellent heat- and mass-transfer performance of spout evaporators and direct-contact condensers using structured packings, which was observed in freshwater experiments and predicted by analytical models. Data on the performance of surface condensers, seawater deaeration, and carbon dioxide emissions were also obtained in HMTSTA experiments. These results provide the required technical basis for confident engineering design of a facility to produce net power for the first time using open-cycle OTEC technology.

\section{Document Analysis}

\section{a. Descriptors}

Ocean Thermal Energy Conversion; Open-Cycle Systems; Seawater; Heat Exchangers;

Flashing; Evaporation; Condensers; Vapor Condensation; Deaerators; Hawail

b. Identifiers/Open-Ended Terms

Direct-Contact Condensers; Noncondensable Gas

c. UC Categories

262

18. Availability Statement National Technical Information Service U.S. Department of Commerce 5285 Port Royal Road

Springfield, Virginia 22161

19. No. of Pages

340

20. Price 